\title{
Abordagens Qualitativa e Quantitativa de \\ Micro-bacias Hidrográficas e Áreas Alagáveis de um Compartimento do Médio Mogi-Superior/SP
}

Ricardo Tezini Minoti

Tese apresentada à Escola de Engenharia de São Carlos, Universidade de São Paulo, como parte dos requisitos para obtenção do título de Doutor em Ciências da Engenharia Ambiental.

Orientador: Prof. Dr. Silvio Crestana

São Carlos

2006 
Ficha catalográfica preparada pela Seção de Tratamento da Informação do Serviço de Biblioteca - EESC/USP

\begin{tabular}{|l}
\hline M666a \\
Minoti, Ricardo Tezini \\
Abordagens qualitativa e quantitativa de micro-bacias \\
hidrográficas e áreas alagáveis de um compartimento do \\
Médio Mogi-Superior/SP / Ricardo Tezini Minoti. -- \\
São Carlos, 2006. \\
Tese (Doutorado) -- Escola de Engenharia de São \\
Carlos-Universidade de São Paulo, 2006. \\
Área: Ciências da Engenharia Ambiental. \\
Orientador: Prof. Dr.Silvio Crestana. \\
1. Erosão. 2. Processos Hidrológicos. 3. Bacia \\
Hidrográfica. 4. Áreas alagáveis. 5. EUPS. 6. SWAT. \\
7. Cenários.
\end{tabular}


FOLHA DE JULGAMENTO

Candidato: Bacharel RICARDO TEZINI MINOTI

Tese defendida e julgada em 11/10/2006 perante a Comissão Julgadora:

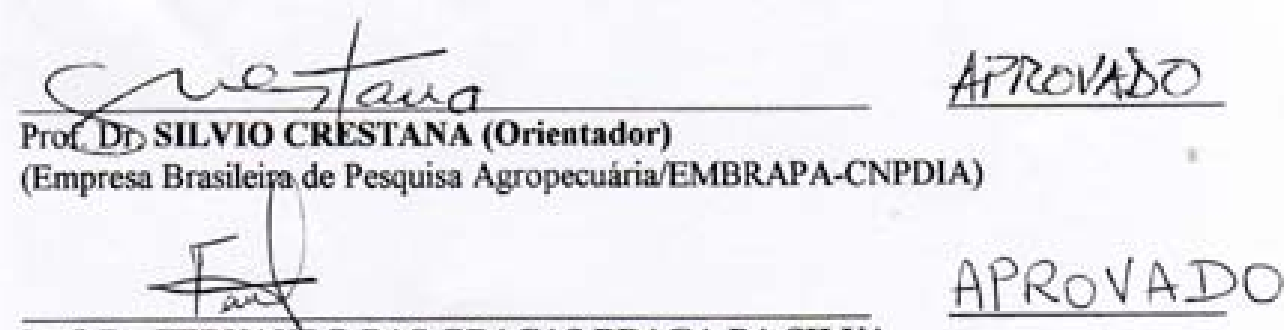

Prof. Dr. FERNANDO DAS GRACAS BRAGA DA SILVA (Universidade Federal de Itajubá/UNIFEI)

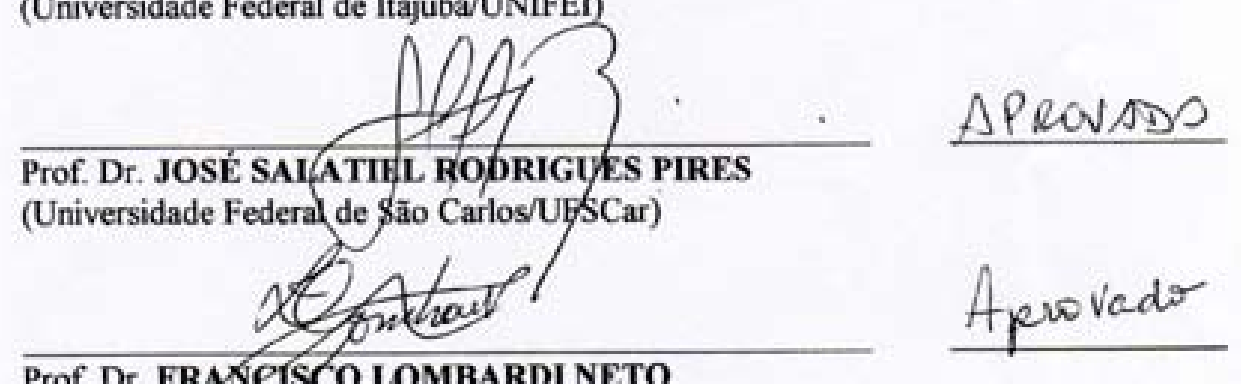

Prof. Dr. FRA (Instituto Agronômico de Campinas/IAC)

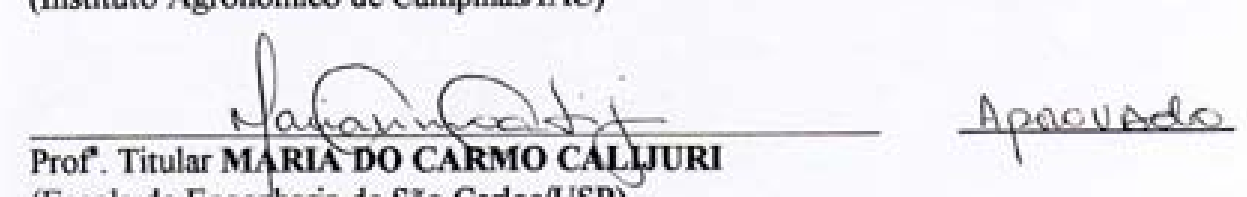

(Escola de Engerharia de São Carlos/USP)
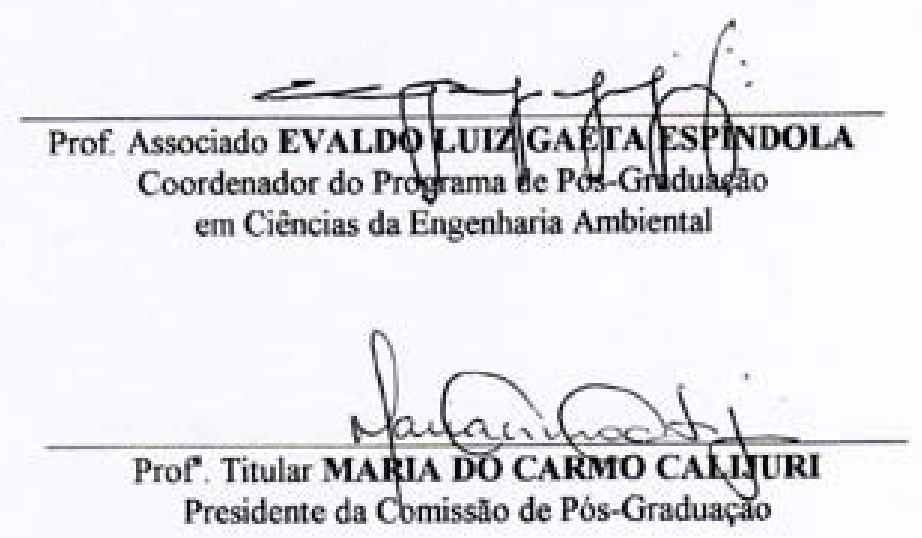


\begin{abstract}
À grande família, Com quem muito aprendi, Principalmente meus queridos pais, Carlos e Maria José, Pela doação incondicional, E meus irmãos, Marcio e Eduardo, pelo apoio de sempre, ...
\end{abstract}

...À pequena grande família, Com quem continuo a aprender, Meus amores Ariuska, Lucas e Beatriz, Pelo dia-a-dia, pelo apoio e pela compreensão. 


\section{AGRADECIMENTOS}

Ao professor Dr. Silvio Crestana pela orientação, oportunidade e confiança, pela enriquecedora convivência em meio a sua eterna sabedoria de vida e, sobretudo, pela amizade.

Ao Dr. Francisco Lombardi Neto pelo apoio, fundamental para a realização deste trabalho, pela oportunidade ao compartilhar seus dados e seu conhecimento, pelas valiosas considerações, sugestões e críticas, pela generosidade ao receber-me em sua casa e pela paciência (também da família) em função dos inúmeros telefonemas.

Ao professor Dr. José Salatiel Rodrigues Pires pelas considerações e críticas e, juntamente com o Dr. José Eduardo dos Santos, pela disponibilidade e pela contribuição, no período de escolha da área de estudo, com importantes informações relacionadas à Estação Ecológica de Jataí.

Ao Professor Dr. Fernando das Graças Braga da Silva pelo apoio no início dos trabalhos com modelagem, pelas discussões científicas e principalmente pela disposição e flexibilidade para trabalhar em todos os horários.

À Professora Dra. Maria do Carmo Calijuri, novamente presente em minha formação acadêmica e profissional, pelas considerações e sugestões.

Ao Professor Dr. Reinaldo Lorandi pela cessão de suas imagens de satélite, seus mapas e sua biblioteca pessoal, e pelas considerações e sugestões.

Ao amigo Engenheiro Antonio Angelotti Netto, doutorando do PPG-SEA, pelos auxílios em temas diversos das ciências agronômicas, pelas discussões científicas e pela fiel companhia ao longo do doutorado, tanto na degustação de café e outras bebidas, como nos momentos sagrados de prosa pra espairecer e fazer a vida ter mais sentido.

Ao amigo Dr. Francisco José Vela (“Chico Vela”), pelos projetos em comum e, também, pela fiel companhia ao longo do doutorado, na prosa e na degustação de café, rituais sagrados em meio à correria do dia-a-dia.

Ao Dr. Odo Primavesi, pesquisador da Embrapa Pecuária Sudeste e ao biólogo Paulo Mancini, Diretor de Política Ambiental da Secretaria Municipal de Desenvolvimento Sustentável, Ciência e Tecnologia da Prefeitura Municipal de São Carlos, pela disponibilidade e valiosas informações concedidas na fase de definição da área de estudo. 
Ao Geógrafo Abimael Cereda Junior, professor do Curso de Especialização em Geoprocessamento/DECiv/UFSCar, pelas aulas ministradas e por todos os auxílios relacionados ao processo de digitalização e ao SIG-Spring e ao Professor Dr. Sérgio Rohn pela oportunidade de assistir a algumas de suas aulas (NGEO/DECiv/UFSCar).

Ao Dr. Ronalton Evandro Machado pelas informações disponibilizadas.

Ao Dr. Nabil Joseph Eid, do Departamento de Engenharia Civil e Ambiental Faculdade de Tecnologia - Universidade de Brasília, pelos comentários e esclarecimentos.

Aos Doutores Ricardo Marques Coelho e Jener Fernando Leite de Moraes, pesquisadores do Instituto Agronômico de Campinas, pelas informações disponibilizadas relacionadas aos mapas de solo.

À Dra. Iris Peeters, pesquisadora da Universidade Católica de Leuven, pelos auxílios na utilização do modelo USLE 2D.

Aos Doutores Chris Renschler, Mauro Di Luzio, Nancy Sammons, G. Vance Justice Jr., Charles R. Meyer, do Serviço de Pesquisa Agrícola dos Estados Unidos (ARS), pela atenção ao responderem os e-mails com dúvidas relacionadas ao modelo SWAT.

Ao Dr. Antonio Carlos Zanato, Diretor do Parque Estadual do Jatay, ao Sr. Alcides, e aos Srs. Gonçalo Bertoloti e Horácio Gomes pelos auxílios nos trabalhos de campo na Estação Ecológica de Jataí.

Á Silvana, Elaine Viana, ao Jorge e Marcelo Frazão de Almeida, funcionários e exfuncionários do Departamento de Meio Ambiente do município de Luiz Antônio/SP, por auxílios diversos na coleta de informações climáticas.

Ao Dr. Marcio de Morrisson Valeriano e Dr. Roberto Formaggio, pesquisadores do Instituto Nacional de Pesquisas Espaciais, e ao Engo. Gonzalo Álvaro Vazquez Fernandez.

À Profa. Dra. Alaíde Fonseca Gessner, do Derpartamento de Hidrobiologia da UFSCar, pela cessão de biblioteca pessoal.

Ao Professor Dr. Mauro Masili, pesquisador da UNICEP.

Ao Eng ${ }^{\circ}$. Edson Mitsuhide Tsuhako, doutorando do PPG-SHS/EESC/USP.

À Engenheira Mônika Bergamaschi, Diretora Executiva da ABAGRP, pela disponibilização de dados sócio-econômicos. 
Ao professor Dr. Evaldo Luiz Gaeta Espíndola, coordenador do PPGSEA/EESC/USP e à secretária Claudete Ap. Poianas da Silva, pela cordialidade e dedicação em todos os momentos, à bibliotecaria Mara (BICRHEA) e a secretária Sonia (CRHEA).

Aos Professores Doutores Valdir Schalch, Luiz Antonio Daniel, Frederico Fred Mauad e Victor Ranieri do SHS/EESC/USP e ao Dr. Marcelo Montaño pelas informações compartilhadas no início dos trabalhos com SIG.

À Rose, funcionária do SHS/EESC/USP, pela solicitude.

Aos companheiros de representação discente, Rita, Illona e Ozelito pelos ideais, pelas xícaras de café, pela convivência, pelo divertimento e por todo trabalho realizado em pró do PPG-SEA e aos demais colegas de doutorado, Fernanda, Suzi, Adriana, Celso e Adeíldo. Aos colegas pós-graduandos, orientados do Dr. Silvio Crestana, Adriana, Julieta, Fernando, Simone e Carol.

Às secretárias Bernadete Aparecida Oscar, Ivani da Silva Moura Cipriano e Lídia da Silva Nobre, do Gabinete da Presidência da Embrapa, e à estagiária Cássia Helena de Morais Lopes e Silva.

À Embrapa Instrumentação Agropecuária pela infra-estrutura oferecida, fundamentais à realização do doutorado, principalmente ao Pesquisador Eng ${ }^{0}$. Lúcio André De Castro Jorge, por auxílios diversos e pela utilização do Laboratório de Imagem e Modelamento para o desenvolvimento da pesquisa e aos demais funcionários da unidade Renê de Oeste, pelo auxílio nos trabalhos de campo, Valeria de Fátima Cardoso, pela simpatia e solicitude, Fabiana Cunha Viana Leonelli, pela disponibilização de dados sócio-econômicos, Alessandra, Socorro, Kelen, Francisca, Terezinha, Álvaro, Edinaldo, Emerson, Valentim, Formiga e Gilmar.

A Capes pela bolsa concedida. 


\section{RESUMO}

Minoti, R. T. (2006). Abordagens Qualitativa e Quantitativa de Microbacias Hidrográficas e Áreas Alagáveis de um Compartimento do Médio Mogi-Superior-SP. Tese (Doutorado) - Escola de Engenharia de São Carlos, Universidade de São Paulo, São Carlos, 2006. Orientador - Prof. Dr. Silvio Crestana.

A busca de ferramentas que contribuam com a melhoria da interpretação de informações referentes aos diversos usos do solo e suas conseqüências aos corpos aquáticos é tarefa importante tendo em vista que as qualidades do solo e da água sempre afetaram a civilização humana. O presente trabalho teve como objetivo a quantificação, com enfoque de primeira aproximação, a partir de dados existentes, da erosão, da produção de sedimentos e de alguns parâmetros do ciclo hidrológico de um compartimento da bacia hidrográfica do rio Mogi-Guaçu, região central do estado de São Paulo, submetida a diferentes usos do solo. Foi construída a base de dados digital e foram delimitadas duas microbacias hidrográficas, uma sub-bacia hidrográfica, duas bacias de drenagem e duas sub-bacias de drenagem que abrangeram os municípios de Luiz Antônio, São Carlos, Rincão, Santa Lúcia e Américo Brasiliense. A área de estudo incluiu, no município de Luiz Antônio, uma parte da Estação Ecológica de Jataí, importante unidade de conservação do estado. A perda de solo anual foi estimada utilizando-se a Equação Universal de Perda de Solo (EUPS) e a produção de sedimentos e os parâmetros do balanço hídrico a partir do modelo "Soil and Water Assessment Tool” (SWAT - 2000). A metodologia desenvolvida, em função da aplicação desses modelos computacionais de maneira simultânea, foi eficaz na caracterização ambiental da área de estudo, na simulação de cenários ambientais e na identificação de áreas mais vulneráveis, gerando respostas complementares. O SWAT foi sensível às mudanças de cenários de uso do solo e ao conjunto de dados disponíveis relacionados à área de estudo.

Palavras-chave: Erosão, Processos Hidrológicos, Bacia Hidrográfica, Áreas Alagáveis, EUPS, SWAT, Cenários. 


\begin{abstract}
Minoti, R. T. (2006). Qualitative and Quantitative Approaches to the Hydrographic Microbasins and Floodable Areas of a Compartment of the Mid-Upper Mogi Guaçu River, SP, Brazil. Doctoral Thesis - São Carlos School of Engineering, University of São Paulo at São Carlos, 2006. Adviser - Prof. Dr. Silvio Crestana.
\end{abstract}

The search for tools that contribute to enhance the interpretation of information about the diverse uses of soil and their consequences on aquatic bodies is an important task, since the qualities of soil and water have always affected human civilization. The goal of the present work was to quantify, by a first approximation and based on existing data, the erosion, the production of sediments and several parameters of the hydrological cycle of a compartment of the hydrographic basin of the Mogi Guaçu river situated in the central region of the state of São Paulo, Brazil and subjected to different soil uses. A digital database was constructed and two hydrographic microbasins, two drainage basins, and two drainage sub-basins were delimited, covering the municipalities of Luiz Antônio, São Carlos, Rincão, Santa Lúcia and Américo Brasiliense. In the municipality of Luiz Antônio, the study area included part of the Jataí Ecological Station, one of the state’s important conservation units. The annual soil loss was estimated based on the Universal Soil Loss Equation (USLE), while sediment production and hydric balance parameters were estimated using the Soil and Water Assessment Tool (SWAT - 2000). Thanks to the simultaneous application of these computational models, the methodology developed here proved effective in the environmental characterization of the study area, in the simulation of environmental scenarios, and in the identification of the most vulnerable areas, generating complementary responses. The SWAT proved sensitive to the changes in soil use scenarios and to the set of available data on the study area.

Keywords: Erosion, Hydrologic Processes, Hydrographic Basin, Floodable Areas, USLE, SWAT, Scenarios. 


\section{LISTA DE ABREVIATURAS E SIGLAS}

A

AGNPS

AnnAGNPS

ANSWERS

APP

ARS

ATTZ

AVSWAT

$\mathrm{BD}$

BDA

BDD

BD-LA

BD-SC

$\mathrm{BF}$

C

CBHRMG

CELPAV

$\mathrm{CN}$

$\mathrm{CP}$

CREAMS

CSTV

EEJ

EELA

EPA

EPIC

ERE

ESRI

$\mathrm{ETM}^{+}$
- Perda de solo por erosão laminar - resultado do produto total dos fatores da EUPS

- Agricultural non-point source pollution model

- The Annualized and ArcView interface for the AGNPS model

- Areal Non-point Source Watershed Environment Response Simulation

- Área de preservação permanente

- USDA Agricultural Research Service

- Aquatic-Terrestrial Transition Zones

- ArcView SWAT

- Bacia de drenagem

- Base de dados analógica

- Base de dados digital

- Bacia de drenagem de Luiz Antônio

- Bacia de drenagem de São Carlos

- Córrego do Beija-Flor

- Fator uso e manejo do solo da EUPS

- Comitê de bacia hidrográfica do rio Mogi Guaçu

- Celulose e Papel Votorantim

- Número da curva do SCS

- Fatores antrópicos da EUPS

- Chemicals, Runoff, and Erosion from Agricultural Management Systems

- Catchment Size Threshold Value

- Estação Ecológica de Jataí

- Estação Experimental de Luiz Antônio

- U.S. Environmental Protection Agency

- Erosion-Productivity Impact Calculator

- Expectativa de Risco à Erosão Laminar

- Environmental Systems Research Institute

- Enhanced thematic mapper, plus 


\begin{tabular}{|c|c|}
\hline EUA & - Estados Unidos da América \\
\hline EUPS & - Equação Universal de Perda de Solo \\
\hline GeoWEPP & - The Geo-spatial interface for the WEPP model \\
\hline GLEAMS & $\begin{array}{l}\text { - Groundwater Loading Effects on Agricultural Management } \\
\text { Systems }\end{array}$ \\
\hline GXbe & - GLEISSOLO HÁPLICO Tb Eutrófico \\
\hline GXbe+CXbd & $\begin{array}{l}\text { - Combinação de GLEISSOLO HÁPLICO Tb Eutrófico com } \\
\text { CAMBISSOLO HÁPLICO }\end{array}$ \\
\hline h & - Hora \\
\hline ha. & - Hectare \\
\hline $\mathrm{H}_{2} \mathrm{O}$ & - Água \\
\hline HRU & - Unidade de resposta hidrológica \\
\hline IAC & - Instituto Agronômico de Campinas \\
\hline IBGE & - Instituto Brasileiro de Geografia e Estatística \\
\hline ICMS & - Imposto sobre operações relativas à circulação de mercadorias \\
\hline INPE & - Instituto Nacional de Pesquisas Espaciais \\
\hline IPEA & - Instituto de Pesquisa Econômica Aplicada \\
\hline $\mathrm{K}$ & - Fator erodibilidade do solo da EUPS \\
\hline $\mathrm{km}^{2}$ & - Quilômetros quadrados \\
\hline $\mathrm{L}$ & - Fator comprimento do declive da EUPS \\
\hline LA & - Município de Luiz Antônio/SP \\
\hline LAPA & - Laboratório de Análise e Planejamento Ambiental \\
\hline LS & - Fator topográfico da EUPS \\
\hline LVef & - LATOSSOLO VERMELHO Eutroférrico \\
\hline LVd & - LATOSSOLO VERMELHO Distrófico \\
\hline LVw & - LATOSSOLO VERMELHO Ácrico \\
\hline LVAd & - LATOSSOLO VERMELHO AMARELO Distrófico \\
\hline $\mathrm{m}$ & - Metro \\
\hline $\mathrm{MBH}$ & - Microbacia hidrográfica \\
\hline $\mathrm{MBH}-\mathrm{BF}$ & - Microbacia hidrográfica do córrego do Beija-Flor \\
\hline MBH-BFJ & - Sub-bacia hidrográfica do Beija-Flor/Jataí \\
\hline $\mathrm{MBH}-\mathrm{G}$ & - Microbacia hidrográfica do ribeirão das Guabirobas \\
\hline MEUPS & - Equação Universal de Perda de Solo Modificada \\
\hline
\end{tabular}




\begin{tabular}{|c|c|}
\hline MJ & - Mega Joule \\
\hline $\mathrm{mm}$ & - Milímetro \\
\hline MNT & - Modelo numérico do terreno \\
\hline $\mathrm{m}^{3} / \mathrm{s}$ & - Metro cúbico por segundo \\
\hline MTo & - CHERNOSSOLO ARGILÚVICO Órtico típico \\
\hline & - Serviço de conservação dos recursos naturais dos Estados \\
\hline IVICS & Unidos \\
\hline $\mathrm{P}$ & - Fator prática conservacionista da EUPS \\
\hline PEJ & - Parque Estadual do Jatay \\
\hline PI & - Plano de Informação \\
\hline PIB & - Produto Interno Bruto \\
\hline PND & - Plano nacional de desenvolvimento \\
\hline PNE & - Potencial Natural de Erosão Laminar \\
\hline PRE & - Potencial de Risco de Erosão Laminar \\
\hline PVd & - ARGISSOLO VERMELHO Distrófico típico \\
\hline $\mathrm{R}$ & - Fator chuva (erosividade) da EUPS \\
\hline RLe & - NEOSSOLO LITÓLICO Eutrófico chernossólico \\
\hline ROTO & - Routing Outputs to Outlet \\
\hline RQg & - NEOSSOLO QUARTZARÊNICO Hidromórfico \\
\hline RQo & - NEOSSOLO QUARTZARÊNICO Órtico típico \\
\hline S & - Fator grau do declive da EUPS \\
\hline SBD-LA & - Sub-bacia de drenagem de Luiz Antônio \\
\hline SBD-SC & - Sub-bacia de drenagem de São Carlos \\
\hline SBH-BFJ & - Sub-bacia hidrográfica do Beija-Flor/Jataí \\
\hline SC & - Município de São Carlos/SP \\
\hline SCS & - U.S. Soil Conservation Service \\
\hline SEADE & - Fundação Sistema Estadual de Análise de Dados \\
\hline SED/USLE & - Razão entre a carga de sedimentos e a erosão \\
\hline SIG & - Sistemas de Informações Geográficas \\
\hline SWAT & - Soil and Water Assessment Tool \\
\hline SWRRB & - Simulator for Water Resources in Rural Basins \\
\hline $\mathrm{T}$ & - Tolerância à erosão \\
\hline $\mathrm{t}$ & - Tonelada \\
\hline
\end{tabular}


TIN

UFSCar

UGRHI

U.S.

USLE

USLE-2D

USDA

UTM

WEPP
- Modelo de Interpolação de Triangulação

- Universidade Federal de São Carlos

- Unidade de Gerenciamento de Recursos Hídricos

- United States

- Universal Soil Loss Equation

- Método automatizado para o cáculo do fator LS da EUPS

- United States Departament Of Agriculture

- Universal Transverso Mercator

- Water erosion prediction project 


\section{SUMÁRIO}

1. INTRODUÇÃO 1

1.1.Considerações Iniciais 1

1.2.Erosão do Solo e Impactos Ambientais 3

1.3.Planejamento Ambiental, Geotecnologias e Modelagem 5

1.4.Modelagem Ambiental 10

1.4.1.Equação Universal de Perda de Solo (EUPS) 13

1.4.2.Soil and Water Assessment Tool (SWAT) 23

1.5.Considerações Finais 32

2. OBJETIVOS 35

3. ÁREA DE ESTUDO 36

3.1.Considerações Iniciais 36

3.2.A Escolha da Área de Estudo 36

3.3.Área de Estudo 41

3.3.1.Estação Ecológica de Jataí 51

4. MATERIAIS E MÉTODOS 54

4.1.Considerações Iniciais 54

4.2.Construção da Base Cartográfica 54

4.3.Modelagem de Sistemas Ambientais 59

4.4.Equação Universal de Perda de Solo (EUPS) 59

4.4.1.Fator chuva (erosividade $-\mathrm{R}$ ) 59

4.4.2.Fator solo (erodibilidade - K) 61

4.4.3.Fator comprimento e grau do declive (fator topográfico - LS) 61

4.4.4.Fator uso e manejo do solo (C) 63

4.4.5.Fator prática conservacionista $(\mathrm{P})$ 64

4.4.6.Potencial Natural de Erosão Laminar (PNE) 64

4.4.7.Limite de Tolerância de Perda de Solo (LTol) 65

4.4.8.Expectativa de Risco de Erosão Laminar (ERE) 66

4.4.9.Perda de Solo por Erosão Laminar (A) 66 
4.4.10.Potencial de Risco de Erosão Laminar (PRE) 67

4.5.Manipulação e Testes dos Modelos Computacionais Conceituais 68

4.6.Soil Water Assessment Tool (SWAT)__ 71

4.6.1.Dados de Entrada do Modelo SWAT _ 71

4.6.1.1.Geração dos Planos de Informação___ 71

4.6.1.2.Dados Tabulares _ 71

4.6.2.Delineamento da bacia hidrográfica e definição do número de sub-bacias_75

4.6.3.Simulação de Cenários 77

5.RESULTADOS e DISCUSSÃO __ 79

5.1.Considerações Iniciais___ 79

5.2.Caracterização Ambiental __ 79

5.2.1.Hidrografia ___ 82

5.2.2.Hipsometria —_ 82

5.2.3.Clinografia___ 85

5.2.4.Tipo de Solo _ـ 92

5.2.5.Uso do Solo _ 98

5.2.6. Malha Viária ___ 103

5.3.Fatores da Equação Universal de Perda de Solo (EUPS) ___ 107

5.4.Potencial Natural de Erosão Laminar (PNE)___ 111

5.5. Expectativa de Risco de Erosão Laminar (ERE) __ 112

5.6. Perda de Solo por Erosão Laminar (A)__ 113

5.7. Potencial de Risco de Erosão Laminar (PRE) ___ 116

5.8. Análise da aplicação da EUPS na área de estudo___ 119

5.9. Resultados gerados pelo Modelo AVSWAT 2000___ 125

5.9.1.Caracterização Ambiental___ 125

5.9.2. Simulações - elaboração de cenários com base em componentes do balanço hídrico na EUPS e na produção de sedimentos __ 128

5.9.2.1.Microbacia Hidrográfica do Córrego Beija Flor____ 128

5.9.2.2. Microbacia Hidrográfica do Ribeirão das Guabirobas____ 136

5.10. Análise da aplicação do modelo SWAT na área de estudo ___ 144

5.11. EUPS e SWAT como indicadores ambientais de bacias hidrográficas ___ 147 
GLOSSÁRIO 171

APÊNDICE A 173

APÊNDICE B 203 


\section{INTRODUÇÃO}

\subsection{Considerações Iniciais}

Em meio aos cenários para o desenvolvimento da agricultura, no horizonte dos próximos anos, discute-se a idéia da "revolução superverde" ou "agroambiental", um esforço internacional ainda mais produtivo que a chamada "revolução verde", que consiga, ao mesmo tempo, preservar os recursos naturais e o meio ambiente (Crestana, 2000).

De um lado existem as preocupações pela busca de soluções mais sustentáveis para os atuais padrões produtivos. Todavia, do lado contrário, existem inúmeras pressões, demandas e interesses frente aos novos contingentes populacionais mundiais, à salubridade alimentar e ao crescimento econômico baseado na agricultura.

As florestas tropicais do mundo estão diminuindo em uma taxa de aproximadamente 29 ha./min (FAO, $2001^{1}$ apud Hewawasam, 2003). As previsões indicam que nos próximos 50 anos a demanda alimentar de uma população mais saudável e 50\% maior será o fator que mais afetará as mudanças ambientais globais. Se os impactos da ocupação das terras para aumento ou manutenção da produção agrícola continuarem como têm ocorrido, $10^{9}$ hectares de ecossistemas naturais serão convertidos para áreas agrícolas até 2050 (Tilman et al., 2001).

Entretanto, as causas do avanço da fronteira agrícola e da necessidade de aumento da produção não se devem unicamente ao crescimento populacional, mas principalmente aos interesses econômicos e à resposta da população às oportunidades econômicas mediadas por fatores institucionais. Dessa forma, a força global é a principal determinante das alterações no uso da terra, mas ela é potencializada ou atenuada por fatores e políticas nacionais, regionais e locais (Lambin et al., 2001).

No Brasil, a opção política pelo modelo exportador, a partir da década de 70 , forçou a busca de aumento da eficiência produtiva das áreas ocupadas e a incorporação de novas áreas (expansão da fronteira agrícola), visando oferecer alimentos em quantidade suficiente para a população urbana, bem como produzir commodities necessárias à geração das divisas requeridas pelo modelo macroeconômico adotado no País (Embrapa, 2003). Além disso, políticas de crédito rural e programas governamentais de desenvolvimento (atualmente extintos), como o Proálcool/1973 para incentivo do plantio da cultura de cana-de-açúcar (Fiorio et al., 2000) e o Provárzeas/1981 para incentivo ao uso agrícola das áreas de várzea (Azevedo, 1999), influenciaram as mudanças do uso da terra. Embora extintos, tais programas trouxeram

\footnotetext{
${ }^{1}$ Food and Agriculture Organization of the United Nations, 2001, State of the world's forest: Rome, Italy, 181p.
} 
consideráveis mudanças no uso da terra com repercussões até os dias atuais. A área ocupada pela monocultura da cana-de-açúcar continua a expandir de maneira drástica conforme foi constatado por Criscuolo et al. (2005).

Segundo Manzatto et al. (2002), durante a década de 90, o Brasil foi um dos poucos países do mundo a aumentar sua área agrícola, estimada ao final da década em cerca de 250 milhões de hectares, ocupando, atualmente, 27,6\% de seu território com atividades agrosilvipastoris. As áreas destinadas às unidades de conservação já demarcadas representam, na atualidade, cerca de 55 milhões de hectares, estimando-se que brevemente alcancem 10\% do território nacional com os processos de demarcação em curso. No entanto, considera-se que esse montante ainda seja insuficiente diante da necessidade de preservar os diversos biomas do país e de proteger a diversidade biológica.

Sauniti et al. (2004) observaram que na bacia hidrográfica do rio Passaúna, Estado do Paraná, entre os anos de 1991 e 2000, houve um incremento de 13\% para as áreas ocupadas com agricultura, pastagem, cultura permanente e desmatamento e redução de $6 \%$ nas áreas de preservação ocupadas por floresta aluvial, campo, reflorestamento e várzea.

Em função das pressões e incentivos, entre outros fatores, a produção agropecuária e florestal vem aumentando no país tanto pela expansão da fronteira agrícola como pelo aprimoramento dos sistemas produtivos. Isso é fundamental por razões econômicas (exportações contribuindo para o equilíbrio das contas públicas e inserção do Brasil no mercado globalizado) e sociais (geração de empregos, diminuição da fome e da pobreza). Porém, associados ao desenvolvimento, existem os custos ambientais (Embrapa, 2003).

Além da conversão dos sistemas naturais, com conseqüente perda da biodiversidade, devese salientar que a produção ainda é baseada, em grande parte, nos sistemas convencionais, intensivos em insumos e tecnologia, causando variados impactos nos ambientes. Em determinadas condições, os impactos podem ser benéficos, contribuindo para a melhoria da qualidade do meio. Entretanto, dependendo das condições em que as atividades são desenvolvidas, os impactos podem ser negativos.

A utilização de recursos limitados como nitrogênio, fósforo e água; o uso contínuo da camada arável do solo, submetida à mecanização pesada e intensa, aliado às práticas de cultivo que desconsideram a importância de sua cobertura, da matéria orgânica e da conservação da biodiversidade, além do uso intensivo de agrotóxicos, são algumas das práticas extremamente impactantes da agricultura moderna. Dentre os efeitos, distinguem-se as várias formas de degradação do solo: compactação, contaminação, desertificação, arenização, salinização, queimadas, mudança no fluxo de gases associado ao efeito estufa, erosão e descaracterização de áreas úmidas (Crestana, 2000; Tilman et al., 2001; Flores et al., 2002). Essas formas de 
degradação contribuem para o comprometimento da qualidade ambiental e o aumento da vulnerabilidade dos ecossistemas.

\subsection{Erosão do Solo e Impactos Ambientais}

Entre os fatores mencionados anteriormente, a erosão do solo é, provavelmente, a forma mais séria de degradação da paisagem ao redor do globo. As atividades antrópicas têm acelerado esse processo de maneira intensa. De acordo com Wilkinson (2005), os seres humanos são considerados os principais agentes causadores da erosão no planeta e isso pode resultar em impactos ambientais diversos além da perda de terras agricultáveis.

Tendo em vista os efeitos das mudanças ambientais globais, uma das incertezas ambientais críticas para os próximos anos refere-se às alterações que poderão ocorrer nos processos erosivos. Segundo Amore et al. (2004), a erosão do solo pode se tornar exagerada no futuro, em muitas partes do mundo, em decorrência das mudanças climáticas e da intensificação dos processos relacionados ao ciclo hidrológico.

Para os trópicos, especificamente, o problema é ainda mais grave, pois os eventos de precipitação e, conseqüentemente, de escoamento superficial de água, são fatores que atuam de maneira mais intensa nessas regiões compondo um cenário extremamente favorável aos processos erosivos e à degradação dos componentes ambientais solo e água. (El-Swaify e Dangler, 1982).

Ao longo dos ciclos produtivos de culturas anuais, existem períodos em que o solo permanece descoberto. De acordo com Troeh et al. (1999), a falta de cobertura do solo reduz sua proteção e pode acelerar as perdas por erosão em 10, 20, 50 e até mesmo 100 vezes. Dessa forma, a formação de novas camadas de solo não pode suprir as altas taxas de erosão. O solo vai se tornando cada vez mais fino, até restar uma pequena camada ou então se extinguir completamente.

Em função da erosão do solo, a qualidade das terras agrícolas em muitos países pobres está em declínio; acredita-se que aproximadamente um quarto das terras agrícolas do mundo em desenvolvimento esteja significativamente degradado e, ao longo dos últimos 50 anos, a taxa de degradação tenha acelerado (Bright, 2003).

Dentre as conseqüências internas e externas às propriedades agrícolas, um dos impactos diretos da aceleração dos processos erosivos é o aumento da produção de sedimentos. Os efeitos das cargas de sedimentos, por serem originados de fontes difusas, atingem o meio como um todo. A deposição de sedimentos ocorre, primeiramente, nas áreas mais baixas e com relevo mais 
plano. Não obstante, por serem os escoadouros naturais da paisagem, é nos recursos hídricos que a degradação ambiental tem sido verificada de maneira mais intensa.

Ao atingirem os corpos aquáticos, os sedimentos provenientes de áreas agrícolas, fontes alóctones, podem ocasionar o assoreamento desses sistemas. Tendo em vista que o Brasil possui um grande número de reservatórios artificiais para os diversos usos, inclusive geração de energia elétrica, as cargas de sedimentos podem diminuir o tempo de vida útil das represas. Leite e Espíndola (2004), estudando o reservatório de Salto Grande (Americana/SP), mensurou a sedimentação bruta na região à montante do reservatório, obtendo o valor de $72,87 \mathrm{~kg} / \mathrm{m}^{2}$.ano.

Um exemplo da prática agrícola moderna, em busca de alta produtividade, pode ser observado na região do município de Guaíra, interior do Estado de São Paulo, onde extensas áreas são ocupadas por agricultura intensiva (produção de feijão, soja, milho e tomate), sendo irrigadas por pivô central e tendo como características o uso intensivo de calcário, fertilizantes e pesticidas. Nessas áreas de produção intensiva, a perda de água e produção de sedimentos devem estar diretamente relacionadas aos processos poluidores. Filizola et al. (2002) realizaram o monitoramento e a avaliação do risco de contaminação por pesticidas em água superficial e subterrânea nessa região. Os resultados obtidos por esses autores indicaram que não houve contaminação da água subterrânea, mas, ocasionalmente, houve contaminação direta das águas de superfície.

Antes de atingirem as águas superficiais, os efeitos dos solos erodidos e poluentes agrícolas - sedimentos (impactos diretos), nutrientes e pesticidas a eles associados (impactos indiretos) - são usualmente observados nos sistemas de transição solo-água, as áreas alagadas, também chamadas de áreas de várzea ou áreas úmidas. Esses sistemas são intermediários entre os corpos aquáticos e o meio terrestre circundante.

As áreas alagadas são as águas temporárias ou intermitentes, geralmente associadas a sistemas de rios, com dimensões variadas e formando um gradiente contínuo entre áreas terrestres e áreas baixas, adjacentes ao sistema lótico, sendo por ele inundadas. Apresentam solo com lençol freático próximo à superfície e, periodicamente, lençol aflorante, além de características próprias de vegetação e fauna. São áreas de transição, denominadas tecnicamente de ecótones, que recebem grandes influências de sistemas terrestres e aquáticos. A flutuação de nível do lençol pode variar durante o ano climatológico de alguns centímetros a metros (Mitsch e Gosselink, 1986; Tundisi, 1989). Esses sistemas são também denominados de ATTZ, sigla em inglês para Aquatic-Terrestrial Transition Zones (Tracy-Smith, 2006).

A grande importância atribuída às áreas alagadas está relacionada ao desempenho de diversas funções: preservação da biodiversidade, contribuição para o suprimento de água de 
forma direta ou pela recarga de água subterrânea, fornecimento de proteção contra enchentes, estocagem de sedimentos impedindo sua transferência a rios e córregos, retenção e reciclagem de nutrientes, melhoramento da qualidade da água (facilitando os processos de degradação natural, podendo remover substâncias tóxicas), extração e fixação do carbono da atmosfera, estabilização das margens de rios e córregos, entre outras (Miller e Gardiner, 2001).

As áreas alagadas no Brasil somam cerca de 44,7 milhões de hectares e ocupam cerca de 5\% do território. Constituídas principalmente pelas classes dos Organossolos, Gleissolos, Planossolos e Neossolos, quando drenadas ou cultivadas, estão sujeitas a mudanças significativas em seus atributos. Embora não se disponha de dados oficiais, estima-se que a descaracterização desses solos seja expressiva em todas as regiões do País, em decorrência da drenagem para diversos fins como a expansão das terras para a agricultura, pecuária extensiva, urbanização, pavimentação de rodovias e ocupação das margens dos rios para fins diversos, ou da inundação por represas hidroelétricas (Flores et al., 2002).

Além das perdas espaciais, a descaracterização das áreas alagadas ocorre, em menor proporção, devido à sedimentação resultante de processos erosivos em terras altas (Flores et al., 2002). Tanto nas áreas alagadas como nos corpos aquáticos, a qualidade e quantidade dos detritos carreados para os sistemas aquáticos dependem das características físicas, químicas e biológicas das bacias de drenagem e da pressão antrópica no entorno (Bianchini Jr., 1999).

O solo, as áreas alagadas e a água são componentes ambientais fundamentais à manutenção da vida. Esses recursos estão se tornando mais limitados e cruciais com o crescente aumento populacional humano. A importância da conservação da produtividade do solo e da proteção da qualidade do solo, dos sistemas de transição e da água é inquestionável. O declínio da produtividade e o aumento da poluição podem espalhar o desastre para todos os habitantes do planeta. Esses componentes ambientais são finitos e já estão submetidos a um uso intensivo (Troeh et al. 1999).

\subsection{Planejamento Ambiental e Geotecnologias}

A conservação do solo, das áreas alagadas e da água está relacionada, devendo ser avaliada e conduzida de maneira conjunta. A degradação ambiental tem se tornado mais evidente e tornase necessário, cada vez mais, não apenas reverter esse processo, mas também prever danos futuros com base no planejamento e na gestão desses recursos.

Pires et al. (2002e) discorreram sobre as vantagens da utilização do conceito de bacia hidrográfica como unidade de planejamento e gerenciamento ambiental. Segundo os autores, as 
abordagens metodológicas utilizadas para estudar e gerenciar o espaço físico compreendido pela Bacia hidrográfica devem estar relacionadas às teorias e modelos que possam explicar, predizer e organizar adequadamente as informações úteis ao processo de gestão ambiental.

As microbacias hidrográficas rurais, extremamente importantes em termos regionais, necessitam de estudos e manejos adequados para que as funções econômicas, sociais e ambientais sejam integradas e harmonizadas.

De acordo com Pires et al. (2002e), a abertura de novas áreas para a agricultura e pecuária não considera aspectos relativos à conservação da biodiversidade, envolvendo desmatamentos em áreas particularmente ricas em diversidade biológica ou consideradas como refúgio ou corredores da fauna e flora silvestre. Segundo os autores, a perda de biodiversidade contempla alguns problemas interconectados como a fragmentação de habitats, o aumento na taxa de extinção de espécies e perda de estoque genético desconhecido de áreas de floresta desmatada. Por essa razão, permanecem como fronteira da ciência aspectos que relacionam a biodiversidade com o funcionamento e a subsistência de bacias hidrográficas.

Além da perda de biodiversidade, vale destacar que os variados usos dos solos das bacias hidrográficas, em todo o mundo, são cada vez mais complexos. Frente às preocupações, pressões mundiais, demandas sociais e interesses econômicos, o processo de gestão ambiental em busca da sustentabilidade agrícola desses sistemas é uma tarefa complexa.

A utilização de métodos para a interpretação de informações referentes aos diversos usos da terra e de possíveis impactos que podem ocorrer nos recursos edafo-hídricos de uma bacia de drenagem é uma tarefa extremamente importante, que contribui para a compreensão das implicações de cada opção de manejo dos sistemas. Nesse sentido, torna-se cada vez mais importante a realização de estudos intensivos em bacias hidrográficas para identificar áreas mais críticas. Em muitos casos, áreas pequenas, sub-bacias que apresentam maior vulnerabilidade ambiental são responsáveis pelos valores mais elevados de perda de solo, água, nutrientes e produção de sedimentos (Shaw et al., 1998; Tripathi et al., 2003; Calijuri e Bubel, 2006).

Por essa razão, torna-se necessário gerar dados sobre a situação inicial de uma determinada área de estudo, de ambientes pouco estudados ou de onde não existam informações, e quantificar os processos, para que sejam diagnosticadas áreas com maior risco ambiental. A partir dos primeiros registros, pode-se realizar o monitoramento e a avaliação, como parte do planejamento, tendo como base os indicadores dos aspectos da realidade que foram, inicialmente, determinados. Nessa fase posterior, é possível melhorar a qualidade das informações, as quais poderão servir, de maneira mais eficaz, para a formulação de políticas públicas ou aos tomadores de decisão, sejam governantes, empresários, representantes do poder público ou da sociedade organizada. 
O processo de tomada de decisão referente ao uso e manejo dos recursos e sistemas ambientais exige profundidade na interpretação das informações. Isso ocorre à medida que se aprimora a compreensão das implicações de cada opção de manejo dos sistemas (Shaw et al., 1998). A Figura 1 mostra a relação entre a quantidade de dados disponíveis e o seu valor e utilidade.

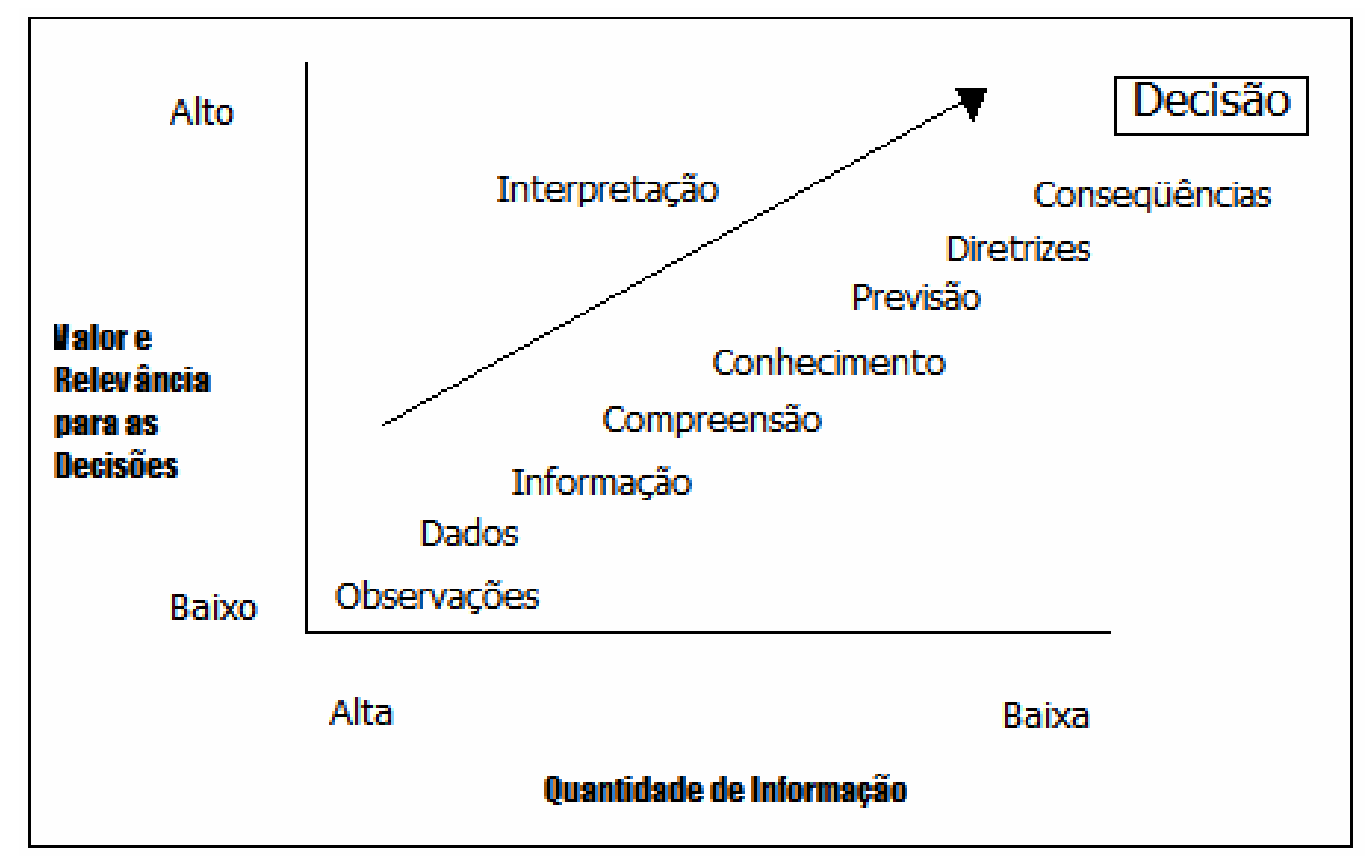

Figura 1 - Relação entre a quantidade de informação e o valor da informação em função do processo de tomada de decisão (Modificado de Whittaker, $1993^{2}$ apud Shaw et al., 1998).

A busca de ferramentas que contribuam com a melhoria da interpretação de informações referentes aos diversos usos da terra e suas conseqüências para os corpos aquáticos inseridos na bacia hidrográfica é uma tarefa extremamente importante tendo em vista que a qualidade do solo e da água sempre afetou a civilização humana.

A forma mais direta de controle das fontes não pontuais de poluição, em uma bacia hidrográfica, é a conservação do solo. Nesse sentido, o aspecto mais importante refere-se ao controle dos processos erosivos pela implementação de práticas conservacionistas, dentre as quais destacam-se o planejamento e o manejo de unidades hidrográficas, principalmente das áreas mais vulneráveis, como a mais promissora (Castro e Valério Filho, 1997).

\footnotetext{
${ }^{2}$ Whittaker, A.D. Decision support systems and expert systems for range science. In: Stuth, J.W.; Lyons, B.G. (eds.) Decision Support Systems for the Management of Grazing Lands: Emerging Issues. The Parthenon Publishing Group. P. 69-81. 1993.
} 
O planejamento conservacionista das terras é de fundamental importância para a conservação do solo, controle da perda de sedimentos e água, gerando informações importantes para o processo de tomada de decisão no gerenciamento de bacias hidrográficas.

Muitas teorias de planejamento e manejo ambiental têm sido desenvolvidas no intuito de reduzir a perda de solo em bacias hidrográficas com o objetivo de reduzir as cargas de sedimentos transportadas para as redes de drenagem hidrológicas (Amore et al., 2004).

De acordo com Alves et al. (2003), no planejamento agrícola ou de uso da terra existe uma seqüência de etapas que precisa ser seguida. Parte-se dos levantamentos e das caracterizações ambientais para as análises e avaliações, a fim de ser possível realizar o planejamento com sucesso (Fig. 2).

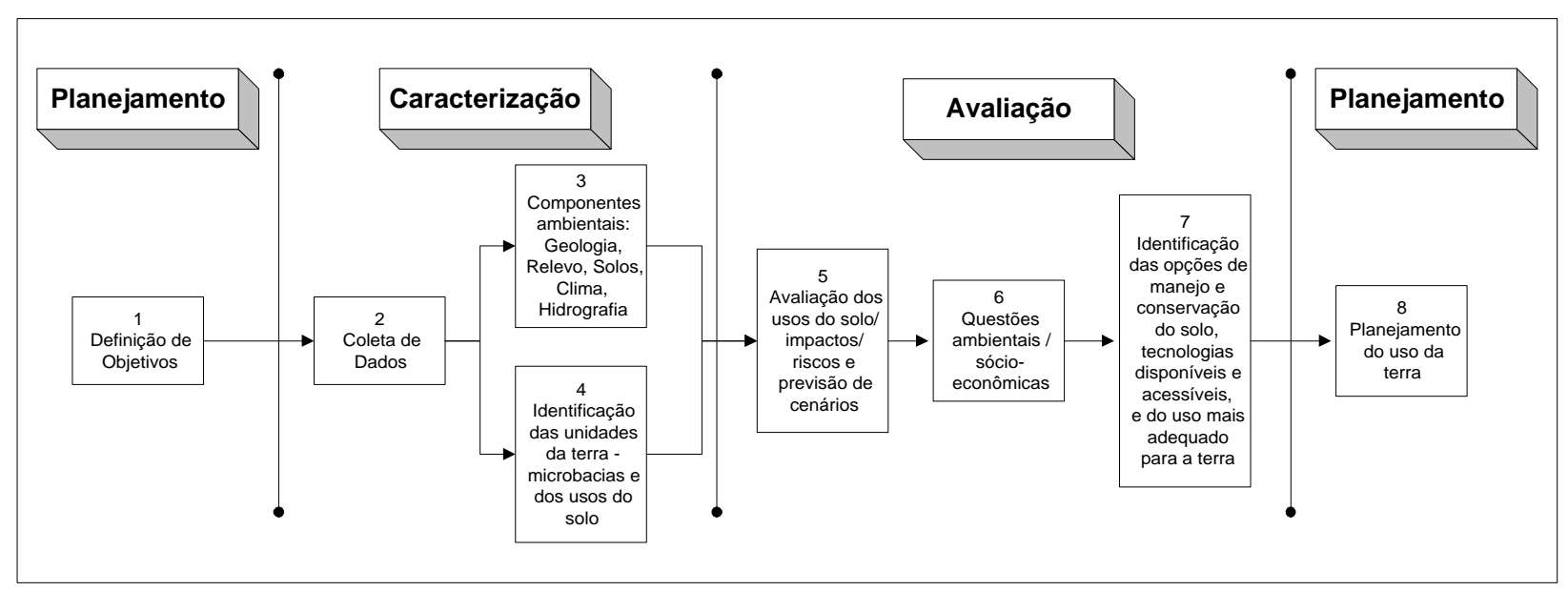

Figura 2. Etapas do processo de planejamento racional do uso da terra

(Modificado de FAO, $1990^{3}$ apud Alves et al., 2003)

A caracterização ambiental é uma etapa fundamental do processo de planejamento baseada no levantamento de dados e informações e no conhecimento da área a ser planejada. Com base no desenvolvimento de bancos de dados digitais e geoprocessamento, e no rápido acesso às informações armazenadas, a utilização de instrumentação computacional tem se tornado uma poderosa ferramenta para a realização da caracterização, de planejamentos e análises ambientais (Pinto e Crestana, 1997).

Um recurso computacional de grande importância é o Sistema de Informações Geográficas (SIG). O SIG é um sistema de informações projetado para trabalhar com dados georeferenciados. Isto é, o SIG é um banco de dados que permite ao usuário trabalhar com dados referenciados espacialmente e utilizá-los em operações computacionais. A estrutura raster, indicada para a realização de operações algébricas, se baseia na organização celular dos dados espaciais, isto é,

\footnotetext{
${ }^{3}$ Water and sustainable agricultural development. Rome: FAO. 1990. 48p. 
os valores existentes dos parâmetros de interesse (altitude, temperatura, uso da terra, entre outros) estão locados para cada célula (pixel) de composição de um mapa. A associação das estruturas raster e vector é fundamental para a realização de trabalhos de análise e planejamento ambiental.

Segundo Mattos (1998), o SIG é uma ferramenta de auxílio ao processamento da informação que pode incluir aspectos de superfícies de culturas, demográficos, econômicos, geográficos, de vistoria, monitoramento, mapeamento, cartografia, fotogrametria, sensoriamento remoto, paisagem e outros com ciências de computação. O SIG une as características de um local, um recurso e ou um aspecto com sua localização espacial. O grande volume de dados requeridos para análise e avaliação de problemas hidrológicos próximos à superfície, em escala regional, tem conduzido a um crescimento da demanda de base de dados computadorizada.

A avaliação ambiental de uma região, realizada com maior agilidade e eficiência pela utilização de SIG, permite que se identifiquem suas potencialidades de uso (inclusive o não uso), de ocupação, suas vulnerabilidades e seu desempenho futuro estimado, possibilitando, dessa maneira, que se otimizem decisões ligadas à sua preservação, conservação e ecodesenvolvimento (Macedo, 1991).

Acrescenta-se ainda que o processo de avaliação ambiental requer a proposição de variáveis facilmente detectáveis e mensuráveis, que possibilitem correlacionar os indicadores de alterações ambientais aos impactos iminentes ou futuros (Pessoa et al., 2003). Dessa forma, é extremamente útil a utilização de índices e de indicadores ambientais, os quais expressam valores ou fornecem informações sobre o estado de um fenômeno/área/ambiente com maior significado que apenas aquele relacionado diretamente ao seu valor quantitativo, respectivamente (OEDC, 1989). Martos e Maia (1997) também definem indicadores ambientais como todos os parâmetros, quantitativos ou qualitativos, capazes de evidenciar modificações no meio.

No intuito de avaliar a qualidade da água, a Agência de Proteção Ambiental dos Estados Unidos (EPA) desenvolveu um índice que envolve indicadores das condições e da vulnerabilidade dos recursos hídricos do país, de forma a avaliá-los antecipadamente (EPA, 2002). Os indicadores de condições foram desenvolvidos para mostrar a qualidade da água dos corpos aquáticos daquele país. Os indicadores de vulnerabilidade foram desenvolvidos com o objetivo de indicar onde as descargas de poluentes e outras atividades podem exercer pressão sobre as bacias hidrográficas.

Minoti e Crestana (2004) avaliaram a adoção e utilização da perda de solo como indicador de vulnerabilidade de bacias hidrográficas, de maneira quantitativa. De acordo com o universo de amostragem utilizado, os autores observaram que as informações eram extremamente 
escassas, principalmente no que se referia à previsão de cenários futuros em ambientes tropicais regionais.

Dentre os indicadores de vulnerabilidade pode-se mencionar o índice de potencial de escoamento superficial agrícola. Um dos componentes desse índice refere-se à modelagem das cargas de sedimentos que atingem os córregos e rios.

Reforçando a tendência de avaliar as condições atuais do ambiente e entender as transformações que estão ocorrendo para prever cenários futuros, a EPA publicou o Relatório de Avaliação Ambiental 2003 (EPA, 2003), no qual destaca como um dos indicadores das condições da água e bacias hidrográficas, a contaminação das águas interiores e costeiras por sedimentos.

Para Macedo (1991), a avaliação ambiental precisa estabelecer uma medida de comparação entre situações alternativas, mensurando-as e comparando-as. Dessa forma, é fundamental a utilização de conceitos de cenários ambientais, temporal e especificamente distintos, de modo que se proceda à avaliação entre as situações concretas e potenciais diversas, porém, essencialmente comparáveis.

Nos estudos de avaliação ambiental, para a elaboração de cenários, emprega-se um conjunto de técnicas específicas, como as de predição de impacto, destinadas a estimar a magnitude das alterações a serem causadas pelas atividades a serem desenvolvidas. Exemplos dessas técnicas envolvem o emprego da modelagem matemática, simulação de sistemas, avaliação da paisagem, projeções estatísticas, além de experimentos e medições no campo e no laboratório (Pessoa et al., 1997).

\subsection{Modelagem Ambiental}

A medição dos processos que ocorrem nas bacias hidrográficas, submetidas a usos diversos, é difícil. Segundo Reichardt e Timm (2004), a determinação das perdas de solo por erosão, por métodos diretos, é morosa e cara, sendo essa uma das principais causas do crescente interesse dos pesquisadores pelos modelos de predição da erosão.

Tendo em vista a complexidade de se estudar e prever os impactos ambientais, torna-se necessário o estudo integrado do problema analisado dado que os processos envolvidos na agricultura ou nos ambientes naturais não ocorrem de modo isolado, não podendo ser analisados de maneira reducionista. No caso das áreas agrícolas, seus sistemas de produção envolvem processos ecológicos, econômicos e sociais. O uso de modelos matemáticos e simuladores que representem e integrem as variáveis envolvidas nos processos de sustentabilidade aparecem 
como importante ferramenta na pesquisa. Os modelos permitem avaliar e compreender o comportamento de processos que possam induzir o aparecimento de impactos negativos. Muitas vezes, permitem visualizar o comportamento futuro do sistema com a criação de cenários ainda não explorados em experimentos reais, alertando o pesquisador para novas alternativas de pesquisas futuras ou para testes mais direcionados, reduzindo gastos e esforços (Pessoa et al., 1997).

Várias áreas do conhecimento integram seus esforços no sentido de diagnosticar, avaliar, monitorar, quantificar e prever os problemas ambientais por modelagem matemática e simulação. Na área de recursos hídricos, vários autores discorrem sobre os modelos hidrológicos, definindo-os e classificando-os.

Segundo Tucci (1998), “o modelo é a representação de algum objeto ou sistema, numa linguagem ou forma de fácil acesso e uso, com o objetivo de entendê-lo e buscar suas respostas para diferentes entradas".

Com base na revisão de Christofoletti (1999) sobre as tipologias dos modelos e nos trabalhos de Tucci (1987), Id. (1998) e Paiva (2001), os modelos podem ser classificados da seguinte forma:

- Quanto à estrutura - modelos empíricos (descritivos) e conceituais:

o Os modelos empíricos ou "caixa preta" são aqueles que ajustam os valores calculados aos dados observados, através de funções que não têm nenhuma relação com os processos físicos envolvidos.

o Os modelos conceituais equacionam os processos de transformação, o transporte de sedimentos e poluentes em escala de campo ou em bacias vertentes estruturados em processos físicos.

- Quanto à forma de análise dos processos - modelos globais (concentrados, genéricos) e distribuídos:

o Um modelo é global, ou concentrado, quando seus parâmetros e variáveis variam somente em função do tempo. Os modelos globais consideram a bacia vertente como uma unidade homogênea em toda a sua superfície. Os limites de aplicação são muito variáveis, podendo-se encontrar valores de $5 \mathrm{~km}^{2}$ a 500 $\mathrm{km}^{2}$.

o O modelo é distribuído quando os componentes variam também em função do espaço. Dividem a bacia vertente em unidades homogêneas de características uniformes, que são simuladas por um modelo global. Esse tipo de modelo não tem limite de área. 
- Quanto à escala temporal - modelos contínuos, discretos, baseados em período diário, mensal ou em períodos anuais. Um modelo é dito contínuo (tempo-contínuo) quando os fenômenos são contínuos no tempo, enquanto que o sistema é discreto quando as mudanças de estado se dão em intervalos discretos. Essa classificação encontra-se fundamentada na categoria dos dados disponíveis para o manejo e a computação. Se ocorrer disponibilidade de dados para intervalos menores, tais como horas ou minutos, o modelo poderá ser enquadrado nessas opções.

- Quanto à avaliação da chance de ocorrência das variáveis: modelos estocásticos (probabilísticos) e determinísticos:

o O modelo é estocástico quando a chance de ocorrência das variáveis é levada em conta e o conceito de probabilidade é introduzido na formulação do modelo.

o É determinístico quando a chance de ocorrência das variáveis é ignorada e o modelo segue uma lei definida que não a lei das probabilidades.

$\mathrm{Na}$ área agropecuária, os modelos matemáticos são utilizados, principalmente, para estudo dos processos erosivos e de transporte de agroquímicos para camadas mais profundas do solo até águas subterrâneas. Com algumas semelhanças aos sistemas de classificação da área de recursos hídricos, os modelos são classificados em conceituais, físicos e matemáticos, os quais são subclassificados em empíricos, determinísticos, estáticos, estocásticos ou dinâmicos (Pessoa et al., 1997). No trabalho desses autores pode-se encontrar, também, uma descrição das linguagens computacionais utilizadas na transcrição dos modelos matemáticos e desenvolvimento dos programas.

Para a elaboração de cenários futuros, em termos quantitativos, os modelos matemáticos de simulação podem auxiliar a incorporação dos variados fatores que influenciam o processo de tomada de decisão. Utilizando informações geradas por medições em campo ou disponibilizadas por pesquisadores ou publicações científicas, os modelos devem integrar tantas escalas quantas forem necessárias, como forma de obter respostas que tenham validades geofísica, biológica e administrativa.

A utilização de modelos matemáticos - empíricos, conceituais, determinísticos e estocásticos - apresenta-se como alternativa válida para a otimização dos processos de integração das variadas informações fornecendo objetividade e orientação mais direta aos processos investigados em SIGs (Castro \& Valério Filho, 1997).

No meio agronômico, os modelos matemáticos mais difundidos são os empíricos, essencialmente descritivos e identificados por equações matemáticas capazes de representar os dados experimentais de forma aceitável (Pessoa et al., 1997). Nas pesquisas relacionadas à perda 
de solo, no Brasil e em várias partes do mundo, utiliza-se, ordinariamente, a Equação Universal de Perda de Solo.

\subsubsection{Equação Universal de Perda de Solo (EUPS)}

De acordo com Wischmeier e Smith (1965), estudos controlados para a avaliação da erosão do solo, em parcelas experimentais no campo e pequenas microbacias hidrográficas, iniciaram-se em 1930 no intuito de conhecer os fatores que causam as perdas de solo e aqueles que reduzem tais perdas na produção agrícola. Esses estudos tiveram o objetivo de gerar e fornecer meios para o planejamento conservacionista de propriedades rurais.

O desenvolvimento de equações para o cálculo da perda de solo iniciou-se na década de 1940, no cinturão do milho nos EUA. Wischmeier e Smith (op. cit.) fornecem um histórico do desenvolvimento de equações para o cálculo da perda de solo até a publicação da Equação Universal de Perda de Solo (Universal Soil Loss Equation - USLE) em 1965.

A EUPS foi originalmente desenvolvida por Wischmeier e Smith (1978) para estimar a erosão laminar do solo em parcelas ou vertentes em áreas cultivadas ao leste das Montanhas Rochosas (EUA). Foi estabelecida com base nos estudos realizados em mais de 10.000 lotes, com distintas características de clima, solo, relevo e cultivo, de dimensões reduzidas e, portanto, submetidos, exclusivamente, a processos de erosão hídrica superficial do tipo laminar. A equação foi posteriormente adaptada para ser utilizada em outras áreas cultivadas nos EUA, Europa e para a região oeste da África tropical (Miller e Gardiner, 2001; Carvalho, 1994).

A EUPS é o principal modelo utilizado para avaliar o risco de erosão. Os conservacionistas do solo utilizam esse modelo, ao redor do mundo, na previsão da média anual da perda de solo devido à erosão laminar e em sulcos, sendo o método mais empregado para o cálculo da erosão em grandes áreas nos trópicos. Corresponde ao produto de seis parâmetros básicos, considerando fatores ativos e passivos. Os valores desses fatores podem sofrer alterações de uma região para outra, exigindo, muitas vezes, uma nova determinação ou a calibração dos parâmetros previamente estabelecidos (Miller e Gardiner, 2001; Carvalho, 1994).

A equação é utilizada com dois objetivos principais: dar suporte ao planejamento conservacionista de terras agrícolas, por possibilitar a simulação de sistemas produtivos com culturas alternativas, manejos e práticas distintas, e para a predição da perda total de solo com dados representativos das condições locais (Wischmeier e Smith, 1978; Özhan et al., 2005).

A utilização de modelos preditivos como a EUPS deve levar em conta que os processos erosivos envolvem uma vasta gama de escalas que incluem a simples parcela experimental para estudos científicos (Basic et al., 2004), a escala de campo ou de propriedade agrícola pelo 
interesse do produtor rural, a escala de bacia hidrográfica atendendo aos interesses da comunidade (Lufafa et al., 2003), e escalas regionais e nacionais de acordo com os interesses de legisladores e com a necessidade de desenvolvimento de políticas. Muitos estudos têm sido desenvolvidos para monitorar a erosão em áreas agrícolas. Esses trabalhos têm demonstrado que as taxas médias de perda de solo em escala de campo são muito menores do que áreas do tamanho de parcelas, reforçando a importância das escalas (Amore et al., 2004).

A EUPS é um dos instrumentos analíticos mais bem sucedidos para estudos prospectivos de processos de erosão superficial. É um modelo extremamente útil em iniciativas voltadas ao zoneamento ambiental em escalas e procedimentos menos detalhados e, ainda, como instrumento de simulação. Sua utilização em conjunto com sistemas digitais é cada vez mais freqüente, embora ainda persistam entraves e lacunas, em especial quanto à adequacidade de utilização em diferentes escalas e contextos ambientais (Castro e Valério Filho, 1997).

Tendo em vista que a equação foi derivada dos estudos em pequenos lotes, era utilizada, anteriormente, para estudo em áreas de até um hectare. $\mathrm{O}$ advento das geotecnologias - a possibilidade de elaboração de bancos de dados espaciais digitais, a utilização de sensoriamento remoto principalmente as imagens de satélite, a elaboração dos modelos numéricos do terreno possibilitou estender a aplicação da EUPS para toda a extensão das bacias hidrográficas e manipular os dados de maneira relativamente rápida nos Sistemas de Informações Geográficas (SIGs). A utilização desses sistemas tem vantagens óbvias possibilitando acesso rápido aos riscos de degradação ambiental de maneira espacializada (Cohen et al. 2005). Dessa forma, o método da EUPS, aliado às técnicas de geoprocessamento, possibilita a extrapolação das estimativas de perda de solo por erosão para trabalhos em escala de bacia hidrográfica.

A integração da EUPS com SIG facilita a manipulação dos dados, a entrada de dados e visualização dos resultados. As análises espaciais no formato grade do SIG permitem que o modelo seja aplicado às células individuais. Em contraste com os modelos concentrados tradicionais para previsão da erosão, o enfoque distribuído contribui para a identificação de áreas mais críticas, auxiliando a identificação dos usos da terra mais apropriados e das práticas de manejo mais adequadas para esses setores. Outra vantagem da utilização de SIG, conforme foi mencionado anteriormente, é a possibilidade de prever a perda de solo em áreas extensas por causa da capacidade de interpolação (Lufafa et al., 2003).

Apesar da relativa facilidade de aplicar a EUPS em regiões extensas e remotas, pela utilização de SIG, Cohen et al. (2005) observaram que o modelo apresentou limitada acurácia de previsão ao estudarem uma pequena bacia hidrográfica pertencente à bacia de drenagem do Lago Vitória, Quênia. Os resultados demonstraram que a aplicação da EUPS sem validação gerou falha na identificação de regiões com maior necessidade de intervenção. Tendo em vista que a 
aplicação da EUPS em escala de bacia hidrográfica é extremamente interessante e tem sido largamente utilizada, é importante observar que esse modelo apresenta algumas limitações, que podem ter ocasionado falhas nos resultados obtidos. Segundo os autores, dentre as limitações podem-se mencionar:

- A incerteza nos valores dos parâmetros, caso estejam incorretos, acarretará erros na sua propagação;

- As suposições de linearidade do modelo não podem ser aplicadas para certos casos que requerem enfoques não lineares;

- A EUPS é um modelo empírico desenvolvido para avaliação da perda de solo em escala de parcelas experimentais ou de campo. Não foi especificamente desenvolvido para aplicação em bacias hidrográficas.

Em relação à incerteza nos valores dos parâmetros, Sonneveld e Nearing (2003) afirmam que a fórmula matemática da EUPS, a multiplicação dos seis fatores, pode levar a erros elevados caso um dos fatores não tenha sido determinado corretamente.

Dentre as limitações da EUPS, Ranieri (1996) menciona o fato de a equação não considerar aspectos morfológicos das encostas, adotando-se para elas condições uniformes (perfís retilíneos).

De acordo com Kinell (2005), uma falha associada à EUPS é que o escoamento superficial não é diretamente considerado pelo modelo. Esse atributo pode gerar erros sistemáticos na previsão de eventos erosivos, o que, por sua vez, pode levar a erros na previsão da média anual de perda de solo.

Calhoun e Fletcher III (1999) utilizaram a EUPS na bacia hidrográfica do rio Hanalei (Havaí, EUA) para testar sua aplicabilidade em ambientes significativamente diferentes daqueles em que o modelo foi desenvolvido. As cargas de sedimentos medidas em campo variaram entre 45 e 101\% das taxas máximas de erosão previstas pelo modelo. Os valores obtidos, mais altos do que o esperado, foram interpretados como provenientes de erosão em voçorocas ou por deslocamento de massa, característicos dessa bacia hidrográfica. Tendo em vista que não é possível separar os materiais e indicar quais são provenientes da erosão superficial e quais são originados pelos movimentos de massa, a utilização da EUPS neste caso específico mostrou-se inadequada em função da limitação do modelo por não considerar os movimentos de massa nas estimativas de erosão.

Dentre os critérios que devem ser considerados ao utilizar SIG para a aplicação da EUPS em bacias hidrográficas, um dos mais importantes refere-se ao tamanho das células da grade. Molnár e Julien (1998) aplicaram a EUPS na bacia hidrográfica de Goodwin Creek, Estado do Mississipi/EUA, em tamanhos de grade variados (de 30x30m a 6x6km) e determinaram fatores 
de correção para a aplicação da equação na utilização de células com tamanhos maiores do que 30x30m. A análise dos autores levou a um aumento da compreensão do efeito do tamanho da célula da grade em cálculos de perda de solo e concluíram que a diminuição da resolução tem efeito direto sobre o fator S da equação. Quando o tamanho das células aumenta, os valores de declividade para células individuais diminuem, o que leva a uma subestimação da perda de solo.

Mati et al. (2000) estimaram a perda de solo por erosão na bacia hidrográfica do alto Ewaso Ng’iro, Quênia, aplicando a EUPS com a utilização de SIG com base em células de grade de 100x100m, resolução máxima conseguida diante dos dados disponíveis e da capacidade computacional. Segundo os autores, apesar de a utilização recomendada para a EUPS ser de escala de pequenos lotes, o tamanho da célula referente a 1 ha. foi considerado adequado em detalhamento pelo fato de o enfoque do trabalho ser baseado em uma escala de reconhecimento. Os resultados das estimativas do modelo foram considerados realistas quando comparados aos valores de perda de solo medidos em parcelas experimentais, às análises de reconhecimento dos processos erosivos em campo e às cargas de sedimentos transportadas pelos maiores cursos d'água, o que mostrou que a equação pode ser aplicada em toda a bacia hidrográfica. Entretanto, os valores mínimos e máximos variaram evidenciando que as previsões são menos acertadas nos extremos.

No Brasil, a EUPS tem sido largamente utilizada em trabalhos de gestão agrícola e de pesquisa. A equação foi adaptada às condições do Estado de São Paulo pelos trabalhos de Bertoni et al. (1975), Lombardi Neto e Bertoni (1975a), Lombardi Neto e Bertoni (1975b) e Lombardi Neto e Moldenhauer (1980). Os trabalhos pioneiros desenvolvidos por esses autores, estimularam o desenvolvimento de inúmeras pesquisas tanto para o estabelecimento dos parâmetros da equação para as diferentes regiões do país como para a aplicação da EUPS. Na Tabela 2, podem-se observar as características de alguns trabalhos de pesquisa mais recentes realizados com base na aplicação da EUPS.

No que se relaciona às escalas, Ranieri et al. (1997) avaliaram diferentes métodos e escalas de trabalho para a determinação do risco de erosão na Bacia hidrográfica do Ribeirão dos Marins (Piracicaba/SP). Utilizando a EUPS como método quantitativo, os autores compararam a aplicação do modelo em escala detalhada (base de dados composta por mapas com escalas variando de 1:10.000 a 1:25.000) e escala generalizada (base de dados composta por mapas com escalas variando de 1:50.000 a 1:100.000) e observaram que não houve grande diferença nos mapas de risco de erosão pela alteração das escalas, os resultados foram semelhantes. 
Tabela 2: Informações gerais sobre alguns trabalhos realizados no Brasil envolvendo a aplicação da Equação Universal de Perda de Solo.

\begin{tabular}{|c|c|c|}
\hline Referência & Local do Estudo & Características \\
\hline Fernández (1996) & $\begin{array}{l}\text { Microbacia hidrográfica do } \\
\text { córrego do Pinheirinho } \\
\text { (Sumaré/SP) }\end{array}$ & $\begin{array}{l}\text { Cálculo manual do fator LS } \\
\text { associado ao SIG-Spring. } \\
\text { Identificou o comprimento de } \\
\text { encosta e a declividade como } \\
\text { causas de superestimação da } \\
\text { erosão em microbacias } \\
\text { hidrográficas. }\end{array}$ \\
\hline Ranieri et al. (1997) & $\begin{array}{c}\text { Bacia hidrográfica do ribeirão } \\
\text { dos Marins (Piracicaba/SP) }\end{array}$ & $\begin{array}{l}\text { Elaboraram mapas de risco à } \\
\text { erosão por método qualitativo e } \\
\text { pela EUPS, em escalas } \\
\text { generalizada e detalhada. As } \\
\text { diferenças nos mapas ocorreram } \\
\text { entre os métodos e não entre as } \\
\text { escalas. }\end{array}$ \\
\hline Ranieri et al. (1998) & $\begin{array}{l}\text { Microbacia hidrográfica do } \\
\text { córrego do Ceveiro } \\
\text { (Piracicaba/SP) }\end{array}$ & $\begin{array}{l}\text { Elaboraram o Índice Ponderado } \\
\text { de Risco de Degradação - IPD } \\
\text { em função das classes de risco à } \\
\text { erosão do solo. }\end{array}$ \\
\hline Lagrotti (2000) & $\begin{array}{l}\text { Microbacia hidrográfica do } \\
\text { córrego do Jardim (Santo } \\
\text { Antônio do Jardim/SP) }\end{array}$ & $\begin{array}{l}\text { Aplicou a EUPS juntamente com } \\
\text { a determinação da Capacidade de } \\
\text { Uso da Terra. Elaborou o risco } \\
\text { ambiental para o município e } \\
\text { mapa de adequação ao uso da } \\
\text { terra. }\end{array}$ \\
\hline Ranieri (2000) & $\begin{array}{c}\text { Microbacia hidrográfica inserida } \\
\text { na MBH do córrego do Ceveiro } \\
\text { (Piracicaba/SP) }\end{array}$ & $\begin{array}{l}\text { Estimou a erosão do solo } \\
\text { utilizando dois modelos - EUPS } \\
\text { e WEPP }\end{array}$ \\
\hline Brandão (2001) & $\begin{array}{l}\text { Bacia do ribeirão Pinhal } \\
\text { (Limeira/SP) }\end{array}$ & $\begin{array}{l}\text { Estimou o potencial natural de } \\
\text { erosão superficial e avaliou as } \\
\text { áreas de risco de degradação dos } \\
\text { recursos hídricos. }\end{array}$ \\
\hline Fujihara (2002) & $\begin{array}{l}\text { Microbacia hidrográfica do } \\
\text { ribeirão Itambi, municípios de } \\
\text { Panorama e Ouro Verde, SP. }\end{array}$ & $\begin{array}{l}\text { EUPS. O manejo inadequado das } \\
\text { terras foi responsável pela } \\
\text { intensificação dos processos } \\
\text { erosivos com a formação de } \\
\text { sulcos, ravinas e voçorocas. }\end{array}$ \\
\hline Marcomin (2002) & $\begin{array}{c}\text { Bacia hidrográfica do rio } \\
\text { Pinheiros (Municípios de } \\
\text { Orleans e São Ludgero/SC). }\end{array}$ & $\begin{array}{l}\text { EUPS. A média de perda de solo } \\
\text { da bacia hidrográfica foi cerca de } \\
14,4 \text { vezes maior que o limite de } \\
\text { tolerância máximo para os solos } \\
\text { da área. }\end{array}$ \\
\hline Silviero e Coiado (2003) & $\begin{array}{l}\text { Sub-bacia hidrográfica do rio } \\
\text { Atibaia (Vários municípios na } \\
\text { região de Campinas/SP) }\end{array}$ & $\begin{array}{l}\text { Comparou os resultados da } \\
\text { EUPS com o volume de } \\
\text { sedimentos transportados em } \\
\text { uma seção de medidas do rio } \\
\text { Atibaia. }\end{array}$ \\
\hline
\end{tabular}


Tabela 2 (Continuação): Informações gerais sobre alguns trabalhos realizados no Brasil envolvendo a aplicação da Equação Universal de Perda de Solo.

\begin{tabular}{|c|c|c|}
\hline Referência & Local do Estudo & Características \\
\hline Paiva et al. (2003) & $\begin{array}{l}\text { Bacia hidrográfica do rio Una } \\
\text { (Taubaté/SP) }\end{array}$ & $\begin{array}{l}\text { EUPS. } 61,53 \% \text { da área de estudo } \\
\left(432,18 \mathrm{~km}^{2}\right) \text { com perdas de solo } \\
\text { acima da tolerância. }\end{array}$ \\
\hline Marques et al. (2003) & $\begin{array}{c}\text { Microbacia hidrográfica do } \\
\text { Córrego Taquara Branca } \\
\text { (Sumaré/SP) }\end{array}$ & $\begin{array}{l}\text { EUPS e MEUPS. Hipótese de } \\
\text { construção de terraços reduziu } \\
\text { em } 68 \% \text { os gastos monetários } \\
\text { necessários à reposição dos } \\
\text { nutrientes perdidos por erosão. }\end{array}$ \\
\hline Galdino et al. (2004) & $\begin{array}{l}\text { Bacia hidrográfica do Alto } \\
\text { Taquari (MS e MT) }\end{array}$ & $\begin{array}{l}\text { EUPS. Valor médio de perda de } \\
\text { solo - } 555,6 \mathrm{t} / \mathrm{ha} \text {.ano } \\
\text { Valor mais elevado - Neossolo } \\
\text { Litólico }-1.839,6 \mathrm{t} / \mathrm{ha} \text {.ano } \\
\text { Perda de solo em pastagens } \\
\text { maior do que o dobro da perda } \\
\text { em áreas cultivadas com soja. }\end{array}$ \\
\hline Bueno e Stein (2004) & $\begin{array}{c}\text { Região do Município de } \\
\text { Brotas/SP }\end{array}$ & $\begin{array}{l}\text { Em uma área de } 580 \mathrm{~km}^{2} \text { foram } \\
\text { estudadas glebas submetidas a } \\
\text { diferentes usos da terra. } 35 \% \text { das } \\
\text { glebas escolhidas apresentaram } \\
\text { expectativa de erosão. }\end{array}$ \\
\hline Barreto Neto (2004) & $\begin{array}{c}\text { Bacia hidrográfica do rio } \\
\text { Quilombo (Vale do Ribeira/SP) }\end{array}$ & $\begin{array}{llr}\text { MEUPS. } & \text { Elaboração de } & 5 \\
\text { cenários de produção } & \text { de } \\
\text { sedimentos }- \text { de ocupação por } \\
\text { floresta até solo descoberto. }\end{array}$ \\
\hline
\end{tabular}

Além dos valores totais de perda de solo, estimados pela EUPS, é importante observar que nos casos onde a taxa de erosão é menor do que a taxa de incremento da profundidade do solo, os solos tornam-se mais profundos com o tempo. Esse é o caso para a maior parte dos bem drenados e cobertos por vegetação densa. No entanto, a agricultura pode modificar, substancialmente, as taxas de formação do solo e de erosão/sedimentação. Com a remoção da cobertura natural do solo e sua substituição por culturas, a proteção dele contra a ação da chuva e do vento torna-se ausente ou menos eficiente. Como conseqüência, a taxa de erosão aumenta e pode tornar-se mais elevada que a taxa de incremento, resultando na perda de sua profundidade (Sparovek e Van Lier, 1997).

No intuito de preservar os solos da perda excessiva de profundidade e conseqüente degradação das propriedades físicas, químicas e biológicas, foi desenvolvido o conceito de tolerância à erosão $(\mathrm{T})$. $\mathrm{O}$ valor de tolerância é suposto com base na taxa natural de formação (recomposição) do solo.

De acordo com Bertoni e Lombardi Neto (1999, p. 86), “a tolerância de perda de solo é a quantidade de terra que pode ser perdida por erosão, expressa em toneladas por unidade de 
superfície e por ano, mantendo ainda o solo com elevado nível de produtividade por longo período de tempo".

Com o produto parcial dos fatores da EUPS, os resultados totais da EUPS e os valores de tolerância do solo à erosão, outros parâmetros podem ser estabelecidos a fim de ampliar a discussão relacionada ao risco à erosão, reforçando as aplicações do modelo. Dentre os parâmetros pode-se citar o Potencial Natural de Erosão Laminar (PNE), a Expectativa de Risco à Erosão Laminar (ERE), e o Potencial de Risco de Erosão Laminar (PRE).

Além das variadas aplicações, a EUPS não prevê o transporte ou a deposição de sedimentos, os resultados apenas prevêem a susceptibilidade à perda de solo nas áreas onde é aplicada. No intuito de simular outros processos, torna-se necessário o uso de modelos que compreendam, de maneira direta, um maior número de processos.

Em sistemas complexos como as bacias hidrográficas, combinando processos naturais como precipitação, evapotranspiração, deflúvio superficial e subterrâneo com fatores relativos às atividades humanas tais como desmatamento, produção agrícola e construção de represas, é impossível uma representação completa de cada processo associado ao ciclo hidrológico, à erosão e à produção e destino dos sedimentos. Nesse sentido, é extremamente vantajosa a utilização de modelos que contemplem essa sucessão de estados ou mudanças simplificando uma realidade complexa por meio da utilização de alguns aspectos de maior importância envolvidos nos processos mencionados (Blackie e Eeles, $1985^{4}$ apud Griebeler et al., 2001).

Modelos computacionais conceituais têm sido desenvolvidos para representar esses processos naturais e antrópicos. Tais modelos vêm sendo utilizados como ferramentas de suporte ao entendimento de processos que são difíceis de mensurar e como forma de prever os efeitos das alterações no uso e na cobertura do solo (Kite e Droogers, 2000).

Com base nos estudos de Ranieri (1996), Souto (1998), Jetten et al. (1999), Paiva (2001), Singh e Frevert (2002), Garrido (2003), Silva e Crestana (2004), Reichardt e Timm (2004), na Tabela 3 estão exemplificados alguns dos modelos conceituais desenvolvidos para simular processos de erosão, produção de sedimentos e processos hidrológicos em escalas de campo e de bacia hidrográfica.

\footnotetext{
${ }^{4}$ Blackie, J.R.; Eeles, C.W. Lumped catchment models. In: Anderson, M.G.; Burt, T.P. (eds.). Hydrological forecasting. Willey, Chichester, 1985. p. 311-345.
} 
Tabela 3: Alguns modelos utilizados para simular processos hidrológicos ou erosivos em escalas de campo e de bacia hidrográfica (Tucci, 1998; Jetten et al., 1999; Paiva, 2001; Silva e Crestana, 2004).

\begin{tabular}{|c|c|c|}
\hline Nome do Modelo & Abreviatura & Referência \\
\hline \multicolumn{3}{|c|}{ Modelos desenvolvidos para trabalhos em escala de campo } \\
\hline $\begin{array}{l}\text { Chemicals, runoff and erosion from } \\
\text { agricultural management systems }\end{array}$ & CREAMS & Knisel, 1985 \\
\hline Climatic index for soil erosion potential & CSEP & Kirkby e Cox, 1995 \\
\hline Erosion-productivity impact calculator & EPIC & Williams, 1985 \\
\hline European soil erosion model & EUROSEM & Morgan et al., 1998; Quinton, 1994 \\
\hline $\begin{array}{lcc}\text { Groudwater loading effects } & \text { of } \\
\text { agricultural management systems } & \end{array}$ & GLEAMS & Knisel, 1991 \\
\hline $\begin{array}{l}\text { Agricultural Soil Erosion Evaluation } \\
\text { Model }\end{array}$ & IMPIERO & Licznar e Nearing, 2003 \\
\hline Revised Universal Soil Loss Equation & RUSLE & Renard et al., 1991 \\
\hline Universal soil loss equation & USLE & Wischmeier e Smith, 1978 \\
\hline Water erosion prediction project & WEPP & Flanagan e Nearing, 1995 \\
\hline \multicolumn{3}{|c|}{ Modelos desenvolvidos para trabalhos em escala de bacia hidrográfica } \\
\hline $\begin{array}{l}\text { Agricultural catchments research unit } \\
\text { model }\end{array}$ & ACRU & Schulze, 1989; New e Schulze, 1996 \\
\hline $\begin{array}{l}\text { Agricultural non-point source pollution } \\
\text { model }\end{array}$ & AGNPS & Young et al., 1989 \\
\hline $\begin{array}{l}\text { Areal Non-point Source Watershed } \\
\text { Environment Response Simulation }\end{array}$ & ANSWERS & Beasley e Huggins, 1981 \\
\hline $\begin{array}{lll}\text { Catchment } & \text { Hydrology } & \text { Distributed } \\
\text { Model } & & \end{array}$ & CHDM & Lopes, 1995 \\
\hline Dynamic Watershed Simulation Model & DWSM & Borah et al. 2002 \\
\hline $3 \mathrm{D}$ erosion model & EROSION3D & Schmidt et al., 1999 \\
\hline European soil erosion model & EUROSEM & Morgan et al., 1998; Quinton, 1994 \\
\hline Kinematic runoff and erosion model & KINEROS2 & Smith et al., 1995 \\
\hline Limburg soil erosion model & LISEM & De Roo et al., 1996a,b \\
\hline $\begin{array}{l}\text { Soil erosion model associated with } \\
\text { MEDALUS project }\end{array}$ & MEDRUSH & Kirkby, 1998 \\
\hline MIKE SHE & MIKE SHE & DHI, 1993; Refsgaard e Storm, 1995 \\
\hline Modified Universal Soil Loss Equation & MUSLE & \\
\hline Routing Outputs to Outlet & ROTO & Arnold et al., 1995 \\
\hline $\begin{array}{l}\text { Semi-distributed Land Use-based Runoff } \\
\text { Processes }\end{array}$ & SLURP & Lacroix et al., 2002 \\
\hline Soil and Water Assessment Tool & SWAT & Arnold et al., 1998 \\
\hline $\begin{array}{l}\text { Simulator for Water Resources in Rural } \\
\text { Basins }\end{array}$ & SWRRB & $\begin{array}{l}\text { Williams et al. 1985; Arnold et al., } \\
1990\end{array}$ \\
\hline TOPMODEL & TOPMODEL & Beven et al., 1994; Beven e Freer, 2001 \\
\hline Watershed Erosion Simulation Program & WESP & Lopes, 1995 \\
\hline
\end{tabular}


A maior limitação ao uso de modelos complexos é a dificuldade em trabalhar a grande quantidade de dados que descrevem a heterogeneidade dos sistemas naturais. A utilização desses modelos associada aos SIGs, com o desenvolvimento de bases de dados digitais, permite que os dados espaciais referentes a grandes áreas heterogêneas sejam divididos em pequenas unidades hidrologicamente homogêneas, sobre as quais os modelos são aplicados (Machado e Vettorazzi, 2003).

Dentre os modelos conceituais que têm sido utilizados, com maior frequência, em trabalhos de pesquisa no Brasil, destacam-se o AGNPS, o WEPP e o SWAT.

Souto (1998) utilizou o modelo AGNPS na previsão dos processos erosivos em microbacias hidrográficas no Estado do Paraná. De acordo com o autor, o modelo foi desenvolvido para a obtenção de estimativas de quantidade e qualidade do escoamento superficial, com ênfase nos nutrientes, pesticidas e sedimentos, e de impactos na qualidade da água em bacias de até 20.000 ha.

A aplicação do AGNPS, utilizando-se microcomputador e Sistemas de Informações Geográficas, ocorre em três estágios, baseados em 23 (vinte e três) parâmetros de informação para cada célula. Os cálculos iniciais são realizados no primeiro estágio. Eles incluem estimativas da erosão do solo, volume e tempo do fluxo de escoamento superficial, nível de poluentes solúveis que deixam a bacia, além de sedimentos e do escoamento superficial que deixam os terraços. No segundo estágio, calcula-se o volume de escoamento superficial que deixa a célula com terraços e a produção de sedimentos para a célula primária. O fluxo de sedimentos e nutrientes através da bacia se realizam no terceiro estágio. Na simulação, o modelo trabalha com um simples evento de base, presumindo que os padrões de precipitação sejam uniformes. Os componentes básicos do modelo incluem: hidrologia, erosão, transporte químico e sedimentos (Souto, 1998).

O modelo WEPP foi utilizado por Ranieri (2000), juntamente com a EUPS, para a estimativa de erosão em microbacia de 75,8 hectares, com vários usos da terra, na região de Piracicaba/SP. A aplicação dos modelos foi feita com o auxílio de Sistema de Informações Geográficas, com base no desenvolvimento de interface computacional para tornar possível o processamento georeferenciado dos resultados de perda e deposição de sedimentos.

Alguns trabalhos de pesquisa utilizaram o modelo SWAT, parte dos processos simulados pelo modelo, em diferentes regiões. Uma breve descrição desses trabalhos pode ser observada na Tabela 4. 
Tabela 4: Informações gerais sobre os trabalhos desenvolvidos no Brasil envolvendo a aplicação do modelo SWAT.

\begin{tabular}{|c|c|c|}
\hline Referência & Local do Estudo & Características \\
\hline Oliveira, 1999 & $\begin{array}{l}\text { Bacia hidrográfica do rio } \\
\text { Joanes (Estado da Bahia) }\end{array}$ & $\begin{array}{l}\text { Avaliação das conseqüências das } \\
\text { alterações no uso da terra e construção de } \\
\text { represas nas características } \\
\text { hidrossedimentológicas da BH e } \\
\text { repercussões na zona costeira. Utilização } \\
\text { da versão SWAT 96.2. Realizou } \\
\text { calibração da vazão líquida. }\end{array}$ \\
\hline $\begin{array}{c}\text { Machado, 2002; } \\
\text { Machado e Vettorazzi, 2003; } \\
\text { Machado et al. } 2003\end{array}$ & $\begin{array}{l}\text { Microbacia hidrográfica do } \\
\text { ribeirão dos Marins } \\
\text { (Piracicaba/SP) }\end{array}$ & $\begin{array}{l}\text { Simulação do escoamento superficial e da } \\
\text { produção de sedimentos na MBH. } \\
\text { Compararam valores simulados aos } \\
\text { observados. Simulação de cenários de uso } \\
\text { da terra. Utilização da versão SWAT- } \\
2000 \text {. }\end{array}$ \\
\hline Garrido, 2003 & $\begin{array}{l}\text { Bacia hidrográfica do rio } \\
\text { Jiquiriçá (Estado da Bahia) }\end{array}$ & $\begin{array}{l}\text { Avaliação da aplicabilidade do modelo } \\
\text { para a simulação do comportamento } \\
\text { hidrológico da BH comparando valores } \\
\text { simulados aos observados. Utilização da } \\
\text { versão SWAT-2000. }\end{array}$ \\
\hline Prado, 2005 & $\begin{array}{l}\text { Bacia hidrográfica do rio } \\
\text { Jundiaí-Mirim } \\
\text { (Jundiaí/SP) }\end{array}$ & $\begin{array}{l}\text { Estimativa da produção de sedimentos e } \\
\text { simulação de cenários frente às mudanças } \\
\text { de uso da terra na BH nas últimas } \\
\text { décadas. Utilização da versão SWAT- } \\
2000 \text {. }\end{array}$ \\
\hline Neves, 2005 & $\begin{array}{c}\text { Microbacia hidrográfica do } \\
\text { rio Bonito } \\
(\text { Descalvado/SP) }\end{array}$ & $\begin{array}{l}\text { Estimativa da produção de sedimentos } \\
\text { relacionando-os com dejetos animais e } \\
\text { potencial contaminação dos corpos } \\
\text { aquáticos. Utilização da versão SWAT- } \\
2000 \text {. }\end{array}$ \\
\hline Silva, 2005 & $\begin{array}{l}\text { Microbacia hidrográfica do } \\
\text { ribeirão Canchim } \\
\text { (São Carlos/SP) }\end{array}$ & $\begin{array}{l}\text { Estimativa da produção de sedimentos em } \\
\text { uma sub-bacia hidrográfica experimental. } \\
\text { Utilização da versão SWAT-2000. }\end{array}$ \\
\hline Silva, 2006 & $\begin{array}{l}\text { Microbacia hidrográfica do } \\
\text { ribeirão Canchim } \\
\text { (São Carlos/SP) }\end{array}$ & $\begin{array}{l}\text { Estimativa da produção de sedimentos } \\
\text { relacionando-os com a qualidade de água } \\
\text { de corpos aquáticos em uma sub-bacia } \\
\text { hidrográfica experimental. Utilização da } \\
\text { versão SWAT-2000. }\end{array}$ \\
\hline
\end{tabular}

Vários modelos físicos de parâmetros distribuídos - ANSWERS, AGNPS, WEPP, SWRRB e SWAT - têm sido modificados e utilizados, no Brasil e ao redor do mundo, para prever o escoamento superficial, a erosão e o transporte de sedimentos e nutrientes de bacias hidrográficas agrícolas submetidas a diferentes manejos. Entre esses modelos, o "Soil and Water Assessment Tool" (SWAT) é o mais recente, utilizado com sucesso na simulação do escoamento, das cargas de sedimentos e da qualidade da água de pequenas bacias hidrográficas (Tripathi et al., 2003). 
Garrido (2003), ao analisar diversos modelos de simulação hidrológica, concluiu que o SWAT mostrou-se o mais completo em termos de número de componentes simulados, representando uma vantagem do modelo, possibilitando a análise de cenários de diversas situações climáticas, uso da terra, aplicação de fertilizantes e pesticidas, implantação de reservatórios, etc.

\subsubsection{Soil and Water Assessment Tool (SWAT)}

O SWAT - "Soil and Water Assessment Tool” (Arnold et al., 1998) - é um simulador desenvolvido pelo Serviço de Pesquisa Agrícola (ARS) dos Estados Unidos, representado por vários modelos matemáticos fundamentados no conhecimento das características físicas de bacias hidrográficas agrícolas. Foi desenvolvido para prever o impacto das práticas de manejo do solo nos ambientes aquáticos superficiais e subterrâneos em bacias de drenagem complexas, em geral de grande extensão, com variação dos tipos de solos, do uso e das condições de manejo em longos períodos de tempo.

Algumas das características básicas do modelo SWAT, versão 2000, são relacionadas a seguir (Arnold et al., 1998; Neitsch et al., 2002):

- O modelo requer informações específicas sobre o clima, as propriedades do solo, a topografia, a vegetação e as práticas de manejo do solo que ocorrem na bacia hidrográfica. Os processos físicos associados ao movimento da água, movimento dos sedimentos, crescimento das culturas, ciclagem de nutrientes, entre outros, são diretamente modelados pelo modelo utilizando esses dados de entrada. O aspecto positivo dessa característica do modelo é que bacias hidrográficas sem dados de monitoramento também podem ser modeladas;

- É computacionalmente eficiente, podendo simular extensas bacias hidrográficas sem gastos excessivos de tempo;

- É um modelo contínuo, capaz de simular os efeitos das mudanças no uso e manejo do solo em longos períodos de tempo. Em alguns processos, os resultados apenas são obtidos após a simulação de décadas. O modelo não foi desenvolvido para simular eventos isolados de precipitação;

- O modelo não requer calibração caso não existam informações disponíveis e de qualidade (a calibração não é possível em bacias hidrográficas não instrumentadas). 
Garrido (2003), utilizando a classificação proposta por Tucci (1998), identificou o SWAT como um modelo de simulação matemática contínuo, semidistribuído, determinístico e semiconceitual.

O SWAT é o resultado da incorporação de fatores de vários modelos desenvolvidos pelo ARS e uma evolução direta da junção dos simuladores SWRRB (Simulator for Water Resources in Rural Basins) (Williams et al., 1985; Arnold et al., 1990) com o ROTO (Routing Outputs to Outlet) (Arnold et al., 1995). Modelos específicos de simuladores conhecidos contribuíram para a elaboração do SWAT como o CREAMS (Chemicals, Runoff, and Erosion from Agricultural Management Systems) (Knisel, 1980), GLEAMS (Groundwater Loading Effects on Agricultural Management Systems) (Leonard et al., 1987), EPIC (Erosion-Productivity Impact Calculator) (Williams et al., 1984). Uma outra característica extremamente positiva do SWAT é que, após sua criação no início da década de 1990, o seu modelo tem sido continuamente aprimorado resultando em novas versões do simulador: SWAT 94.2, SWAT 96.2, SWAT 98.1, SWAT 99.2, SWAT 2000 e, a mais recente, SWAT 2005. Além dessas modificações, foi desenvolvida, também, interface no Windows (Visual Basic) com o ArcView - ArcView versão 3.1 (com extensão ArcView Spatial Analyst v. 1.1) (Esri, 1998). Ao utilizar a interface com o ArcView o simulador recebe o nome de "ArcView Soil Water Assessment Tool" - AVSWAT 2000 (Neitsch et al., 2002a).

O modelo SWAT permite que diferentes processos físicos sejam simulados em uma bacia hidrográfica e, também, que bacias ou microbacias hidrográficas sejam divididas em sub-bacias. A utilização de sub-bacias pode ser particularmente benéfica quando diferentes áreas da bacia hidrográfica são dominadas por solos ou usos diferentes, o que resulta em diferenças nas suas características hidrológicas.

O balanço hídrico é a força que conduz todos os processos simulados pelo SWAT. A simulação hidrológica da bacia hidrográfica é separada em duas grandes divisões: a fase terrestre do ciclo hidrológico e a fase aquática. A fase terrestre controla a quantidade de água e as cargas de sedimento, nutrientes e pesticidas que atingem o canal principal de cada sub-bacia. A fase aquática está relacionada ao movimento de água, sedimentos, entre outros, pela rede de canais em direção à saída (vertedouro) da bacia hidrográfica.

O modelo apresenta os seguintes componentes: clima, ciclo hidrológico, nutrientes e pesticidas, erosão, cobertura do solo e crescimento de plantas, práticas de manejo, processos no canal principal e corpos d'água.

Uma síntese dos processos físicos que exprimem, no modelo, a ação dos principais fatores que afetam, exclusivamente, as perdas de solo, de água e produção de sedimentos, com base nos trabalhos de Neitsch et al. (2002a), Neitsch et al. (2002b) e Di Luzio et al. (2002), é apresentada 
a seguir. Os componentes nutrientes e pesticidas, processos no canal principal e corpos d'água não foram considerados.

\section{Clima}

O clima de uma bacia hidrográfica fornece a umidade do ar e a energia que controlam o balanço hídrico. As variáveis climáticas solicitadas pelo modelo são: dados diários de precipitação, temperaturas do ar máxima e mínima, radiação solar, velocidade do vento e umidade relativa do ar. O SWAT permite a entrada de dados diários observados.

Os dados diários de precipitação são requeridos quando o método do número da curva (“SCS curve number”) é escolhido para modelar o escoamento de superfície. Quanto aos dados diários de radiação solar e velocidade do vento, caso não estejam disponíveis, podem ser gerados pelo modelo.

O modelo SWAT requer dados diários referentes à umidade relativa do ar para estimar a evapotranspiração potencial caso as equações de Penman-Monteith ou Priestley-Taylor sejam escolhidas para simulação.

Os valores diários de evapotranspiração potencial podem ser calculados pelos métodos de Penman-Monteith, Priestley-Taylor ou Hargreaves.

A temperatura do solo influencia o movimento da água e a taxa de decaimento dos resíduos. A média da temperatura diária do solo é calculada para a superfície e para o centro de cada camada. A temperatura da superfície é uma função da cobertura e dos resíduos culturais, da temperatura da superfície sem cobertura e da temperatura da superfície no dia anterior.

A temperatura de uma camada do solo é uma função da temperatura da superfície, da média anual de temperatura do ar e da profundidade do solo em que variações de temperatura, devido às mudanças nas condições climáticas, não ocorrem mais. Essa profundidade é definida em função da densidade e teor de água no solo.

\section{Ciclo Hidrológico}

$\mathrm{Na}$ fase terrestre, diretamente relacionada ao desenvolvimento do presente trabalho, o ciclo hidrológico é baseado na equação do balanço hídrico:

$$
S W_{t}=S W_{0}+\sum_{i=1}^{t}\left(R_{\text {day }}-Q_{\text {surf }}-E_{a}-w_{\text {seep }}-Q_{g w}\right)
$$

Sendo: 
$\mathbf{S W t}=$ quantidade final de água no solo $\left(\mathrm{mm} \mathrm{H}_{2} \mathrm{O}\right)$;

$\mathbf{S W}_{\mathbf{0}}=$ quantidade inicial de água no solo no dia $\mathrm{i}\left(\mathrm{mm} \mathrm{H}_{2} \mathrm{O}\right)$;

$\mathbf{t}=$ tempo (dias);

$\mathbf{R}_{\text {day }}=$ quantidade de precipitação no dia i $\left(\mathrm{mm} \mathrm{H}_{2} \mathrm{O}\right)$;

$\mathbf{Q}_{\text {surf }}=$ quantidade de escoamento superficial no dia $\mathrm{i}\left(\mathrm{mm} \mathrm{H}_{2} \mathrm{O}\right)$;

$\mathbf{E}_{\mathbf{a}}=$ quantidade de evapotranspiração no dia i $\left(\mathrm{mm} \mathrm{H}_{2} \mathrm{O}\right)$;

$\mathbf{w}_{\text {seep }}=$ quantidade de água que percola da camada simulada para a camada inferior no dia $\mathrm{i}$ $\left(\mathrm{mm} \mathrm{H}_{2} \mathrm{O}\right)$;

$\mathbf{Q}_{\mathbf{g w}}=$ quantidade de água que retorna ao curso d'água no dia i devido ao escoamento subsuperficial $\left(\mathrm{mm} \mathrm{H}_{2} \mathrm{O}\right)$.

\section{Escoamento Superficial}

O escoamento superficial ocorre quando a taxa de aplicação de água no solo (precipitação ou irrigação) excede a taxa de infiltração. O modelo SWAT fornece dois métodos para o cálculo do escoamento superficial: o método do número da curva do SCS (Soil Conservation Service) ou o método de infiltração de Green e Ampt. Este último é apenas utilizado quando se possuem dados subdiários de precipitação. O método do número de curva já considera também, na sua formulação, a quantidade de água interceptada pelas plantas.

A equação para o cálculo do número da curva do SCS é:

$$
Q_{\text {surf }}=\frac{\left(R_{d a y}-I_{a}\right)^{2}}{\left(R_{d a y}-I_{a}+S\right)}
$$

Sendo:

$\mathbf{Q}_{\text {surf }}=$ quantidade de escoamento superficial acumulado ou excesso de chuva (mm);

$\mathbf{R}_{\text {day }}=$ altura da chuva em um dia (mm);

$\mathbf{I}_{\mathbf{a}}=$ as perdas iniciais que incluem acumulação superficial, interceptação e infiltração anterior ao escoamento superficial $(\mathrm{mm})$;

$\mathbf{S}=$ parâmetro de retenção $(\mathrm{mm})$.

O parâmetro de retenção varia espacialmente com mudanças no tipo e uso da terra, manejo, inclinação e temporalmente em função das variações da quantidade de água no solo. O parâmetro de retenção é calculado por: 


$$
S=25,4 \cdot\left(\frac{1000}{C N}-10\right)
$$

Sendo:

$\mathbf{C N}=$ o número da curva para um dia. É função da permeabilidade e uso da terra e umidade do solo anterior à precipitação.

O número da curva do SCS $(\mathrm{CN})$ é uma função da permeabilidade do solo, uso da terra e condições antecedentes de água no solo. O CN é definido de acordo com o tipo hidrológico do solo. O Serviço de Conservação dos Recursos Naturais dos Estados Unidos (NRCS) classifica os solos em quatro grupos hidrológicos baseados nas características de infiltração. Um grupo hidrológico é definido como um grupo de solos que apresentam potenciais similares de escoamento superficial sob mesmas condições de chuva e cobertura. Os solos podem ser classificados nos grupos A, B, C ou D.

Em relação aos grupos hidrológicos dos solos, Sartori (2004) realizou levantamento dos dados de solos para as condições brasileiras e apresentou a classificação hidrológica dos solos para as atuais classes de solos do Estado de São Paulo. Além disso, apresentou os valores de CN em função do uso da terra, manejo e grupo hidrológico.

As perdas iniciai, $I_{a}$ (acumulação superficial, interceptação e infiltração anterior ao escoamento superficial), são normalmente aproximadas para $0,2 \mathrm{~S}$, fazendo com que a Equação 1.2 se transforme na equação 1.4 :

$$
Q_{\text {surf }}=\frac{\left(R_{d a y}-0,2 S\right)^{2}}{\left(R_{d a y}+0,8 S\right)}
$$

O escoamento superficial só poderá ocorrer se $R_{\text {day }}>I_{a}$, ou seja, quando a precipitação for maior do que as perdas iniciais.

Outro fator importante refere-se ao valor da vazão de pico. Esse valor é utilizado para quantificar a energia erosiva provocada pelo escoamento superficial na previsão da perda de sedimentos. Essa vazão é calculada segundo uma modificação realizada no método racional, em que resulta a Equação 1.5.

$$
q_{\text {peak }}=\frac{\left(\alpha_{\text {tc }} \cdot Q_{\text {surf }} \cdot \text { Area }\right)}{\left(3,6 \cdot t_{\text {conc }}\right)}
$$




\section{Evapotranspiração}

A evapotranspiração é um termo coletivo e inclui todos os processos responsáveis pela conservação da água da superfície da Terra em vapor. Os processos incluem a evaporação de água das plantas, transpiração e evaporação de água do solo.

O modelo SWAT realiza o cálculo da evapotranspiração potencial e da evapotranspiração real.

\section{$\underline{\text { Evapotranspiração Potencial }}$}

A evapotranspiração potencial foi definida por Thornthwaite $\left(1948^{5}\right.$ apud Neitsch et al., 2002a). como a taxa de evapotranspiração que ocorreria numa grande área completamente e uniformemente coberta com vegetação em crescimento, com acesso a uma disponibilidade ilimitada de água no solo e não exposta a efeitos de mudanças microclimáticas, a exemplo da advecção ou acúmulo de energia.

A evapotranspiração potencial pode ser estimada no modelo SWAT por três métodos distintos: Penman-Monteith (Monteith, $1965^{6}$ apud Neitsch et al., 2002a), Priestley-Taylor (Priestley-Taylor, $1972^{7}$ apud Neitsch et al., 2002a) e Hargreaves (Hargreaves et al. $1985^{8}$ apud Neitsch et al., 2002a). O método deve ser selecionado pelo usuário. O modelo permite também a entrada de dados diários de evapotranspiração potencial.

\section{Evapotranspiração Real}

Depois de determinada a evapotranspiração potencial, a evaporação real é calculada. O modelo SWAT considera, primeiramente, a evaporação da água interceptada pelas plantas e, posteriormente, a quantidade de água transpirada pelas plantas e evaporada do solo.

O modelo considera que, se a evapotranspiração potencial for inferior à quantidade de água livre nas plantas:

$$
E_{a}=E_{0} \rightarrow R_{I N T(f)}=R_{I N T(i)}-E_{a}
$$

se superior:

$$
E_{c a n}=R_{I N T(i)} \rightarrow R_{I N T(f)}=0
$$

\footnotetext{
${ }^{5}$ Thornthwaite, C.W. An approach toward a rational classification of climate. Geographical Review, v. 38, p. 55-94. 1948.

${ }^{6}$ Monteith, J.L. Evaporation and the environment. In: The State and Movement of Water in Living Organisms, XIXth Symposium. Swansea: Soc. For Exp. Biol. Cambridge University Press. 1965. p. 205-234.

7 Priestley, C.H.B.; Taylor, R.J. On the assessment of surface heat flux and evaporation using large-scale parameters. Mon. Weather. Rev., v. 100, p. 81-92. 1972.

${ }^{8}$ Hargreaves, G.L.; Hargreaves, G.H.; Riley, J.P. Agricultural benefits for Senegal River Basin. J. Irrig. And Drain. Engr., v. 111, n. 2, p. 113-124. 1985.
} 
Sendo:

$\mathbf{E}_{\mathbf{a}}=$ evapotranspiração real diária $(\mathrm{mm})$;

$\mathbf{E}_{\mathbf{c a n}}=$ a quantidade de evaporação diária da água livre nas plantas (mm);

$\mathbf{E}_{\mathbf{0}}=$ evapotranspiração potencial diária $(\mathrm{mm})$;

$\mathbf{R}_{\mathbf{I N T ( i )}}=$ a quantidade inicial diária da água livre nas plantas (mm);

$\mathbf{R}_{\mathbf{I N T}(\mathbf{f})}=$ a quantidade final diária da água livre nas plantas em um dia (mm).

A evaporação potencial no solo é calculada em função da evapotranspiração potencial e índice de cobertura foliar. Quanto ocorre demanda para evaporação de água do solo, o modelo divide a demanda entre as diferentes camadas da seguinte maneira:

$$
E_{\text {soil }, z}=E^{\prime \prime} \cdot \frac{Z}{Z+\exp (2,374-0,00713 \cdot z)}
$$

Sendo:

$\mathbf{E}_{\text {soil,z }}=$ a demanda por evaporação em uma camada de solo à profundidade z (mm);

$\mathbf{E}_{\mathrm{s}}=$ a evaporação máxima de água do solo $(\mathrm{mm})$;

$\mathbf{z}=$ a profundidade a partir da superfície $(\mathrm{mm})$.

Variadas equações são utilizadas pelo modelo SWAT para o cálculo de processos específicos relacionados com a Evapotranspiração como na determinação da evaporação da precipitação interceptada pela vegetação e nas determinações da transpiração, da sublimação e da evaporação do solo. Essas equações são descritas de maneira extensa e detalhada por Neitsch et al., 2002a.

\section{Água no Solo - Percolação}

A percolação é calculada no SWAT em cada camada do perfil de solo. A água poderá percolar se a quantidade de água exceder a capacidade de campo para uma determinada camada de solo.

O volume de água disponível para percolação na camada do solo é calculado por:

$$
\begin{aligned}
& S W_{l y, \text { excess }}=S W_{l y}-F C_{l y} \text { se } \mathrm{SWly}>\text { FCly } \\
& S W_{l y, \text { excess }}=0 \text { se } \quad \mathrm{SW}_{\text {ly }} \leq \mathrm{FC}_{\mathrm{ly}}
\end{aligned}
$$

Sendo: 
$\mathbf{S} \mathbf{W}_{\mathrm{ly} \text {,excess }}=$ é o volume de água drenável, em uma camada de solo, em um determinado dia $\left(\mathrm{mm} \mathrm{H}_{2} \mathrm{O}\right)$;

$\mathbf{S} \mathbf{W}_{\mathbf{l y}}=$ é a quantidade de água, em uma camada de solo, em um determinado dia (mm $\mathrm{H}_{2} \mathrm{O}$ );

$\mathbf{F C}_{\mathbf{l y}}=$ é a quantidade de água de uma camada de solo na capacidade de campo $\left(\mathrm{mm} \mathrm{H}_{2} \mathrm{O}\right)$

\section{Água no Solo - Fluxo Lateral e Vazão Sub-superficial}

O fluxo lateral poderá ser significante em áreas em que os solos apresentem elevada condutividade hidráulica nas camadas superficiais e camadas impermeáveis ou semipermeáveis em profundidades rasas. Em tais sistemas a precipitação irá percolar verticalmente até atingir a camada impermeável. A água poderá se acumular acima dessa camada formando uma zona saturada de água que será a fonte para o fluxo lateral sub-superficial. Esse fluxo poderá contribuir para a vazão dos rios.

O SWAT utiliza um modelo de armazenamento cinemático baseado na equação de continuidade de massa, em que todo o comprimento da rampa é utilizado como volume de controle.

\section{Erosão}

A erosão causada pela chuva e o escoamento são estimados, no modelo SWAT, com a Equação Universal de Perda de Solos Modificada (Modified Universal Soil Loss Equation MEUPS):

sed $=11,8 \cdot\left(Q_{\text {surf }} \cdot q_{\text {peak }} \cdot \text { area }_{\text {hru }}\right)^{0,56} \cdot K_{\text {USLE }} \cdot C_{\text {USLE }} \cdot P_{\text {USLE }} \cdot L S_{\text {USLE }} \cdot C F R G$

Sendo:

sed $=$ produção de sedimento em um dia (tonelada métrica);

$\mathbf{Q}_{\text {surf }}=$ lâmina de escoamento superficial ( $\left.\mathrm{mm} / \mathrm{ha}\right)$;

$\mathbf{q}_{\text {peak }}=$ vazão de pico $\left(\mathrm{m}^{3} / \mathrm{s}\right)$;

area $_{\text {hru }}=$ área da HRU (ha);

$\mathbf{K}_{\mathbf{U S L E}}=$ fator erodibilidade da EUPS;

$\mathbf{C}_{\text {USLE }}=$ fator cobertura e manejo da EUPS;

$\mathbf{P}_{\text {USLE }}=$ fator práticas conservacionistas da EUPS; 
$\mathbf{L S}_{\text {USLE }}=$ fator topografia da EUPS;

$\mathbf{C F R G}=$ fator fragmentos grosseiros.

O modelo simula também a contribuição de sedimentos a partir das vazões subsuperficiais e de base em função das vazões, área de cotribuição e concentração de sedimentos.

Com todos os componentes e processos mencionados acima, intrínsecos ao modelo, além de outros que não foram apresentados por não estarem relacionados aos objetivos do presente trabalho, o modelo SWAT, por sua abrangência, características e acessibilidade, tem sido largamente utilizado em trabalhos ao redor do mundo.

Um dos critérios mais importantes relacionados à aplicação de modelos associados a SIGs, conforme foi visto para a EUPS, refere-se às escalas. De acordo com Romanowicz et al. (2005), muitas questões têm sido discutidas, em trabalhos científicos, relacionadas à resolução apropriada dos dados de entrada espacialmente distribuídos. De acordo com os autores, tais estudos têm comprovado que a resolução e agregação dos dados nos SIGs têm um impacto considerável na modelagem de processos relativos à precipitação e ao escoamento superficial.

Segundo Chaplot (2005), a qualidade da informação espacial afeta, diretamente, os resultados dos modelos hidrológicos de simulação. A acuracidade do modelo depende, em grande parte, das características dos parâmetros de entrada que descrevem as características relevantes da bacia hidrográfica. Além desses parâmetros, a precisão do modelo numérico do terreno pode afetar o delineamento dos canais de escoamento, das áreas de contribuição, das bacias hidrográficas, o que, por sua vez, irá influenciar a qualidade preditiva dos modelos.

Ao avaliar o impacto da precisão das informações de solo na estimação das cargas de água e sedimentos, Chaplot (op cit.) realizou quinze simulações com o modelo SWAT, combinando diferentes tamanhos de grade dos modelos numéricos do terreno $(20,30,50,100$ e $200 \mathrm{~m}$ - escala de processamento) e escalas de mapas de solo (1:25.000; 1:250.000 e 1:500.000 - escala da base de dados cartográfica). O estudo indicou que as estimações de escoamento superficial e sedimentos com mapas em escala 1:25.000 foram mais precisas do que as realizadas com mapas em escalas menores.

Os resultados obtidos por Romanowicz et al. (2005) indicaram que o modelo SWAT é extremamente sensível à qualidade dos dados de entrada referente aos solos, ao uso da terra e aos procedimentos geográficos de distribuição dos dados realizados na etapa que antecede a fase de processamento do modelo. Um dos fatores-chave, na etapa de pré-processamento, é a determinação da área de contribuição ao ponto inicial da rede hídrica, a área do "threshold" (CSTV - Catchment Size Threshold Value). De acordo com os autores, as melhores estimativas, 
geradas pela utilização do modelo sem calibração, somente são obtidas com a utilização de um valor ótimo do threshold.

Chanasyk et al. (2003) utilizaram o modelo SWAT para determinar o escoamento em áreas com diferentes intensidades de pastoreio, na região de Alberta (Canadá). Os autores utilizaram o modelo para avaliar sua capacidade de previsão de escoamento superficial em microbacias hidrográficas. De acordo com os autores, o SWAT é um modelo de parâmetro distribuído, contínuo no tempo, desenvolvido para ser utilizado em bacias hidrográficas não instrumentadas, que não apresentem dados de medições.

Tripathi et al. (2003), estudando a bacia hidrográfica de Nagwan (Índia), confirmou que o modelo SWAT pode simular acuradamente o escoamento superficial, as cargas de sedimentos e as perdas de nutrientes em microbacias hidrográficas agrícolas. O trabalho desses autores revelou que nem todas as sub-bacias contribuíram com os volumes de água, as cargas de sedimentos e de nutrientes medidos no vertedouro da bacia estudada. Poucas áreas foram responsáveis pelos valores mais elevados de perdas desses materiais. Com o uso do modelo foi possível identificar as sub-bacias críticas, que contribuem mais intensamente com esses parâmetros, podendo ser utilizado, de maneira eficaz, no desenvolvimento de planos de manejo de bacias hidrográficas com priorização de áreas críticas.

\subsection{Considerações Finais}

Tendo em vista a importância social e econômica da agricultura na região central do Estado de São Paulo, numerosos estudos prospectivos ou de diagnóstico ambiental, realizados em bacias hidrográficas agrícolas ou nos municípios como um todo, têm sido desenvolvidos na região do município de São Carlos. Como exemplo desses trabalhos, podem-se citar:

- Feres (2002), Moraes (2003), Cançado (2003) e Neves (2005), relacionados à Bacia hidrográfica do Rio Bonito (Municípios de Descalvado e Porto Ferreira);

- Bueno e Stein (2004), desenvolvido na região do Município de Brotas;

- Pires (1995) e Pires et al. (2000d), relacionados às microbacias do Município de Luiz Antônio;

- Pires (1999) e Pires et al. (2000b), relacionados ao zoneamento ambiental do PEJ e ao plano de manejo dessa unidade de conservação;

- Lima (2002), realizado na Bacia hidrográfica do Ribeirão dos Negros e Pinto (1996) e Laurito (2004), desenvolvidos no Município de São Carlos. 
A maior parte dos trabalhos, realizados com o auxílio de Sistemas de Informações Geográficas, foram efetuados no intuito de desenvolver metodologias a serem utilizadas no processo de planejamento racional do uso da terra e dos recursos hídricos e, também, no gerenciamento e proteção de unidades de conservação e dos remanescentes de vegetação natural.

Ainda assim, são poucos os trabalhos desenvolvidos em bacias hidrográficas rurais tendo em vista que, no que se refere à questão ambiental, grande ênfase é dada às questões urbanas, relacionadas principalmente às indústrias ou ao saneamento, com vistas às fontes pontuais de poluição.

Existem poucas informações disponíveis sobre os ambientes rurais e os impactos das atividades agrícolas. Indicadores quantitativos nos órgãos governamentais, relativos às condições ambientais nessas áreas, são praticamente inexistentes.

No que se refere à expansão das áreas e atividades agrícolas e seus impactos nas áreas alagáveis, as informações são praticamente inexistentes, tanto para a região do município de São Carlos, como para o Estado de São Paulo e para o Brasil. Alguns raros trabalhos foram encontrados na literatura científica relacionados ao impacto dos agrotóxicos em áreas de várzea (Cruciani et al., 1996; Barros et al., 1997; Armas, 2002), à degradação de áreas de várzea (Silva et al., 1990), ao derrame de petróleo em áreas de mangue (Torrado, et al., 2003).

As informações utilizadas no presente trabalho, para efeito comparativo, foram encontradas, basicamente, na literatura científica. A maior parte dos trabalhos disponíveis relacionou-se aos processos erosivos em parcelas experimentais, propriedades rurais ou bacias hidrográficas, em função da aplicação da EUPS.

A avaliação quantitativa da perda de solo por erosão, da perda de água e das cargas de sedimentos que atingem os corpos d'água é fundamental para o planejamento ambiental em escala de bacia hidrográfica contribuindo para o processo de tomada de decisão relacionado às melhores opções de manejo do solo e à manutenção da qualidade da água. A realização de estimativas desses parâmetros, com base na utilização de modelos empíricos ou conceituais, é fundamental no desenvolvimento de registros desses processos em locais onde os dados são inexistentes. Além de uma forma econômica no levantamento das informações e na elaboração de cenários, os modelos ambientais, associados aos sistemas de informações geográficas, contribuem para a localização de áreas críticas fornecendo indicativos para a realização de medições e estudos posteriores, além da realização de operações emergenciais para a contenção ou controle de processos em estado crítico.

Nesse sentido, as informações produzidas no presente trabalho, em função da área de estudo, poderão ser úteis ao zoneamento ambiental da Estação Ecológica de Jatay, proposto por Pires (1999) e Pires et al. (2000b), principalmente para as zonas de uso intensivo, de recuperação 
e de entorno e, também, ao plano de manejo dessa Estação, proposto pelos mesmos autores, do qual faz parte o Programa de Pesquisa e Treinamento, no qual se insere o Subprograma de Análise e Caracterização da Estrutura e Processos Ambientais e o Programa de Monitoramento, no qual se insere o Subprograma de Monitoramento de Riscos e Impactos.

Desta forma justifica-se a investigação relacionada à perda de solo por erosão superficial na área estudada pela ausência de estudos quantitativos e comparativos anteriores, pela ausência de estudos anteriores no Brasil utilizando-se os dois modelos distintos utilizados, pela ausência de abordagem de estudos anteriores na perda de solo por erosão hídrica superficial em região de áreas alagadas. 


\section{OBJETIVOS}

O objetivo geral do presente trabalho foi testar método de caracterização e análise ambiental, com ênfase no manejo dos recursos solo e água, em abordagem de primeira aproximação, pela construção de base de dados e utilização de ferramentas computacionais de simulação, que possibilitassem:

1. Estimar potencial natural de perda de solos da área de estudo;

2. Estimar o balanço hídrico de microbacias hidrográficas não instrumentadas;

3. Identificar áreas com risco ambiental;

4. Estimar o impacto dos processos erosivos na zona rural em áreas alagáveis;

5. Elaborar diferentes cenários ambientais para a área de estudo em função de diferentes usos do solo.

Especificamente, pretendeu-se:

- Estimar a erosão do solo em microbacias hidrográficas submetidas a diferentes usos e ocupações do solo utilizando-se a Equação Universal de Perda de Solos (EUPS);

- Estimar a erosão do solo nas áreas alagáveis da planície de inundação do rio Mogi-Guaçu e em seu entorno, na área das bacias de drenagem da área de estudo, em função de diferentes usos e ocupações do solo, utilizando-se a Equação Universal de Perda de Solos (EUPS);

- Estimar a erosão e as cargas de sedimentos de microbacias hidrográficas, em diferentes cenários de uso e ocupação do solo, utilizando-se o modelo hidrossedimentológico SWAT;

- Estimar alguns parâmetros relacionados ao balanço hídrico de microbacias hidrográficas (percolação, evapotranspiração, escoamento superficial), em diferentes cenários de uso e ocupação do solo, utilizando-se o modelo SWAT. 


\section{3. ÁREA DE ESTUDO}

\subsection{Considerações Iniciais}

Após discorrer sobre as bases científicas e os objetivos do trabalho, a escolha do local de estudo foi uma das fases mais importantes da elaboração do projeto de pesquisa.

Este capítulo visa descrever os critérios utilizados para a determinação do local de estudo, discorrer sobre as características do meio físico da área de estudo e sobre aspectos socioeconômicos.

\subsection{A Escolha da Área de Estudo}

Deve-se salientar que no Brasil, um país de dimensões continentais, torna-se cada vez mais importante desenvolver a competência de focalizar, em termos ambientais, novos assuntos e problemas. No dia-a-dia das instituições de pesquisa e dos setores ambientais nas esferas pública e privada, os profissionais têm que lidar com situações complexas, muitas vezes conflitantes, e responder, utilizando dados e informações das ferramentas disponíveis, de forma rápida e eficiente, às pressões e demandas.

Segundo dados publicados no Relatório de Qualidade Ambiental do Estado de São Paulo (DAEE e IPT, 2005), com base em um mapeamento realizado desde 1986, 183 dos 645 municípios do Estado de São Paulo apresentam problemas críticos de erosão.

A erosão hídrica no Estado de São Paulo é causada pela erosividade das chuvas, erodibilidade do solo, topografia do terreno e uso e manejo do solo. A distribuição das chuvas concentra-se de 74 a 94\% no período coincidente com o de mobilização do solo, durante o qual fica menos protegido pela vegetação e mais desagregado, portanto mais vulnerável ao processo erosivo. Devido às características climáticas e à erodibilidade do solo, 60,2\% da área territorial do estado é altamente suscetível à erosão quando cultivada. Em relação à topografia, 71,8\% do estado apresenta áreas com relevo suave ondulado, ou ondulado, com declividades variando de 0 a $20 \%$. No que se refere ao uso e manejo do solo, grande parte do Estado sofreu ocupação inadequada, não se levando em consideração a capacidade de uso das terras. Com isso, apareceram sérios problemas de erosão e degradação do solo e da água (Bertolini e Lombardi Neto, 1994).

Bertolini e Lombardi Neto (op cit.) identificaram que o uso agrícola da terra no Estado de São Paulo é baseado em culturas anuais e temporárias, culturas perenes, pastagens e reflorestamento. Em quaisquer dessas situações, são comuns fatores causadores ou agravadores 
da erosão, como baixa ou inexistente cobertura arbórea; despreocupação sobre a necessidade de se adequar o uso ao potencial do recurso natural; insuficiência da cobertura vegetal (viva ou morta) em períodos críticos; e estrutura superficial ou subsuperficial degradada em relação às condições naturais.

Vários são os fatores que levam à degradação dos recursos edáficos, como o uso e manejo inadequado dos solos, insumos e restos culturais e a erosão hídrica. A degradação do solo, no Estado de São Paulo, é caracterizada pelo desequilíbrio nutricional, pulverização excessiva e compactação do solo, diminuição das atividades biológicas e dos níveis de matéria orgânica. A falta de resíduos na superfície intensifica as perdas de solo por erosão. Observa-se, dessa forma, que os processos erosivos apresentam uma relação de causa e efeito da degradação do solo (Bertolini e Lombardi Neto, op cit.).

Os sistemas de cultivo, no Estado de São Paulo, envolvem a mobilização inadequada do solo. Utiliza-se, de maneira generalizada, maquinário pesado e implementos a disco (arado, grades niveladoras e aradoras), os quais, associados aos fatores climáticos, mais intensos nas épocas de movimentação do solo, representam o principal fator agravante da erosão (Bertolini e Lombardi Neto, op cit.).

Com base nessas premissas, observou-se que o Estado de São Paulo apresentava uma série de problemas ambientais originados, em grande parte, pelos processos erosivos. Assim, optou-se por identificar o local de estudo em uma área no interior do Estado. Após essa definição, para facilitar a logística dos trabalhos e minimizar os custos do projeto de pesquisa, foi decidido que a área de estudo deveria estar situada nas proximidades do local sede da pesquisa (Embrapa Instrumentação Agropecuária - São Carlos/SP).

Um outro critério que serviu de base para a identificação do local de estudo relacionou-se ao enfoque que se pretendia adotar na pesquisa. A maneira de focalizar o assunto estava baseada no aprofundamento das informações, na sua interpretação, com o objetivo de aprimorar as respostas que poderiam ser dadas frente às demandas, conforme abordado na introdução do presente trabalho.

De acordo com a abordagem mencionada, a busca pela área de estudo foi baseada, essencialmente, nos seguintes aspectos:

- Disponibilidade de dados ambientais sobre a área em questão e existência de trabalhos anteriores;

- Demanda local ou regional pelo tipo de informação que se pretende desenvolver no trabalho. 
A primeira experiência adquirida envolveu, certamente, a noção de como identificar possíveis áreas de estudo que sejam relevantes em função do campo do conhecimento científico relacionado ao estudo.

No passo seguinte, foi realizada busca de informações científicas, publicações, referentes às áreas identificadas. Primeiramente, realizou-se a busca em bancos de dados governamentais e, em seguida, buscaram-se publicações científicas em sites de busca variados (Portal de Periódicos CAPES, PROBE, Web of Science, Science Direct).

A experiência seguinte relacionou-se à busca de informações com pessoas que realizam trabalhos nas respectivas áreas (pesquisadores, gerentes ambientais, tomadores de decisão ligados a órgãos públicos), no intuito de averiguar as realidades e perspectivas políticoadministrativas e técnico-científicas. Dessa forma, seguiu-se a fase de estabelecimento de contatos com os responsáveis ou conhecedores da temática ambiental em questão, que pudessem contribuir com sugestões em relação à escolha da área definitiva.

O levantamento de dados das áreas que estavam sendo analisadas foi baseado na busca por estudos relacionados aos impactos de atividades agrícolas em áreas alagadas e nos sistemas lóticos das bacias hidrográficas, à quantificação dos impactos e à origem de problemas (poluentes) encontrados.

Dessa forma, efetuou-se a busca por microbacias hidrográficas que atendessem os seguintes critérios:

- Presença de áreas alagadas;

- A representatividade da área de uso agrícola e apresentação de ocupações diversas;

- Apresentação de variedade de classes de solos;

- Apresentação de variabilidade topográfica;

- Importância local ou regional em termos sociais, econômicos e ambientais;

- Importância local ou regional por ser uma área de mananciais para zonas urbana ou rural;

- Disponibilidade de dados relacionados às diversas variáveis mencionadas anteriormente;

- Sustentabilidade em termos das atividades desenvolvidas na bacia e da utilização dos dados a serem produzidos nesse estudo.

Um dado importante levantado estava relacionado às áreas de várzea do Município de São Carlos. De acordo com a Lei Orgânica desse município, a várzea é considerada como Área de Preservação Permanente (APP), diferentemente de como é tratada no Código Florestal. Esse é um fator extremamente importante para trabalhos que envolvem as áreas alagadas desse 
Município, devido à sua sustentabilidade. Outro fator interessante refere-se ao fato de esse município ser um dos primeiros no país a considerar no seu Plano Diretor o espaço urbano e rural (95\% da área), com grande ênfase na preservação dos seus recursos edafo-hídricos.

Assim, no intuito de o estudo abranger o município de São Carlos, foram identificadas duas áreas extremamente interessantes: a bacia hidrográfica do Ribeirão do Feijão (inserida na bacia hidrográfica do Tietê-Jacaré) e um compartimento da bacia hidrográfica do Rio Mogi Guaçu, com área inserida na região norte do Município de São Carlos e no Município de Luiz Antonio.

A bacia hidrográfica do ribeirão do Feijão é o principal manancial do Município de São Carlos, contribuindo com 35\% a 40\% da água captada para abastecimento. É importante por apresentar áreas de recarga do Aqüífero, ter dimensão regional (abrangendo os Municípios de São Carlos, Analândia e Itirapina) e estar localizada à montante da bacia hidrográfica do TietêJacaré. Porém, na busca realizada, foram encontrados apenas dois trabalhos referente às áreas alagadas dessa bacia hidrográfica (Amaral, 2002) e (Sidagis Galli, 2003). O local de estudo desses trabalhos referia-se a uma propriedade particular, o que não favorecia a pesquisa por não ter sustentabilidade das atividades e do uso do solo, a médio e longo prazo.

No compartimento da bacia hidrográfica do Rio Mogi Guaçu está inserido (no município de Luiz Antonio) o Parque Estadual do Jatay (PEJ), com uma área aproximada de 11.000 ha, que está representado pela Estação Ecológica de Jataí (EEJ) e pela Estação Experimental de Luiz Antônio (EELA).

A EEJ é uma das mais importantes unidades de conservação do Estado de São Paulo, tanto para a conservação da biodiversidade como na melhoria das condições ambientais locais e regionais (Santos e Cavalheiro, 1988).

De acordo com Cabral e Souza (2002), visando à proteção ambiental, o estabelecimento das áreas protegidas tem importante papel dentre as medidas preventivas, apresentando dois procedimentos básicos:

I. Em alguns casos, interromper a atuação antrópica, de modo a permitir a manutenção e a recuperação de atributos naturais;

II. Em outros casos, de maneira concomitante ou não, no mesmo espaço, permitir o uso desses recursos, garantindo sua manutenção no longo prazo em condições regulares, minimizando, assim, em ambos os casos, os procedimentos às respostas negativas de ação antrópica.

Conseqüentemente, a manutenção da área da EEJ no médio e longo prazo vem ao encontro de um dos critérios propostos para a escolha da área de estudo no presente trabalho. Além disso, um dos pontos mais relevantes, relacionados à EEJ, foi a quantidade e qualidade das informações 
científicas acumuladas ao longo dos últimos anos. Dessa forma, por atender a maior parte dos critérios propostos para a escolha da área de estudo do presente trabalho, o compartimento da bacia hidrográfica do Rio Mogi Guaçu foi selecionado.

Entre os conhecimentos acumulados referentes à EEJ, extremamente utilizados como suporte à realização do presente trabalho, podem-se destacar:

- Trabalhos de caracterização e mapeamento dos solos das bacias hidrográficas - Lorandi et al. (1993a), Lorandi et al. (1993b), Lorandi e Lacerda (1992), Lorandi et al. (1990);

- Trabalhos de caracterização das lagoas, planície de inundação e córregos inseridos na EEJ - Albuquerque et al. (2000), Guereschi e Fonseca-Gessner (2000), Pinto et al. (2000), Simões Filho (1993), Simões Filho et al. (2000), Andrade et al. (1993);

- Trabalhos de caráter mais holístico, envolvendo caracterização da paisagem, análise ambiental, monitoramento, diretrizes para a conservação, planos de manejo para a área da EEJ e valoração de serviços: Pires (1994), Pires e Santos (1995), Pires e Santos (1996), Pires (1999), Pires et al. (2000a), Pires et al. (2000b), Pires et al. (2000c), Santos et al. (2000);

- Trabalhos desenvolvidos no intuito de analisar o entorno da Estação Ecológica de Jataí e o Município de Luiz Antonio: Pires et al. (2000d), Roque \& Trivinho-Strixino (2000).

Além desses materiais, existe uma série de informações acumuladas sobre a região pelos trabalhos desenvolvidos no Laboratório de Análise e Planejamento Ambiental (DHBUFSCar/www.lapa.ufscar.br).

Em relação aos estudos dos solos da Estação Ecológica de Jataí, assim como dados referentes ao município de São Carlos, destacam-se os trabalhos realizados pelo Laboratório de Solos do Programa de Pós-Graduação em Engenharia Urbana (DEC/UFSCar/ www.ufscar.br/ ppgeu).

Dessa forma, por atender a todos os critérios propostos para a escolha da área de estudo do presente trabalho de maneira extremamente satisfatória, foi selecionado um compartimento da bacia hidrográfica do Rio Mogi Guaçu. Vale ressaltar que inexistem trabalhos anteriores sobre caracterização quantitativa das perdas de solo por escoamento superficial tanto na margem direita do rio Mogi-Guaçu, onde está localizada a Estação Ecológica do Jataí como na margem esquerda, parte oposta à EEJ, onde são desenvolvidas atividades agrícolas. 


\section{3 Área de Estudo}

A área de estudo está localizada na região central do Estado de São Paulo, entre as coordenadas Universal Transverso Mercator (UTM) 7.594.000m e 7.618.000m de latitude Sul, 195.000m e 220.000m de latitude Oeste, abrangendo os Municípios de São Carlos, Luiz Antônio, Rincão, Santa Lúcia e Américo Brasiliense. Uma ilustração da localização das unidades de estudo no Estado (microbacias hidrográficas e bacias de drenagem) é apresentada na Fig. 3.

O rio Mogi-Guaçu é um dos limites do Município de Luiz Antônio, na região sudoeste. Nessa área o Município de Luiz Antônio faz divisa com os Municípios de São Carlos e Rincão.

Dessa forma, ao delimitar unidades de estudo em ambos os lados do rio Mogi-Guaçu, têmse no compartimento em estudo, duas áreas com características estruturais semelhantes, ambas contendo a planície de inundação do rio Mogi-Guaçu e áreas alagadas, mas, em função dos usos a que são submetidas, extremamente diferentes, com complexidades distintas e de fundamental importância para a região.

A área de estudo está inserida na Unidade de Gerenciamento de Recursos Hídricos do Mogi Guaçu (UGRHI - 09). Esta unidade está localizada na região nordeste do Estado de São Paulo e sudoeste de Minas Gerais. O trecho paulista da Bacia do Mogi Guaçu está compreendido entre os pararelos $21^{\circ} 45^{\prime}$ e $22^{\circ} 45^{\prime}$, e os meridianos 46 $15^{\prime}$ e $47^{\circ} 45^{\prime}$ (Comitê de bacia hidrográfica do rio Mogi Guaçu - CBHRMG, 1999). O rio Mogi Guaçu, por sua vez, pertence à bacia hidrográfica do Rio Paraná, a qual abrange boa parte das regiões Sudeste, Centro-Oeste e Sul do Brasil.

A bacia hidrográfica do rio Mogi-Guaçu foi subdividida em cinco compartimentos econômico-ecológicos, em função de Macrozoneamento realizado em 1995 (CBHRMG, 1999). Em um desses compartimentos, intitulado subbacia hidrográfica do Médio Mogi-Superior, está inserida a área de estudo do presente trabalho.

São descritas, a seguir, algumas características da área de estudo e, também, da região da sub-bacia hidrográfica do Médio Mogi-Superior.

A área de drenagem da sub-bacia hidrográfica do Médio Mogi Superior, situada na Bacia Geológica do Paraná, é formada, em grande parte, pelo grupo São Bento. Esse grupo é representado, na sub-bacia, pelas Formações Botucatu/Pirambóia e Serra Geral. Essas formações apresentam-se representadas pelos seguintes tipos de rochas: efusivas básicas, arenitos, argilitos e conglomerados (CBHRMG, 1999). 
A geologia da área do Parque Estadual de Jatay (PEJ), onde está localizada a EEJ, município de Luiz Antônio/SP, é constituída por três formações principais (Cavalheiro et al., 1990):

a) Formação Botucatu - constituída por arenitos triássicos;

b) Formação Serra Geral - constituída pela seqüência de derrames basálticos do Jurássico-Cretáceo;

c) Formação Santa Rita do Passa-Quatro, constituída por depósitos sedimentares do Quaternário.

Segundo o Mapa de Substrato Rochoso elaborado por Muro (2000), para o Município de São Carlos, a região da Microbacia hidrográfica do Ribeirão das Guabirobas inserida no Muncípio de São Carlos, está situada em uma área da Formação Botucatu, com presença de arenitos finos a médios bem selecionados (Triássico-Jurássico) e na área da planície de inundação do rio Mogi-Guaçu, a presença de aluviões. Observando-se a Carta de Perfis Hidrogeológicos, o Muncípio de São Carlos apresenta a formação Botucatu/Pirambóia nas regiões de menor elevação, a Formação Serra Geral (intermediária) e a formação Itaqueri nas regiões de maior elevação. De acordo com o autor, o aqüífero Botucatu, que representa um imenso manancial de água de subsuperfície, composto pela formação Botucatu, é constituído de arenito, por vezes silicificado e grande parte de sua área está coberta por derrames básicos da Formação Serra Geral, que o torna confinado nessas áreas.

A forma do relevo da área de estudo é representada por duas grandes unidades morfoesculturais, as províncias geomorfológicas Cuestas Basálticas e Planalto Ocidental. A província geomorfológica Cuestas Basálticas ocupa a região centro e oeste sendo cortada pelo rio Mogi Guaçu. Trata-se de um relevo dissimétrico, constituído, de um lado, por um perfil côncavo em declive íngreme, denominado fronte e, do outro, por um perfil suavemente inclinado, denominado reverso. É na área do reverso que se situa o solo conhecido como Latossolo Vermelho Eutroférrico. O relevo Cuestas é formado por chapadões, com altitudes de 400m, $600 \mathrm{~m}$ e $800 \mathrm{~m}$. Nas escarpas das Cuestas as altitudes chegam a alcançar 1200m. O Planalto Ocidental apresenta-se na porção mais a oeste. Essa região apresenta grande uniformidade, o que confere certa monotonia ao relevo, com predomínio de baixas e amplas colinas. As altitudes oscilam entre $400 \mathrm{~m}$ e $600 \mathrm{~m}$. Latossolos constituem a maior parte do solo da sub-bacia, seguidos por solos hidromórficos e regossolos - areias quartzosas (CBHRMG, 1999). 


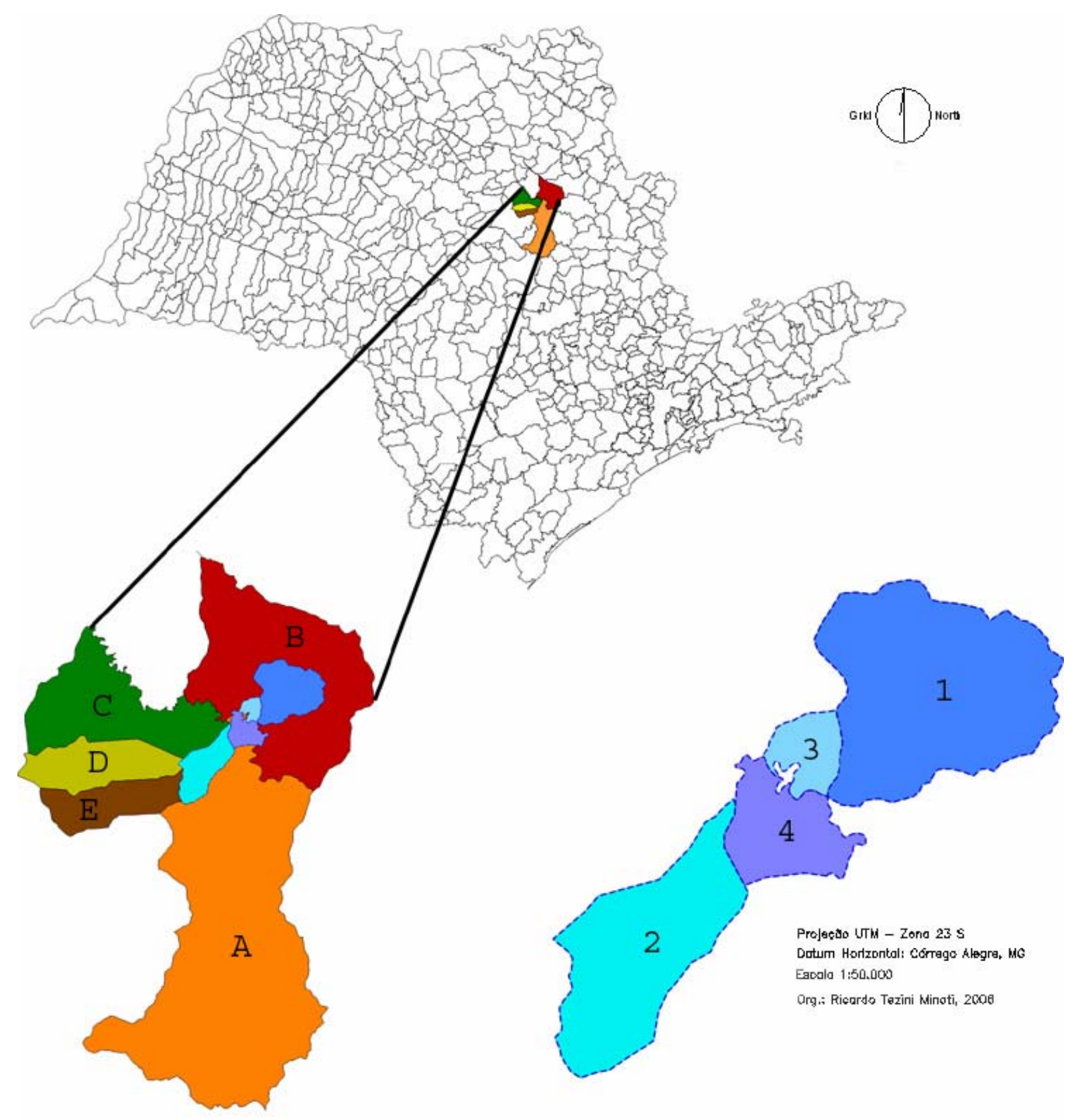

Figura 3. Localização da Área de Estudo no Estado de São Paulo. A - Município de São Carlos. B - Município de Luiz Antônio. C - Município de Rincão. D - Município de Santa Lúcia. E Município de Américo Brasiliense. 1 - Microbacia hidrográfica do córrego Beija-Flor (MBHBF). 2 - Microbacia hidrográfica do ribeirão das Guabirobas (MBH-G). 3 - Bacia de Drenagem de Luiz Antônio (BD-LA). 4 - Bacia de Drenagem de São Carlos (BD-SC). 
De acordo com Muro (2000), o Planalto Ocidental Paulista ocupa praticamente 50\% da área total do Estado de São Paulo. Seu relevo é levemente ondulado com predomínio de colinas amplas e baixas com topos aplanados. Neste planalto podem-se identificar unidades geomorfológicas distintas, como o Patamar Estrutural de Ribeirão Preto e o Planalto Residual de São Carlos.

As principais formas estruturais encontradas na área do PEJ são (IPT, 1981):

a) Áreas com relevo de agradação constituídas por planícies aluviais com terrenos baixos e razoavelmente planos, junto às margens dos córregos e do rio MogiGuaçu, sujeitos a inundações periódicas;

b) Relevo de morros de encostas suavizadas onde predominam baixas declividades de até $12 \%$ e amplitudes locais de 100 a 300 metros.

De acordo com Muro (2000), estão presentes na região do município de São Carlos as Planícies Fluviais, as quais contêm a unidade Planícies Fluviais Diversas. Essa unidade é composta por terrenos planos, gerados por processos de agradação. Apresentam declividades inferiores a $2 \%$, em diferentes níveis altimétricos. São formadas por sedimentos fluviais arenosos e argilosos inconsolidados. Possuem potencial de fragilidade muito alto por serem áreas sujeitas às inundações periódicas, com lençol freático pouco profundo e sedimentos inconsolidados sujeitos a acomodações constantes.

Segundo o mapa das formas de relevo "Landforms" elaborado por Muro (2000), a região da MBH-G, inserida no Muncípio de São Carlos, apresenta as seguintes unidades de terreno: Terraços Aluvionares, Vales Abertos, Morrotes Suaves e Platôs.

Tendo em vista que a margem esquerda do Ribeirão das Guabirobas (área da MBH-G referente aos municípios de Rincão, Santa Lúcia e Américo Brasiliense) apresenta a mesma configuração de relevo da margem direita, as características geológicas e geomorfológicas devem ser semelhantes.

No Sistema Internacional de Köeppen, é possível identificar duas divisões climáticas na área da sub-bacia: Cwa e Aw. Como médias anuais de precipitação (período de 30 anos - 1961 a 1990), a região apresenta valores que variam entre 1400 a 1450 mm (CBHRMG, 1999).

As condições climáticas da região onde está inserido o PEJ pertencem ao clima Aw de Koppen (Setzer, 1966) ou Tropical do Brasil Central (Nimer, 1977) com as temperaturas mais elevadas ocorrendo no período de maior precipitação (dezembro a fevereiro) e as menos elevadas, no período de menor precipitação (maio a outubro). 
Em relação aos riscos ambientais das atividades que são desenvolvidas na sub-bacia hidrográfica do Médio Mogi-Superior, a utilização de agroquímicos pode ser uma das fontes de poluentes. Com referência aos adubos minerais, possíveis contribuintes do processo de eutrofização das águas superficiais, sua utilização, em termos de quantidade e tipicidade, varia dependendo das necessidades dos solos a serem cultivados. No que se relaciona aos pesticidas, das culturas que são desenvolvidas na região, alguns produtos são comumente utilizados, na atualidade, em quantidades variadas:

- Cana-de-açúcar

o Cupinicidas, inseticidas, nematicidas, acaricidas e formicidas utilizados no sulco de plantio - Evidence (Imitacloprido), Furadan (Carbofuran), Regente (800 WG Dipronil), Temik (Aldicarb), Tiodan (Endosulfan) e Mirex (Dodecloro Octahydro);

o Herbicidas utilizados após o plantio - Velpar K (Composto de Tiuron mais Hexazizone), Advance (mesma composição do Velpar K), Herbipak 500 (Ametryne), Gamit (Fenoxan), Combine (Tebuthiuron), Aminol (2,4 D).

o Herbicida utilizado na fase pós-emergente - Dessecan (MSMA);

o Herbicida utilizado durante a reforma do solo - Roundup (Glyphosate).

- Laranja

o Acaricidas - Dicofol Fersol 185 CE (Dicofol), Kumulus S (Sulphur), Omite 300 PMBR (Propargite), Savey PM (Hehythiazox), Sipcatim 500 SC (Cyhexatin), Tanger (Fenbutatin Oxide), Torque 500SC (Óxido de Fenibutatina) e Vertimec 18CE (Abamectin);

o Inseticidas - Folidol 600 (Parathion Metil), Dipterex 500 (Trichlorfon), Malatol 1000CE (Malathion);

o Fungicidas - Dithane PM (Mancozeb), Benlate (Benomyl);

o Inseticida e acaricida - Dimetoato CE (Dimetoato).

- Eucalipto - Roundup (Glyphosate) utilizado ao longo dos primeiros anos de plantio.

Os riscos de contaminação associados ao uso de agroquímicos não estão relacionados apenas às águas superficiais. A sub-bacia do Médio Mogi-Superior concentra índices elevados de vulnerabilidade em relação às águas subterrâneas, pois engloba área aflorante do Aqüífero Botucatu-Pirambóia, nos municípios de Descalvado, Luiz Antônio, Santa Rita do Passa Quatro, além de todo o trecho do rio Mogi-Guaçu. Esse aqüífero, por ser mais permeável, está mais 
susceptível à contaminação biológica e química, podendo haver contaminação do lençol freático (Muro, 2000; CBHRMG, 1999).

Um dos riscos à saúde humana, asssociados à aplicação de pesticidas na região, pode ser observado no município de Luiz Antônio. A aspersão de agrotóxicos, observada na área desse município, constitui um sério problema para a população urbana, que é cercada por cultura canavieira (Pires, 1995).

O processo de mineração por dragagem e escavação é outra atividade que está inserida na sub-bacia e que pode gerar impactos ambientais severos. As áreas mais atingidas pelas atividades minerárias são as várzeas dos rios e córregos. Existem, na região, mineradoras nos municípios de São Carlos e Rincão, mas apenas a mineradora de São Carlos encontra-se localizada na área de estudo, na MBH-G.

Em relação à diminuição das áreas preservadas (matas e florestas naturais) em função do desmatamento para fins antrópicos, podem-se observar as variações nos dados dos municípios abrangidos pela área de estudo, no período entre 1970 e 1995 (Tabela 5).

Tabela 5: Áreas preservadas dos municípios da área de estudo.

\begin{tabular}{|l|c|c|c|c|c|}
\hline \multicolumn{1}{|c|}{ Área de matas e florestas naturais - ha (Dados IPEA Data/IBGE, 2005) } \\
\hline \multicolumn{1}{|c|}{ Município } & $\mathbf{1 9 7 0}$ & $\mathbf{1 9 7 5}$ & $\mathbf{1 9 8 0}$ & $\mathbf{1 9 8 5}$ & $\mathbf{1 9 9 5}$ \\
\hline Américo Brasiliense & 3.444 & 1.333 & 698 & 281 & 238 \\
\hline Luís Antônio & 2.408 & 8.466 & 7.567 & 7.025 & 7.746 \\
\hline Rincão & 1.062 & 2.642 & 1.237 & 600 & 425 \\
\hline Santa Lúcia & 2.752 & 1.717 & 1.010 & 671 & 1.347 \\
\hline São Carlos & 10.825 & 8.821 & 7.409 & 7.046 & 9.425 \\
\hline
\end{tabular}

Um outro fator de estresse ambiental refere-se ao processo de erosão do solo. Esse é o primeiro problema causado pelo uso inadequado do solo e o mais importante para a agricultura na região da bacia hidrográfica do rio Mogi-Guaçu. O problema vem se agravando a cada ano e causando degradação dos solos, poluição das águas, assoreamento de mananciais, além de enchentes no período das chuvas ou escassez no período de estiagem. As chuvas concentradas entre outubro e março são coincidentes com o período de movimentação do solo, quando esse fica menos protegido pela vegetação e, portanto, mais vulnerável ao processo erosivo (CBHRMG, 1999).

Quanto aos solos encontrados na região, de acordo com CBHRMG (1999), pode-se concluir que: 
- Os solos podzolicos (com horizonte B textural) e os litossolos são mais suscetíveis à erosão tendo em vista as baixas taxas de infiltração e o relevo movimentado em que ocorrem;

- Devido à boa drenagem, os solos com horizonte B latossólico e os regossolos apresentam limites mais elevados de perda de solo.

Entretanto, como a quantidade de solo perdida por erosão não depende somente do grupamento do solo, sendo influenciada principalmente pelo manejo, identificam-se os seguintes problemas CBHRMG (1999):

- Culturas Temporárias: sérios problemas de erosão, mesmo em áreas aptas, devido ao uso intensivo de máquinas, tendência de monocultura, baixa cobertura vegetal no período crítico e, em alguns casos, dois cultivos por ano sem observar as condições ideais para o preparo e movimentação excessiva do solo, coincidindo com período de alta erosividade;

- Culturas Perenes: processo erosivo acelerado em função de cultivo mecanizado alterando a estrutura do solo, reduzindo a taxa de infiltração e causando déficit hídrico no período seco;

- Pastagens: no caso das pastagens extensivas, os problemas de erosão vinculados ao manejo do pasto, cuja cobertura vegetal favorece a erosão, possibilita a degradação precoce do próprio pasto, competição com invasoras, etc;

- Reflorestamento: erosão causada pela excessiva movimentação do solo, na ocasião do plantio, inobservância do plantio em nível no período chuvoso, inadequação dos caminhos e utilização de solos altamente suscetíveis ou em topografia acentuada.

Além desses fatores, podem-se mencionar, ainda, outros que têm colaborado para o agravamento do processo erosivo: divisão física da propriedade, construção de estradas e baixa produtividade (CBHRMG, 1999).

Em relação aos aspectos socioeconômicos, a bacia hidrográfica do Mogi-Guaçu é caracterizada por sua diversidade em termos de processos históricos de ocupação, de exploração agrícola e de crescimento urbano e populacional. Apesar desta diversidade, pode-se afirmar que tanto sua dinâmica econômica quanto a demográfica refletem o processo recente da interiorização da indústria e de intensa modernização e ganhos de produtividade agropecuária estadual. Apesar do esgotamento do modelo de financiamento associado ao II PND, que propiciou este dinamismo, os complexos sucroalcooleiros e cítricos ainda são responsáveis pela extensa ocupação das terras agricultáveis da região, pela maior contribuição desta ao PIB estadual, assim como pelas suas características demográficas (CBHRMG, 1999). 
Observa-se, entre os anos de 1970 e 2004, a ocorrência de crescimento populacional em todos os municípios abrangidos pela área de estudo (Tabela 6). Nesse mesmo período, houve um decréscimo da população rural nesses municípios (Tabela 7). Na Tabela 8, podem-se observar a área dos municípios e a densidade populacional no ano de 2004.

Tabela 6: População total dos municípios abrangidos pela área de estudo.

\begin{tabular}{|l|c|c|c|c|c|c|}
\hline \multicolumn{7}{|c|}{ População Total (Dados IPEA Data/IBGE, 2005) } \\
\hline \multicolumn{1}{|c|}{ Município } & $\mathbf{1 9 7 0}$ & $\mathbf{1 9 8 0}$ & $\mathbf{1 9 9 1}$ & $\mathbf{1 9 9 6}$ & $\mathbf{2 0 0 0}$ & $\mathbf{2 0 0 4}$ \\
\hline Américo Brasiliense & 5.368 & 11.864 & 20.067 & 23.993 & 28.287 & 31.824 \\
\hline Luís Antônio & 3.083 & 2.926 & 5.840 & 6.885 & 7.160 & 7.706 \\
\hline Rincão & 6.538 & 7.301 & 10.356 & 10.494 & 10.330 & 10.460 \\
\hline Santa Lúcia & 4.347 & 5.038 & 6.284 & 7.310 & 7.853 & 8.497 \\
\hline São Carlos & 85.425 & 119.535 & 158.221 & 175.517 & 192.998 & 209.009 \\
\hline * Dados Fundação SEADE
\end{tabular}

Tabela 7: População rural dos municípios abrangidos pela área de estudo.

\begin{tabular}{|l|c|c|c|c|c|c|}
\hline \multicolumn{7}{|c|}{ População residente rural (Dados IPEA Data/IBGE, 2005) } \\
\hline \multicolumn{1}{|c|}{ Município } & $\mathbf{1 9 7 0}$ & $\mathbf{1 9 8 0}$ & $\mathbf{1 9 9 1}$ & $\mathbf{1 9 9 6}$ & $\mathbf{2 0 0 0}$ & $\mathbf{2 0 0 4}$ \\
\hline Américo Brasiliense & 1.586 & 2.089 & 1.852 & 1.345 & 646 & 597 \\
\hline Luís Antônio & 2.459 & 1.667 & 2.031 & 624 & 602 & 535 \\
\hline Rincão & 2.376 & 2.299 & 2.635 & 2.390 & 2.073 & 1.922 \\
\hline Santa Lúcia & 2.463 & 2.054 & 1.478 & 987 & 808 & 747 \\
\hline São Carlos & 9.713 & 9.299 & 9.813 & 11.414 & 9.565 & 8.849 \\
\hline * Dados Fundação SEADE
\end{tabular}

Tabela 8: Área e Densidade Populacional dos municípios abrangidos pela área de estudo.

\begin{tabular}{|l|c|c|}
\hline \multicolumn{1}{|c|}{ Município } & $\begin{array}{c}\text { Área } \\
\left(\mathbf{K m}^{2}\right)\end{array}$ & $\begin{array}{c}\text { Densidade Populacional } \\
\left(\mathbf{H a b} . \mathbf{K m}^{\mathbf{2}} \mathbf{)}\right.\end{array}$ \\
\hline Américo Brasiliense & 127 & 250.58 \\
\hline Luís Antônio & 611 & 12.61 \\
\hline Rincão & 280 & 37.36 \\
\hline Santa Lúcia & 169 & 50.28 \\
\hline São Carlos & 1.132 & 184.64 \\
\hline \multicolumn{2}{|c|}{ Dados Fundação SEADE 2004 } \\
\hline
\end{tabular}


Observa-se, entre os anos de 1970 e 1995, o aumento das áreas ocupadas por lavouras temporárias (Tabela 9) - nas quais se inclui a cana-de-açúcar - e diminuição das áreas ocupadas por lavouras permanentes (Tabela 10), com exceção para o município de Rincão onde, nesse período, ocorreu o processo inverso. Isso deve ter acontecido em função do aumento das áreas ocupadas pela cultura da laranja, ainda presentes no município nos dias atuais. Porém, observando-se os dados econômicos dos municípios na época atual (Tabela 11), pode-se observar que no período de 1995 a 2005 as características referentes ao município de Rincão devem ter se alterado, apresentando na atualidade, assim como os demais municípios, predominância de culturas temporárias, principalmente cana-de-açúcar.

Tabela 9: Área de lavouras temporárias dos municípios abrangidos pela área de estudo.

\begin{tabular}{|l|c|c|c|c|c|}
\hline \multicolumn{1}{|c|}{ Área de lavouras temporárias - ha (Dados IPEA Data/IBGE - 2005) } \\
\hline \multicolumn{1}{|c|}{ Município } & $\mathbf{1 9 7 0}$ & $\mathbf{1 9 7 5}$ & $\mathbf{1 9 8 0}$ & $\mathbf{1 9 8 5}$ & $\mathbf{1 9 9 5}$ \\
\hline Américo Brasiliense & 6.317 & 7.947 & 8.186 & 10.335 & 9.069 \\
\hline Luís Antônio & 4.953 & 7.111 & 17.429 & 24.335 & 24.552 \\
\hline Rincão & 8.051 & 8.439 & 10.893 & 11.523 & 1.221 \\
\hline Santa Lúcia & 7.591 & 9.020 & 12.420 & 17.169 & 8.236 \\
\hline São Carlos & 9.903 & 10.929 & 14.173 & 21.173 & 32.569 \\
\hline
\end{tabular}

Tabela 10: Área de lavouras permanentes dos municípios abrangidos pela área de estudo.

\begin{tabular}{|l|c|c|c|c|c|}
\hline \multicolumn{6}{|c|}{ Área de lavouras permanentes - ha (Dados IPEA Data/IBGE - 2005) } \\
\hline \multicolumn{1}{|c|}{ Município } & $\mathbf{1 9 7 0}$ & $\mathbf{1 9 7 5}$ & $\mathbf{1 9 8 0}$ & $\mathbf{1 9 8 5}$ & $\mathbf{1 9 9 5}$ \\
\hline Américo Brasiliense & 457 & 2.378 & 2.391 & 2.062 & 1.275 \\
\hline Luís Antônio & 548 & 1.272 & 1.663 & 2.590 & 819 \\
\hline Rincão & 457 & 2.708 & 2.293 & 3.218 & 3.907 \\
\hline Santa Lúcia & 842 & 1.296 & 1.199 & 1.508 & 429 \\
\hline São Carlos & 3.018 & 4.902 & 7.345 & 4.634 & 8.595 \\
\hline
\end{tabular}


Tabela 11: Aspectos econômicos dos Municípios abrangidos pela área de estudo (Fonte: AGRONEGÓCIO, 2002; 2003a; 2003b; 2005).

\begin{tabular}{|c|c|}
\hline Município & Aspectos Econômicos \\
\hline Américo Brasiliense & $\begin{array}{l}\text { Cana-de-açúcar, principal atividade econômica, apesar de ser a sede de apenas } \\
\text { uma usina (Usina Santa Cruz). A agroindústria responde por mais de } 50 \% \text { do } \\
\text { repasse do ICMS estadual ao município, cerca de } \mathrm{R} \$ 46.086 .288,00 \text { de um total } \\
\text { de R\$80.400.000,00. } \\
\text { Cana-de-açúcar: } 3.000 .000 \text { de toneladas } \\
\text { Álcool: } 1.200 .00 \text { litros/dia } \\
\text { Açúcar: } 25.000 \text { sacas/dia }\end{array}$ \\
\hline Luiz Antônio & $\begin{array}{l}\text { Repasse de ICMS é de cerca de R\$20 milhões/ano provenientes, em sua maior } \\
\text { parte, da atuação do agronegócio no município. } \\
\text { Cana-de-açúcar: } 22.385 \text { hectares (Usinas Moreno, Santa Rita e São Martinho) } \\
\text { Laranja: } 2.600 \text { hectares (Cutrale) } \\
\text { Eucalipto: } 3.180 \text { hectares (Votorantim Celulose e Papel - VCP) }\end{array}$ \\
\hline Rincão & $\begin{array}{l}\text { A principal atividade econômica é a agricultura. } \\
\text { Cana-de-açúcar: } 16.000 \text { ha., } 80 \text { ton/ha.ano } \\
\text { Laranja: } 2.300 \text { ha., } 2 \text { caixas/pé.ano } \\
\text { Propriedades rurais cadastradas: } 212\end{array}$ \\
\hline Santa Lúcia & $\begin{array}{l}\text { A principal atividade econômica é a agricultura. Pequena área ocupada pela } \\
\text { produção de laranja e a maior parte da área do município ocupada por cana-de- } \\
\text { açúcar. }\end{array}$ \\
\hline São Carlos & $\begin{array}{l}800 \text { propriedades rurais na cidade, } 95 \% \text { da área do município } \\
\text { A agricultura é importante, mas a cidade é mais lembrada, na atualidade, pelo } \\
\text { pólo educacional, tecnológico e científico. O setor econômico mais forte é o } \\
\text { industrial ( } 460 \text { indústrias - } 40.000 \text { postos de trabalho). } \\
\text { Granjas: são cerca de } 85 \text {, abatem o equivalente a } 75 \text { milhões de quilos de carne } \\
\text { de frango por ano, e empregam mais de } 1000 \text { pessoas. } \\
\text { Milho: } 3.000 \text { ha., } 240.000 \text { sacas/ano } \\
\text { Soja: } 1.000 \text { ha., } 46.000 \text { sacas/ano } \\
\text { Laranja: } 1,5 \text { milhão de pés, } 3 \text { milhões de caixas/ano } \\
\text { Cana-de-açúcar: } 21.000 \text { ha., } 1.764 \text { mil ton/ano } \\
\text { Café: } 770 \text { ha., } 38.500 \text { sacas/ano } \\
\text { Reflorestamento: } 3.000 \text { ha. } \\
\text { Gado: } 20 \text { mil cabeças (gado de corte e leite) } \\
\text { Suínos: } 15.000 \text { cabeças } \\
\text { Frango de corte: } 5,5 \text { milhões de cabeças }\end{array}$ \\
\hline
\end{tabular}




\subsubsection{Estação Ecológica de Jataí (EEJ)}

A Estação Ecológica de Jataí (EEJ) apresentava, originalmente, uma área de 4.532,18 ha., regulamentada pelos Decretos Lei $n^{0} 18.997$ (15/06/82,SP) e $n^{0} 20.809$ (11/03/83, SP) - (Pires et al., 2000a). Após a aprovação do Decreto 47.096/SP de 18 de setembro de 2002, a área da Estação praticamente duplicou, passando a ter 9.010,7 ha., estando dividida em duas glebas Tabela 12 - (Henke-Oliveira, 2006). A localização e a área da EEJ podem ser visualizadas na Figura 4.

A EEJ é uma das mais importantes unidades de conservação do estado de São Paulo, apresentando uma série de funções ambientais (Santos, 2003):

- Funções de Regulação: regulação climática, prevenção da inundação, prevenção à erosão do solo, fixação bioenergética, armazenamento e reciclagem de matéria orgânica, nutrientes, resíduos industriais e domésticos, controle biológico, migração e habitats reprodutivos, manutenção da biodiversidade.

- Funções de Suporte: recreação, proteção da natureza.

- Funções de Produção: recursos genéticos, recursos medicinais, matéria prima para a constução civil e trabalhos artesanais.

- Funções de Informação: estética e histórica, científica e educacional.

As atividades econômicas que são desenvolvidas no Município de Luiz Antônio (sub-bacia hidrográfica do Médio Mogi-Superior), na área de entorno da Estação Ecológica do Jataí, são descritas por Santos et al. (2000):

- Setor Primário: ocupa a maior parte da área de entorno da EEJ, com atividades relacionadas a uma agricultura altamente tecnificada, correspondendo a 40.163,30 ha ou 67,37\% da área total do município de Luiz Antônio, incluindo o cultivo de cana-deaçúcar, reflorestamento, citricultura, pecuária e outras culturas.

- Setor Secundário: destacam-se duas indústrias - Votorantin Celulose e Papel (CELPAV) e a Usina de Álcool e Açúcar Moreno. Outras agroindústrias influenciam o uso do solo no município, em especial as usinas de álcool e açúcar localizadas nas cidades de Pradópolis e Santa Rita do Passa-Quatro.

- Setor Terciário: é bastante inexpressivo, com poucas instalações comerciais e serviços essenciais à saúde.

Pires et al. (2000d) analisaram a zona rural do município de Luiz Antônio, SP, para a identificação dos riscos ambientais resultantes das atividades agrícolas, urbanas e industriais nos componentes solo (riscos de erosão e deslizamento de encostas) e hidrografia (desperenização de rios e deterioração da qualidade da água). Identificou oito unidades de gerenciamento do 
município de Luiz Antônio. Quatro dessas unidades, abrangidas pela área da EEJ, são listadas na Tabela 13.

De acordo com Pires et al. (2000d), a bacia hidrográfica do córrego Beija-Flor apresentou o maior trecho de córregos com baixo risco de degradação da qualidade da água. Isso se deve, em grande parte, à proteção efetuada pela Estação Ecológica de Jataí. Entretanto, a bacia do córrego Boa Sorte, apesar de exibir 45\% de áreas naturais, apresenta a margem direita do córrego ocupada por cultivo de cana-de-açúcar. Segundo os autores, a maior parte da extensão do córrego apresenta risco de degradação por entrada de sólidos em suspensão (risco de assoreamento) e agrotóxicos.

Tabela 12: Área e Perímetro da Estação Ecológica de jataí e da Estação Experimental de Luiz Antônio após o Decreto 47.096/SP de 18 de setembro de 2002 (Henke-Oliveira, 2006).

\begin{tabular}{|c|c|c|}
\hline UNIDADE & Área (ha) & Perímetro (km) \\
\hline Estação Ecológica de Jataí (GLEBA A) & $8.068,0$ & 67,45 \\
\hline Estação Ecológica de Jataí (GLEBA B) & 942,7 & 13,06 \\
\hline Estação Ecológica de Jataí (Total) & $9.010,7$ & 80,51 \\
\hline Estação Experimental de Luiz Antônio & $2.021,0$ & 20,98 \\
\hline TOTAL & $\mathbf{1 1 . 0 3 1 , 7}$ & \\
\hline \multicolumn{2}{|c|}{} \\
\hline
\end{tabular}

Foi verificado, também, que as áreas alagáveis da área de estudo (áreas úmidas - termos relacionados apresentados no glossário) vêm sendo continuamente degradadas pelo avanço da agricultura, envolvendo riscos ambientais associados à diminuição da pesca de caráter recreacional e da qualidade da água Pires et al. (2000d). 


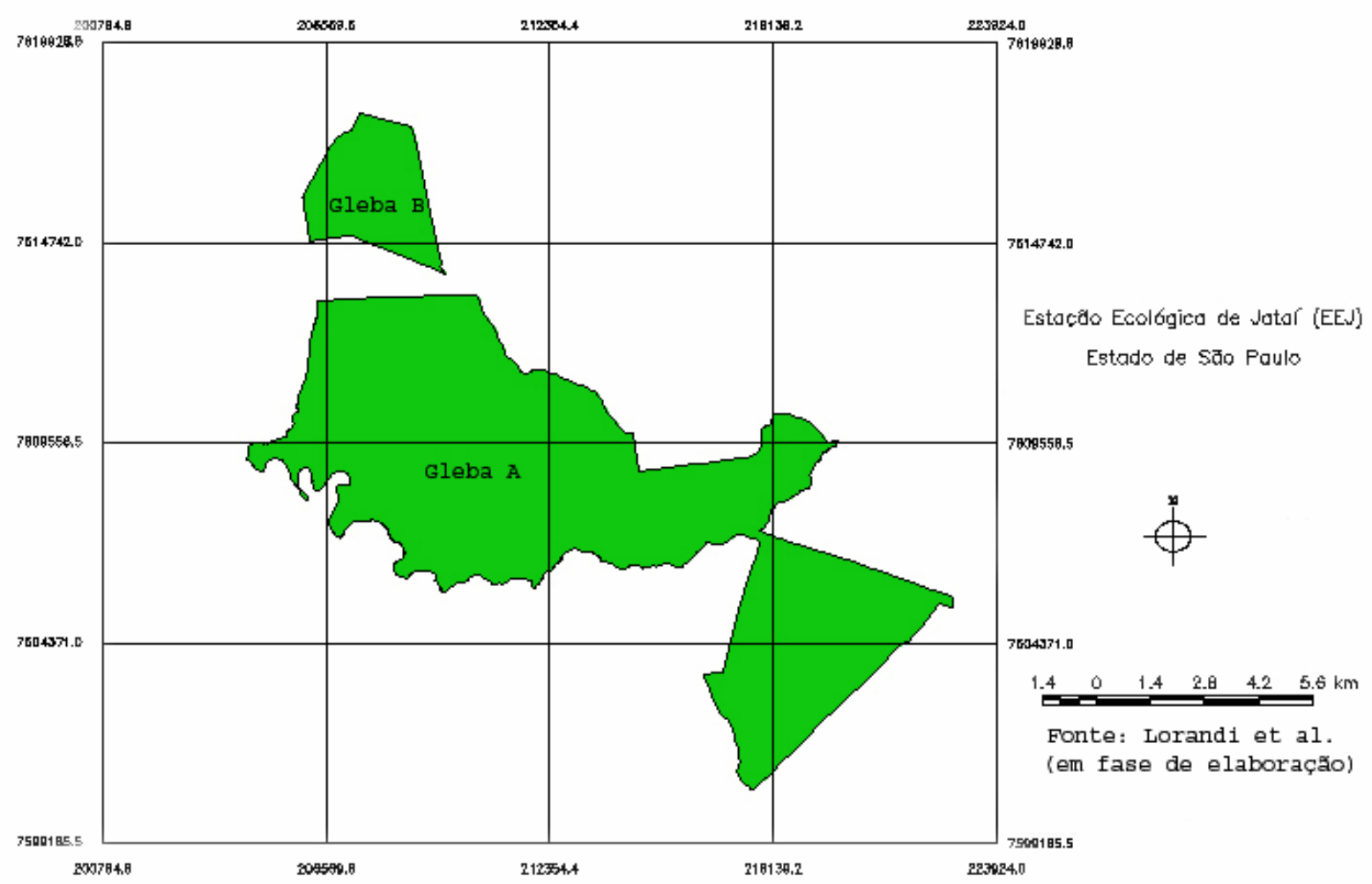

Figura 4. Área da Estação Ecológica de Jataí - EEJ (Lorandi et al. ${ }^{9}$ em fase de elaboração).

Tabela 13: Unidades de Gerenciamento do Município de Luiz Antônio, representadas pelas áreas (ha) e por porcentagem da área total do Município (\%) das bacias hidrográficas e seus rios principais, onde está inserida a área da Estação Ecológica de Jataí (Pires et al., 2000d):

\begin{tabular}{|c|c|c|}
\hline Rios Principais & Área (ha) & Área (\%) \\
\hline Ribeirão Vassununga & $10.278,08$ & 17,25 \\
\hline Córrego Cafundó (ou Manoel Rodrigues) & $6.077,14$ & 10,19 \\
\hline Córrego Beija-Flor (ou Jataí) & $9.345,83$ & 15,65 \\
\hline Córrego Boa Sorte & $4.563,25$ & 7,66 \\
\hline
\end{tabular}

\footnotetext{
${ }^{9}$ Relações entre a natureza dos solos e suas posições na paisagem da Estação Ecológica de Jataí (Luiz Antônio, SP), de autoria de Lorandi, R.; Gonçalves, A.R.L.; Freire, O.; Trindade, M.; Minoti, R.T. In: a ser publicado no Livro "Estudos Integrados em Ecossistemas. Estação Ecológica de Jataí. Vol. 3, editado por Santos, J.E. e Pires, J.S.R., Edufscar, São Carlos/SP.
} 


\section{MATERIAIS E MÉTODOS}

\subsection{Considerações Iniciais}

Este capítulo visa descrever os procedimentos para a construção da base cartográfica analógica e digital da área de estudo, a preparação dos dados necessários para a aplicação da Equação Universal de Perda de Solo (EUPS), o levantamento e a elaboração dos dados de entrada do modelo AVSWAT 2000 e sua manipulação.

\subsection{Construção da Base Cartográfica}

A construção da base cartográfica é a primeira e mais demorada etapa para o desenvolvimento de trabalhos em geoprocessamento. Esta etapa envolve o levantamento de informações, a definição do limite da área de estudo, a busca e aquisição de cartas e mapas temáticos para o reconhecimento da área e a conversão dos dados em formato analógico para o formato digital.

A base de dados cartográfica analógica utilizada no desenvolvimento do trabalho foi a seguinte:

- Carta topográfica elaborada pelo Instituto Brasileiro de Geografia e Estatística IBGE (1971), escala 1:50.000 no sistema de projeção UTM, correspondendo às folhas Porto Pulador/SP, SF.23-V-C-IV-1, e Luis Antônio, SF.23-V-C-IV-2.

- Mapa de Solos - Levantamento pedológico semidetalhado do Estado de São Paulo, Instituto Agronômico de Campinas/IAC - Divisão de Solos (1982), escala 1:50.000 ${ }^{10}$, sistema de projeção UTM, quadrícula de Descalvado, folha SF.23-V-CIV.

- Mapa de Solos da Bacia do Córrego do Jataí e Áreas Adjacentes. Escala 1:25.000 (UFSCar - Lorandi et al., 1990).

Para o escaneamento dessas cartas, utilizou-se scanner cilindro marca OCÉ, modelo 9400. Após a transformação dos mapas analógicos para imagens digitais, iniciou-se o desenvolvimento da base de dados digital do trabalho de pesquisa. Utilizou-se, para o desenvolvimento das atividades, um microcomputador AMD Athlon XP 1800+, 1,49 GHz, 512MB de memória RAM. Os aplicativos utilizados para a digitalização, geração e manipulação das imagens foram os seguintes:

\footnotetext{
${ }^{10}$ Escala real do mapa, informação fornecida pelo Dr. Ricardo Coelho, pesquisador do Instituto Agronômico de Campinas/IAC em 2005.
} 
- AutoCAD Map 2000 e CAD Overlay 2000 (desenvolvidos pela Autodesk, 1999).

- SPRING versão 4.1 (desenvolvido pelo Instituto Nacional de Pesquisas Espaciais INPE - São José dos Campos SP, 2004) - utilizado para a elaboração da base de dados digital.

- IDRISI32 versão I32.02 (desenvolvido pela Clark Labs, Worcester MA, 2001) utilizado para a aplicação da Equação Universal de Perda de Solo (EUPS).

- ArcView versão 3.1 (com extensão ArcView Spatial Analyst v. 1.1, desenvolvido pela Environmental Systems Research Institute - ESRI - Redlands CA, 1998) programa utilizado pelo modelo SWAT para rodar as interfaces de geoprocessamento.

A partir das imagens digitais foram digitalizados, utilizando-se o Programa AutoCAD, as curvas em nível, os pontos cotados, corpos aquáticos, a hidrografia e a área de várzea, referentes à carta topográfica e, também, as unidades de mapeamento referentes aos mapas de solos, gerando arquivos vetoriais. Iniciou-se, dessa forma, o desenvolvimento da base de dados digital (BDD).

No Spring, para iniciar o desenvolvimento da BDD criou-se um banco de dados tendo o Programa Access como gerenciador. Em seguida, gerou-se um projeto com as seguintes características:

Projeção

- Sistema de Coordenadas: UTM (Universal Transversa de Mercator)

- Zona: $23 \mathrm{Sul}$

- Datum: Córrego Alegre

Retângulo Envolvente

- $\mathrm{X} 1=195.000$

- $\mathrm{X} 2=220.000$

- $\mathrm{Y} 1=7.594 .000$

- $\mathrm{Y} 2=7.618 .000$

No passo seguinte foram formadas diversas categorias, nas quais foram inseridos os planos de informação. Parte dos planos de informação como curvas de nível, hidrografia, corpos aquáticos, tipo e uso do solo, contorno das microbacias e malha viária originaram-se, diretamente, da importação de arquivo no formato .dxf, conforme foi mencionado anteriormente. Os demais planos de informação foram criados no próprio programa, como o modelo de elevação digital, imagens em nível de cinza, imagem sombreada, declividade, entre outros. 
No Idrisi, para iniciar o desenvolvimento da BDD, basta criar uma pasta no Windows, que servirá de local de armazenamento das imagens geradas, e indicar o nome dessa pasta no programa no módulo Data Paths/Project Environment. O ArcView apresenta um tipo de organização da base de dados semelhante ao Idrisi.

As curvas de nível foram digitalizadas com eqüidistância de 20 metros, salvas na extensão .dxf e levadas aos três programas utilizados no desenvolvimento do trabalho, citados anteriormente, para posterior elaboração do Modelo Numérico do Terreno (MNT). Os demais arquivos vetoriais gerados foram salvos, também, na extensão .dxf e importados pelo programa Spring para atribuição das classes em cada plano de informação, a qual foi realizada no módulo de Edição Topológica.

Os arquivos vetoriais referentes aos corpos aquáticos, à hidrografia, à área de várzea e aos solos, após a atribuição de classes, foram salvos no Spring no formato Shapefile para posterior importação no Idrisi e ArcView.

Após o reconhecimento da área, utilizando-se os dados obtidos pela digitalização das curvas em nível, realizou-se a delimitação das microbacias hidrográficas (unidades de estudo), no AutoCAD, com base em metodologia desenvolvida por Argento e Cruz (2002).

Os arquivos vetoriais, gerados pelo processo de digitalização, foram rasterizados utilizando-se rotinas dos aplicativos utilizados no estudo. Fujihara (2002) analisou estatisticamente os Modelos Numéricos do Terreno (MNT) elaborados com base em quatro modelos de interpolação: interpolador de distância (IDW), interpolador linear (Intercon), Tin e Spline. O autor concluiu que o modelo de triangulação (TIN) representou melhor as isolíneas intermediárias entre as cotas originiais.

Com base nessas premissas, o MNT, fundamental para geração de diversas imagens, assim como para a determinação do fator LS da EUPS, foi elaborado da seguinte forma:

- No Spring, o modelo de rede triangular irregular (Tin) foi gerado pelo método de Delaunay, com resolução de $25 \mathrm{~m}$, para a elaboração das imagens de hipsometria, clinografia, em níveis de cinza, de sombreamento e dos perfis topográficos.

- No Idrisi, o MNT foi gerado, para a utilização nos cálculos dos parâmetros da Equação Universal de Perda de Solo, em duas etapas. A partir da imagem de curvas de nível (vetorial) por meio do módulo Tin, que, assim como o Spring, utiliza o método de triangulação de Delauney, gera um modelo de rede triangular irregular. Com o uso do módulo Tinsurf, esse modelo é utilizado para gerar uma imagem de superfície no formato raster, com resolução de $15 \mathrm{~m}$.

- No ArcView, para a preparação dos dados de entrada no modelo AVSWAT 2000, o MNT foi gerado utilizando-se o módulo Create Tin From Features. 
A partir do MNT, foram geradas as cartas hipsométrica e clinográfica e elaborados os perfis topográficos das unidades de estudo. As classes de declividade, utilizadas na elaboração da carta clinográfica, foram propostas por Ramalho Filho e Beek (1995) em função dos graus de limitação ao desenvolvimento de culturas por suscetibilidade à erosão (Tab. 14).

Tabela 14. Classes de Declividade, Relevo e Graus de limitação por suscetibilidade à erosão (Modificado de Ramalho Filho e Beek, 1995)

\begin{tabular}{|c|c|c|}
\hline Classes de Declividade & Relevo & Grau de Limitação \\
\hline 0 a $3 \%$ & Plano/praticamente plano & Nulo (N) \\
\hline 3 a $8 \%$ & Suave ondulado & Ligeiro (L) \\
\hline 8 a $13 \%$ & Moderadamente ondulado & Moderado (M) \\
\hline 13 a $20 \%$ & Ondulado & Forte (F) \\
\hline 20 a $45 \%$ & Forte ondulado & Muito forte (MF) \\
\hline 45 a $100 \%$ & Montanhoso & Extremamente forte \\
\hline Acima de $100 \%$ & Escarpado & \\
\hline
\end{tabular}

Complementando a base de dados digital, o levantamento de informações sobre o uso e a ocupação do solo foi realizado com a utilização de dados de sensoriamento remoto e com a utilização de sistemas de informação geográfica. Foi utilizada uma imagem digital ETM+ do satélite LANDSAT-7, de 27 de abril de 2002, contendo as bandas 1, 2, 3, 4, 5, 6 (formatos 1 e 2), 7 e 8, abrangendo toda a região central do Estado de São Paulo, gentilmente cedida pelo Prof. Dr. Reinaldo Lorandi do Depto. de Engenharia Civil e Programa de Pós-Graduação em Engenharia Urbana - UFSCar.

A interpretação da imagem ETM+-LANDSAT-7 foi realizada no Idrisi. Primeiramente todas as bandas da imagem foram georreferenciadas, por meio do módulo Resample, utilizandose pontos com coordenadas conhecidas, identificadas na carta topográfica (IBGE, 1971). Em seguida, foi realizada uma fusão entre as bandas, utilizando-se módulo Colspace, o que permitiu expressar a resolução espacial da Banda 8 (Pancromática) nas demais bandas. Dessa forma, as composições com as bandas puderam ser realizadas com resolução de $15 \mathrm{~m}$. Posteriormente, foi produzida uma composição de três bandas, de cores falsas escolhidas ao acaso utilizando-se o módulo Composite. As composições que apresentaram as melhores combinações de cores para a diferenciação dos espaços geográficos foram utilizadas nos passos seguintes. 
Após essas etapas, foi realizada uma primeira tentativa de identificação dos elementos da paisagem pela interpretação de algumas características da imagem produzida como cor, textura, tamanho, forma, padrão e localização geográfica. Em seguida, com a identificação de algumas culturas agrícolas na área de estudo, realizou-se uma tentativa de classificação automática da imagem de satélite no Idrisi. No entanto, os resultados obtidos não foram satisfatórios. Vários pontos não foram classificados corretamente, não correspondendo aos usos do solo observados no campo. Dessa forma, optou-se por melhorar o conhecimento sobre a área de estudo em viagens a campo.

Segundo Florenzano (2002), o trabalho de campo é praticamente indispensável ao estudo e mapeamento do meio ambiente por meio de imagens de sensores remotos. Ele faz parte do processo de interpretação de imagens. Por meio dele, o resultado da interpretação torna-se mais confiável.

Tendo em vista que á área a ser observada não era tão extensa (aproximadamente 16.500 ha), que grande parte da área estava ocupada por áreas preservadas (Estação Ecológica de Jataí/LA) e que as culturas agrícolas e áreas de reserva legal apresentavam padrões de distribuição espacial bem definidos, optou-se por georreferenciar os contornos de todos os polígonos referentes aos diferentes usos e verificar a correspondência dos padrões espectrais delimitados nas imagens coloridas, sem o tratamento de classificação, com os diferentes tipos de cultura. O georreferenciamento foi realizado com o auxílio de receptor GPS (Global Positioning System) marca Garmin, modelo eTrex Summit. Em cada ponto amostrado, esperava-se de 5 a 10 minutos para a estabilização da precisão do aparelho em 7 ou 8 metros. Essa etapa foi fundamental para a validação da interpretação e classificação das imagens.

Após o levantamento de todos os pontos necessários para a confirmação dos diferentes usos do solo na área de estudo, os dados obtidos foram digitalizados no Programa AutoCAD, e os polígonos, referentes às diferentes culturas, foram sendo formados. Após a digitalização de toda a área de estudo, os dados foram conferidos e confirmados com a carta topográfica e com a imagem de satélite. Os arquivos gerados pela digitalização dos diferentes usos do solo, conforme foi mencionado para os demais arquivos vetoriais, foram salvos, na extensão .dxf e importados pelo Spring para a atribuição das classes de uso do solo. Após a atribuição de classes, foram salvos no Spring, no formato Shapefile, para posterior importação no Idrisi e ArcView. 


\subsection{Modelagem de Sistemas Ambientais}

Os diversos modelos matemáticos relacionados às estimativas dos parâmetros que seriam estudados no presente trabalho, para que pudessem ser utilizados na pesquisa, foram analisados em função dos dados de entrada que requeriam e dos dados de saída que eram gerados.

Pelas diversas características discorridas na introdução do presente trabalho, para estimar a perda de solo por erosão, a produção de sedimentos e o balanço hídrico das unidades de estudo, foram utilizados um modelo empírico (EUPS) e um modelo conceitual (AVSWAT 2000), ambos gerados com utilização (ou interface) de Sistemas de Informações Geográficas SIG.

\subsection{Equação Universal de Perda de Solo (EUPS)}

Segundo Bertoni e Lombardi Neto (1999), a equação de perda de solo, desenvolvida por Wischmeier e Smith (1965), é expressa da seguinte forma:

$$
\mathbf{A}=\mathbf{R} . \mathbf{K} \cdot \mathbf{L} \cdot \mathbf{S} \cdot \mathbf{C} \cdot \mathbf{P}
$$

Sendo:

$$
\begin{aligned}
& \mathbf{A}=\text { perda de solo por erosão em unidade de área (t/ha.ano); } \\
& \mathbf{R}=\text { fator chuva, erosividade (MJ.mm/ha.h); } \\
& \mathbf{K}=\text { fator de erodibilidade do solo (t.h/MJ.mm); } \\
& \mathbf{L}=\text { fator comprimento do declive; } \\
& \mathbf{S}=\text { fator grau do declive; } \\
& \mathbf{C}=\text { fator uso e manejo; } \\
& \mathbf{P}=\text { fator prática conservacionista. }
\end{aligned}
$$

Os componentes da EUPS, os quais exprimem a ação dos principais fatores que afetam as perdas de solo, foram descritos de maneira detalhada por Bertoni e Lombardi Neto (1999). Uma síntese do significado desses fatores, com base no trabalho desses autores e em outros trabalhos específicos que serão citados ao longo do texto, é apresentada a seguir.

\subsubsection{Fator chuva (erosividade $-\mathrm{R}-\mathrm{MJ} . \mathrm{mm} / \mathrm{ha.h}$ )}

O fator chuva $(\mathrm{R})$ é um índice numérico que representa o potencial da chuva e enxurrada, esperadas em dada localidade, de provocar erosão em uma dada área sem proteção. Estudos de dados das perdas de solo mostraram que a perda de solo ocasionada pela chuva nos terrenos cultivados é diretamente proporcional ao produto da energia cinética total da chuva pela sua 
intensidade máxima em 30 minutos. Esse produto representa um termo de interação que mede o efeito de como a erosão por impacto, o salpico e a turbulência se combinam com a enxurrada para transportar as partículas de solo desprendidas. $\mathrm{O}$ resultado desse produto é o $\mathrm{El}_{30}$ (índice de erosão). Esse índice é considerado a melhor relação encontrada para medir a potencialidade erosiva da chuva. A média dos valores anuais de $\mathrm{El}_{30}$ de um longo período de tempo (mais de 20 anos) é o valor R da equação (Bertoni e Lombardi Neto, 1999).

De acordo com Marques et al. (1997), entre os fatores da EUPS, apenas a erosividade é computada diretamente, a partir de registros pluviográficos, enquanto os demais são relativos à parcela-padrão proposta por Wischmeier e Smith (1978).

Com base em vinte e dois anos de registros de precipitação (chuva) em Campinas, Lombardi Neto e Moldenhauer (1992) desenvolveram uma expressão para o cálculo de R a partir de dados de pluviômetros:

Lombardi Neto \& Moldenhauer (1992), utilizando vinte e dois anos de registros de precipitação (chuva) em Campinas, encontraram alto coeficiente de correlação para regressão linear entre a média mensal do índice de erosão $\left(\mathrm{El}_{30}\right)$ e a média mensal do coeficiente de chuva (relação entre a precipitação mensal e a anual de uma localidade). Com base nos resultados obtidos, desenvolveram um modelo para o cálculo da erosividade.

Lombardi Neto et al. (1999), utilizando dados de 140 locais do Estado de São Paulo e com base na expressão desenvolvida por Lombardi Neto e Moldenhauer (1992), desenvolveram um programa computacional denominado "Erosividade - Sistema para o cálculo da erosividade da chuva para o Estado de São Paulo".

O fator R, para cada unidade hidrográfica de estudo do presente trabalho, foi obtido utilizando-se o software Erosividade. Dessa forma, os valores de erosividade anual, utilizados no presente estudo, foram:

- Américo Brasiliense - 7.199 MJ.mm/ha.h;

- Luiz Antônio - 7.383 MJ.mm/ha.h;

- Rincão - 7.241 MJ.mm/ha.h;

- Santa Lúcia - 7.213 MJ.mm/ha.h;

- São Carlos - 7.321 MJ.mm/ha.h. 


\subsubsection{Fator solo (erodibilidade $-\mathrm{K}-$ t.h/MJ.mm)}

A erodibilidade $(\mathrm{K})$ do solo representa a sua suscetibilidade à erosão, a facilidade com que ele pode ser erodido. Alguns solos são mais erodíveis que outros mesmo quando o declive, a precipitação, a cobertura vegetal e as práticas de controle de erosão são as mesmas. Essa diferença ocasionada pelas propriedades inerentes ao solo é referida como erodibilidade do solo (Bertoni e Lombardi Neto, 1999).

As propriedades do solo que influenciam a erodibilidade pela água são aquelas que afetam a velocidade de infiltração, a permeabilidade e capacidade total de armazenamento de água; resistem às forças de dispersão, salpico, abrasão e transporte pela chuva e escoamento. De acordo com Miller e Gardiner (2001), o aumento da quantidade de matéria orgânica, a presença de agregados maiores e a rápida permeabilidade do solo contribuem para a redução da erodibilidade.

Lombardi Neto e Bertoni (1975) estudaram 66 perfis de solo para dois agrupamentos que ocorrem no Estado de São Paulo. Os autores consideraram os valores obtidos como uma estimativa do fator erodibilidade do solo para os principais solos paulistas.

Os valores do fator $\mathrm{K}$ e de tolerância de perda de solo por erosão (Tab. 15) utilizados no presente trabalho, específicos para a região de São Carlos, foram fornecidos pelo Dr. Francisco Lombardi Neto (informação verbal).

\subsubsection{Fator comprimento e grau do declive (fator topográfico LS)}

O fator comprimento e grau do declive influi sobre a velocidade do escoamento superficial e, conseqüentemente, sobre as perdas de solo por erosão. Esses dois fatores são considerados conjuntamente na EUPS como um fator topográfico LS (Bertoni e Lombardi Neto, 1999).

O fator LS é um dos fatores que oferece maiores dificuldades para a sua determinação. Existem várias metodologias para estimar os valores de LS. O cálculo pode ser feito manualmente, pode ser manual adaptado ao ambiente SIG e pode ser automatizado. Na presente pesquisa, foram testadas variadas metodologias para a obtenção do Fator LS utilizando-se diferentes tipos de software de geoprocessamento (Spring, Idrisi e ArcView). Optou-se por obter o fator LS utilizando-se um método automatizado, o programa LS-USLE2D, Versão 4.1/2000 (Rocha et al., 1997; Fujihara, 2002). 
Tabela 15. Valores de erodibilidade do solo $(\mathrm{K})$ e tolerância de perdas de solo por erosão para os solos da região de São Carlos/SP (Dr. Francisco Lombardi Neto - informação verbal).

\begin{tabular}{|c|c|c|}
\hline Classe de Solo & $\begin{array}{c}\text { Erodibilidade } \\
\text { (MJ.mm/ha.h) }\end{array}$ & $\begin{array}{c}\text { Tolerância* } \\
\text { (t/ha) }\end{array}$ \\
\hline LATOSSOLO VERMELHO Eutroférrico (LVef) & 0,0177 & 12,0 \\
\hline LATOSSOLO VERMELHO Distrófico (LVd) & 0,0168 & 15,0 \\
\hline LATOSSOLO VERMELHO Ácrico (LVw) & 0,0193 & 12,3 \\
\hline LATOSSOLO VERMELHO AMARELO Distrófico (LVAd) & 0,0223 & 14,2 \\
\hline ARGISSOLO VERMELHO Distrófico típico (PVd) & 0,0405 & 8,6 \\
\hline CHERNOSSOLO ARGILÚVICO Órtico típico (MTo) & 0,0304 & 12,7 \\
\hline NEOSSOLO LITÓLICO Eutrófico chernossólico (RLe) & 0,0480 & 6,7 \\
\hline NEOSSOLO QUARTZARÊNICO Órtico típico (Rqo) & 0,0161 & 8,2 \\
\hline NEOSSOLO QUARTZARÊNICO Hidromórfico (RQg) & 0,0161 & 7,5 \\
\hline GLEISSOLO HÁPLICO Tb Eutrófico (GXbe) & 0,0354 & 7,5 \\
\hline Combinação de GLEISSOLO HÁPLICO Tb Eutrófico com & 0,0326 & 7,1 \\
\hline CAMBISSOLO HÁPLICO (GXbe + CXbd) & & \\
\hline
\end{tabular}

* Média ponderada em relação à profundidade.

O programa USLE2D foi desenvolvido pelo Laboratório de Geomorfologia Experimmental da Universidade Católica de Leuven (Bélgica) para calcular o fator LS da Equação Universal de Perda de Solos a partir de um modelo de elevação digital. Em vez de utilizar o comprimento da rampa o programa realiza o cálculo determinando a área de contribuição, fornecendo diferentes algoritmos para o cálculo dessa área e para o cálculo do fator LS. O programa LS-USLE2D versão 4.1 para ambiente Windows é compatível com o software Idrisi 32.

O programa funciona com base em um conjunto de rotinas referentes aos algoritmos para o cálculo do fluxo das áreas de contribuição. Primeiramente, ocorre a determinação da área de contribuição, em estrutura de grade, em duas etapas:

1. Pela movimentação de uma submatriz $3 \times 3$, determina-se a célula vizinha para onde seguirá o fluxo da célula central;

2. Determina-se a proporção do fluxo total que será transferida para a célula vizinha.

O aplicativo requisita um primeiro arquivo do MNT que abrange toda a área de estudo juntamente com um segundo arquivo o qual define a área da microbacia (máscara). Dentre as rotinas existentes, utilizaram-se os algoritmos "Flux Decomposition" para a área de contribuição, 
que consideram os fluxos convergente, pararelo e divergente; e o algoritmo baseado no modelo Wischmeier \& Smith (1978) para o cálculo do fator LS.

\subsubsection{Fator uso e manejo do solo (C)}

O fator uso e manejo do solo (C) é a relação esperada entre as perdas de solo de um terreno cultivado em dadas condições e as perdas correspondentes de um terreno mantido continuamente descoberto e cultivado. Os efeitos das variáveis uso e manejo não podem ser avaliados independentemente, devido às diversas interações que ocorrem (Bertoni e Lombardi Neto, 1999).

De acordo com Bertoni e Lombardi Neto (op cit.), as combinações dessas variáveis envolvem aspectos como:

a. A cultura pode ser plantada continuamente em um mesmo local ou, então, pode ocorrer a rotação de culturas;

b. Os restos da cultura podem ser removidos, deixados na superfície ou enterrados durante o preparo do solo;

c. A proteção da cultura vegetal depende do tipo de vegetação, do seu desenvolvimento e, também, da época do ano.

$\mathrm{O}$ fator $\mathrm{C}$ mede o efeito combinado de todas essas variáveis de cobertura e manejo. Segundo Carvalho (1994), em áreas sem nenhuma vegetação, o fator C tende a 1, enquanto que em florestas virgens tende a valores próximos a 0,0001 .

Os valores do fator C (Tab. 16) utilizados no presente trabalho, específicos para a área de estudo, foram fornecidos pelo Dr. Francisco Lombardi Neto (informação verbal).

Tabela 16. Valores do fator C para alguns usos de solo da região de São Carlos/SP (Dr. Francisco Lombardi Neto, informação verbal).

\begin{tabular}{|l|c|}
\hline \multicolumn{1}{|c|}{ Classe de Uso do Solo } & Fator C \\
\hline Cana-de-açúcar & 0,1124 \\
\hline Citros (estágio formado) & 0,1350 \\
\hline Pastagem com manejo & 0,001 \\
\hline Pastagem nativa & 0,005 \\
\hline Eucalipto & 0,047 \\
\hline Mata e vegetação nativa & 0,0004 \\
\hline
\end{tabular}




\subsubsection{Fator prática conservacionista $(P)$}

O fator prática conservacionista $(\mathrm{P})$ é a relação entre a intensidade esperada das perdas de solo com determinada prática conservacionista e aquelas quando a cultura está plantada no sentido do declive (morro abaixo). As práticas conservacionistas mais comuns para as culturas anuais são: plantio em contorno, plantio em faixas de contorno, terraceamento e alternância de capinas (Bertoni e Lombardi Neto, 1999).

Para a região de São Carlos/SP, os valores de $\mathrm{P}$, para o plantio em nível e em função da declividade, foram obtidos conforme a seguinte equação (Lagrotti, 2000):

$P=0,69947-0,08911 . D+0,01184 . D^{2}-0,000335 . D^{3}$

Sendo:

$\mathbf{P}$ - fator prática conservacionista

D - Declividade

Para declive $<0,5 \% \rightarrow$ valor de $\mathbf{P}=0,6$

Para declive $>20 \% \rightarrow$ valor de $\mathbf{P}=1$

\subsubsection{Potencial Natural de Erosão Laminar (PNE)}

O PNE representa a interação dos principais fatores naturais do meio físico relacionados ao processo erosivo (Bueno, 1994).

O PNE foi calculado conforme a equação descrita por Marcomin (2002):

$$
\text { PNE = R.K.LS }
$$

Sendo:

PNE - Potencial Natural de Erosão Laminar (t/ha.ano)

$\mathbf{R}$ - fator erosividade da EUPS (MJ.mm/ha.h)

$\mathbf{K}$ - fator erodibilidade da EUPS (t.h/MJ.mm)

LS - fator topográfico da EUPS

Os planos de informação referentes a cada um desses fatores foram multiplicados utilizando-se o módulo Image Calculator do Idrisi. Dessa forma obtiveram-se os valores de PNE para cada unidade de estudo e, com base no módulo Extract do Idrisi, foram obtidos os valores de PNE médio e máximo de todas as unidades.

As classes de PNE e respectivas faixas de amplitude (valores mínimos, máximos e número de classes a ser considerado), utilizadas no presente trabalho, foram definidas com a orientação do Dr. Francisco Lombardi Neto (informação verbal).

$\mathrm{Na}$ Figura 5, é apresentado um fluxograma ilustrando todas as etapas realizadas para o desenvolvimento dos cálculos do PNE. 


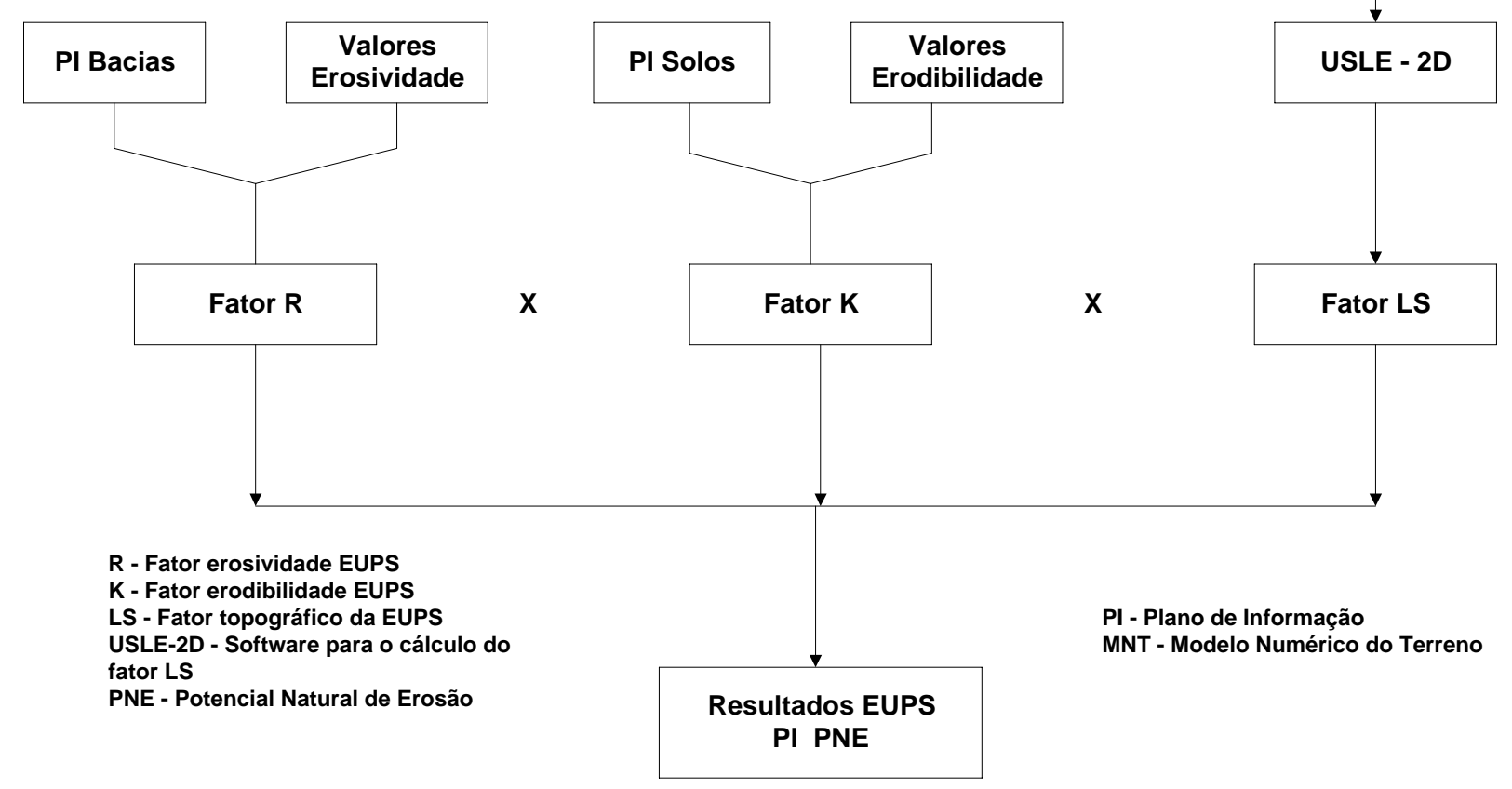

Figura 5. Fluxograma ilustrativo das etapas realizadas para a obtenção do Potencial Natural de Erosão Laminar (PNE).

\subsubsection{Limite de Tolerância de Perda de Solo (LTol)}

O termo "tolerância de perda de solo" representa um valor máximo de erosão do solo que permitirá um alto nível de produtividade de uma determinada cultura a ser sustentada economicamente e indefinidamente (Wischmeier e Smith, 1978).

Quando se compara a previsão das perdas de solo por erosão de uma determinada área, obtida pela aplicação da EUPS, com a tolerância de perdas de solo para a mesma área, segundo Bertoni e Lombardi Neto (1999), é possível determinar as combinações de cultivo e manejo a adotar, nas quais a previsão de perdas de solo é menor do que a tolerância, proporcionando uma verificação satisfatória do controle da erosão.

Para o estado de São Paulo, os valores de tolerância de perda de solo variam de 4,5 a 15,0 t/ha/ano. Solos profundos, de textura média e bem drenados têm um valor de tolerância mais elevado. Solos pouco profundos, ou que possuem horizontes superficiais, apresentam um valor de tolerância mais baixo (Bertoni e Lombardi Neto, 1999). 
Os valores de tolerância de perda de solo utilizados na determinação da Expectativa de Risco de Erosão Laminar e do Potencial de Risco de Erosão Laminar, itens descritos a seguir, referentes aos solos da área de estudo, foram fornecidos pelo Dr. Francisco Lombardi Neto (informação verbal).

\subsubsection{Expectativa de Risco de Erosão Laminar (ERE)}

A expectativa de risco de erosão laminar pode ser definida como a possibilidade de ocorrência de erosão em função do uso e manejo máximo permissível para uma determinada área (Marcomin, 2002).

A ERE foi calculada conforme a equação e metodologia descrita por Marcomin (2002):

\section{$\mathrm{ERE}=\mathrm{CP}$ atual $-\mathrm{CP}$ tolerável}

Sendo:

ERE - expectativa de risco de erosão laminar

CP atual = multiplicação das imagens dos fatores da EUPS C e P (obtido pelo módulo Overlay do Idrisi).

CP tolerável $=\underline{\mathrm{A}}$ tolerável $/ \mathrm{PNE}$, sendo $\underline{\mathrm{A}}$ tolerável a perda máxima tolerável para cada tipo de solo da área de estudo e o PNE = R.K.LS, conforme descrito anteriormente.

Utilizando-se o módulo Overlay do Idrisi, operação divisão, foi calculado o CP tolerável para cada unidade de estudo. Novamente com o módulo Overlay, operação de subtração, foi efetuada a diferença entre o CP atual e o CP tolerável, obtendo as imagens finais do ERE.

As classes de ERE e respectivas faixas de amplitude (valores mínimos, máximos e número de classes a serem consideradas), utilizadas no presente trabalho, foram definidas por Marcomin (2002) e podem ser visualizadas na Tabela 17.

Tabela 17. Classes de Expectativa de Risco de Erosão Laminar - ERE (Marcomin, 2002).

\begin{tabular}{|c|c|c|}
\hline Classes & Faixa de Amplitude & Descrição da ERE \\
\hline 1 & $<0$ & Ausente \\
\hline 2 & 0 a 0,05 & Baixa \\
\hline 3 & 0,05 a 0,10 & Moderada \\
\hline 4 & igual ou $>0,10$ & Alta \\
\hline
\end{tabular}

\subsubsection{Perda de Solo por Erosão Laminar (A)}

A perda de solo por erosão laminar compreende a aplicação da EUPS, pelo produto de todos os seus componentes. Diferentemente do PNE, que representa apenas os fatores naturais no processo erosivo, a EUPS engloba, também, os fatores antrópicos C e P. 
A equação, conforme foi descrito anteriormente, é expressa:

$A=R$. K . L . S . C . P (t/ha.ano)

Os planos de informação gerados para cada um dos fatores da equação foram multiplicados utilizando-se o módulo Image Calculator do Idrisi. Dessa forma, obtiveram-se os valores de PNE para cada unidade de estudo e, com base no módulo Extract do Idrisi, foram obtidos os valores de A médio e máximo de todas as unidades.

As classes de A e respectivas faixas de amplitude (valores mínimos, máximos e número de classes a serem consideradas), utilizadas no presente trabalho, foram definidas por Marcomin (2002) e podem ser visualizadas na Tabela 18.

Tabela 18. Classes de Perda de Solo por Erosão Laminar - A (Marcomin, 2002).

\begin{tabular}{|c|c|c|}
\hline Classes & Faixa de Amplitude & Descrição da Perda de Solo \\
\hline 1 & $<10$ t/ha/ano & Muito Baixa \\
\hline 2 & de 10 a 20 t/ha/ano & Baixa \\
\hline 3 & de 20 a 50 t/ha/ano & Moderada \\
\hline 4 & de 50 a 100 t/ha/ano & Alta \\
\hline 5 & igual ou $>100$ t/ha/ano & Muito Alta \\
\hline
\end{tabular}

Na Figura 6 é apresentado um fluxograma ilustrando todas as etapas realizadas para o desenvolvimento dos cálculos do A.

\subsubsection{Potencial de Risco de Erosão Laminar (PRE)}

O cruzamento das informações referentes aos resultados gerados pela EUPS e pelos dados de tolerância de perda de solo para a área de estudo possibilita o desenvolvimento do potencial de risco de erosão laminar (PRE).

Com base nas informações descritas por Cavalli (1999) e Marcomin (2002), o potencial de risco de erosão laminar foi calculado da seguinte forma:

$$
P R E=\frac{A}{L T o l}
$$

Sendo:

PRE - potencial de risco de erosão laminar

A - perda de solo por erosão laminar ( $t /$ ha.ano)

LTol - limite de tolerância de perda de solo (t/ha.ano)

As classes de PRE e respectivas faixas de amplitude, utilizadas no presente trabalho, foram definidas por Marcomin (2002) e podem ser visualizadas na Tabela 19. 
Tabela 19. Classes de Potencial de Risco de Erosão Laminar - PRE (Marcomin, 2002).

\begin{tabular}{|c|c|c|}
\hline Classes & Faixa de Amplitude & Descrição Potencial de Risco \\
\hline 1 & $<1 \times$ tolerância & Risco Nulo \\
\hline 2 & 1 a $2 \times$ tolerância & Baixo \\
\hline 3 & 2 a $5 \times$ tolerância & Moderado \\
\hline 4 & 5 a $10 \times$ tolerância & Alto \\
\hline 5 & $>10 \times$ tolerância & Muito Alto \\
\hline
\end{tabular}

\subsection{Manipulação e Testes dos Modelos Computacionais Conceituais}

Conforme foi mencionado na introdução do presente trabalho, existem muitos modelos para simular processos de erosão, produção de sedimentos e processos hidrológicos em bacias hidrográficas. Com base em alguns estudos que sintetizaram as características de variados modelos, Ranieri (1996), Souto (1998), Jetten et al. (1999), Paiva (2001), Garrido (2003), Silva e Crestana (2004), Reichardt e Timm (2004) e, também, nas informações disponibilizadas pelo Dr. Fernando das Graças Braga da Silva (comunicação pessoal), associadas às facilidades ou dificuldades para aquisição desses programas, custos para aquisição e disponibilidade de recursos do projeto de pesquisa, foram escolhidos quatro modelos conceituais para serem testados nas fases iniciais dos trabalhos no intuito de averiguar quais seriam compatíveis com os objetivos da pesquisa. Todos os modelos escolhidos para os testes são de domínio público.

Os modelos testados foram:

- WEPP

- GeoWEPP

- AnnAGNPS

- SWAT

Considerou-se a etapa de testes fundamental para analisar os limites e possibilidades de oferecidos por cada modelo. Foi estabelecido um período curto, cerca de 10 dias para cada modelo, com o propósito de realizar uma rápida análise de cada um desses programas. Para essa análise, utilizaram-se os seguintes critérios:

- Acessibilidade do programa (verificar qual programa era mais “amigável”);

- Dados de entrada requeridos;

- Dados de saída gerados;

- Possibilidade de interface com Sistemas de Informações Geográficas; 


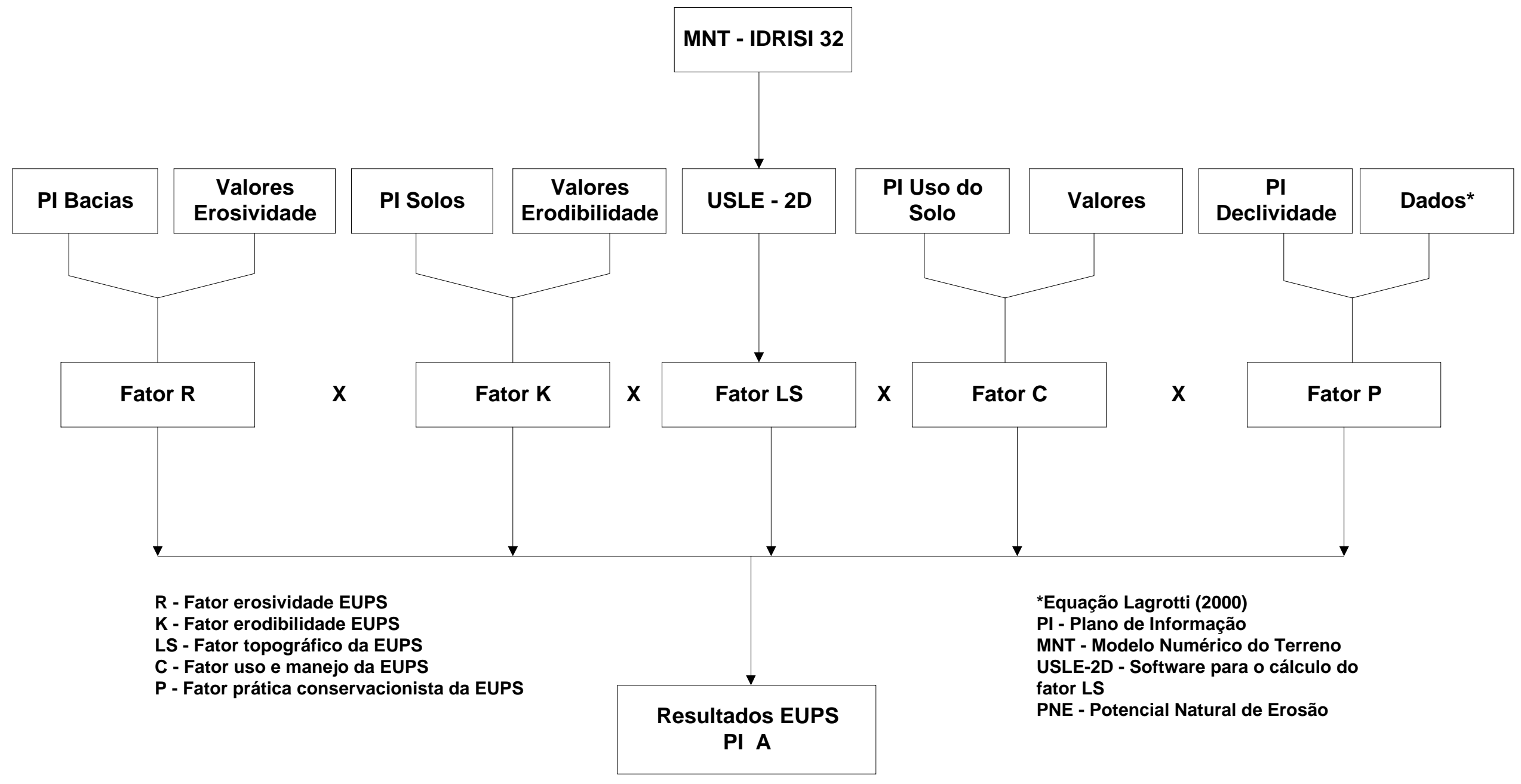

Figura 6. Fluxograma ilustrativo das etapas realizadas para a obtenção da Perda de Solo por Erosão Laminar (A). 
- Análise de sensibilidade das variáveis de entrada utilizadas pelo modelo;

- Bibliografia disponível - manuais, publicações científicas, informações adicionais na internet e possibilidade de comunicação com os elaboradores do programa.

Dos modelos escolhidos para a fase de testes, o WEPP - interface Windows - é o único que não apresenta interface com Sistemas de Informações Geográficas. Mesmo assim, o modelo foi testado pela facilidade com que pode ser manipulado para a entrada de dados e o cálculo da erosão em vertentes e, também, por permitir a simulação de bacias hidrográficas por meio de múltiplas vertentes. Entretanto, a discretização da bacia hidrográfica em planos (vertentes) e canais exige um conhecimento aprofundado de cada um desses elementos a serem criados no modelo. Ao se trabalhar em bacias hidrográficas de médio a grande porte, as dificuldades na realização dos trabalhos seriam bem maiores. Por essa razão, a utilização desse modelo tornou-se inviável.

Todos os demais modelos testados - GeoWEPP, AnnAGNPS e SWAT - apresentam interface com o Programa ArcView, versões 3.1 ou 3.2. A rotina inicial de trabalhos dos três modelos é muito semelhante. Primeiramente, ativa-se o modelo dentro da plataforma ArcView, e cria-se um novo diretório. A primeira etapa é a elaboração do modelo numérico do terreno da região de estudo. Em seguida a bacia hidrográfica é delineada. Após essa etapa, as rotinas variam, iniciando-se pela adição dos planos de informação restantes (solo, uso do solo) ou pela entrada de dados tabelados.

Os três modelos apresentavam formas complexas de trabalhos ao longo de suas rotinas entrada das imagens, entrada de dados, correção dos dados, etc. Em todos, os bugs que ocorreram durante o período de testes foram numerosos. A solução desses bugs demandou, muitas vezes, um grande período de tempo, criatividade e, em algumas ocasiões, a necessidade de entrar em contato com os elaboradores dos modelos, o que tomava ainda mais tempo. Ao final desse período, observou-se que o SWAT, versão AVSWAT 2000, era o modelo que apresentava, ao mesmo tempo, maior complexidade (era o modelo mais completo), envolvendo um maior número de componentes simulados, interface mais “amigável”, maior disponibilidade de informações para solução dos problemas, tanto pelo extenso volume dos manuais como pelas publicações científicas. Por ter sido o que demonstrou características mais promitentes, o AVSWAT 2000 foi o modelo conceitual escolhido para o desenvolvimento da pesquisa. 


\subsection{Soil Water Assessment Tool (SWAT)}

O modelo SWAT, versão AVSWAT 2000, é integrado com o ArcView ${ }^{\circledR}$ (Neitsch et al., 2002a).

Para a utilização do modelo SWAT, foram utilizados os seguintes sistemas computacionais:

- Programa de geoprocessamento ArcView v.3.1 com extensão ArcView Spatial Analyst v. 1.1, desenvolvido pela Environmental Systems Research Institute (ESRI), Redlands, CA, EUA;

- Programa SWAT (Soil and Water Assessment Tool), Agricultural Research Service e pela Texas A\&M University;

- Programa de interface ArcView - SWAT, versão 2000, desenvolvido por Di Luzio et al. (2002).

Uma síntese das etapas e metodologias relacionadas à manipulação do modelo SWAT , a entrada de dados, a definição do número de sub-bacias, a simulação de cenários, a calibração do modelo, a análise de sensibilidade do modelo e os dados que foram gerados pelo modelo serão descritos a seguir, de maneira sucinta, com base nos trabalhos de Neitsch et al. (2002a), Neitsch et al. (2002b) e Di Luzio et al. (2002).

\subsubsection{Dados de Entrada do Modelo SWAT}

\subsubsection{Geração dos Planos de Informação}

A elaboração dos planos de informação, necessários à geração da base de dados de entrada do modelo SWAT, como o modelo numérico do terreno, mapas de solos e de uso e ocupação da terra, assim como a importação da base de dados para o programa ArcView, foi descrita no item Construção da Base Cartográfica.

\subsubsection{Dados Tabulares}

No que se refere à entrada de dados tabulares, o SWAT divide-se em cinco tipos de níveis de abrangência. A entrada de dados pode envolver:

1. Toda a área da bacia hidrográfica;

2. A área da sub-bacia hidrográfica; 
3. A unidade de resposta hidrológica (HRU);

4. Os reservatórios (represas inseridas na bacia hidrográfica);

5. Apenas as entradas pontuais (descargas) nos corpos aquáticos.

A entrada de dados referente a toda a bacia hidrográfica envolve sete bancos de dados alfanuméricos a serem alimentados: dados de solos (.SOL), climáticos (.WGN), de uso do solo e crescimento vegetal (CROP.DAT), de fertilizantes (FERT.DAT), de pesticidas e toxinas (PEST.DAT), de preparo do solo (TILL.DAT) e de áreas urbanas (URBAN.DAT).

Além desses bancos de dados, existem outros, no próprio SWAT, relacionados aos cinco níveis de abrangência de entrada de dados, outras formas de entradas de dados tabulares no modelo, que abarcam as demais informações ambientais. Esses dados, de maneira geral, relacionam-se:

- À qualidade da água das áreas alagadas e dos corpos aquáticos em geral (sistemas lóticos e lênticos);

- À̀ captação de água dos sistemas aquáticos (usos consultivos);

Todos esses dados mencionados podem, ainda, ser adicionados especificamente em cada sub-bacia originada na área de estudo durante o processo de simulação. Um tipo de dado que foi utilizado em cada sub-bacia criada pelo modelo SWAT, na simulação das unidades de estudo do presente trabalho, referiu-se aos valores do procedimento do número da curva $(C N)$ para estimar o escoamento superficial.

A entrada dos dados alfanuméricos foi realizada pela interface entre o modelo SWAT e o programa ArcView.

\section{A. Dados de Solo}

Os dados de entrada referentes aos solos são os seguintes: número de camadas do solo, grupo hidrológico, máxima profundidade da raiz no perfil do solo, fração de porosidade, textura, profundidade das camadas, densidade, capacidade de água disponível, condutividade hidráulica saturada, conteúdo de carbono orgânico, conteúdos de argila, silte, areia e fragmentos de rochas, albedo e fator erodibilidade do solo (fator K da EUPS). Esses dados foram obtidos nos estudos de Lorandi (1991), Calderano Filho et al. (1998), Oliveira (1999), Primavesi et al. (1999) e Dr. Francisco Lombardi Neto (informação verbal), com exceção para os dados referentes aos grupos hidrológicos dos solos, os quais foram baseados na classificação hidrológica dos solos para as condições brasileiras e também no enquadramento das atuais classes de solos do Estado de São Paulo, informações disponibilizadas no trabalho de Sartori (2004). 
De acordo com informações fornecidas pelo Dr. Francisco Lombardi Neto (informação verbal), os valores de erodibilidade do solo (K), para os solos da região de São Carlos/SP, apresentados anteriormente, foram transformados (fator de multiplicação de 10 vezes - $10 \mathrm{X}$ ) para se ajustarem ao formato dos dados de entrada do modelo SWAT.

Os dados dos perfis dos solos das unidades de estudo do município de Luiz Antônio (MBH-BF e MBH-BFJ) foram obtidos no trabalho de Lorandi (1991). Para a unidade de estudo MBH-G (município de São Carlos), foram utilizados os dados dos perfis de solo obtidos nos trabalhos de Calderano Filho et al. (1998) e Primavesi et al. (1999). Para os solos CHERNOSSOLO ARGILÚVICO, GLEISSOLO HÁPLICO e NEOSSOLO LITÓLICO, encontrados nas unidades de estudo, foram utilizados os dados dos perfis apresentados por Oliveira (1999).

\section{B. Dados Climáticos}

Em relação aos fatores climáticos, os dados de entrada do modelo dividem-se em dois tipos: dados diários e dados mensais. Os dados diários utilizados foram médias diárias ou somas diárias relacionados aos seguintes fatores: precipitação, temperatura do ar e umidade relativa do ar.

Os dados mensais foram médias (do respectivo mês) referentes a todos os anos simulados. As variáveis climáticas mensais solicitadas pelo modelo foram: localização geográfica da estação, altitude, número de anos dos dados acumulados, média mensal da temperatura máxima diária, média mensal da temperatura mínima diária, desvio padrão para a temperatura máxima diária de cada mês, desvio padrão para a temperatura mínima diária de cada mês, média mensal da precipitação total, desvio padrão para a precipitação diária no mês, probabilidade de dias úmidos seguidos de dias secos para o determinado mês, probabilidade de dias úmidos seguidos de dias úmidos para o determinado mês, média mensal de dias de precipitação, valor máximo de meia hora de chuva em todo o período de registros de um determinado mês, média de radiação solar diária para um determinado mês, média diária do ponto de orvalho para determinado mês, média diária da velocidade do vento para determinado mês.

Para as unidades de estudo MBH-BF e MBH-BFJ, foram utilizados dados da estação climática da Fazenda Cutrale (2130’55” lat. S, e 4746’12” long. W, 680m de altitude), localizada no município de Luiz Antônio/SP, que foram cedidos pelo Departamento de Agricultura e Meio Ambiente desse município. Na Figura 7a pode-se visualizar o pluviômetro utilizado nas medições. Essa estação dista 1,3 km do ponto mais próximo (contorno) da MBHBF e 6,5 km da região central dessa microbacia. Os dados disponibilizados pela estação climática 
da Fazenda Cutrale, utilizados na simulação do modelo SWAT, foram referentes aos anos de 1999 a 2003, constituindo um total de cinco anos de dados contínuos.

Em relação à MBH-G, optou-se por utilizar os dados da estação climática da Embrapa Pecuária Sudeste - Fazenda Canchim (2157’42'’ lat. S, 47050’28’' long. W, 860m de altitude), localizada no município de São Carlos (Fig. 7b). A estação da Fazenda Canchim dista 27,3 km do ponto mais próximo (contorno) da MBH-G e 32,1 km da região central dessa microbacia. Os dados utilizados, disponibilizados diretamente no site dessa Unidade de Pesquisa (Embrapa, 2005), foram referentes aos anos de 1992 a 2004, constituindo um total de treze anos de dados contínuos.

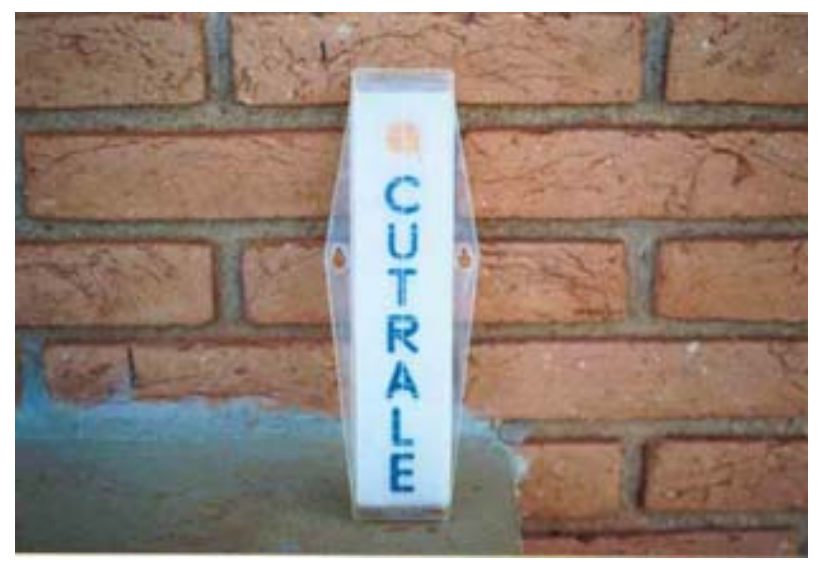

(a)

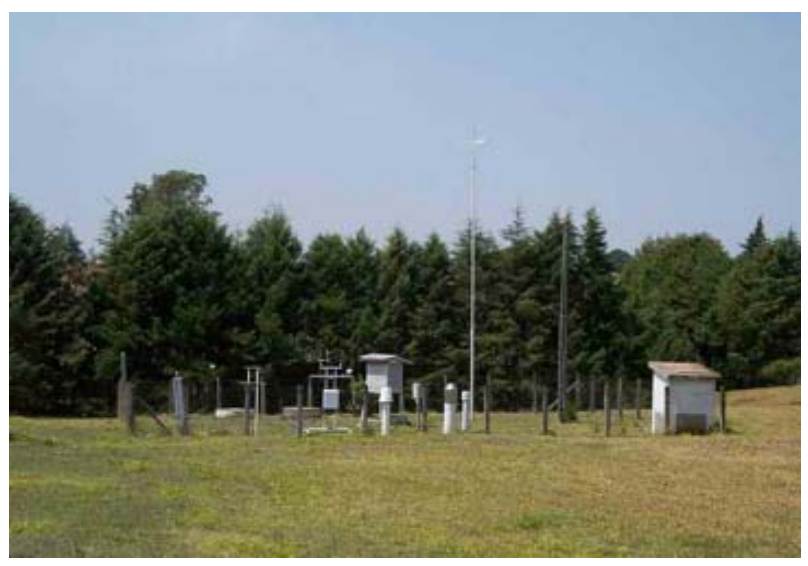

(b)

Figura 7. (a) Pluviômetro utilizado na fazenda da Cutrale no município de Luiz Antônio/SP. (b) Estação climática da Fazenda Canchim - Sede da Embrapa Pecuária Sudeste - no município de São Carlos/SP.

\section{Utilização de dados do número da curva de escoamento superficial $(C N)$}

O Serviço Nacional de Conservação dos Recursos (NRCS) dos Estados Unidos desenvolveu o procedimento do número da curva $(C N)$ para estimar o escoamento superficial. Os efeitos do uso do solo e do tratamento foram inseridos no método. Esse procedimento foi desenvolvido empiricamente a partir de estudos em pequenas bacias hidrográficas agrícolas (< 800 ha) daquele país. A curva número é função do uso do solo, antecedentes referentes às condições de escorrimento e características hidrológicas do solo (Scott, 2000).

No Brasil foram desenvolvidos trabalhos para estimar os valores de $C N$ em função do uso do solo, manejo e grupo hidrológico. Sartori (2004) apresenta uma tabela de valores de $C N$ para 
usos agrícolas brasileiros, adaptadas desses trabalhos. Os valores apresentados por esse autor foram utilizados como dados de entrada das sub-bacias geradas nas simulações do modelo SWAT, conforme foi mencionado anteriormente.

\section{Demais dados}

Em relação aos dados de entrada referentes à cobertura do solo e crescimento vegetal, assim como ao preparo do solo - tendo em vista que as culturas predominantes da área de estudo, e respectivos preparos e manejos, constam na base de dados do SWAT - optou-se por utilizar os dados do próprio modelo. Dados referentes aos fertilizantes e pesticidas, à qualidade da água dos corpos aquáticos, às entradas pontuais e aos usos consultivos não foram adicionados ao modelo, pois os estudos qualitativos e quantitativos dos sistemas aquáticos não foram objetos de estudo do presente trabalho. Tendo em vista que nas unidades de estudo existem, apenas, áreas agrícolas ou de reserva natural (Estação Ecológica), não houve entrada de dados de áreas urbanas.

\subsubsection{Delineamento da bacia hidrográfica e definição do número de sub-bacias}

O delineamento da bacia hidrográfica, no modelo SWAT, envolve funções avançadas de Sistemas de Informações Geográficas (programa ArcView) e a utilização do modelo numérico do terreno. Este procedimento pode ser realizado de maneira automática (o programa delineia a bacia hidrográfica com base no MNT) ou pode ser utilizada uma máscara (plano de informação com o contorno da bacia hidrográfica previamente demarcado).

O processo automático para o delineamento da bacia hidrográfica foi testado com o uso de modelos numéricos de terreno referentes a diferentes áreas geográficas. Observou-se que em regiões com maiores variações de relevo e declividade mais acentuada, a interface SWAT/ArcView é capaz de delinear o contorno das bacias hidrográficas com maior precisão.

De maneira semelhante ao delineamento da bacia hidrográfica, a rede de canais (rede hídrica) da bacia hidrográfica pode ser obtida automaticamente utilizando-se a interface SWAT/ArcView.

Como a área de estudo do presente trabalho abrange a planície de inundação do rio MogiGuaçu, uma região de relevo suave, as tentativas de delineamento automático das microbacias e da rede de drenagem não geraram bons resultados. Dessa forma, tornou-se necessária a utilização de uma máscara das unidades de estudo (configuração das microbacias), para que o 
delineamento fosse equivalente aos formatos das unidades de estudo utilizados nos estudos da EUPS, e do mapa da rede hídrica da área de estudo proveniente da BDD do presente trabalho.

Após o delineamento das unidades de estudo, o primeiro passo na simulação de bacias hidrográficas é definir a configuração das partes ou elementos que compõem as bacias. De acordo com Neitsch et al. (2002a), se a bacia hidrográfica apresentar apenas um canal de escoamento principal e ocorrer pouca variação topográfica e de clima em sua área, não existe a necessidade de divisão em unidades menores. No entanto, a maioria das bacias hidrográficas exibe suficiente complexidade na rede hídrica, topografia ou clima que justificam a repartição para os propósitos de modelagem.

Mesmo com a utilização de máscara com o contorno das unidades de estudo, o SWAT divide, automaticamente, as bacias hidrográficas em sub-bacias. Cada uma dessas subunidades é associada a um curso d'água. A configuração das sub-bacias, delineada pelo modelo, pode ser alterada caso haja interesse. No presente trabalho, a configuração delineada pelo modelo foi mantida.

Após as etapas de delineamento da bacia hidrográfica e das sub-bacias, e da inserção das imagens de uso da terra e tipo de solo, um último passo de subdivisão no modelo SWAT envolve a opção de criação das unidades de resposta hidrológica (HRU’s). Nessa fase existem duas opções:

I. Em cada sub-bacia, o uso da terra e o tipo de solo que apresentarem maior extensão, que predominarem, serão considerados para toda a área da sub-bacia, e os demais tipos serão descartados;

II. Múltiplas HRU’s serão estabelecidas. A elaboração das HRU’s envolve dois passos: primeiro os usos da terra da sub-bacia são identificados. Uma vez que esses usos a serem modelados foram determinados, os diferentes tipos de solo são selecionados. Dessa forma, cada HRU estabelecida apresentará uma combinação única entre um tipo de uso da terra com um tipo de uso do solo.

Para as simulações realizadas no presente trabalho, optou-se pelo estabelecimento das múltiplas HRU's para evitar a perda ou alteração das informações reais relacionadas aos usos da terra e aos tipos de solo que são encontrados nas unidades de estudo.

Na Figura 8, é apresentado um fluxograma ilustrando as etapas realizadas para a manipulação do modelo SWAT. 


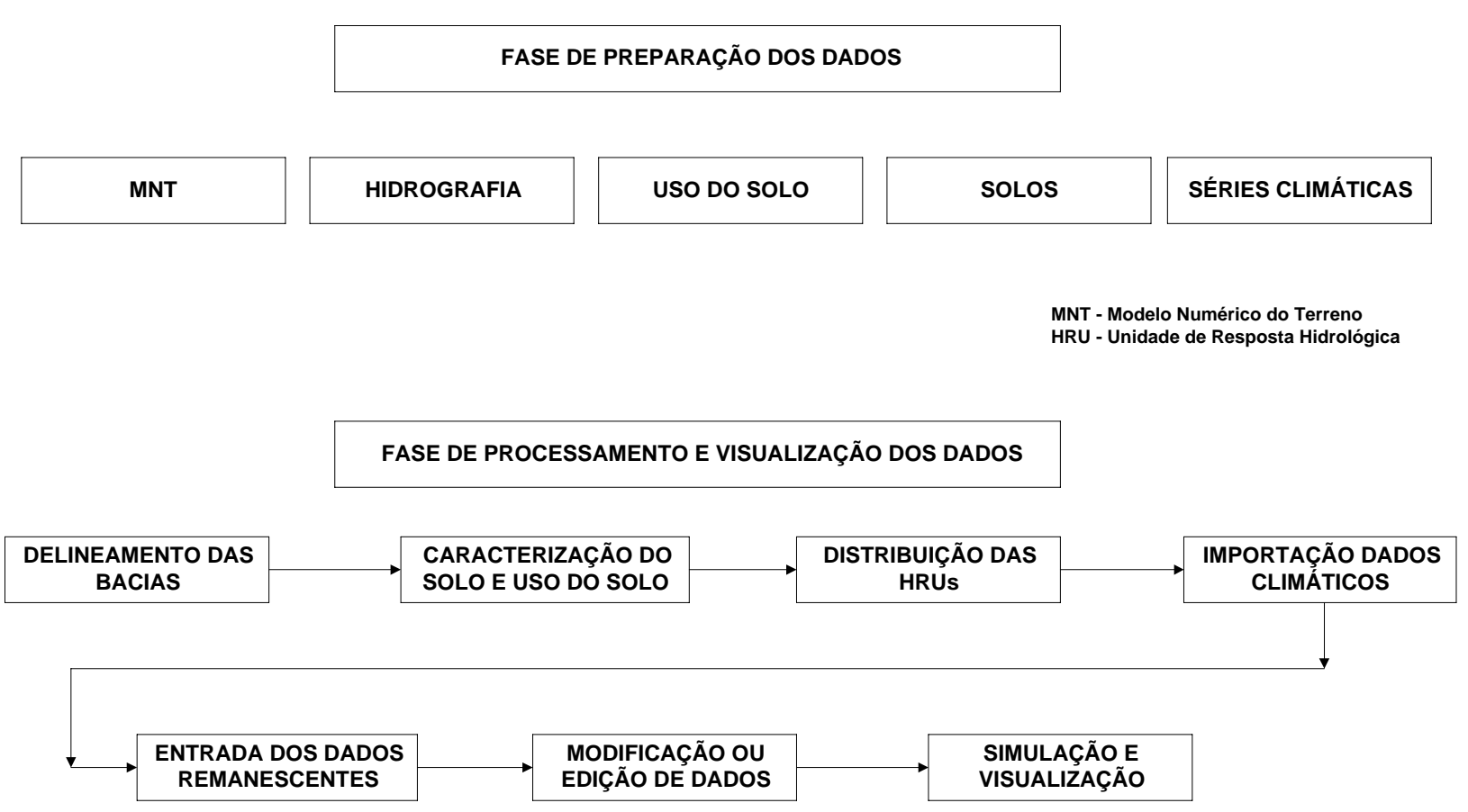

Figura 8. Fluxograma ilustrativo das etapas realizadas na manipulação do modelo SWAT.

\subsubsection{Simulação de Cenários}

Dentre as vantagens da utilização de modelos matemáticos, uma das mais importantes refere-se à elaboração de cenários, ou seja, à possibilidade de alterar as configurações dos parâmetros de entrada do modelo no intuito de gerar novos conjuntos de condições virtuais, as quais permitem, de antemão, a visualização das conseqüências geradas por um determinado grupo de fatores hipotéticos.

O objetivo da simulação de cenários não é caracterizar, de maneira completa, a eficiência das alternativas de manejo ou uso da terra, mas exemplificar a aplicação das vantagens da utilização da integração de modelos matemáticos e sistemas de informações geográficas (Machado, 2002).

Os cenários desenvolvidos no presente estudo, em função dos componentes do balanço hídrico, da erosão (dados da EUPS aplicada pelo modelo SWAT), e geração de sedimentos foram elaborados para duas bacias hidrográficas simuladas no SWAT com as seguintes configurações: 


\section{1. $\mathrm{MBH}-\mathrm{BF}$}

a. Cenário Original (vegetação natural ocupando toda a microbacia);

b. Cenário Atual (uso da terra atual da microbacia);

c. Cenário Cana-de-Açúcar (ocupação hipotética da microbacia com cana-deaçúcar).

2. $\mathrm{MBH}-\mathrm{G}$

a. Cenário Original (vegetação natural ocupando toda a microbacia);

b. Cenário Atual (uso da terra atual da microbacia);

c. Cenário Cana-de-Açúcar (ocupação hipotética da microbacia com cana-deaçúcar). 


\section{RESULTADOS E DISCUSSÃO}

\subsection{Considerações Iniciais}

Com base nas informações da revisão bibliográfica, e de acordo com os materiais e métodos descritos, este capítulo visa descrever e discutir os resultados obtidos no desenvolvimento da pesquisa.

Primeiramente, serão apresentados os resultados referentes à caracterização ambiental da área de estudo, envolvendo: a localização das unidades e subunidades de estudo, a hidrografia, a clinografia, os solos, os usos do solo e a malha viária (item 5.2).

A descrição e discussão das estimativas de perda de solo por erosão da área de estudo, resultados obtidos pela aplicação da EUPS, estão apresentados nos itens 5.3 a 5.10. Para efeitos comparativos, a área foi dividida em duas partes: unidades de estudo que não abrangem a planície de inundação do rio Mogi-Guaçu (item 5.8 - MBH-BF, SBH-BFJ e MBH-G) e as unidades localizadas na planície de inundação do rio Mogi-Guaçu (item 5.9 - BD-LA, SBD-LA, BD-SC e SBD-SC).

Em seguida, serão apresentados os resultados produzidos pela manipulação do modelo AVSWAT 2000, relacionados à caracterização ambiental, às simulações da produção de sedimentos, à elaboração de cenários, ao balanço hídrico, à calibração e à análise de sensibilidade do modelo (itens 5.11 e 5.12).

No item 5.13, serão apresentadas uma análise dos modelos EUPS e SWAT e sua utilização na elaboração de informações que possam ser utilizadas como indicadores ambientais de bacias hidrográficas. Por último, no item 5.14, serão apresentadas as considerações finais.

\subsection{Caracterização Ambiental}

A área de estudo foi dividida em quatro unidades de estudo (conforme foi ilustrado na Figura 3) e nas três subunidades. As unidades de estudo compreendem duas microbacias hidrográficas - MBH-BF e MBH-G - e duas bacias de drenagem - BD-LA e BD-SC (Fig. 9). As subunidades de estudo, as quais são segmentos das unidades de estudo, incluem a SBH-BFJ, SBD-LA e SBD-SC. As características das unidades e subunidades de estudo serão descritas a seguir.

Na margem direita do rio Mogi-Guaçu, em uma área do município de Luiz Antônio, foi delimitada a microbacia hidrográfica do Córrego do Beija-Flor (MBH-BF). Essa unidade compreende uma área aproximada de 7.980 hectares. Uma seção dessa microbacia é ocupada pela EEJ, sendo coberta por vegetação natural. No intuito de comparar resultados das estimativas 
de perda de solo por erosão de áreas agrícolas e áreas preservadas, foi delimitada nessa seção uma subunidade de estudo, a qual foi intitulada sub-bacia hidrográfica Beija-Flor Jataí (SBHBFJ). Essa subunidade abrange uma área aproximada de 2.660 hectares (Fig. 10).

Na margem esquerda do rio Mogi-Guaçu, com o objetivo de comparar os resultados das estimativas de perda de solo por erosão e produção de sedimentos com a MBH-BF e SBH-BFJ, em uma área que abrange o Município de São Carlos na margem direita do córrego das Guabirobas e os municípios de Rincão, Santa Lúcia e Américo Brasiliense na margem esquerda do córrego das Guabirobas, foi delimitada a microbacia hidrográfica do Ribeirão das Guabirobas (MBH-G). Essa unidade de estudo compreende uma área de, aproximadamente, 5.145 hectares. Excetuando as áreas de preservação permanente e áreas de reserva legal, essa microbacia é totalmente ocupada por atividades agrícolas: cana-de-açúcar, laranja, pasto, eucalipto e avicultura.

Na margem direita do rio (município de Luiz Antônio), foi delimitada uma bacia de drenagem, intitulada Bacia de Drenagem de Luiz Antônio (BD-LA), inteiramente situada na área da EEJ (área aproximada de 960 ha.). Por não apresentar um curso d’água principal, as águas dessa bacia de drenagem escoam para o rio Mogi-Guaçu. Com o objetivo de estimar os efeitos dos processos erosivos na região de áreas alagadas desse rio, em uma região ocupada por vegetação natural, foi delimitada uma porção da BD-LA sem abranger a área da planície de inundação do rio Mogi-Guaçu. Essa subunidade foi intitulada Sub-bacia de Drenagem de Luiz Antônio - SBD-LA (área aproximada de 620 ha.).

Na margem esquerda do rio Mogi-Guaçu (município de São Carlos) foi delimitada, também, uma bacia de drenagem, intitulada Bacia de Drenagem de São Carlos (BD-SC), inteiramente situada nas áreas desse município (área aproximada de 2.175 ha.). Por não apresentar um curso d’água principal, as águas dessa bacia de drenagem escoam para o rio MogiGuaçu. Com o objetivo de estimar os efeitos dos processos erosivos na região de áreas alagadas desse rio, em uma região ocupada por atividades agrícolas, foi delimitada uma porção da BD-SC sem abranger a área da planície de inundação do rio Mogi-Guaçu. Essa subunidade foi intitulada Sub-bacia de Drenagem de São Carlos - SBD-SC (área aproximada de 1.525 ha.). Na Figura 11, pode-se visualizar a localização das bacias de drenagem e na Figura 12, a localização das subbacias de drenagem. 


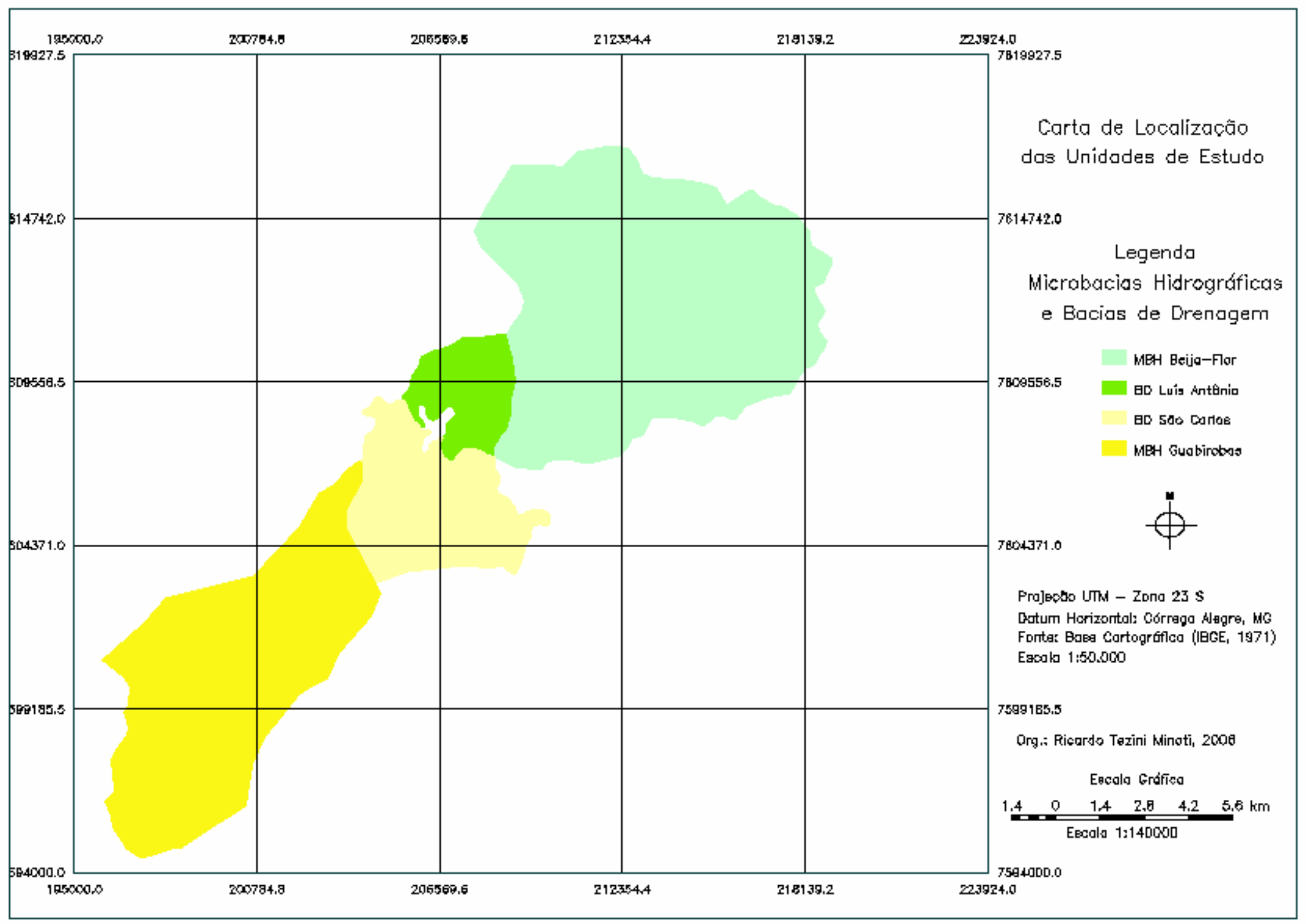

Figura 9. Localização das unidades de estudo. 


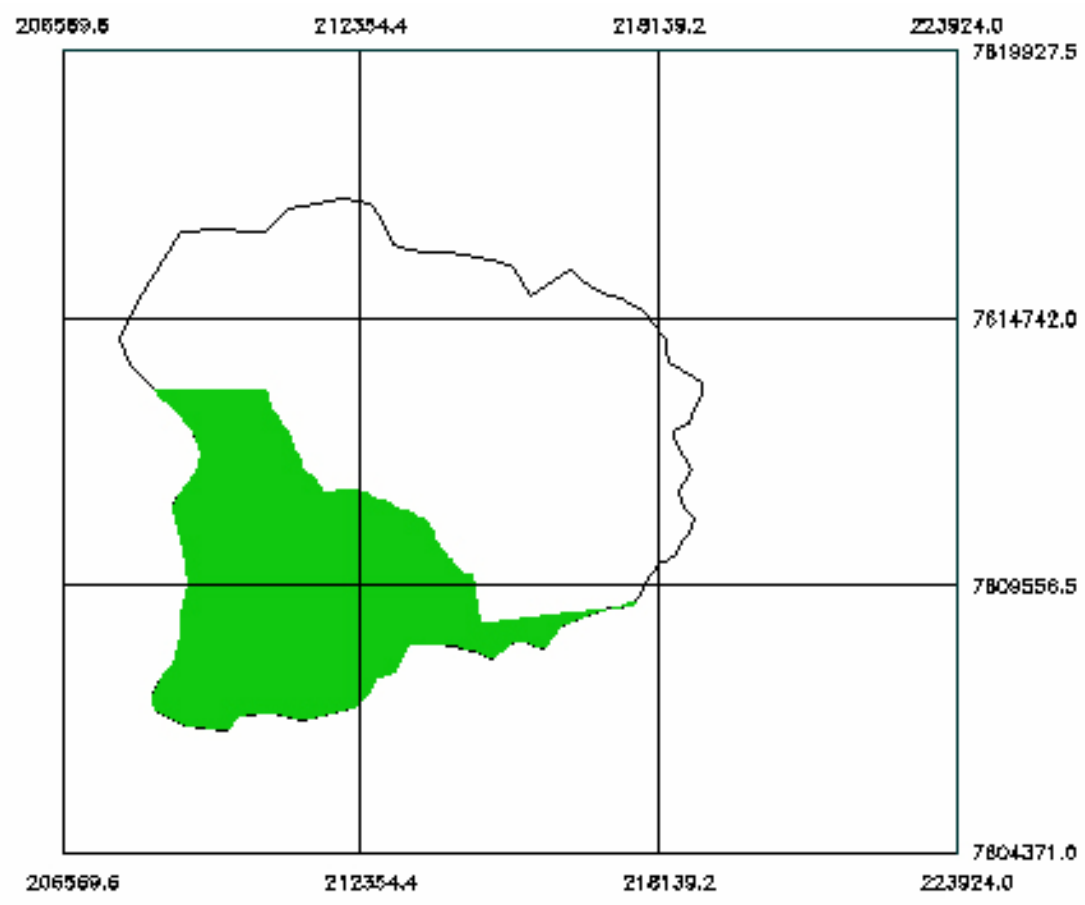

Carta de Localizacâo

da Subunidade de Estudo

Legenda

Sub-bacia Hidrografíca

$5 B H-B F J$

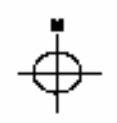

Prajecto UTM - Zona $23 \mathrm{~s}$

[ustum Horizontal: Corraga Alagre, wG

Forta: Baes Cartogrfiflca (IBGE, 1971)

Eacola 1:50.000

Org.: Ricardo Tezini Mlinoti, 2000

Encola Grófien

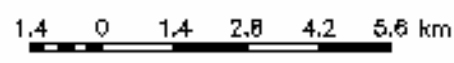

Figura 10. Localização da sub-bacia hidrográfica Beija-Flor/Jataí (SBH-BFJ) e área de abrangência no interior da microbacia hidrográfica do córrego do Beija-Flor (MBH-BF).

\subsubsection{Hidrografia}

Em relação à hidrografia, a área de estudo possui os seguintes corpos d’água (Fig. 13): córregos Beija-Flor (ou Jataí), da Bandeira, do Jordão e do Retiro, ribeirão das Guabirobas e pequenos cursos d’água isolados.

Além disso, na área de estudo encontram-se algumas represas. Na região da planície de inundação do rio Mogi-Guaçu, as bacias de drenagem apresentam várias lagoas marginais. Podese observar um número maior de lagoas na BD-LA (Fig. 13).

\subsubsection{Hipsometria}

Com base no modelo numérico do terreno, foram obtidos os valores mínimos, máximos e médios de altitude, em relação ao nível do mar. A área de estudo apresenta os seguintes valores de cotas altimétricas:

- $\quad$ Altitude máxima - 840 m;

- Altitude mínima - $538 \mathrm{~m}$;

- Altitude média - 619 m. 


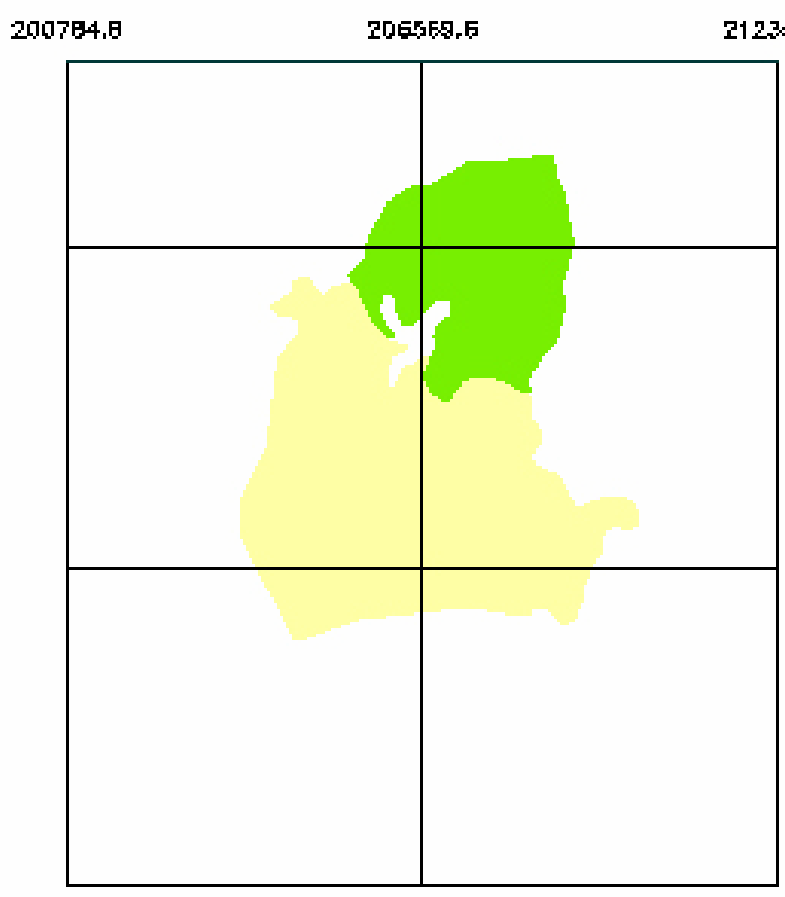

Carta de Localizaçấo das Unidades de Estudo Legenda

7609556.5

Bacios de Drenogem

日D Luis s.nténid

时 Són Cortos

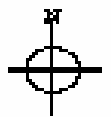

704371.0

Projęalo பTH - Zona $23 \mathrm{~S}$

Dotum Horizontsl: Cfrrese Alogre, WG

Forite: Bose Cartagrdilea (BBGE, 1871)

Escala 1:50.000

Orģ,: Ricardo Tezini klinoti, 2000

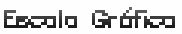

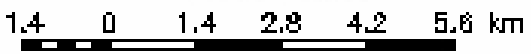

7599185.5

Figura 11. Localização das bacias de drenagem.

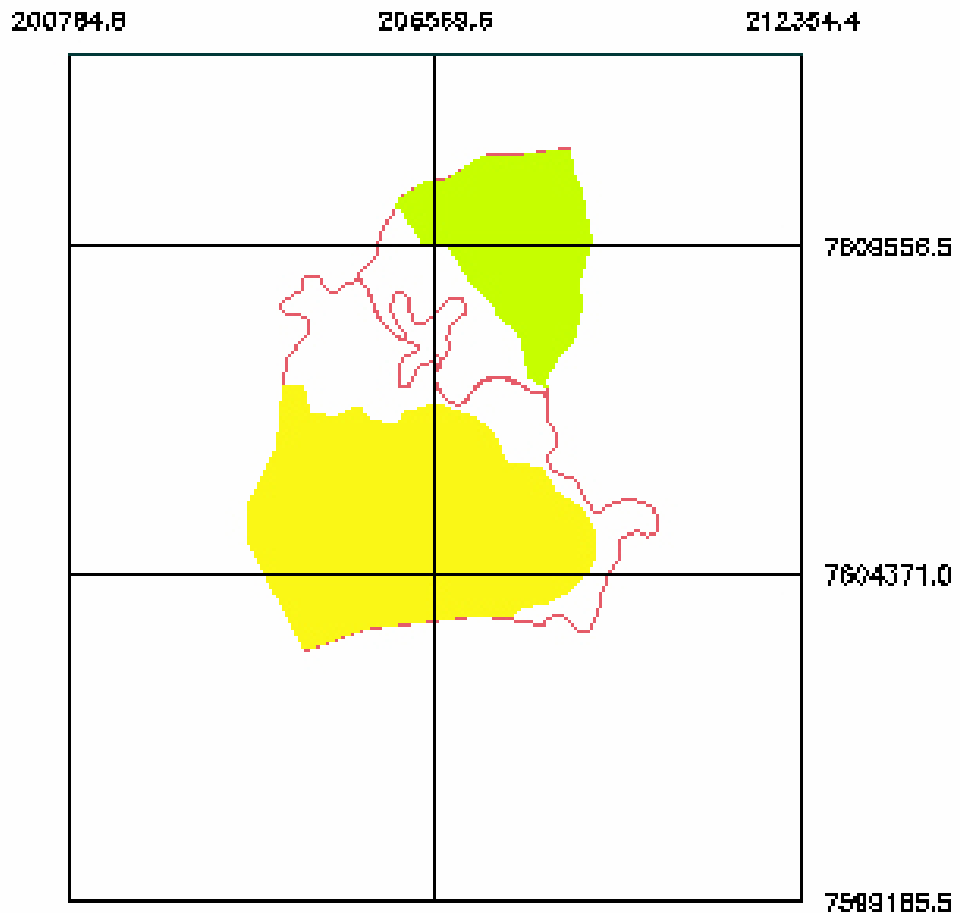

Carta de Localizaçầo das Unidades de Estudo Legenda Sub-Bucios de Drenagem SED Lúz Antónle 580 5do Cance

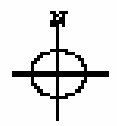

Projęăo LTH - Zona $23 \mathrm{~s}$

[xatum Horizontsl: Cfrege Alegre, w6 Forite: Bose cartagrdflea (IBGE, 1871) Escala 1:50.000

Orga.; Ricardo Tezini klinoti, 2000 Exola Gráning

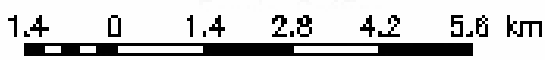
7599185.5

Figura 12. Localização das sub-bacias de drenagem. 


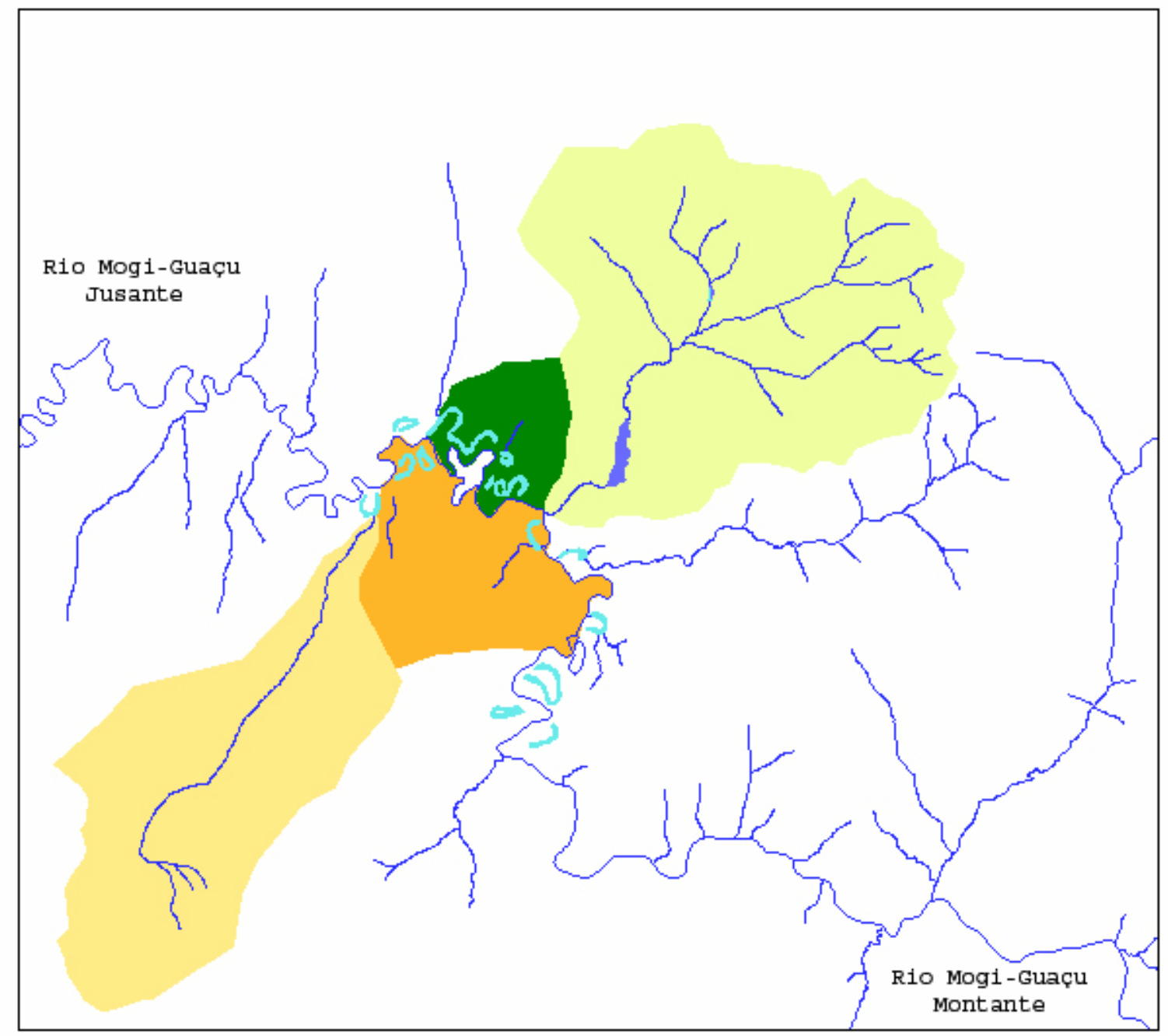

Hidrografia da Area

de Estudo e

Microbacias Hidrográficas

Legenda

Drenagem_SC

Bolje_Flor

Guabirabe

Repremos

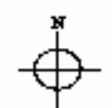

Projeça UTW - Zana $23 \mathrm{~s}$ Dartum horizontal: Gorrage \&lagre, WG Orğ.: Ricardo Tezini Mlinoti, 2000 Escala Gráfica $1.4 \quad 0 \quad 1.4 \quad 2.8 \quad 4.2 \quad 5.6 \mathrm{~km}$

Figura 13. Rede hidrográfica e unidades de estudo. 
Os valores mínimos e máximos de altitude das unidades e subunidades de estudo podem ser visualizados na Fig. 14. Pode-se observar que a MBH-BF apresenta a maior altitude de toda a área de estudo e, também, a maior variação entre as altitudes mínima e máxima. A BD-SC e a SBD-SC apresentam os mais baixos valores de cota altimétrica máxima e menores variações entre as altitudes mínima e máxima.

Na Tabela 20, podem-se observar as áreas e respectivas percentagens referentes às classes hipsométricas para a área de estudo. Os valores e as percentagens das unidades e subunidades de estudo podem ser visualizados na Tabela 21.

A área de estudo foi dividida, ao todo, em nove classes hipsométricas, e apenas a MBH-BF e a MBH-G estão inseridas nas últimas cinco classes (valores entre 660 e 860m). Na Figura 15, pode-se visualizar a distribuição das classes hipsométricas na área de estudo.

Os perfis topográficos da MBH-BF, longitudinal (Fig. 16) e lateral (Fig. 17). No perfil topográfico longitudinal, pode-se observar a região da planície de inundação do rio Mogi-Guaçu (à esquerda). Nos dois perfis, longitudinal e lateral (traçado na região mediana da microbacia), observa-se, claramente, a grande variação de altitudes que ocorre nessa unidade de estudo.

Nas Figuras 18 e 19, podem-se observar os perfis topográficos, longitudinal e lateral (respectivamente), da MBH-G. Evidencia-se a menor variação de altitudes quando comparada a MBH-BF. No perfil longitudinal, pode-se visualizar a região da planície de inundação do rio Mogi-Guaçu (à direita). Vale ressaltar que esse perfil não abrangeu a região de valores altimétricos mais elevados da microbacia.

O perfil topográfico das bacias de drenagem (BD-SC e BD-LA), traçado longitudinalmente, evidencia a pequena variação altimétrica (Fig. 20). No entremeio do perfil, pode-se observar a área do rio Mogi-Guaçu e da planície de inundação.

\subsubsection{Clinografia}

Com base no modelo numérico do terreno, foram obtidos os valores máximos e médios de declividade da área de estudo:

- Declividade máxima - 90,69\%;

- Declividade média - 3,54\%.

Os valores máximos e médios de declividade das unidades e subunidades de estudo podem ser visualizados na Fig. 21.

A análise da clinografia da área de estudo é extremamente importante, pois esse é um dos fatores da EUPS, sendo de grande influência nos processos erosivos. O valor da declividade indica a inclinação da vertente. 
Com base na carta clinográfica, foram obtidas as áreas e respectivas percentagens referentes às classes clinográficas para a área de estudo (Tab. 22). Os valores e as percentagens das unidades e subunidades de estudo podem ser visualizados na Tabela 23. A área de estudo foi dividida, ao todo, em seis classes. Nota-se que as extensões territoriais da BD-SC e da SBD-SC estão contidas, quase integralmente, nas duas primeiras classes (relevo plano/praticamente plano a suave ondulado - 0 a $8 \%$ ).

A SBH-BFJ, MBH-G, BD-LA e SBD-LA apresentaram uma maior amplitude, com o relevo variando de plano/praticamente plano a forte ondulado (0 a 45 \%). Entretanto, as áreas inseridas na faixa de 20 a 45 \%, dessas unidades e subunidades de estudo, foram extremamente pequenas (variando de 2 a 5 hectares).

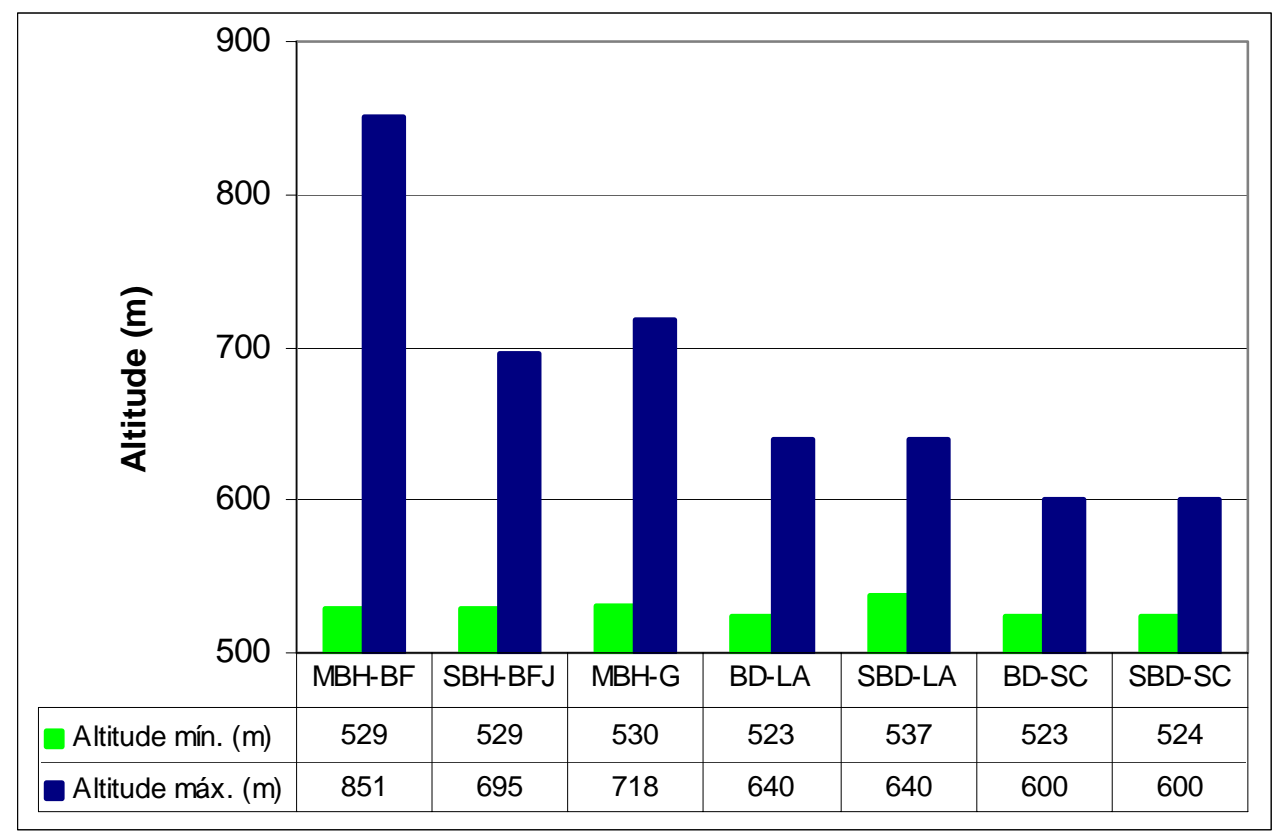

Figura 14. Valores das cotas altimétricas (mínima e máxima) das unidades e subunidades de estudo.

Tabela 20. Hipsometria da área de estudo.

\begin{tabular}{|c|c|c|}
\hline Classe Hipsométrica & Área (ha) & $\%$ \\
\hline $500-540$ & 2173.9 & $13 \%$ \\
\hline $540-580$ & 3625.3 & $22 \%$ \\
\hline $580-620$ & 4895.3 & $30 \%$ \\
\hline $620-660$ & 3504.6 & $22 \%$ \\
\hline $660-700$ & 1479.1 & $9 \%$ \\
\hline $700-740$ & 263.1 & $2 \%$ \\
\hline $740-780$ & 129.3 & $1 \%$ \\
\hline $780-820$ & 131.5 & $1 \%$ \\
\hline $820-860$ & 62.1 & $0.4 \%$ \\
\hline Área Total & $\mathbf{1 6 2 6 4}$ & $\mathbf{1 0 0} \%$ \\
\hline
\end{tabular}


Tabela 21. Hipsometria das unidades de estudo.

\begin{tabular}{|c|c|c|c|c|c|c|c|c|c|c|c|c|c|c|}
\hline \multirow{2}{*}{$\begin{array}{c}\text { Classe } \\
\begin{array}{c}\text { Altimétrica } \\
(\mathrm{m})\end{array}\end{array}$} & \multicolumn{2}{|c|}{$\begin{array}{l}\text { MBH Beija- } \\
\text { Flor }\end{array}$} & \multicolumn{2}{|c|}{$\begin{array}{l}\text { SBH Beija- } \\
\text { Flor/Jataí }\end{array}$} & \multicolumn{2}{|c|}{$\begin{array}{c}\text { MBH } \\
\text { Guabirobas }\end{array}$} & \multicolumn{2}{|c|}{$\begin{array}{l}\text { BD Luiz } \\
\text { Antônio }\end{array}$} & \multicolumn{2}{|c|}{$\begin{array}{l}\text { SBD Luiz } \\
\text { Antônio }\end{array}$} & \multicolumn{2}{|c|}{ BD São Carlos } & \multicolumn{2}{|c|}{$\begin{array}{c}\text { SBD São } \\
\text { Carlos }\end{array}$} \\
\hline & $\begin{array}{c}\text { Área } \\
\text { (ha) }\end{array}$ & $(\%)$ & $\begin{array}{c}\text { Área } \\
\text { (ha) }\end{array}$ & $(\%)$ & $\begin{array}{c}\text { Área } \\
\text { (ha) }\end{array}$ & (\%) & $\begin{array}{c}\text { Área } \\
\text { (ha) }\end{array}$ & $(\%)$ & $\begin{array}{c}\text { Área } \\
\text { (ha) }\end{array}$ & $(\%)$ & $\begin{array}{c}\text { Área } \\
\text { (ha) }\end{array}$ & $(\%)$ & $\begin{array}{c}\text { Área } \\
\text { (ha) }\end{array}$ & $(\%)$ \\
\hline $500-540$ & 251 & $3 \%$ & 248 & $9 \%$ & 178 & $3 \%$ & 387 & $41 \%$ & 60 & $10 \%$ & 1421 & $66 \%$ & 775 & $51 \%$ \\
\hline $540-580$ & 1794 & $22 \%$ & 1221 & $46 \%$ & 1025 & $20 \%$ & 250 & $26 \%$ & 236 & $38 \%$ & 551 & $25 \%$ & 548 & $36 \%$ \\
\hline $580-620$ & 2358 & $30 \%$ & 937 & $36 \%$ & 2035 & $40 \%$ & 263 & $27 \%$ & 263 & $42 \%$ & 203 & $9 \%$ & 203 & $13 \%$ \\
\hline $620-660$ & 1965 & $24 \%$ & 249 & $9 \%$ & 1465 & $29 \%$ & 61 & $6 \%$ & 61 & $10 \%$ & 0 & $0 \%$ & 0 & $0 \%$ \\
\hline $660-700$ & 1049 & $13 \%$ & 2 & $0 \%$ & 427 & $8 \%$ & 0 & $0 \%$ & 0 & $0 \%$ & 0 & $0 \%$ & 0 & $0 \%$ \\
\hline $700-740$ & 247 & $3 \%$ & 0 & $0 \%$ & 15 & $0.3 \%$ & 0 & $0 \%$ & 0 & $0 \%$ & 0 & $0 \%$ & 0 & $0 \%$ \\
\hline $740-780$ & 128 & $2 \%$ & 0 & $0 \%$ & 0 & $0 \%$ & 0 & $0 \%$ & 0 & $0 \%$ & 0 & $0 \%$ & 0 & $0 \%$ \\
\hline $780-820$ & 130 & $2 \%$ & 0 & $0 \%$ & 0 & $0 \%$ & 0 & $0 \%$ & 0 & $0 \%$ & 0 & $0 \%$ & 0 & $0 \%$ \\
\hline $820-860$ & 61 & $1 \%$ & 0 & $0 \%$ & 0 & $0 \%$ & 0 & $0 \%$ & 0 & $0 \%$ & 0 & $0 \%$ & 0 & $0 \%$ \\
\hline Total & 7983 & $100 \%$ & 2657 & $100 \%$ & 5145 & $100 \%$ & 961 & $100 \%$ & 620 & $100 \%$ & 2175 & $100 \%$ & 1526 & $100 \%$ \\
\hline
\end{tabular}




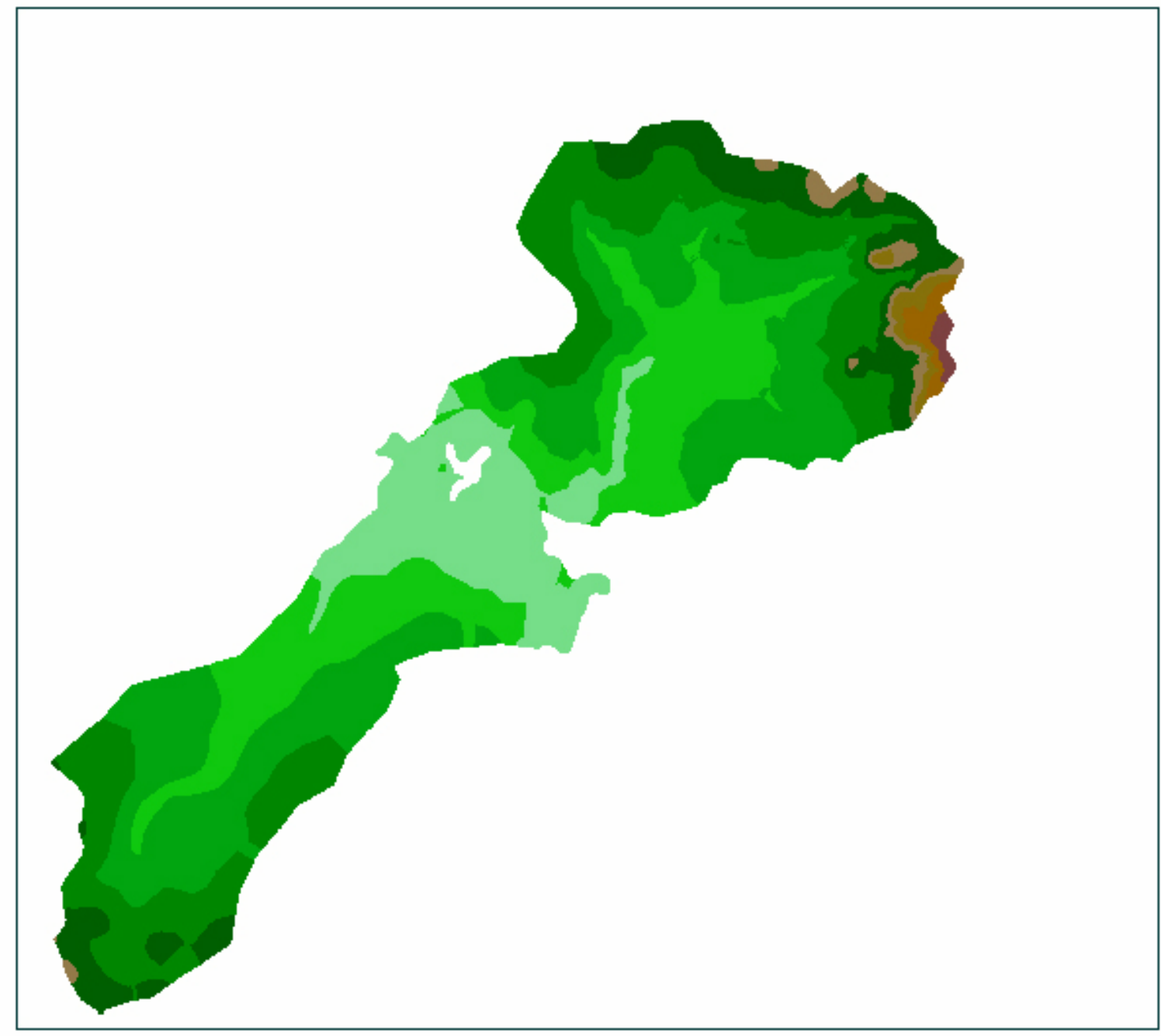

Carta de Hipsometrio

do Area de Estudo

Legends

Clege日e日 Hlpeométricou $\langle m\rangle$

$500-540$

$-540-580$

$580-820$

$1820-850$

$560-700$

$700-740$

$740-780$

$780-820$

a20- 850

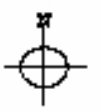

Projecto UTh - Zona $23 \mathrm{~S}$

Dortum Hortzontal: Cótago ilegra, Ho

Fonta: Baes Cortográflca (IBGE, 1971) Eacala 1:50.000

Org.; Risardo Tezini Mlinoti, 2000

Escala Eróriea

\begin{tabular}{rrrrrr}
4 & 0 & 1.4 & 2.8 & 4.2 & $5.6 \mathrm{~km}$ \\
\hline
\end{tabular}

Figura 15. Hipsometria da área de estudo. 


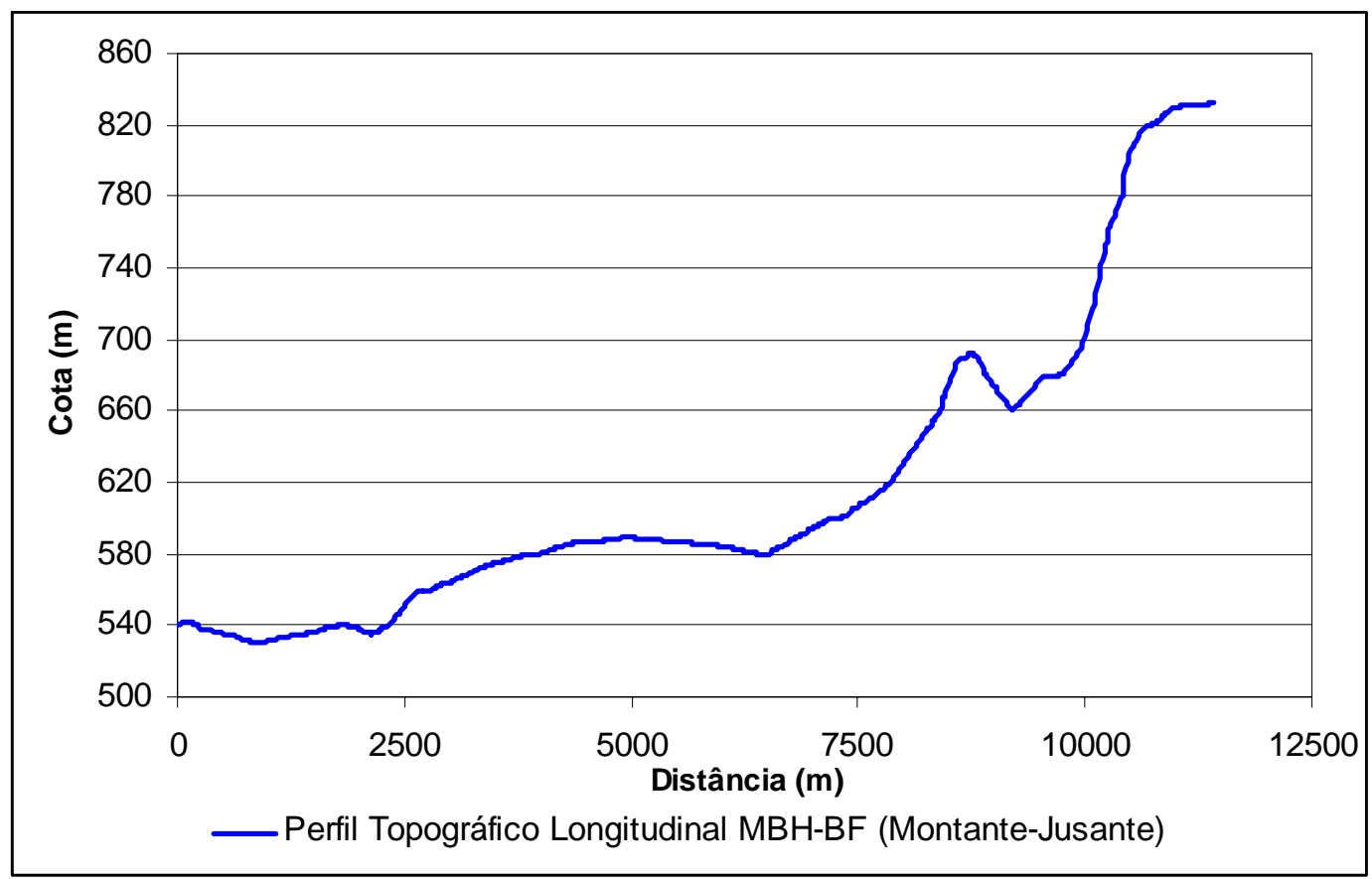

Figura 16. Perfil topográfico longitudinal associado ao Modelo Numérico do Terreno da microbacia do córrego do Beija-Flor.

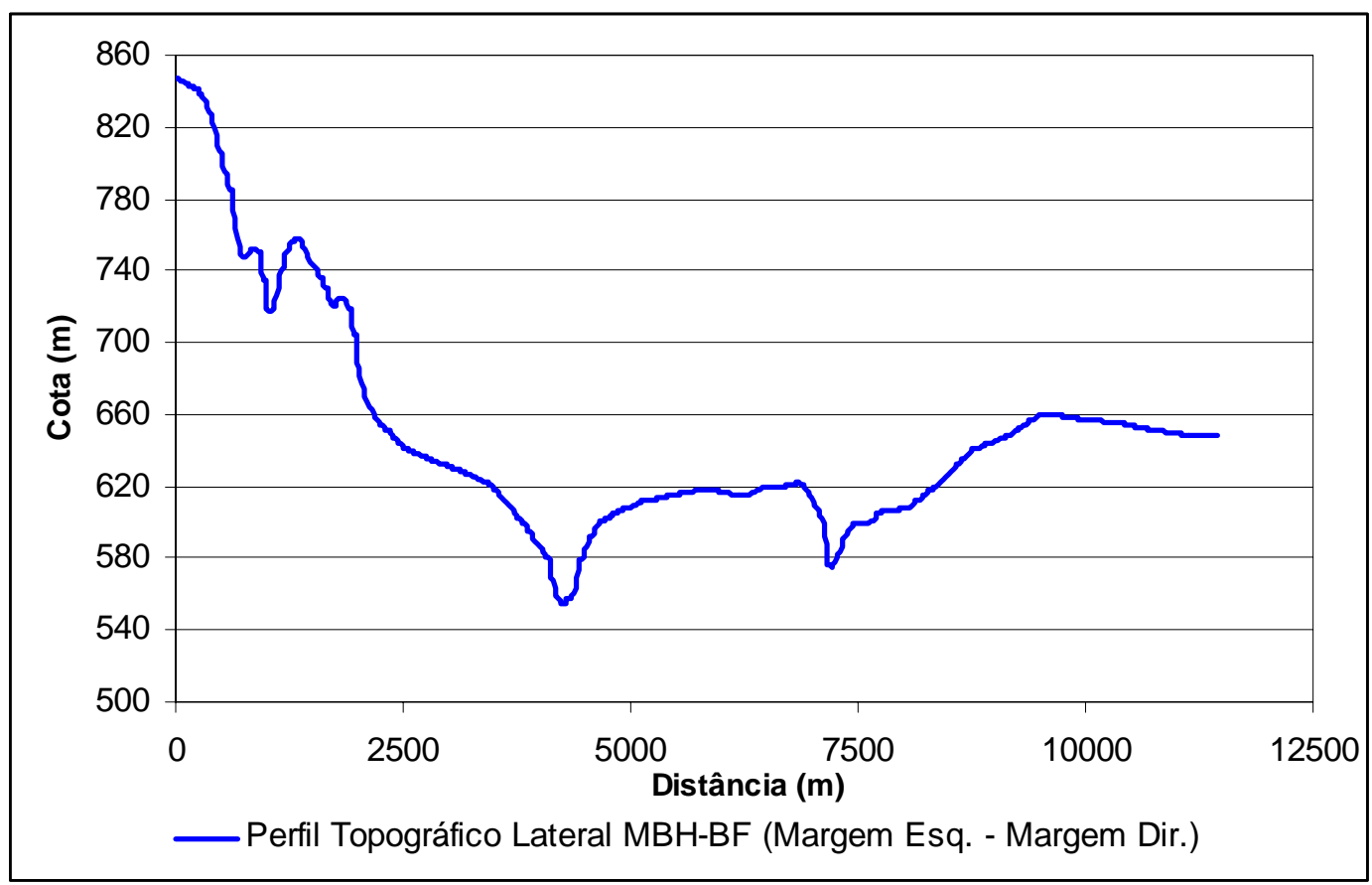

Figura 17. Perfil topográfico lateral associado ao Modelo Numérico do Terreno da microbacia do córrego do Beija-Flor. 


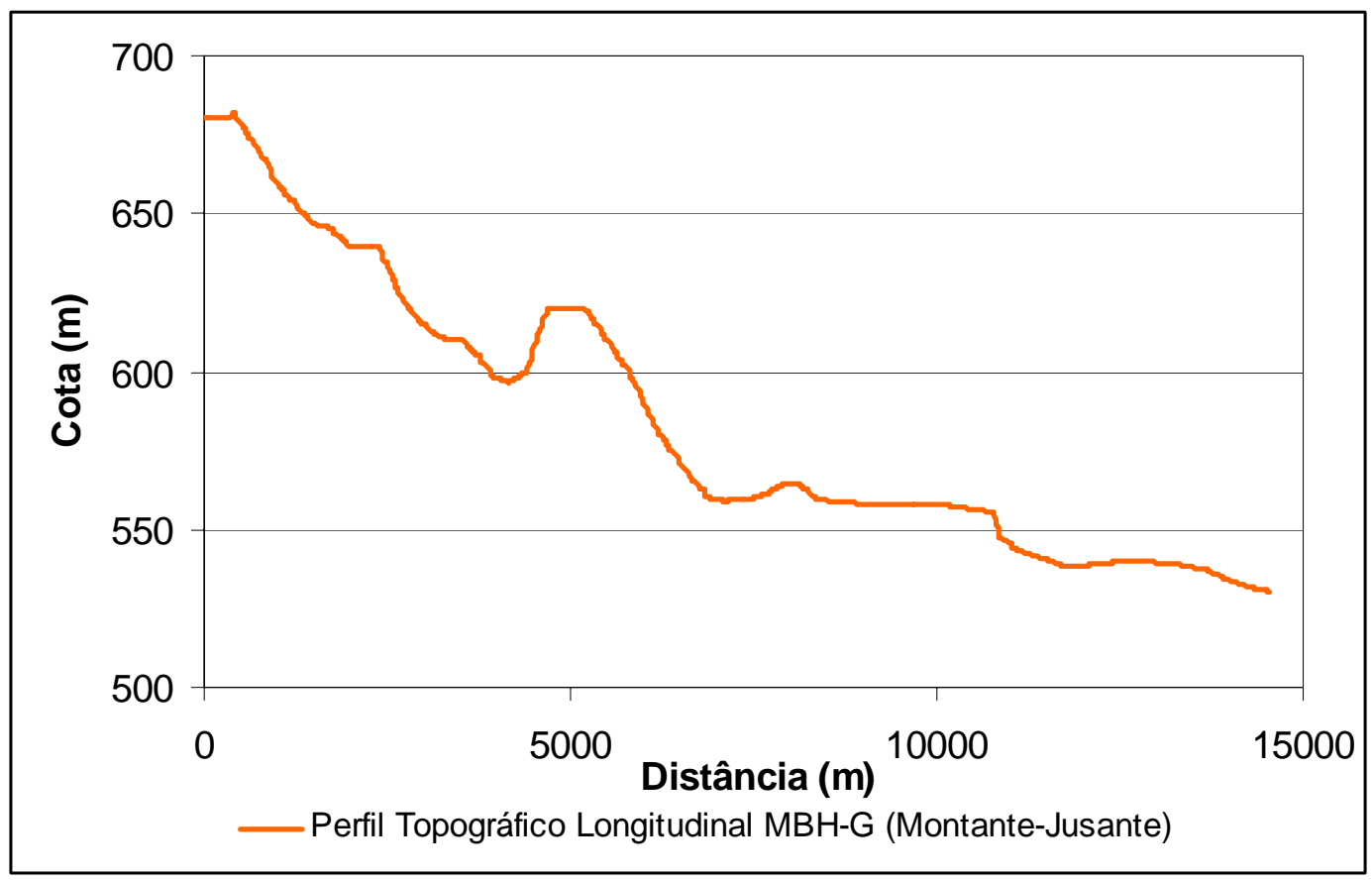

Figura 18. Perfil topográfico longitudinal associado ao Modelo Numérico do Terreno da microbacia do ribeirão das Guabirobas.

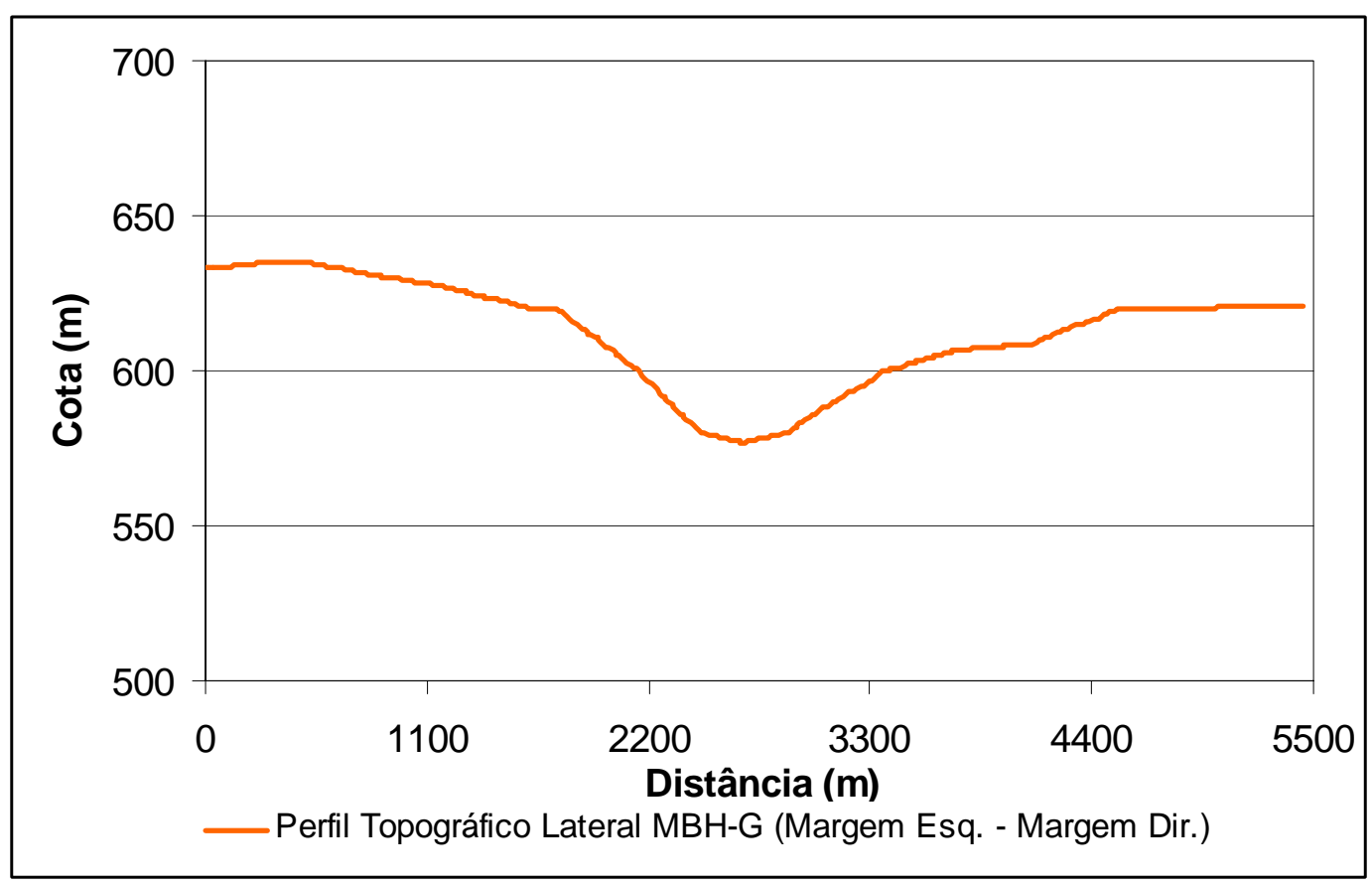

Figura 19. Perfil topográfico lateral associado ao Modelo Numérico do Terreno da microbacia do ribeirão das Guabirobas. 


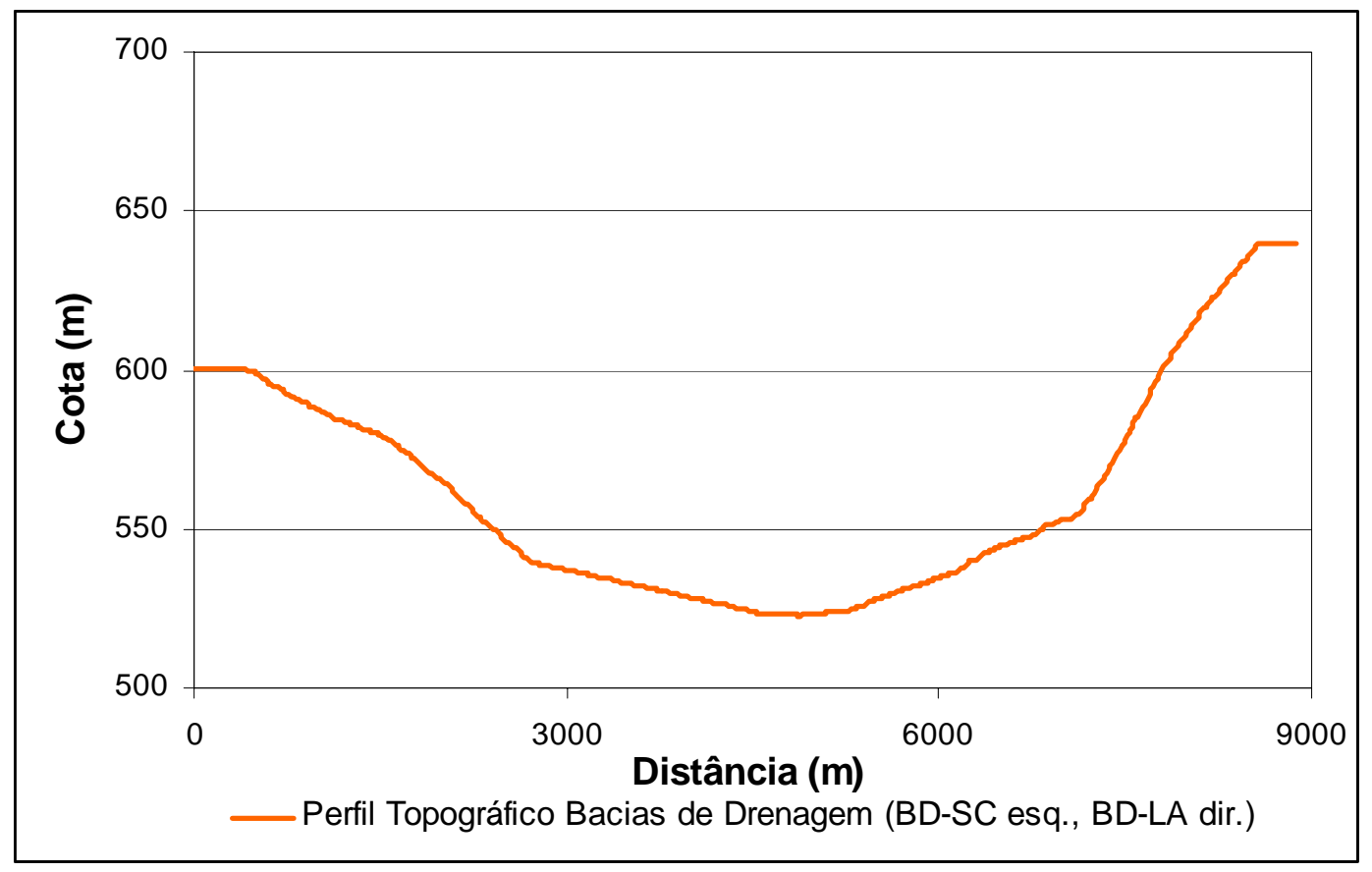

Figura 20. Perfil topográfico longitudinal associado ao Modelo Numérico do Terreno das bacias de drenagem de São Carlos e Luiz Antônio.

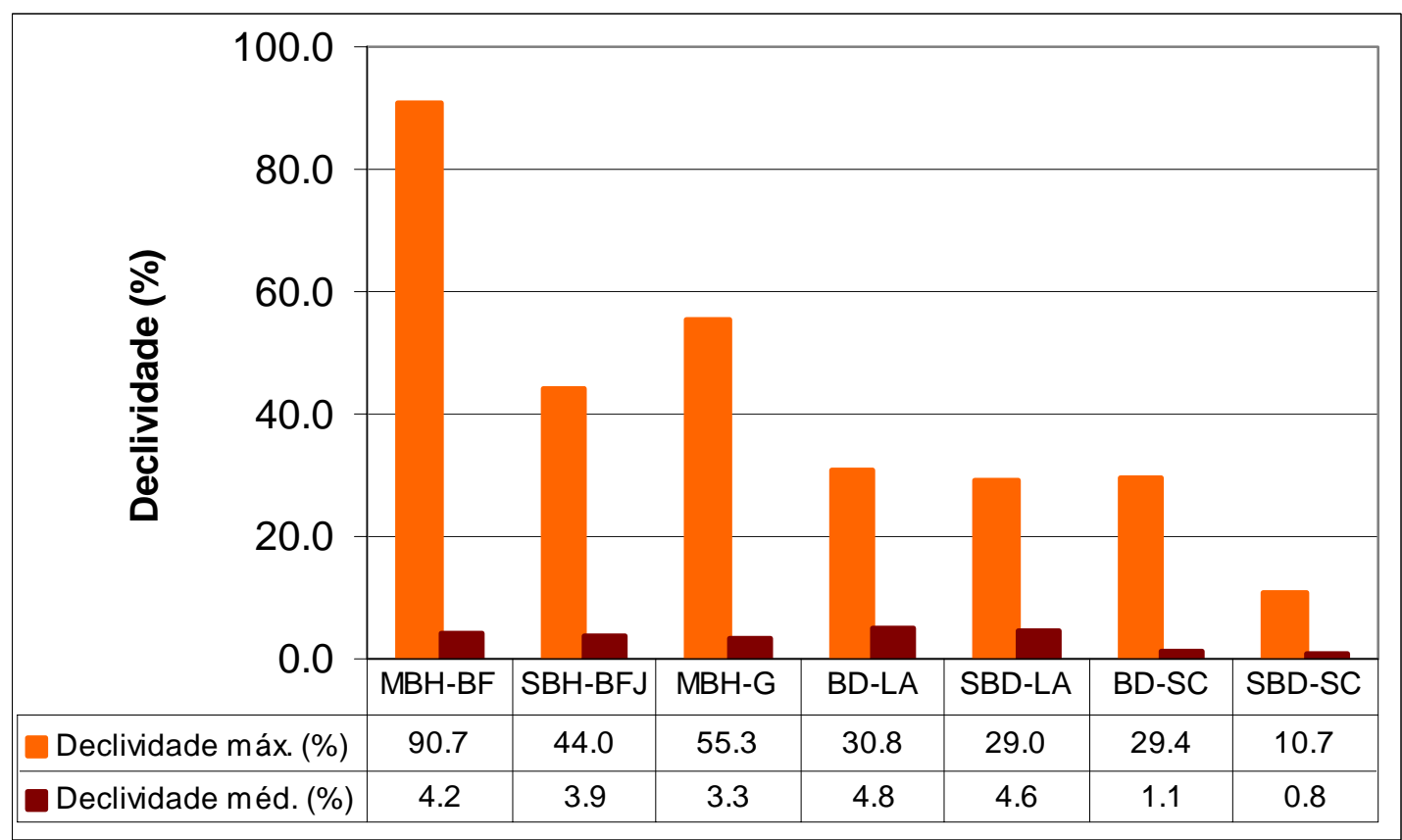

Figura 21. Declividade das unidades de estudo (máxima e média). 
Em toda a área de estudo, apenas a MBH-BF abrangeu, em toda a sua extensão, todas as classes clinográficas. Apesar de a área inserida na faixa de 45 a 100 \% ter sido de apenas 13 hectares, essa microbacia apresentou declividades mais acentuadas, com grande extensão de terras (1.557 ha) na faixa entre 8 e $45 \%$ e com o relevo variando de plano/praticamente plano a montanhoso. Na Figura 22, pode-se visualizar a conformação do relevo da área de estudo em função das classes clinográficas.

\subsubsection{Tipo de Solo}

Com base nos dados de solos encontrados nos mapas utilizados no presente trabalho, em informações fornecidas pelo Dr. Reinaldo Lorandi (comunicação pessoal), na classificação de solos (Embrapa, 1999) e na descrição das classes de solo do Estado de São Paulo (Oliveira, 1999), na região estudada no presente trabalho, foram identificadas 10 classes de solo e uma combinação de solos: LATOSSOLO VERMELHO Eutroférrico (LVef), LATOSSOLO VERMELHO Distrófico (LVd), LATOSSOLO VERMELHO Ácrico (LVw), LATOSSOLO VERMELHO AMARELO Distrófico (LVAd), ARGISSOLO VERMELHO Distrófico típico (PVd), CHERNOSSOLO ARGILÚVICO Órtico típico (MTo), NEOSSOLO LITÓLICO Eutrófico chernossólico (RLe), NEOSSOLO QUARTZARÊNICO Órtico típico (Rqo), NEOSSOLO QUARTZARÊNICO Hidromórfico (RQg), GLEISSOLO HÁPLICO Tb Eutrófico (GXbe), combinação de GLEISSOLO HÁPLICO Tb Eutrófico com CAMBISSOLO HÁPLICO (GXbe + CXbd).

Na Tabela 24, podem-se observar as áreas e respectivas percentagens referentes às classes de solo identificadas na área de estudo. Os resultados para as unidades e subunidades de estudo podem ser observados nas Figuras 23, 24 e 25. A maior variação em relação às classes de solo pode ser observada na MBH-BF (10 classes de solos), e a menor, na SBD-SC ocorrendo, apenas, dois tipos de solos. Pode-se notar, na área de estudo situada na margem esquerda do rio MogiGuaçu (MBH-G, BD-SC e SBD-SC) a dominância dos latossolos. A distribuição das classes de solo na área de estudo pode ser visualizada na Figura 26.

Tabela 22. Clinografia da área de estudo.

\begin{tabular}{|c|c|c|}
\hline Classe Clinográfica & Área (ha) & $\%$ \\
\hline $0-3 \%$ & 8174 & $50 \%$ \\
\hline $3-8 \%$ & 6274 & $39 \%$ \\
\hline $8-13 \%$ & 1130 & $7 \%$ \\
\hline $13-20 \%$ & 405 & $2 \%$ \\
\hline $20-45 \%$ & 268 & $2 \%$ \\
\hline $45-100 \%$ & 13 & $0 \%$ \\
\hline Área Total & $\mathbf{1 6 2 6 4}$ & $\mathbf{1 0 0 \%}$ \\
\hline
\end{tabular}


Tabela 23. Clinografia das unidades e subunidades de estudo.

\begin{tabular}{|c|c|c|c|c|c|c|c|c|c|c|c|c|c|c|}
\hline \multirow{2}{*}{$\begin{array}{c}\text { Classe } \\
\text { Clinográfica }\end{array}$} & \multicolumn{2}{|c|}{ MBH Beija-Flor } & \multicolumn{2}{|c|}{$\begin{array}{l}\text { SBH Beija- } \\
\text { Flor/Jataí }\end{array}$} & \multicolumn{2}{|c|}{$\begin{array}{c}\text { MBH } \\
\text { Guabirobas }\end{array}$} & \multicolumn{2}{|c|}{ BD Luiz Antônio } & \multicolumn{2}{|c|}{$\begin{array}{l}\text { SBD Luiz } \\
\text { Antônio }\end{array}$} & \multicolumn{2}{|c|}{ BD São Carlos } & \multicolumn{2}{|c|}{ SBD São Carlos } \\
\hline & $\begin{array}{l}\text { Área } \\
\text { (ha) }\end{array}$ & (\%) & $\begin{array}{l}\text { Área } \\
\text { (ha) }\end{array}$ & (\%) & $\begin{array}{l}\text { Área } \\
\text { (ha) }\end{array}$ & (\%) & $\begin{array}{c}\text { Área } \\
\text { (ha) }\end{array}$ & (\%) & $\begin{array}{l}\text { Área } \\
\text { (ha) }\end{array}$ & $(\%)$ & $\begin{array}{l}\text { Área } \\
\text { (ha) }\end{array}$ & (\%) & $\begin{array}{l}\text { Área } \\
\text { (ha) }\end{array}$ & (\%) \\
\hline $0-3 \%$ & 3386 & $42 \%$ & 1659 & $62 \%$ & 2634 & $51 \%$ & 448 & $47 \%$ & 122 & $20 \%$ & 1751 & $80 \%$ & 1147.7 & $75 \%$ \\
\hline $3-8 \%$ & 3028 & $38 \%$ & 679 & $26 \%$ & 2356 & $46 \%$ & 442 & $46 \%$ & 427 & $69 \%$ & 414 & $19 \%$ & 371.4 & $24 \%$ \\
\hline $8-13 \%$ & 935 & $12 \%$ & 262 & $10 \%$ & 122 & $2 \%$ & 56 & $6 \%$ & 56 & $9 \%$ & 8 & $0 \%$ & 6.0 & $0 \%$ \\
\hline $13-20 \%$ & 362 & $5 \%$ & 54 & $2 \%$ & 28 & $1 \%$ & 13 & $1 \%$ & 13 & $2 \%$ & 2 & $0 \%$ & 0.6 & $0 \%$ \\
\hline $20-45 \%$ & 260 & $3 \%$ & 4 & $0 \%$ & 5 & $0 \%$ & 2 & $0 \%$ & 2 & $0 \%$ & 0 & $0 \%$ & 0.0 & $0 \%$ \\
\hline $45-100 \%$ & 13 & $0 \%$ & 0 & $0 \%$ & 0 & $0 \%$ & 0 & $0 \%$ & 0 & $0 \%$ & 0 & $0 \%$ & 0.0 & $0 \%$ \\
\hline Total & 7983 & $100 \%$ & 2657 & $100 \%$ & 5145 & $100 \%$ & 961 & $100 \%$ & 620 & $100 \%$ & 2175 & $100 \%$ & 1526 & $100 \%$ \\
\hline
\end{tabular}




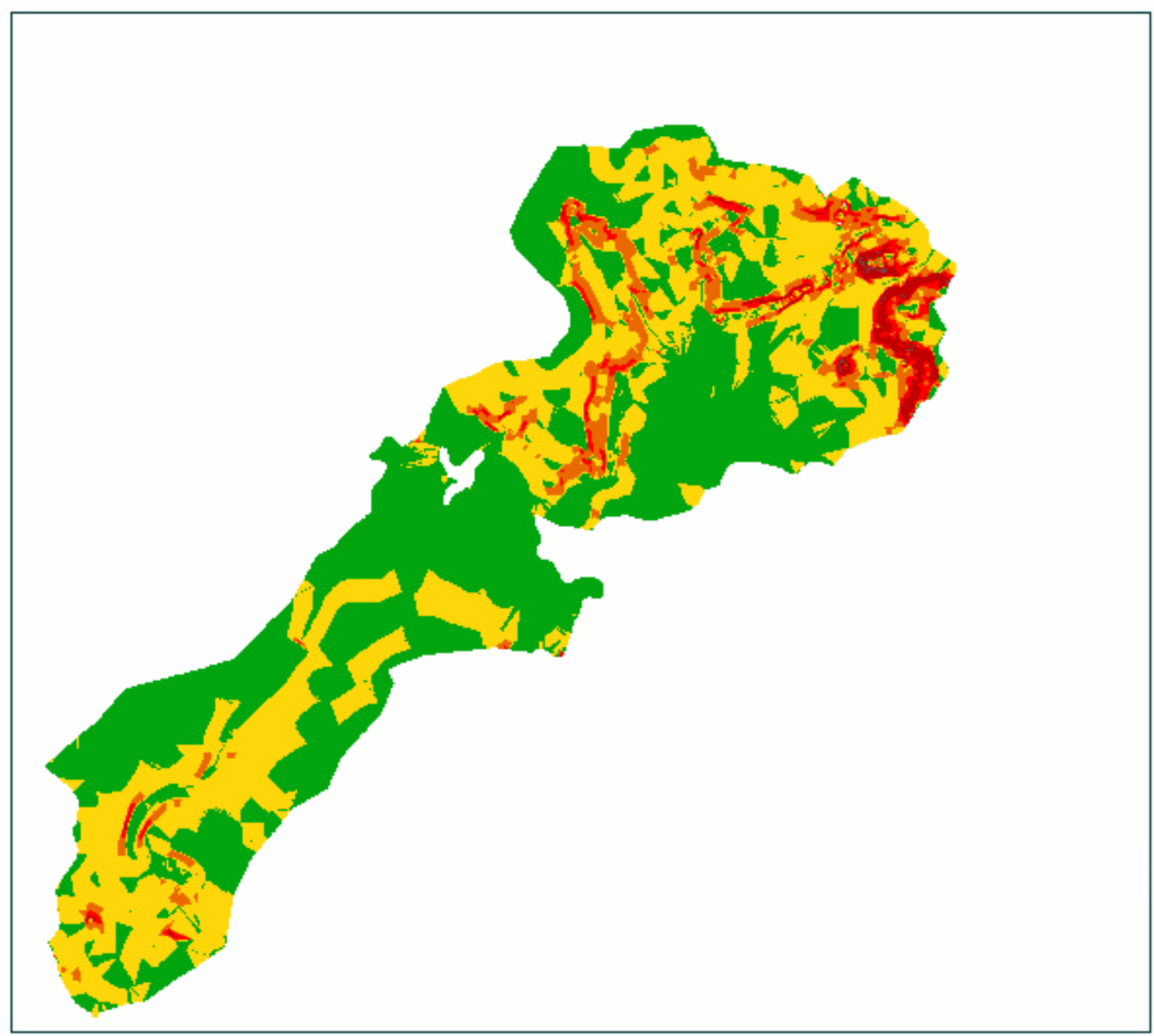

Carta de Clinografía da Area de Estudo

Legendo Classes Clinográficas

- 0 a $3,0 \%$

3,0 $\square, 0 \%$

8,0 a $13,0 \%$

- 13,0 o $20,0 \%$

- 20,0 व $45 \%$

$\square>45,0 \%$

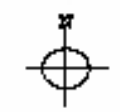

Projeçto UTH - Zona $23 \mathrm{~S}$

Dotum Horlzontal: CGrTago Alegra, WG

Fonta: Base Cortográffca (IBGE, 1971)

Escala 1:50.000

Org,: Ricardo Tezini Minoti, 2000

Escala Gróriea

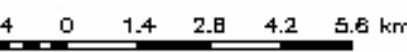

Figura 22. Clinografia da área de estudo. 
Tabela 24 Área das classes de solo.

\begin{tabular}{|l|c|c|}
\hline \multicolumn{1}{|c|}{ Solo } & Área (ha) & $\%$ \\
\hline Gxbe & 340.2 & $2 \%$ \\
\hline Gxbe+Cxbd & 857.4 & $5 \%$ \\
\hline LVAd & 5567.9 & $34 \%$ \\
\hline LVd & 2558.3 & $16 \%$ \\
\hline LVef & 1091.1 & $7 \%$ \\
\hline LVw & 2671.8 & $16 \%$ \\
\hline MTo & 57.3 & $0.4 \%$ \\
\hline PVd & 331.3 & $2 \%$ \\
\hline RLe & 312.1 & $2 \%$ \\
\hline RQg & 177.0 & $1 \%$ \\
\hline RQo & 1976.3 & $12 \%$ \\
\hline TT & 5.9 & $0.04 \%$ \\
\hline LVAd + RQo & 78.3 & $0.5 \%$ \\
\hline Corpos d'água & 239.0 & $1 \%$ \\
\hline \multicolumn{1}{|c|}{ Área Total } & $\mathbf{1 6 2 6 4}$ & $\mathbf{1 0 0 \%}$ \\
\hline
\end{tabular}

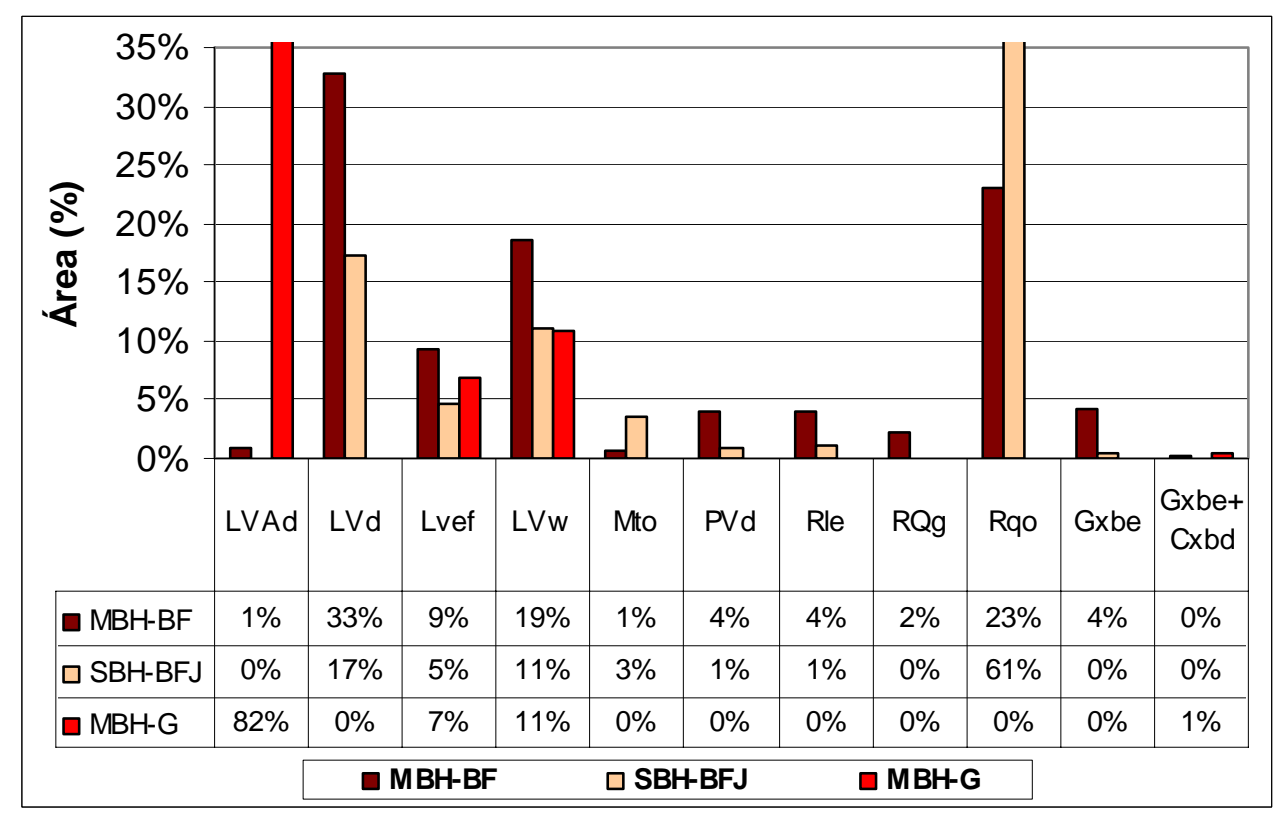

Figura 23. Tipos de solos e respectivas porcentagens em relação às áreas da MBH-BF, SBH-BFJ e MBH-G. 


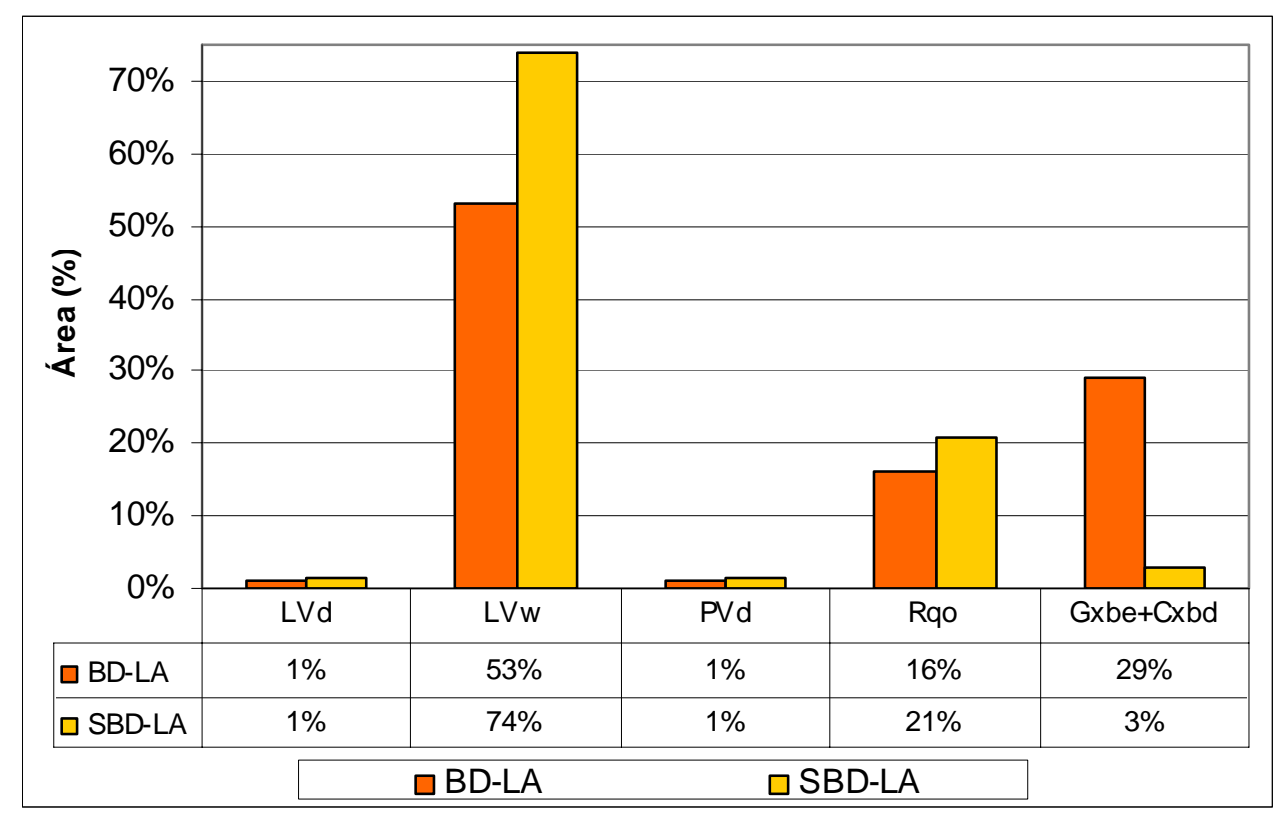

Figura 24. Tipos de solos e respectivas porcentagens em relação à área da BD-LA e SBD-LA.

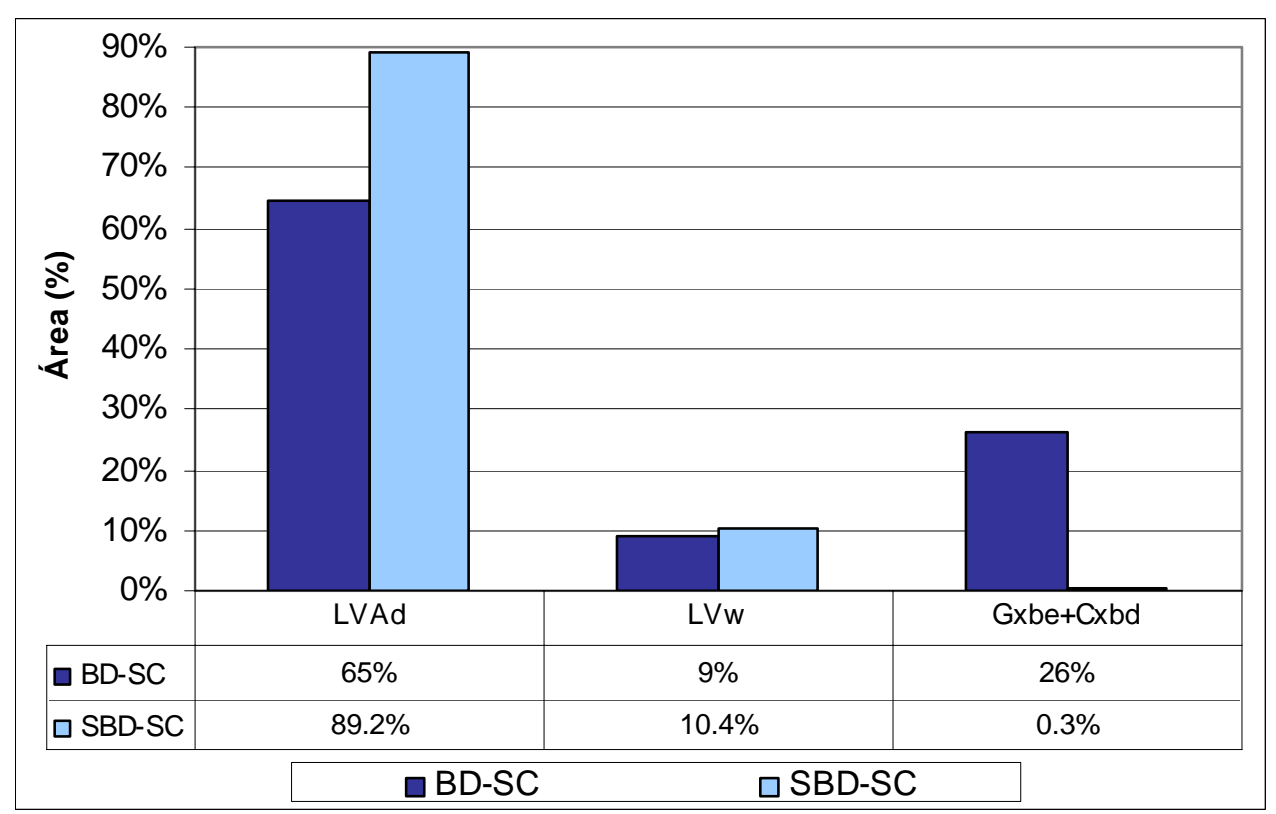

Figura 25. Tipos de solos e respectivas porcentagens em relação à área da BD-SC e SBD-SC. 


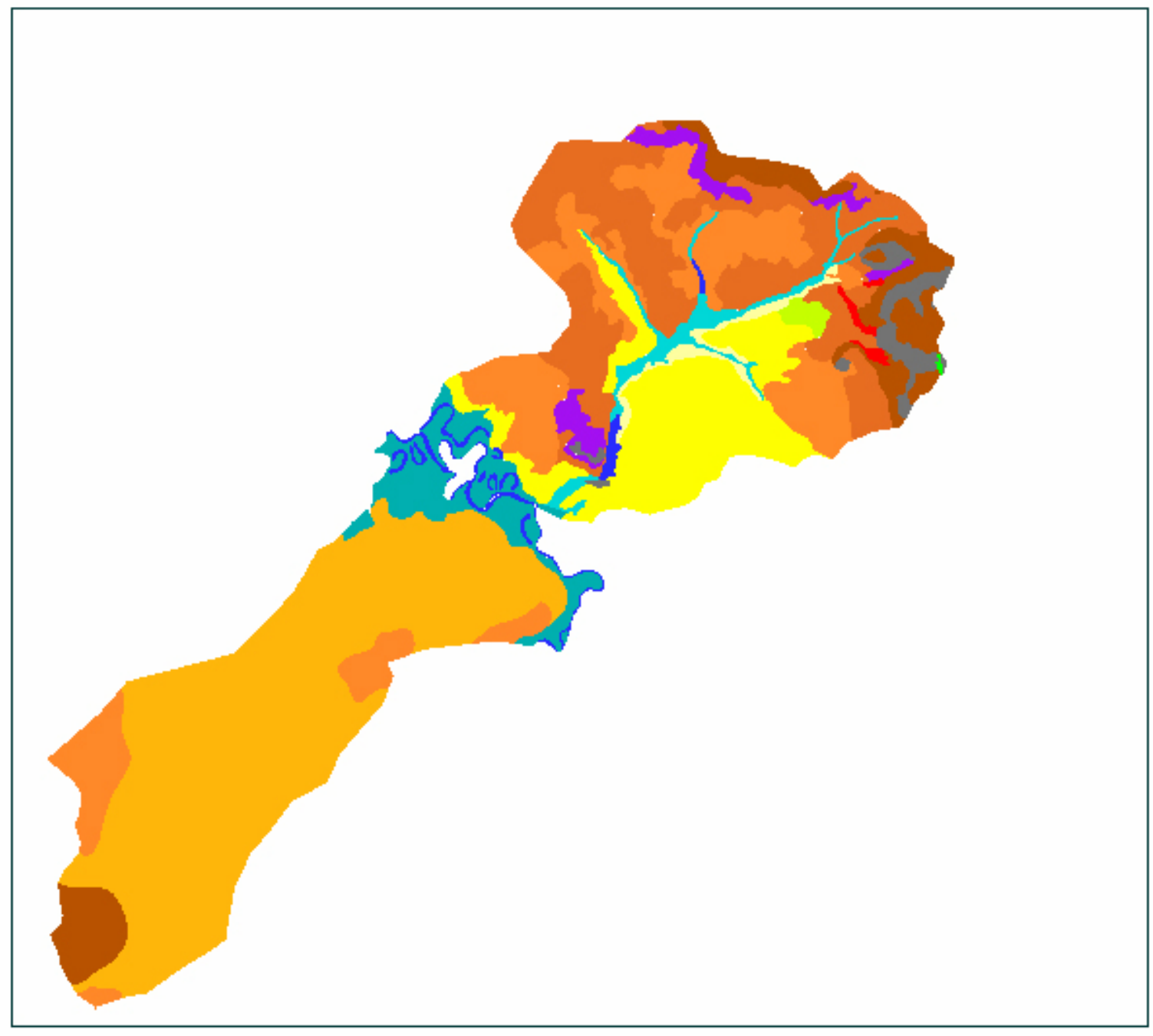

Carto de Solos da Area de Estudo Legenda

Classes de Solos

LVAd + RQo

GXbe + cxbd

RLd

RLe

PVAd

- LVef

LVd

LVAd

- PVd

GXbe

MTo

$\mathrm{RQg}$

$\stackrel{\mathrm{RQ}}{\pi}$

- Corpos d água

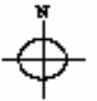

Prolacto UTH - Zona $23 \mathrm{~S}$

Dotum Horlzontal: CGrTago Alegra, WO

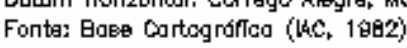

Escala 1:50.000

Ong.: Ricardo Tezini klinoti, 2000

Escala Endíiea

\begin{tabular}{rrrrr}
$4 \quad 0$ & 1.4 & 2.18 & $4.2 \quad 5.6 \mathrm{~km}$ \\
\hline
\end{tabular}

Figura 26. Solos da área de estudo. 


\subsubsection{Uso do Solo}

Com o levantamento do uso e ocupação do solo em campo, realizado pela utilização de GPS, e posterior comparação dos resultados obtidos com a imagem de satélite, na região estudada no presente trabalho, foram identificadas 10 classes de uso do solo (Tab. 25). As áreas e respectivas percentagens referentes às classes de uso do solo para as unidades e subunidades de estudo podem ser observadas na Tabela 26.

A classe "Vegetação Natural” inclui os segmentos que são abrangidos pela EEJ, os quais apresentam vegetação de cerrado em diferentes estágios de desenvolvimento, podendo apresentar diferentes tipos fitofisionômicos. Além da área da EEJ, a vegetação de cerrado aparece, também, em fragmentos no restante da área de estudo. Não obstante, a classe vegetação natural inclui, também, as vegetações de mata ciliar encontradas ao longo dos cursos dos córregos e ribeirões da área de estudo, além de outros tipos de vegetação nativa encontrados nas áreas de reserva legal das propriedades rurais.

A classe "Pasto + Várzea” (ocorrência em 48\% da extensão da BD-SC e 28\% da SBD-SC) foi dessa forma intitulada por apresentar uma mistura de áreas ocupadas por pastagem, cobertura residual e várzea. Além disso, a APP da margem esquerda do rio Mogi-Guaçu, por apresentar extensão variável, foi inserida nessa classe de uso do solo.

Analisando-se os dados de campo (Fig. 27) e comparando-os com os dados obtidos com a imagem de satélite, observou-se que tanto no segmento da área de estudo situado na margem direita do rio Mogi-Guaçu (MBH-BF, SBH-BFJ, BD-LA e SBD-LA) como no segmento da área de estudo situado na margem esquerda do rio Mogi-Guaçu (MBH-G, BD-SC e SBD-SC) não ocorreram variações significativas no período compreendido entre os anos de 2002 (imagem de satélite) e 2005 (levantamento dos dados de campo).

Na margem direita do rio Mogi-Guaçu, os usos dividem-se entre as áreas destinadas à conservação (EEJ), uma porção de experimentação (EELA), e o restante, ao uso agrícola.

Em relação aos usos verificados na margem esquerda do rio Mogi-Guaçu, assim como na margem direita, não ocorreram alterações significativas no período compreendido entre os anos de 2002 e 2005. Os resultados podem estar relacionados ao fato de que as propriedades rurais da microbacia hidrográfica apresentam extensões médias ou grandes. Não foi observada a presença de pequenos produtores.

As propriedades maiores, muitas vezes ligadas a empresas, possivelmente apresentem menor variação das culturas e sistemas produtivos. Os custos para transição do tipo de cultura agrícola a ser desenvolvida em uma determinada área podem ser onerosos. Os implementos agrícolas, em geral específicos para cada cultivo, devem ser trocados. Além das mudanças de 
infra-estrutura (tecnologias), a permuta pode envolver o treinamento ou, mesmo, troca da mãode-obra.

Nas Figuras 28, 29, 30 e 31 podem-se observar os cruzamentos entre as classes de solos e usos do solo das unidades e subunidades de estudo. Vale ressaltar que não foram realizados cruzamentos para a SBH-BFJ, BD-LA e SBD-LA, pois essas unidades apresentam apenas um tipo de uso do solo (vegetação natural).

O cruzamento dos dados de solo e uso do solo para a MBH-BFJ (Fig. 28) indicou que a cana-de-açúcar, a vegetação natural e as áreas ocupadas por eucaliptos e pinheiros ocorrem em praticamente todas as classes de solos identificadas nessa unidade de estudo. A cana-de-açúcar predomina nas áreas de Latossolos, a vegetação natural predomina onde ocorrem os Neossolos Quartzarênicos e os eucaliptos e pinheiros ocupam, principalmente, os Latossolos e os Neossolos Quartzarênicos.

Na MBH-G, praticamente todo o território destinado à produção agrícola ocorre em áreas de Latossolos (Fig. 29). A BD-SC apresenta um grande segmento ocupado pela classe "pasto + várzea”, predominantemente, em áreas de Gleissolos. Cana-de-açúcar, laranja e pasto, nessa unidade de estudo, desenvolvem-se nas áreas de latossolos. Tendo em vista que a SBD-SC se diferencia da BD-SC pela ausência, quase total, de Gleissolos, todas as classes de uso do solo identificadas nessa subunidade de estudo ocorrem em latossolos.

Tabela 25. Área das classes de uso do solo da área de estudo.

\begin{tabular}{|c|c|c|}
\hline Uso do solo & Área (ha) & $\%$ \\
\hline Avicultura & 36.6 & $0.2 \%$ \\
\hline Cana-de-Açúcar & 6570.1 & $40 \%$ \\
\hline Cerrado & 2871.3 & $18 \%$ \\
\hline Eucalipto & 297.8 & $2 \%$ \\
\hline Lagoas & 43.6 & $0.3 \%$ \\
\hline Laranja & 1422.8 & $9 \%$ \\
\hline Pasto & 495.9 & $3 \%$ \\
\hline Pasto e Várzea & 1041.8 & $6 \%$ \\
\hline Pinus e Eucalipto & 1985.8 & $12 \%$ \\
\hline Vegetação Natural & 1498.3 & $9 \%$ \\
\hline Área Total & 16264 & $100 \%$ \\
\hline
\end{tabular}


Tabela 26. Área das classes de uso do solo das unidades e subunidades de estudo e respectivas porcentagens.

\begin{tabular}{|c|c|c|c|c|c|c|c|c|c|c|c|c|c|c|}
\hline \multirow{2}{*}{$\begin{array}{c}\text { Classe } \\
\text { Uso do Solo }\end{array}$} & \multicolumn{2}{|c|}{ MBH Beija-Flor } & \multicolumn{2}{|c|}{$\begin{array}{l}\text { SBH Beija- } \\
\text { Flor/Jataí }\end{array}$} & \multicolumn{2}{|c|}{$\begin{array}{c}\text { MBH } \\
\text { Guabirobas }\end{array}$} & \multicolumn{2}{|c|}{ BD Luiz Antônio } & \multicolumn{2}{|c|}{$\begin{array}{l}\text { SBD Luiz } \\
\text { Antônio }\end{array}$} & \multicolumn{2}{|c|}{ BD São Carlos } & \multicolumn{2}{|c|}{ SBD São Carlos } \\
\hline & $\begin{array}{l}\text { Área } \\
\text { (ha) }\end{array}$ & $(\%)$ & $\begin{array}{c}\text { Área } \\
\text { (ha) }\end{array}$ & $(\%)$ & $\begin{array}{c}\text { Área } \\
\text { (ha) }\end{array}$ & (\%) & $\begin{array}{l}\text { Área } \\
\text { (ha) }\end{array}$ & (\%) & $\begin{array}{c}\text { Área } \\
\text { (ha) }\end{array}$ & (\%) & $\begin{array}{c}\text { Área } \\
\text { (ha) }\end{array}$ & $(\%)$ & $\begin{array}{c}\text { Área } \\
\text { (ha) }\end{array}$ & (\%) \\
\hline $\begin{array}{l}\text { Cana-de- } \\
\text { açúcar }\end{array}$ & 3125 & $39 \%$ & 0 & $0 \%$ & 3078 & $60 \%$ & 0 & $0 \%$ & 0 & $0 \%$ & 374 & $17 \%$ & 378 & $25 \%$ \\
\hline $\begin{array}{l}\text { Pinus e } \\
\text { Eucalipto }\end{array}$ & 1986 & $25 \%$ & 0 & $0 \%$ & $298^{\#}$ & $6 \%{ }^{\#}$ & 0 & $0 \%$ & 0 & $0 \%$ & 0 & $0 \%$ & 0 & $0 \%$ \\
\hline Laranja & 0 & $0 \%$ & 0 & $0 \%$ & 942 & $18 \%$ & 0 & $0 \%$ & 0 & $0 \%$ & 489 & $22 \%$ & 480 & $31 \%$ \\
\hline Veg. Nat.* & 2872 & $36 \%$ & 2657 & $100 \%$ & 472 & $9 \%$ & 961 & $100 \%$ & 620 & $100 \%$ & 74 & $3 \%$ & 65 & $4 \%$ \\
\hline Pasto & 0 & $0 \%$ & 0 & $0 \%$ & 318 & $6 \%$ & 0 & $0 \%$ & 0 & $0 \%$ & 186 & $9 \%$ & 177 & $12 \%$ \\
\hline Pasto+Várzea & 0 & $0 \%$ & 0 & $0 \%$ & 0 & $0 \%$ & 0 & $0 \%$ & 0 & $0 \%$ & 1052 & $48 \%$ & 425 & $28 \%$ \\
\hline Avicultura & 0 & $0 \%$ & 0 & $0 \%$ & 37 & $1 \%$ & 0 & $0 \%$ & 0 & $0 \%$ & 0 & $0 \%$ & 0 & $0 \%$ \\
\hline Total & 7983 & $100 \%$ & 2657 & $100 \%$ & 5145 & $100 \%$ & 961 & $100 \%$ & 620 & $100 \%$ & 2175 & $100 \%$ & 1526 & $100 \%$ \\
\hline
\end{tabular}

* Vegetação Natural

\# Apenas Eucaliptos 


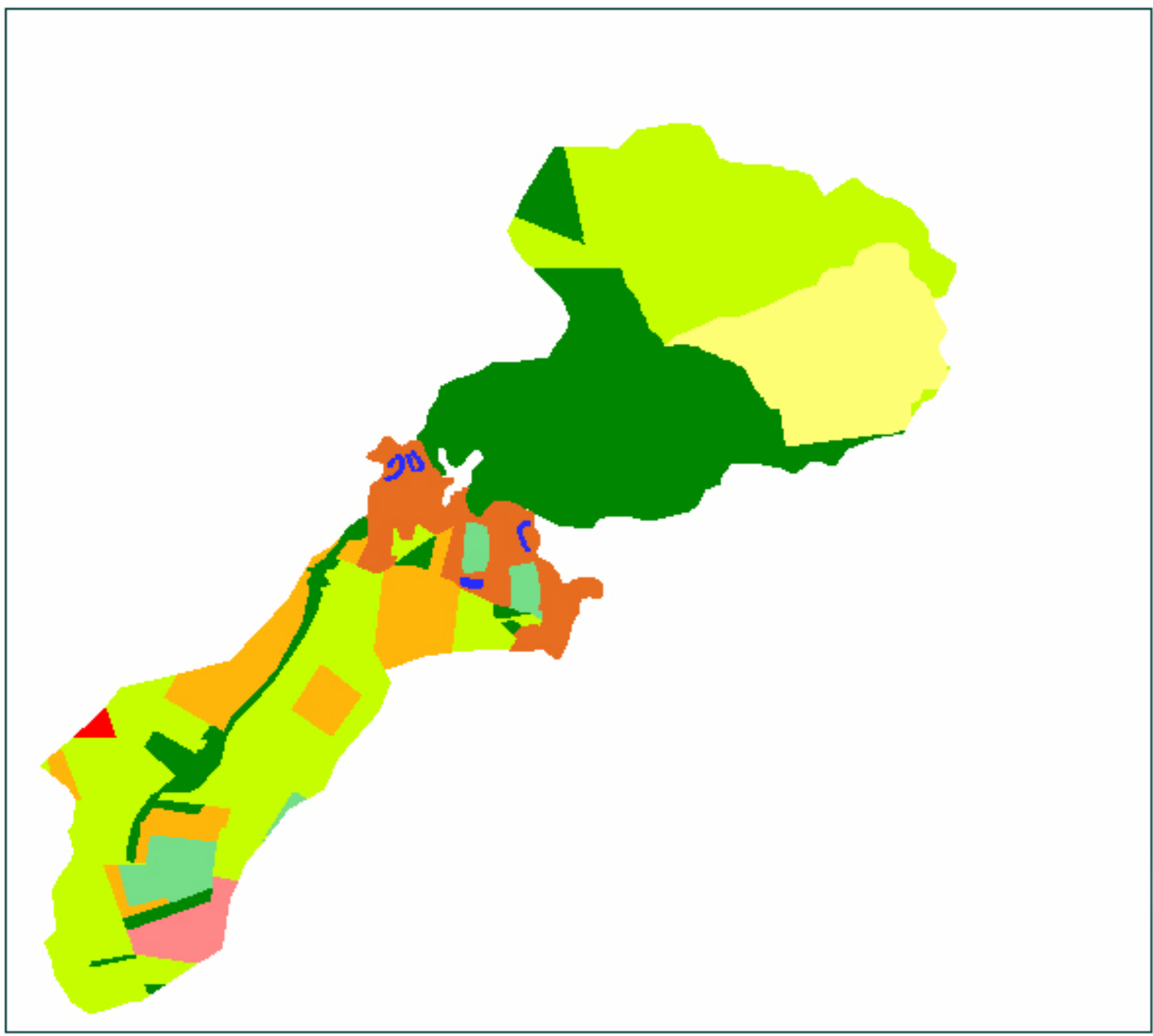

Carta de Uso dos Solos da Area de Estudo

\section{Legendo}

Classes de Uso do Solo

Pasta e Vúrzeo

Pasto

Vepetacio Notural

Plnue o Eucalipto

Euraliptr

Laronjo

Cona-de-Ágicar

aviculturo

Lagoo

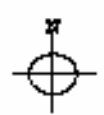

Projeçto UTW - Zona $23 \mathrm{~S}$

Dutum Horlzontal: Córtago Alegra, WG

Fonta: LANDSAT- ETH+ 7

B verflecaço atm oampo

Org.; Ricardo Tezini Mlinoti, 2000

Escala Erórica

\begin{tabular}{rrrrrr}
4 & 0 & 1.4 & 2.8 & 4.2 & $5.6 \mathrm{~km}$ \\
\hline
\end{tabular}

Figura 27. Uso do solo da área de estudo. 


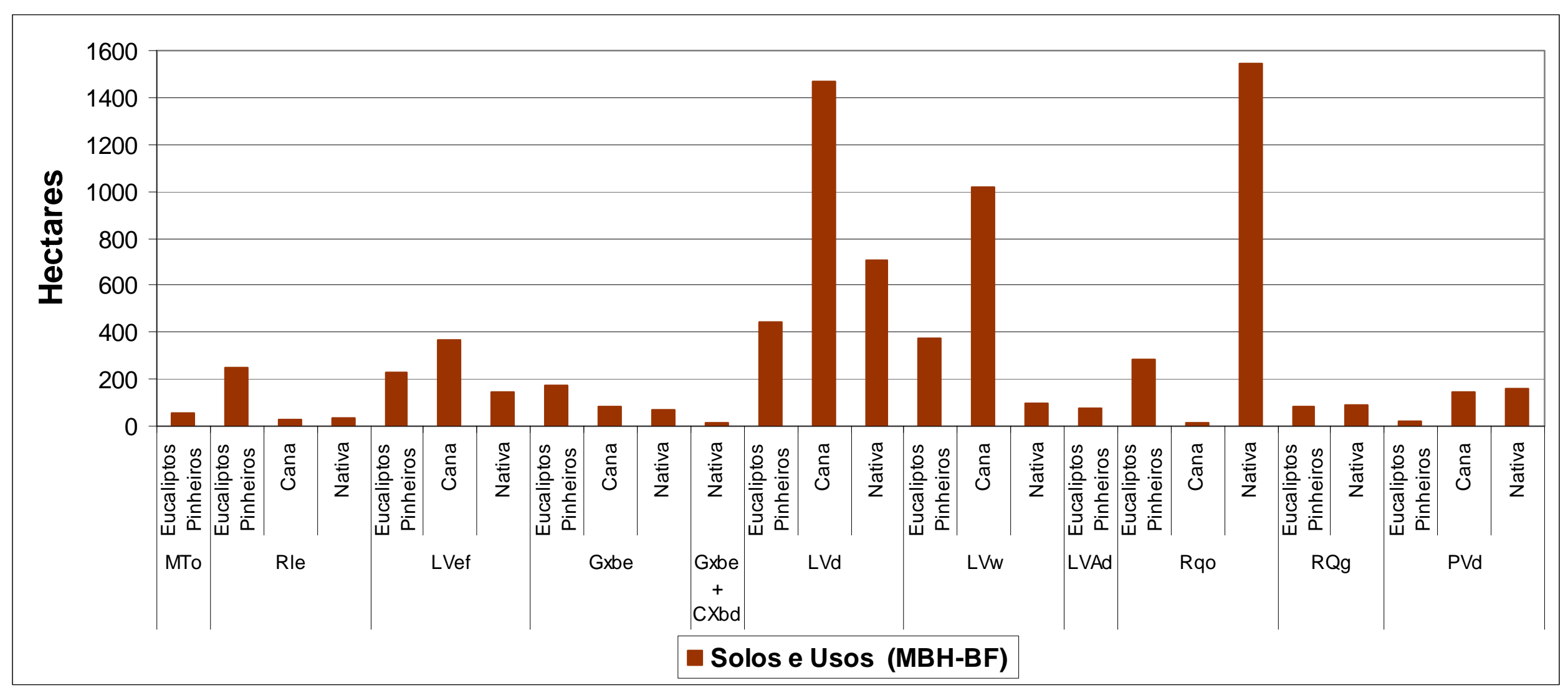

Figura 28. Cruzamento dos dados de tipo de solo e uso do solo para a Microbacia Hidrográfica do Córrego Beija-Flor. 


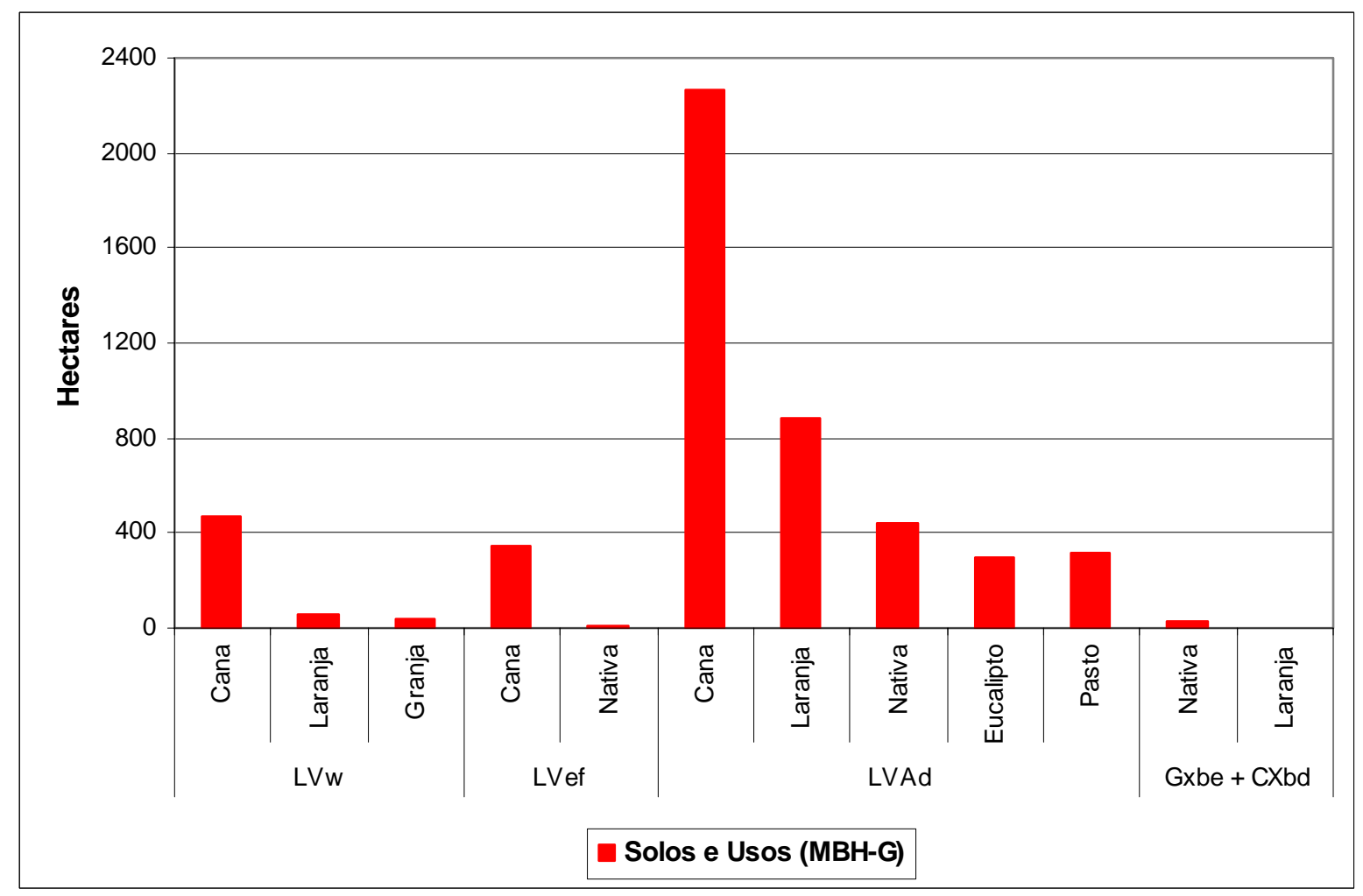

Figura 29. Cruzamento entre tipo de solo e uso do solo da microbacia hidrográfica do Ribeirão das Guabirobas.

\subsubsection{Malha Viária}

A malha viária da área de estudo pode ser visualizada na Figura 32. Deve-se salientar que a base cartográfica utilizada no processo de digitalização das estradas é referente ao ano de 1971. Nas áreas de uso agrícola, que abrangem parte da MBH-BF e quase toda a área da MBH-G, BDSC e SBD-SC, existem, na atualidade, inúmeros carreadores, os quais subdividem os talhões de cultivo permitindo o acesso de caminhões e máquinas agrícolas. Muitos desses carreadores não estão representados nessa Figura.

A microbacia hidrográfica do Córrego do Beija-Flor apresenta apenas estradas não pavimentadas. O segmento dessa unidade de estudo, que é ocupado pela EEJ, contém estradas sem pavimentação, caminhos e trilhas. 


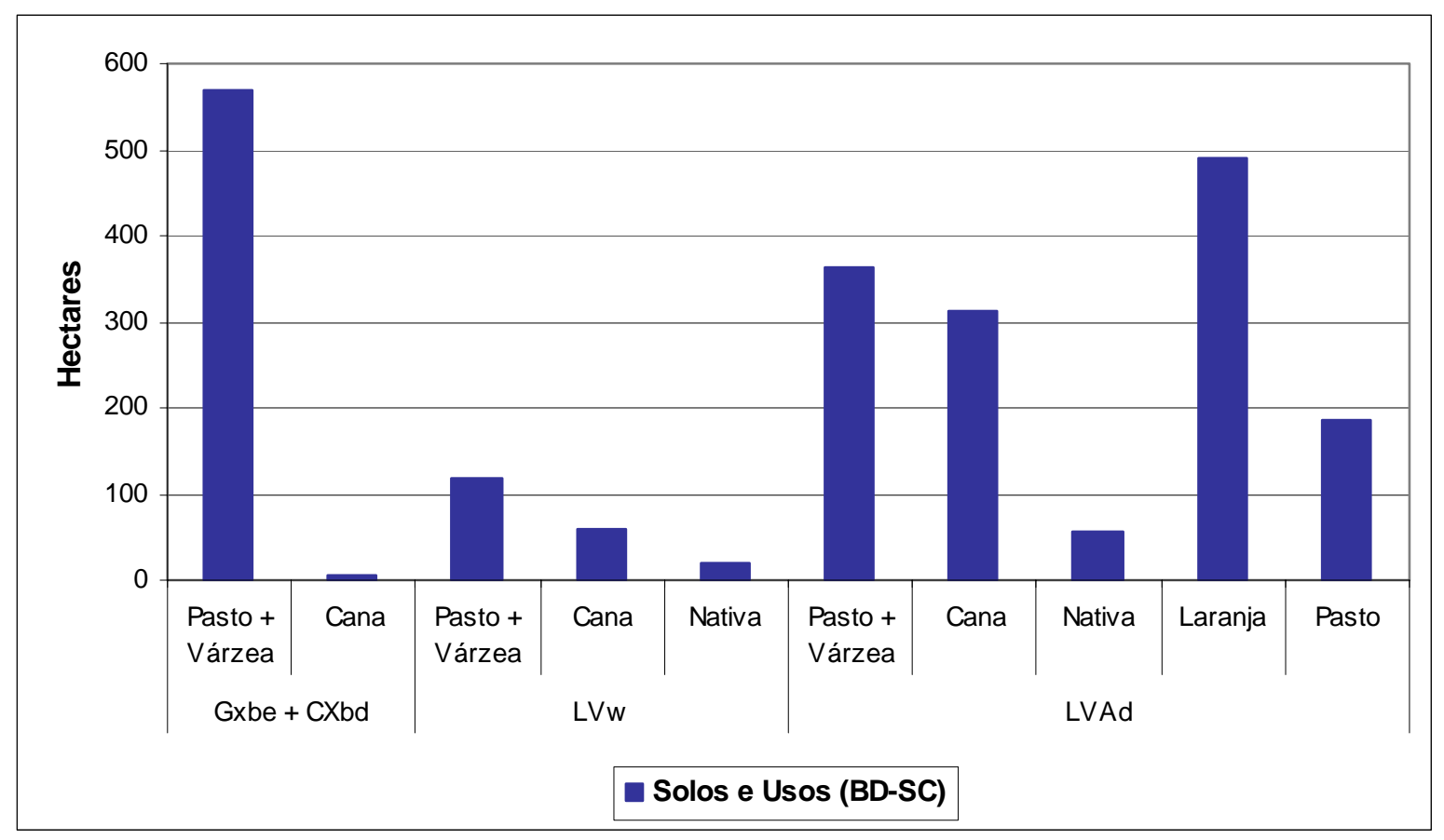

Figura 30. Cruzamento entre tipo de solo e uso do solo da Bacia de Drenagem de São Carlos.

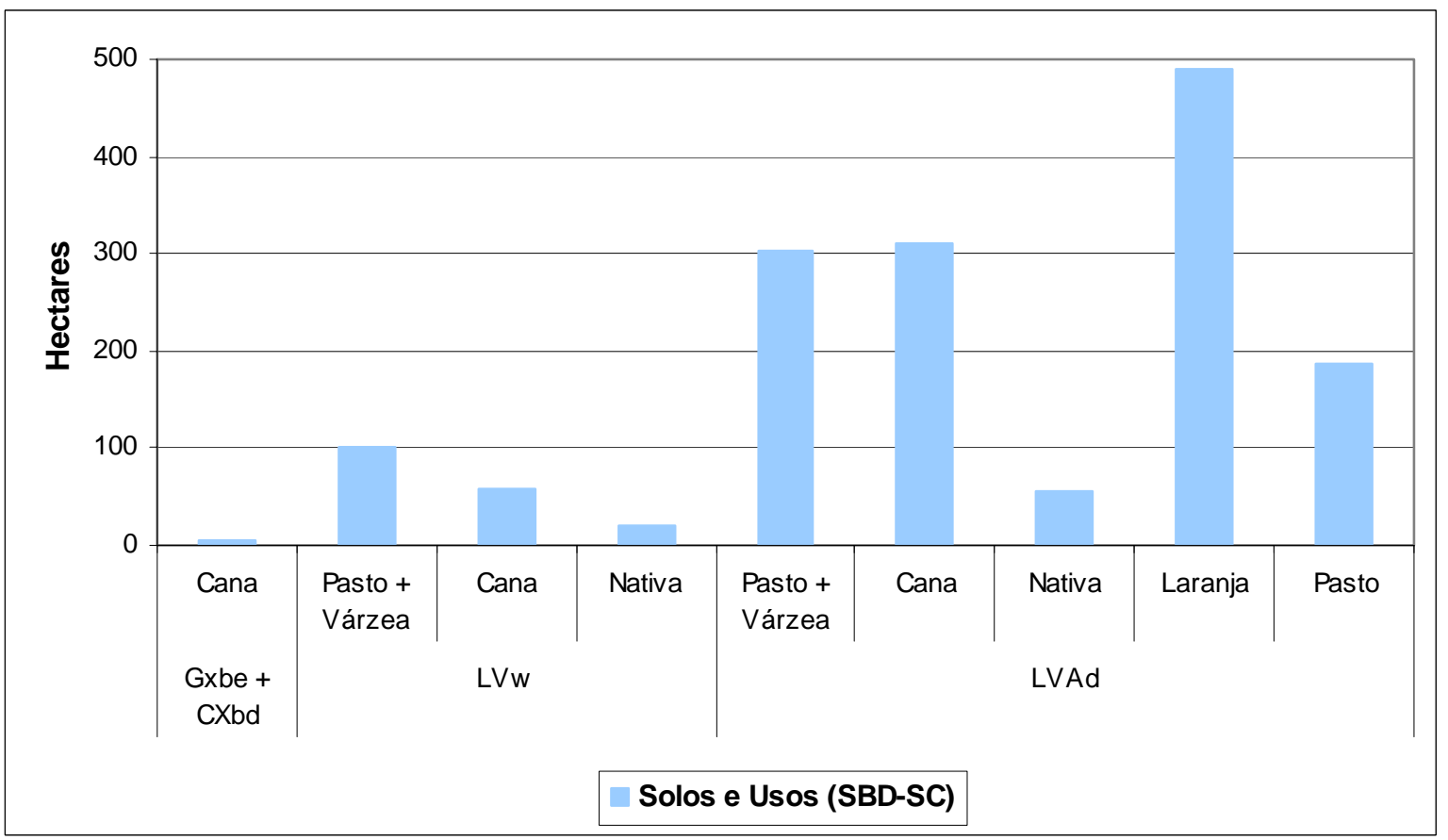

Figura 31. Cruzamento entre tipo de solo e uso do solo da Sub-bacia de Drenagem de São Carlos. 
A infra-estrutura viária da EEJ foi detalhadamente descrita por Pires et al. (2000), que estimaram a densidade dessas vias no interior da Estação Ecológica em 38 m/ha. De acordo com informações desses autores, assim como dos técnicos de campo, colaboradores do PEJ, Srs. Gonçalo Bertoloti e Horácio Gomes, essa densidade resulta da divisão da área do PEJ em talhões destinados ao manejo agroflorestal, antes da criação da Estação Ecológica de Jataí. Pode-se observar, atualmente, que parte dessas estradas, situadas no interior da EEJ, foram ou estão sendo abandonadas para que ocorra o processo de regeneração natural da vegetação.

A MBH-G apresenta uma estrada com pavimentação (SP-318, estrada que liga o município de São Carlos a Ribeirão Preto) que cruza a $\mathrm{MBH}$ na região a montante e estradas sem pavimentação que cruzam grande parte da $\mathrm{MBH}$ ligando as microbacias vizinhas e, também, a região à montante da microbacia com a baixada do rio Mogi-Guaçu. Além dessas estradas, a MBH apresenta uma extensa rede de carreadores que atravessam as diferentes culturas agrícolas que são desenvolvidas na área.

A densidade de estradas nos setores de produção agrícola da área de estudo é elevada, principalmente em função dos carreadores. Observando-se a imagem de satélite, nota-se a diferença entre esses setores e as áreas de preservação, onde estão situadas a SBH-BFJ, BD-LA e SBD-LA. Com a diminuição das vias situadas no interior da EEJ, pode-se esperar, na área de estudo, um aumento dessa diferença (densidade de estradas) entre os segmentos de produção agrícola e os demais.

As bacias de drenagem apresentam estradas sem pavimentação. Na BD-LA pode-se visualizar (Fig. 33) que parte dessas estradas estão situadas na planície de inundação do rio Mogi-Guaçu, permanecendo intransitáveis no período das cheias. Pode-se observar a menor densidade de vias na BD-LA, situada no interior na EEJ, quando comparada à BD-SC, inteiramente situada em área de produção agrícola. 


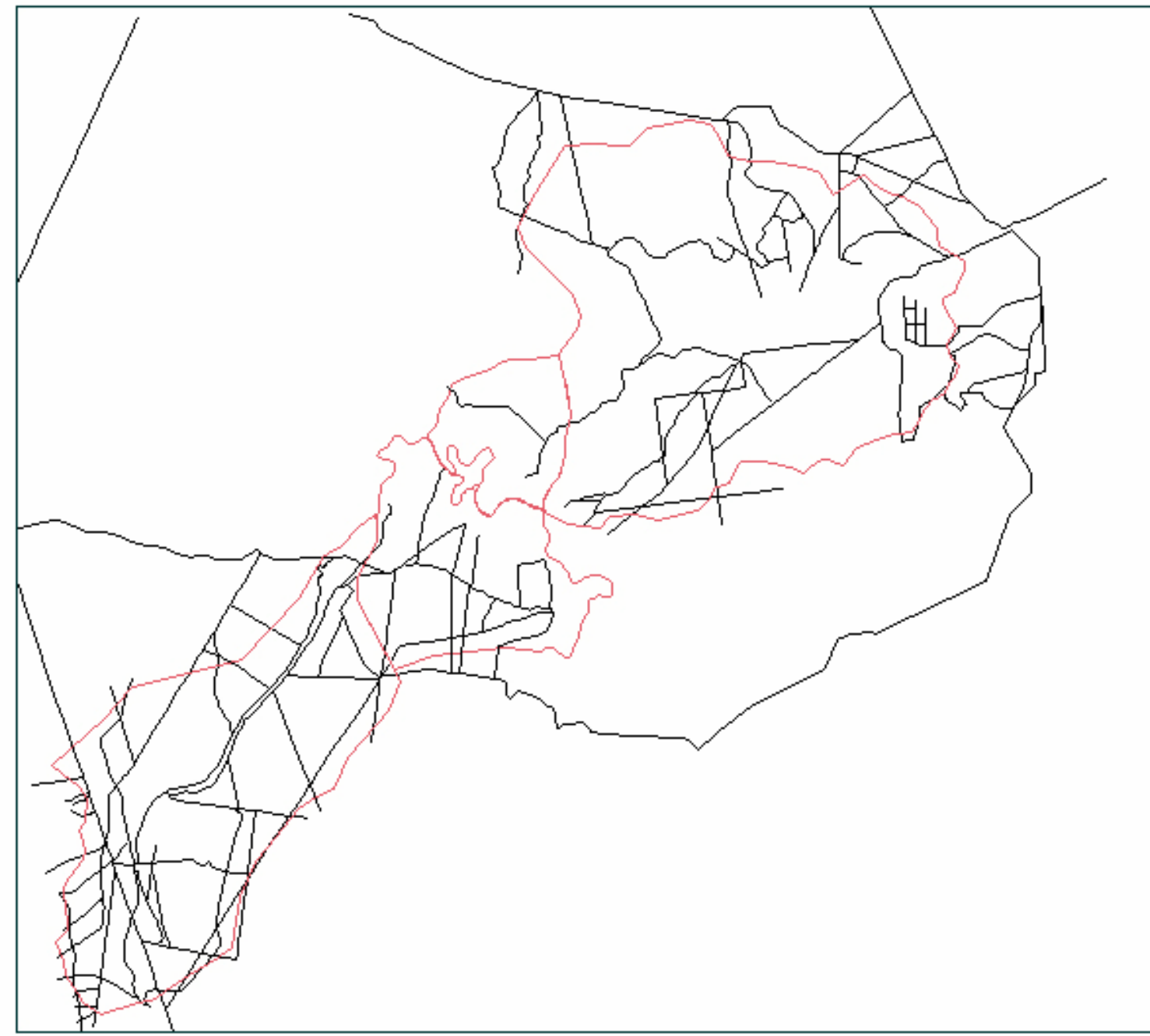

Malha Viária

da Areo de Estudo

Legenda

Malha Vírì

- Estradas

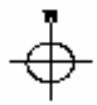

Projeçto UTM - Zona $23 \mathrm{~S}$

Dotum Horlzontal: CGTago Alegra, WC

Fonta: Base Dortogríflca (IBGE, 1971) Escala 1:50.000

Orga,: Ricardo Tezini Minoti, 2000

Escala Grórica

Figura 32. Malha viária da área de estudo. 


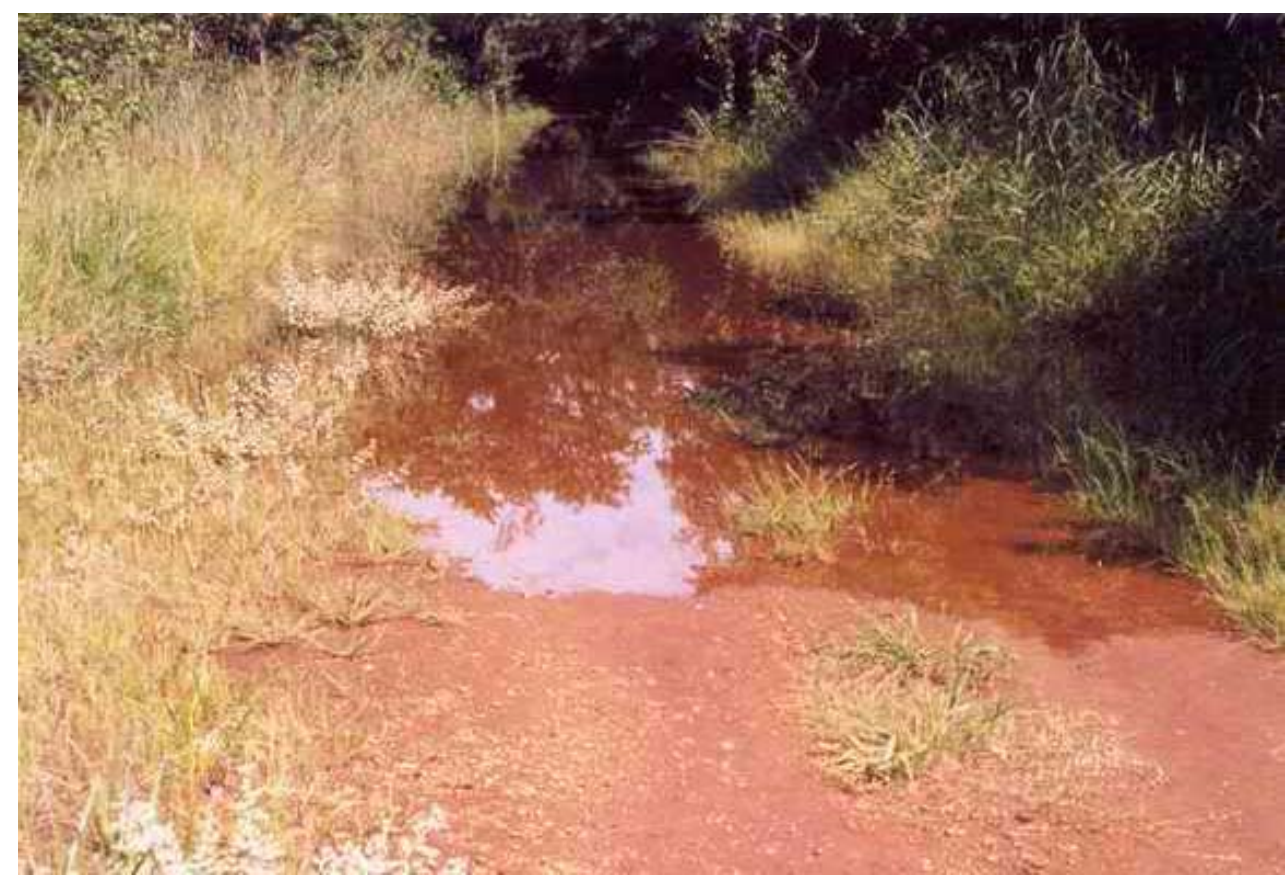

Figura 33. Estrada da microbacia hidrográfica do córrego do Beija-Flor inundada no período de cheia do rio Mogi-Guaçu.

\subsection{Fatores da Equação Universal de Perda de Solo (EUPS)}

Os valores utilizados como dados de entrada para os fatores R, K e C da EUPS, conforme foi discorrido no Capítulo 5, foram previamente estabelecidos. Apenas os valores dos fatores LS e P foram gerados pelo presente trabalho, o fator LS com a utilização do modelo USLE-2D e o fator P com equação desenvolvida por Lombardi Neto (1995). Os resultados referentes a esses dois fatores serão discutidos a seguir.

Na Tabela 27, são apresentadas as classes e respectivas faixas de amplitude do fator LS em função dos valores obtidos para a área de estudo. Com base nos resultados obtidos (Tab. 28, Fig. 34), pode-se observar que a maior parte da área (91,3\%) das unidades e subunidades de estudo está inserida nas classes 1 e 2. Observando-se o histograma apresentado na Figura 35, que apresenta a freqüência dos valores das células da imagem do fator LS, pode-se notar a predominância da primeira coluna (faixa de valores de LS entre 0 e 2,38), totalizando 590.565 células (equivalente a aproximadamente 13.290 ha). Os espaços onde foram obtidos os valores mais elevados do fator LS foram extremamente reduzidos: 27,63 hectares (1.228 células) na faixa de valores entre 50 e 100; 3,31 hectares (147 células) na faixa entre 100 e 150; e 0,67 hectares (30 células) na faixa entre 150 e 238,1.

Nos setores localizados na margem esquerda do rio Mogi-Guaçu, podem-se visualizar segmentos espalhados inseridos nas classes 3 e 4. Apenas em dois locais da MBH-G, zona de maior variação do relevo, encontram-se duas regiões contínuas inseridas na classe 4. Em uma 
dessas regiões, na região a montante da microbacia, encontra-se uma área de aproximadamente 1 hectare inserida na classe 5 (Valor máximo do Fator LS igual a 52,46).

Nos setores localizados no município de Luiz Antônio, em função da variação mais acentuada do relevo, foram obtidos os valores mais elevados do fator LS. Na SBH-BFJ, observam-se áreas inseridas nas classes de 1 a 4 . A maior parte dos segmentos inseridos na classe 4 apresentam valores do fator LS entre 10 e 20 . O valor mais alto obtido nessa subunidade de estudo foi de 42,09.

A MBH-BF apresentou os valores mais elevados do fator LS de toda a área de estudo. O mais elevado - 238,1 - foi obtido em apenas uma célula da imagem do fator LS (225 $\left.\mathrm{m}^{2}\right)$. Aproximadamente 26 ha. dessa unidade estão inseridos na faixa de valores entre 50 e 238,1.

Tabela 27: Classes do Fator LS para o presente trabalho em função dos valores obtidos na área de estudo.

\begin{tabular}{|c|c|c|}
\hline Classes & Faixa de Amplitude & Descrição do Fator LS \\
\hline 1 & 0 a 1 & Muito Baixo \\
\hline 2 & 1 a 5 & Baixo \\
\hline 3 & 5 a 10 & Moderado \\
\hline 4 & 10 a 50 & Alto \\
\hline 5 & 50 a 238 & Muito Alto \\
\hline
\end{tabular}

Tabela 28: Percentagem (\%) de área de cada classe do Fator LS para a área de estudo.

\begin{tabular}{|c|c|c|}
\hline Fator LS & Área (ha) & \% \\
\hline Classe 1 & 11549.63 & 71.0 \\
\hline Classe 2 & 3307.45 & 20.3 \\
\hline Classe 3 & 916.60 & 5.6 \\
\hline Classe 4 & 459.11 & 2.8 \\
\hline Classe 5 & 31.61 & 0.2 \\
\hline Total da área de estudo & $\mathbf{1 6 2 6 4}$ & $\mathbf{1 0 0}$ \\
\hline
\end{tabular}

Na Tabela 29, são apresentadas as classes, faixas de amplitude, área ocupada e percentagens relativas ao fator $\mathrm{P}$ em função dos valores obtidos para a área de estudo. Os resultados variaram entre 0,50 e 1,0, como pode ser visualizado na Figura 36. Entretanto, 92,7 \% da área apresentou valores entre 0,50 e 0,65 . 


\section{Fator Topografico (LS)}
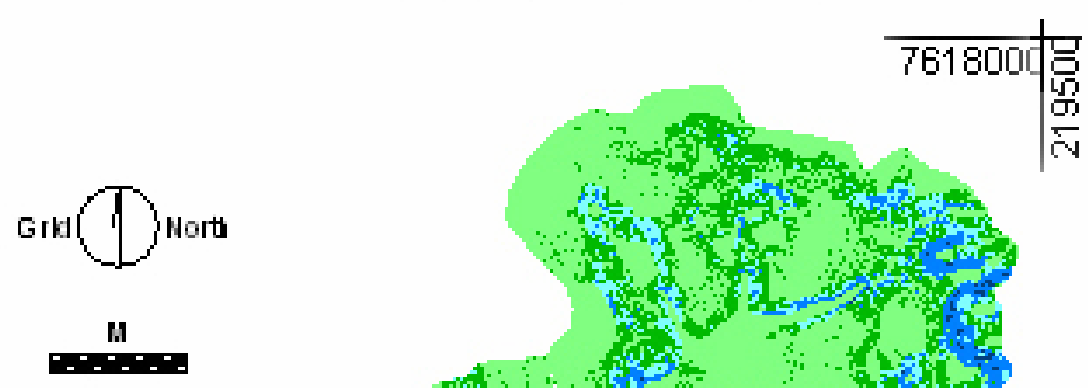

3000,00

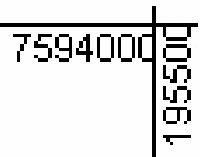

0 a 1

1 a 5

5 a 10

10 a 50

50 a 238

Projeçăo UTM - Zona 23S

Datum Horizontal: Córrego Alegre, MG

Org.: Ricardo Tezini Minoti, 2006

Figura 34: Fator topográfico (LS) da área de estudo.

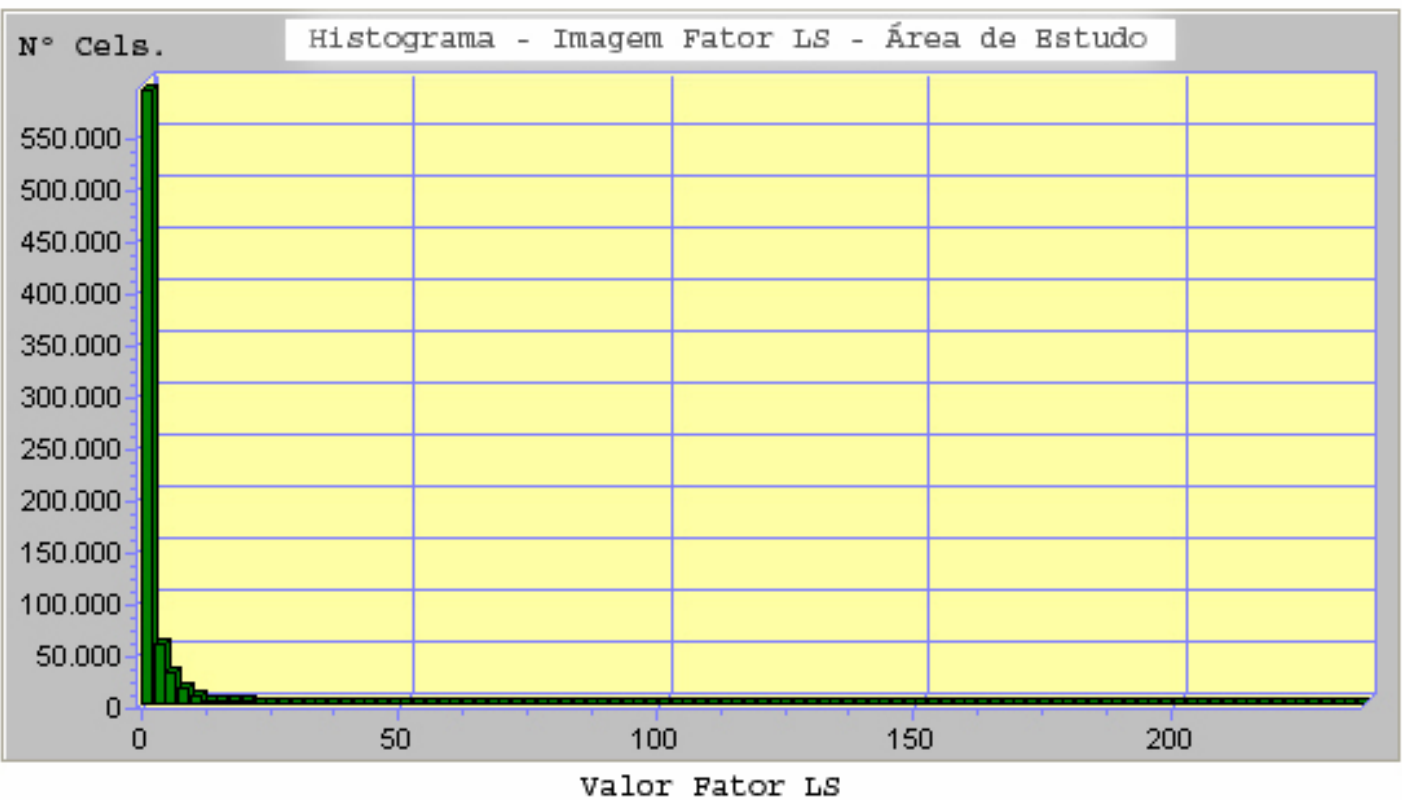

Figura 35: Fator topográfico (LS) da área de estudo. 
Tabela 29: Classes do fator P, área e respectivas percentagens (\%) para a área de estudo.

\begin{tabular}{|c|c|c|c|}
\hline Classes & Faixa de Amplitude & Área (ha) & \% \\
\hline 1 & 0.50 a 0.55 & 6457 & 39.7 \\
\hline 2 & 0.55 a 0.65 & 8621 & 53.0 \\
\hline 3 & 0.60 a 1 & 1186 & 7.3 \\
\hline \multicolumn{2}{|c|}{ Total área de estudo } & $\mathbf{1 6 2 6 4}$ & 100 \\
\hline
\end{tabular}

\section{Fator praticas Conservacionistas (P)}
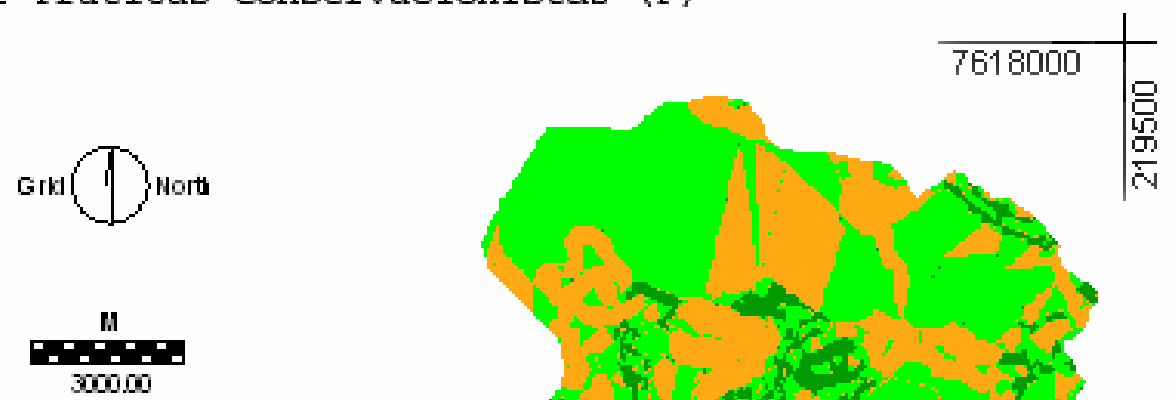

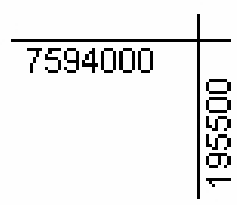

Projeçăo UTM - Zona 23 S

Datum Horizontal: Corrego Alegre, MC

Org.: Ricardo Tezini Minoti, 2006

Figura 36: Fator práticas conservacionistas (P) da área de estudo. 


\subsection{Potencial Natural de Erosão Laminar (PNE)}

Os valores de PNE, obtidos pelo produto dos fatores R, K e LS da EUPS, representam os efeitos dos fatores naturais na perda de solo por erosão superficial. As classes e respectivas faixas de amplitude de PNE foram definidas de acordo com os resultados obtidos no presente estudo e com a orientação do Dr. Francisco Lombardi Neto (comunicação pessoal). A caracterização de cada classe e os resultados obtidos para a área de estudo podem ser observados na Tabela 30.

A área de cada classe de Potencial Natural de Erosão Laminar e os valores médios e máximos para as unidades e subunidades de estudo são apresentados na Tabela 31. Vale salientar que os valores médios estão relacionados à média da área total de cada segmento, e os valores máximos estão relacionados aos dados pontuais obtidos nas células das imagens de PNE geradas no presente trabalho.

Pode-se observar que as unidades e a subunidade de estudo localizadas na margem esquerda do rio Mogi-Guaçu apresentaram valores de PNE, em geral, mais baixos do que os segmentos situados na margem direita (Fig. 37). A BD-SC e a SBD-SC apresentaram os valores mais baixos de PNE de toda a área de estudo. Os valores mais elevados, tanto o valor médio de PNE como o máximo, foram obtidos na MBH-BF.

Tabela 30. Área de cada classe (hectares) de Potencial Natural de Erosão Laminar (PNE) para a área de estudo.

\begin{tabular}{|c|c|c|c|}
\hline Classes & Faixa de Amplitude & Descrição do PNE & Área de Estudo (ha) \\
\hline 1 & $<100$ t/ha/ano & Muito Baixo & 10391 \\
\hline 2 & de 100 a 250 t/ha/ano & Baixo & 2429 \\
\hline 3 & de 250 a 500 t/ha/ano & Moderado & 1354 \\
\hline 4 & de 500 a 1000 t/ha/ano & Alto & 1151 \\
\hline 5 & igual ou > 1000 t/ha/ano & Muito Alto & 939 \\
\hline \multicolumn{3}{|r|}{ Área total } & 16264 \\
\hline
\end{tabular}

Tabela 31. Percentagem (\%) de área de cada classe de Potencial Natural de Erosão Laminar (PNE), valores médio e máximo das unidades e subunidades de estudo.

\begin{tabular}{|c|c|c|c|c|c|c|c|}
\hline $\begin{array}{c}\text { Unidades e } \\
\text { Subunidades } \\
\text { de Estudo }\end{array}$ & $\begin{array}{c}\text { Classe 1 } \\
\%\end{array}$ & $\begin{array}{c}\text { Classe 2 } \\
\%\end{array}$ & $\begin{array}{c}\text { Classe 3 } \\
\%\end{array}$ & $\begin{array}{c}\text { Classe 4 } \\
\%\end{array}$ & $\begin{array}{c}\text { Classe 5 } \\
\%\end{array}$ & $\begin{array}{c}\text { PNE Médio } \\
\text { (t/ha/ano) }\end{array}$ & $\begin{array}{c}\text { PNE Máx } \\
\text { (t/ha/ano) }\end{array}$ \\
\hline MBH-BF & 57.5 & 13.7 & 9.3 & 9.7 & 9.9 & 485.7 & 84381.5 \\
\hline SBH-BFJ & 69.1 & 12.2 & 6.4 & 6.2 & 6.1 & 222.5 & 20202.3 \\
\hline MBH-G & 62.0 & 20.6 & 9.4 & 5.7 & 2.2 & 157.9 & 6725.5 \\
\hline BD-LA & 57.0 & 15.0 & 12.5 & 10.4 & 5.1 & 211.9 & 6011.8 \\
\hline SBD-LA & 40.2 & 21.0 & 17.4 & 14.4 & 7.0 & 319.1 & 6011.8 \\
\hline BD-SC & 87.7 & 9.3 & 2.1 & 0.7 & 0.2 & 47.9 & 2407.6 \\
\hline SBD-SC & 84.0 & 12.4 & 2.7 & 0.8 & 0.1 & 57.4 & 2407.6 \\
\hline
\end{tabular}


potencial Natural de Erosāo Laminar (PNE)

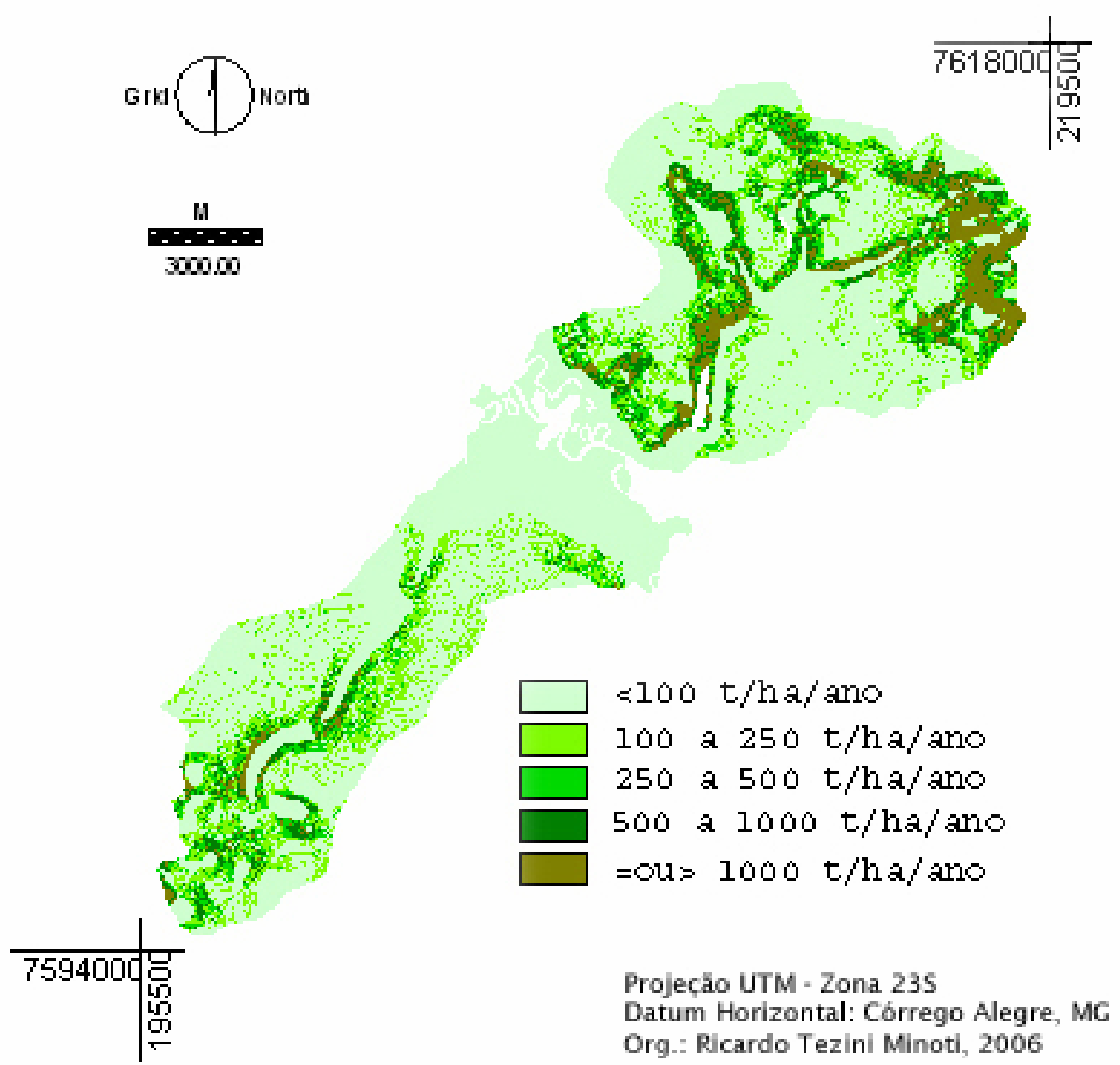

Figura 37: Potencial Natural de Erosão Laminar (PNE) da área de estudo.

\subsection{Expectativa de Risco de Erosão Laminar (ERE)}

A expectativa de risco de erosão laminar representa os possíveis riscos de sua ocorrência em função dos componentes antrópicos da EUPS, sendo obtida pela subtração dos produtos dos fatores C e P (atual e tolerável). Porém, tendo em vista que na obtenção do CP tolerável é utilizado o valor de PNE, todos os componentes (naturais e antrópicos) são considerados.

As classes de ERE e a definição das respectivas faixas de amplitude foram descritas anteriormente. As áreas referentes a cada classe para a área de estudo são apresentadas na Tabela 32. Vale ressaltar que os valores negativos de ERE indicam que o uso atual não está induzindo a perdas de solo acima do tolerável e, dessa forma, a ocupação do solo está condizente com a capacidade de uso das terras. 
Observando-se os valores de percentagem de área da classe 1 das unidades e subunidades de estudo (Tabela 33), pode-se inferir que na maior parte das terras a expectativa de risco de erosão é nula. A SBH-BFJ, BD-LA e SBD-LA, inteiramente ocupadas por vegetação natural, apresentaram, praticamente, $100 \%$ das áreas na classe 1 . Os resultados evidenciaram que as unidades que apresentaram maior quantidade de áreas nas classes de valores mais elevados de ERE foram a MBH-G e a MBH-BF (Fig. 38).

\subsection{Perda de Solo por Erosão Laminar (A)}

As classes de perda de solo por erosão laminar $(\underline{A})$ e a definição das respectivas faixas de amplitude foram descritas anteriormente. As áreas referentes a cada classe para a área de estudo são apresentadas na Tabela 34. A área de cada classe de $\underline{A}$, os valores médios e máximos (t/ha/ano) e a perda total de solo (t/ano) para as unidades e subunidades de estudo são apresentados na Tabela 35. Os resultados obtidos no presente trabalho pela aplicação da EUPS podem ser visualizados na Figura 39.

Os valores mais elevados de perda de solo por erosão laminar foram observados na MBHBF. Essa unidade de estudo, apesar de conter 36\% de área ocupada por vegetação natural, apresenta uma região com variação mais acentuada do relevo submetida à ocupação por eucalipto, pinus e cana-de-açúcar. Na MBH-G, ocupada por culturas agrícolas, os resultados de perda média e perda máxima foram bem mais baixos do que na MBH-BF.

Pode-se observar que a SBH-BFJ, BD-LA e SBD-LA, apresentaram $100 \%$ das áreas na classe 1 e valores médios e máximos de $\underline{\mathrm{A}}$, assim como os resultados de perda total de solo, extremamente baixos. A BD-SC e SBD-SC apresentaram valores acima de $90 \%$ na classe 1.

Elaborou-se um gradiente de classificação em relação aos valores médios de $\underline{A}$ - média da área total de cada segmento (Tabela 36). O gradiente evidenciou que as bacias e a sub-bacia, localizadas na margem direita do rio Mogi-Guaçu, ocupadas por vegetação natural, apresentaram valores de A mais baixos de toda a área de estudo. A BD-SC e a SBD-SC, bacias agrícolas, apresentaram valores intermediários, e a MBH-G e MBH-BF, valores mais elevados. 
Tabela 32: Área de cada classe (hectares) de Expectativa de Risco de Erosão Laminar (ERE) para a área de estudo.

\begin{tabular}{|c|c|c|c|}
\hline Classes & Faixa de Amplitude & $\begin{array}{c}\text { Descrição da } \\
\text { ERE }\end{array}$ & Área de Estudo (ha) \\
\hline 1 & $<0$ & Ausente & 13717 \\
\hline 2 & 0 a 0.05 & Baixa & 2173 \\
\hline 3 & 0.05 a 0.10 & Moderada & 372 \\
\hline 4 & igual ou $>0.10$ & Alta & 2 \\
\hline \multicolumn{2}{r}{} & Área total & 16264 \\
\hline
\end{tabular}

Expectativa de Risco de Erosāo (ERE)

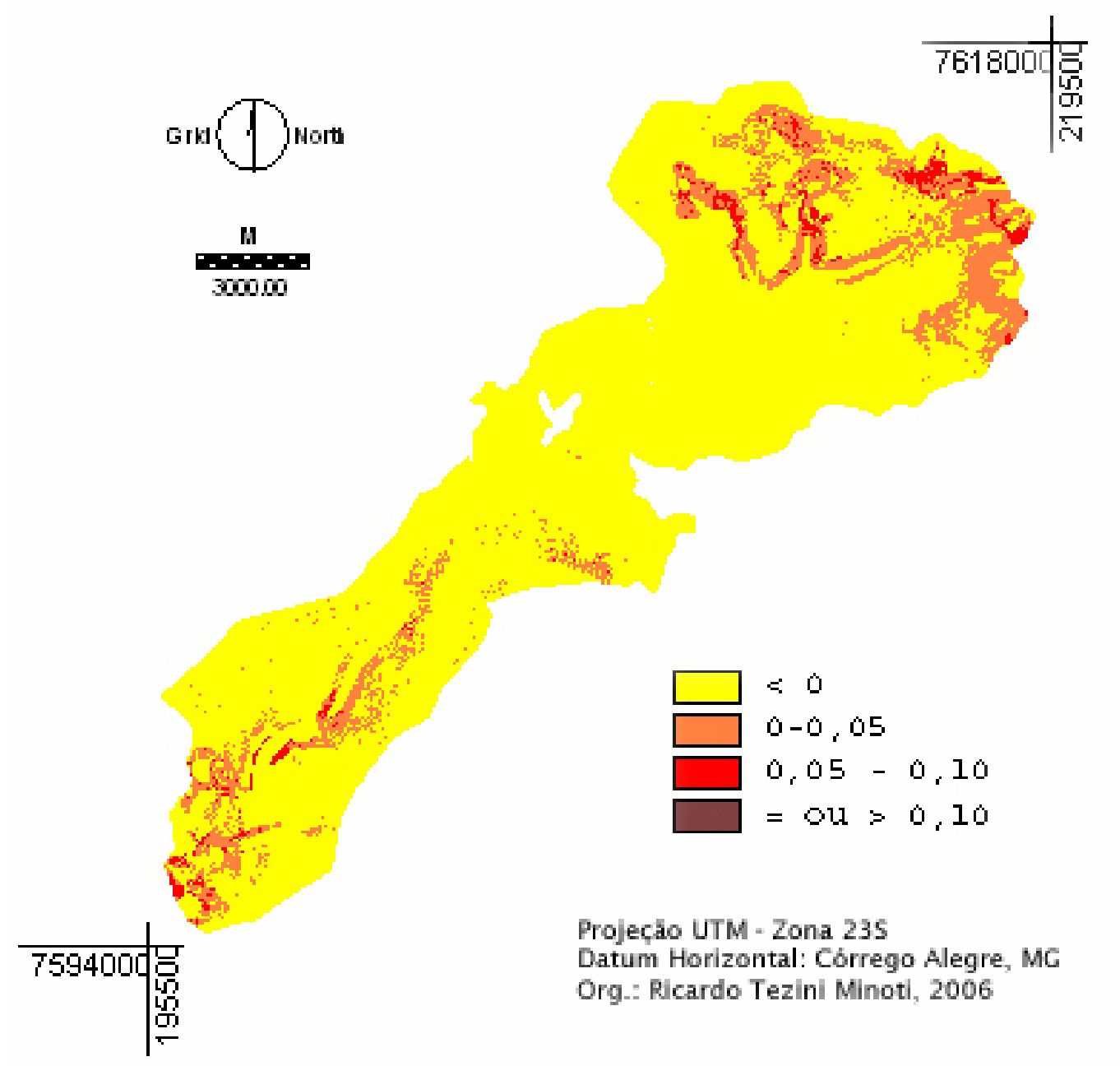

Figura 38: Expectativa de risco de erosão laminar (ERE) da área de estudo. 
Tabela 33. Percentagem (\%) de área de cada classe de Expectativa de Risco de Erosão Laminar (ERE) das unidades e subunidades de estudo.

\begin{tabular}{|c|c|c|c|c|}
\hline $\begin{array}{c}\text { Unidades e } \\
\text { Subunidades de } \\
\text { Estudo }\end{array}$ & $\begin{array}{c}\text { Classe 1 } \\
\text { \% }\end{array}$ & $\begin{array}{c}\text { Classe 2 } \\
\text { \% }\end{array}$ & $\begin{array}{c}\text { Classe 3 } \\
\%\end{array}$ & $\begin{array}{c}\text { Classe 4 } \\
\%\end{array}$ \\
\hline MBH-BF & 78.4 & 18.4 & 3.2 & 0 \\
\hline SBH-BFJ & 100 & 0 & 0 & 0 \\
\hline MBH-G & 85.6 & 12.2 & 2.2 & 0 \\
\hline BD-LA & 99.9 & 0.1 & 0 & 0 \\
\hline SBD-LA & 100 & 0 & 0 & 0 \\
\hline BD-SC & 96.6 & 3.5 & 0.2 & 0 \\
\hline SBD-SC & 94.8 & 5 & 0.2 & 0 \\
\hline
\end{tabular}

Tabela 34. Área de cada classe (hectares) de Perda de Solo por Erosão Laminar (A) para a área de estudo.

\begin{tabular}{|c|c|c|c|}
\hline Classes & Faixa de Amplitude & Descrição da Perda de Solo & Área de Estudo (ha) \\
\hline 1 & $<10 \mathrm{t} / \mathrm{ha} / \mathrm{ano}$ & Muito Baixa & 13179 \\
\hline 2 & de 10 a 20 t/ha/ano & Baixa & 1185 \\
\hline 3 & de 20 a 50 t/ha/ano & Moderada & 1138 \\
\hline 4 & de 50 a 100 t/ha/ano & Alta & 479 \\
\hline 5 & igual ou $>100 \mathrm{t} / \mathrm{ha} / \mathrm{ano}$ & Muito Alta & 283 \\
\hline \multicolumn{3}{|r|}{ Área total } & 16264 \\
\hline
\end{tabular}

Tabela 35. Percentagem (\%) de área de cada classe de Perda de Solo por Erosão Laminar (A), valores médio e máximo das unidades e subunidades de estudo.

\begin{tabular}{|c|c|c|c|c|c|c|c|c|}
\hline $\begin{array}{c}\text { Unidades e } \\
\text { Subunidades } \\
\text { de Estudo }\end{array}$ & $\begin{array}{c}\text { Classe } \\
\mathbf{1} \\
\mathbf{\%}\end{array}$ & $\begin{array}{c}\text { Classe } \\
\mathbf{2} \\
\mathbf{\%}\end{array}$ & $\begin{array}{c}\text { Classe } \\
\mathbf{3} \\
\mathbf{\%}\end{array}$ & $\begin{array}{c}\text { Classe } \\
\mathbf{4} \\
\mathbf{\%}\end{array}$ & $\begin{array}{c}\text { Classe } \\
\mathbf{5} \\
\mathbf{\%}\end{array}$ & $\begin{array}{c}\text { Perda } \\
\text { Média (A) } \\
\text { (t/ha.ano) }\end{array}$ & $\begin{array}{c}\text { Perda } \\
\text { Máxima (A) } \\
\text { (t/ha.ano) }\end{array}$ & $\begin{array}{c}\text { Perda } \\
\text { Total } \\
\text { (t/ano) }\end{array}$ \\
\hline MBH-BF & 75.7 & 7 & 9.5 & 4.5 & 3.3 & 16.00 & 2538.4 & 127723 \\
\hline SBH-BFJ & 100 & 0 & 0 & 0 & 0 & 0.05 & 10.5 & 142 \\
\hline MBH-G & 79.4 & 10.6 & 7.1 & 2.4 & 0.4 & 7.77 & 450.9 & 39977 \\
\hline BD-LA & 100 & 0 & 0 & 0 & 0 & 0.05 & 1.3 & 48 \\
\hline SBD-LA & 100 & 0 & 0 & 0 & 0 & 0.07 & 1.3 & 47 \\
\hline BD-SC & 93.3 & 4.9 & 1.6 & 0.2 & 0 & 2.40 & 138.5 & 5221 \\
\hline SBD-SC & 90.8 & 6.7 & 2.2 & 0.3 & 0 & 3.38 & 138.5 & 5158 \\
\hline
\end{tabular}




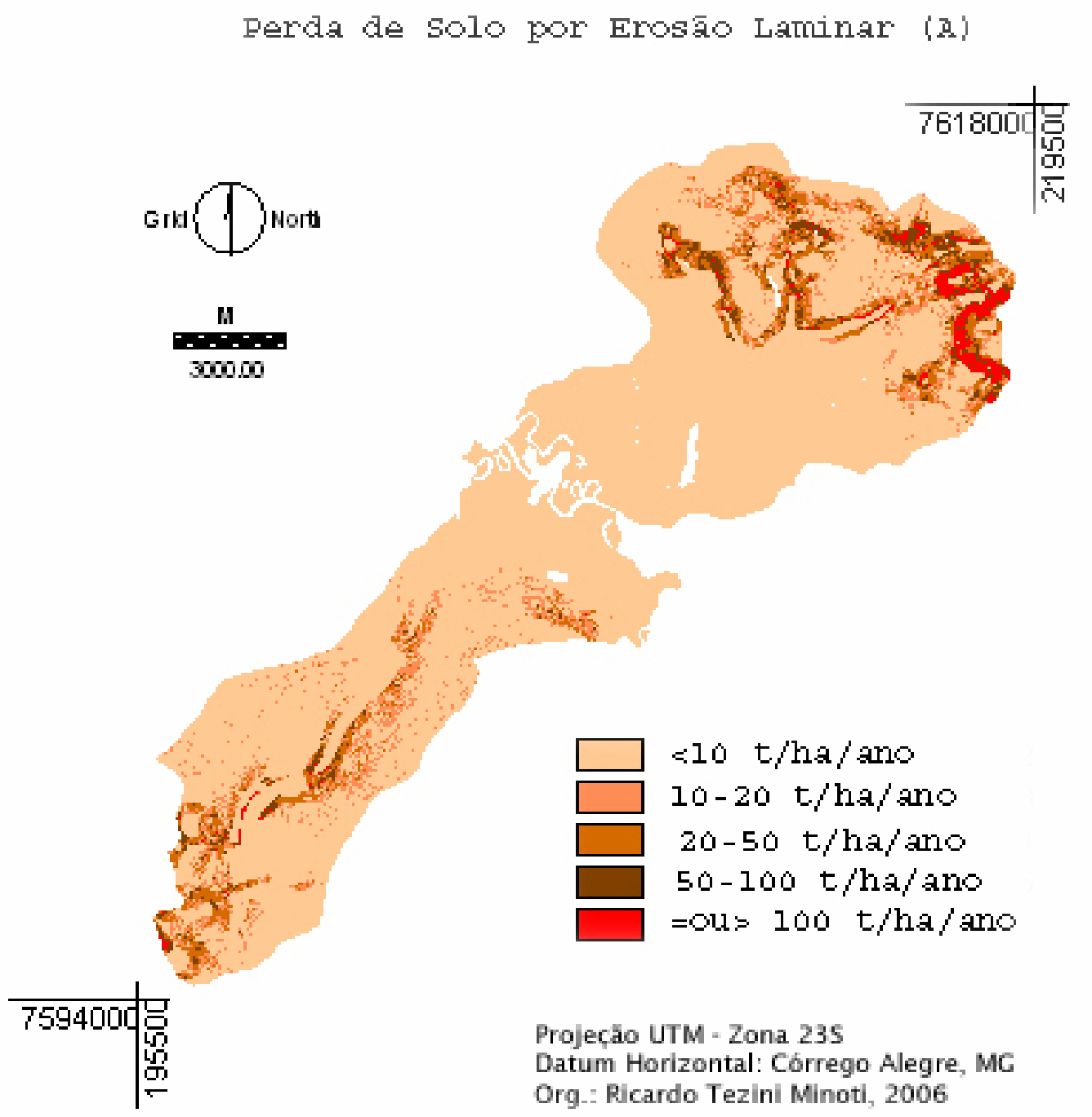

Figura 39: Perda de solo por erosão laminar (A) da área de estudo.

\subsection{Potencial de Risco de Erosão Laminar}

Tendo em vista que a perda média de solo da MBH-BF, 16 t/ha/ano, foi $6 \%$ maior do que o valor mais elevado de limite de tolerância de erosão para os solos da área de estudo, poder-seia inferir que essa microbacia é a unidade de estudo que apresenta maior vulnerabilidade em relação aos processos erosivos. Entretanto, a determinação do potencial de risco de erosão laminar (PRE) é realizada com o objetivo de analisar, de maneira quantitativa, em cada tipo de solo das bacias e sub-bacias em estudo, em que locais o risco é elevado e, conseqüentemente, a vulnerabilidade em função dos processos erosivos é maior. 
Tabela 36. Representação do gradiente de classificação das unidades e subunidades de estudo de acordo com os maiores valores médios de perda de solo.

\begin{tabular}{|c|c|c|c|}
\hline Gradiente & Unidades e Subunidades & A (t/ha/ano) & \multirow{2}{*}{ A $>$} \\
\hline $1^{\circ}$ & MBH-BF & 16,00 & \\
\hline $2^{\circ}$ & MBH-G & 7,77 & \\
\hline $3^{\circ}$ & SBD-SC & 3,38 & \\
\hline $4^{0}$ & BD-SC & 2,40 & \multirow{2}{*}{ A $<$} \\
\hline $5^{\circ}$ & SBD-LA & 0,07 & \\
\hline $6^{\circ}$ & SBH-BFJ & 0,05 & \\
\hline $7^{\circ}$ & BD-LA & $\mathbf{0 , 0 5}$ & \\
\hline
\end{tabular}

As classes de potencial de risco de erosão laminar (PRE) e a definição das respectivas faixas de amplitude foram descritas anteriormente. As áreas referentes a cada classe para a área de estudo são apresentadas na Tabela 37. As percentagens das áreas ocupadas pelas classes de PRE para as unidades e subunidades de estudo são apresentadas na Tabela 38 e podem ser visualizadas na Figura 40.

Tendo em vista que o valor médio de perda de solo na MBH-BF insere-se na classe 2 do potencial de risco de erosão laminar, poder-se-ia sugerir, apenas, a adoção de práticas conservacionistas nessa unidade de estudo para diminuição do risco. No entanto, tanto nessa microbacia como na MBH-G, foram obtidos, em determinadas regiões, valores pontuais de $\underline{A}$ muito elevados, que se inserem nas classes 3, 4 e 5 . Nesses pontos específicos, torna-se necessária uma análise mais detalhada nesses locais para avaliar a possibilidade de adoção de práticas conservacionistas, mudança no manejo ou, até mesmo, a necessidade de mudança na ocupação do solo.

Nas demais unidades e subunidades de estudo, apenas a BD-SC e SBD-SC apresentam regiões com valores de perda de solo que se inserem nas classes 2, 3 e 4. A SBH-BFJ, BD-LA e SBD-LA apresentaram valores baixos de perda de solo por erosão laminar (Classe 1). 
Tabela 37. Área de cada classe (hectares) de Potencial de Risco de Erosão Laminar (PRE) para a área de estudo.

\begin{tabular}{|c|c|c|c|}
\hline Classes & Faixa de Amplitude & Descrição Potencial de Risco & Área de Estudo (ha) \\
\hline 1 & $<1 \times$ tolerância & Risco Nulo & 13723 \\
\hline 2 & 1 a $2 \times$ tolerância & Baixo & 998 \\
\hline 3 & 2 a $5 \times$ tolerância & Moderado & 989 \\
\hline 4 & 5 a $10 \times$ tolerância & Alto & 310 \\
\hline 5 & $>10 \times$ tolerância & Muito Alto & 243 \\
\hline \multicolumn{3}{|r}{ Área total } & 16264 \\
\hline
\end{tabular}

Tabela 38. Percentagem (\%) de área de cada classe de Potencial de Risco de Erosão Laminar (PRE) das unidades e subunidades de estudo.

\begin{tabular}{|c|c|c|c|c|c|}
\hline $\begin{array}{c}\text { Unidades e } \\
\text { Subunidades de } \\
\text { Estudo }\end{array}$ & $\begin{array}{c}\text { Classe } \\
1\end{array}$ & $\begin{array}{c}\text { Classe } \\
2\end{array}$ & $\begin{array}{c}\text { Classe } \\
3\end{array}$ & $\begin{array}{c}\text { Classe } \\
4\end{array}$ & $\begin{array}{c}\text { Classe } \\
5 \\
\%\end{array}$ \\
\hline MBH-BF & 78.2 & 6.9 & 8.8 & 3.2 & 3 \\
\hline SBH-BFJ & 100 & 0 & 0 & 0 & 0 \\
\hline MBH-G & 85.1 & 7.9 & 5.7 & 1.09 & 0.2 \\
\hline BD-LA & 100 & 0 & 0 & 0 & 0 \\
\hline SBD-LA & 100 & 0 & 0 & 0 & 0 \\
\hline BD-SC & 96.1 & 3 & 0.9 & 0 & 0 \\
\hline SBD-SC & 94.7 & 4 & 1.2 & 0.1 & 0 \\
\hline
\end{tabular}

Pela junção de algumas classes de risco de erosão de solos, Lagrotti (2000) enquadrou os valores obtidos em três categorias de risco ambiental:

- Baixo Risco Ambiental - classe de risco ambiental muito baixa ou nula;

- Moderado Risco Ambiental - classes de risco de erosão baixa e moderada;

- Alto Risco Ambiental - classes de risco de erosão alta e muito alta.

Os segmentos que apresentaram baixo risco ambiental corresponderam às áreas da SBHBFJ e BD-LA, totalmente ocupadas por vegetação natural (área de abrangência da EEJ), a grande parte da BD-SC, devido provavelmente ao relevo plano, e uma parte das áreas da $\mathrm{MBH}-\mathrm{BF}$ e MBH-G.

Os setores de moderado risco ambiental corresponderam às áreas com variação de relevo, principalmente suave ondulado ou moderadamente ondulado, encontradas na MBH-BF, MBH-G e BD-SC.

As áreas de alto risco ambiental foram identificadas nas regiões de relevo ondulado, forte ondulado e montanhoso localizadas da MBH-BF (aproximadamente 488 hectares), ocupadas com cana-de-açúcar, pinus e eucalipto e nas regiões de relevo moderadamente ondulado, 
ondulado e fortemente ondulado da MBH-G (aproximadamente 65 hectares), ocupada principalmente com cana-de-açúcar.

potencial de Risco de Erosāo Laminar
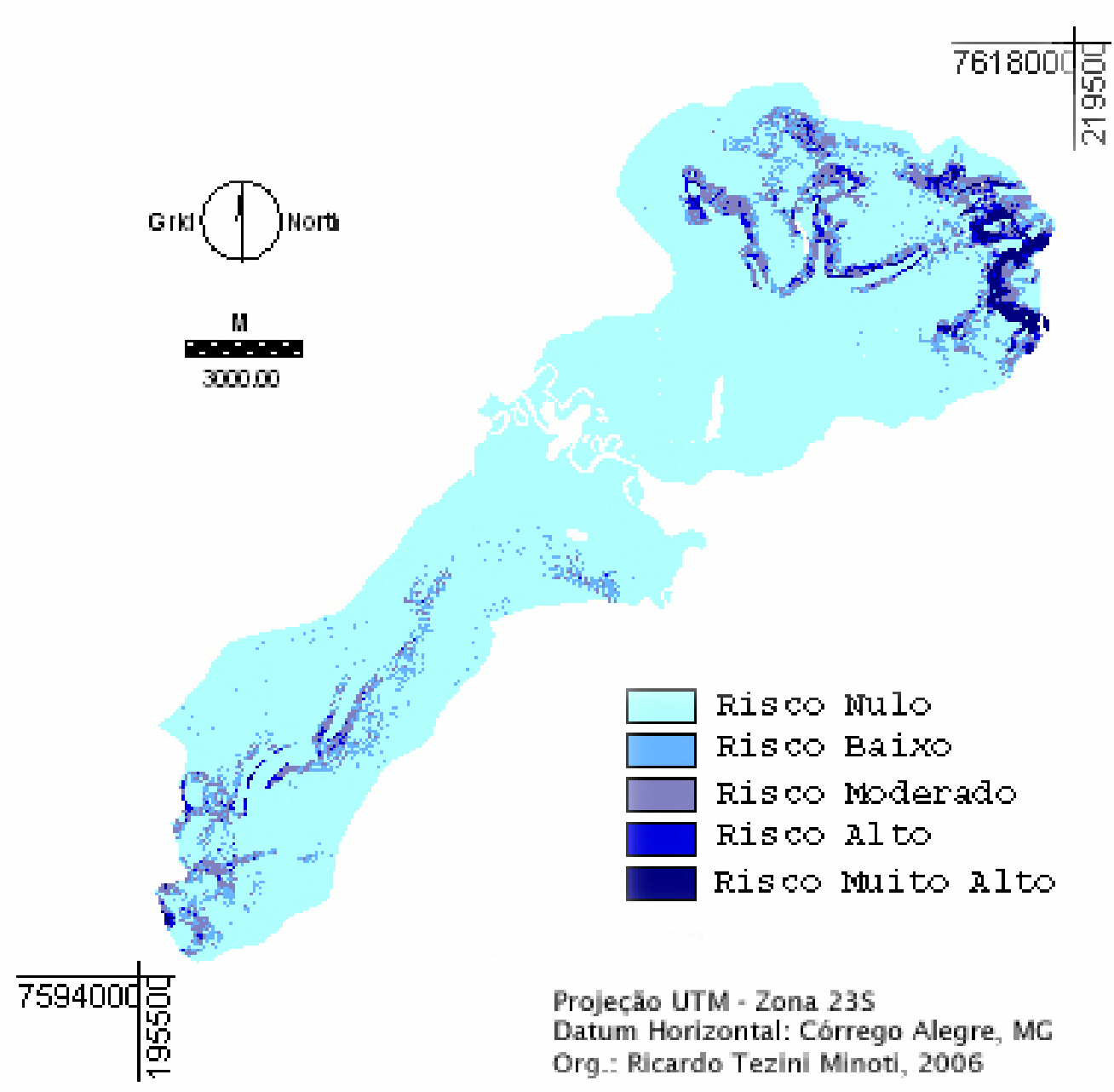

Figura 40: Potencial de risco de erosão laminar da área de estudo.

\subsection{Análise da aplicação da EUPS na área de estudo}

Complementando a discussão relacionada à aplicação da EUPS nas unidades e subunidades de estudo, vale enfatizar alguns aspectos relativos aos benefícios e, também, a possíveis dificuldades decorrentes da utilização desse modelo na previsão da erosão.

Ranieri et al. (1997) identificaram possíveis fontes de erro ocorridas na obtenção dos mapas finais de risco à erosão pela aplicação da EUPS como o critério utilizado para a 
transformação de dados quantitativos de perda de solo em classes de risco de erosão, a utilização da EUPS em bacia hidrográfica e não em glebas homogêneas, os possíveis erros no cálculo do comprimento de rampa, e a escassez de trabalhos desenvolvidos com o intuito de testar e aprimorar o método.

Lin et al. (2002) afirmaram que, ao utilizar a EUPS associada a SIG, pode-se gerar superestimativas de erosão em bacias hidrográficas, ocasionadas por falhas na determinação dos parâmetros da equação.

Em relação ao Fator R, a distribuição da precipitação ao longo do ano, observada nos dados de entrada utilizados na aplicação do modelo SWAT, indicou que ocorre uma concentração do potencial erosivo na estação chuvosa, entre os meses de outubro e março, época em que o valor de erosividade deve ser mais elevado. Essa variação temporal, mensal ou sazonal, não foi considerada pela EUPS, tendo em vista que esse modelo utiliza o valor total anual de erosividade. Entretanto, como a equação foi desenvolvida para a elaboração de estimativas anuais de perda de solo, era esperado que os resultados fossem produzidos nessa escala temporal.

Pesquisas mostram que eventos climáticos extremos são mais importantes do que a média de perda de solo anual (Haregeweyn e Yohannes, 2003). Talvez, em relação à cana-de-açúcar, por exemplo, seria interessante utilizar modelos relacionados a eventos como o AGNPS na época de maior precipitação. Tais modelos poderiam ser aplicados na comparação dos processos erosivos em períodos variados, entre os quais, o período em que o solo está descoberto (entressafra).

Na aplicação da EUPS, o valor do Fator C diminuiu abruptamente nos locais de transição de áreas agrícolas para áreas de mata, reduzindo bruscamente as perdas de solo. Talvez fosse necessária a utilização de um fator de correção na aplicação desse modelo, em áreas de transição, para que os impactos dos processos erosivos nos solos a montante da EEJ e a conseqüente produção de sedimentos, um tipo de efeito “borda”, pudessem ser considerados.

Comparando com a EUPS, Ranieri (2000) constatou que, ao utilizar o modelo WEPP na predição da erosão, a diminuição abrupta do Fator C não ocorre. Ao atingir as áreas de mata, com conseqüente alteração do elemento de fluxo, o WEPP considera a enxurrada advinda das áreas de mata morro acima, o que faz as perdas no início das áreas de mata não serem reduzidas tão rapidamente como no caso da EUPS. Assim, os valores de perda média para o WEPP foram mais elevados do que os estimados pela EUPS.

Conforme foi averiguado por Mati et al. (2000), o fator uso e manejo do solo teve influência marcante, em condições variadas, nos resultados finais da EUPS. Em regiões que apresentaram mais de $70 \%$ da área coberta por vegetação, as taxas previstas de perda de solo 
foram menores do que 1,0 t/ha.ano. Os riscos foram baixos nessas áreas mesmo em locais com elevados valores de erosividade e erodibilidade. A topografia foi considerada um fator secundário, mesmo em áreas com declives acentuados, em locais cobertos por florestas naturais. Entretanto, os riscos foram elevados em áreas que apresentaram terras cultivadas. Observações de campo mostraram que os maiores estragos foram observados em locais onde havia sinais de erosão em sulcos.

Um dos parâmetros mais críticos na aplicação da EUPS é o fator LS. De acordo com Lin et al. (2002), a estimação do fator L para uma bacia hidrográfica apresenta o problema de sua determinação para paisagens reais e complexas no ambiente SIG.

O fator grau do declive e comprimento de rampa (LS) foi o condicionante de maior influência nos resultados finais da EUPS, no presente trabalho. Resultados semelhantes foram obtidos por Özhan et al. (2005), ao estudarem duas bacias hidrográficas experimentais cobertas por florestas na Turquia. Os resultados do trabalho desses autores indicaram que, mesmo sob idênticas condições de uso do solo e manejo, os valores das suas perdas anuais variaram em função do grau e comprimento das vertentes.

Ao comparar dois métodos para determinação do fator LS, um método manual adaptado ao SIG (Rocha et al. 1997) e um método automatizado (USLE-2D), Fujihara (2002) constatou que a determinação automatizada apresentou valores muito superiores aos obtidos pelo método manual (SIG), ocasionados, principalmente, pelo algoritmo utilizado, específico para identificar áreas com risco de erosão em sulco. Segundo o autor, a distribuição dos valores de LS apresenta uma tendência de aumentar no sentido do topo até a vertente de cada setor, encontrando-se valores altos nos locais em que há concentração do escoamento superficial. Isso decorre da utilização do conceito de área de contribuição no algoritmo do programa USLE-2D. Partindo-se dessa premissa, o método manual subestima os valores de LS e, conseqüentemente, de risco de erosão quando comparado com o método automatizado.

Um outro benefício da utilização do cálculo automatizado para a determinação do Fator LS é que os procedimentos são simplificados acarretando a simplificação do processo de aplicação da EUPS, tornando a utilização desse modelo, além de interessante, mais facilitada.

O fator LS ainda precisa ser testado sob diferentes métodos de determinação, de maneira padrão, sob diferentes relevos para que seja realizada uma análise mais apurada dos erros e acertos em diferentes escalas e seja determinado o grau de acuracidade na determinação desse fator em Sistemas de Informações Geográficas. 
Outro aspecto que deve ser ressaltado refere-se às áreas onde estão localizados os carreadores e as estradas rurais. Como foi visto anteriormente na discussão dos resultados (MBH-BF e MBH-G), os riscos ambientais relacionados aos processos erosivos, identificados visualmente nas microbacias, como erosão laminar ou em sulco nos carreadores rurais ou formação de canais de escoadouro de água e sedimentos, não foram considerados nas estimativas dos processos erosivos, obtidos pela aplicação da EUPS.

Esses fatores poderiam interferir nos valores dos componentes LS e P, em função da ausência de terraços (camaleões) e outras práticas conservacionistas e da conseqüente formação de rampa no sentido morro abaixo. Dessa forma, os valores da EUPS poderiam ser um pouco mais elevados. Deve-se salientar, no entanto, como um fator complicador à quantificação da erosão nas microbacias mencionadas, que nem todos os carreadores ou estradas rurais apresentaram má conservação do solo ou sinais de erosão.

Os valores do fator LS, no presente estudo, tiveram influência direta nas estimativas dos valores de PNE, ERE, $\underline{A}$ e PRE. Fujihara (2002) considerou aceitável a variação do LS gerado pelo método automatizado USLE-2D e analisou a influência dos valores desse fator na variação dos valores de potencial natural de erosão (PNE) para os solos da microbacia hidrográfica do Ribeirão Itambi, municípios de Ouro Verde e Panorama (SP). O autor concluiu que, pelo fato de a equação ser multiplicativa, os valores de PNE tiveram uma variação diretamente proporcional ao aumento do LS. O autor obteve maior valor de PNE (168.790) nas condições onde o LS atingiu o valor de 782 .

De maneira semelhante aos resultados obtidos por Fujihara (2002), o maior valor de PNE do presente trabalho, 84.381, foi obtido na MBH-BF, unidade onde foi observado o maior valor de LS, 238. De forma inversa, o valor mais baixo de PNE, em toda a área de estudo, foi referente à BD-SC, unidade onde se verificou o menor valor de LS, 14,7.

Em relação ao diagnóstico de risco de erosão pela aplicação da EUPS, a área de estudo apresentou locais com perda de solo de até 200 vezes acima do limite tolerado, mas esse resultado está restrito a uma área inferior a 1 hectare na MBH-BF. Pelas estimativas de erosão para a área de estudo, aproximadamente 1000 hectares, localizados nas unidades de estudo MBH-BF, MBH-G e BD-SC, são áreas que apresentam risco moderado, devendo ser monitoradas para a avaliação das práticas conservacionistas em uso, estando sujeitas a alguma alteração no manejo. Outros 310 hectares, localizados nas unidades MBH-BF e MBH-G, áreas com risco alto de erosão, devem ser monitorados estando sujeitos a mudanças no manejo ou no uso do solo. Por último, aproximadamente 250 hectares da MBH-BF devem ser avaliados de maneira mais aprofundada para possível mudança no uso do solo. 
Vale ressaltar, no entanto, que os picos de A, tanto na MBH-BF (2.538 ton/ha.ano) como na MBH-G (450 ton/ha.ano), e conseqüentemente os valores mais elevados obtidos de PRE, estão relacionados aos elevados valores obtidos para o fator LS em algumas regiões dessas unidades de estudo. Tendo em vista que foi utilizado método automatizado (Modelo USLE-2D), não foi possível realizar correção manual desse fator.

Seria interessante, na seqüência do trabalho de pesquisa, ou no desenvolvimento de processo de gestão ambiental para a área de estudo, uma averiguação mais detalhada de tais áreas, talvez uma simulação com o uso de escala maior, levantamento de cotas altimétricas com o uso de equipamentos de precisão, para averiguar a criticidade dos processos erosivos que vêm ocorrendo e a necessidade de adoção de medidas de conservação do solo eficazes ou, até mesmo, mudança na sua ocupação, tendo em vista o desenvolvimento rural sustentável de tais áreas.

Um outro aspecto relacionado ao cálculo de alguns dos parâmetros gerados com os resultados da EUPS é que tais elementos, como o ERE e o PRE, foram calculados com os valores de limite de tolerância à erosão do solo. Esses valores, nos diferentes solos, foram desenvolvidos com um enfoque agronômico, em função, exclusivamente, da manutenção da capacidade produtiva do solo. Além disso, a EUPS não prevê o transporte ou a deposição de sedimentos e as perdas de água; os resultados apenas prevêem a susceptibilidade à perda de solo nas áreas onde é aplicada.

Dessa forma, excluindo-se a perda do recurso solo por erosão, os demais impactos ambientais do processo são desconsiderados. Fatores relacionados aos impactos da perda de solo por erosão nos diversos ambientes não são contemplados pela equação.

No que se refere à escala espacial, Molnár \& Julien (1998) determinaram fatores de correção para a utilização da EUPS em células com tamanhos maiores do que 30x30m. No presente trabalho, a escala da base de dados foi de 1:50.000 (células de 500x500m) e a escala de processamento foi baseada em células de $15 \times 15 \mathrm{~m}$. O tamanho elevado das células da base de dados, com conseqüente diminuição dos valores de declividade para células individuais, pode ter levado a uma subestimação da perda de solo.

No entanto, conforme foi observado por Ranieri et al. (1997) na utilização da EUPS para avaliação do risco à erosão, não houve grande diferença nos mapas de risco de erosão pela alteração das escalas detalhada e generalizada.

Em relação aos movimentos de massa, tendo em vista que nos levantamentos de campo não foi observada nenhuma ocorrência de processos erosivos desse tipo, a taxa de erosão prevista pela EUPS para a área de estudo deve estar bem próxima dos valores reais. 
No que se refere à visualização espacial dos resultados da EUPS, pode-se dizer que o modelo foi extremamente eficiente na identificação de áreas vulneráveis aos processos erosivos. Quando comparados com os resultados obtidos por Pires (1995), por exemplo, para a microbacia hidrográfica do córrego do Beija-Flor, as áreas com maior risco foram praticamente idênticas.

Em relação à interpretação quantitativa dos resultados gerados pela EUPS, Cohen et al. (2005) afirmam que a EUPS tem sido comumente aplicada para a avaliação do risco à erosão nos trópicos, mas raramente tem sido validada pela observação da perda de solo no campo. Como qualquer modelo empírico, a aplicação em novas regiões requer a calibração antes que os resultados sejam utilizados como suporte à decisão. De acordo com esses autores, a intervenção eficiente para o controle da erosão em áreas rurais tropicais requer modelos acurados para prever a localização espacial da intensidade da degradação.

Apesar de não terem sido realizados experimentos no campo, em parcelas experimentais, para a quantificação da erosão, deve-se salientar que a aplicação da EUPS foi realizada com base em dados específicos para o Estado de São Paulo e, muitos deles, relacionados à região estudada. Os resultados gerados, quando comparados com outros trabalhos realizados em microbacias do Estado de São Paulo, mostraram-se promissores e próximos do esperado. Os resultados confirmaram as expectativas pré-estudo de que os valores de erosão na área da EEJ seriam mais baixos. Porém, os resultados foram reveladores em função da média de perda de solo por erosão superficial da MBH-BF ser maior do que a MBH-G.

Um dos aspectos positivos da quantificação dos processos erosivos é a possibilidade de associá-los aos valores de tolerância de perda de solo por erosão hídrica superficial; dessa maneira, com base nos resultados do potencial de risco à erosão laminar, elaborar a classificação do risco ambiental. Apesar de o conceito de tolerância à perda de solo ter sido desenvolvido com enfoque agronômico, baseado na produção agrícola, é um índice extremamente útil na identificação de áreas vulneráveis. Quando houver a possibilidade de utilização de um índice de tolerância de perda de solo com enfoque agronômico e também ambiental, a análise dos dados de risco à erosão poderá ser enriquecida.

A EUPS, apesar de algumas limitações intrínsecas ao modelo, mostrou ser uma valiosa ferramenta de predição de erosão pela simplicidade do cálculo, disponibilidade dos dados de entrada no Estado de São Paulo e facilidade de comparação dos resultados com inúmeros trabalhos realizados no estado e no país. O gerenciamento ambiental e a implementação de manejo em bacias hidrográficas devem incluir, impreterivelmente, estudos quantitativos de expectativa de erosão hídrica superficial. 


\subsection{Resultados gerados pelo Modelo AVSWAT 2000}

Os resultados obtidos pela aplicação do modelo SWAT, demonstrados a seguir, são referentes à caracterização ambiental da área de estudo, dados dos componentes hidrológicos, estimativas de erosão e da produção de sedimentos das unidades e subunidades de estudo.

\subsubsection{Caracterização Ambiental}

Os resultados referentes à caracterização ambiental da área de estudo foram apresentados anteriormente. Porém, para a manipulação do modelo SWAT foi necessária, também, a elaboração dos planos de informação no programa ArcView, interface AVSWAT 2000. Nas Figuras 41 e 42 são apresentados os planos de informação, gerados nesse programa, referentes ao modelo numérico do terreno, solo, uso do solo, e a divisão das unidades e subunidades de estudo em sub-bacias.

Em relação ao uso do solo, a área de avicultura da MBH-G foi definida, no modelo SWAT, como área agrícola genérica.

A MBH-BF foi dividida em 33 sub-bacias e subdividida em 70 unidades de resposta hidrológica (HRU) e a MBH-G, em 18 sub-bacias e 45 HRUs.

Convém enfatizar que a interface entre o modelo SWAT e o programa ArcView configura, automaticamente, as bacias hidrográficas, as sub-bacias e as unidades de resposta hidrológica (HRUs). 


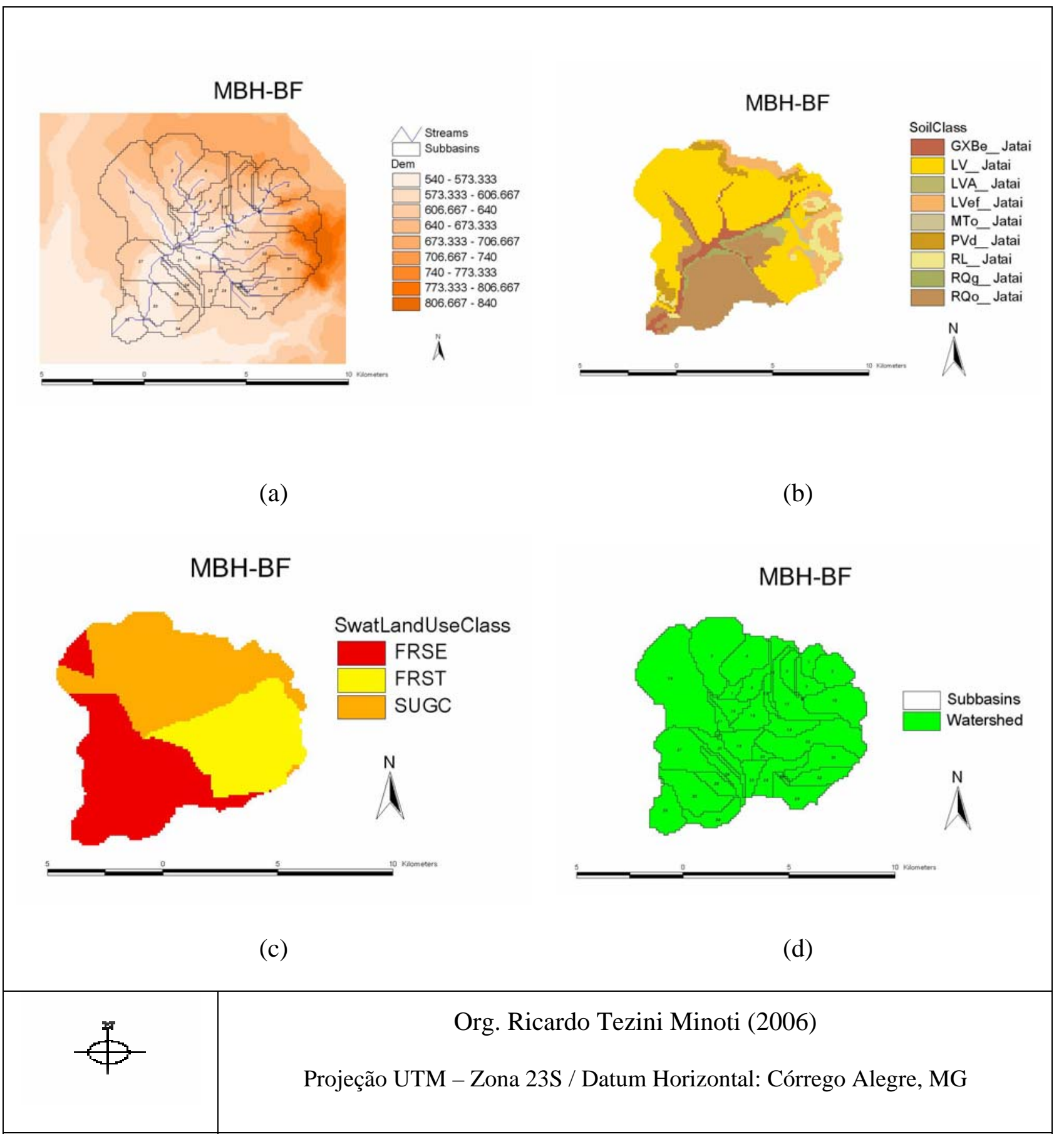

Figura 41. Microbacia hidrográfica do córrego Beija-Flor (MBH_BF). (a) Mapa de classes hipsométricas. (b) Mapa de Solos. (c) Mapa de uso do solo. (d) Mapa das sub-bacias. 


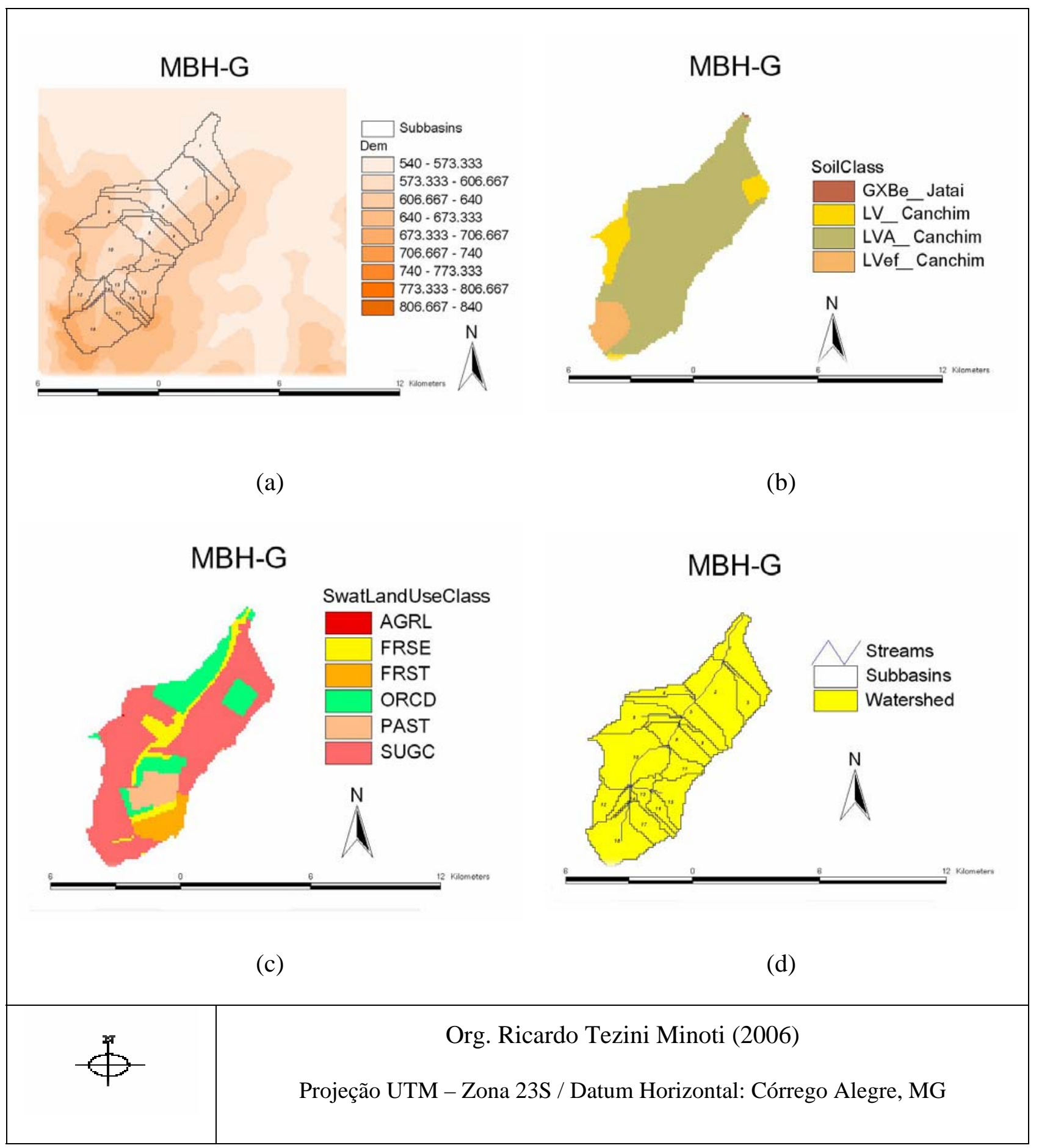

Figura 42. Microbacia hidrográfica do ribeirão das Guabirobas (MBH-G). (a) Mapa de classes hipsométricas. (b) Mapa de Solos. (c) Mapa de uso do solo. (d) Mapa das sub-bacias. 
5.9.2 Simulações - elaboração de cenários com base em componentes do balanço hídrico, na EUPS e na produção de sedimentos.

\subsubsection{Microbacia hidrográfica do córrego Beija-Flor (7.830 hectares)}

Nas Figuras 43 a 51, são apresentadas estimativas de componentes do balanço hídrico, de erosão (USLE/modelo SWAT) e produção de sedimentos para as 33 sub-bacias da microbacia hidrográfica do córrego Beija-Flor (MBH-BF), em função dos três cenários de uso do solo simulados. Nas Figuras 52 e 53, são apresentados os resultados totais, referentes aos cenários, para toda a área de abrangência da microbacia.

Os resultados de estimativa de perda de solo por erosão, obtidos pela aplicação do modelo SWAT, foram designados de USLE para diferenciá-los dos resultados obtidos pela aplicação da EUPS no presente trabalho.

Os valores do Fator SED/USLE, relacionados aos três cenários simulados pelo Modelo SWAT para a MBH-BF, médias anuais das 33 sub-bacias referentes ao período de 1999 a 2003, podem ser observados na Figura 53.

Deve-se observar que o relevo da MBH-BF, com cerca de 320 metros de variação altimétrica e locais de elevada declividade, favorece o escoamento superficial. Observando-se as Figuras 43 e 46 pode-se identificar, até mesmo no cenário floresta, várias sub-bacias que apresentaram valores médios de escoamento superficial mais elevados do que os valores de percolação. No cenário cana-de-açúcar (Fig. 49) pode-se observar que os valores de escoamento superficial foram elevados em praticamente todas as sub-bacias.

De maneira semelhante aos resultados da EUPS, conforme era esperado, os valores mais altos de escoamento superficial e de produção de sedimentos, foram obtidos nas sub-bacias que apresentaram maior variação de declividade e maiores valores de PNE, principalmente as subbacias de drenagem dos cursos d'água inseridos na MBH-BF como a sub-bacia do córrego das Cabaças (incluindo a região do Morro do Pique), as sub-bacias que abrangeram o córrego do Jordão, a sub-bacia do córrego do Debruado, a sub-bacia do córrego da Bandeira e, por último, a sub-bacia referente à margem direita do córrego do Beija-Flor na área da EEJ (margem direita do córrego na área da SBH-BFJ).

Dentre os riscos ambientais das atividades desenvolvidas na área rural do município de Luiz Antônio, incluindo a área da MBH-BF, apresentados por Pires (1995), mencionados anteriormente, deve-se salientar os riscos de degradação por erosão de solos, sólidos em suspensão em corpos d’água e assoreamento de córregos associados às atividades desenvolvidas pela monocultura de cana-de-açúcar e outras culturas. 
O valor médio de erosão na MBH-BF, cenário atual de uso do solo, obtido pela USLEModelo SWAT, foi de 16.585 ton/ano e o valor médio da carga de sedimentos produzidos na microbacia, que atingiu os corpos aquáticos, foi de 16.104 ton/ano. O valor total de perda de solo foi de 372.000 toneladas métricas/ano (Cenário Atual), 688.800 toneladas métricas/ano (Cenário Cana) e 323 toneladas métricas/ano (Cenário Mata Nativa).- 72.110 toneladas métricas/ano.

Vale destacar que, semelhante à aplicação da EUPS, a ponderação em relação aos processos erosivos em carreadores rurais, sem práticas mecânicas de controle à erosão, não foi considerada nas simulações com o modelo SWAT. A utilização dessas informações poderia gerar um aumento nos valores obtidos pela aplicação do modelo SWAT.

Os resultados referentes à produção de sedimentos na região a montante da MBH-BF, semelhantes aos dados obtidos pela aplicação da EUPS, indicaram que o uso agrícola da região à montante dessa unidade de estudo exerce pressão ambiental na área de entorno da EEJ - zona de entorno proposta no zoneamento ambiental do PEJ por Pires (1999) e Pires et al. (2000b). Salienta-se, novamente, a importância da área ocupada pela EEJ nessa microbacia, ocasionando a diminuição da produção de sedimentos e proporcionando melhoria da qualidade ou manutenção das condições ambientais em relação aos recursos edáficos, às áreas alagadas e aos recursos hídricos.

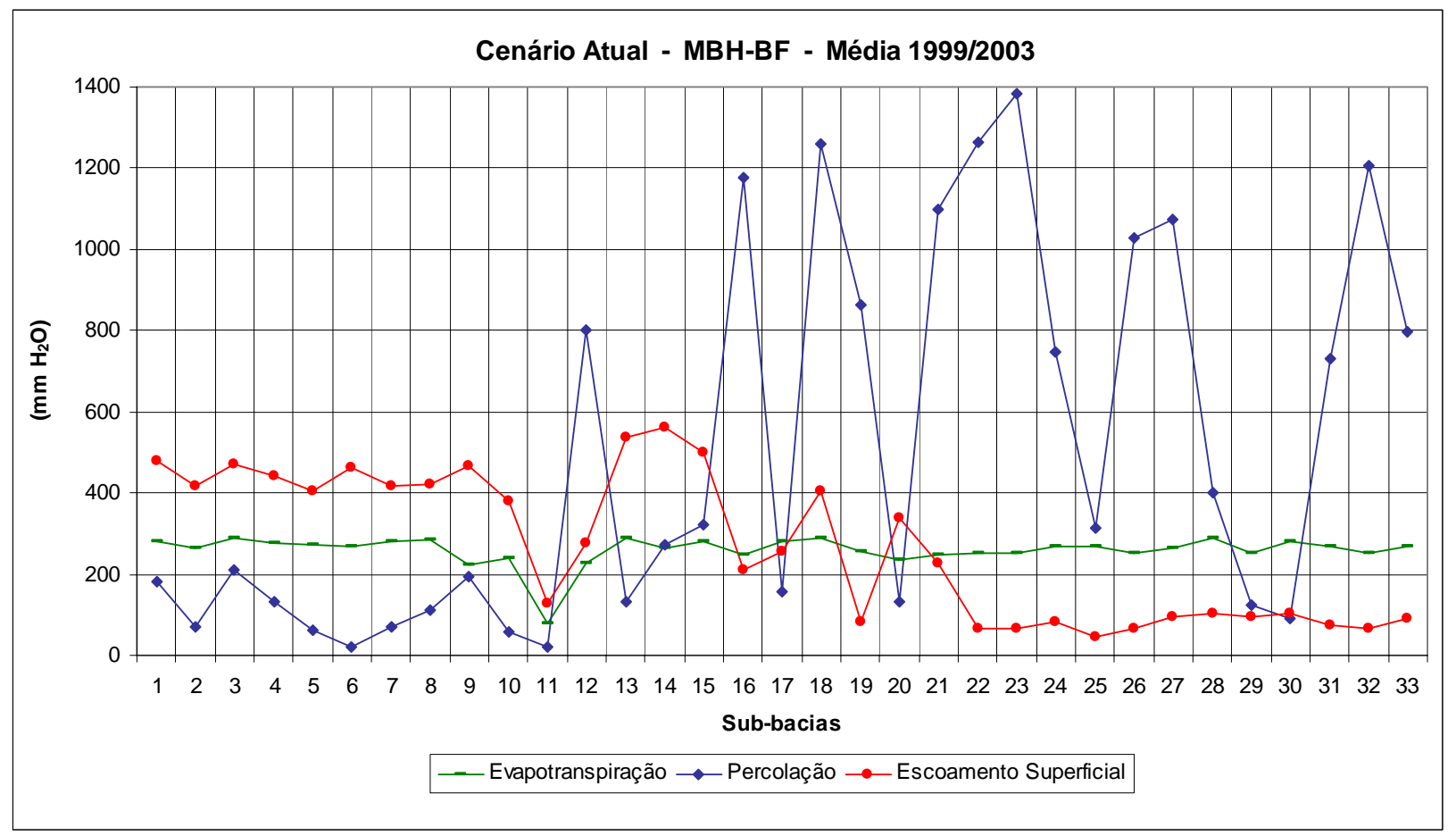

Figura 43. Médias anuais de Evapotranspiração, Percolação e Escoamento Superficial, referente ao período de 1999 a 2003, relacionadas ao cenário de uso do solo atual, simuladas pelo Modelo SWAT para 33 sub-bacias da Microbacia Hidrográfica do Córrego Beija-Flor. 


\section{$\mathrm{MBH}-\mathrm{BF}$}

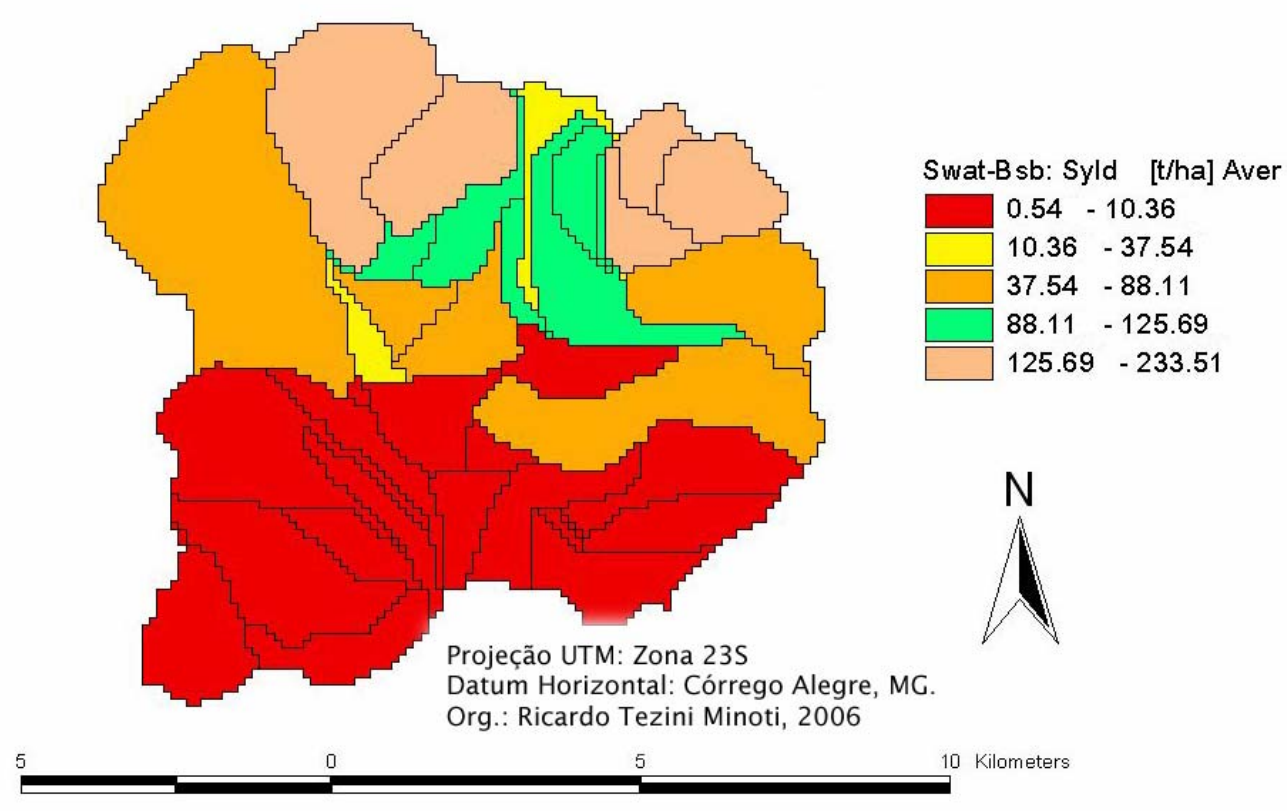

Figura 44. Cenário da produção de sedimentos (ton métrica/ha - médias anuais referentes ao período de 1999 a 2003) simulado pelo Modelo SWAT com base no atual uso do solo da Microbacia Hidrográfica do Córrego Beija-Flor.

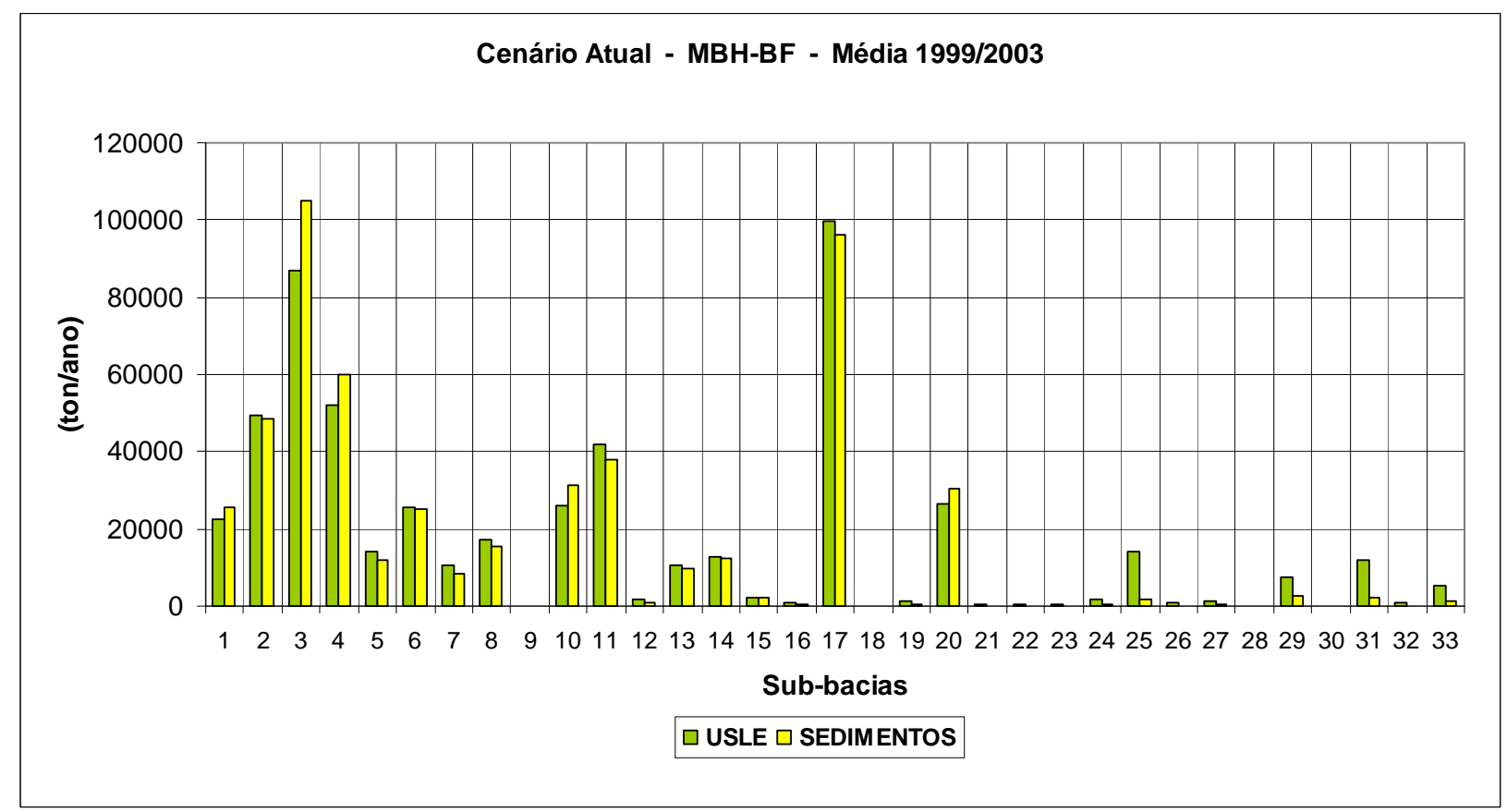

Figura 45. Estimativas dos valores totais de erosão (USLE - ton métrica/ano) e produção de sedimentos (ton métrica/ano), médias anuais referentes ao período de 1999 a 2003, relacionadas ao cenário atual de uso do solo, simuladas pelo Modelo SWAT para as 33 sub-bacias da Microbacia Hidrográfica do Córrego Beija-Flor. 


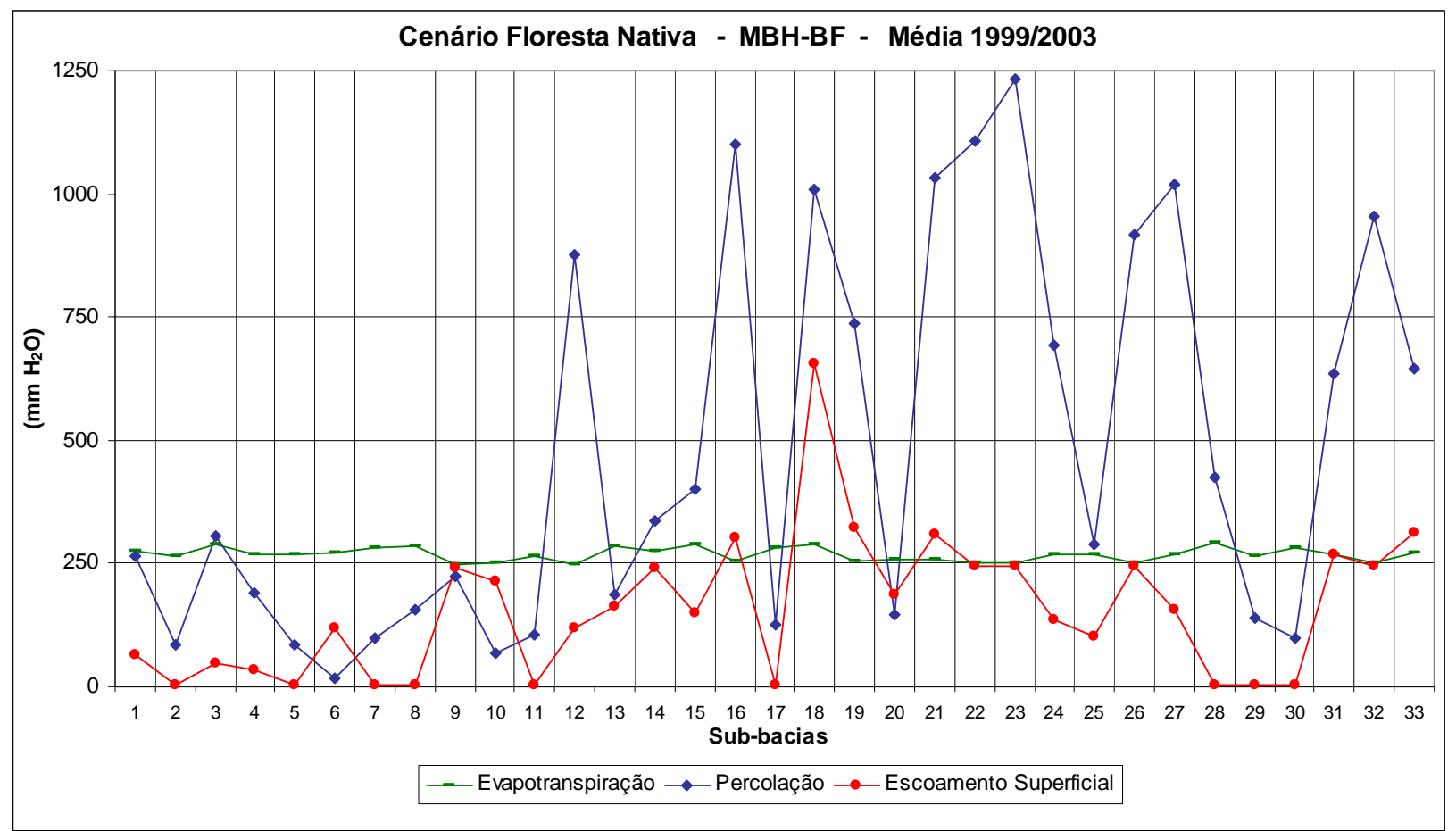

Figura 46. Médias anuais de Evapotranspiração, Percolação e Escoamento Superficial, referente ao período de 1999 a 2003, relacionadas ao cenário de uso do solo com Floresta Nativa, simuladas pelo Modelo SWAT para 33 sub-bacias da Microbacia Hidrográfica do Córrego BeijaFlor.

\section{$\mathrm{MBH}-\mathrm{BF}$}

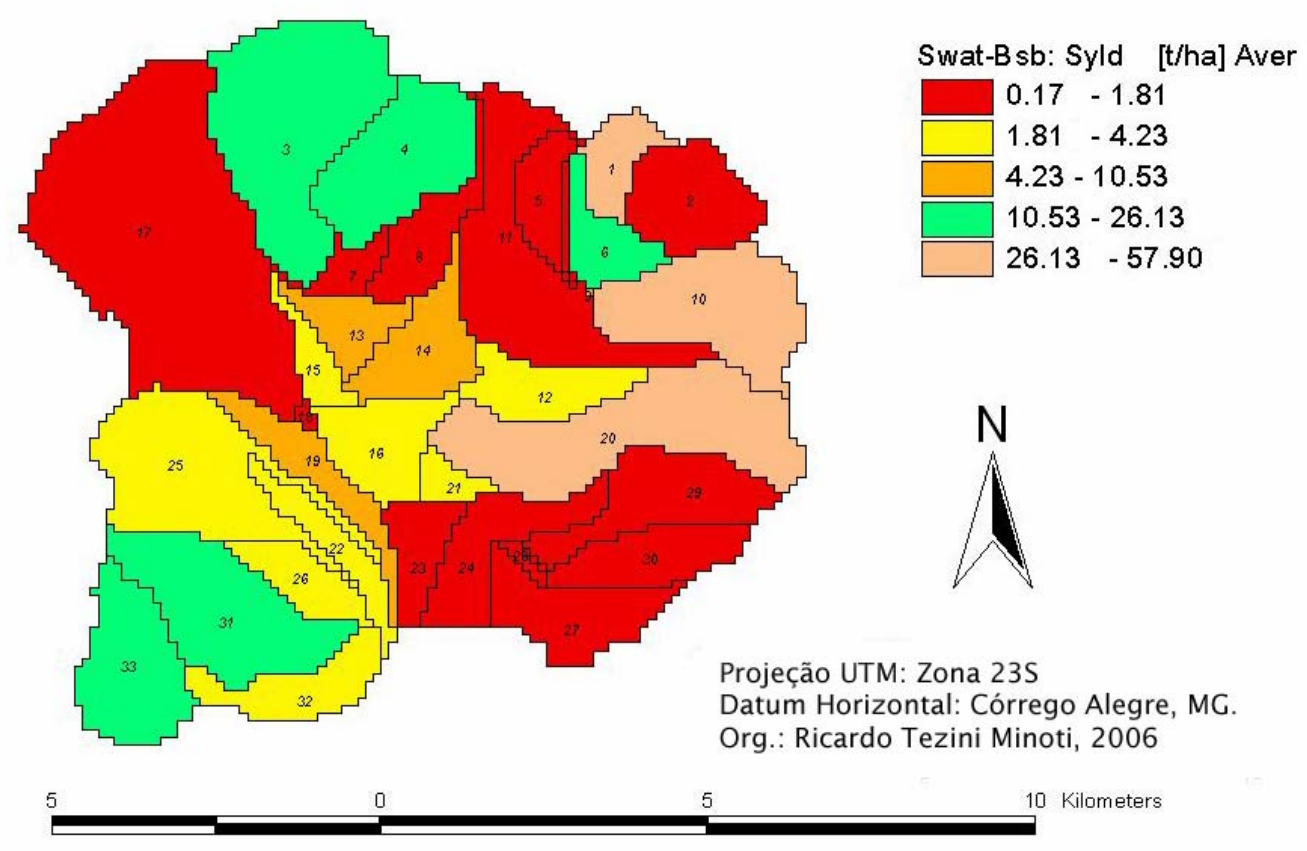

Figura 47. Cenário da produção de sedimentos (ton métrica/ha - médias anuais referentes ao período de 1999 a 2003) simulado pelo Modelo SWAT, baseado na ocupação de toda a área da Microbacia Hidrográfica do Córrego Beija-Flor por floresta nativa. 


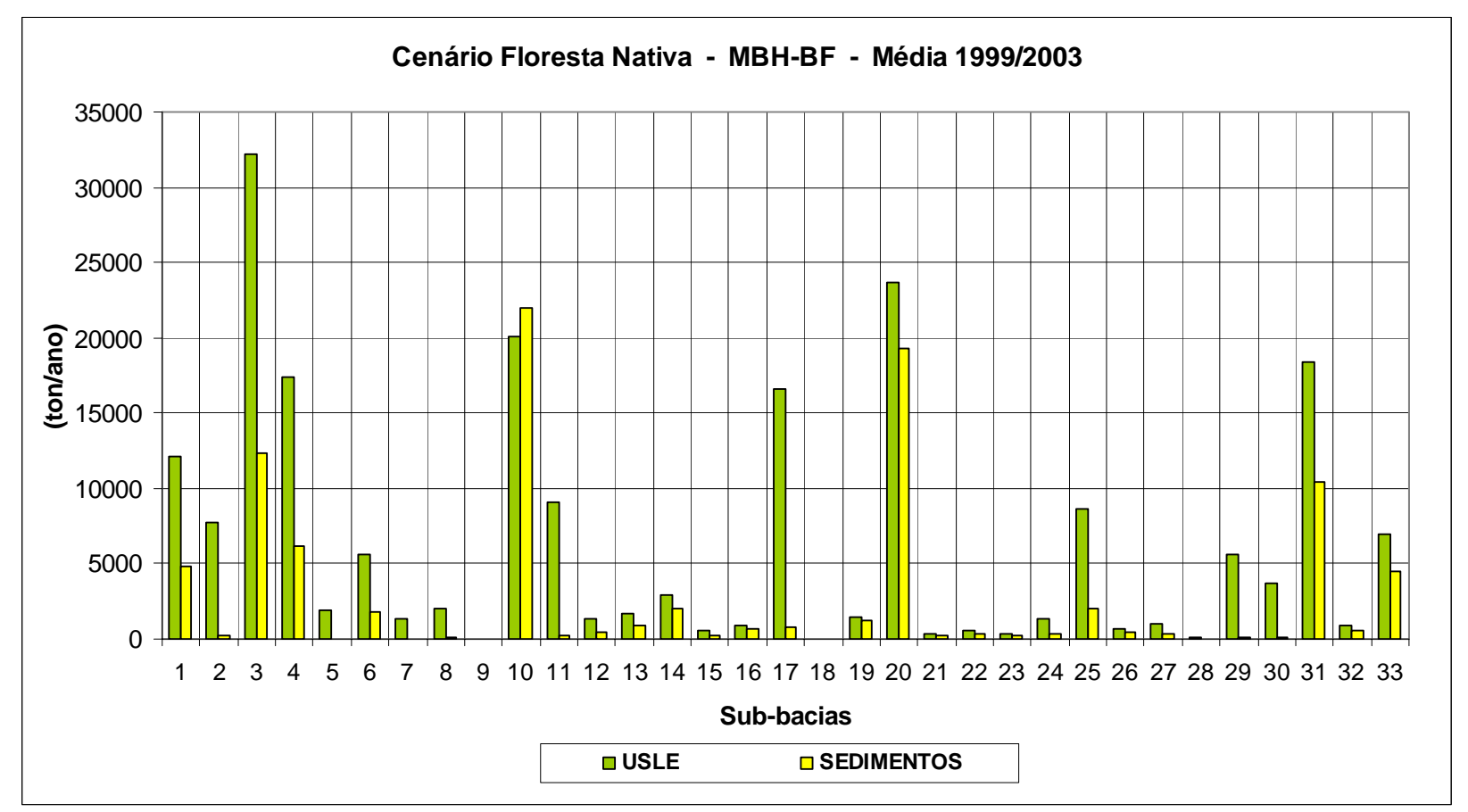

Figura 48. Estimativas dos valores totais de erosão (USLE - ton métrica/ano) e produção de sedimentos (ton métrica/ano), médias anuais referentes ao período de 1999 a 2003, relacionadas ao cenário de uso do solo com floresta nativa, simuladas pelo Modelo SWAT para as 33 subbacias da Microbacia Hidrográfica do Córrego Beija-Flor. 


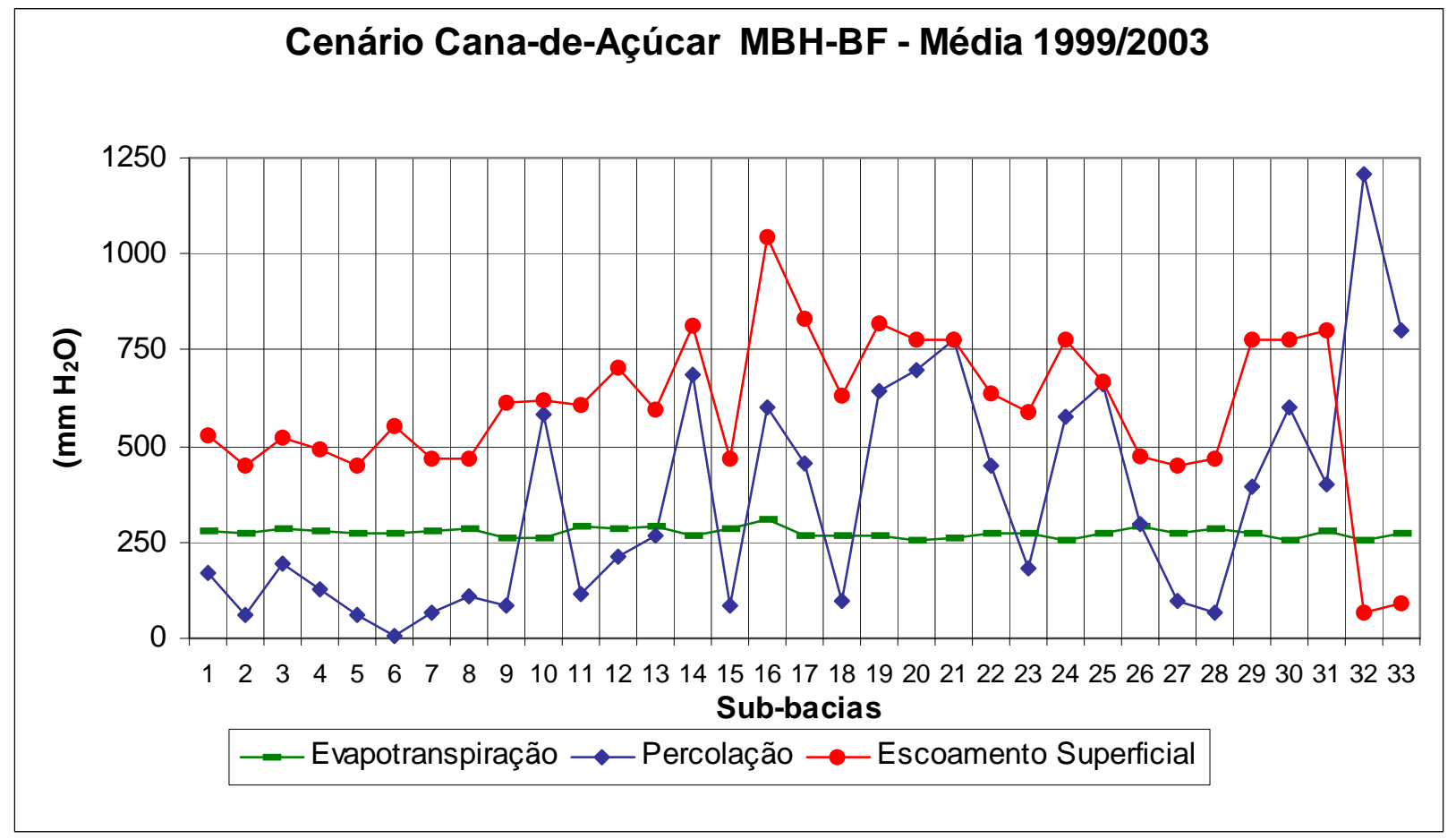

Figura 49. Médias anuais de Evapotranspiração, Percolação e Escoamento Superficial, referente ao período de 1999 a 2003, relacionadas ao cenário de uso do solo com cana-de-açúcar, simuladas pelo Modelo SWAT para 33 sub-bacias da Microbacia Hidrográfica do Córrego BeijaFlor.

\section{MBH-BF Cenário Cana-de-Açúcar}

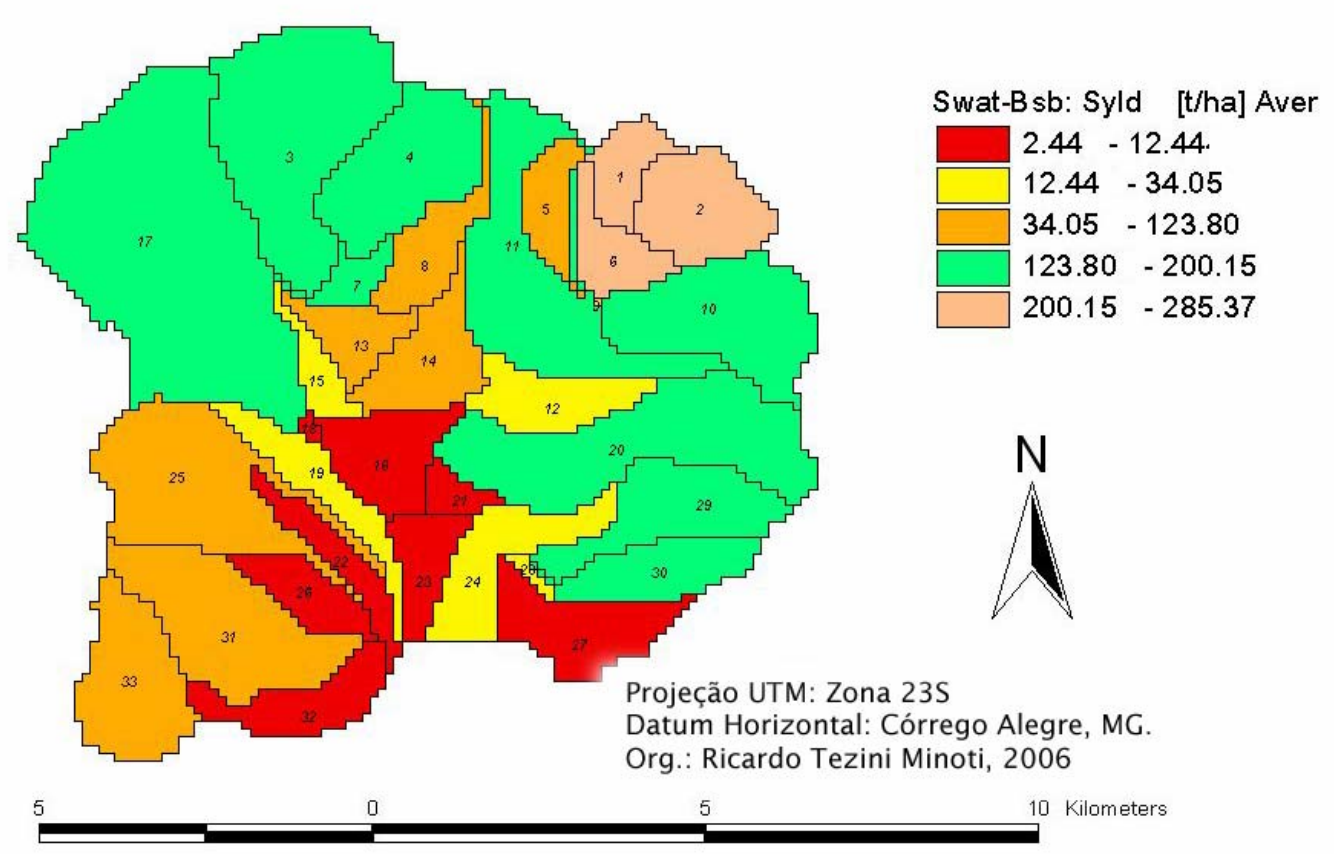

Figura 50 Cenário da produção de sedimentos (ton métrica/ha - médias anuais referentes ao período de 1999 a 2003) simulado pelo Modelo SWAT, baseado na ocupação de toda a área da Microbacia Hidrográfica do Córrego Beija-Flor por cana-de-açúcar. 


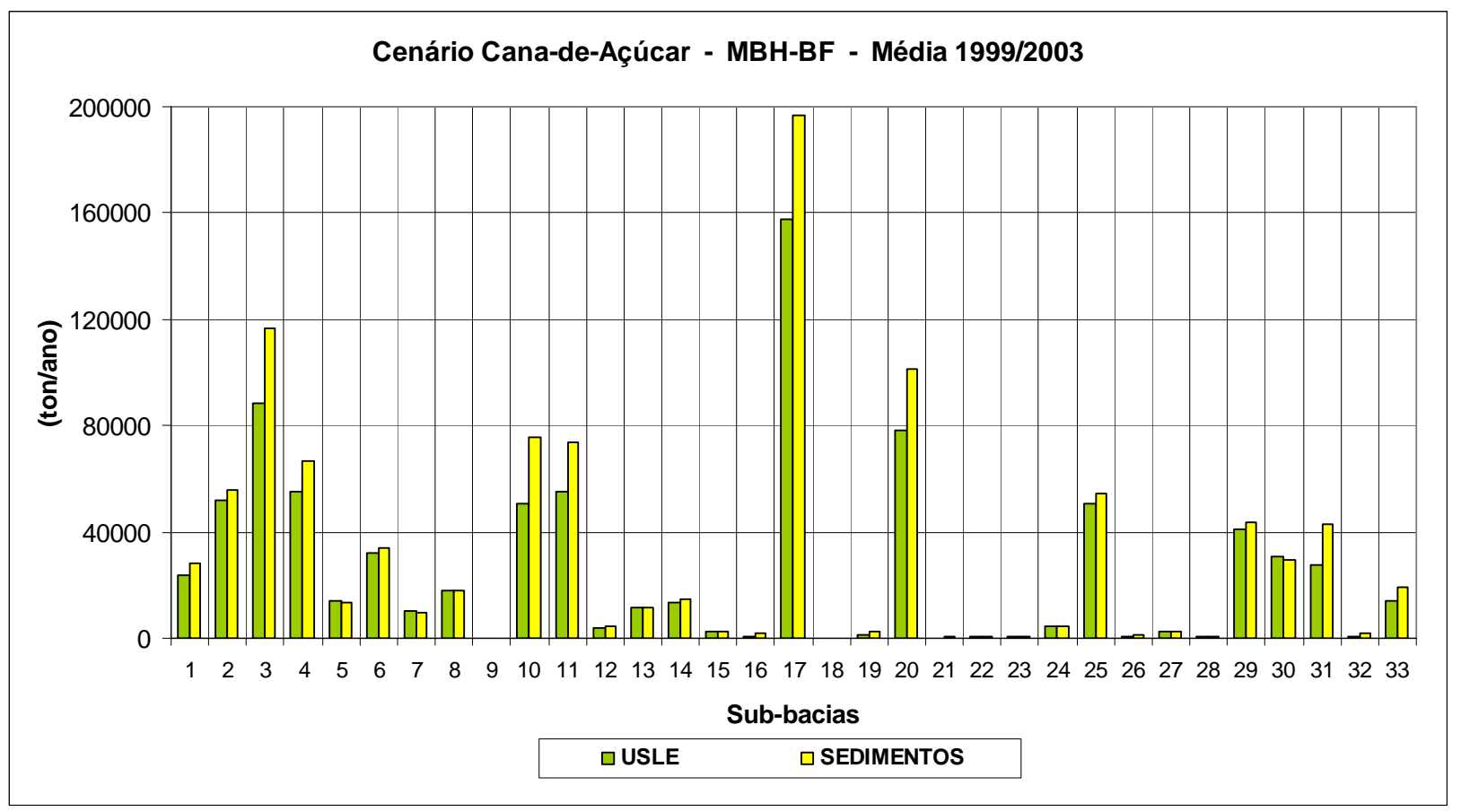

Figura 51. Estimativas dos valores totais de erosão (EUPS - ton métrica/ano) e produção de sedimentos (ton métrica/ano), médias anuais referentes ao período de 1999 a 2003, relacionadas ao cenário de uso do solo com cana-de-açúcar, simuladas pelo Modelo SWAT para as 33 subbacias da Microbacia Hidrográfica do Córrego Beija-Flor. 


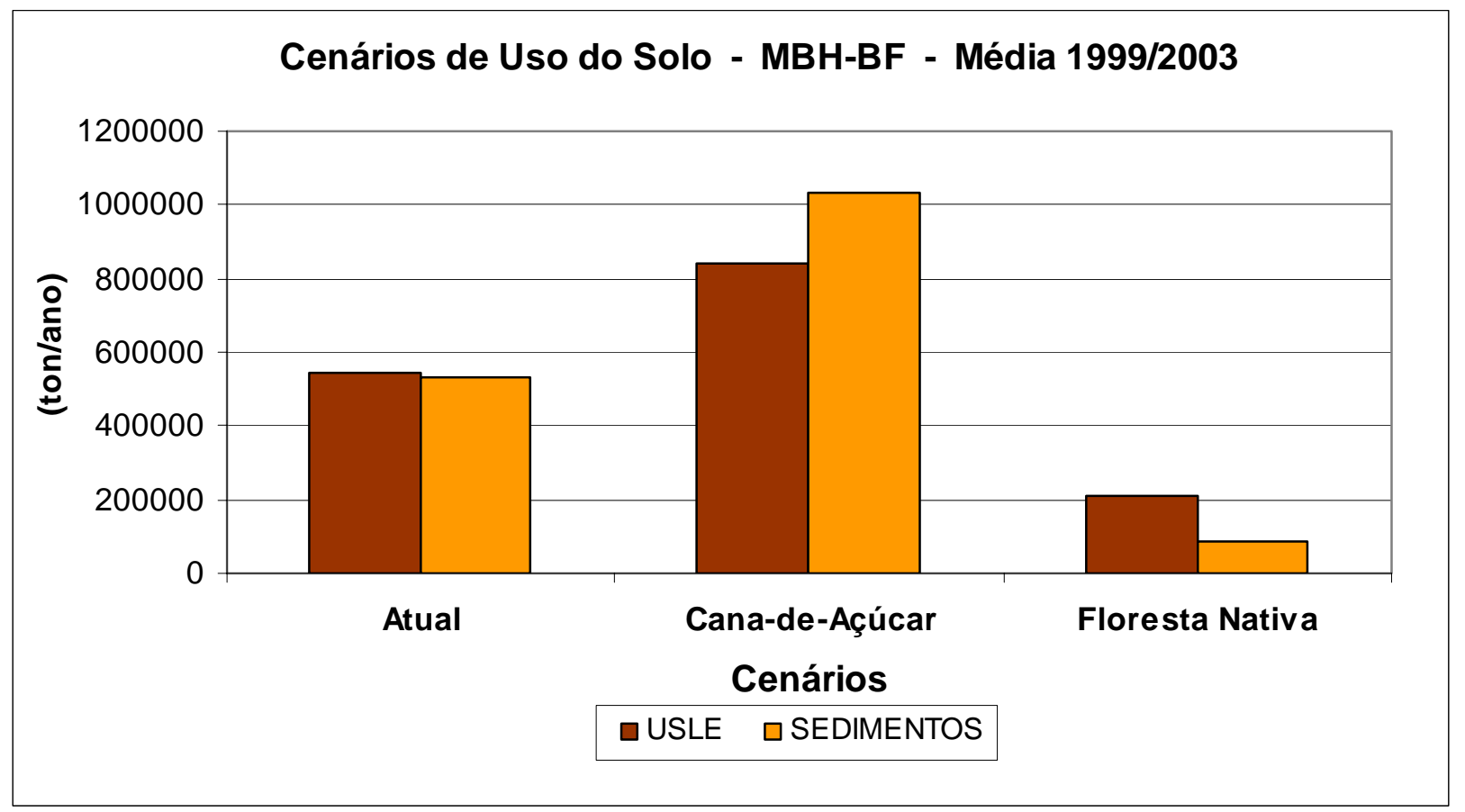

Figura 52. Estimativas dos valores totais de erosão/USLE (ton métrica/ano) e produção de sedimentos (ton métrica/ano), médias anuais referentes ao período de 1999 a 2003, relacionadas aos cenários simulados pelo Modelo SWAT para a Microbacia Hidrográfica do Córrego BeijaFlor.

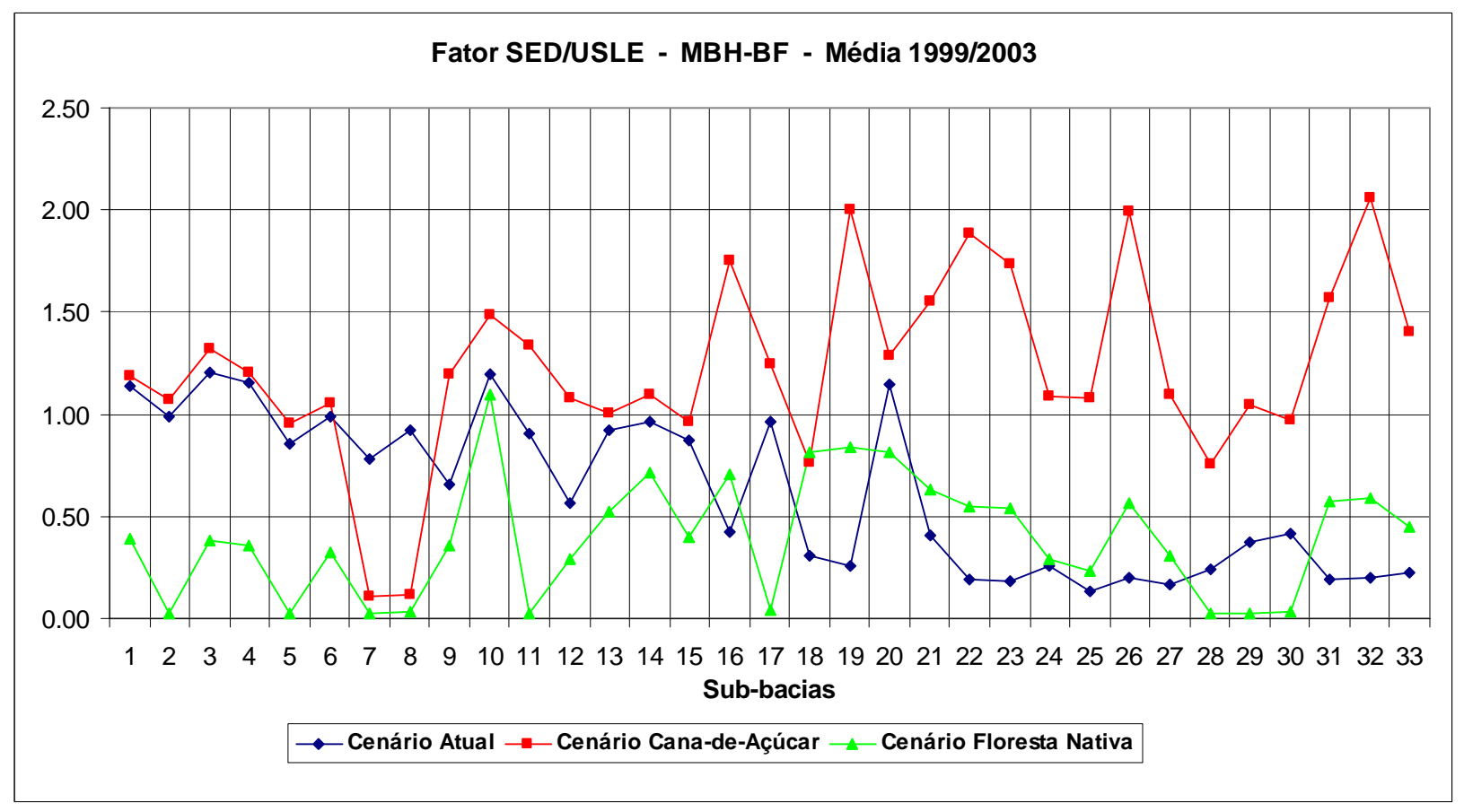

Figura 53. Valores do Fator SED/USLE relacionados aos cenários simulados pelo Modelo SWAT, médias anuais referentes ao período de 1999 a 2003, para 33 sub-bacias da Microbacia Hidrográfica do Córrego Beija-Flor. 


\subsubsection{Microbacia hidrográfica do ribeirão das Guabirobas (4.721 hectares)}

Nas Figuras 54 a 62, são apresentadas as estimativas de componentes do balanço hídrico, de erosão (USLE/modelo SWAT) e produção de sedimentos para as 18 sub-bacias da microbacia hidrográfica do ribeirão das Guabirobas (MBH-G), em função dos três cenários de uso do solo simulados. Nas Figuras 63 e 64, são apresentados os resultados totais, referentes aos cenários simulados, para toda a área de abrangência da microbacia.

Embora a região a montante da MBH-G apresente declividades mais elevadas, pode-se dizer que, de maneira contrária ao que ocorre na MBH-BF, o relevo da MBH-G não favorece o escoamento superficial. Essa característica foi constatada nos resultados referentes aos cenários de uso atual do solo e cana-de-açúcar. Em nenhuma dessas simulações, os valores de escoamento superficial foram muito elevados e foram sempre mais baixos que os valores de percolação. Além disso, comparando-se os cenários floresta nativa e cana-de-açúcar de todas as microbacias simuladas, observou-se na MBH-G os menores valores de escoamento superficial.

O valor total de perda de solo na MBH-G, simulado pelo SWAT, foi de 54.530 toneladas métricas/ano (Cenário Atual), 88.980 toneladas métricas/ano (Cenário Cana) e 323 toneladas métricas/ano (Cenário Mata Nativa).

Semelhante ao que foi observado na MBH-BF, os resultados de escoamento superficial e produção de sedimentos da MBH-G foram semelhantes aos dados de erosão observados pela aplicação da EUPS, em que os valores mais elevados ocorreram nas regiões de maior declividade e maiores valores de PNE. A região a montante, e algumas áreas ao longo do curso do ribeirão das Guabirobas, foram as áreas de maior vulnerabilidade ambiental. 


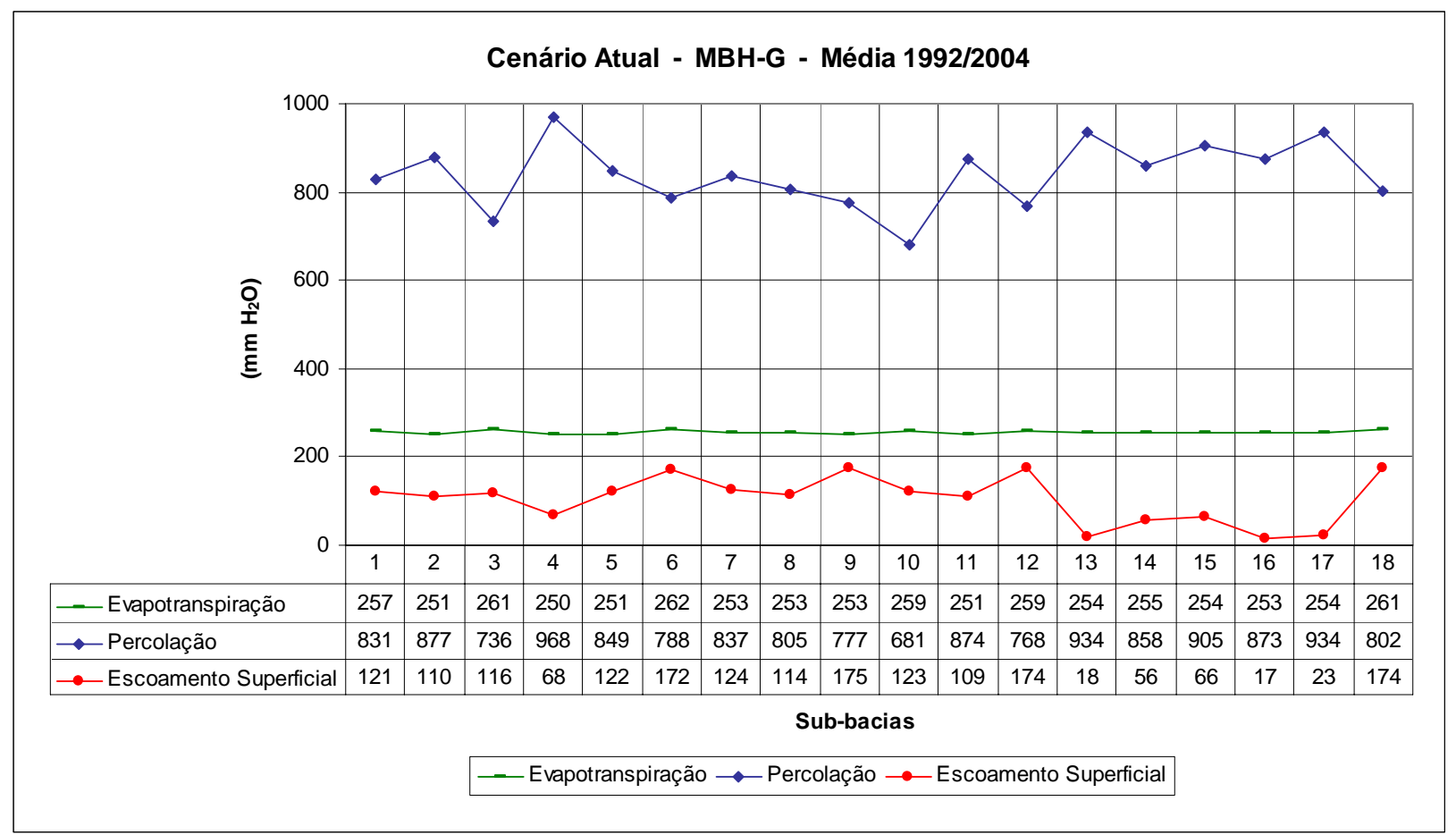

Figura 54. Médias anuais de Evapotranspiração, Percolação e Escoamento Superficial, referente ao período de 1992 a 2004, relacionadas ao cenário de uso atual do solo, simuladas pelo Modelo SWAT para 18 sub-bacias da Microbacia Hidrográfica do Ribeirão das Guabirobas.

\section{$\mathrm{MBH}-\mathrm{G}$}

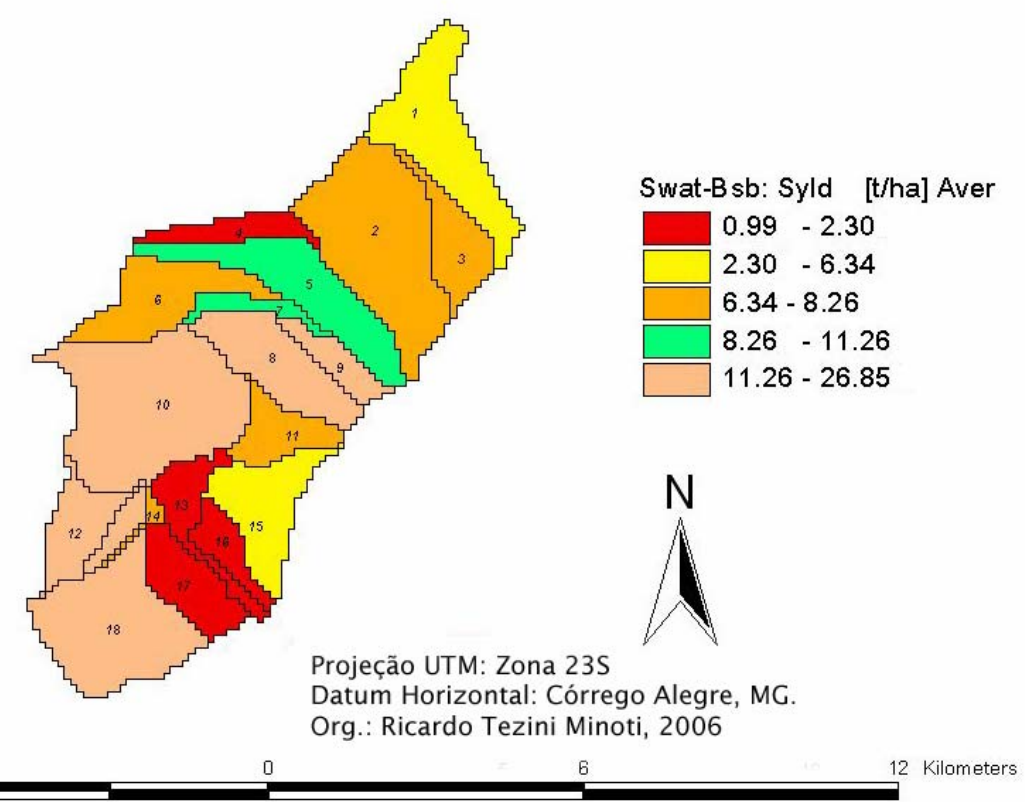

Figura 55. Cenário da produção de sedimentos (ton métrica/ha - médias anuais referentes ao período de 1992 a 2004) simulado pelo Modelo SWAT com base no atual uso do solo da Microbacia Hidrográfica do ribeirão das Guabirobas. 


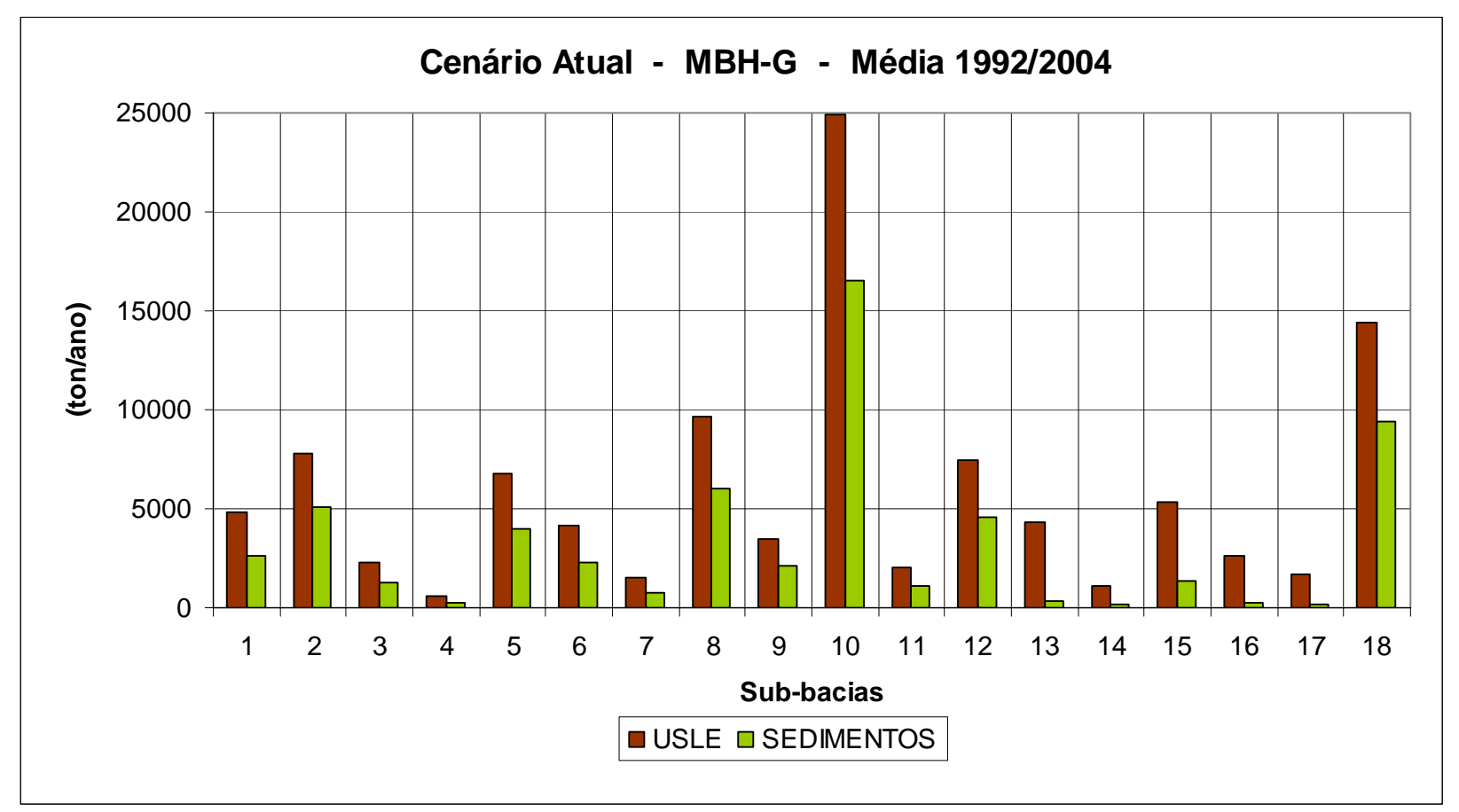

Figura 56. Estimativas dos valores totais de erosão (USLE- ton métrica/ano) e produção de sedimentos (ton métrica/ano), médias anuais referentes ao período de 1992 a 2004, relacionadas ao cenário atual de uso do solo, simuladas pelo Modelo SWAT para as 18 sub-bacias da Microbacia Hidrográfica do Ribeirão das Guabirobas. 


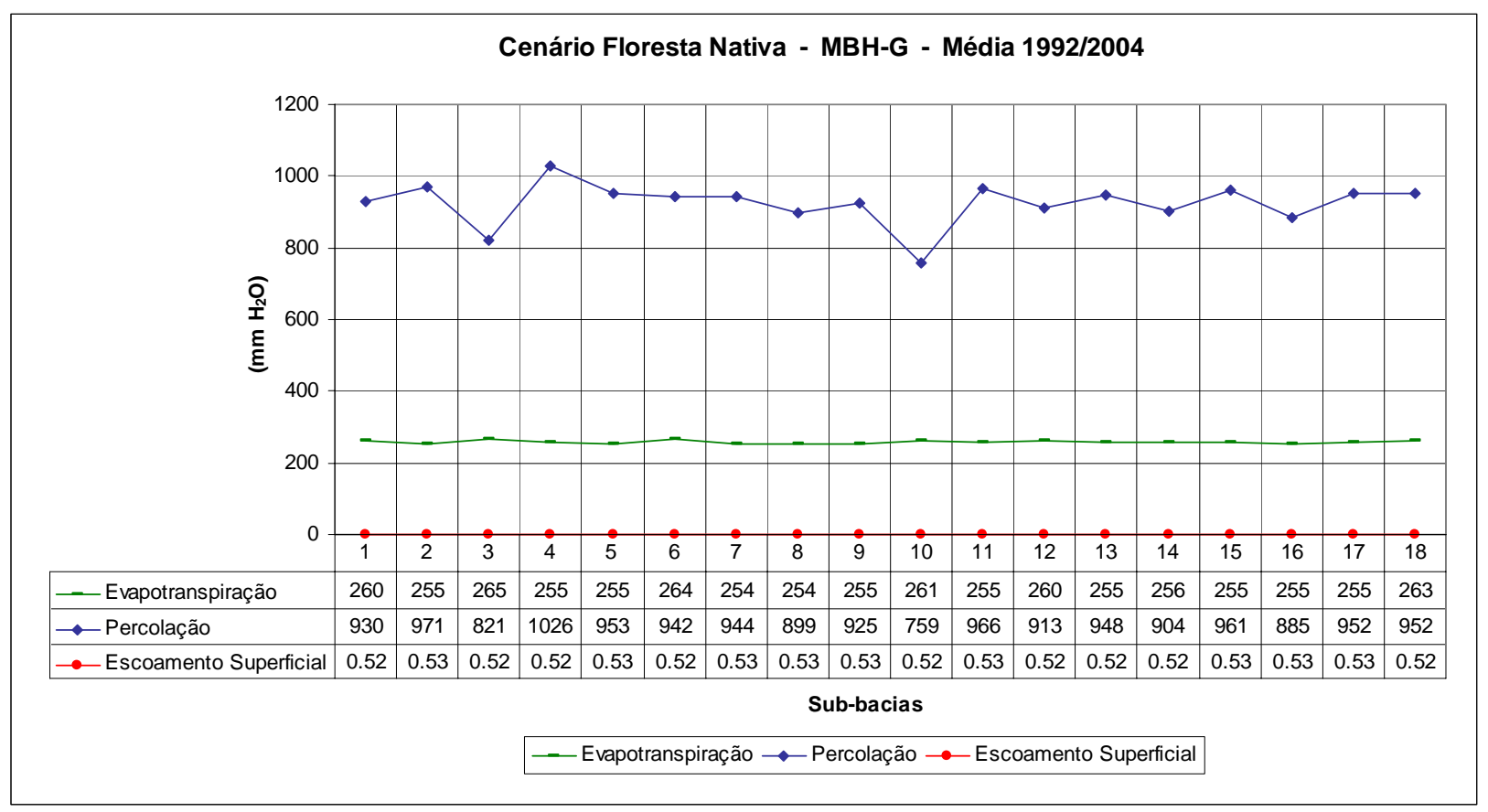

Figura 57. Médias anuais de Evapotranspiração, Percolação e Escoamento Superficial, referentes ao período de 1992 a 2004, relacionadas ao cenário de uso do solo com Floresta Nativa, simuladas pelo Modelo SWAT para 18 sub-bacias da Microbacia Hidrográfica do Ribeirão das Guabirobas.

\section{MBH-G Cenário Original}

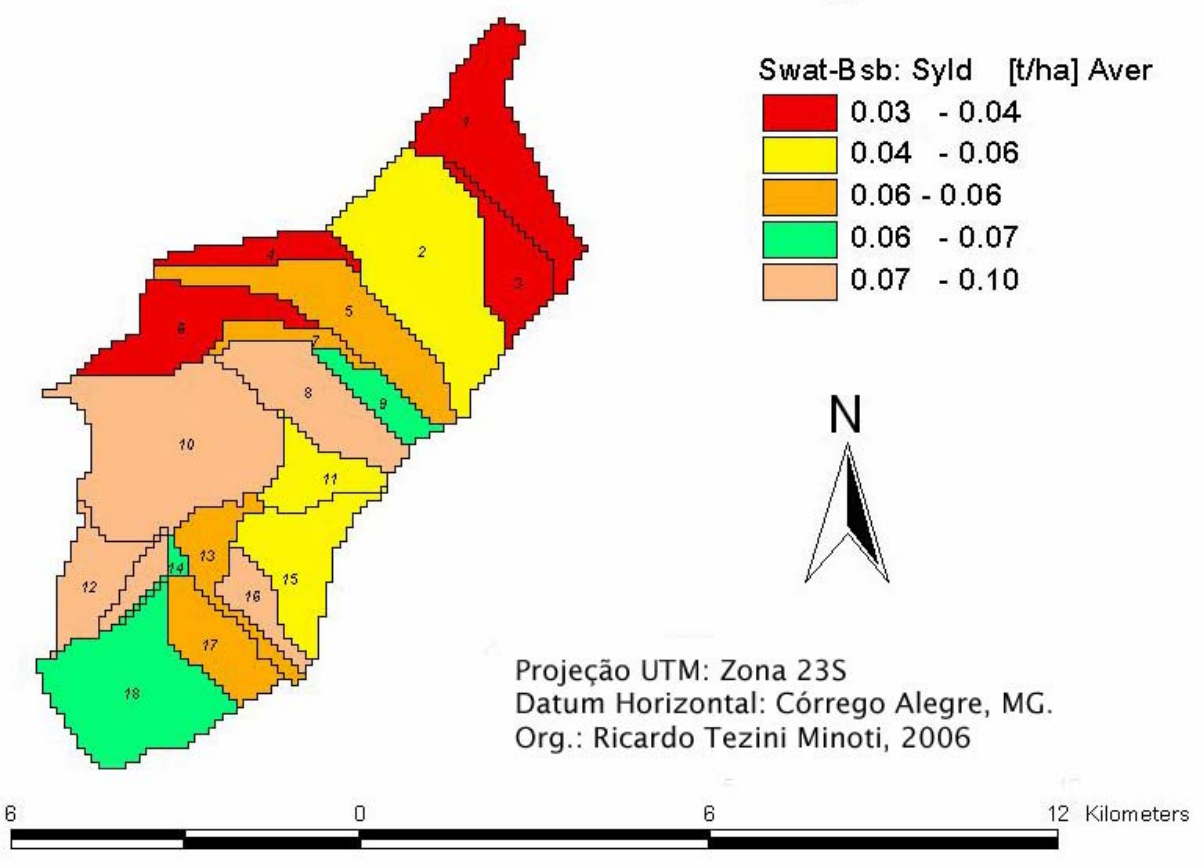

Figura 58. Cenário da produção de sedimentos (ton métrica/ha - médias anuais referentes ao período de 1992 a 2004) simulado pelo Modelo SWAT, baseado na ocupação de toda a área da Microbacia Hidrográfica do ribeirão das Guabirobas (MBH_G) por floresta nativa. 


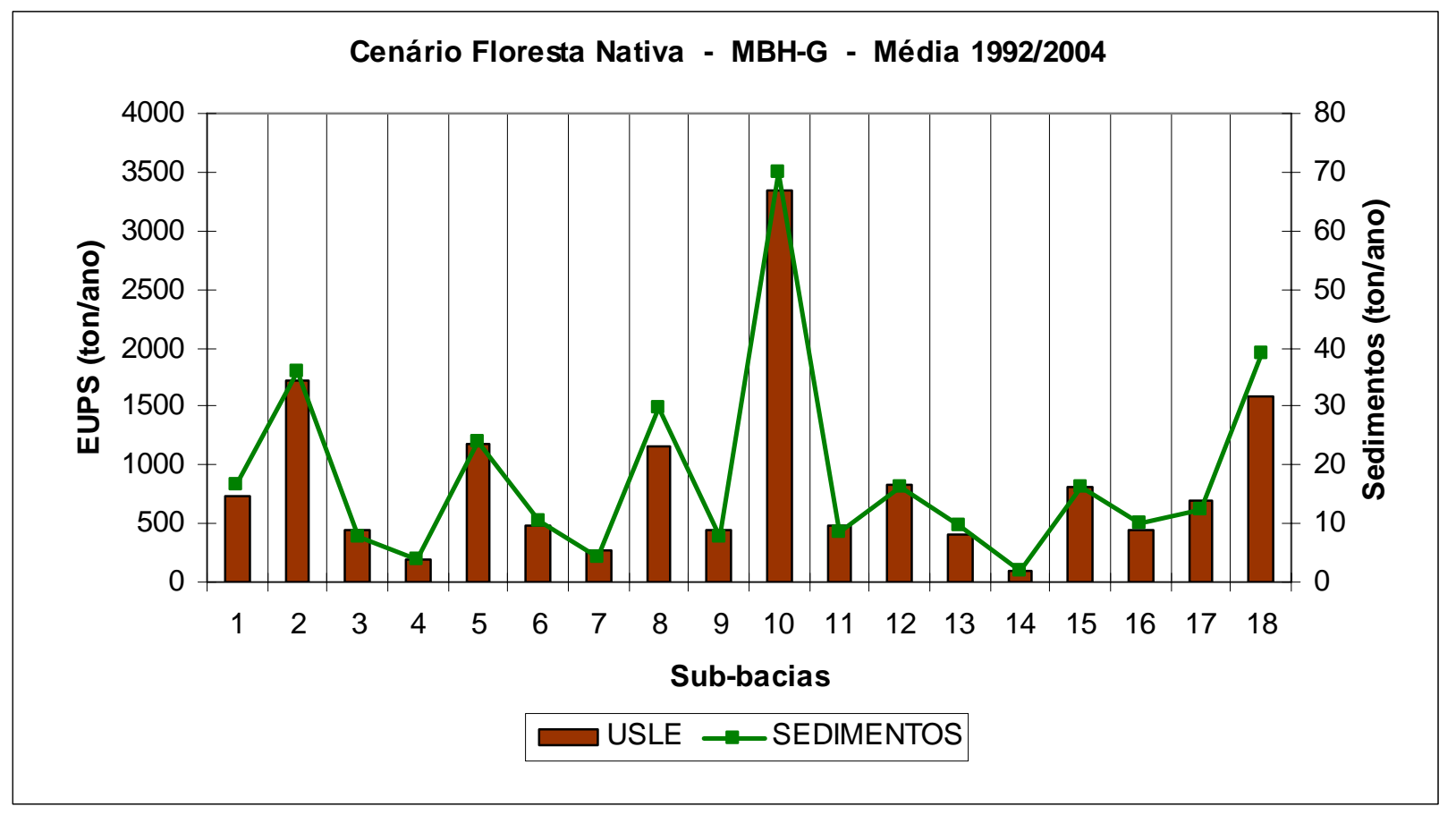

Figura 59. Estimativas dos valores totais de erosão (USLE - ton métrica/ano) e produção de sedimentos (ton métrica/ano), médias anuais referentes ao período de 1992 a 2004, relacionadas ao cenário de uso do solo com floresta nativa, simuladas pelo Modelo SWAT para as 18 subbacias da Microbacia Hidrográfica do Ribeirão das Guabirobas. 


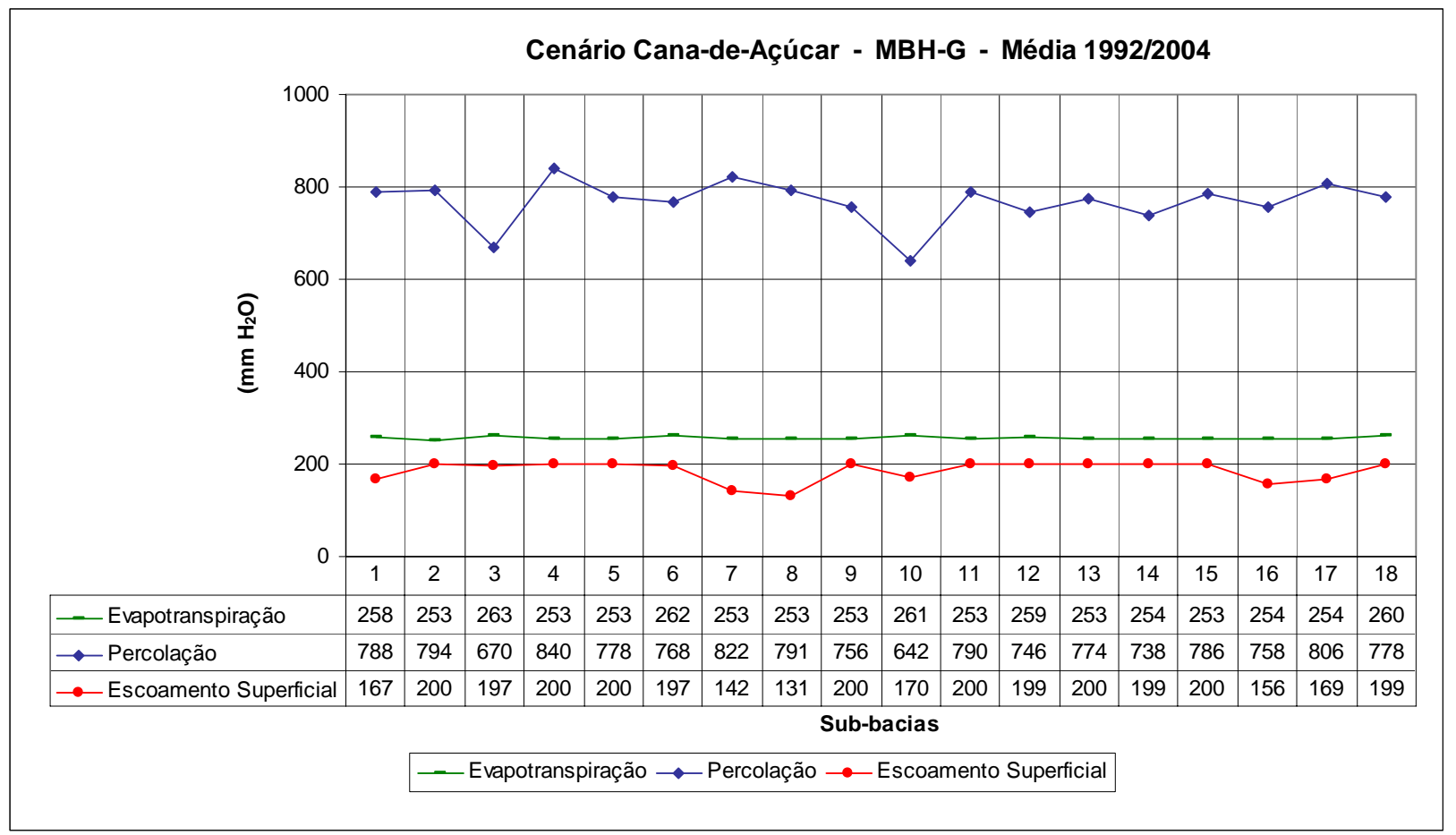

Figura 60. Médias anuais de Evapotranspiração, Percolação e Escoamento Superficial, referentes ao período de 1992 a 2004, relacionadas ao cenário de uso do solo com cana-de-açúcar, simuladas pelo Modelo SWAT para 18 sub-bacias da Microbacia Hidrográfica do Ribeirão das Guabirobas.

\section{MBH-G Cenário Cana-de-Açúcar}

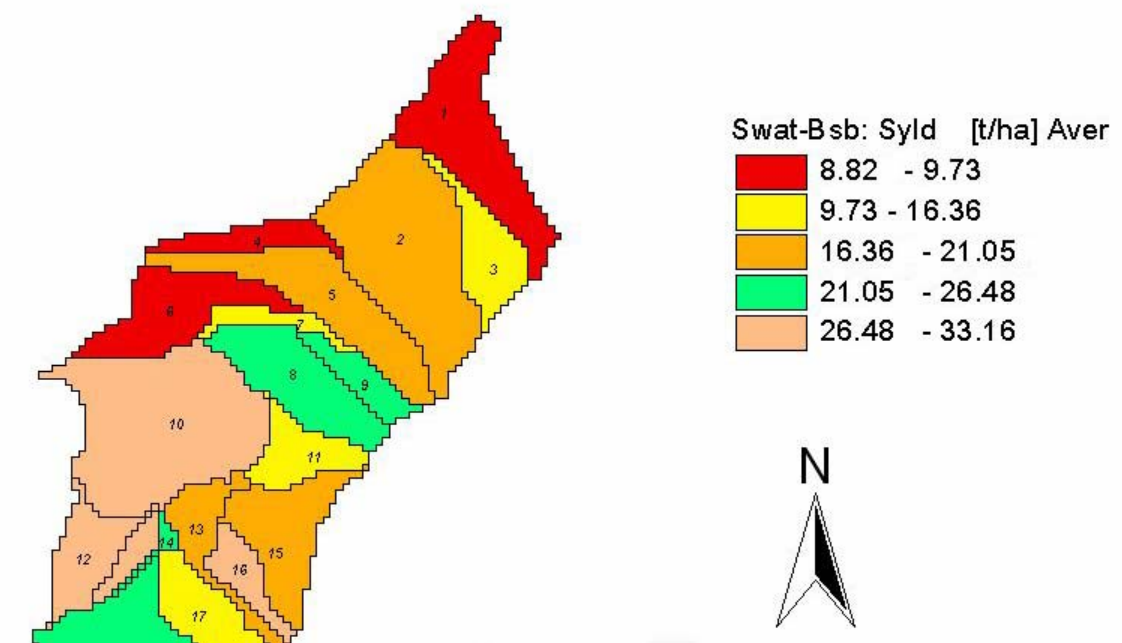

Projeção UTM: Zona 23S

Datum Horizontal: Córrego Alegre, MG.

Org.: Ricardo Tezini Minoti, 2006

Fig. 61. Cenário da produção de sedimentos (ton métrica/ha - médias anuais referentes ao período de 1992 a 2004) simulado pelo Modelo SWAT, baseado na ocupação de toda a área da Microbacia Hidrográfica do ribeirão das Guabirobas por cana-de-açúcar. 


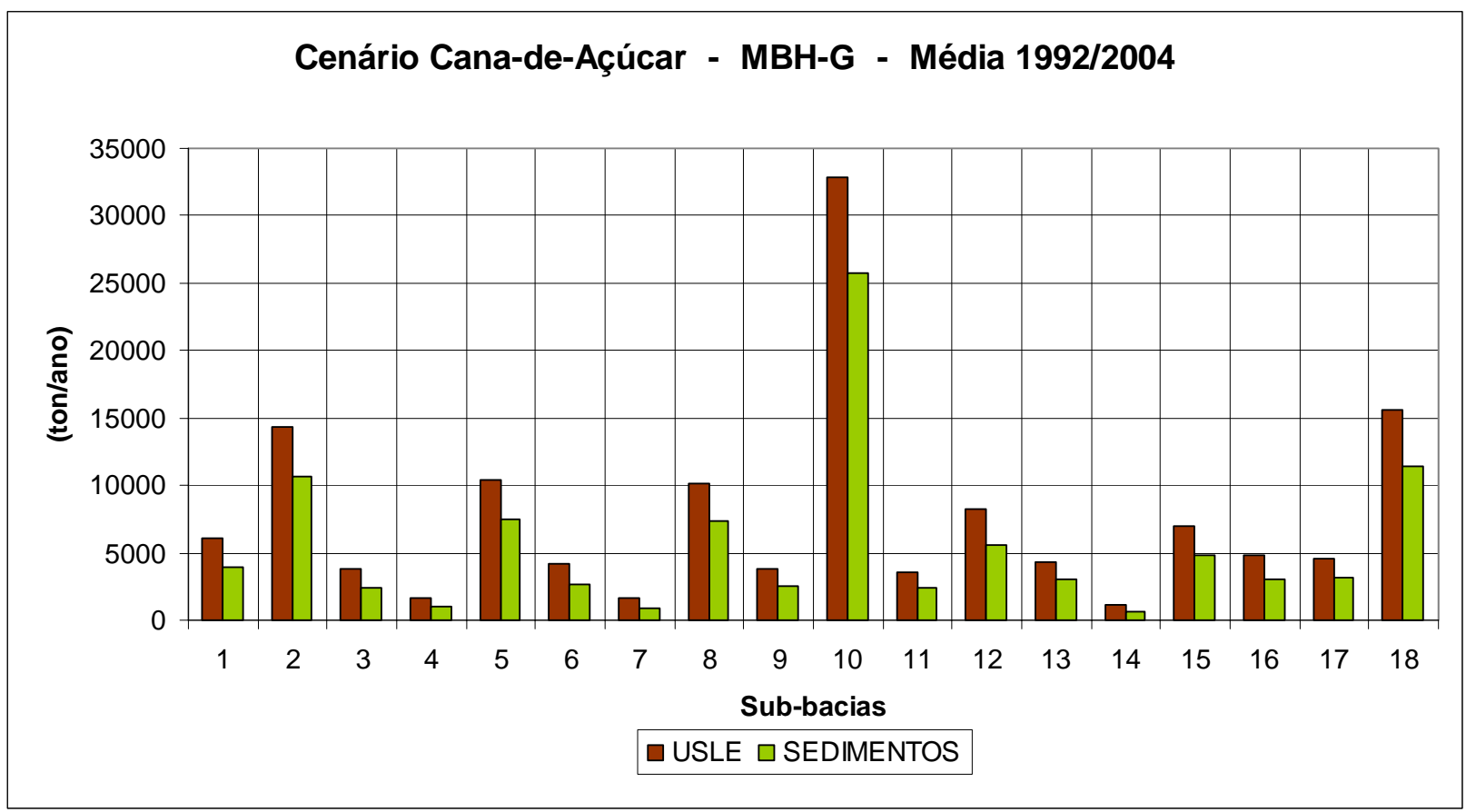

Figura 62. Estimativas dos valores totais de erosão (USLE - ton métrica/ano) e produção de sedimentos (ton métrica/ano), médias anuais referentes ao período de 1992 a 2004, relacionadas ao cenário de uso do solo com cana-de-açúcar, simuladas pelo Modelo SWAT para as 18 subbacias da Microbacia Hidrográfica do Ribeirão das Guabirobas. 


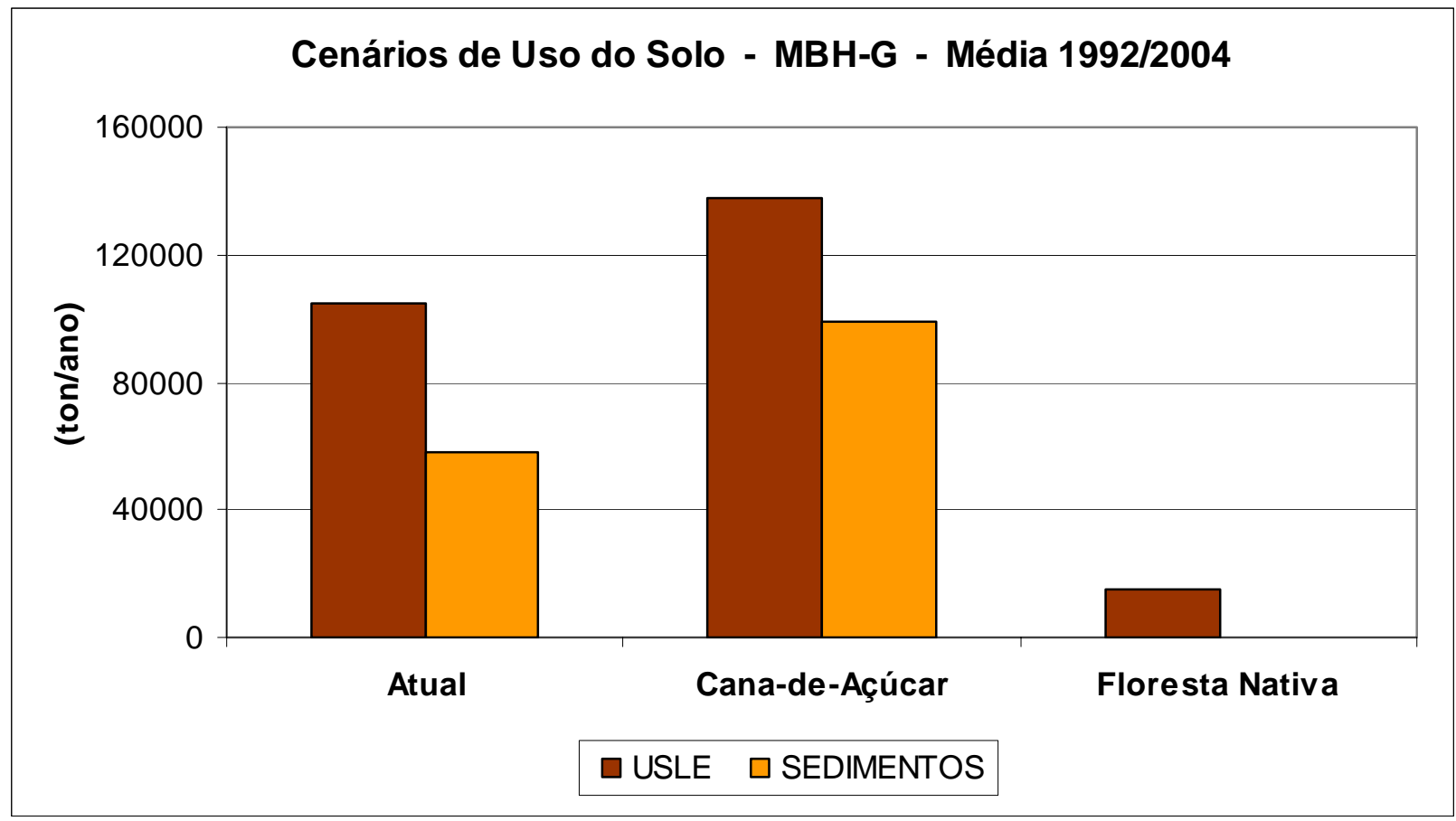

Figura 63. Estimativas dos valores totais de erosão/USLE (ton métrica/ano) e produção de sedimentos (ton métrica/ano), médias anuais referentes ao período de 1992 a 2004, relacionadas aos cenários simulados pelo Modelo SWAT para a Microbacia Hidrográfica do Ribeirão das Guabirobas.

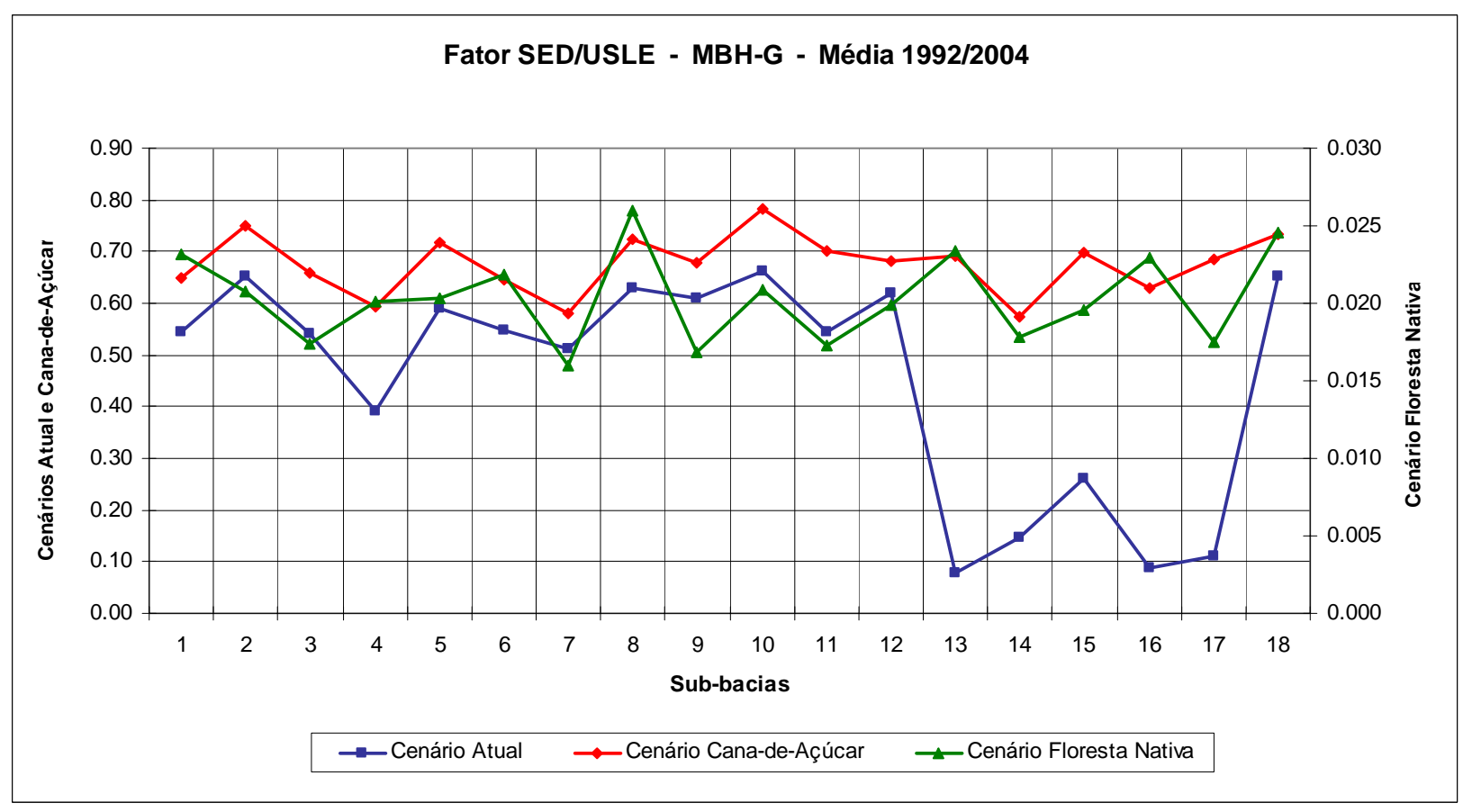

Figura 64. Valores do Fator SED/USLE relacionados aos cenários simulados pelo Modelo SWAT, médias anuais referentes ao período de 1992 a 2004, para 18 sub-bacias da Microbacia Hidrográfica do Ribeirão das Guabirobas. 


\subsection{Análise da aplicação do modelo SWAT na área de estudo}

Complementando a discussão relacionada à aplicação do modelo SWAT nas unidades e subunidades de estudo, vale enfatizar alguns aspectos relativos aos benefícios e, também, às dificuldades referentes à utilização desse modelo na estimação dos variados parâmetros.

A variação das condições hidrológicas é decorrente da combinação de vários fatores como: condições climáticas de precipitação, evapotranspiração, radiação solar; relevo; geologia; geomorfologia e solos; cobertura vegetal e uso do solo (Tucci, 2002).

Nesse sentido, além da disponibilidade dos dados, um dos critérios mais importantes no processo de modelagem refere-se às escalas dos dados de entrada, o quão representativos são os dados e em como as escalas podem indicar os enfoques dos trabalhos (Muleta e Nicklow, 2005).

No presente trabalho, em função da base de dados cartográfica utilizada, da carência de dados relacionados às bacias (não instrumentadas), e das séries de dados regionais ou de literatura utilizados na simulação do SWAT, considerou-se que o estudo foi realizado em escala de reconhecimento, de primeira aproximação em relação à quantificação dos processos erosivos, à produção de sedimentos e à estimação de parâmetros do ciclo hidrológico.

Uma parte dos dados, que poderiam ser utilizados no refinamento das respostas geradas pelo modelo, são inexistentes na área de estudo. As variáveis hidrológicas, sedimentológicas e meteorológicas não são monitoradas nas microbacias estudadas.

O estudo de Machado e Vettorazzi (2003), em microbacia localizada na região de Piracicaba/SP, mostrou que a quantidade de chuva na microbacia, durante um mesmo período de tempo, medida em dois postos pluviográficos situados no interior da microbacia a uma distância de 4.500m. Os dados obtidos apresentaram pequena diferença nos valores totais (42 mm) mas foi observada grande diferença na distribuição da precipitação. Os trabalhos de Goodrich et al., 1995 e Faures et al., 1995, discorrendo sobre o mesmo problema, indicaram que a quantidade de chuva em uma microbacia não é uniforme. Tormentas raramente são uniformes. Por essa razão, a densidade dos medidores de chuva em uma bacia hidrográfica é extremamente importante. Nesse sentido, vale ressaltar que os dados climáticos utilizados no presente trabalho, devido à falta de monitoramento nas microbacias estudadas, foram obtidos em estações climáticas fora da área de estudo. Esse fator pode ter prejudicado a precisão da simulação dos processos nas unidades de estudo.

Conforme foi mencionado por Pereira-Silva et al. (2006), ao estudar os córregos da microbacia hidrográfica do córrego do Beija-Flor, a instalação de vertedouros e dados referentes ao balanço hídrico auxiliariam na obtenção dos valores de descarga do corpo d’água. Além disso, a medição da velocidade da água e de outras variáveis que pudessem evidenciar alterações 
longitudinais e transversais que eventualmente ocorram no canal dos corpos d'água estudados, seria importante para o programa de monitoramento. A situação verificada por esses autores na MBH-BF é semelhante ao que ocorre na MBH-G.

Os dados hidrológicos são de fundamental importância para o entendimento dos processos ambientais que ocorrem na área de estudo. De acordo com Guereschi (2004) a precipitação pluvial é um fator com forte influência na dinâmica dos sistemas aquáticos da EEJ, especialmente na área da planície de inundação. Os resultados obtidos por esse trabalho indicaram a ocorrência de alterações no volume e na qualidade da água na foz do córrego BeijaFlor, localizada na planície de inundação do rio Mogi-Guaçu. Segundo a autora, as alterações são ocasionadas pelo transbordamento das águas desse rio na época de chuvas intensas. A água invade a planície de inundação e mistura-se com a água do córrego, aumentando o nível, verificado pelo aumento brusco da profundidade, e gerando diminuição da transparência e alteração da cor da água.

A precipitação é um fator que influencia na composição das comunidades de organismos aquáticos, como os macroinvertebrados bentônicos, no córrego Beija-Flor, sendo provavelmente responsável pelas alterações na densidade de indivíduos e riqueza taxonômica (Guereschi, 2004). Isso ressalta a importância do monitoramento das variações do volume de escoamento superficial nas áreas de produção agrícola, no período de maior precipitação, que atingem os corpos aquáticos.

Em função da escassez de uma série de dados da área de estudo e do curto espaço de tempo da pesquisa, algumas etapas que fazem parte da seqüência de etapas do processo de modelagem como validação, calibração e análise de sensibilidade não foram realizadas. Esses são os passos finais quando a modelagem é utilizada como ferramenta no processo de gerenciamento ambiental. Vale ressaltar que são necessários 10 a 20 anos de dados coletados para calibrar o modelo SWAT de maneira acurada (Fitzhugh e Mackay, 2000).

No entanto, séries de dados de poucos anos podem contribuir para melhoria aceitável dos resultados gerados pelo modelo. Machado e Vettorazzi (2003) compararam o resultado da simulação da produção de sedimentos na microbacia do ribeirão dos Marins (Piracicaba/SP), pela aplicação do modelo SWAT, com os dados observados em posto hidrossedimentométrico localizado no interior da microbacia. Os autores utilizaram dois anos de dados. Na análise estatística comparativa, foi elaborado o coeficiente de eficiência (COE) e o desvio dos dados simulados em relação aos dados medidos, possibilitando a determinação da eficiência do modelo. Os resultados mostraram que o modelo SWAT apresentou uma boa estimativa em relação aos dados observados. Os valores mensais simulados, referentes à produção de sedimentos, 
apresentaram boa correlação com os valores medidos, sendo o $r^{2}$ entre as variáveis de 0,92 , significativo a $1 \%$.

De acordo com Machado e Vettorazzi (op cit.), embora o modelo SWAT tenha representado a variação da produção de sedimentos da microbacia razoavelmente bem como um todo, houve períodos em que a produção de sedimentos foi superestimada em relação aos dados observados e, em outros, subestimada.

Um fator importante na aplicação do SWAT, relaciona-se aos dados de entrada de cobertura e desenvolvimento vegetal, e, também, aos dados de preparo e manejo do solo. Esses dados, extremamente numerosos, não foram alterados, tendo sido utilizada a própria base de dados do modelo.

Tendo em vista que os dados referentes aos citros não estavam disponíveis na base de dados do modelo, foi utilizada a cobertura genérica intitulada pomar (“orchard”). Os dados genéricos utilizados pelo modelo para esse tipo de cultura genérica são referentes à cultura da maçã. Além dos citros, os dados de entrada utilizados para as áreas de vegetação natural são relacionados às florestas de Pinheiros (Pinus). Assim, os dados de entrada do modelo SWAT não foram alterados para as condições de florestas brasileiras como o cerrado, a mata ciliar, a mata atlântica, as quais são observadas no estado de São Paulo.

A interpretação qualitativa dos resultados gerados pelo modelo SWAT foi extremamente coerente com os resultados obtidos pela aplicação da EUPS. Não obstante, a interpretação quantitativa deve ser realizada com cuidados. Na simulação dos cenários cana-de-açúcar, com ocupação dessa cultura em toda a área da MBH-BF e SBH-BFJ (Figuras 108 e 116), foi observado aumento excessivo nos valores das estimativas de perda de sedimentos. Tendo em vista a ocorrência de regiões de maior vulnerabilidade ambiental nessas áreas, a magnitude da variação na produção de sedimentos pode ser considerada como um bom indicativo das mudanças que ocorreriam com o desenvolvimento de tal cenário.

Um problema identificado nos resultados obtidos pela aplicação do modelo SWAT referiuse aos valores do fator SED/USLE. Os valores deveriam ser menores do que um, ou seja, a erosão deveria ser maior do que as cargas de sedimentos produzidas nas microbacias. No entanto, foi observado na MBH-BF, valores maiores do que um em todos os cenários simulados. Na MBH-BFJ foram observados valores maiores do que um no cenário cana-de-açúcar. Apenas na MBH-G os valores permaneceram abaixo de um em todos os cenários. Esse é um tipo de problema que deveria ser corrigido na realização da validação, calibração e análise de sensibilidade dos parâmetros do modelo. 
No que se refere à qualidade da água, estudos foram realizados apenas na MBH-BF. Tendo em vista que as informações foram escassas em função dos dados de entrada requeridos pelo modelo, os resultados de qualidade da água gerados pelo modelo SWAT não foram considerados.

A utilização do SWAT no estudo dos processos ambientais em áreas alagáveis não foi realizada, em função da escala da base de dados utilizada. Na região da planície de inundação do rio Mogi-Guaçu, a pequena variação altimétrica impossibilitou o processo de simulação. Tendo em vista que o modelo dispõe, também, de análises específicas para esse tipo de ecossistema, a geração de dados mais precisos de cotas altimétricas para a planície de inundação do rio, e do contorno atualizado dos corpos aquáticos existentes na área, permitirá a inclusão desse tipo de análise em estudos posteriores.

\subsection{EUPS e SWAT como Indicadores Ambientais de Bacias Hidrográficas}

Modelos empíricos como a EUPS têm sido utilizados em função de sua estrutura simples e facilidade de aplicação. No entanto, por serem baseados em coeficientes computados ou calibrados com base em medidas ou observações, esses modelos não podem descrever ou simular processos erosivos como um conjunto de fenômenos físicos (Amore et al., 2004).

O propósito dos modelos empíricos como a EUPS, desenvolvidos pelos resultados de trabalhos experimentais, é descrever o que foi observado experimentalmente ou coletado em um levantamento. Portanto, qualquer tipo de extrapolação para condições diferentes daquelas em que os dados originais foram obtidos, é extremamente perigosa. Isso limita muito a capacidade preditiva do modelo. Em conseqüência, a experimentação é feita de forma repetitiva no espaço e no tempo, até que se consiga acumular um volume considerável de informações que permitam parametrizar os resultados e fazer inferências e previsões calibradas (Pessoa et al., 1997).

Os modelos físicos apresentam vantagens em relação aos modelos empíricos por simularem os componentes individuais de todo o processo erosivo pela solução das equações correspondentes. Esses modelos possibilitam a aplicação em grande variedade de condições e contribuem para o entendimento dos processos associados à natureza por meio do relacionamento da teoria com a realidade. São, geralmente, melhores em termos de sua capacidade de acessar tanto a variabilidade espacial como temporal dos processos naturais de erosão (Amore et al., 2004; Anderson e Burt, $1985^{11}$ apud Griebeler et al., 2001).

A integração da EUPS com SIG, assim como do modelo hidrossedimentológico SWAT versão AVSWAT 2000, também integrada ao SIG, facilitou a manipulação dos dados de entrada

\footnotetext{
${ }^{11}$ Anderson, M.G.; Burt, T.P. Modelling strategies. In: Anderson, M.G.; Burt, T.P. (eds.), Hydrological forecasting, Willey, Chichester, 1985. p. 1-13.1985
} 
e a visualização dos resultados finais. Em contraste aos modelos concentrados tradicionais, o enfoque distribuído, tanto da EUPS como do modelo SWAT, contribuiu para a identificação de áreas mais críticas relacionadas aos processos erosivos e à produção de sedimentos. Os resultados obtidos pela utilização desses modelos poderão ser utilizados, indubitavelmente, na identificação dos usos do solo mais apropriados e das práticas de manejo mais adequadas para os setores mais vulneráveis da microbacia hidrográfica do córrego do Beija-Flor/Jataí.

A utilização de um modelo baseado em processos físicos como o SWAT-2000 não é tão prática como a da EUPS, em função do número de dados requeridos para sua aplicação. Entretanto, por ser um modelo mais complexo, fornece estimativas de variados parâmetros, possibilitando o entendimento de um maior número de processos na bacia hidrográfica.

A utilização pioneira no Brasil dos dois modelos ambientais, um empírico e outro conceitual, foi extremamente interessante para a pesquisa. Os resultados referentes à aplicação da EUPS puderam ser comparados com os resultados gerados pelo SWAT. E, nos demais parâmetros, os modelos foram complementares, devido às inúmeras informações geradas pelo modelo SWAT.

A EUPS, modelo tradicional, largamente aplicado em estudos em diferentes escalas inclusive em bacias hidrográficas, comprovou ser eficaz na avaliação do risco à erosão no enfoque do trabalho ( $1^{\mathrm{a}}$ aproximação, reconhecimento, identificação de áreas de maior vulnerabilidade).

De acordo com Sonneveld e Nearing (2003) a estrutura simples da fórmula da EUPS facilita a formulação de cenários baseados em diferentes usos do solo (Fatores C e P) em diferentes condições ecológicas (Fatores R, K, L e S). Essas características citados por esses autores, associadas à reduzida quantidade de dados necessária para manipulação do modelo, quando comparada ao SWAT ou outros modelos físicos, tornou o seu uso bastante interessante.

Entretanto, é importante ressaltar que na modelagem com a EUPS, cada um dos seis fatores da equação, relacionados à erosão, são uma função de numerosas variáveis sedundárias e suas interações. Isso deve ser considerado quando são computados valores locais dos fatores. Além disso, cada fator é derivado independentemente, enquanto que na realidade, os fatores interagem em um sistema dinâmico e várias suposições devem ser realizadas para adaptar o modelo a um dado conjunto de condições que é alcançado ao usar valores médios anuais (Mati et al. 2000).

Nesse sentido, em comparação ao SWAT, versão AVSWAT-2000, o uso da EUPS no estado de São Paulo apresenta vantagens operacionais pela disponibilidade de dados de entrada relacionados a maior parte dos parâmetros da equação, gerados nos estudos de longos períodos de Bertoni e Lombardi Neto (1999). 
Da mesma forma que a EUPS, o SWAT envolve determinação separada dos dados de entrada que, posteriormente, são considerados conjuntamente pelo modelo. Os dados da USLE, obtidos pelo modelo SWAT, foram muito mais elevados do que os obtidos pela aplicação da EUPS. Isso ressalta os extensos estudos realizados no Brasil, principalmente no estado de São Paulo, e todo o conhecimento adquirido, possibilitando a utilização da EUPS, de maneira acurada, na previsão dos processos erosivos.

O SWAT mostrou-se como uma ferramenta promissora, nessa primeira aproximação relacionada às microbacias da área de estudo, com ressalvas aos dados quantitativos. Deve-se considerar que nenhum modelo apresentará 100\% de acuracidade (Silva e Oliveira, 1999). No entanto, mesmo com a complexidade para levantamento dos dados necessários aos processos de validação e calibração, o processo de modelagem deve caminhar no sentido de melhorar a qualidade da simulação aproximando-se do real.

Outras partes do modelo não foram aplicadas para a área de estudo nessa primeira aproximação por não fazerem parte do escopo do estudo. A quantificação dos químicos, a simulação da qualidade da água nos corpos aquáticos, entre outras partes, poderão contribuir com informações de grande utilidade para o conhecimento dos sistemas.

Existem poucos trabalhos na literatura relacionados ao modelo SWAT. Dessa forma, os trabalhos com esse modelo devem ser estimulados no país. Além disso, tendo em vista as mudanças climáticas regionais e globais, torna-se fundamental a quantificação dos processos relacionados ao ciclo hidrossedimentológico em ambientes carentes de estudos e, também, o acompanhamento das alterações em ambientes onde os processos são conhecidos. 


\section{CONCLUSÕES}

Os resultados permitiram concluir que a carência de dados referentes aos processos hidrossedimentológicos constituiu uma limitação ao refinamento dos dados produzidos, principalmente os dados gerados pelo modelo SWAT. Dessa forma, o trabalho de pesquisa foi realizado em escala de reconhecimento.

A utilização do modelo empírico EUPS e do modelo conceitual SWAT, foi considerada como uma primeira aproximação para a previsão do risco à erosão, da produção de sedimentos e da perda de água. Tendo em vista o enfoque adotado para o trabalho, a aplicação desses modelos foi extremamente satisfatória gerando informações importantes para a área de estudo e para o aprofundamento do conhecimento relacionado aos recursos solo, áreas alagadas e água, inseridos nas unidades e subunidades de estudo.

Foi possível estimar a perda de solo por erosão para microbacias hidrográficas submetidas a diferentes usos e ocupações do solo

As perdas de solo, estimadas pela EUPS, foram, em geral, proporcionais aos valores mais elevados de declividade, do fator LS e do PNE. O fator grau do declive e comprimento de rampa (LS) foi o condicionante de maior influência nos resultados finais da EUPS.

Os resultados confirmaram as expectativas pré-estudo de que os valores de erosão na área da EEJ seriam mais baixos. Porém, os resultados foram reveladores em função da média de perda de solo por erosão superficial da MBH-BF ser maior do que a MBH-G.

Foi possível estimar a perda de solo por erosão na região de áreas alagáveis do rio MogiGuaçu e entorno.

Conforme era esperado, foi observado que a erosão referente à parte baixa da BD-SC foi bem maior do que a verificada na parte baixa da BD-LA. O uso agrícola da área a montante da bacia BD-SC, e de algumas áreas na parte baixa, faz com que o risco provocado pelas cargas de sedimentos geradas na área da bacia seja bem mais elevado na região agrícola (margem esquerda do rio Mogi-Guaçu) do que na região ocupada pela EEJ (margem direita do rio). 
Foram identificadas áreas de maior vulnerabilidade ambiental na área de estudo.

Grande parte dos riscos de processos erosivos, identificados nos setores agrícolas da área de estudo, foi relacionada aos carreadores e às estradas rurais. Isso foi observado principalmente na cultura de cana-de-açúcar.

Devido ao uso agrícola dos solos na região à montante da $\mathrm{MBH}-\mathrm{BF}$, inclusive na zona de entorno, pode-se inferir que a área da Estação Ecológica de Jataí (a SBH-BF) está submetida a acentuado estresse ambiental.

Foi possível estimar parâmetros do balanço hídrico e as cargas de sedimentos para as microbacias hidrográficas estudadas

Foi possível elaborar cenários ambientais, frente a usos e ocupações do solo hipotéticos, para as microbacias hidrográficas estudadas

O modelo SWAT foi sensível às mudanças de cenários de uso do solo e possibilitou identificar áreas de maior vulnerabilidade ambiental 


\section{SUGESTÕES FUTURAS}

Com base no presente estudo, sugere-se algumas linhas de pesquisa poderiam ser desenvolvidas a fim de contribuir com a compreensão dos processos ambientais relacionados a área de estudo:

$\checkmark$ Realizar o monitoramento de variáveis hidrossedimentológicas nas unidades e subunidades de estudo a fim de gerar dados específicos para as etapas de validação e calibração do modelo SWAT.

$\checkmark$ Desenvolver estudos com parcelas experimentais para medição da erosão nas áreas de maior variação clinográfica, e que apresentaram os maiores valores do Fator LS e de PNE.

Desenvolver estudos para medição da erosão nas áreas dos carreadores rurais e para inclusão dessas áreas nas estimativas de perda de solo por erosão.

$\checkmark$ Realizar levantamento mais detalhado da área de preservação permanente do rio MogiGuaçu na margem localizada no município de São Carlos e, também, da extensão das áreas alagáveis da BD-SC.

Realizar medidas da profundidade do lençol freático nas bacias de drenagem e variação anual do nível confrontando essas informações com a utilização de agroquímicos nas áreas de uso agrícola

$\checkmark$ As estimações da perda de solo relacionadas à região da Serra do Jataí e demais regiões da MBH-BF, que apresentam variação clinográfica acentuada, necessitam de um número maior de observações de campo. Essas observações deverão verificar a ocorrência e os tipos de processos erosivos, e a necessidade de alteração no uso do solo nas regiões de maior vulnerabilidade ambiental. 
$\checkmark$ Realizar trabalhos de pesquisa para avaliação geocronológica dos sedimentos das lagoas marginais do rio Mogi-Guaçu, localizadas no município de São Carlos (área da BD-SC). 


\section{REFERÊNCIAS BIBLIOGRÁFICAS}

AGRONEGÓCIO. Informativo mensal. Ribeirão Preto: ABAG-RP, n. 21, set. 2002.

AGRONEGÓCIO. Informativo mensal. Ribeirão Preto: ABAG-RP, n. 31, ago. 2003.

AGRONEGÓCIO. Informativo mensal. Ribeirão Preto: ABAG-RP, n. 33, out. 2003.

AGRONEGÓCIO. Informativo mensal. Ribeirão Preto: ABAG-RP, n. 49, abr. 2005.

ALBUQUERQUE, A.L.S.; FERNANDES, M.A.; CORDEIRO, R.C.; SIMÕES FILHO, F.F.L. Secular trophic changes in the Infernão Lake (Jataí Ecological Station, SP) based on sedimentary pigments profiles. In: SANTOS, J.E.; PIRES, J.S.R. (eds.), Estudos Integrados em Ecossistemas: Estação Ecológica de Jataí. São Carlos: RIMA, 2000. v. 2. p. 359-364.

ALVES, H.M.R.; ALVARENGA, M.I.N.; LACERDA, M.P.C.; VIEIRA, T.G.C. Avaliação das terras e sua importância para o planejamento racional do uso. Informe Agropecuário. Belo Horizonte, v. 24, n. 220, p. 82-93, 2003.

AMARAL, J.A.B. Estudo da várzea da planície de inundação da bacia do Ribeirão do Feijão-SP. 2002. 109p. Tese (Doutorado em Hidráulica e Saneamento) - Escola Superior de Agricultura “Luiz de Queiroz”, Universidade de São Paulo, Piracicaba.

AMARAL, T.M. Inclusão do controle de deflúvio em modelos de gestão florestal: um estudo no Vale do Paraíba - SP. 2002. 64p. Dissertação (Mestrado em Recursos Florestais) Escola Superior de Agricultura “Luiz de Queiroz”, Universidade de São Paulo, Piracicaba.

AMORE, E.; MODICA, C.; NEARING, M.A.; SANTORO, V.C. Scale effect in USLE and WEPP application for soil erosion computation from three Sicilian basins. Journal of Hydrology, v. 293, p. 100-114, 2004.

ANDRADE, M.; LORANDI, R.; TRINDADE, M.; FERNANDES, M.; MINOTI, R.T. Caracterização Física, Química e Mineralógica dos Sedimentos das Lagoas do Infernão e Diogo (SP). Geociências, v. 12, n. 2, p.503-514, 1993.

ARGENTO, M.S.F.; CRUZ, C.B.M. Mapeamento Geomorfológico. In: Geomorfologia: exercícios, técnicas e aplicações. Orgs. Cunha, S.B. \& Guerra, A.J.T. Rio de Janeiro, Bertrand Brasil. 2002. p. 265-282.

ARMAS, E.D. Comportamento de glifosate em solo de várzea sob sistema plantio direto e a eletroforese capilar na análise de resíduos. 2002. 186p. Dissertação (Mestrado em Ciências -Área de concentração - Energia Nuclear na Agricultura) - Centro de Energia Nuclear na Agricultura, Universidade de São Paulo, Piracicaba.

ARNOLD, J.G.; WILLIAMS, J.R.; NICKS, A.D.; SAMMONS, N.B. SWRRB: A basin scale simulation model for soil and water resources management. Texas: A\&M Univ. Press, College Station, 1990.115p.

ARNOLD, J.G.; WILLIAMS, F.R.; MAIDMENT, D.R. Continuous-time water and sediment routing model for large basins. Hydr. Engin., v. 121, p.171-183, 1995. 
ARNOLD, J.G.; SRINIVASAN, R.; MUTTIAH, R.S.; WILLIAMS, J.R. Large area hydrologic modeling and assessment. Part I: model development. JAWRA, v. 34, n. 1, p. 73-89, 1998.

BERTOLINI, D.; KROLL, F.M.; LOMBARDI NETO, F.; CRESTANA, M.S.M.; DRUGOWICH, M.I.; ELIAS, R.; CORREAA, R.O.; BELLINAZI JR.; R. Tecnologias Disponíveis para a Implementação de Técnicas Complementares no Solo. In: Manual Técnico de Manejo e Conservação do Solo e Água. Coords. Lombardi Neto, F.; Drugowich, M.I. Vol. V. Manual nº 42. CATI. 1994.

BARRETO NETO, A.A. Modelagem Dinâmica de Processos Ambientais. 2004. 123p. Tese (Doutorado em Geociências) - Instituto de Geociências, Universidade Estadual de Campinas, Campinas.

BARROS, E. S.; PEIXOTO, M. F. S. P.; FAY, E. F.; MONTEIRO, R.T.R. Efeito de doses crescentes dos herbicidas Trifuralina e Glifosato sobre a atividade microbiana de um solo de várzea. In: XXVI Congreso Brasileiro de Ciência do Solo, 1997, Rio de Janeiro/ RJ.

BASIC, F.; KISIC, I.; MESIC, M.; NESTROY, O.; BUTORAC, A. Tillage and crop management effects on soil erosion in central Croatia. Soil \& Tillage Research, v. 78, p. 197-206, 2004.

BEASLEY,D.B.; HUGGINS, L.F.; MONKE, E.J. ANSWERS: a model for Watershed Planning. Transactions of the ASAE, v. 23, n.4, p. 938-944, 1981.

BERTONI, J.; LOMBARDI NETO, F. Conservação do Solo. Piracicaba: Livroceres, 1999. 392p.

BERTONI, J.; LOMBARDI NETO, F.; BENATTI JR. Equação de perdas de solo. Instituto Agronômico, Campinas, 1975. 25p. (Boletim Técnico, 21).

BEVEN, K.; FREER, J. A dynamic TOPMODEL. Hydrological Processes, v. 15, p. 1993-2011, 2001.

BIANCHINI JR., I. A decomposição da vegetação e o consumo de oxigênio nos reservatórios: implicações ecológicas. In: HENRY, R. ed. Ecologia de Reservatórios: Estrutura, Função e Aspectos. Botucatu, Fundibio, FAPESP. 1999. Cap. 21, p. 627-50.

BORAH, D.K.; XIA, R.; BERA, M. DWSM - A Dynamic Watershed Simulation Model. IN: SINGH, V.P.; FREVERT, D. (EDS.). Mathematical models of small watershed hydrology applications. Chelsea: Water Resources Publications, 2002. P. 113-166.

BRANDÃO, D. Risco de degradação dos recursos hídricos na Bacia do Ribeirão PinhalLimeira (SP): uma proposta metodológica. 2001. 85p. Dissertação (Mestrado em Engenharia Agrícola) - Faculdade de Engenharia Agrícola, Universidade Estadual de Campinas, Campinas.

BRIGHT, C. Estado do Mundo, 2003; A Impossível Revolução Ambiental Está Acontencendo. Salvador. Uma Ed. 2003. 296p.

BUENO, C.R.P. Zoneamento da susceptibilidade à erosão dos solos da alta e média bacia do rio Jacaré-Pepira - SP, com vistas ao planejamento ambiental. 1994. 137p. Tese 
(Doutorado em Geociências - área de concentração: Geociências e Meio Ambiente) - Curso de Pós-Graduação em Geociências, Universidade Estadual Paulista, Rio Claro.

BUENO, C.R.P.; STEIN, D.P. Potencial natural e antrópico de erosão na região de Brotas, Estado de São Paulo. Acta Scientiarum, Maringá, v. 26, n. 1, 1-5, 2004.

CABRAL; N.R.A.J.; SOUZA, M.P. Área de Proteção Ambiental. Planejamento e Gestão de Paisagens Protegidas. São Carlos. RIMA. 2002. 154p.

CALDERANO FILHO, B.; SANTOS, H.G.; FONSECA, O.O.M.; SANTOS, R.D.; PRIMAVESI, O.; PRIMAVESI, A.C. Os solos da Fazenda Canchim, Centro de Pesquisa de Pecuária Sudeste, São Carlos, SP: Levantamento semidetalhado, propriedades e potenciais. Rio de Janeiro: Embrapa CNPS / São Carlos: Embrapa CPPSE. 1998. 95 p.

CALHOUN, R.S. e FLETCHER III, C.H. Measured and predicted sediment yield from a subtropical, heavy rainfall, steep-sided river basin: Hanalei, Kauai, Hawaiian Islands. Geomorphology, v. 30, p.213-226, 1999.

CALIJURI, M. C.; BUBEL, A. P. M. Conceituação de Microbacias. In: Lima, W.P.; Zakia, M. J. B.(eds). As florestas plantadas e a água: implementando o conceito da microbacia hidrográfica como unidade de planejamento. RIMA. São Carlos: RIMA, 2006. p. 45 - 59.

CANÇADO, C.J. Zoneamento conceitual da expansão das atividades antrópicas relacionado à inundação - estudo de caso: Bacia do Rio Bonito (SP). 2003. 388p. Tese (Doutorado em Ciências - área de concentração: Ecologia e Recursos Naturais) - Programa de PósGraduação em Ecologia e Recursos Naturais, Universidade Federal de São Carlos, São Carlos.

CARVAlHO, N.O. Hidrosedimentologia Prática. Companhia de Pesquisa de Recursos Minerais e Eletrobrás. 1994.

CASTRO, A.G.; VALÉRIO FILHO, M. Simulação da expectativa de perdas de solo em microbacia sob diferentes manejos florestais. R. bras. Ci. Solo, Viçosa, v. 21, p. 419-426, 1997.

CAVALLI, A.C. Utilização de dados espectrais dos sensores TM/LANDSAT-5 e AVHRR/NOAA-14 como indicadores de processos de degradação do solo. 1999. 153p. Tese (Doutorado em Geociências - área de concentração: Geociências e Meio Ambiente) Curso de Pós-Graduação em Geociências, Universidade Estadual Paulista, Rio Claro.

CHAPLOT, V. Impact of DEM mesh size and soil map scale on SWAT runoff, sediment, and $\mathrm{NO}_{3}-\mathrm{N}$ loads predictions. Journal of Hydrology, v. 312, p. 207-222, 2005.

CHRISTOFOLETTI, A. Modelagem de Sistemas Ambientais. São Paulo: Edgard Blücher, 1999. 236p.

COHEN, M.J.; SHEPHERD, K.D.; WALSH, M.G. Empirical reformulation of the universal soil loss equation for erosion risk assessment in a tropical watershed. Geoderma, v. 124, p. 235252, 2005. 
COMITÊ DE BACIA HIDROGRÁFICA DO RIO MOGI GUAÇU (1999). Diagnóstico da Bacia Hidrográfica do Rio Mogi Guaçu “Relatório Zero”. Comitê da Bacia Hidrográfica do Rio Mogi Guaçu. 252p.

CRESTANA, S. Harmonia e Respeito Entre Homens e Natureza: Uma Questão de Vida - A Contribuição da Agricultura. In: CASTELLANO, E.G.; CHAUDHRY, F.H. (eds.), Desenvolvimento Sustentado: Problemas e Estratégias. São Carlos. EESC-USP. 2000. Cap.9, p. 169-180.

CRISCUOLO, C.; QUARTAROLI, C.F.; MIRANDA, E.E.; GUIMARÃES, M.; HOTT, M.C. Dinâmica do uso e cobertura das terras na região nordeste do estado de São Paulo. Campinas: Embrapa Monitoramento por Satélite - Documentos, 45. 2005. 65p.

CRUCIANI, D.E.; BAPTISTA, G.C.; CHRISTOFFOLETI, P.J.; MINAMI, K. Comportamento de herbicida em solo de várzea com drenagem subterrânea. Scientia Agricola, v. 53, n. 2-3, p. 316-323. 1996.

DAEE e IPT. Relatório de Qualidade Ambiental do Estado de São Paulo. Lei no 9509/97. 2004/2005. São Paulo: 2005, 278p.

DE ROO, A.P.J.; WESSELING, C.G.; RITSEMA, C.J. LISEM: a single event physically-based hydrologic and soil erosion model for drainage basins: I. Theory, input and output. Hydrological Processes, v. 10, n. 8, p. 1107-1117, 1996a.

DE ROO, A.P.J.; OFFERMANS, R.J.E.; CREMERS, N.H.D.T. LISEM: a single event physically-based hydrologic and soil erosion model for drainage basins: II. Sensitivity analysis, validation and application. Hydrological Processes, v. 10, n. 8, p. 1119-1126, 1996b.

DI LUZIO, M.Di.; SRINIVASAN, R.; ARNOLD, J.G.; NEITSCH, S.L.; WILLIAMS, J.R. ArcView Interface for SWAT2000 - User's Guide. Temple, Blackland Research Center, Texas Agricultural Experiment Station, 2002. 345p.

EL-SWAIFY, S.A.; DANGLER, F.W. Rainfal Erosion in the Tropics: A State-of-the Art. In: EL-SWAIFY, S.A. et al. (orgs), Soil Erosion and Conservation in the Tropics. Madison. American Society of Agronomy. Special Publication Number 43. 1982. Cap. 1. p. 1-25.

EMBRAPA. Sistema Brasileiro de Classificação de Solos. Rio de Janeiro: Embrapa Solos, 1999. 306p.

EMBRAPA Pesquisa, desenvolvimento e inovação para o agronegócio brasileiro. Cenários 2002-2012. Brasília: Embrapa Informação Tecnológica, 2003. 91p.

EMBRAPA Pecuária Sudeste. Dados Meteorológicos. 2005. Base de dados disponível em : < http://www.cppse.embrapa.br/servicos/dados-meteorologicos>. Acesso em 17 de janeiro de 2005.

EPA. Index of Watershed Indicators. An Overview. United States Environmental Protection Agency. Office of Wetlands, Oceans, and Watersheds. 2002.

EPA. Draft Report on the Environment 2003. United States Environmental Protection Agency. 2003. 
ESRI - Environmental Systems Research Institute. Redlands CA, 1998

FAURÈS, J.M.; GOODRICH, D.C.; WOOLHISER, D.A.; SOROOSHIAN, S. Impact of smallscale spatial rainfall variability on runoff modeling. Journal of Hydrology, v. 173, p. 309326, 1995.

FERES, R. Análise de processos de erosão acelerada, com base em fotografias aéreas e geoprocessamento: Bacia do Rio Bonito (Descalvado, SP). 2002. 142p. Tese (Doutorado em Ciências - área de concentração: Ecologia e Recursos Naturais) - Programa de PósGraduação em Ecologia e Recursos Naturais, Universidade Federal de São Carlos, São Carlos.

FERNÀNDEZ, G.A.V. Análise da erosão do solo usando a EUPS, através de técnicas de sensoriamento remoto e geoprocessamento. 1996. 143p. Dissertação (Mestrado em Sensoriamento Remoto) - Instituto Nacional de Pesquisas Espaciais, São José dos Campos.

FILIZOLA, H.F.; PESSOA, M.C.P.Y.; GOMES, M.A.F.; SOUZA, M.D. Contaminação dos solos em áreas agrícolas. In: Uso Agrícola dos Solos Brasileiros. Eds. MANZATTO, C.V.; FREITAS JUNIOR, E.; PERES, J.R.R. Rio de Janeiro, 2002. Embrapa Solos. p. 79-86. 2002.

FIORIO, P.R.; DEMATTÊ, J.A.M.; SPAROVEK, G. Cronologia e impacto ambiental do uso da terra na microbacia hidrográfica do Ceveiro, em Piracicaba, SP. Pesq. agropec. bras., Brasília, v. 35, n. 4, p. 671-679, abr. 2000.

FITZHUGH, T.W.; MACKAY, D.S. Impacts of input parameter spatial aggregation on an agricultural nonpoint source pollution model. Journal of Hydrology, v. 236, p. 35-53, 2000.

FLANAGAN, D.C.; NEARING, M.A. USDA Water Erosion Prediction Project: Hillslope Profile and Watershed Model Documentation. NSERL Report $\mathrm{N}^{\circ}$ 10, USDA-ARS National Soil Erosion Research Laboratory, West Lafayette, 1995.

FLORENZANO, T.G. Imagens de satélite para estudos ambientais. São Paulo: Oficina de Textos, 2002. 97p.

FLORES, C.A.; MANZATTO, C.V.; SÁ, I.B.; ACCIOLY, L.J.O.; SÁ, T.D.A.; SILVA, F.H.B.B.; SILVA, T.C.C. Outras formas de degradação do solo. In: Uso Agrícola dos Solos Brasileiros. Eds. MANZATTO, C.V.; FREITAS JUNIOR, E.; PERES, J.R.R. Rio de Janeiro, 2002. Embrapa Solos. p. 93-104. 2002.

FUJIHARA, A.K. Predição de erosão e capacidade de uso do solo numa microbacia do oeste paulista com suporte de geoprocessamento. 2002. 118p. Dissertação (Mestrado em Ciências Florestais) - Escola Superior de Agricultura "Luiz de Queiroz", Universidade de São Paulo, Piracicaba.

FUNDAÇÃO SEADE. Informações Municipais. Disponível em: <http://www.seade.gov.br> Acesso em: 12 dezembro 2004. 
GALDINO, S.; VIEIRA, L.M.; PADOVANI, C.R.; SORIANO, B.M.A. Erosão Potencial Laminar Hídrica na Bacia do Alto Taquari. Revista Brasileira de Recursos Hídricos, v. 9, n. 2, p. 125-133, 2004.

GARRIDO, J.M. Aplicação de Modelo Matemático de Simulação com Utilização de SIG à Bacia do Rio Jiquiriçá - Bahia. 2003. 186p. Dissertação (Mestrado em Tecnologia Ambiental e Recursos Hídricos) - Faculdade de Tecnologia, Departamento de Engenharia Civil e Ambiental, Universidade de Brasília, Brasília.

GOODRICH, D.C.; FAURÈS, J.M.; WOOLHISER, D.A.; LANE, L.J.; SOROOSHIAN, S. Measurement and analysis of small-scale convective storm rainfall variability. Journal of Hydrology, v. 173, p. 283-308, 1995.

GRIEBELER, N.P.; PRUSKI, F.F.; JÚNIOR, D.M.; SILVA, D.D. Avaliação de um modelo para a estimativa da lâmina máxima de escoamento superficial. R. bras. Ci. Solo, Viçosa, v. 25, p. 411-417, 2001.

GRIZETTI, B.; BOURAOUI, F.; GRANLUND, K.; REKOLAINEN, S.; BIDOGLIO, G. Modelling diffuse emission and retention of nutrients in the Vantaanjoki watershed (Finland) using the SWAT model. Ecological Modelling, v. 169, p. 25-38, 2003.

GUERESCHI, R.M. Macroinvertebrados Bentônicos em Córregos da Estação Ecológica de Jataí, Luiz Antônio, SP: Subsídios para Monitoramento Ambiental. 2004. 82p. Tese (Doutorado em Ciências - área de concentração: Ecologia e Recursos Naturais) - Programa de Pós-Graduação em Ecologia e Recursos Naturais, Universidade Federal de São Carlos, São Carlos.

GUERESCHI, R.M.; FONSECA-GESSNER, A.A. Avaliação das variáveis físicas e químicas da água e do sedimento de três córregos da Estação Ecológica de Jataí, Luiz Antônio, SP, Brasil. In: SANTOS, J.E.; PIRES, J.S.R. (eds.), Estudos Integrados em Ecossistemas: Estação Ecológica de Jataí. São Carlos: RIMA, 2000. v. 2. p. 387-402.

HAREGEWEYN, N.; YOHANNES, F. Testing and evaluation of the agricultural non-point source pollution model (AGNPS) on Augucho catchment, western Hararghe, Ethiopia. Agricultural Ecosystems \& Environment, v. 99, p. 201-212, 2003.

HENKE-OLIVEIRA, C. Mapa da Estação Ecológica de Jataí (Luiz Antônio-SP) após o decreto da sua ampliação. http://lapa.ufscar.br 2006 (2 fev).

HERNANI, L.C.; FREITAS, P.L.; PRUSKI, F.F.; De MARIA, I.C.; CASTRO FILHO, C.; LANDERS, J.N. A Erosão e seu Impacto. In: Uso Agrícola dos Solos Brasileiros. Eds. MANZATTO, C.V.; FREITAS JUNIOR, E.; PERES, J.R.R. Rio de Janeiro, 2002. Embrapa Solos. p. 47-60. 2002.

HEWAWASAM, T.; BLANCKENBURG, F.v.; SCHALLER, M.; KUBIK, P. Increase of human over natural erosion rates in tropical highlands constrained by cosmogenic nuclides. Geology, v. 31, n. 7, p. 597-600, jul. 2003.

HUISMAN, J.A.; BREUER, L.; FREDE, H.G. Sensitivity of simulated hydrological fluxes towards changes in soil properties in response to land use change. Physics and Chemistry of the Earth, v. 29, p. 749-758, 2004. 
INSTITUTO AGRONÔMICO de CAMPINAS - IAC (Campinas, SP). Mapa de Solos do Estado de São Paulo. Campinas, 1982. 1 mapa. Folha: SF.23-V-C-IV. Escala 1:50.000.

INSTITUTO BRASILEIRO de GEOGRAFIA e ESTATÍSTICA (IBGE). Mapa Topográfico. 1971. Folha: SF.23-V-C-IV-1. Escala 1:50.000.

INSTITUTO de PESQUISAS TECNOLÓGICAS (IPT). Mapa Geomorfológico do Estado de São Paulo. Governo do Estado de São Paulo. São Paulo, 1981. 1 Mapa. Escala 1:1.000.000.

IPEADATA/IBGE. Indicadores Sociais e de Agropecuária. Disponível em: <http://www.ipeadata.gov.br>. Acesso em: 17 setembro 2005.

JETTEN, V.; ROO, A.; FAVIS-MORTLOCK, D. Evaluation of field-scale and catchment-scale soil erosion models. Catena, v. 37, p. 521-541, 1999.

KINELL, P.I.A. Slope length factor for applying the USLE-M to erosion in grid cells. Soil \& Tillage Research, v. 58, p. 11-17, 2001.

KIRKBY, M.J. Modelling across scales: the MEDALUS family of models. In: Boardman, J., Favis-Mortlock, D.T. (Eds.) Modelling Soil Erosion by Water. NATO-ASI Series I-55. Berlin: Springer, 1998, p. 161-174.

KIRKBY, M.J.; COX, N.J. A climatic index for soil erosion potential (CSEP) including seasonal and vegetation factors. Catena, v. 25, p. 333-352, 1995.

KITE, G.; DROOGERS, P. Integrated Basin Modelling. Research Report 43. International Water Management Institute. Colombo, 2000.

KNISEL, W.G. CREAMS, a field scale model for chemicals, runoff and erosion from agricultural management systems. USDA Conservation Research Rept. № 26. 1980.

KNISEL, W.G. CREAMS - a Field Scale Model for Chemicals, Runoff and Erosion from Agricultural Management Systems. US Department of Agriculture Research Report, $\mathrm{N}^{\circ}$ 26, 643p. 1985.

KNISEL, W.G. CREAMS/GLEAMS: a development overview. In: Beasley, D.B.; Knisel, W.G.; Rice, A.P. (Eds.), Proceedings of the CREAMS/GLEAMS Symposium, Publication 4, Agricultural Engineering Dept., University of Georgia, 1991. Atenas, GA, p. 9-17.

LACROIX, M.P. et al. Using Digital Terrain Analysis Modelling Techniques for the Parameterization of a Hydrologic Model. Environmental Modelling \& Software, v. 17, n. 2, p.127-136, 2002.

LAGROTTI, C.A.A. Planejamento Agroambiental do muniípio de Santo Antônio do Jardim - SP: Estudo de caso na Microbacia Hidrográfica do Córrego do Jardim. 2000. 124p. Tese (Doutorado em Engenharia Agrícola) - Faculdade de Engenharia Agrícola, Universidade Estadual de Campinas, Campinas.

LAMBIM, E.F.; TURNER, B.L.; GEIST, H.J.; AGBOLA, S.B.; ANGELSEN, A.; BRUCE, J.W.; COOMES, O.T.; DIRZO, R.; FISCHER, G.; FOLKE, C.; GEORGE, P.S.; HOMEWOOD, K.; IMBERNON, J.; LEEMANS, R.; LI, X.; MORAN, E.F.; 
MORTIMORE, M.; RAMAKRISHNAN, P.S.; RICHARDS, J.F.; SKANES, H.; STEFFEN, W.; STONE, G.D.; SVEDIN, U.; VELDKAMP, T.A.; VOGEL, C.; XU, J. The causes of land-use and land-cover change: moving beyond the myths. Global Environmental Change, v. 11, p. 261-269, 2001.

LAURITO, S.F. Estudo prospectivo visando o uso de sistemas agroflorestais no município de São Carlos, SP. 2004. 85p. Dissertação (Mestrado em Ciências da Engenharia Ambiental) - Escola de Engenharia de São Carlos, Universidade de São Paulo, São Carlos.

LEITE, M.A.; ESPÍNDOLA, E.L.G. Aporte e taxa de sedimentação de material em suspensão e nutrientes (nitrogênio orgânico total e fósforo total) no reservatório de Salto Grande. In: ESPÍNDOLA, E.L.G.; LEITE, M.A.; DORNFELD, C.B. (orgs.), Reservatório de Salto Grande (Americana, SP): Caracterização, Impactos e Propostas de Manejo. São Carlos: RIMA, 2004. p. Cap. 5, 71-90.

LEONARD, R.A.; KNISEL, W.G.; STILL, D.A. GLEAMS: Groundwater loading effects on agricultural management systems. Trans. ASAE, v. 30, n. 5, p. 1403-1428. 1987.

LICZNAR, P.; NEARING, M.A. Artificial Neural Networks of Soil Erosion and Runoff Prediction at the Plot Scale. CATENA, v. 51, p.89-114. 2003.

LIN, C.Y.; LIN, W.T. e CHOU, W.C. Soil erosion prediction and sediment yield estimation: the Taiwan experience. Soil \& Tillage Research, v. 68, p. 143-152, 2002.

LOMBARDI NETO, F. Equação Universal de Perda de Solo. Campinas. Instituto Agronômico. 1995. 6p.

LOMBARDI NETO, F. e BERTONI, J. Erodibilidade dos solos paulistas. Campinas, Instituto Agronômico, 1975a. 12p. (Boletim Técnico, 27).

LOMBARDI NETO, F. e BERTONI, J. Tolerância de perdas de terra para alguns solos do Estado de São Paulo. Campinas, Instituto Agronômico, 1975b. 12p. (Boletim Técnico, 28).

LOMBARDI NETO, F. e MOLDENHAUER, W.C. Erosividade da chuva: sua distribuição e relação com perdas de solo em Campinas, SP. In: Encontro Nacional de Pesquisa sobre Conservação do Solo, 3., Recife, 1980. Anais, fl. 13.

LOMBARDI NETO, F.; PRUSKI, F.F.; TEIXEIRA, A.F. Sistema para o cálculo da erosividade da chuva para o Estado de São Paulo. Grupo de Pesquisa em Recursos Hídricos, Departamento de Engenharia Agrícola, Universidade Federal de Viçosa. 1999. Software.

LORANDI, R.; GONÇALVES, A.R.L.; FREIRE, O.; TRINDADE, M. Levantamento pedológico semidetalhado da bacia do córrego do Jataí (SP) e áreas adjacentes. Relatório Técnico. Departamento de Engenharia Civil, UFSCAR. 1991. 84p.

LORANDI, R.; LACERDA, F.S. Mineralogia da Fração Argila dos Solos da Bacia do Córrego do Jataí (Luiz Antonio, SP). Científica, v. 20, n. 1, p. 9-17. 1992.

LORANDI, R.; FREIRE, O.; GONÇALVES, A.R.L.; TRINDADE, M. Mapa de Solos da Bacia do Córrego do Jataí e áreas adjacentes. São Carlos, 1990. 1 Mapa. Escala 1:25.000. 
LORANDI, R.; GONÇALVES, A.R.L.; TRINDADE, M.; SOBREIRA, M.L. Levantamento pedológico semidetalhado da microbacia do Córrego Cafundó e áreas adjacentes. In: Congresso Latinoamericano de La Ciencia del Suelo, 12, 1993a, Salamanca. Anais...Salamanca-Sevilla.

LORANDI, R.; CINTRA, V.C.U., SOUZA, J.A., BACHEGA, J.A. Caracterização geoquímica dos solos da microbacia hidrográfica do Córrego do Cafundó (SP, Brasil). In: Congresso Latinoamericano de La Ciencia del Suelo, 1993b, Salamanca. Anais. p. 255-263.

LUFAFA, A.; TENYWA, M.M.; ISABIRYE, M.; MAJALIWA, M.J.G.; WOOMER, P.L. Prediction of soil erosion in a Lake Victoria basin catchment using a GIS-based Universal Soil Loss model. Agricultural Systems, v. 76, p. 883-894, 2003.

MACEDO, R.K. (). A Importância da Avaliação Ambiental. In: TAUK, S.M., org. Análise Ambiental: uma visão multidisciplinar. São Paulo: Editora da Universidade Estadual Paulista. 1991. p. 11-26.

MACHADO, R.E. Simulação de escoamento e de produção de sedimentos em uma microbacia hidrográfica utilizando técnicas de modelagem e geoprocessamento. 2002. 152p. Tese (Doutorado em Agronomia) - Escola Superior de Agricultura "Luiz de Queiroz”, Universidade de São Paulo. Piracicaba.

MACHADO, R.; VETORAZZI, C.A. Simulação da produção de sedimentos para a microbacia hidrográfica do ribeirão dos Marins (SP). R. bras. Ci. Solo, Viçosa, v. 27, p. 735-741, 2003.

MACHADO, R.; VETORAZZI, C.A.; XAVIER, A.C. Simulação de cenários alternativos de uso da terra em uma microbacia utilizando técnicas de modelagem e geoprocessamento. R. bras. Ci. Solo, Viçosa, v. 27, p. 727-733, 2003.

MANZATTO, C.V.; FILHO, A.R.; COSTA, T.C.C.; SANTOS, M.L.M.; COELHO, M.R.; SILVA, E.F.; OLIVEIRA, R.P. Potencial de uso e uso atual das terras. In: Uso Agrícola dos Solos Brasileiros. Eds. MANZATTO, C.V.; FREITAS JUNIOR, E.; PERES, J.R.R. Rio de Janeiro, Embrapa Solos. 2002. p. 13-21.

MARCOMIN, F.E. Análise Ambiental da Bacia Hidrográfica do Rio Pinheiros (Municípios de Orleans e São Rudgero, SC) com Base na Caracterização e Diagnóstico dos Elementos da Paisagem e da Perda de Solo por Erosão Laminar. 2002. 155p. Tese (Doutorado em Ciências - área de concentração: Ecologia e Recursos Naturais) - Programa de Pós-Graduação em Ecologia e Recursos Naturais, Universidade Federal de São Carlos, São Carlos.

MARQUES, J.J.G.S.M.; ALVARENGA, R.C.; CURI, N.; SANTANA, D.P.; SILVA, M.L.N. Índices de erosividade da chuva, perdas de solo e fator erodibilidade para dois solos da região dos cerrados - primeira aproximação. R. bras. Ci. Solo, Viçosa, v. 21, p. 427-434. 1997.

MARQUES, J.F.; NETO, F.L.; BACELLAR, A.A.A. Erosão do Solo: Indicadores Físicos e Econômicos. In: Indicadores de Sustentabilidade em Agroecossistemas. Eds. MARQUES, J.F.; Skorupa, L.A.; Ferraz, J.M.G. Jaguariúna, Embrapa Meio Ambiente. 2003. p. 129-153. 
MARTOS, H.L.; MAIA, N.B. Indicadores Ambientais. Sorocaba. Esalq USP. 1997. 266p.

MATI, B.M.; MORGAN, R.P.C.; GICHUKI, F.N.; QUINTON, J.N.; BREWER, T.R.; LINIGER, H.P. Assessment of erosion hazard with the USLE and GIS: A case study of the Upper Ewaso Ng'iro North basin of Kenya. JAG, v. 2, n. 2, p. 78-86, 2000.

MATTOS, L.M. Uso dos Índices AF (Attenuation factor) e RF (Retardation factor) como Metodologia de Estudo de Contaminação por Pesticidas de Solo e Água Subterrânea. 1998. 189p. Dissertação (Mestrado em Ciências da Engenharia Ambiental) - Escola de Engenharia de São Carlos, Universidade de São Paulo, São Carlos.

MICHELLON, E. O êxito ambiental e econômico do manejo de solo e da água na microbacia Rio do Campo. Acta Scientiarum, Maringá, v. 25, n. 2, p. 329-337, abr. 2003.

MILLER, R.W. \& GARDINER, D.T. Soils in our Environment. New Jersey. Prentice Hall. 2001. 642p.

MINOTI, R.T. e CRESTANA, S. A perda de solo como indicador de vulnerabilidade de bacias hidrográficas: artigos publicados na Revista Brasileira de Ciência do Solo e em Congressos Brasileiros de Ciência do Solo, Manejo e Conservação. In: Espíndola, E.L.G.; SCHALCH, V. (orgs.), Bacia hidrográfica: diversas abordagens em pesquisa. São Carlos: RIMA, 2004. p. 47-54.

MITSCH, W.J.; GOSSELINK, J.G. Wetlands. New York. Van Nostrand. 1986. 586 p.

MOLNÁR, D.K.; JULIEN, P.Y. Estimation of upland erosion using GIS. Computers \& Geosciences, v. 24, n. 2, p. 183-192, 1998.

MORAES, M.E.B. Zoneamento ambiental de bacias hidrográficas: uma abordagem metodológica aplicada na Bacia do Rio Bonito (SP). 2003. 123p. Tese (Doutorado em Ciências - área de concentração: Ecologia e Recursos Naturais) - Programa de PósGraduação em Ecologia e Recursos Naturais, Universidade Federal de São Carlos, São Carlos.

MORGAN, R.P.C.; QUINTON, J.N.; SMITH, R.E.; GOVERS, G.; POESEN, J.W.A.; CHISCI, G.; TORRI, D. The EUROSEM Model. In: Boardman, J., Favis-Mortlock, D.T. (Eds.) Modelling Soil Erosion by Water. NATO-ASI Series I-55. Berlin: Springer, 1998, p. 389398.

MULETA, M.K.; NICKLOW, J.W. Sensitivity and uncertainty analysis coupled with automatic calibration for a distributed watershed model. Journal of Hydrology, v. 306, p. 127-145, 2005.

MURO, M.D. 2000 Carta de zoneamento para seleção de áreas frente à instalação de aterros sanitários no município de São Carlos - SP - escala 1:50.000. 2000. 278p. Dissertação (Mestrado em Geotecnia) - Escola de Engenharia de São Carlos, Universidade de São Paulo, São Carlos.

MUTTIAH, R.S.; WURBS, R.A. Scale-dependent soil and climate variability effects on watershed water balance of the SWAT model. Journal of Hydrology, v. 256, p. 264-285, 2002. 
NEITSCH, S.L.; ARNOLD, J.G.; KINIRY, J.R.; WILLIAMS, J.R.; KING, K.W. Soil and Water Assessment Tool - Theoretical Documentation: Version 2000. Temple, Blackland Research Center, Texas Agricultural Experiment Station, 2002a. 458p.

NEITSCH, S.L.; ARNOLD, J.G.; KINIRY, J.R.; SRINIVASAN, R.; WILLIAMS, J.R. Soil and Water Assessment Tool - User's Manual: Version 2000. Temple, Blackland Research Center, Texas Agricultural Experiment Station, 2002b. 412p.

NEVES, F.F. Análise prospectiva das áreas de risco à erosão na microbacia hidrográfica do rio Bonito (Descalvado - SP), potencialmente poluidoras por dejeto de granjas. 2005. 183p. Dissertação (Mestrado em Ciências da Engenharia Ambiental) - Escola de Engenharia de São Carlos, Universidade de São Paulo, São Carlos.

NEW, M.G. e SCHULZE, R.E. Hydrologic sensitivity to climate change in the Langrivier catchment, Stellenbosch, South Africa and some implications for geomorphic processes. Zeitschrift fur Geomorphologie Supplementband, v.107, p. 11-34, 1996.

OECD. OECD Environmental Indicators (English version). Paris, 1989. p. 8-16.

OLIVEIRA, J.B. Solos do Estado de São Paulo: descrição das classes registradas no mapa pedológico. Campinas, Instituto Agronômico. 112p. 1999.

OLIVEIRA, M.Q.C. Impacto de Mudanças no Uso do Solo nas Características Hidrossedimentológicas da Bacia Hidrográfica do Rio Joanes e sua Repercussão na Zona Costeira. 1999. 90p. Dissertação (Mestrado em Geologia) - Curso de Pós-Graduação em Geologia, Universidade Federal da Bahia, Salvador.

ÖZHAN, S.; NIHAT BALC1, A.; ÖZYUVACI, N.; HIZAL, A.; GÖKBULAK, F.; SERENGIL, $Y$. Cover and management factors for the Universal Soil-Loss Equation for forest ecosystems in the Marmara region, Turkey. Forest Ecology and Management, v. 214, p. 118-123, 2005.

PAIVA, C.F.E.; OLIVEIRA, V.S.; VENDRAME, I.R.; AULICINO, L.C.M. Estimativa das perdas de olo por erosão hídrica na bacia do rio Uma Taubaté-SP com o emprego de sensoriamento remoto. Anais XI SBSR, Belo Horizonte, 2003.

PESSOA, M.C.P.Y.; LUCHIARI JUNIOR, A.; FERNANDES, E.N.; LIMA, M.A. Principais modelos e simuladores utilizados para análise de impactos ambientais das atividades agrícolas. Jaguariúna: Embrapa, 1997. 91p.

PINTO, L.F.G. Estudo prospectivo visando o planejamento do uso da adubação verde nos agroecossistemas de São Carlos, SP. 1996. 89p. Dissertação (Mestrado em Ciências da Engenharia Ambiental) - Escola de Engenharia de São Carlos, Universidade de São Paulo, São Carlos.

PINTO, L.F.G.; CRESTANA, S. Digitalização e Processamento de Imagens Aplicados ao Estudo Prospectivo de um Agroecossistema. In: CRUVINEL, P.S. et al. (eds.), ANAIS do I SIAGRO. São Carlos, 1996. Brasília, EMBRAPA-SPI. p. 416-421. 1997.

PINTO, M.T.C.; MOZETO, A.A.; TOLENTINO, M. Dinâmica de nutrientes na mata ripária à Lagoa do Diogo no sistema planície de inundação do Rio Mogi-Guaçu. In: SANTOS, J.E.; 
PIRES, J.S.R. (eds.), Estudos Integrados em Ecossistemas: Estação Ecológica de Jataí. São Carlos. EESC-USP. 2000. v. 1, p. 267-284.

PIRES, A.M.Z.C.R Elaboração de um banco de dados digitais georeferenciados como subsídio ao planejamento e manejo de uma unidade de conservação - Estação Ecológica de Jataí (Luiz Antônio, SP). 1994. 68p. Dissertação (Mestrado em Ciências área de concentração: Ecologia e Recursos Naturais) - Programa de Pós-Graduação em Ecologia e Recursos Naturais, Universidade Federal de São Carlos, São Carlos.

PIRES, A.M.Z.C.R Diretrizes para a Conservação da Biodiversidade em Planos de Manejo de Unidades de Conservação. Caso de Estudo: Estação Ecológica de Jataí e Estação Experimental de Luiz Antônio (Luiz Antônio - SP). 1999. 192p. Tese (Doutorado em Ciências - área de concentração: Ecologia e Recursos Naturais) - Programa de PósGraduação em Ecologia e Recursos Naturais, Universidade Federal de São Carlos, São Carlos.

PIRES, A.M.Z.C.R. Diretrizes para a Conservação da Biodiversidade em Planos de Manejo de Unidades de Conservação: Caso de Estudo: Estação Ecológica de Jataí e Estação Experimental de Luiz Antônio (Luiz Antônio - SP). Disponível em < http://lapa.ufscar.br>. Acesso em 12 de maio de 2003.

PIRES, A.M.Z.C.R.; SANTOS, J.E.; PIRES, J.S.R. Caracterização e diagnóstico ambiental de uma unidade da paisagem. Estudo de Caso: Estação Ecológica de Jataí e Estação Experimental de Luiz Antônio. In: SANTOS, J.E.; PIRES, J.S.R. (eds.), Estudos Integrados em Ecossistemas: Estação Ecológica de Jataí. São Carlos: RIMA, 2000a. v. 1. p. $1-26$.

PIRES, A.M.Z.C.R.; SANTOS, J.E.; PIRES, J.S.R. Zoneamento ambiental e plano de manejo para uma unidade da paisagem. Estudo de Caso: Estação Ecológica de Jataí e Estação Experimental de Luiz Antônio. In: SANTOS, J.E.; PIRES, J.S.R. (eds.), Estudos Integrados em Ecossistemas: Estação Ecológica de Jataí. São Carlos: RIMA, 2000b. v. 1. p. 27-58.

PIRES, A.M.Z.C.R.; SANTOS, J.E.; PIRES, J.S.R. Caracterização Ambiental de uma Unidade de Conversação. Estação Ecológica de Jataí, Luiz Antônio, SP. In: SANTOS, J.E.; PIRES, J.S.R. (eds.), Estudos Integrados em Ecossistemas: Estação Ecológica de Jataí. São Carlos: RIMA, 2000c. v. 1. p. 59-72.

PIRES, J.S.R. Análise Ambiental voltada ao Planejamento e Gerenciamento do Ambiente Rural: Abordagem metodológica aplicada ao município de Luiz Antônio, SP. 1995. 192p. Tese (Doutorado em Ciências - área de concentração: Ecologia e Recursos Naturais) Programa de Pós-Graduação em Ecologia e Recursos Naturais, Universidade Federal de São Carlos, São Carlos.

PIRES, J.S.R.; SANTOS, J.E. Bacias Hidrográficas - Integração entre o meio ambiente e desenvolvimento. Ciência Hoje. v. 40, n. 110, p. 40-45. 1995.

PIRES, J.S.R.; SANTOS, J.E. (1996). Preliminary analysis of environmental impacts applied to a rural area of São Paulo State (Luiz Antônio, SP, Brazil). International Association for Impact Assessment, II: p. 969-974. 
PIRES, J.S.R.; SANTOS, J.E.; PIRES, A.M.Z.C.R. Análise de riscos ambientais no entorno de uma Unidade de Conservação (Estação Ecológica de Jataí, Luiz Antônio, SP). In: SANTOS, J.E.; PIRES, J.S.R. (eds.), Estudos Integrados em Ecossistemas: Estação Ecológica de Jataí. São Carlos: RIMA, 2000d. v. 1. p.73-94.

PIRES, J.S.R.; SANTOS, J.E.; DEL PRETE, M.E. A utilização do conceito de bacia hidrográfica para a conservação dos recursos naturais. In: Schiavetti, A.; Camargo, A.F.M. (Eds.). Conceitos de Bacias Hidrográficas: Teorias e Aplicações. Ilhéus: Editus, 2002e. cap. 1, p. 17-36.

PRADO, T.B.G. Evolução do Uso das Terras e Produção de Sedimentos na Bacia Hidrográfica do Rio Jundiaí-Mirim. 2005. 69p. Dissertação (Mestrado em Agricultura Tropical e Subtropical) - Instituto Agronômico, Campinas.

PRIMAVESI, O.; PRIMAVESI, A.C.P.A.; PEDROSO, A.F.; CAMARGO, A.C.; RASSINI, J.B.; ROCHA FILHO, J.; OLIVEIRA, G.P.; CORREA, L.A.; ARMELIN, M.J.A.; VIEIRA, S.R.; DECHEN, S.C.F. Microbacia Hidrográfica do Ribeirão Canchim. São Carlos, Embrapa Pecuária Sudeste - Boletim de Pesquisa No 5. 133p. 1999.

PRIMAVESI, O.; FREITAS, A.R.; PRIMAVESI, A.C.; OLIVEIRA, H.T. Water Quality of the Canchim's Creek Watershed in São Carlos, SP, Brazil, Occupied by Beef and Dairy Cattle Activities. Brazilian Archives of Biology and Technology, v.45, n.2, p.209-217, 2002.

QUINTON, J.N. Validation of physically-based models, with particular reference to Eurosem. In: Rickson, R.J. (Ed.) Conserving Soil Resources: European Perspectives. CAB International, Cambridge, 1994, p. 300-313.

RAMALHO FILHO, A.; BEEK, K.J. Sistema de Avaliação da Aptidão Agrícola das Terras. Rio de Janeiro, Embrapa-CNPS. 65p. 1995.

RANIERI, S.B.L. Avaliação de Métodos e Escalas de Trabalho para Determinação de Risco de Erosão em Bacia Hidrográfica Utilizando Sistema de Informações Geográficas (SIG). 1996. 128p. Dissertação (Mestrado em Ciências da Engenharia Ambiental) - Escola de Engenharia de São Carlos, Universidade de São Paulo. São Carlos.

RANIERI, S.B.L. Estimativa da Erosão do Solo em uma Bacia Hidrográfica no Município de Piracicaba (SP) utilizando os Modelos USLE e WEPP. 2000. 95p. Tese (Doutorado em Agronomia) - Escola Superior de Agricultura “Luiz de Queiroz”, Universidade de São Paulo, Piracicaba.

RANIERI, S.B.L.; SOUZA, M.P.; SPAROVEK, G. Avaliação de Métodos e Escalas de Trabalho para Determinação de Risco de Erosão em Bacia Hidrográfica Utilizando Sistema de Informações Geográficas (SIG). Resumo. XXVI Cong. Bras. Ciência do Solo. Rio de Janeiro, 1997.

RANIERI, S.B.L. et al. Aplicação de Índice Comparativo para a Avaliação de Risco de Erosão. In: XII Reunião Brasileira de Manejo e Conservação do Solo e da Água. Agricultura e Sustentabilidade no Semi-Árido, Fortaleza, 1998. Resumos Expandidos. SBCS/UFC/DCS.p. 234-235.

REICHARDT, K.; TIMM, L.C. Solo, planta e atmosfera: conceitos, processos e aplicações. Barueri: Manole, 2004. 478p. 
RENARD, K.G.; FOSTER, G.R.; WEESIES, G.A.; PORTER, J.P. Revised Universal Soil Loss Equation. Journal of Soil and Water Conservation, v. 46, n.3, p. 30-33, 1991.

ROCHA, J.V.; LOMBARDI NETO, F.; BACELLAR, A.A.A. Metodologia para Determinação do Fator Comprimento de Rampa (L) para a Equação Universal de Perdas de Solo. Caderno de Informações Georreferenciadas, v. 1, n. 2, 1997.

ROMANOWICZ, A.A.; VANCLOOSTER, M.; ROUNSEVELL, M.; LA JUNESSE, I. Sensitivity of the SWAT model to the soil and land use data parametrisation: a case study in the Thyle catchment, Belgium. Ecological Modelling, n. 187, p. 27-39, 2005.

ROQUE, F. de O.; TRIVINHO-STRIXINO, S. Avaliação preliminar da qualidade da água dos córregos do município de Luiz Antônio (SP) utilizando macroinvertebrados. In: SANTOS, J.E.; PIRES, J.S.R. (eds.), Estudos Integrados em Ecossistemas: Estação Ecológica de Jataí. São Carlos: RIMA, 2000a. v. 2. p. 721-732.

SANO, E.E.; ASSAD, E.D.; ORIOLI, A.L. Monitoramento da Ocupação Agrícola. In: Sistemas de Informações Geográficas - Aplicações na Agricultura. Eds. Assad, E.D.; Sano, E.E. Brasília, EMBRAPA SPI/EMBRAPA CPAC. p. 179-190. 1998.

SANTOS, J.E. Funções ambientais e valoração de ecossistemas naturais: Estação Ecológica de Jataí. http://lapa.ufscar.br 2003 (12 mai).

SANTOS, J. E. ; CAVALHEIRO, F. Procedimentos básicos para o manejo dos ecossistemas: Ecologia de Sistemas. ANAIS DO SEMINARIO REGIONAL DE ECOLOGIA, n. VI, p. 73-109, 1988.

SANTOS, J.E.; NOGUEIRA, F.; PIRES, J.S.R OBARA, A.T.; PIRES, A.M.Z.C.R. Os valores dos serviços dos ecossistemas e do capital natural da Estação Ecológica de Jataí (Luiz Antônio, SP). In: SANTOS, J.E.; PIRES, J.S.R. (eds.), Estudos Integrados em Ecossistemas: Estação Ecológica de Jataí. São Carlos: RIMA, 2000. v. 1. p. 95-120.

SARTORI, A. Avaliação da Classificação Hidrológica para a Determinaçãodo Excesso de Chuva do Método do Serviço de Conservação do Solo dos Estados Unidos. 2004. 161p. Dissertação (Mestrado em Engenharia Civil) - Faculdade de Engenharia Civil, Arquitetura e Urbanismo, Universidade Estadual de Campinas, Campinas.

SAUNITI, R.M.; FERNANDES, L.A.; BITTENCOURT, A.V.L. Estudo do assoreamento do reservatório da barragem do rio Passaúna - Curitiba - PR. Boletim Paranaense de Geociências, Curitiba, n. 54, p. 65-82, 2004.

SCHMIDT, R.E.; WERNER, V.; MICHAEL, A. Application of the Erosion 3D model to the Catsop watershed, The Netherlands. In: Modelling of Soil Erosion by Water on a Catchment Scale. CATENA, v. 37, n. 3-4, p. 449-456, 1999.

SCHULZE, R. ACRU: background, concepts and theory. Report 35, Agricultural Catchments Research Unit, Department of Agricultural Engineering, University of Natal, Pietermaritzburg, South Africa, 1989.

SCOTT, H.D. Soil Physics. Agricultural and Environmental Applications. Ames. IOWA State University Press. 2000. 421p. 
SHAW, R.; DOHERTY, J.; BREBBER, L.; COGLE, L.; LAIT, R. The Use of Multiobjective Decision Making for Resolution of Resource Use and Environmental Management Conflicts at a Catchment Scale. In: EL-SWAIFY, S.A.; YAKOWITZ, D.S. (eds.). Multiple Objective Decision Making for Land, Water and Environment Management. Boca Raton. Lewis Publishers, 1998. Cap. 57, p. 697-716.

SIDAGIS GALLI Análise da função de uma várzea na ciclagem de nitrogênio. 2003. 88p. Tese (Doutorado em Ciências da Engenharia Ambiental) - Escola de Engenharia de São Carlos, Universidade de São Paulo, São Carlos.

SILVA, C.L.; OLIVEIRA, C.A.S. Runoff measurement and prediction for a watershed under natural vegetation in central Brazil. R. Bras. Ci. Solo, v. 23, p. 695-701, 1999.

SILVA, F. G. B.; MINOTI, R. T.; NETTO, A. A.; REIS, J. A. T.; TSUHAKO, E. M.; CRESTANA, S. Simulação da Produção de Sedimentos em uma Sub-bacia Hidrográfica Experimental com o modelo SWAT. VI Encontro Nacional de Engenharia de Sedimentos. Livro de Resumos Expandidos. 2005.

SILVA, F. G. B. ; CRESTANA, S. Determinações Iniciais de Correlações entre Transporte de Sedimentos e Parâmetros de Qualidade de Água em Bacias Hidrográficas. In: VIII SIBESA, 2006, FORTALEZA. Anais do VIII SIBESA. Resumos Expandidos. 2006.

SILVA, F.G.B. e CRESTANA, S. Reunião de modelos e formulações para análise de erosão de solos em bacias hidrográficas voltados ao planejamento ambiental. In: Espíndola, E.L.G.; SCHALCH, V. (orgs.), Bacia hidrográfica: diversas abordagens em pesquisa. São Carlos: RIMA, 2004. p. 55-72.

SILVA, T.E.; TAKAHASHI, L.T.; VERAS, F.A.V. As Várzeas Ameaçadas - um estudo preliminar das relações entre as comunidades humanas e os rercursos naturais na Várzea de Marituba no rio São Francisco. Programa de Pesquisa e Conservação de Áreas Úmidas no Brasil. Pró-Reitoria de Pesquisa da Universidade de São Paulo. União Internacional para a Conservação da Natureza. Fundação Ford. Aracajú/São Paulo. 1990. $144 p$.

SIMÕES FILHO, F.F.L. A hidrodinâmica de particulados em planícies de inundação: um estudo sobre as taxas de sedimentação de lagoas marginais do rio Mogi-Guaçu, E.E. de Jataí (Luiz Antonio, SP). 1993. 108p. Dissertação (Mestrado em Ciências - área de concentração: Ecologia e Recursos Naturais) - Programa de Pós-Graduação em Ecologia e Recursos Naturais, Universidade Federal de São Carlos, São Carlos.

SIMÕES FILHO, F.F.L.; ALBUQUERQUE, A.L.S.; MOZETO, A.A.; GODOY, J.M.O. Role of Mogi-Guaçu flood-pulse on sedimentation and particulate composition in the Infernão Lake. In: SANTOS, J.E.; PIRES, J.S.R. (eds.), Estudos Integrados em Ecossistemas: Estação Ecológica de Jataí. São Carlos: RIMA, 2000. v. 2. p. 347-358.

SMITH, R. E.; GOODRICH, D. C.; QUINTON, J. N. DYNAMIC, distributed simulation of watershed erosion: the KINEROS2 and EUROSEM models. Journal of Soil and Water Conservation, Ankeny, v. 50, n. 5, p. 517-520, 1995.

SINGH, V.P.; FREVERT, D. Mathematical models of small watershed hydrology applications. Chelsea: Water Resources Publications, 2002. 947p. 
SONNEVELD, B.G.J.S. e NEARING, M.A. A nonparametric/parametric analysis of the Universal Soil Loss Equation. Catena, v. 52, p. 9-21, 2003.

SOUTO, A.R. Análise Espacial e Temporal da Produção de Sedimentos em uma Microbacia Rural com o Modelo AGNPS e Técnicas de SIG. 1998. 111p. Dissertação (Mestrado em Ciências da Engenharia Ambiental) - Escola de Engenharia de São Carlos, Universidade de São Paulo, São Carlos.

SPAROVEK, G.; VAN LIER, Q.J. Definition of tolerable soil erosion values. R. bras. Ci. Solo. Viçosa, v. 21, p. 467-471, 1997.

TATTARI, S.; BÄRLUND, I. The concept of sensitivity in sediment yield modelling. Phys. Chem. Earth (B), v. 26, p. 27-31, 2001.

TILMAN, D.; FARGIONE, J.; WOLFF, B.; D’ANTONIO, C.; DOBSON, A.; HOWARTH, R.; SCHINDLER, D.; SCHLESINGER, W.H.; SIMBERLOFF, D.; SWACKHAMER, D. Forecasting agriculturally driven global environmental change. Science, v. 292, p. 281-284, 2001.

TORRADO, P.V.; FERREIRA, T.O.; GAMERO, R.M.P.; SILVA, M.I.S.; FIRME, L.P.; SOUZA, V.S.; GOMES, J.F.; LAMBAIS, M.R.; CURY, J.C.; GOMES, M.R.H.; PÉREZ, X.L.O.; VÁZQUEZ, F.M.; TREVISAN, L.R.P.; MORTATTI, J.; BICEGO, M.C.; SCHAEFFER-NOVELLI, Y. A importância de estudos de sols do ponto de vista ambiental: solos em áreas de mangue em São Paulo. Boletim Informativo. Sociedade Brasileira de Ciência do Solo. v. 28, n. 1, p. 16-18, 2003.

TRACY-SMITH, E. Relation of Missouri River flows to Sandbar. Morphology with implications for selected biota. 2006. 195p. Dissertação (Mestrado em Ciências) - Faculty of the Graduate School, University of Missouri-Columbia, Columbia.

TRIPATHI, M.P.; PANDA, R.K.; RAGHUWANSHI, N.S. Identification and prioritization of critical sub-watersheds for soil conservation management using the SWAT model. Biosystems Engineering, v. 85, n. 3, p. 365-379, 2003.

TROEH, F.R.; HOBBS, J.A.; DONAHUE, R.L. Soil and Water Conservation. Englewood Cliffs. Prentice-Hall. 1991. 530p.

TUCCI, C. E. M. (Org.) Hidrologia: Ciência e Aplicação. 2. ed. Porto Alegre: Editora da Universidade (UFRGS), Edusp, ABRH, 1997. v. 1. 952 p.

TUCCI, C. E. M. Modelos Hidrológicos. 1. ed. Porto Alegre-RS: Editora da UFRGS e ABRH, 1998. v. 1. 652 p.

TUCCI, C.E.M. Regionalização de Vazões. Porto Alegre: Ed. Universidade/UFRGS, 2002. Cap. 1, p.13-22.

TUNDISI, J.G. Impacto Ambiental da Represa de Porto Primavera nas Áreas Alagadas do Rio Feio. Relatório Técnico CRHEA-EESC-USP. 1989. 18 p. 
WILKINSON, B.H. Humans as geologic agents: A deep-time perspective. Geology, v. 33, n. 3, p.161-164, 2005.

WILLIAMS, J.R.; JONES, C.A.; DYKE, P.T. A modeling approach to determining the relationship between erosion and soil productivity. Trans. ASAE v. 27, n.1, p. 129-144. 1984.

WILLIAMS, J.R. The physical components of the EPIC model. In: El-Swaify, S.A.; Moldenhauer, W.C.; Lo, A. (Eds.) Soil Erosion and Conservation. Soil Conservation Society of America. Ankeny, IA: 1985, p. 272-284.

WILLIAMS; J.R.; NICKS, A.D.; ARNOLD, J.G. Simulator for water resources in rural basins. Journal of Hydraulic Engineering, v. 111, n.6, p. 970-986, 1985.

WISCHMEIER, W.H.e SMITH, D.D. Rainfall-Erosion losses from cropland East of the Rocky Mountains. Washington D.C., USDA, Agriculture Research Service. 1965. 47p. (Agriculture Handbook, 282).

WISCHMEIER, W.H.; SMITH, D.D. Predicting rainfall erosion losses - a guide to conservation planning. Washington D.C., USDA, Agriculture Research Service. 1978. 58p. (Agriculture Handbook, 735).

YOUNG, R.A.; ONSTAD, C.A.; BOSCH, D.D.; ANDERSON, W.P. AGNPS: a nonpoint-source pollution model for evaluating agricultural watersheds. Journal of Soil and Water Conservation. v. 44, n. 2, p. 168-173, 1989. 
GLOSSÁRIO - Termos relacionados às Áreas Úmidas

ACIESP. Glossário de Ecologia. São Paulo: ACIESP. 1997. 352p.

FERREIRA, A.B.H.. Dicionário Aurélio Eletrônico. Versão 3.0. Rio de Janeiro: Nova Fronteira.1999.

SOARES, J.L. Dicionário etimológico e circunstanciado de Biologia. São Paulo: Scipione. 1993. 534p. 
Banhado $^{1}$ - pântano coberto de vegetação (Ferreira, 1999).

Banhado $^{2}$ - Setor de uma planície de inundação em que habitualmente se processa o extravazamento de águas fluviais, durante a estação chuvosa. Os banhados são áreas preferenciais de ambientes de brejos, onde há rica produtividade primária e formação de solos ditos hidromórficos (ecossistema brejo). Alguns setores dos banhados podem ficar secos durante a estiagem; outros, permanecem encharcados. No Brasil, os banhados são reconhecidos por termos regionais: várzeas, vazantes (ACIESP, 1997).

Brejo - Área de solo permanente ou periodicamente saturado de água, onde se desenvolvem campos e/ou macrófitas aquáticas (ACIESP, 1997).

Pântano $^{1}$ - Terreno inundável, de pequena profundidade, em planícies costeiras ou planícies de inundação interiores, cujo fundo é mais ou menos lodoso e pouco consistente. Os terrenos pantanosos no brasil recebem preferentemente a designação de brejos, o seu conjunto espacial sendo designado por banhados, várzeas, vazantes (ACIESP, 1997).

Pântano $^{2}$ - 1. Terreno inundável, Região inundada por águas estagnadas.

2. Terras baixas e alagadiças. Sinônimos gerais: aguaçal, atolador, atoladouro, atoleiro, atoledo, bamburral, banhado, brejo, charco, charneca, enxurdeiro, lamaçal, lamaceiro, lameirão, marnel, palude, paul, tremedal (Ferreira, 1999).

Várzea $^{1}$ - 1. Terreno baixo e mais ou menos plano que se encontra junto às margens de córregos e rios. 2. Tipo de lago raso formado em terrenos de várzea. 3. Tipo de floresta inundada periodicamente. 4. Vegetação associada aos terrenos de várzea (ACIESP, 1997)..

Várzea $^{2}$ - Formação florística dos vales ou lugares baixos, parcialmente alagados (Soares, 1993).

Várzea $^{3}$ - Planície fértil e cultivada, em um vale (Ferreira, 1999).

Termos relacionados - áreas úmidas, sistemas de transição solo-água (em inglês - “ATTZ” - aquatic terrestrial transition zone), áreas alagadas, áreas alagáveis, ecótonos entre sistemas terrestres e aquáticos. 
APÊNDICE A - Análise das unidades e subunidade de estudo que não abrangem a planície de inundação do rio Mogi-Guaçu. 


\section{A.1 Microbacia hidrográfica do córrego Beija-Flor (7.980 hectares)}

Nas Figuras 65 e 66, podem-se visualizar os resultados da caracterização ambiental e da EUPS relacionados à microbacia hidrográfica do córrego Beija-Flor (MBH-BF). A microbacia apresenta uma extensa rede hídrica. O principal corpo d’água é o córrego Beija-Flor (ou Jataí), afluente do rio Mogi-Guaçu (margem direita do rio) e seus tributários, os córregos da Bandeira, Debruado, do Jordão e das Cabaças.

Com relação à hipsometria, a microbacia apresenta grande variação altimétrica - 322 metros - a cota mínima é de 529m, situada na região da planície de inundação do rio MogiGuaçu, e a máxima de 851m, situada na região da Serra do Jataí. A MBH-BF apresenta 21\% de sua área inserida na faixa de valores entre 660 e $860 \mathrm{~m}$.

A declividade máxima é de $90,7 \%$ e a mínima, de 4,2\%. Cerca de $80 \%$ da área da microbacia é constituída por declividades entre zero e 8\% e o restante entre 8 e $100 \%$.

Foram identificadas 10 classes de solos na microbacia. Os principais tipos de solos são os latossolos (62\% da área) e os neossolos quartzarênicos (25\%). As demais classes de solos encontradas, ocupando menores áreas, foram os gleissolos, argissolos, chernossolos e neossolos litólicos.

Os latossolos constituem o agrupamento mais extenso do estado de São Paulo (cerca de 52\%. O relevo, com exceção dos solos situados em região serrana, é pouco movimentado, com declives inferiores a 5\%. Apresentam boas propriedades físicas, boa drenagem interna, e, em geral, estão situados em relevo favorável ao uso intensivo de máquinas agrícolas. Mesmo os latossolos muito argilosos apresentam excelente porosidade total, que, associada à elevada friabilidade, permite que o seu preparo para o cultivo seja facilmente efetuado (Oliveira, 1999). Na MBH-BF, são encontrados latossolos situados tanto em relevo favorável ao uso agrícola como em áreas com elevada variação de declividade.

Os neossolos quartzarênicos são, em geral, solos essencialmente arenoquartzosos. Devido à baixa adesão e coesão, apresentam elevada erodibilidade, mas em geral são solos muito profundos. Em conseqüência da textura grosseira, são muito porosos e muito permeáveis. Tal atributo, juntamente com a baixa capacidade adsortiva, caracteriza-os como material pouco adequado para receber agroquímicos devido à facilidade de contaminação dos aqüíferos (Oliveira, 1999). A maior parte dos Neossolos Quartzarênicos da MBH-BF encontram-se situados na área ocupada pela EEJ, aspecto extremamente positivo, tendo em vista que os riscos ambientais associados a esses tipos de solos são mais elevados.

Nas regiões com maior declividade da MBH-BF e valores do Fator LS mais elevados, predominam os Neossolos Litólicos e os Latossolos. De acordo com Oliveira (1999), assim 
como foi observado na MBH-BF, a maioria dos Neossolos Litólicos do Estado de São Paulo encontra-se em relevo forte ondulado ou montanhoso, sendo muito suscetíveis à erosão.

O uso do solo na microbacia é dividido entre a área de preservação (área da EEJ), predominando vegetação natural (36\% da área da microbacia), a área de experimentação florestal da EELA, onde são cultivadas diferentes espécies de Pinus e eucalipto (25\%), e a área agrícola, que é ocupada com a monocultura da cana-de-açúcar (39\%). Os dados de uso do solo da EEJ e EELA foram obtidos nos levantamentos de campo e, também, com base nas informações fornecidas pelos técnicos de campo, colaboradores do PEJ, Senhores Gonçalo Bertoloti e Horácio Gomes.

A região da Serra do Jataí, leste da microbacia, onde está localizada a cabeceira do córrego das Cabaças, foi o setor que apresentou valores mais elevados de hipsometria. Nessa área, os valores de declividade foram muito elevados. Além desse local, os valores mais elevados de declividade na microbacia foram obtidos na área do morro do Pique, na região de cabeceira do córrego do Jordão e ao longo do curso dos córregos do Debruado e do Jordão. Por último, a margem direita do córrego Beija-Flor apresentou, também, variação acentuada do relevo e valores elevados de declividade. Por essas condições, nessas regiões foram obtidos os valores mais elevados do fator LS e do PNE.

Assim, a microbacia hidrográfica do córrego Beija-Flor/Jataí, apesar de conter 36\% de área ocupada por vegetação natural, apresenta uma região com variação mais acentuada do relevo submetida à ocupação por eucalipto, pinus e cana-de-açúcar. Grande parte da região ocupada por essas culturas refere-se a essas áreas com valores elevados de LS e PNE.

Nas regiões de maior variação do relevo, a serra do Jataí, o morro do Pique, a região de cabeceira do córrego do Jordão e as regiões situadas ao longo do curso dos córregos do Debruado e do Jordão, foram encontrados os valores mais elevados de ERE, perda de solo por erosão laminar ( $\underline{\mathrm{A}})$ e PRE, com exceção da margem direita do córrego Beija-Flor e demais áreas ocupadas por vegetação natural (EEJ), que apresentaram, claramente, os mais baixos valores de toda a microbacia.

Os valores de ERE na região da Serra do Jataí permaneceram entre zero e 0,05 em uma faixa menor do que nas outras áreas de maior variação do relevo. Esse fator deve estar relacionado ao tipo de ocupação do solo na área, pinus e eucalipto, em contraposição ao uso nas demais áreas, ocupadas por cana-de-açúcar, onde foram obtidos os valores mais elevados de ERE. Diferindo dos resultados da ERE, os mais altos valores de $\underline{A}$ e PRE foram obtidos na região da Serra do Jataí.

Na Figura 67 podem-se observar os valores de perda média e perda total de solo para a MBH-BF em cada intervalo de declividade. Nota-se que a perda de solo apresentou uma relação 
linear com a quantidade de área de cada faixa de declividade (Fig. 68) no intervalo de 3 a 100\%. Apenas no intervalo de zero a 3\% a relação com a área ocupada não foi proporcional em função, provavelmente, dos baixos valores de declividade, um dos fatores que mais interferiram nas estimativas dos processos erosivos.

Nas Figuras 69 e 70, podem-se observar os valores de erosão em função dos tipos de solo da MBH-BF. Os neossolos litólicos, por apresentarem os valores mais elevados de erodibilidade de todas as classes de solo identificadas, foram responsáveis por 34\% da perda total por erosão hídrica na microbacia, mesmo ocupando apenas 4\% da área total.

Os resultados referentes aos latossolos (LVd, LVef, LVw) foram significativos. Tendo em vista que esses solos apresentam baixos valores de erodibilidade, os resultados podem estar relacionados a outros fatores como declividade ou uso a que eles foram submetidos.

Observando-se os resultados de estimativa de erosão em função dos usos do solo da MBHBF (Figs. 71 e 72), notam-se valores elevados tanto para a cultura da cana-de-açúcar como para a área da EELA submetida ao plantio de pinus e eucalipto. A média de perda de solo por erosão superficial para a microbacia, resultado obtido pela aplicação da EUPS, foi de 16 t/ha.ano, e, na área ocupada por vegetação natural, de 0,05 t/ha.ano. Observa-se, dessa forma, que, apesar de grande parte da microbacia ser ocupada por vegetação natural, a taxa de perda anual de solo ainda é elevada tendo em vista a ocupação do solo por culturas agrícolas em regiões de maior declividade e maiores valores do fator LS, de PNE, ERE e PRE.

Ao realizar uma análise qualitativa dos riscos de degradação a que estão submetidos os componentes solo, água e biodiversidade, em função das principais atividades desenvolvidas na área rural do município de Luiz Antônio, incluindo a área da MBH-BF, Pires (1995) apresentou os riscos associados aos principais usos do solo:

- Degradação por erosão de solos, sólidos em suspensão em corpos d’água e assoreamento de córregos foram associados às atividades desenvolvidas pela monocultura de cana-de-açúcar e outras culturas;

- Contaminação e eliminação biológica dos corpos d’água e fragmentos de áreas naturais foram relacionados à deriva de agrotóxicos devido às atividades praticadas pela monocultura da cana-de-açúcar, citricultura e outras culturas;

- Degradação e eliminação biológica por queimadas, devido às práticas de uso do fogo, ou fogo acidental ou criminoso, foram relacionados às atividades de monocultura de cana-de-açúcar, pastagens, silvicultura e presença de estradas;

- Degradação e eliminação biológica devido à caça e coleta foram relacionados à presença de estradas e área urbana; 
- Contaminação da água por matéria orgânica em excesso e materiais tóxicos foram relacionados à presença de tanques de tratamento de efluentes industriais e urbanos e estradas, devido à possibilidade de desastres envolvendo cargas perigosas;

- Deslizamentos de encostas foram atribuídos às condições naturais de terreno (declividade).

Tendo em vista que a perda de solo na área da MBH-BF ocupada por vegetação natural foi de 48 ton/ano e que a perda total da microbacia foi de 127.723 ton/ano, observa-se que os sedimentos produzidos numa fração da perda total de solo na região à montante da microbacia, ocupada por culturas, podem ocasionar um impacto nos recursos hídricos a jusante da unidade hidrográfica, principalmente nos corpos d’água que margeiam a EEJ e no córrego Beija-Flor, que atravessa a Estação Ecológica na parte inferior da microbacia.

No zoneamento ambiental do Parque Estadual do Jatay, proposto por Pires (1999) e Pires et al. (2000b), foram definidas várias zonas de manejo distintas. A zona de entorno foi considerada área crítica para a proteção da biodiversidade do PEJ. As bordas constituem ameaças variadas associadas à entrada de espécies exóticas, patógenos, poluentes e contaminantes. A zona de entorno do PEJ abrange as áreas circundantes do PEJ, em um raio de $10 \mathrm{~km}$. A área abrangida pela zona de entorno na MBH-BF é extensa.

Dessa forma, tendo em vista os resultados obtidos no presente trabalho, devido ao uso agrícola dos solos na região a montante da MBH-BF, inclusive na zona de entorno, pode-se inferir que a área da Estação Ecológica de Jataí (a SBH-BF) está submetida a acentuado estresse ambiental.

Pereira-Silva et al. (2006) realizaram estudo comparativo, relacionado ao monitoramento da qualidade da água, de três microbacias ocupadas, em maior ou menor grau, pela vegetação natural da EEJ. A microbacia hidrográfica do córrego Beija-Flor, correspondendo às áreas da MBH-BF e BD-LA, apesar de apresentar a maior área ocupada pela EEJ, foi a segunda unidade a apresentar os maiores valores médios anuais de turbidez, sólidos em suspensão e matéria orgânica e inorgânica. A variação dos valores de turbidez entre os pontos a montante e a jusante dessa unidade de gerenciamento foi elevada, e os autores relacionaram os resultados obtidos à atividade florestal de corte raso de pinus, ocorrida anos atrás, além da proximidade de uma estrada cujo impacto ambiental pode ter influenciado esse parâmetro.

Pires (1995) realizou uma análise das atividades desenvolvidas no município de Luiz Antônio/SP e dos impactos e riscos ambientais associados. Dentre as oito Unidades de Gerenciamento da Paisagem (bacias hidrográficas) delimitadas nesse estudo, a UG 4 correspondeu às áreas da MBH-BF e BD-LA. Pelas imagens apresentadas por Pires (1995) e 
Pires et al. (2000d), pode-se observar que na UG 4, região da MBH-BF, foram identificadas áreas com risco alto de erosão e algumas zonas instáveis com riscos de deslizamento de encostas. Essas áreas de maior risco corresponderam, visualmente, às áreas de valores elevados do fator LS, de PNE, ERE e PRE, identificadas no presente estudo.

Em algumas dessas áreas com risco médio, alto ou muito alto de erosão, práticas de manejo para evitar a erosão devem ser utilizadas; em certos casos, as culturas anuais não devem ser utilizadas continuamente e, quando necessário, a cobertura vegetal nativa deve ser mantida ou reestabelecida (Pires, 1995).

Na Figura 73, observando-se algumas imagens da microbacia hidrográfica do Córrego Beija-Flor, podem-se notar áreas cobertas por vegetação natural com menor risco de erosão, áreas de cana-de-açúcar com práticas mecânicas para controle à erosão e áreas de maior risco, os carreadores, com solo descoberto em locais com menor e maior declividade. A altenância dos usos do solo, principalmente da vegetação natural e monocultura de cana-de-açúcar, separadas por carreadores, é uma paisagem comum na microbacia.

Grande parte dos riscos de processos erosivos, identificados visualmente na MBH-BF, foram relacionados aos carreadores. Na cultura de cana-de-açúcar, em locais de declividade elevada, foram encontrados carreadores sem a construção de “camaleões”, formando rampas de solo exposto no sentido morro abaixo. Nesses locais, verificou-se a existência de terraços bem construídos na área de produção da cultura, mas sem continuação nos carreadores, sem reforço para captação das águas. Esses dados corroboram os resultados apresentados por Pereira-Silva et al. (2006), os quais relacionaram valores elevados de turbidez no córrego Beija-Flor com impacto ambiental em estrada rural próxima a ponto de monitoramento de qualidade da água.

Dessa forma, observaram-se, em diversos locais, sinais de erosão laminar, erosão em sulco (tanto no meio como nas margens dos carreadores) e, até mesmo, formação de canais de escoadouro de água e sedimentos. Esses canais, caminhos preferenciais da água de enxurrada, formados em função dos processos erosivos, ao atingirem os corpos aquáticos, originam locais de entrada pontual de água de escoamento superficial com elevada concentração de sedimentos. A ponderação em relação aos processos erosivos em carreadores rurais sem práticas mecânicas de controle à erosão não foi considerada na metodologia. Caso esse fator seja considerado em trabalhos futuros, os resultados da aplicação da EUPS na região agrícola da MBH-BF poderão ser mais elevados. Além dos sinais de processos erosivos nos carreadores, foi observado, também, erosão em sulco raso em meio à cultura da cana-de-açúcar (Figura 74).

Devido à vulnerabilidade ambiental da região a montante da MBH-BF, associando regiões

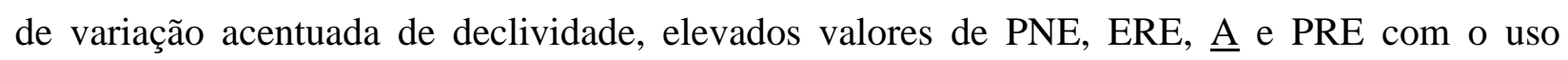


agrícola dos solos, deve-se ressaltar a importância da área ocupada pela EEJ (SBH-BFJ). Vale destacar que, devido às características edáficas e do relevo, a área ocupada pela EEJ na MBH-BF é, também, extremamente vulnerável aos processos erosivos. Foram observados valores elevados de declividade e de PNE em parte da área, e o restante apresentou neossolos quartzarênicos. Dessa forma, pode-se inferir que a área ocupada pela EEJ nessa unidade de estudo tem função estratégica para minimização dos impactos ambientais da SBH-BFJ, assim como de toda a área da MBH-BF.

As estimações da perda de solo, relacionadas à região da Serra do Jataí e demais regiões da MBH-BF, que apresentam variação clinográfica acentuada, necessitam de um número maior de observações de campo. Essas observações deverão verificar a ocorrência e os tipos de processos erosivos, e a necessidade de alteração no uso do solo nas regiões de maior vulnerabilidade ambiental. 


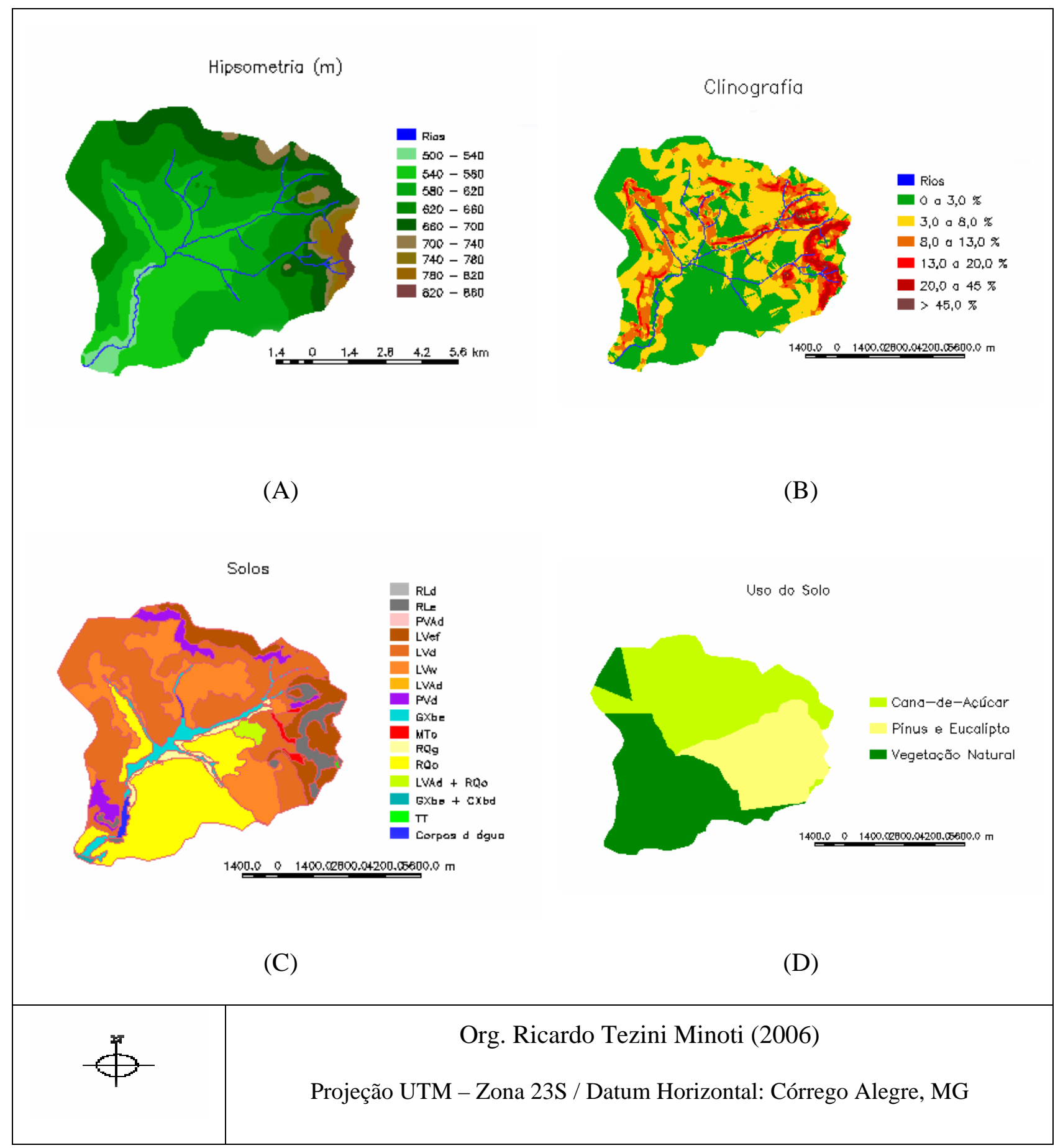

Fig. 65. Microbacia do córrego do Beija-flor (MBH-BF). (A) Hipsometria (m). (B) Clinografia (\%). (C) Solos. (D) Uso do Solo. 


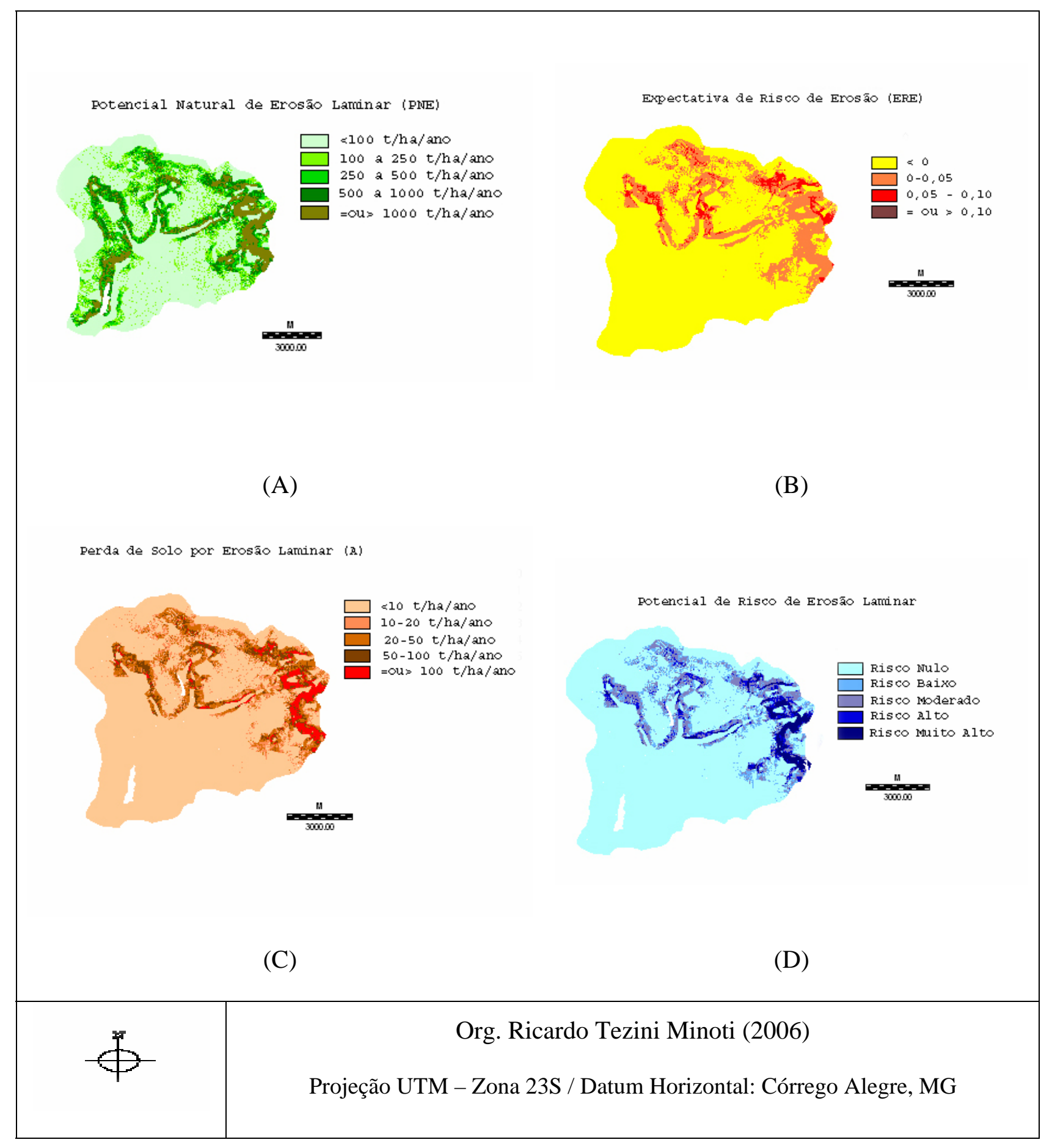

Fig. 66. Microbacia do córrego do Beija-flor (MBH-BF). 


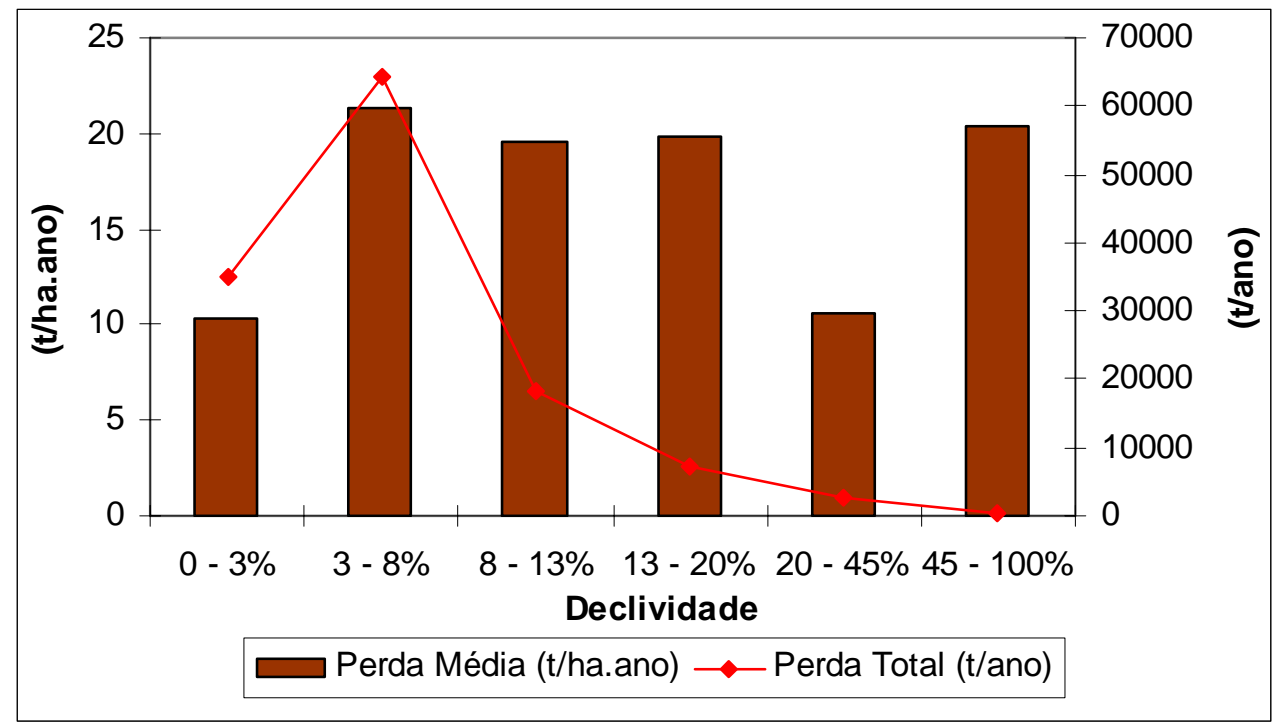

Figura 67. Perdas média e total de solo da microbacia hidrográfica do córrego do Beija-Flor (MBH-BF) nos intervalos de declividade.

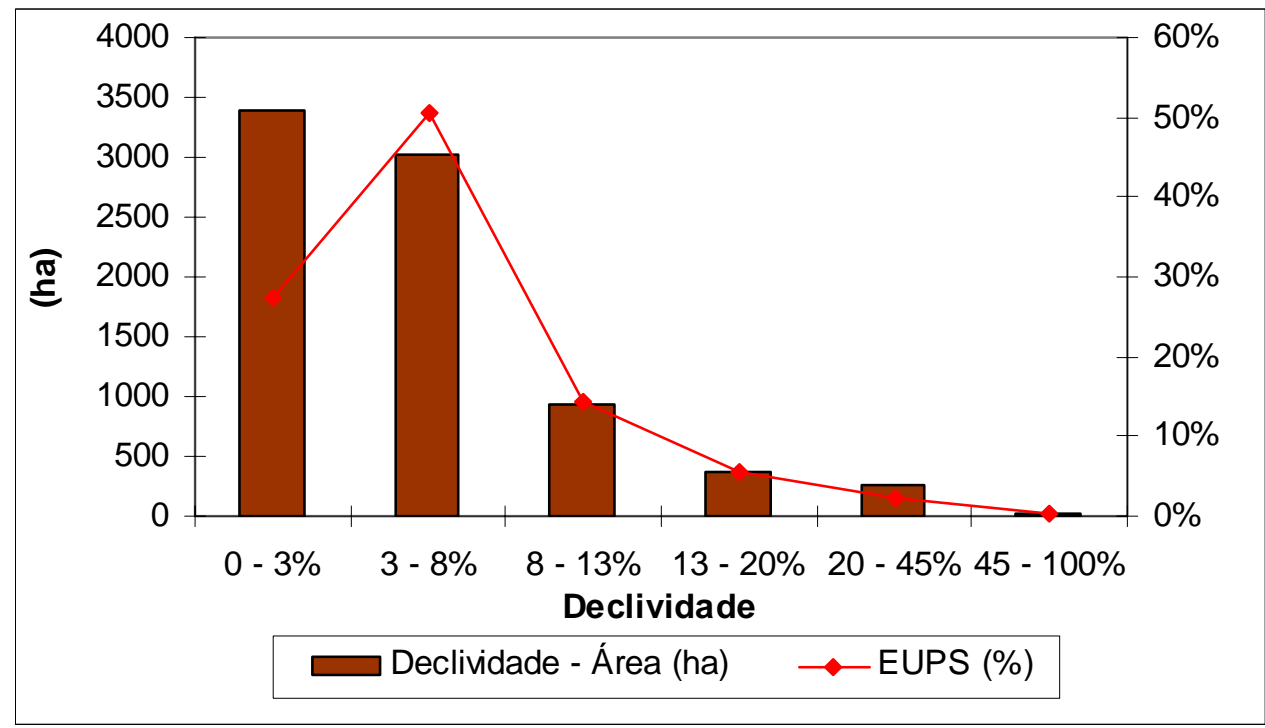

Figura 68. Área dos intervalos de declividade (ha.) e percentagem da perda total de solo na MBH-BF (EUPS). 


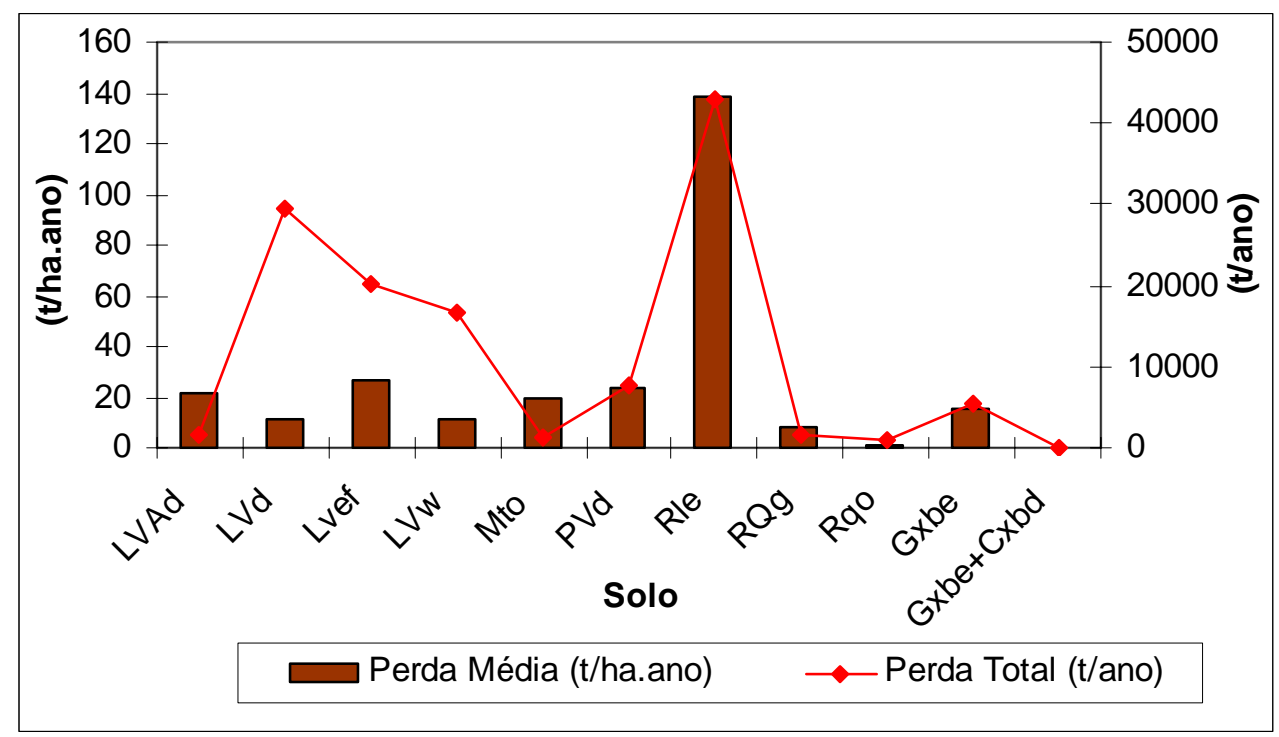

Figura 69. Perdas média e total de solo da microbacia hidrográfica do córrego do Beija-Flor (MBH-BF) referentes aos tipos de solo.

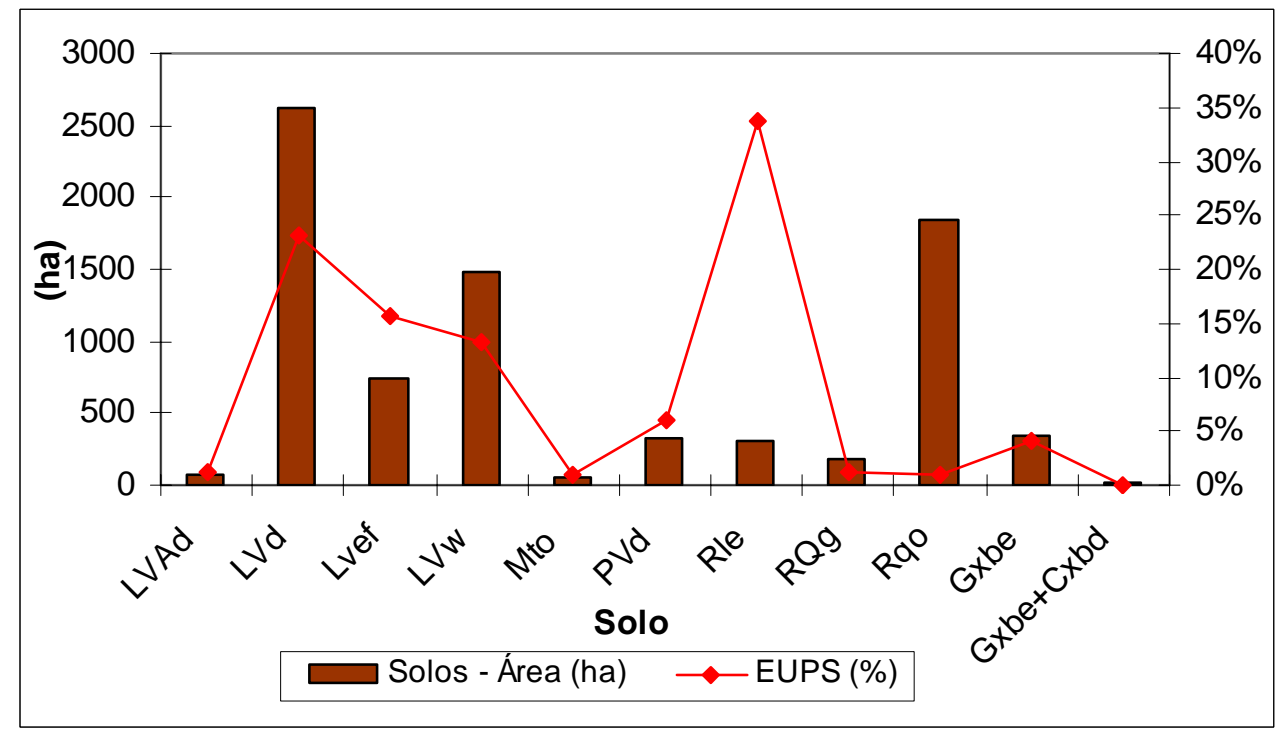

Figura 70. Área ocupada pelos diferentes tipos de solos (ha.) e percentagem da perda total de solo na MBH-BF (EUPS). 


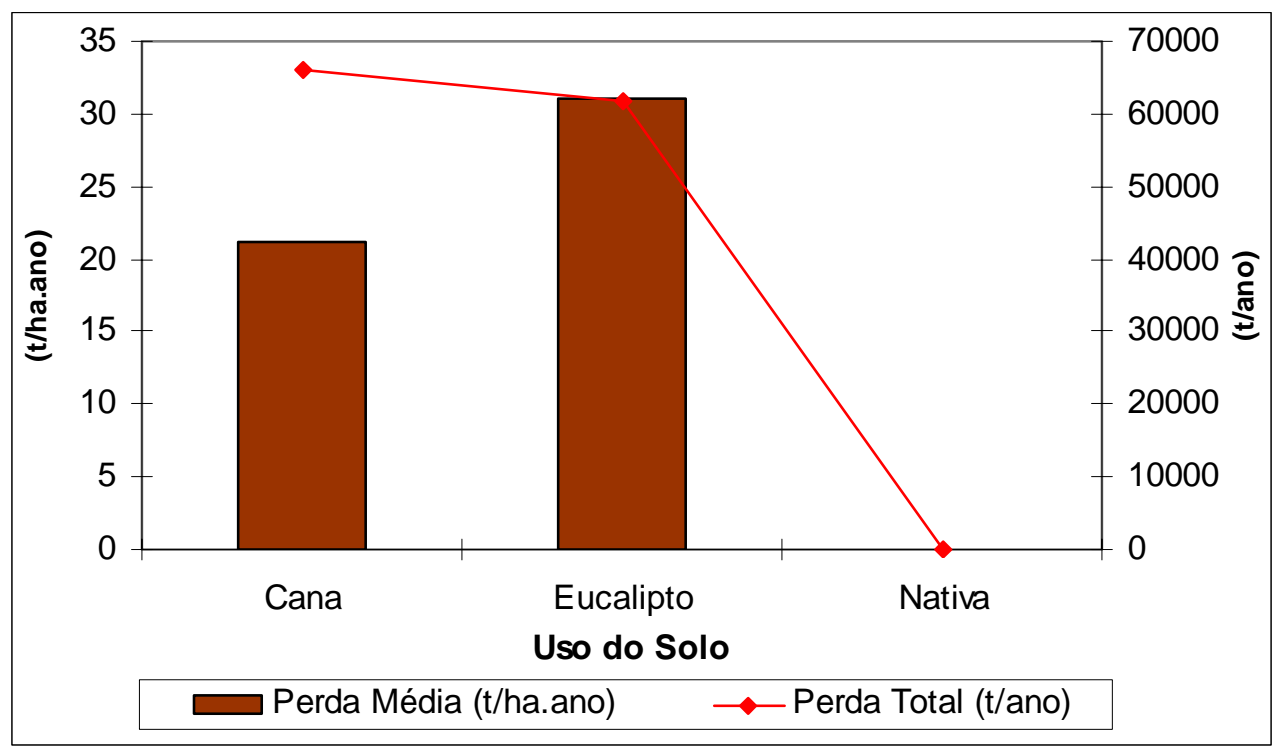

Figura 71. Perdas média e total de solo da microbacia hidrográfica do córrego do Beija-Flor (MBH-BF) referentes aos tipos de uso do solo.

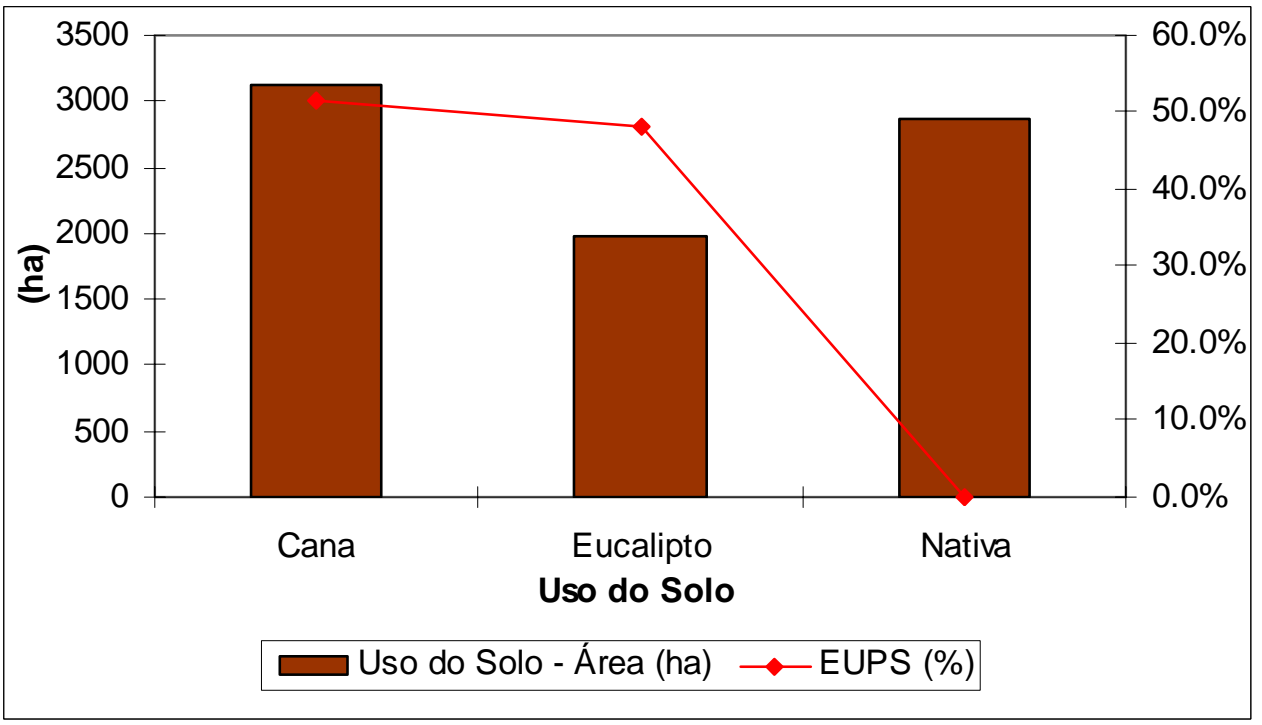

Figura 72. Área ocupada pelos diferentes tipos de solo (ha.) e percentagem da perda total de solo na MBH-BF (EUPS). 


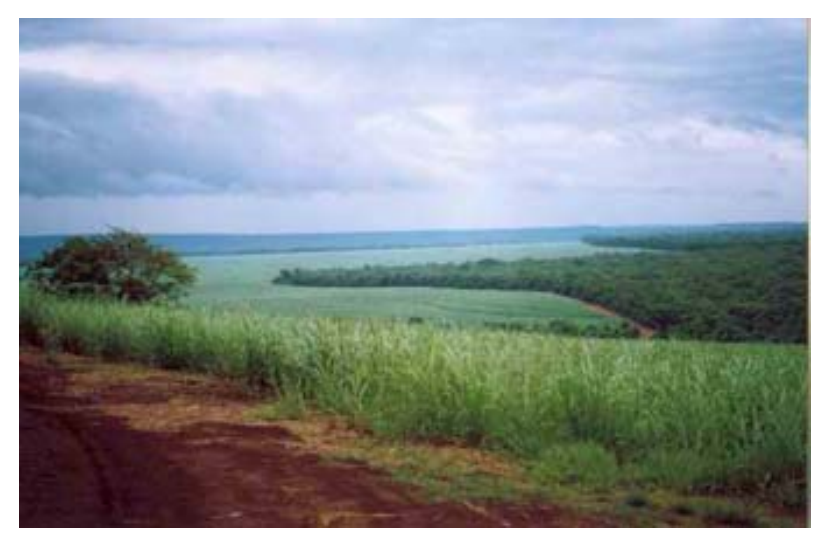

(a)

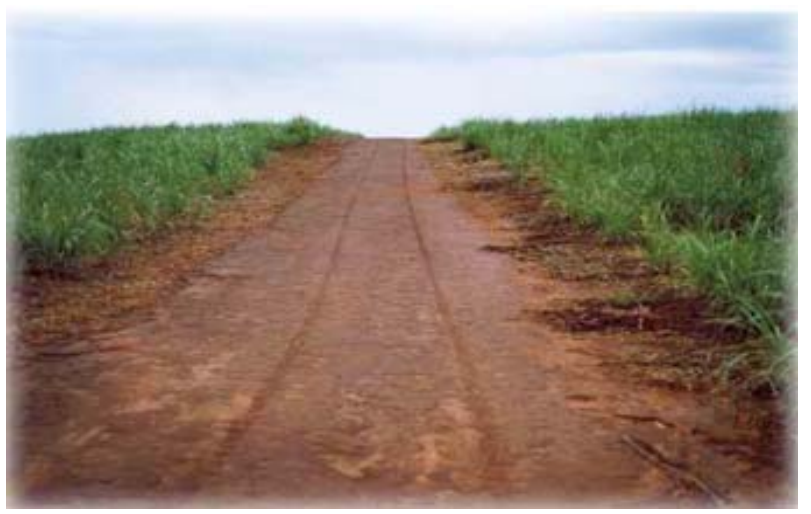

(c)

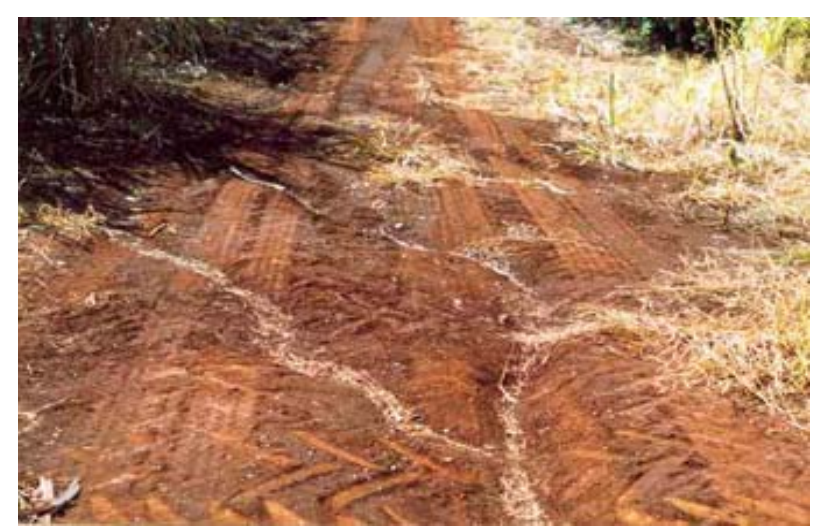

(e)

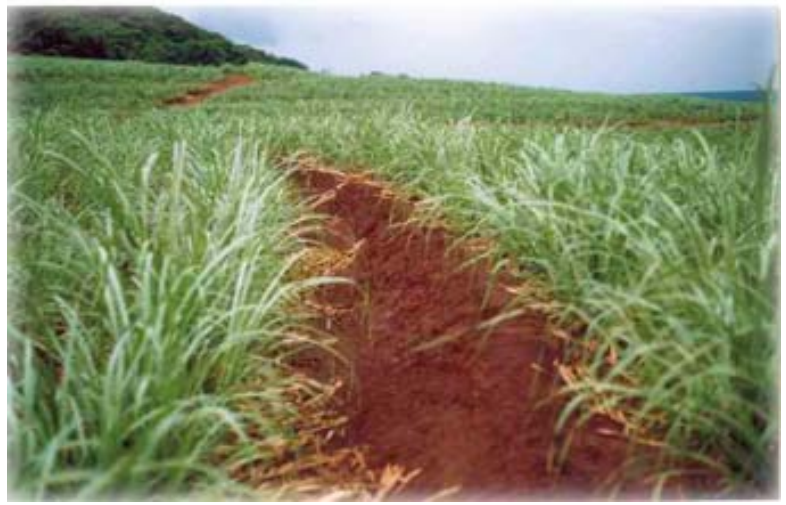

(b)

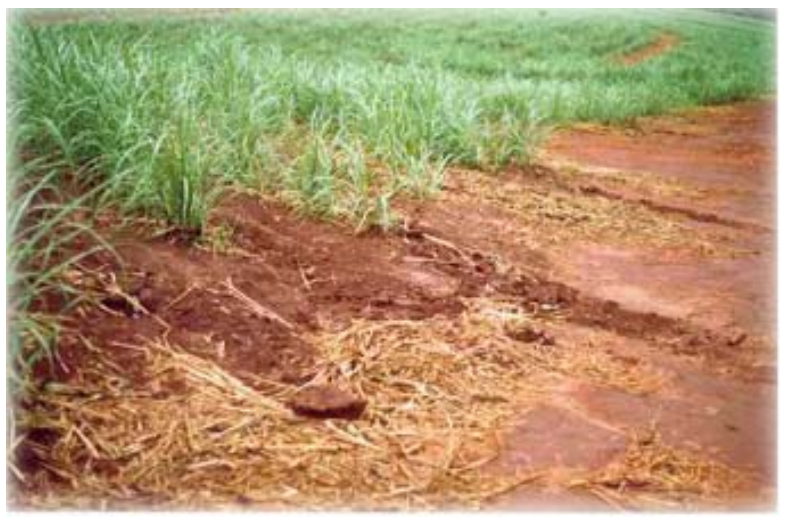

(d)

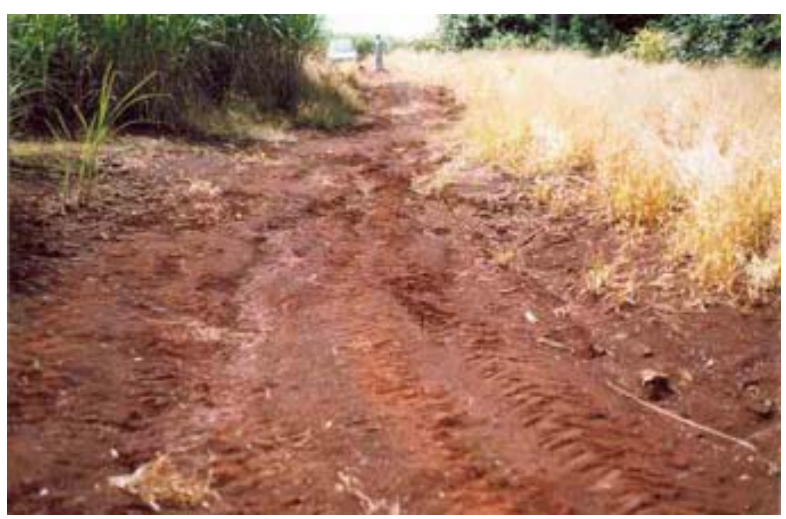

(f)

Org. Ricardo Tezini Minoti (2006)

Figura 73. Fotos das diferentes culturas agrícolas desenvolvidas na microbacia hidrográfica do Córrego Beija-Flor. (a) Transição entre vegetação natural e monocultura de cana-de-açúcar. (b) Exemplo de prática mecânica para controle à erosão - terraço "embutido" em meio à cultura de cana-de-açúcar. (c) Carreador em meio à cultura da cana-de-açúcar, com declive acentuado e início dos terraços em uma das margens. (d) Margem do carreador sem reforço dos terraços para captação das águas. (e) Erosão em sulcos rasos em carreador rural, bem visível pelo acúmulo de palha, localizado em área de transição entre cana-de-açúcar e vegetação natural. (f) Erosão em sulcos rasos em carreador rural. 


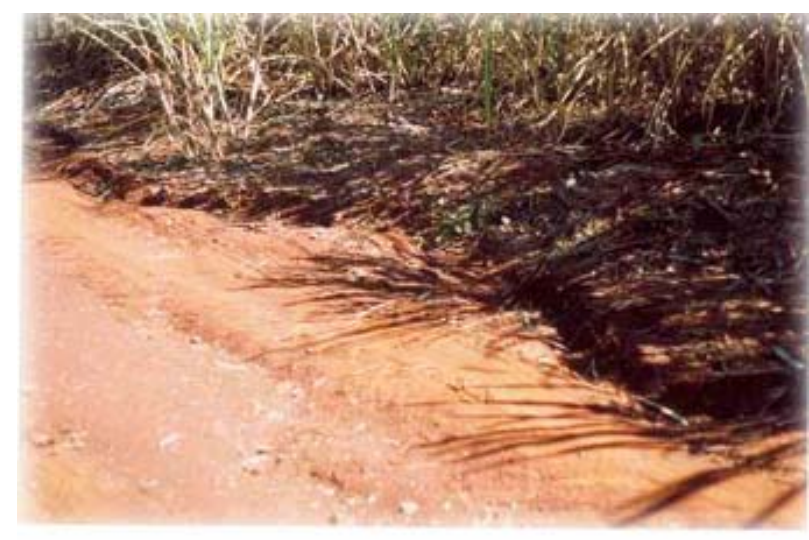

(a)

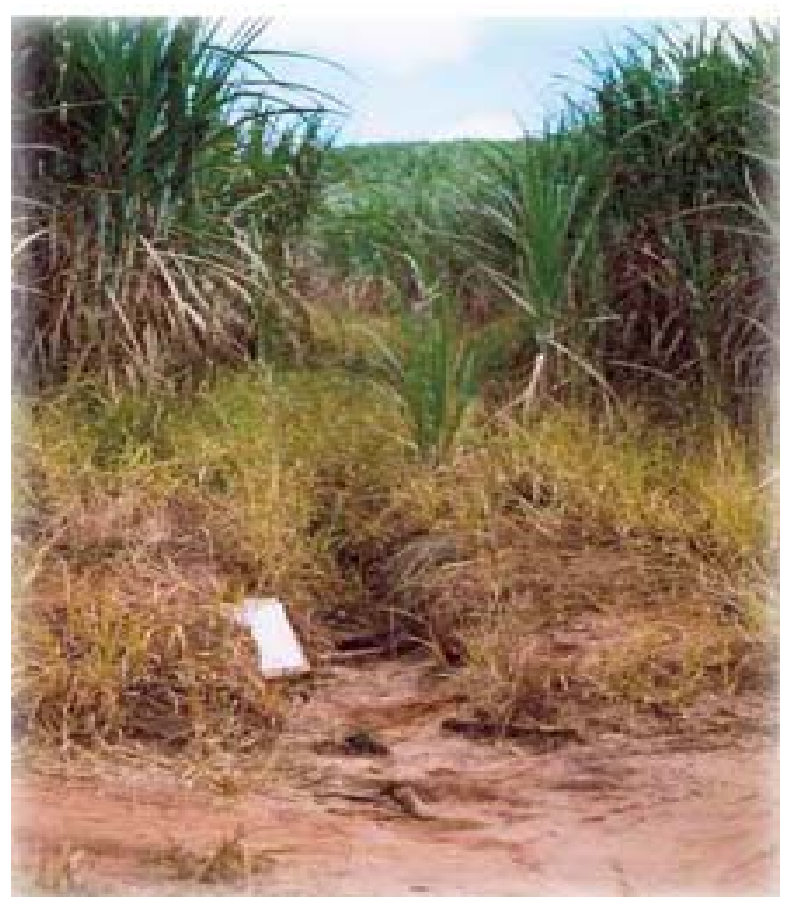

(c)

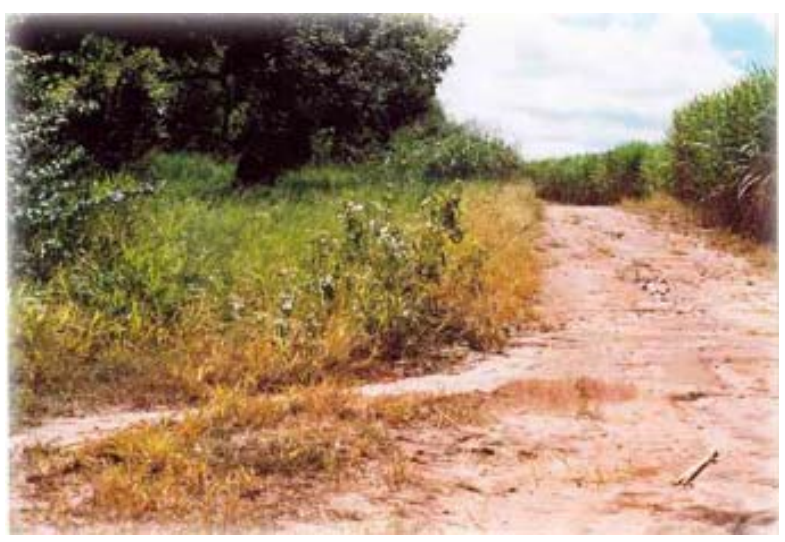

(b)

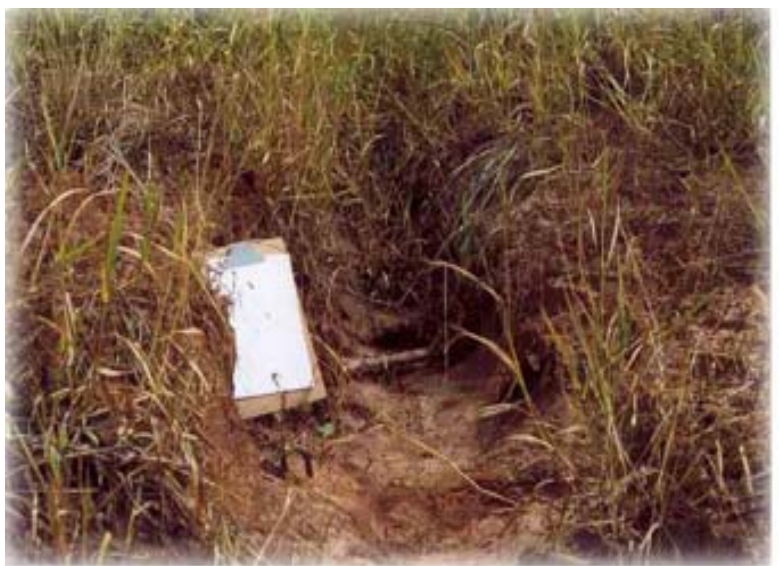

(d)

Org. Ricardo Tezini Minoti (2006)

Figura 74. Fotos de diferentes locais da microbacia hidrográfica do Córrego Beija-Flor. (a) Erosão em sulco raso na margem de carreador rural. (b) Canal escoadouro, em uma das margens do carreador. (c) Erosão em sulco raso em maio à cultura da cana-de-açúcar. (d) Foto mais aproximada da imagem anterior. 


\section{A.2 Sub-bacia hidrográfica Beija-Flor/Jataí (2.660 hectares)}

Os resultados da caracterização ambiental e da aplicação da EUPS, relacionados à Subbacia hidrográfica Beija-Flor/Jataí (SBH-BFJ), podem ser observados nas Figuras 75 e 76 . A SBH-BFJ é um segmento da MBH-BF e, portanto, sua hidrografia fica reduzida ao trecho baixo do córrego Beija-Flor. Nesse setor, inserido na sub-bacia, o córrego apresenta uma represa. Com relação à hipsometria, toda a área da sub-bacia está inserida na faixa de valores entre 500 e 660m. A cota mínima é de 529m, situada na região da planície de inundação do rio Mogi-Guaçu, e a máxima, de 642m. Quanto à declividade, a microbacia apresenta toda a área inserida na faixa de valores de zero a 45\% e praticamente $90 \%$ da área apresentam valores entre zero e $8 \%$.

Os valores mais elevados de declividade foram encontrados na região oeste dessa subunidade de estudo, margem direita do córrego Beija-Flor. Essa área é constituída, principalmente, por latossolos. Na margem esquerda do córrego, região leste da subunidade, a declividade permanece, quase totalmente, na faixa de zero a 3\%. Nessa área predominam os neossolos quartzarênicos.

Os valores de PNE, obtidos nessa sub-bacia, foram elevados, principalmente na região onde ocorrem as declividades mais elevadas. Foram encontradas áreas que apresentaram valores maiores do que 1000 t/ha.ano.

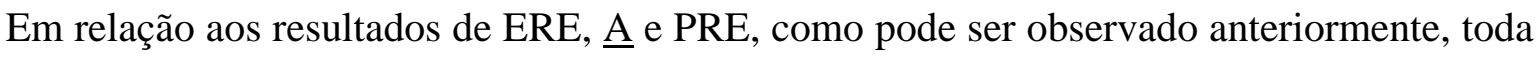
a área da SBH-BFJ, ocupada por vegetação natural (EEJ), apresentou os valores mais baixos de toda a área de estudo. Pode-se verificar a importância da presença da EEJ, tanto na margem direita do córrego Beija-Flor, região de maior declividade, como na margem esquerda, constituída por Neossolos Quartzarênicos. A presença da vegetação natural contribuiu para a diminuição dos valores de risco de erosão.

Como era de esperar, os valores das estimativas de erosão da SBH-BFJ foram extremamente baixos. As perdas média e total de solo nos intervalos de declividade (Figs. 77 e 78) mostraram que os resultados estiveram linearmente relacionados com o tamanho das áreas dos intervalos.

Quanto aos tipos de solo identificados nessa subunidade de estudo, os valores mais elevados de perda média por erosão relacionaram-se ao Neossolo Litólico, Latossolo Vermelho Ácrico e Gleissolo (Figs. 79 e 80). No entanto, apenas o LVw apresentou valores altos de perda total de solo.

Mesmo apresentando médias baixas de perda de solo, o Neossolo Quartzarênico órtico apresentou extensa área na sub-bacia e, por essa razão, os valores totais foram mais elevados. 


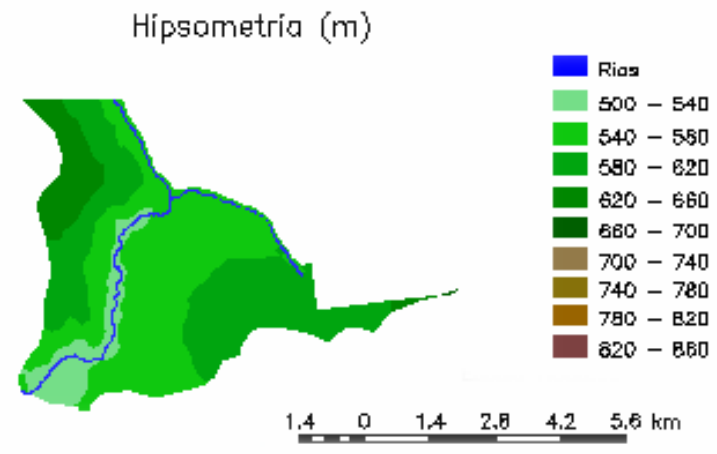

(A)

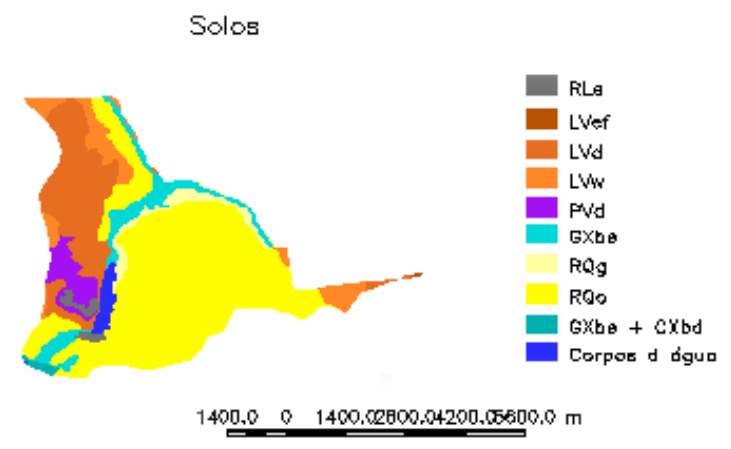

(C)
Clinografia

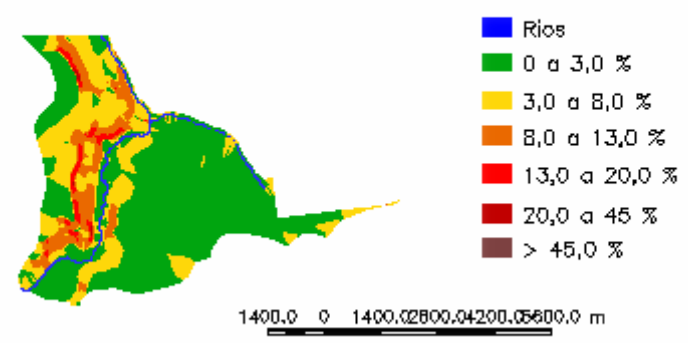

(B)

Uso do Solo

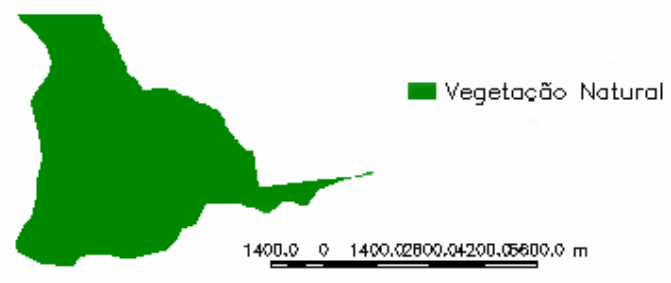

(D)

Fig. 75. Microbacia hidrográfica do córrego do Beija-flor/Jataí (MBH-BFJ). 

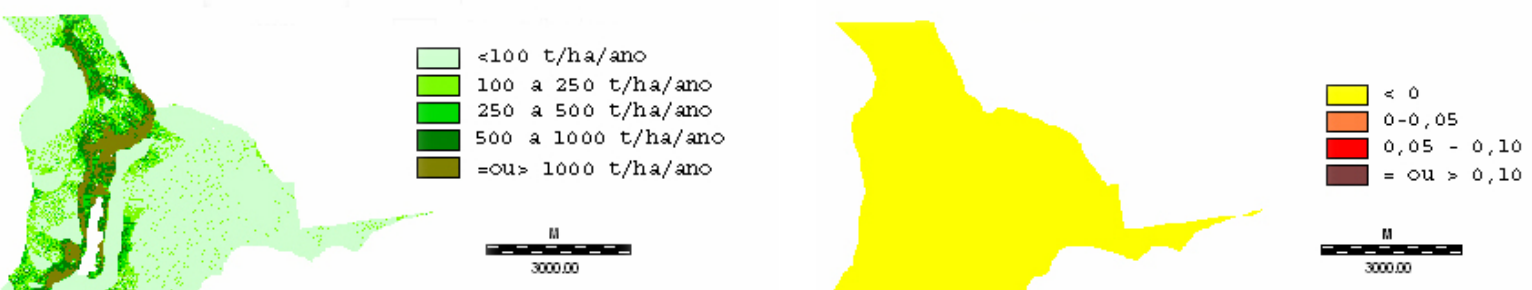

(A)

(B)

Perda de solo por Erosāo Laminar (A)

potencial de Risco de Erosāo Laminar

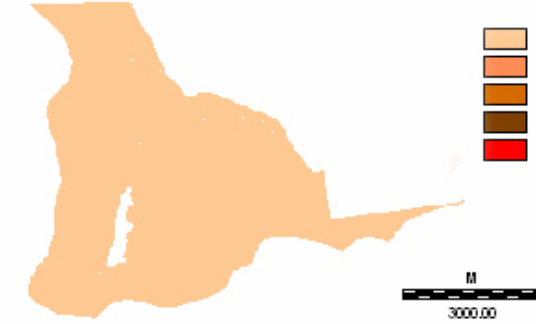

$10 \mathrm{t} / \mathrm{ha} / \mathrm{ano}$

$10-20 \mathrm{t} / \mathrm{ha} / \mathrm{ano}$

$20-50 \mathrm{t} / \mathrm{h} 2 / \mathrm{an} 0$

$=$ ou $=100 \mathrm{t} / \mathrm{ha} / \mathrm{ano}$

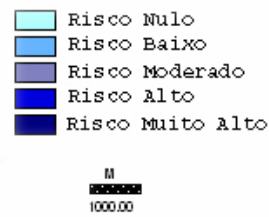

(C)

(D)

Org. Ricardo Tezini Minoti (2006)

Projeção UTM - Zona 23S / Datum Horizontal: Córrego Alegre, MG

Fig. 76. Microbacia hidrográfica do córrego do Beija-flor/Jataí (MBH-BFJ). 


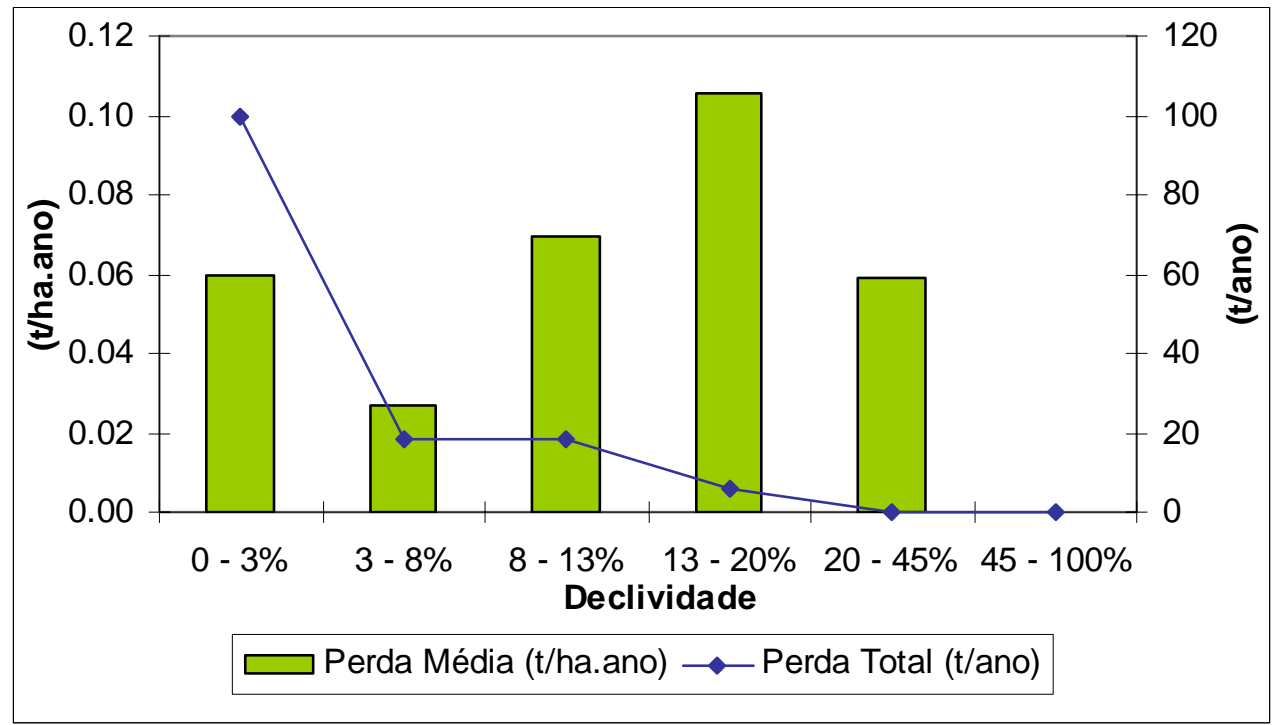

Figura 77. Perdas média e total de solo da Sub-bacia hidrográfica Beija-Flor/Jataí (SBH-BFJ) nos intervalos de declividade.

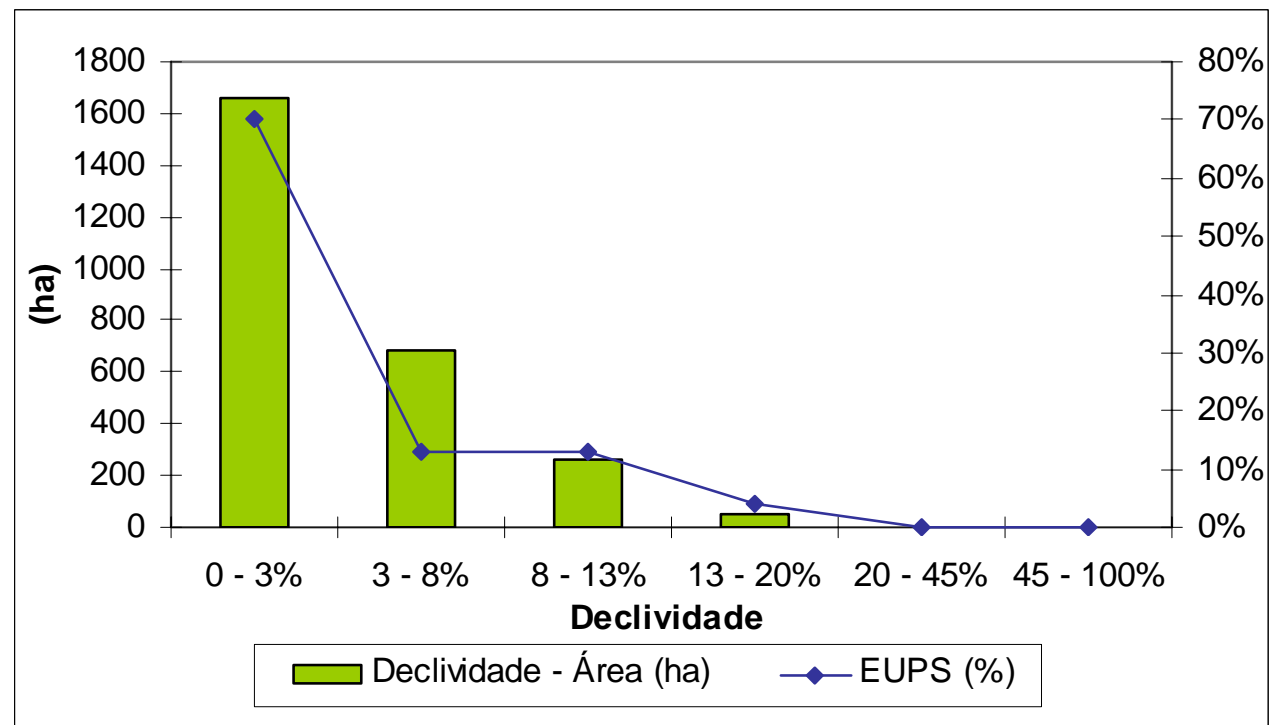

Figura 78. Área dos intervalos de declividade (ha.) e percentagem da perda total de solo na SBH-BFJ (EUPS). 


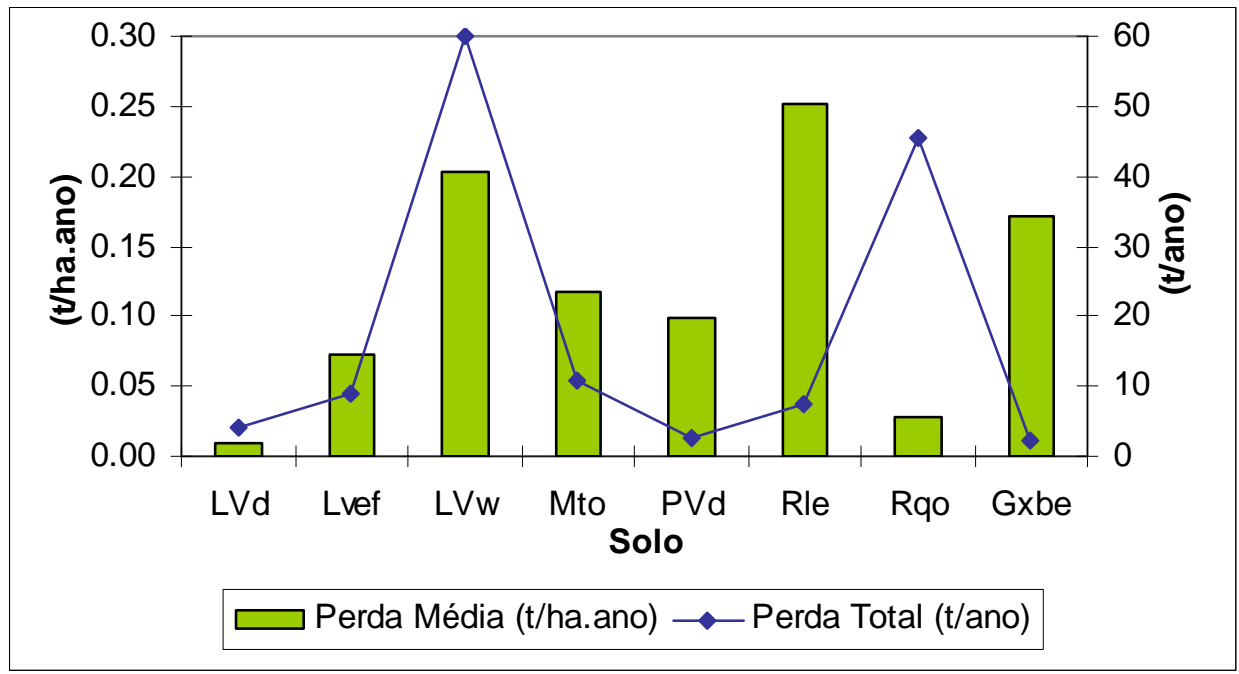

Figura 79. Perdas média e total de solo da Sub-bacia hidrográfica Beija-Flor/Jataí (SBH-BFJ) referentes aos tipos de solo.

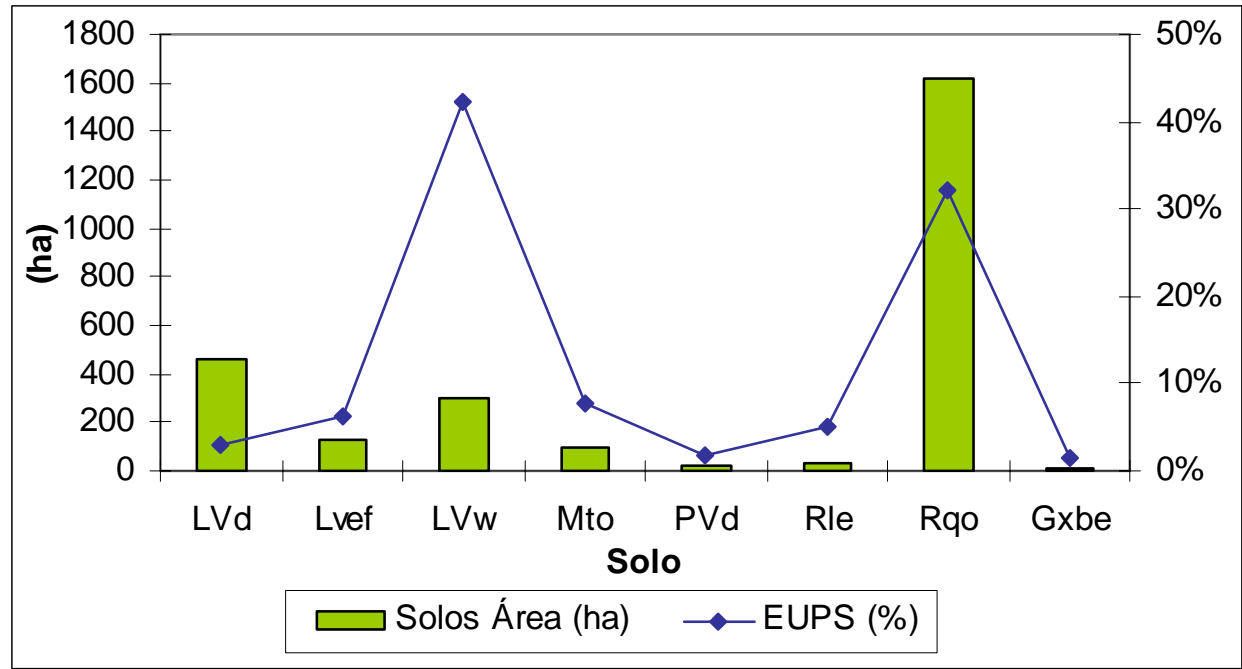

Figura 80. Área ocupada pelos diferentes tipos de solos (ha.) e percentagem da perda total de solo na SBH-BFJ (EUPS). 


\section{A.3 Microbacia hidrográfica do ribeirão das Guabirobas (5.145 hectares)}

O único curso d’água a drenar a microbacia hidrográfica do ribeirão das Guabirobas (MBH-G) é o ribeirão das Guabirobas, que percorre, longitudinalmente, grande parte da microbacia até desaguar na planície de inundação do rio Mogi-Guaçu. Com relação à hipsometria, mais de $90 \%$ da microbacia está inserida na faixa de valores entre 500 e $660 \mathrm{~m}$. A cota mínima é de 530m, situada na região da planície de inundação do rio Mogi-Guaçu, e a máxima, de 718m. Quanto à declividade, mais de 95\% da microbacia insere-se na faixa de valores de zero a 8\%, e 165 hectares, aproximadamente, apresentam declividades entre 8 e $45 \%$ (Fig. 81).

Foram identificadas 4 classes de solos na microbacia. Os principais tipos de solos são os Latossolos (LVAd, LVw e LVef), que ocupam praticamente toda a área da microbacia (99\%). Apenas $1 \%$ da área, região da planície de inundação do rio Mogi-Guaçu, é ocupado por uma associação entre Gleissolos e Cambissolos.

A microbacia do ribeirão das Guabirobas, com exceção das áreas de reserva legal e de preservação permanente, é inteiramente submetida ao uso agrícola (Fig. 82). A maior parte da área é ocupada pelas culturas de cana-de-açúcar (60\%) e laranja (18\%). O restante da microbacia é ocupado por plantação de eucalipto, por pastagem e uma pequena área é ocupada por granja (avicultura).

Apenas 2\% da área total da MBH-G apresentou valores de PNE superiores a 1000 t/ha.ano. Pode-se inferir que, semelhantemente aos resultados obtidos na MBH-BF, os valores mais elevados de PNE relacionaram-se às regiões com maior variação de declividade. Essa variação

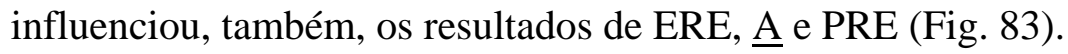

O valor médio de perda de solo da microbacia hidrográfica do Ribeirão das Guabirobas, calculado por meio da EUPS, foi de 7,77 t/ha.ano, e o valor total foi de 39.977 t/ano. Os valores baixos obtidos devem estar relacionados, em grande parte, ao meio físico, à presença de relevo plano ou suavemente ondulado em cerca de 80 \% da área total e à ocorrência de tipos de Latossolos, que apresentam menor susceptibilidade à erosão, em praticamente toda a área da microbacia.

As médias mais elevadas de perda de solo da MBH-G ocorreram nas declividades entre 8 e 45\% (Fig. 84). Entretanto, os valores de perda total de solo foram baixos em função da pequena porção de área da microbacia inserida nessa faixa de valores (Fig. 85). As áreas com declividade entre zero e $8 \%$, 97\% do total da microbacia, foram responsáveis por 93\% da perda total de solo.

Em relação aos solos da MBH-G (Figs. 86 e 87), a maior média de perda de solo, 19,11 t/ha.ano, referiu-se ao Latossolo Vermelho eutroférrico. No entanto, em função da área ocorrente 
na microbacia, a maior contribuição para a perda total de solo referiu-se ao Latossolo Vermelho Amarelo distrófico. A perda total de solo relacionou-se linearmente com os valores de área ocupada pelos solos.

A perda total de solo em função do uso e da ocupação (Figs. 88 e 89) foi proporcional às áreas ocupadas pelas culturas na MBH-G.

Em relação às atividades agrícolas, a adoção de práticas conservacionistas, específicas para cada cultura implantada na microbacia, contribuiu para a manutenção dos baixos valores de perda de solo observados. Nas áreas cultivadas com cana-de-açúcar e citros (laranja), que correspondem a 78\% da área da microbacia, adotam-se, além do plantio em nível, práticas mecânicas de conservação edáfica (terraços), as quais proporcionam excelentes resultados de retenção do deflúvio superficial.

Pode-se inferir que os riscos das atividades humanas nessa microbacia rural, em relação ao recurso solo e eventos de superfície, são baixos, tendo em vista que as medidas de controle de erosão, em função do que foi observado, estão sendo adotadas em quase toda a extensão dela. Além das medidas de controle, os baixos riscos devem-se, em grande parte, ao relevo plano ou suavemente ondulado que ocorre em cerca de $80 \%$ da área e a grande extensão de Latossolos com menor susceptibilidade à erosão.

Entretanto, grande parte dos riscos aos processos erosivos, identificados visualmente na MBH-G (Fig. 90), foram relacionados aos carreadores, semelhantemente ao que se notou na MBH-BF. Foram observados carreadores sem a construção de “camaleões”, em pontos isolados, formando rampas de solo exposto no sentido morro abaixo. Em algumas dessas "rampas”, observou-se ausência de mata ciliar na parte mais baixa dos carreadores, em locais próximos ao córrego das Guabirobas. Foram percebidos sinais de acúmulo de sedimentos nas entrelinhas da cultura de cana-de-açúcar provenientes do canal formado na margem de carreador. Observou-se, dessa maneira, que os riscos relacionados aos processos erosivos em carreadores da MBH-G foram elevados. A ponderação em relação a esse fator agravante não foi considerada na metodologia e, se inserida, poderia, provavelmente, elevar o grau de risco de erosão da microbacia em estudo.

A ausência de mata ciliar em alguns pontos da margem do ribeirão das Guabirobas foi considerada outro fator de aumento do risco para os processos erosivos nessa unidade hidrográfica (Fig. 91). Além das baixadas dos carreadores, esse fator de estresse ambiental foi notado em locais próximos aos carreadores que separam a área de produção agrícola da área de preservação permanente, em áreas de proteção de áreas alagadas e nascentes e, também, nas margens de um represamento na região a jusante do ribeirão. 
Vale ressaltar que, além dos riscos citados, relacionados aos processos erosivos, principalmente em carreadores, estradas rurais e em áreas com ausência de mata ciliar, outros riscos relacionados às atividades agrícolas como lixiviação profunda de agroquímicos, por exemplo, não foram contemplados neste trabalho. Na Figura 91, pode-se observar o cultivo de citros, estágio inicial de desenvolvimento, em região próxima à área de inundação do rio MogiGuaçu. Nesse local o solo deve ser pouco profundo, e o lençol freático deve estar localizado próximo à superfície.

Nesse sentido, alguns dos riscos ambientais listados por Pires (1995), associados às práticas agrícolas do município de Luiz Antônio, podem ser característicos, também, da área da MBH-G, como: riscos de degradação por erosão de solos, sólidos em suspensão em corpos d’água e assoreamento de córregos, associados principalmente às atividades desenvolvidas pela monocultura de cana-de-açúcar, citricultura ou pastagem; riscos de contaminação e eliminação biológica dos corpos d’água e fragmentos de áreas naturais, relacionados à deriva de agrotóxicos devido às atividades praticadas por essas mesmas culturas e também pelo cultivo de eucalipto; riscos de degradação e eliminação biológica por queimadas devido às práticas de uso do fogo, ou fogo acidental ou criminoso, relacionadas às atividades de monocultura de cana-de-açúcar, pastagens, silvicultura e à presença de estradas. 

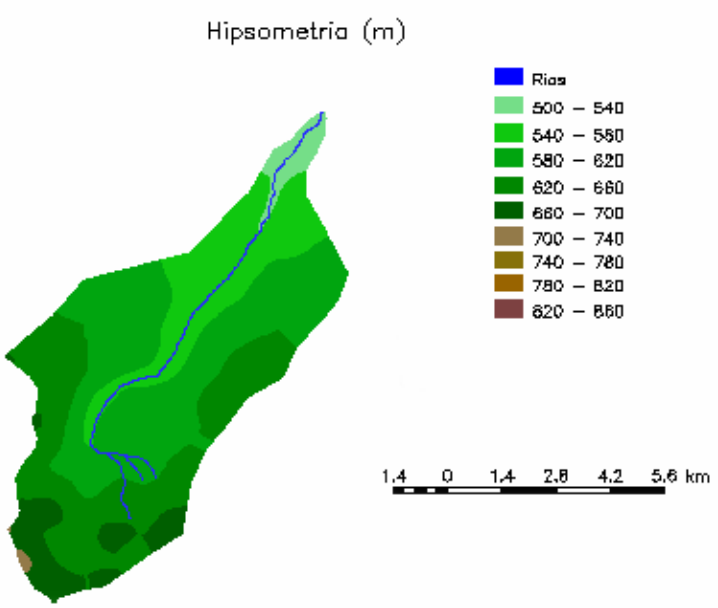

Clinografia

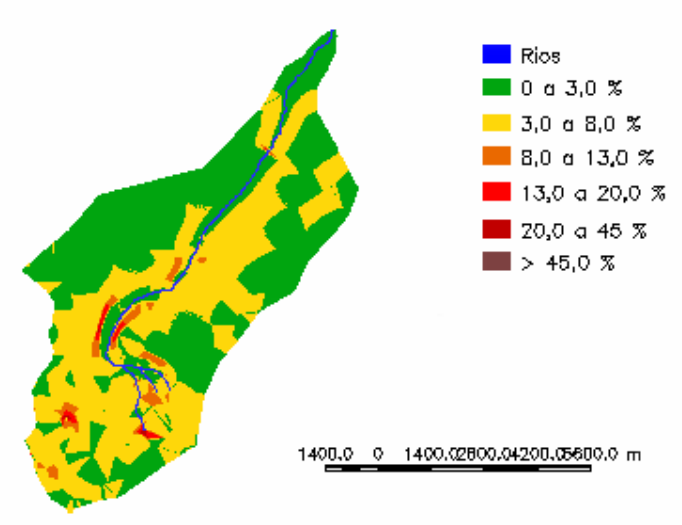

(B)

(A)
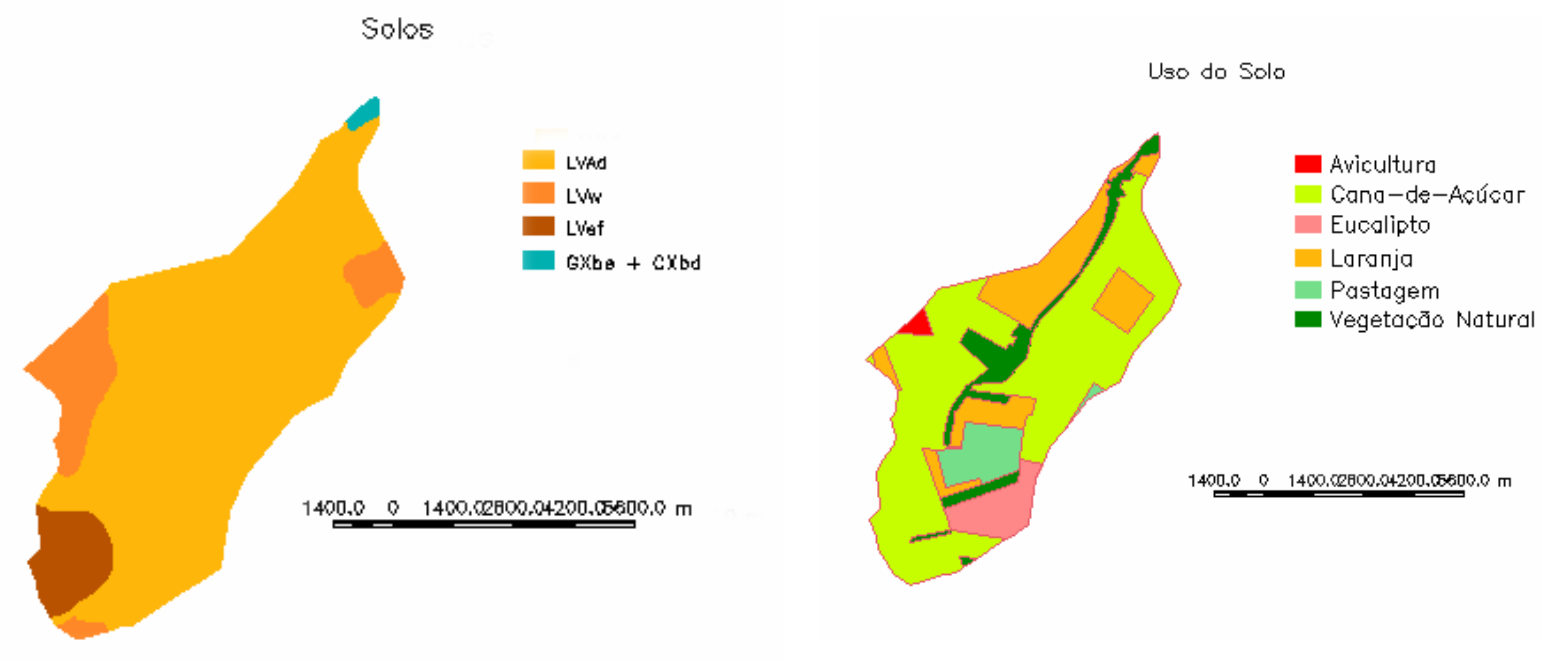

(C)

(D)

Projeção UTM - Zona 23S / Datum Horizontal: Córrego Alegre, MG

Fig. 81. Microbacia hidrográfica do ribeirão das Guabirobas (MBH-G). 


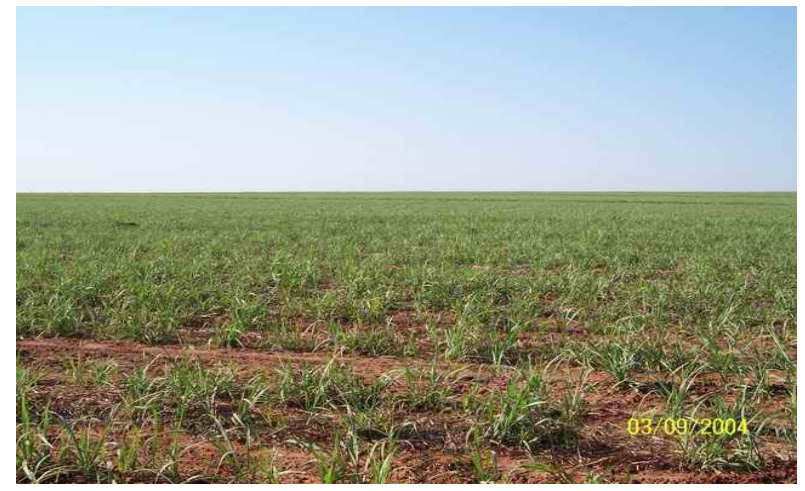

(a)

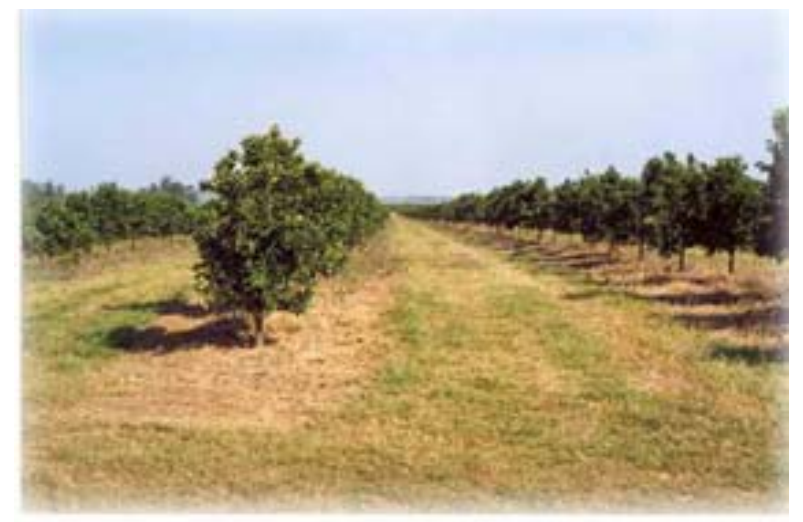

(c)

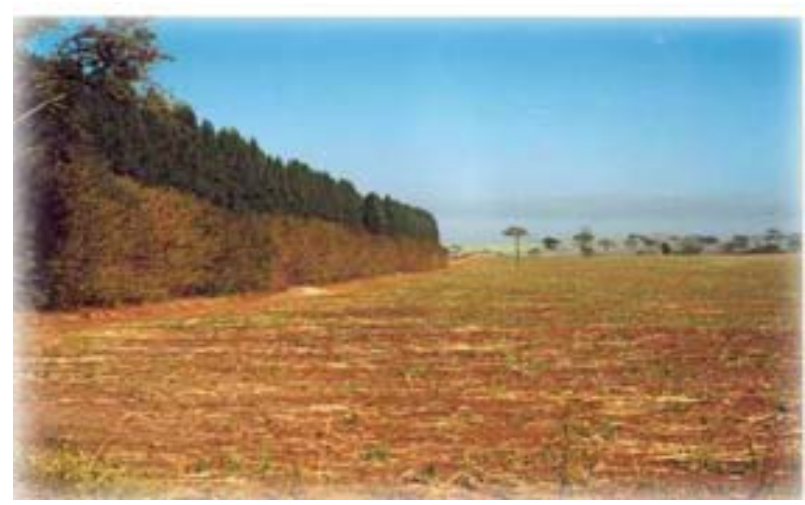

(e)

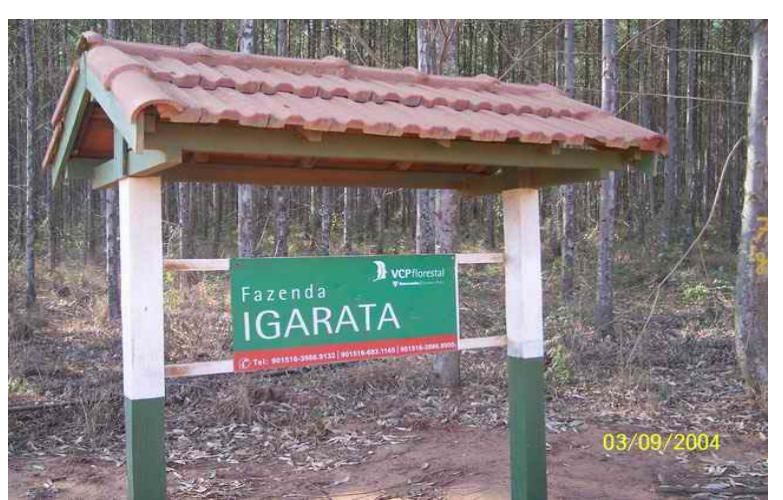

(b)

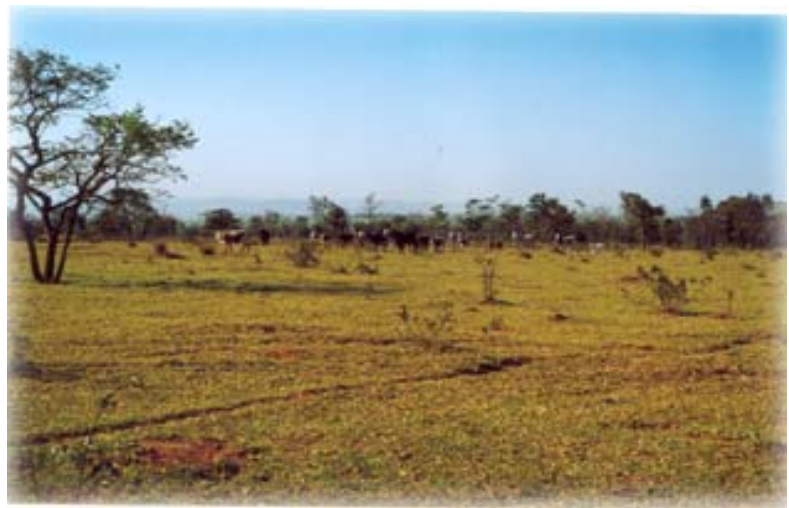

(d)

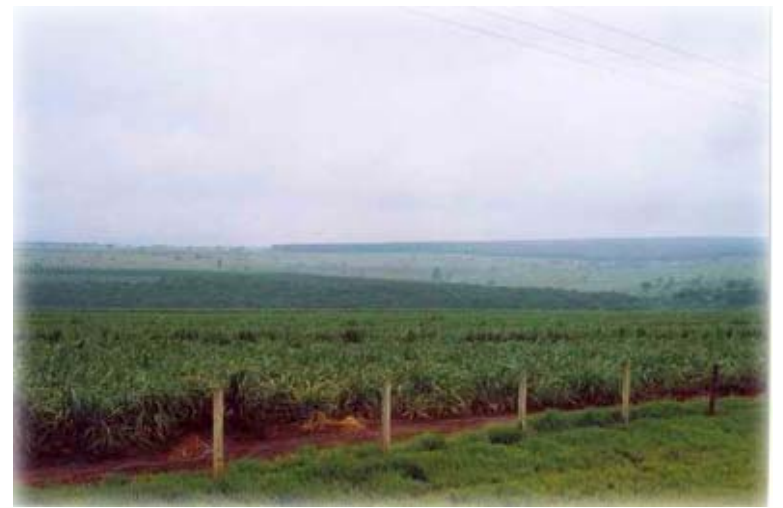

(f)

Org. Ricardo Tezini Minoti (2006)

Figura 82. Diferentes culturas agrícolas desenvolvidas na microbacia hidrográfica do Ribeirão das Guabirobas. (a) Monocultura de cana-de-açúcar. (b) Plantação de Eucalipto da Votorantim Celulose e Papel. (c) Citricultura. (d) Pastagem com criação de gado. (e) Transição entre as culturas de cana-de-açúcar (em estágio inicial de desenvolvimento) e eucalipto. (f) Culturas diversas na MBH-G: cana-de-açúcar, vegetação natural na baixada do ribeirão das Guabirobas, citros, pasto e eucalipto ao fundo. 

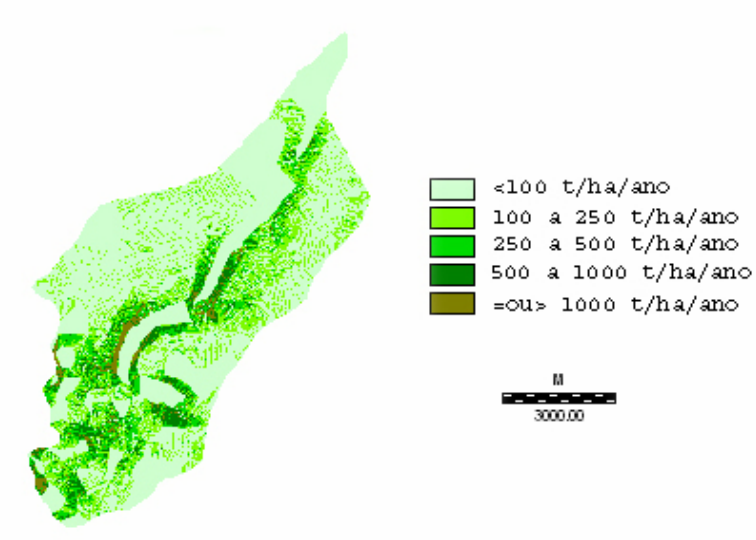

(A)

(B)

Perda de solo por Erosāo Laminar (A)

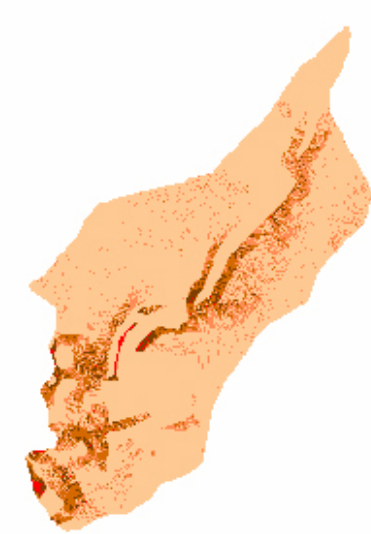

$\square<10 \mathrm{t} / \mathrm{ha} / \mathrm{ano}$

$10-20 \mathrm{t} / \mathrm{ha} / \mathrm{ano}$

$20-50 \mathrm{t} / \mathrm{ha} / \mathrm{ano}$

50-100 t/ha/ano

$=$ ou $=100 \mathrm{t} / \mathrm{ha} / \mathrm{ano}$
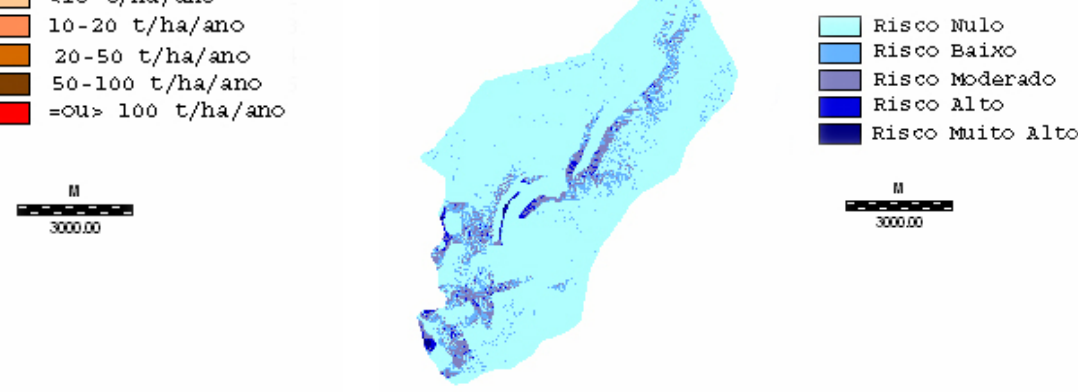

(C)

(D)

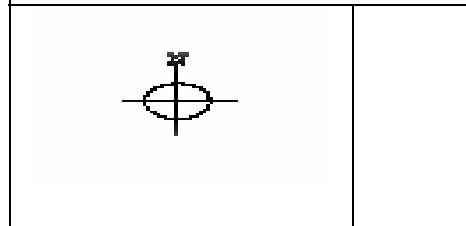

Org. Ricardo Tezini Minoti (2006)

Projeção UTM - Zona 23S / Datum Horizontal: Córrego Alegre, MG

Fig. 83. Microbacia hidrográfica do ribeirão das Guabirobas (MBH-G). 


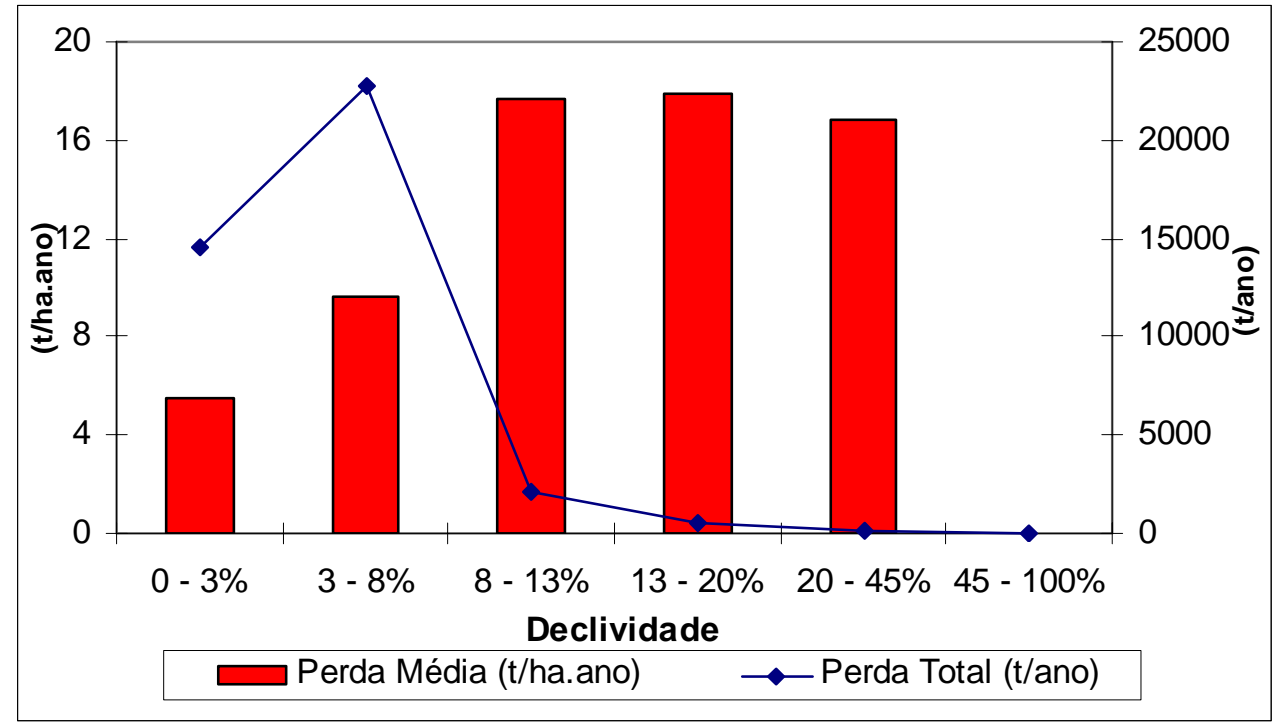

Figura 84. Perdas média e total de solo da microbacia hidrográfica do ribeirão das Guabirobas (MBH-G) nos intervalos de declividade.

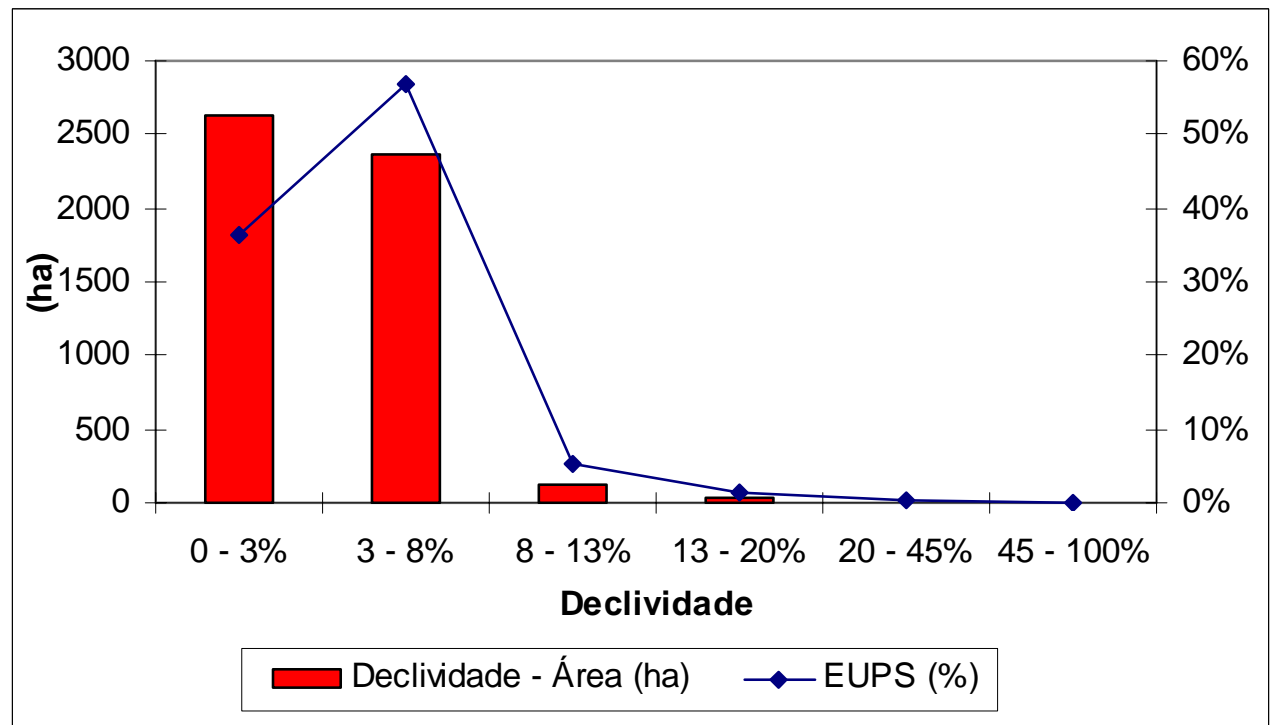

Figura 85. Área dos intervalos de declividade (ha.) e percentagem da perda total de solo na MBH-G (EUPS). 


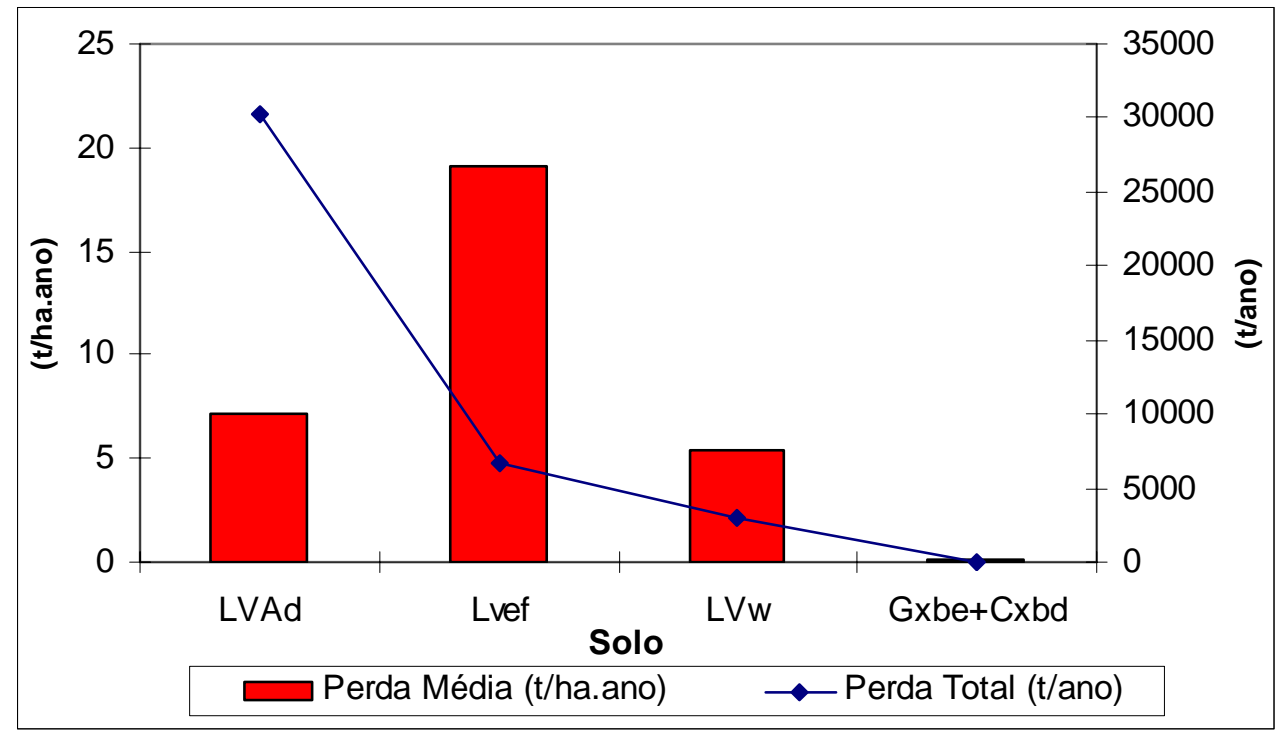

Figura 86. Perdas média e total de solo da microbacia hidrográfica do ribeirão das Guabirobas (MBH-G) referentes aos tipos de solo.

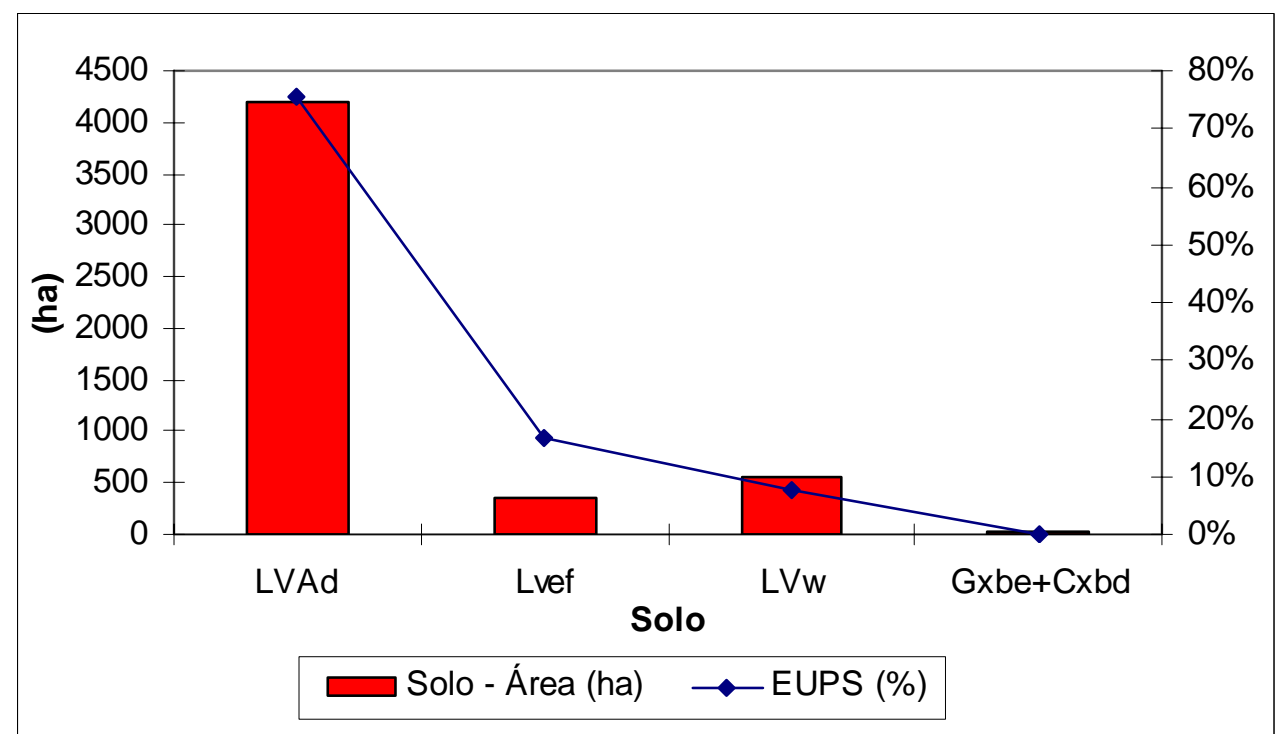

Figura 87. Área ocupada pelos diferentes tipos de solos (ha.) e percentagem da perda total de solo na MBH-G (EUPS). 


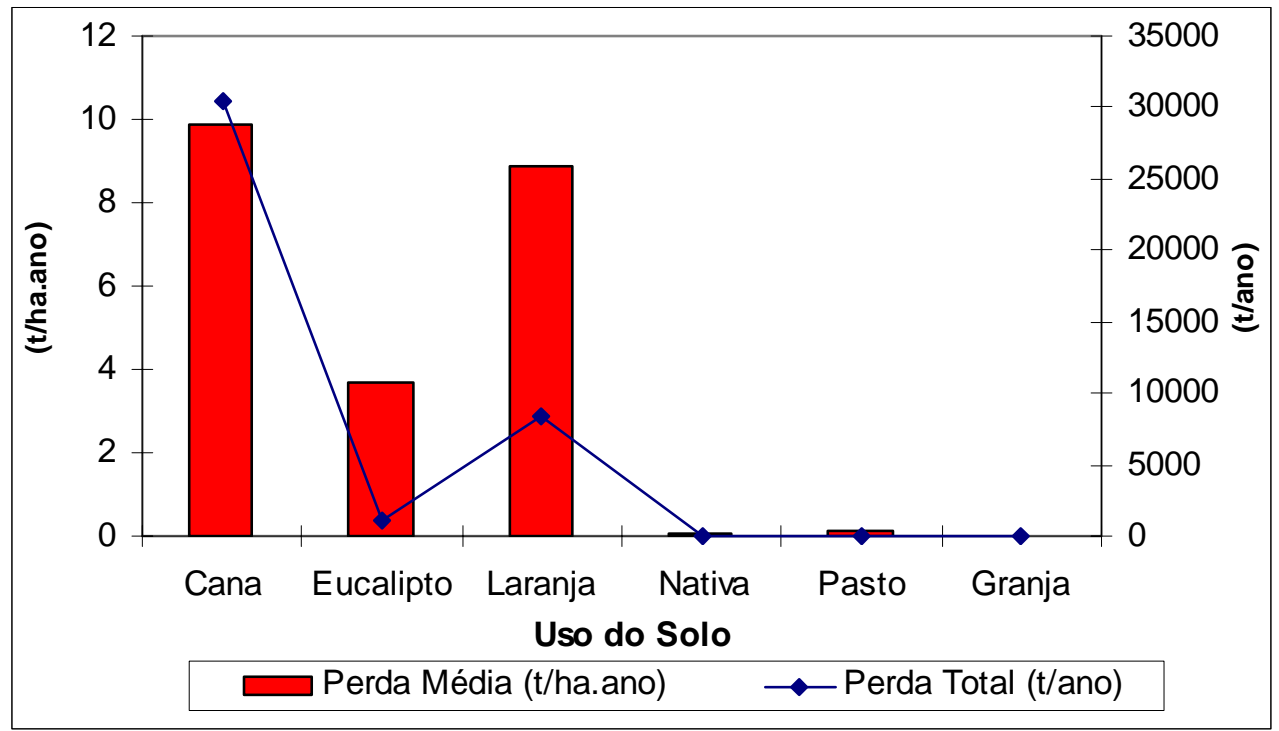

Figura 88. Perdas média e total de solo da microbacia hidrográfica do ribeirão das Guabirobas (MBH-G) referentes aos tipos de uso do solo.

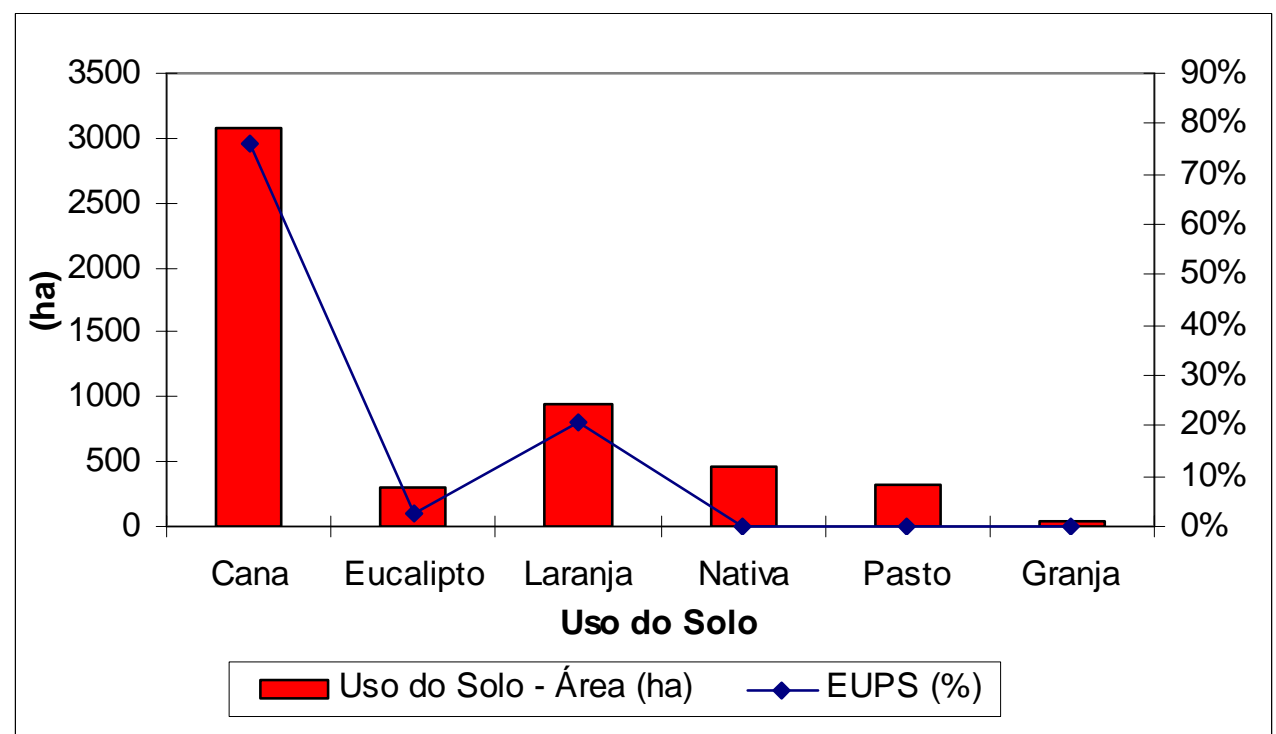

Figura 89. Área ocupada pelos diferentes tipos de solo (ha.) e percentagem da perda total de solo na MBH-G (EUPS). 


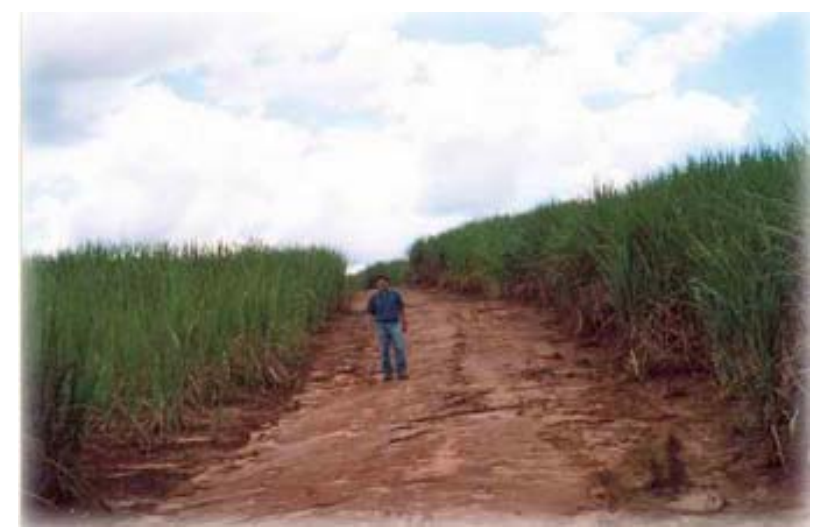

(a)

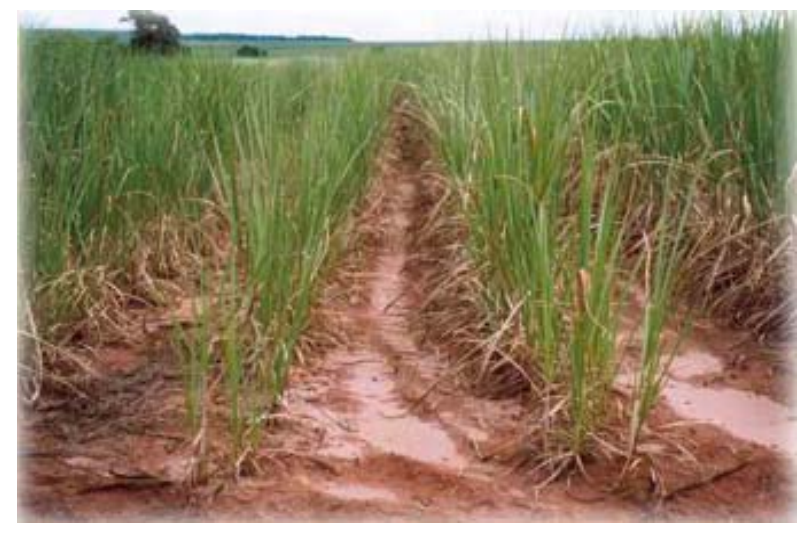

(c)

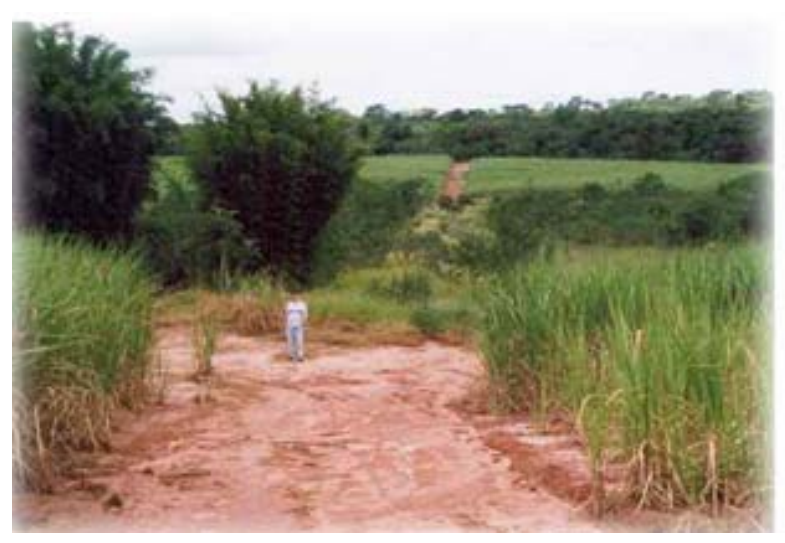

(b)

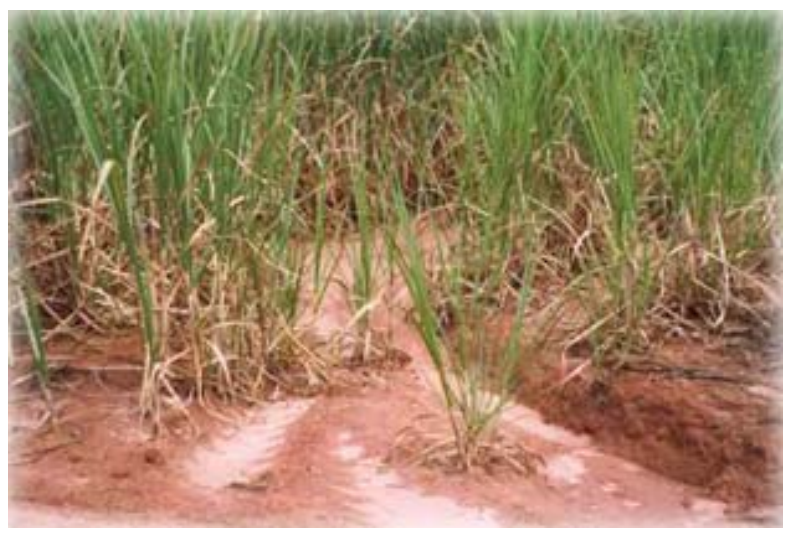

(d)

Org. Ricardo Tezini Minoti (2006)

Figura 90. Diferentes áreas da microbacia hidrográfica do Ribeirão das Guabirobas. (a) Rampa formada por carreador construído no sentido morro abaixo com acúmulo de sedimentos e sinais de erosão em sulcos rasos. (b) Ausência de mata ciliar na parte mais baixa do mesmo carreador, na margem do ribeirão das Guabirobas. (c) e (d) Sedimentos acumulados nas entrelinhas da cultura de cana-de-açúcar provenientes de canal formado na margem do carreador. 


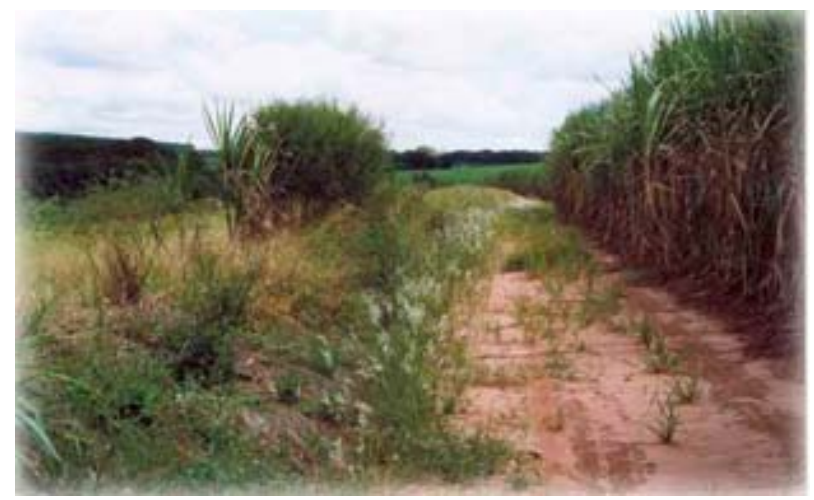

(a)

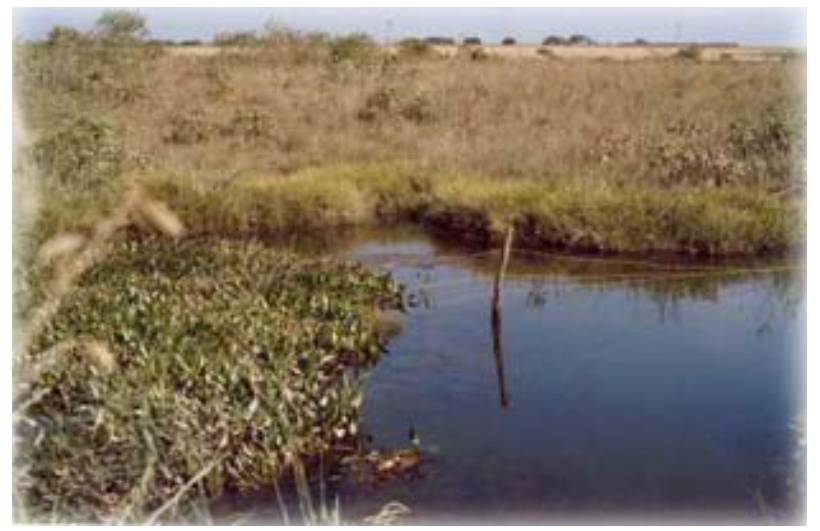

(c)

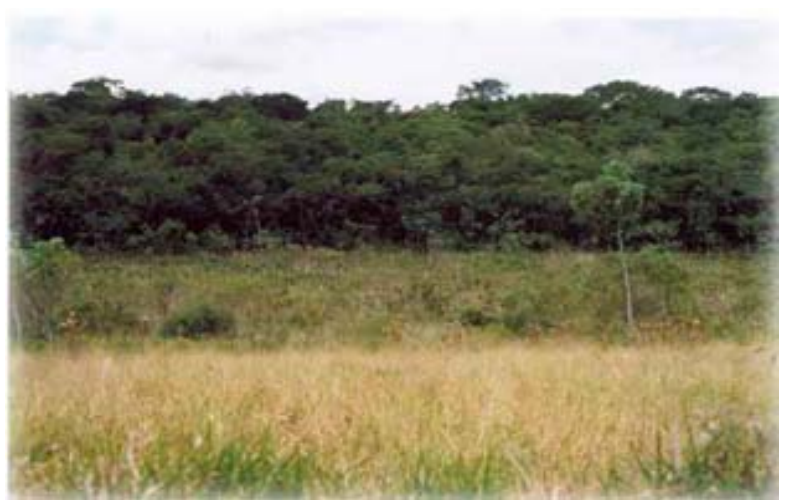

(b)

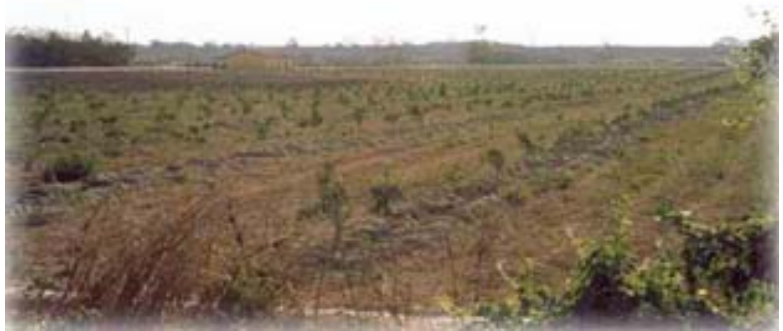

(d)

Org. Ricardo Tezini Minoti (2006)

Figura 91. Diferentes áreas da microbacia hidrográfica do Ribeirão das Guabirobas. (a) Carreador pararelo ao ribeirão das Guabirobas em área com ausência de mata ciliar. (b) Área de gramíneas com ausência de mata ciliar, seguida de área alagada localizada na região à montante da microbacia e mata ciliar visível do outro lado da área alagada. (c) Pequeno represamento do ribeirão das Guabirobas com ausência de mata ciliar na região à jusante da microbacia. (d) Estágio inicial de desenvolvimento de citros em região próxima à área de inundação do rio Mogi-Guaçú. 
APÊNDICE B - Análise das subunidades e unidades de estudo que abrangem a planície de inundação do rio Mogi-Guaçu. 


\section{B.1 Sub-bacia de drenagem de Luiz Antônio (620 hectares)}

A sub-bacia de drenagem do município de Luiz Antônio (SBD-LA) é um segmento da BDLA localizado na região a montante da bacia. Por não abranger a área da planície de inundação do rio Mogi-Guaçu, apresenta um valor mais baixo de variação altimétrica, 103m. A cota mínima é de 537m e a máxima, de 640m (Fig. 92).

Em relação à clinografia, a SBD-LA abrange a área de maiores declividades da BD-LA. Praticamente, toda a área da sub-bacia está inserida na faixa de valores entre zero e 20\%, e 69\% da área apresenta declividade entre 3 e 8\%. Quanto aos solos, 75\% da sub-bacia é constituída por Latossolos, 21\% por Neossolos Quartzarênicos e o restante da área por Argissolos Vermelhos e Gleissolos.

Os resultados de PNE (Fig. 93 evidenciaram valores elevados e variação acentuada em toda a área da sub-bacia. Os valores e as variações de declividade, observados nessa subunidade de estudo, influenciaram, marcadamente, os valores de PNE. Os valores de ERE, $\underline{A}$ e PRE, extremamente baixos, relacionaram-se à ocupação da bacia por vegetação natural.

Na Figura 94, podem-se observar os valores de perda média e perda total de solo para a SBD-LA em cada intervalo de declividade. Foi constatada a influência marcante da declividade e, conseqüentemente, do Fator LS, nos resultados da aplicação da EUPS nessa subunidade de estudo.

Apesar de os valores obtidos de perda média e total de solo para a SBD-LA terem sido extremamente baixos, em função da ocupação da sub-bacia por vegetação natural, nota-se que a perda total foi mais elevada no intervalo entre 3 e $8 \%$ devido, provavelmente, à dimensão desse segmento, perfazendo um total de 427 hectares, 69\% da área da sub-bacia (Fig. 95).

Em relação aos solos da SBD-LA (Figs. 96 e 97), assim como na BD-LA, a maior perda, 38 t/ano, referiu-se ao latossolo vermelho ácrico. Esse valor deve estar relacionado à área relativa de solo na bacia, $74 \%$ do total. 


\section{Hipsometria (m)}
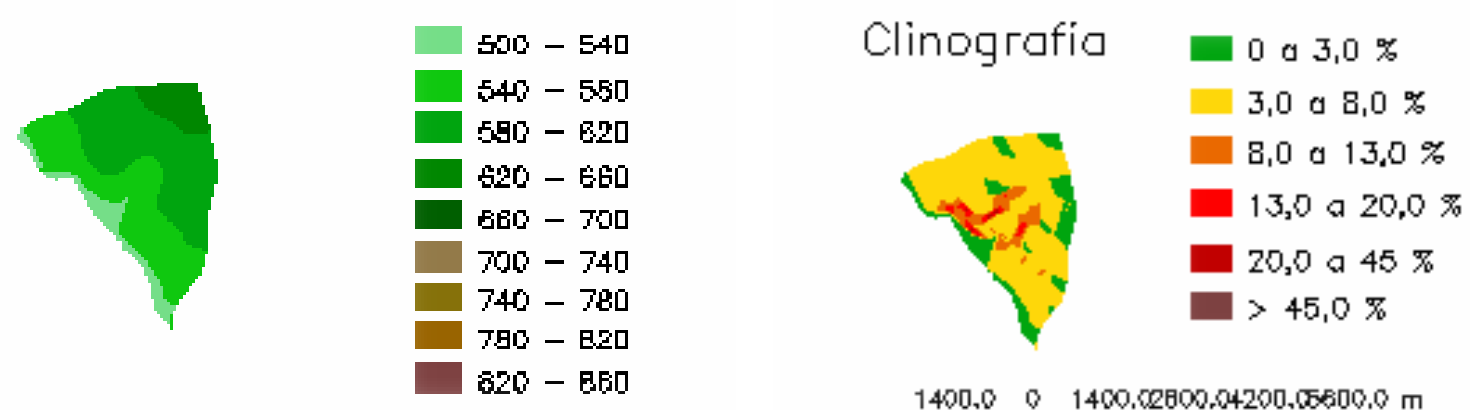

$1400,0 \quad 0 \quad 1400,02800,04200.0 \times 500.0 \mathrm{~m}$

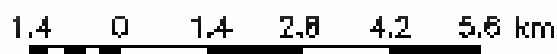

(A)

(B)

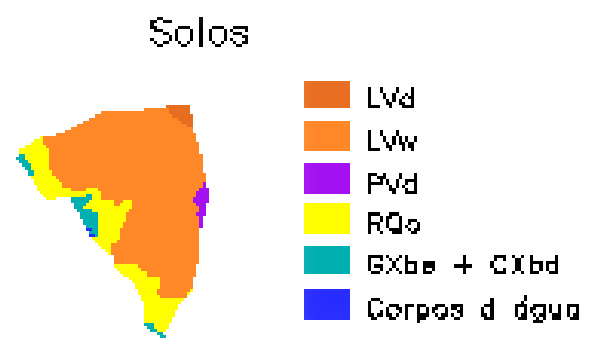

$1400,0 \quad 0 \quad 1400,02800,04200,05000.0 \mathrm{~m}$

Uso do Solo

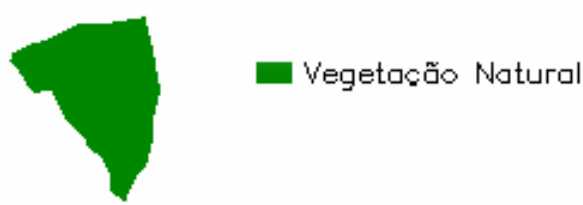

$1400,0 \quad 0 \quad 1400,02800,04200,05000.0 \mathrm{~m}$

(C)

(D)

\begin{tabular}{|c|c|}
\hline Org. Ricardo Tezini Minoti (2006) \\
\hline
\end{tabular}

Fig. 92. Sub-bacia de drenagem de Luiz Antônio (SBD-LA). 

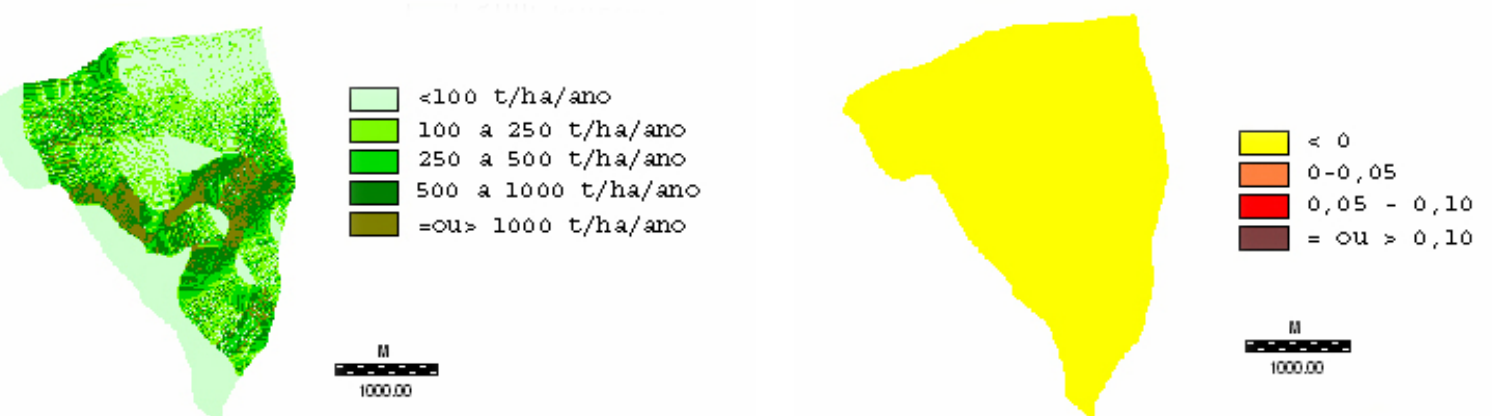

(A)

(B)

Perda de solo por Erosāo Laminar (A)

potencial de Risco de Erosāo Laminar
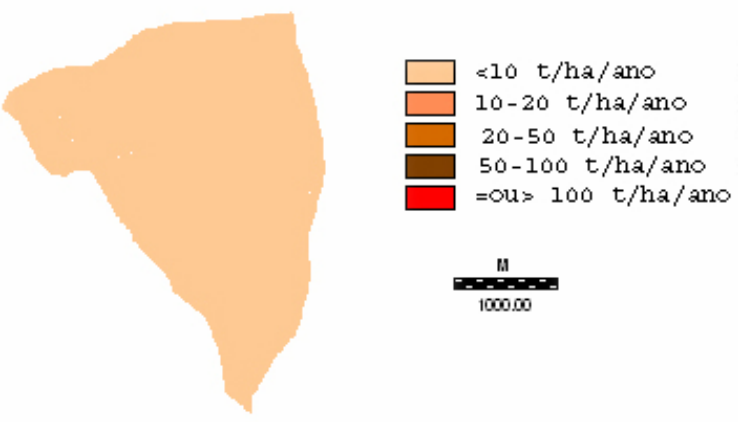

Risco Nulo

Risco Baixo

Risco moderado

Risco sl to

Risco mito alto

1000.00

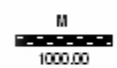

(C)

(D)

Org. Ricardo Tezini Minoti (2006)

Projeção UTM - Zona 23S / Datum Horizontal: Córrego Alegre, MG

Fig. 93. Sub-bacia de drenagem de Luiz Antônio (SBD-LA). 


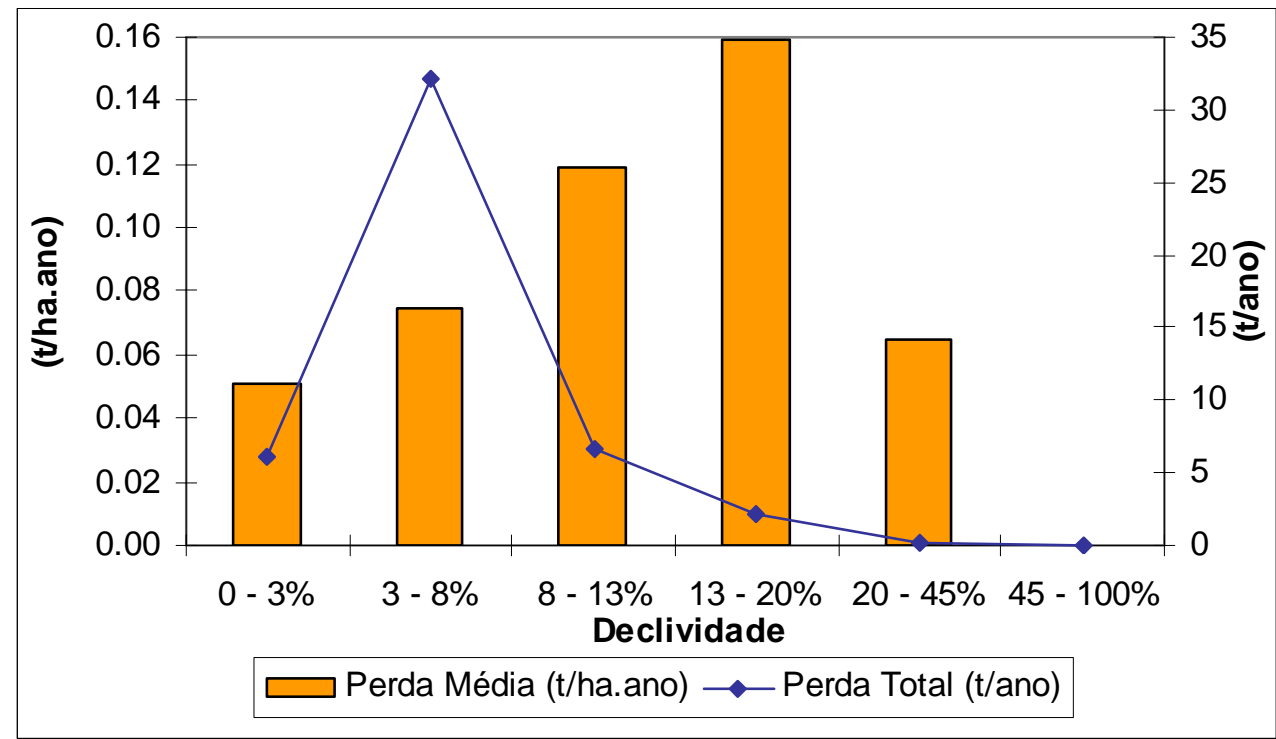

Figura 94. Perdas média e total de solo da Sub-bacia de Drenagem de Luiz Antônio (SBD-LA) nos intervalos de declividade.

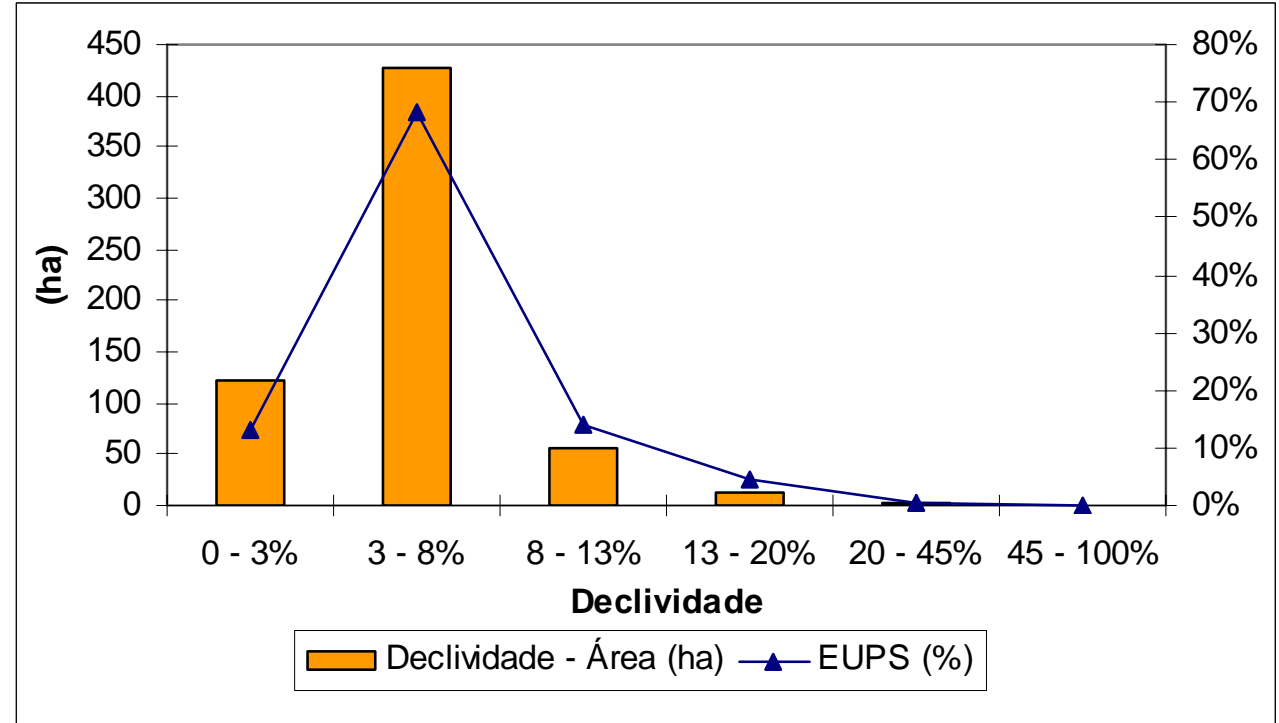

Figura 95 Área dos intervalos de declividade (ha.) e percentagem da perda total de solo na SBD-LA (EUPS). 


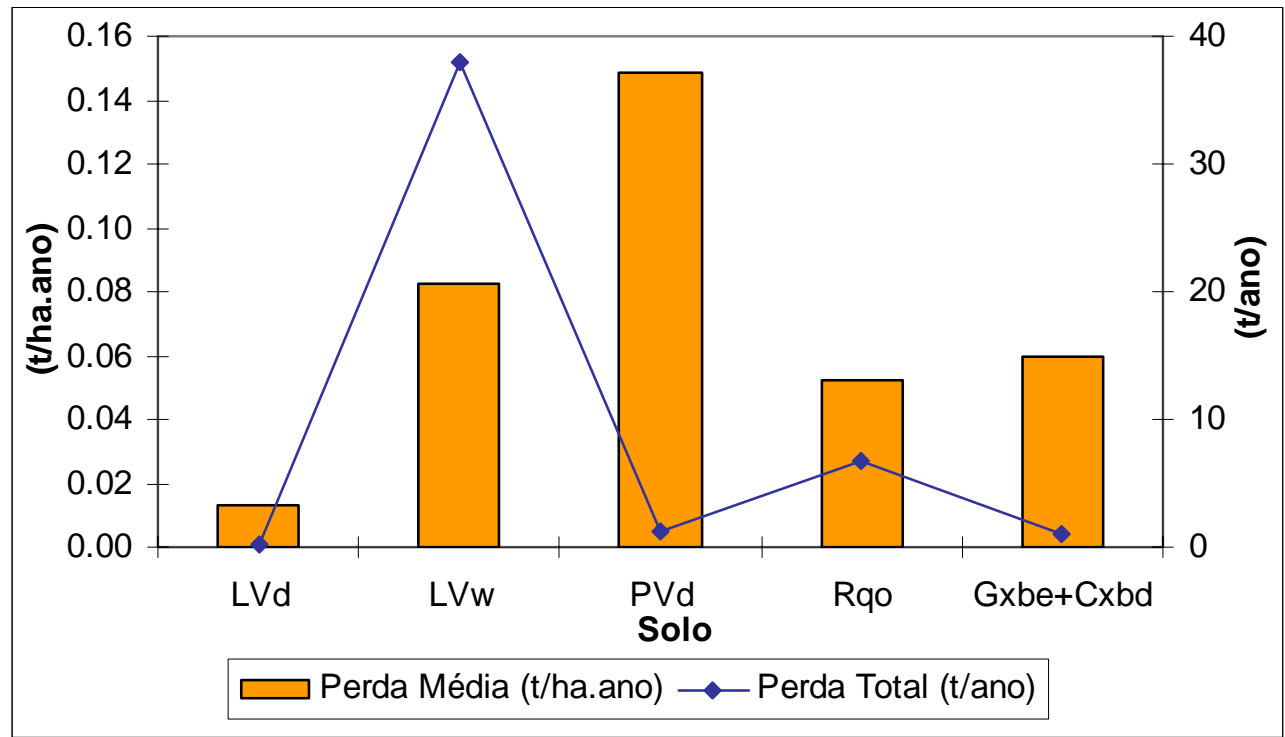

Figura 96. Perdas média e total de solo da Sub-bacia de Drenagem de Luiz Antônio (SBD-LA) referentes aos tipos de solo.

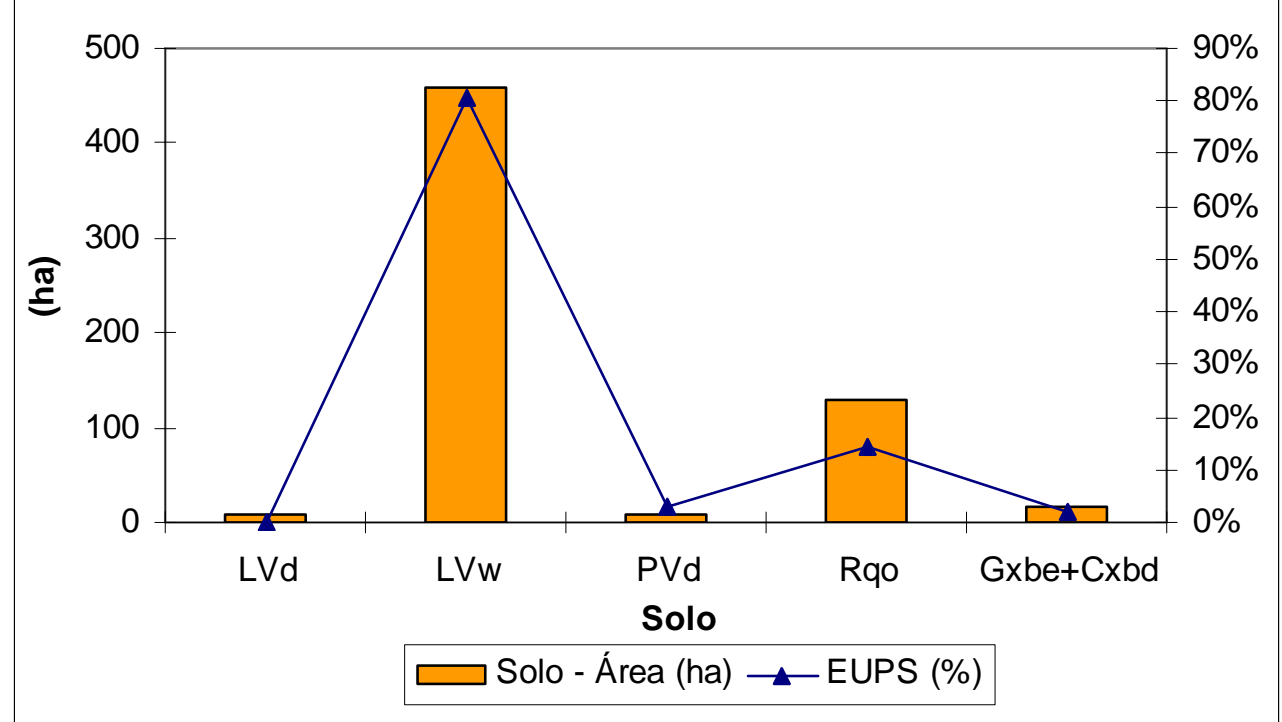

Figura 97. Área ocupada pelos diferentes tipos de solos (ha.) e percentagem da perda total de solo na SBD-LA (EUPS). 


\section{B.2 Bacia de drenagem de Luiz Antônio (960 hectares)}

A bacia de drenagem do Município de Luiz Antônio (BD-LA), assim como a BD-SC e as sub-bacias de drenagem, não apresenta um curso d’água principal que drene toda a bacia. Nessa unidade de estudo, segundo a configuração dos corpos aquáticos, observada na base cartográfica (IBGE, 1971), aparecem apenas pequenos cursos d’água e muitas lagoas marginais. Portanto, a bacia drena suas águas para essas lagoas ou diretamente para o rio Mogi-Guaçu (Fig. 98).

Uma característica peculiar da BD-LA refere-se à área da planície de inundação do rio Mogi-Guaçu. Nessa área são encontradas várias lagoas e, no período de maior precipitação, esse segmento é inundado, parcialmente ou na sua totalidade. Além da variação do nível de água do rio, outra característica interessante refere-se à diferença na coloração da água nos períodos seco e chuvoso (Fig. 99).

Em relação à hipsometria, as áreas da BD-LA estão inseridas nas classes hipsométricas de 500 a 640m. A variação altimétrica da bacia é de $117 \mathrm{~m}$, a cota mínima é de 523m (na região da planície de inundação do rio Mogi-Guaçu) e a máxima, de 640m. Cerca de 90\% da área da bacia de drenagem está inserida na faixa de zero a 8\% de declividade. O restante da unidade apresenta declividades entre 8 e $45 \%$.

Foram identificadas cinco classes de solos na BD-LA: Latossolos (54\% da área), Gleissolos (29\%), Neossolo Quartzarênico (16\%) e uma pequena área com Argissolos Vermelhos (1\%). Quanto ao uso do solo, toda a área da bacia é abrangida pela EEJ e sendo ocupada por vegetação natural.

Os resultados de PNE (Fig. 100) evidenciaram a diferença entre a área da planície de inundação do rio Mogi-Guaçu e o restante da bacia (área da SBD-LA). Os valores obtidos na planície de inundação foram extremamente baixos e, no restante da bacia, a variação sobre os valores obtidos, associada aos elevados valores de PNE em certos setores, ultrapassou 1.000 t/ha.ano, nas áreas com maiores variações de declividade. Os baixos valores de ERE, $\underline{A}$ e PRE estão relacionados à ocupação da bacia por vegetação natural.

Na Figura 101, podem-se observar os valores de perda média e perda total de solo para a BD-LA em cada intervalo de declividade. Apesar de os valores obtidos terem sido extremamente baixos, nota-se que a perda total de solo foi mais elevada no intervalo entre 3 e $8 \%$ devido, provavelmente, à dimensão desse segmento, perfazendo um total de 441 hectares, $46 \%$ da área da bacia (Fig. 102).

Em relação aos solos da BD-LA (Figs. 103 e 104), a maior perda, 38 t/ano, referiu-se ao latossolo vermelho ácrico. Esse valor deve estar relacionado, também, à dimensão da área constituída por esse solo na bacia, 53\% do total. 
Pires (1995), conforme foi mencionado anteriormente, realizou uma análise das atividades desenvolvidas no município de Luiz Antônio/SP e dos impactos e riscos ambientais associados. Dentre as oito unidades de gerenciamento da paisagem (bacias hidrográficas) delimitadas nesse estudo, a UG 4 correspondeu às áreas da MBH-BF e BD-LA. Pelas imagens apresentadas por Pires (1995) e Pires et al. (2000d), pode-se observar que na UG 4, região da BD-LA, foram identificadas como áreas com risco médio e alto de erosão, porém sem riscos de deslizamentos. Essas áreas de maior risco corresponderam, visualmente, às áreas de valores elevados de declividade e PNE, identificadas no presente estudo. Tendo em vista que a área da bacia de drenagem é ocupada por vegetação natural, torna-se desnecessária a discussão de aspectos relacionados às práticas de manejo para controle da erosão nas áreas de maior risco.

A parte baixa da BD-LA, uma área de aproximadamente 340 hectares, é formada pela planície de inundação do rio Mogi-Guaçu. Esse segmento, como mencionado anteriormente, é parcialmente ou totalmente inundado na época da cheia do rio. Conseqüentemente, essa área recebe sedimentos provenientes tanto da região à montante da bacia de drenagem (área da SBDLA) como do rio Mogi-Guaçu, em função do pulso de inundação.

Apesar da nítida diferença na coloração da água do rio Mogi-Guaçu nos períodos de menor e maior precipitação, em função da elevada concentração de sedimentos, Simões Filho (1993) e Simões Filho et al. (2000), ao investigarem o processo de sedimentação nas lagoas marginais (lagoas do Infernão e Óleo - inseridas na BD-LA), verificaram que, embora o transbordamento tenha produzido registros nos inventários sedimentares levantados, e que a influência sazonal sobre a produtividade e a sedimentação nessas lagoas seja inegável, o rio tem importância secundária no que tange aos aspectos quantitativos da sedimentação, a qual depende preponderantemente da produção primária autóctone e de materiais terrestres advindos da bacia local das lagoas marginais.

Os valores da estimativa de erosão para essa bacia, parte baixa da BD-LA, referem-se à diferença entre o valor total obtido para a área da BD-LA e o valor obtido para a área da SBDLA (parte alta da bacia de drenagem). Tendo em vista que a erosão total da BD-LA foi de 48 ton/ano e a erosão total da SBD-LA foi de 47 ton/ano, o valor total do processo erosivo na parte baixa da BD-LA foi estimado em aproximadamente 1 ton/ano. Esse valor, extremamente baixo, pode ser associado à pequena variação hipsométrica e clinográfica nessa área.

Apesar dos baixos valores de erosão obtidos na parte baixa da BD-LA, Simões Filho (1993) encontrou taxas de acumulação de sedimentos nas lagoas marginais que variaram entre 135 e $454 \mathrm{mg} / \mathrm{cm}^{2}$.ano. Outros fatores como produção primária autóctone ou ressuspensão de sedimentos do fundo (aspectos mencionados por Simões Filho op cit.) assim como sedimentos 
provenientes da SBD-LA (parte alta da BD-LA), de acordo com os resultados obtidos no presente trabalho, podem ter uma atuação marcante nas taxas de acumulação das lagoas.

A bacia da lagoa do Infernão (149,4 hectares), que abrange áreas da parte baixa e da parte alta da BD-LA, apresenta topografia bastante irregular. Simões Filho (1993) encontrou valores de cota dessa bacia variando entre 515 e 652m (valores ligeiramente diferentes do que foi observado no presente trabalho) e observou que essa conformação geomorfológica peculiar determina contribuição preponderante da vegetação terrestre da bacia, durante a maior parte do ano, em termos da composição do particulado que chega à coluna d'água e aos sedimentos da lagoa.

Assim como foi observado em relação ao material particulado, os sedimentos provenientes da parte alta da BD-LA, parte das 47 toneladas de solos erodidos, pode estar causando impactos na parte baixa da bacia e nas lagoas existentes na planície de inundação do rio Mogi-Guaçu. Dessa forma, tanto a área de entorno da lagoa (parte baixa da bacia), como a parte alta dessa unidade de estudo podem estar contribuindo com sedimentos para as lagoas e para as demais áreas alagáveis desse rio.

Albuquerque et al. (2000), no intuito de analisar a variação do processo de eutrofização ao longo do tempo, realizaram estudo geocronológico dos sedimentos, por meio da técnica de datação com ${ }^{210} \mathrm{~Pb}$, na Lagoa do Infernão (EEJ). Os resultados mostraram que a Lagoa está sendo submetida a intensa eutrofização, que parece refletir tanto influências do processo natural de sucessão ecológica quanto do aumento da entrada de nutrientes antropogênicos na lagoa. Os autores associaram as elevadas concentrações de nutrientes às cargas de sedimentos na água do rio Mogi-Guaçu. Os sedimentos foram associados às mudanças no uso do solo na região, ao longo do último século, com conseqüente aumento dos processos erosivos.

Tendo em vista as variadas origens das cargas de sedimentos que podem atingir a parte baixa da BD-LA, vale ressaltar, novamente, a importância da área ocupada pela EEJ. Ao estudarem a geocronologia dos sedimentos nas lagoas marginais do rio Mogi-Guaçu (área da BD-LA), Simões Filho (1993) e Simões Filho et al. (2000) identificaram condições hidrodinâmicas particulares deste sistema rio-planície de inundação. De acordo com a análise de perfis de sedimentos, a partir de 1982-1983, época que coincide com a decretação da unidade de conservação (EEJ), verificou-se a existência de um período de acumulação constante deles. 


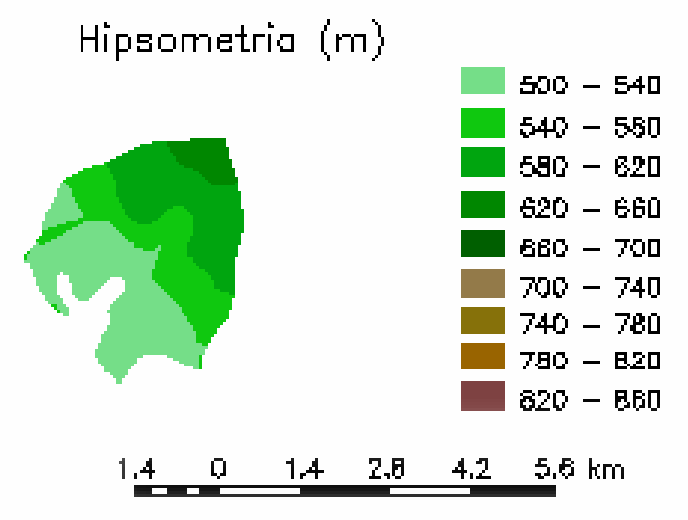

(A)

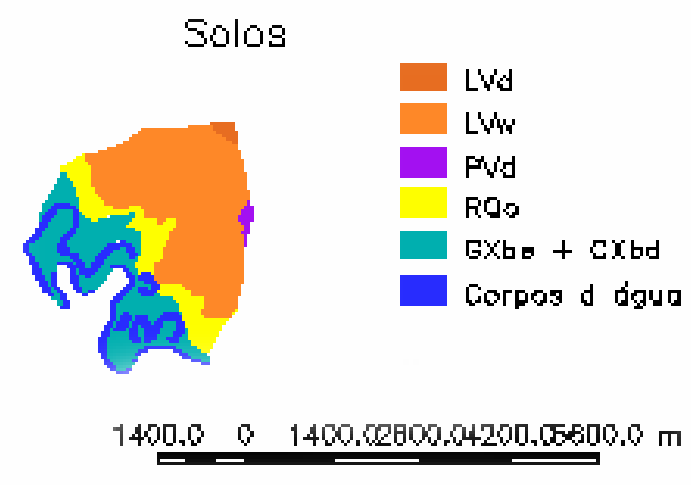

(C)

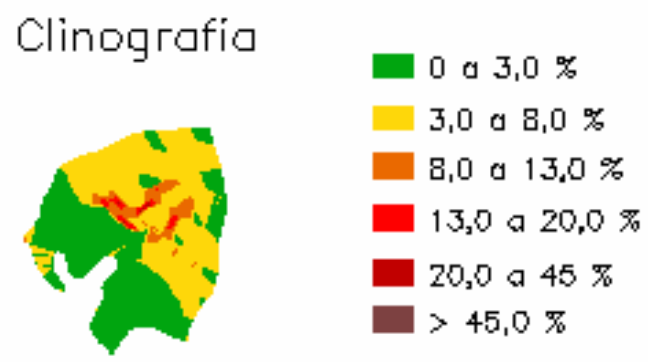

$1400,0 \quad 0 \quad 1400.02600,04200,0 \times 500.0 \mathrm{~m}$

(B)

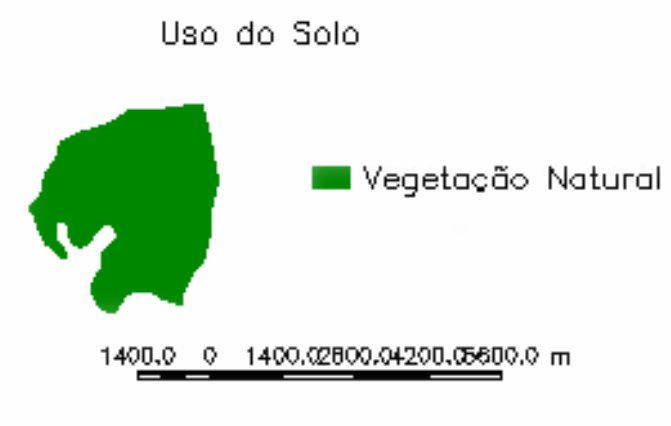

(D)

Projeção UTM - Zona 23S / Datum Horizontal: Córrego Alegre, MG

Fig. 98. Bacia de drenagem de Luiz Antônio (BD-LA). 


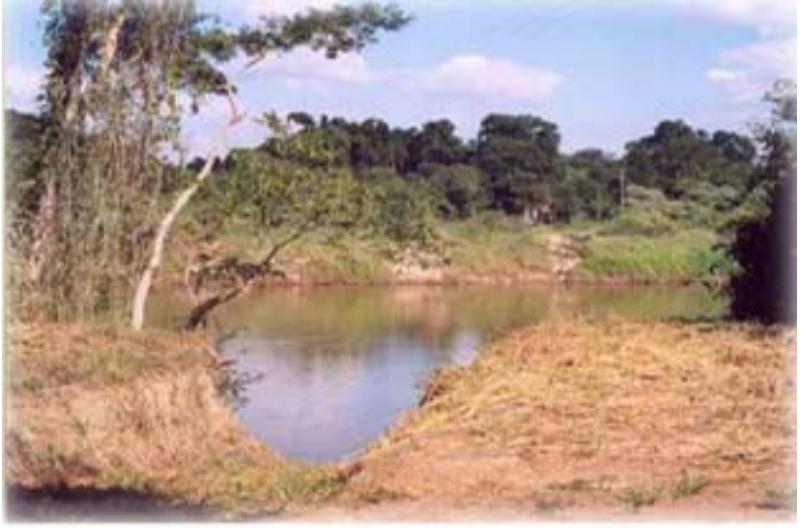

(a)

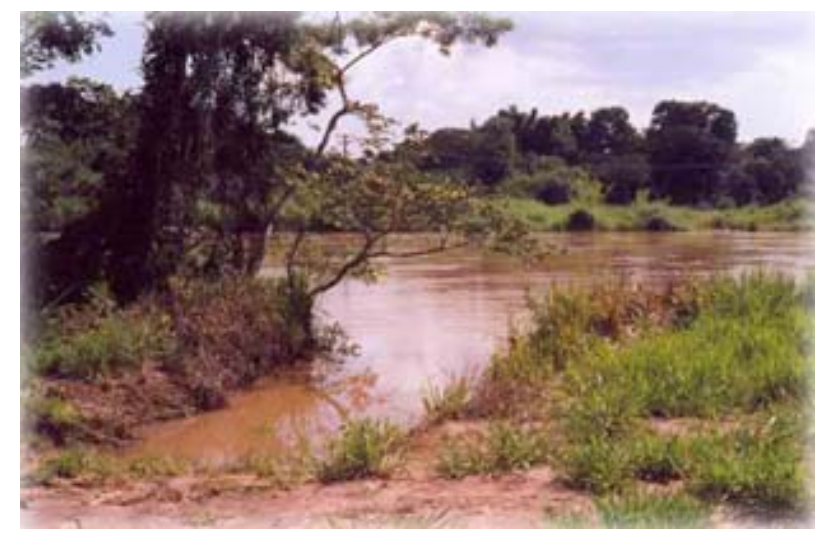

(c)

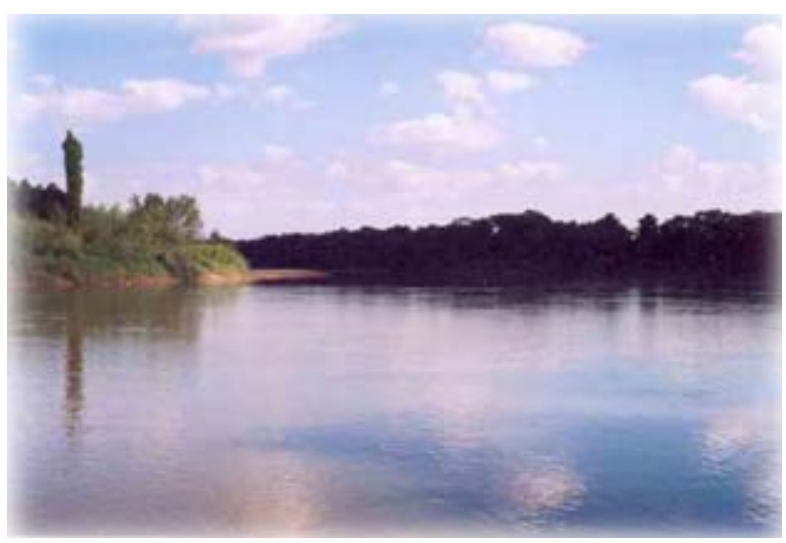

(b)

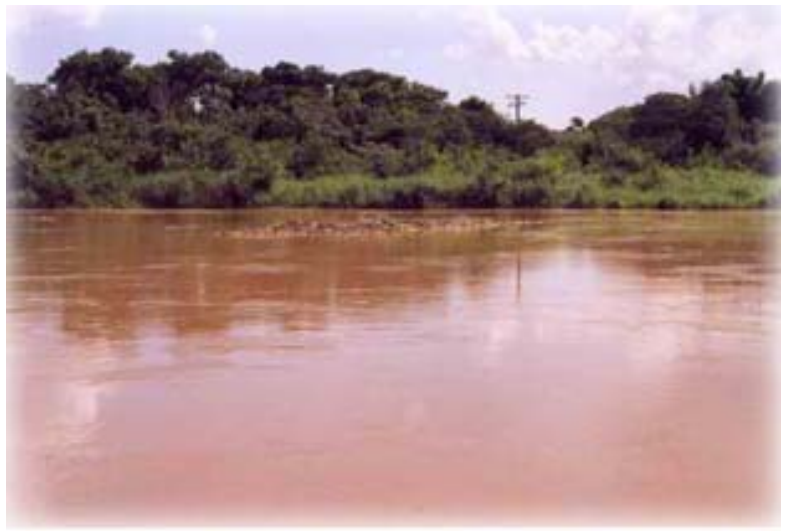

(d)

Org. Ricardo Tezini Minoti (2006)

Figura 99. Área da Bacia de Drenagem de Luiz Antônio na margem direita do rio Mogi-Guaçu. (a) Rampa para saída de barcos na época de seca com vista para a margem esquerda do rio MogiGuaçu, município de São Carlos (margem do outro lado do rio). (b) Coloração da água do rio Mogi-Guaçu em época de seca. (c) Rampa para saída de barcos na época de cheia do rio MogiGuaçu. (d) Coloração da água do rio Mogi-Guaçu, em época de cheia, com elevada concentração de sedimentos. 

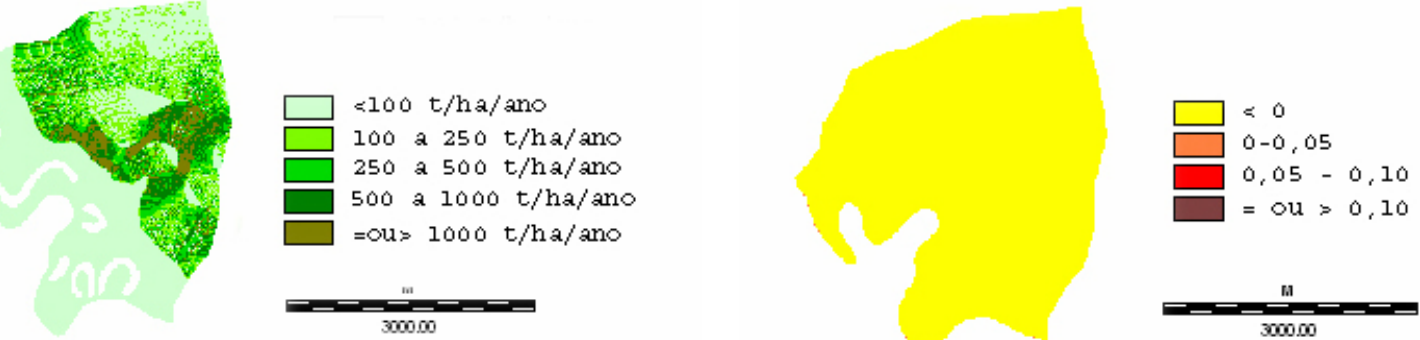

(A)

(B)

Perda de solo por Erosāo Laminar (A)

(C)

(D)

\section{Org. Ricardo Tezini Minoti (2006)}

Projeção UTM - Zona 23S / Datum Horizontal: Córrego Alegre, MG

Figura 100. Bacia de drenagem de Luiz Antônio (BD-LA). 


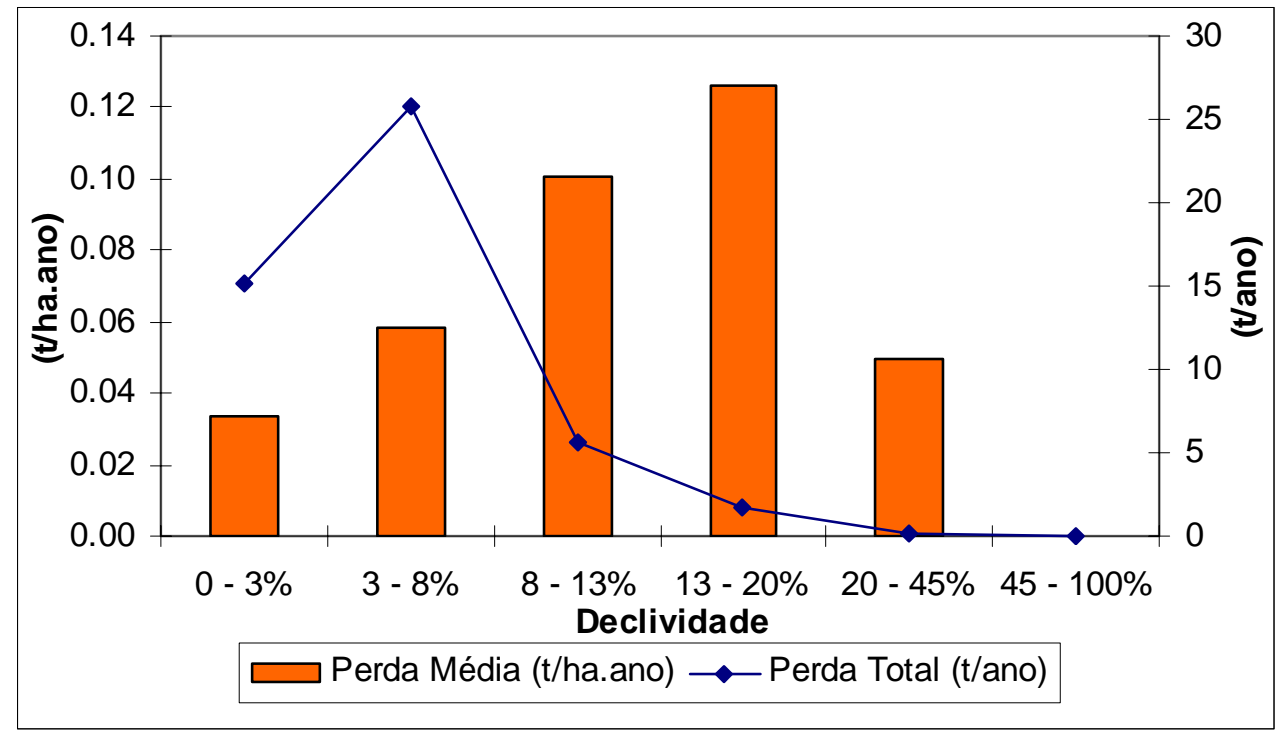

Figura 101. Perdas média e total de solo da Bacia de Drenagem de Luiz Antônio (BD-LA) nos intervalos de declividade.

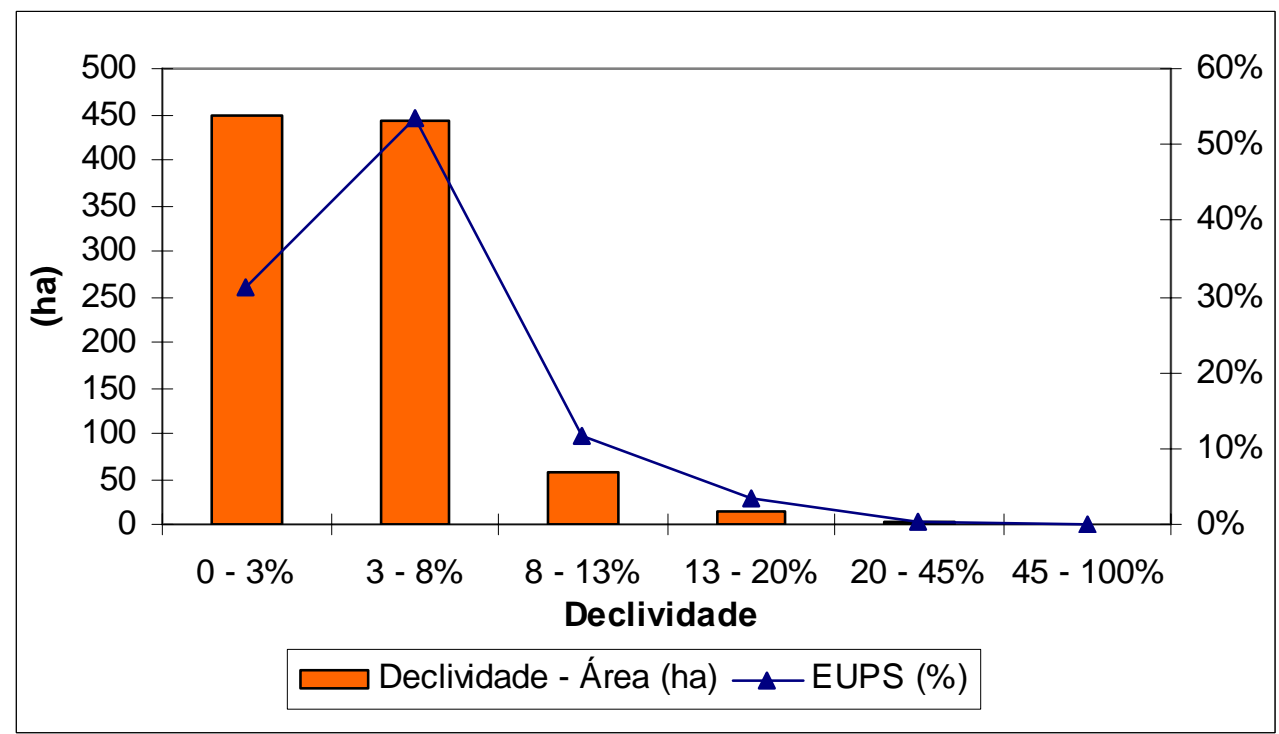

Figura 102. Área dos intervalos de declividade (ha.) e percentagem da perda total de solo na BD-LA (EUPS). 


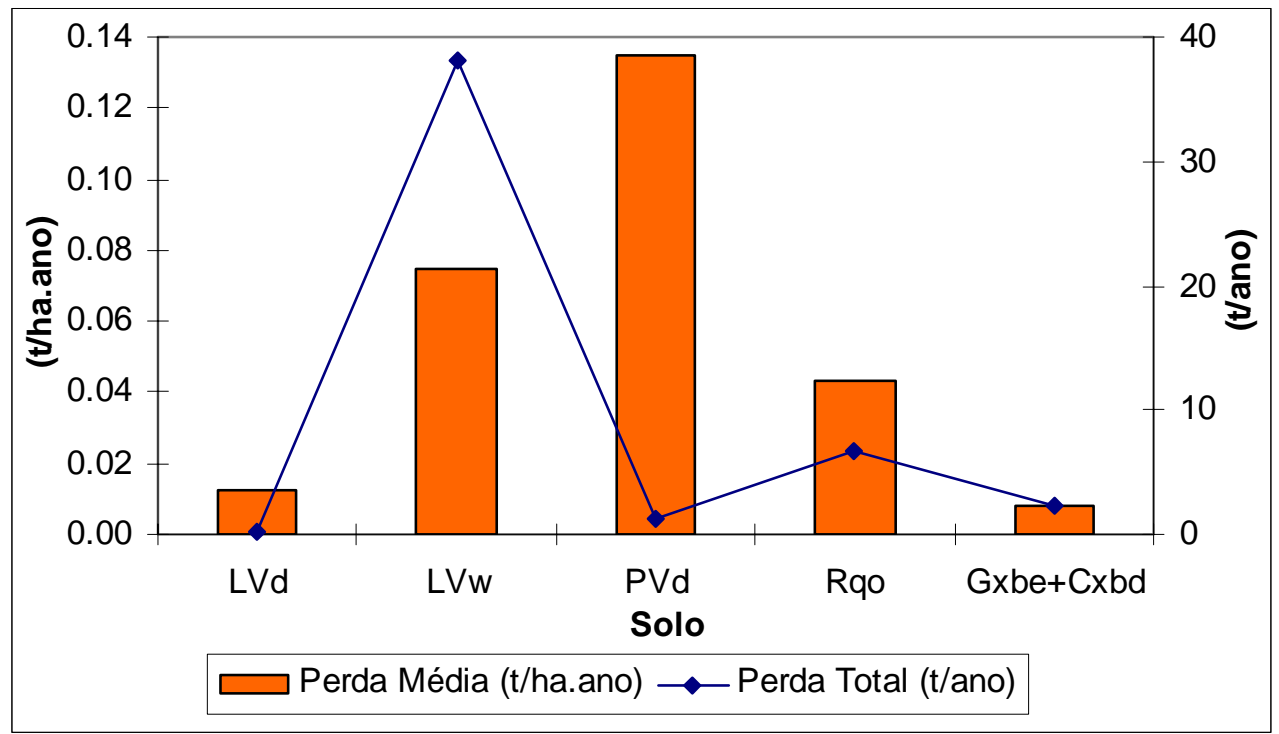

Figura 103. Perdas média e total de solo da Bacia de Drenagem de Luiz Antônio (BD-LA) referentes aos tipos de solo.

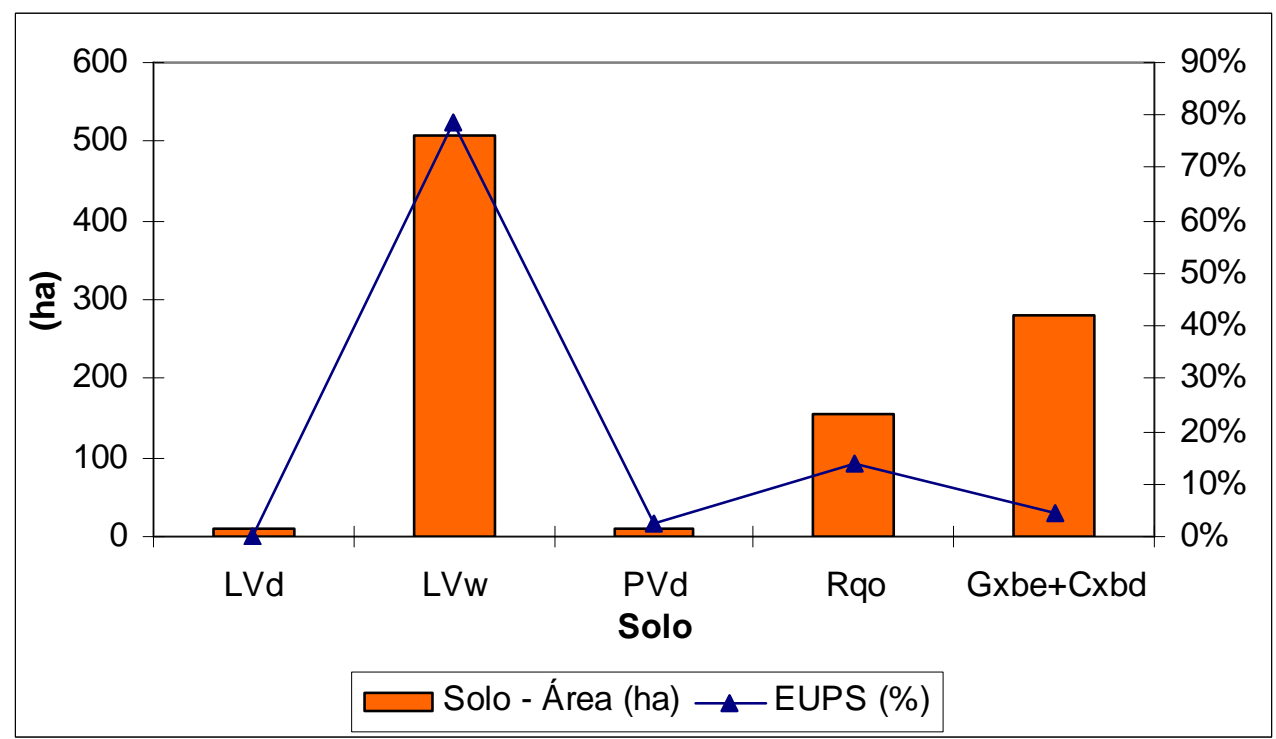

Figura 104. Área ocupada pelos diferentes tipos de solos (ha.) e percentagem da perda total de solo na BD-LA (EUPS). 


\section{B.3 Sub-bacia de drenagem de São Carlos (1.525 hectares)}

A sub-bacia de drenagem do município de São Carlos (SBD-SC) é um segmento da BD-SC localizado na região a montante dela. Por não abranger a área da planície de inundação do rio Mogi-Guaçu, apresenta um valor mais baixo de variação altimétrica, 76m (1 metro menor). A cota mínima é de 524m e a máxima, de 600m (Fig. 105).

Em relação à clinografia, a SBD-SC abrange a área de maior declividade da BD-SC. Praticamente toda a área da sub-bacia está inserida na faixa de valores entre zero e 8\%, 75\% da área apresenta declividade entre zero e 3\%, e 24\% da bacia, declividades entre 3 e 8\%. Quanto aos solos, praticamente toda a área da sub-bacia é constituída por Latossolos.

Os resultados de PNE, ERE, $\underline{A}$ e PRE (Fig. 106) foram ligeiramente mais elevados do que a BD-SC, em termos médios, em função de não estar sendo considerada a região da planície de inundação do rio Mogi-Guaçu. Entretanto, assim como a BD-SC, os valores obtidos foram os mais baixos de toda a área de estudo.

Na Figura 107 podem-se observar os valores de perda média e perda total de solo para a SBD-SC em cada intervalo de declividade. Nota-se que a perda total de solo foi mais elevada no intervalo entre 3 e 8\% devido, provavelmente, à média de perda desse segmento - 9,3 ton/ha.ano. No intervalo entre zero e 3\%, a perda de solo foi significativa em função da área existente na bacia, um total de 1147 hectares, 75\% da área da sub-bacia (Fig. 108).

Em relação aos solos da SBD-SC (Figs. 109 e 110), assim como na BD-SC, a maior perda de solo, 4.295 t/ano, referiu-se ao Latossolo Vermelho Amarelo distrófico. Esse valor deve estar relacionado à área relativa de solo na bacia, 89,2\% do total.

Os resultados das estimativas de erosão, em função do uso do solo (Figs. 111 e 112), evidenciaram que as áreas de produção de cana-de-açúcar e de citros foram responsáveis por, praticamente, $100 \%$ da perda de solo da SBD-SC.

A erosão observada na SBD-SC - 3,38 ton/ha.ano e 5.158 ton/ano - foi bem maior do que a observada na SBD-LA - 0,08 ton/ha.ano e 47 ton/ano. Mesmo com a diferença de área entre as duas subunidades (1526 ha. e 620 ha., respectivamente), a disparidade nas médias de erosão está associada aos diferentes usos do solo observados. Dessa maneira, a contribuição de sedimentos da SBD-SC, parte do material que foi erodido e que pode atingir a área da planície de inundação do rio Mogi-Guaçu, foi potencialmente muito mais elevada do que o que foi observado na SBDLA. 
Hipsometria (m)

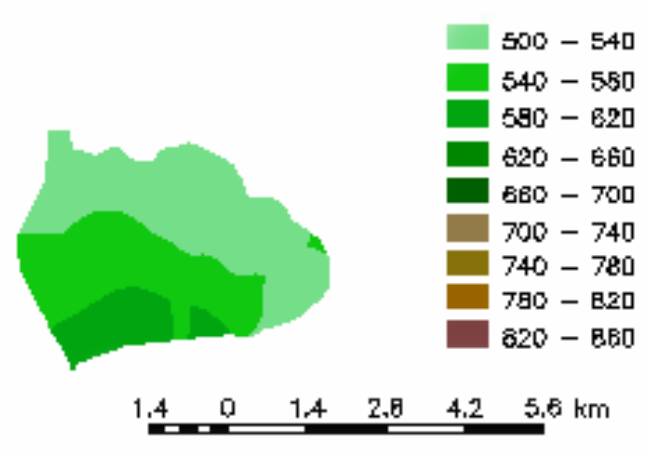

(A)

Solos

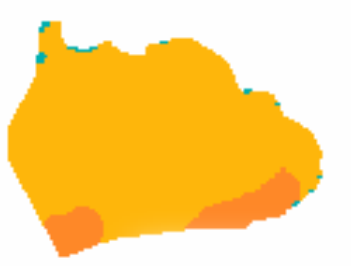

$1400,0 \quad 0 \quad 1400,02800,04200,05000,0 \mathrm{~m}$

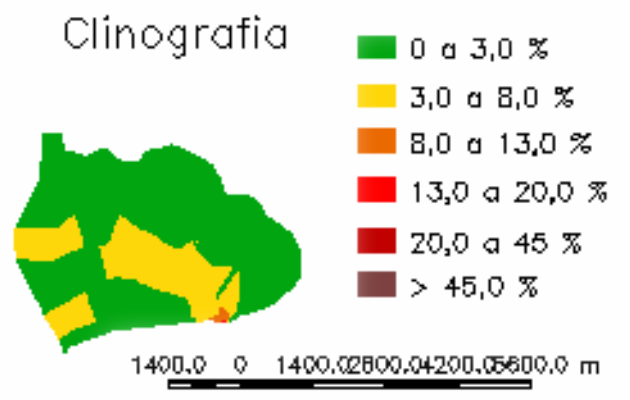

(B)

Uso do Solo

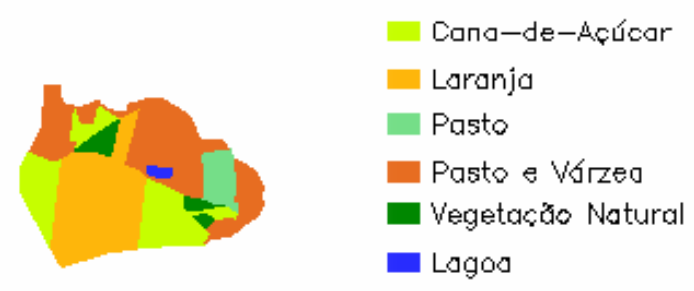

$1400,0 \quad 0 \quad 1400,02800,04200,05 \times 00.0 \mathrm{~m}$

(C)

(D)

Org. Ricardo Tezini Minoti (2006)

Projeção UTM - Zona 23S / Datum Horizontal: Córrego Alegre, MG

Fig. 105. Sub-bacia de drenagem de São Carlos (SBD-SC). 


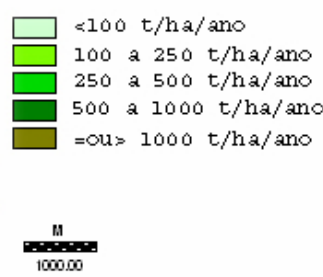

(A)

Perda de solo por Erosāo Laminar (A)

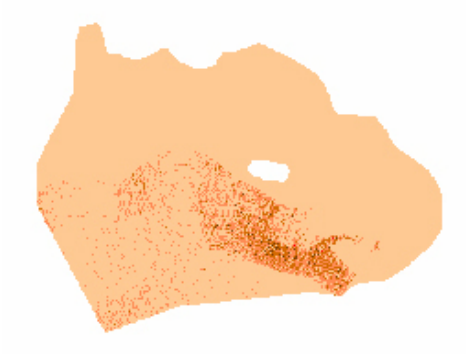

(C)

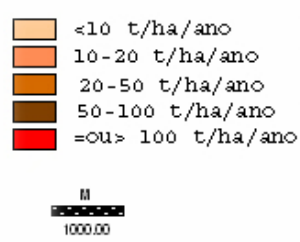

potencial de Risco de Erosão Laminar

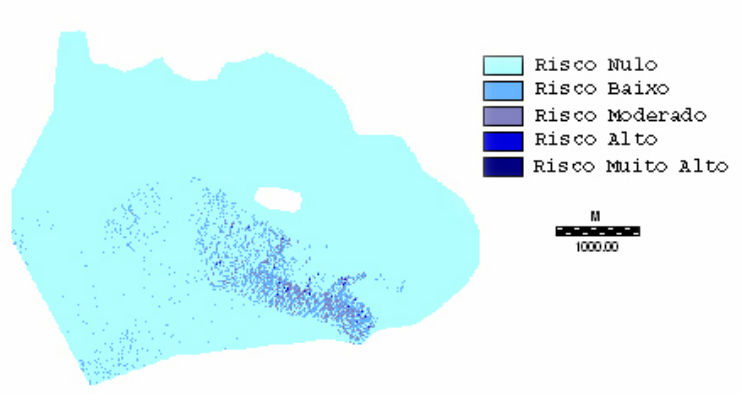

(D)

\begin{tabular}{|c|c|}
\hline \multirow{2}{*}{ Org. Ricardo Tezini Minoti (2006) } \\
\hline
\end{tabular}

Fig. 106. Sub-bacia de drenagem de São Carlos (SBD-SC). 


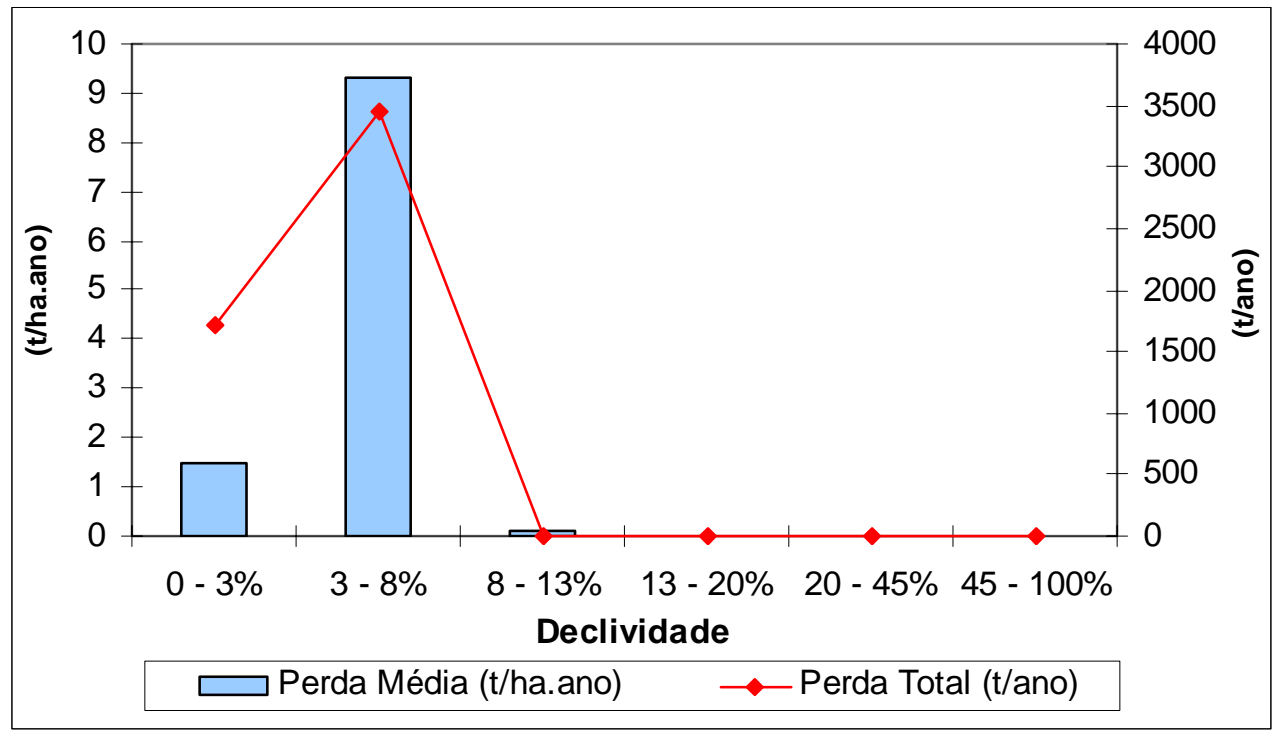

Figura 107 Perdas média e total de solo da Sub-bacia de Drenagem de São Carlos (SBD-SC) nos intervalos de declividade.

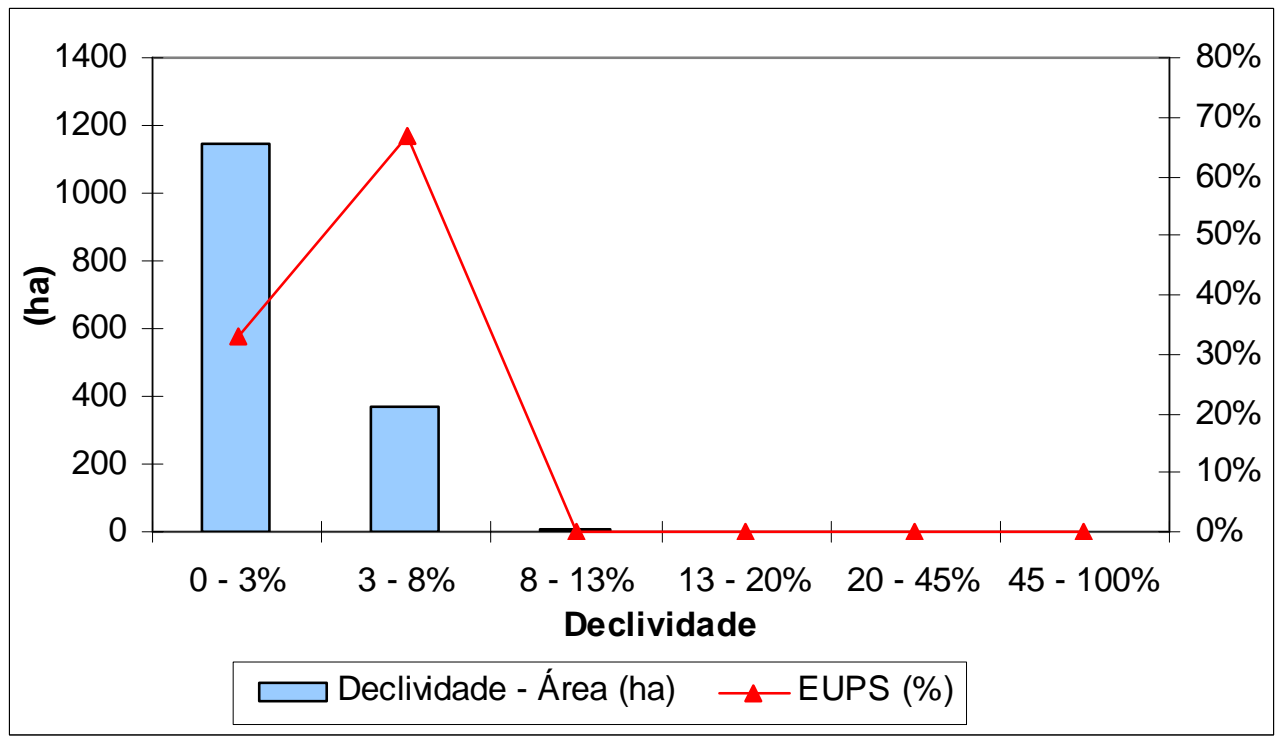

Figura 108. Área dos intervalos de declividade (ha.) e percentagem da perda total de solo na SBD-SC (EUPS). 


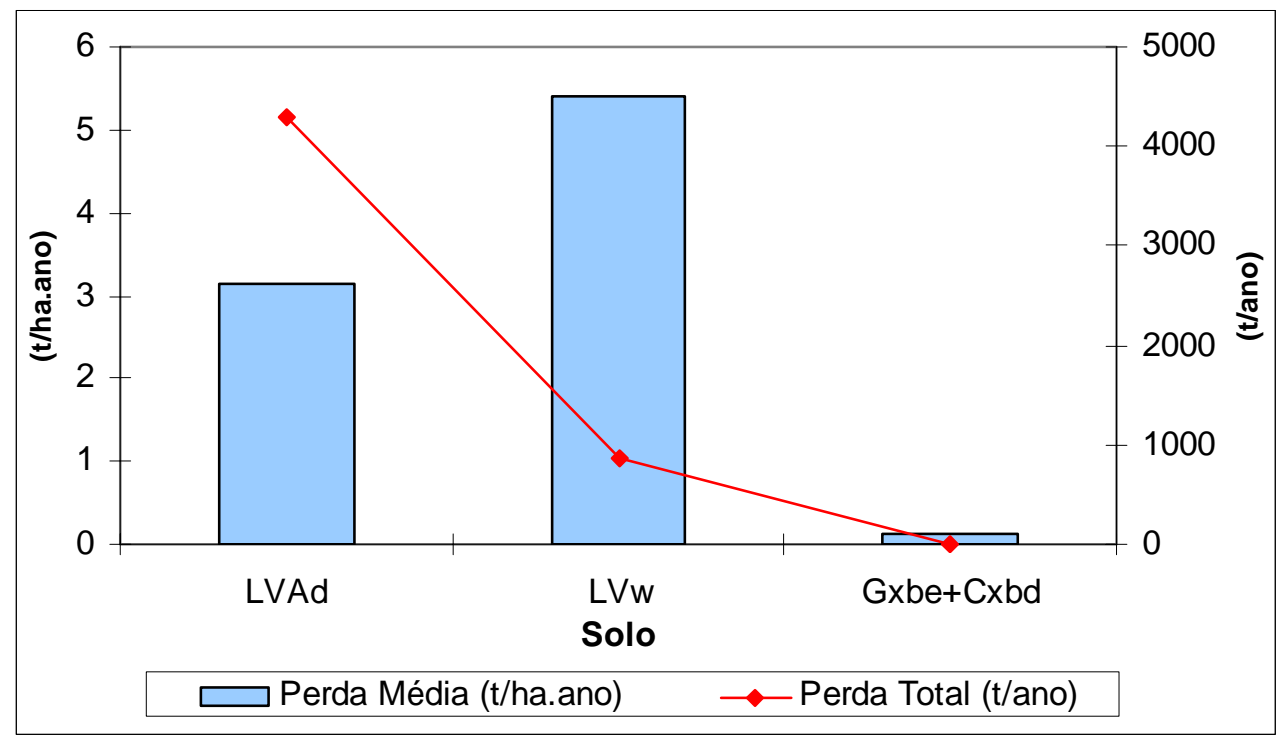

Figura 109. Perdas média e total de solo da Sub-bacia de Drenagem de São Carlos (SBD-SC) referentes aos tipos de solo.

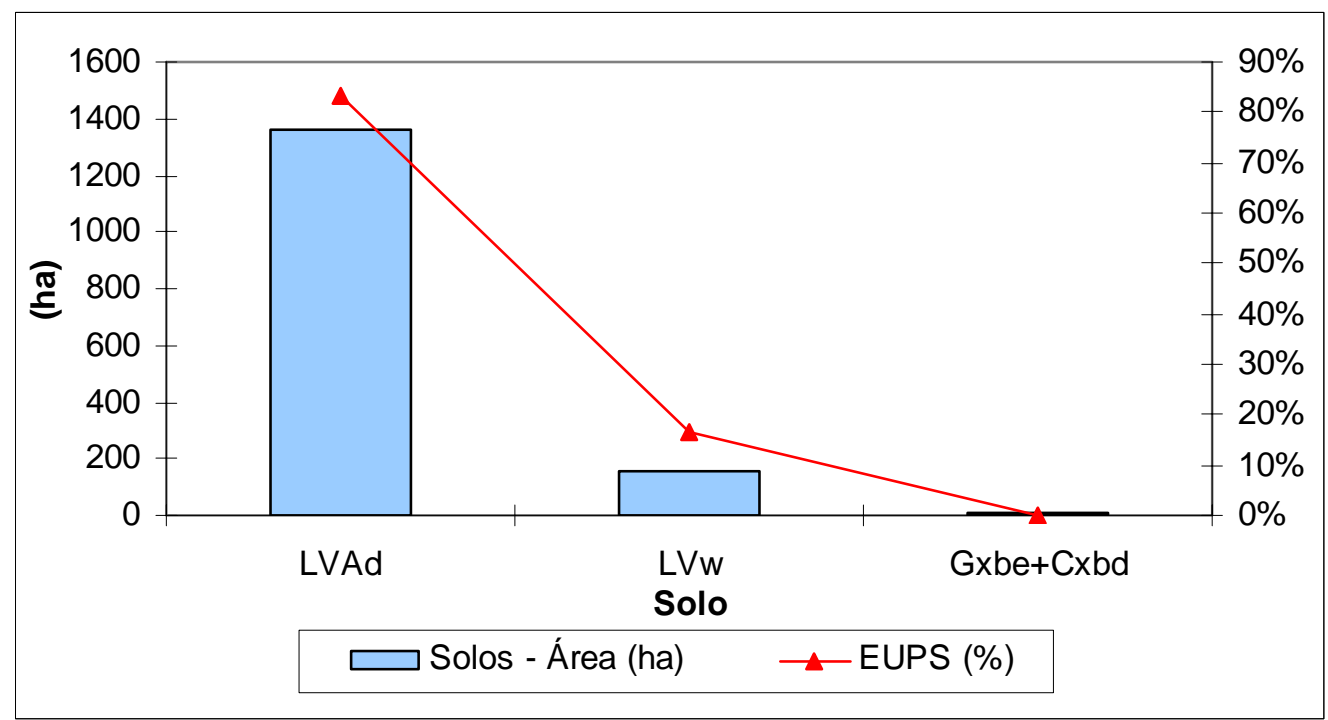

Figura 110. Área ocupada pelos diferentes tipos de solos (ha.) e percentagem da perda total de solo na SBD-SC (EUPS). 


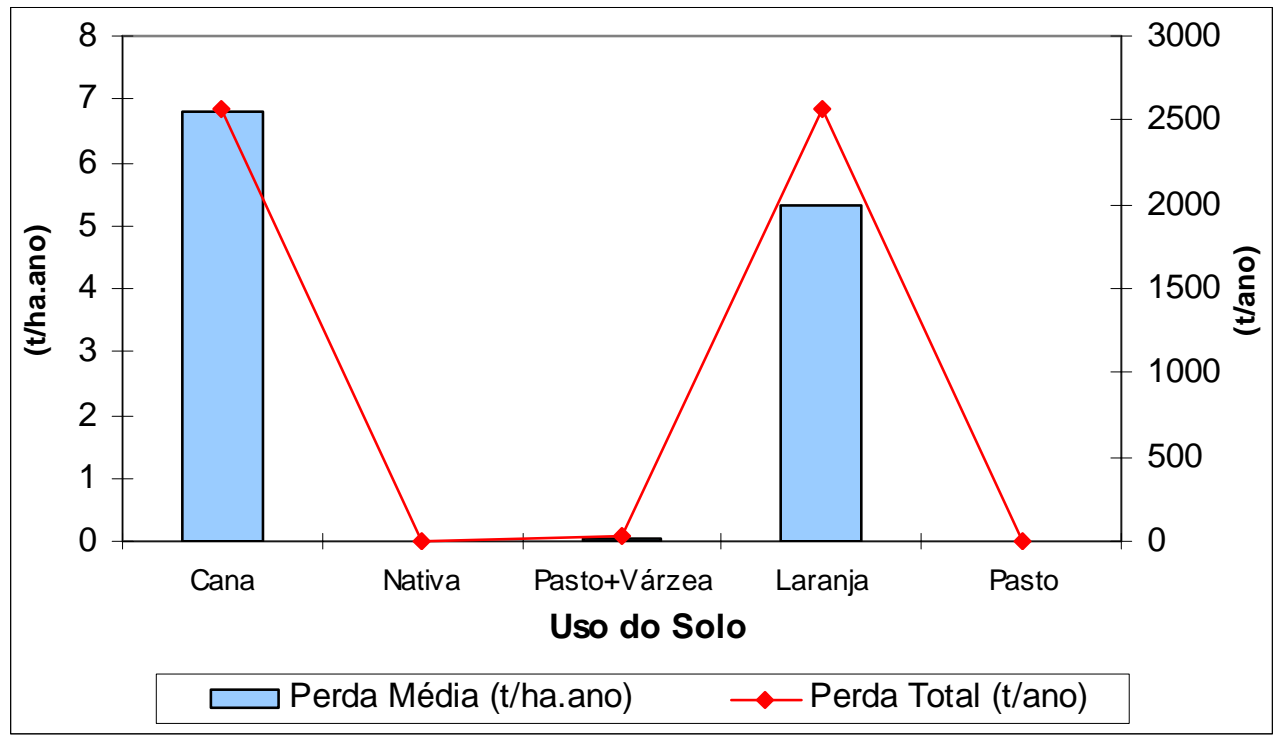

Figura 111. Perdas média e total de solo da Sub-bacia de Drenagem de São Carlos (SBD-SC) referentes aos tipos de uso do solo.

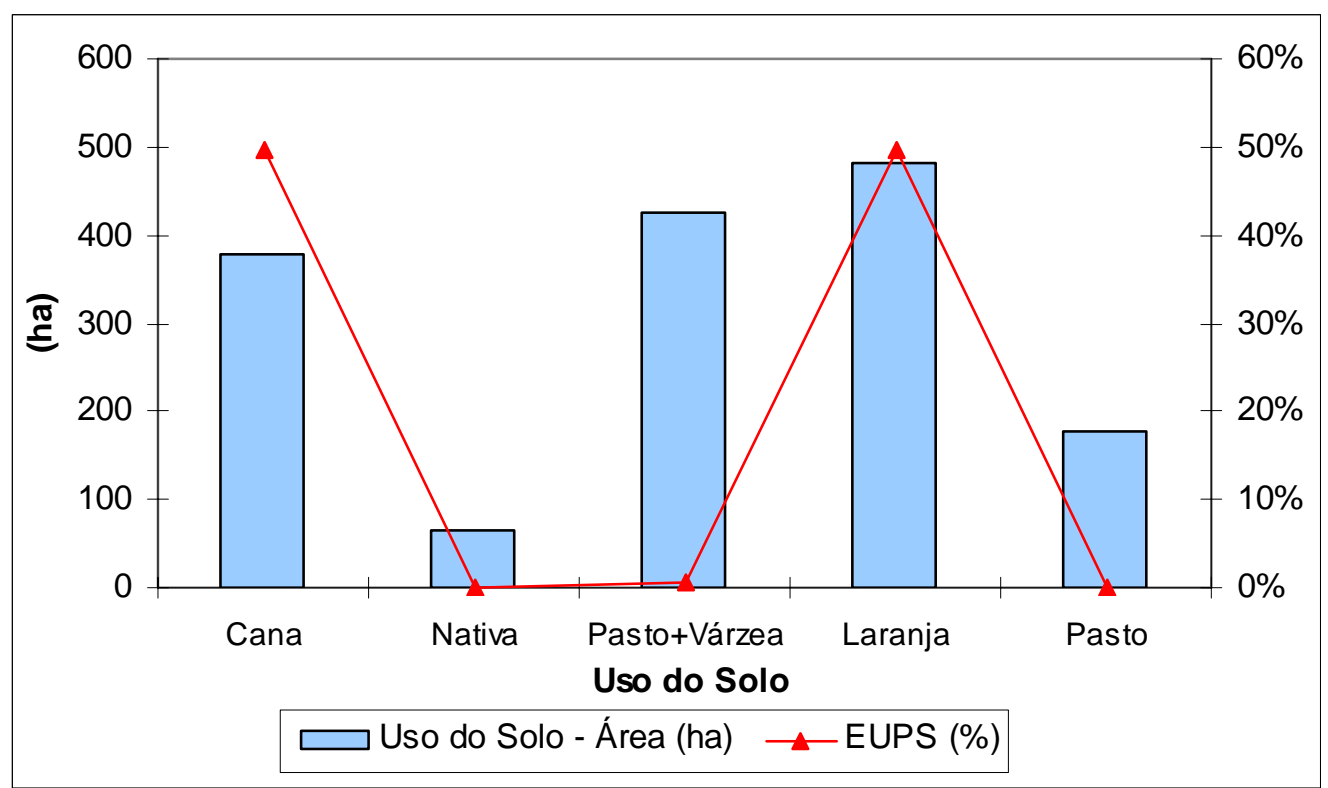

Figura 112. Área ocupada pelos diferentes tipos de solo (ha) e percentagem da perda total de solo na SBD-SC (EUPS). 


\section{B.4 Bacia de Drenagem de São Carlos (2.175 hectares)}

A Bacia de Drenagem do Município de São Carlos (BD-SC) apresenta algumas lagoas marginais na área da planície de inundação do rio Mogi-Guaçu. Além das lagoas marginais, uma outra pode ser visualizada na área agrícola da bacia, entre áreas de pastagem e de produção de cana-de-açúcar (Fig. 113).

Nota-se que as extensões territoriais da BD-SC e da SBD-SC estão contidas nas três primeiras classes (entre 500 e $620 \mathrm{~m}$ ). A variação altimétrica é de $77 \mathrm{~m}$, sendo a cota mínima da bacia de 523m e a máxima, de 600m.

Foram identificadas 2 classes de Latossolos na microbacia e uma combinação de solos: os Latossolos constituem 74\% da área e a combinação de GLEISSOLO HÁPLICO Tb Eutrófico com CAMBISSOLO HÁPLICO (GXbe + CXbd), 26\%.

As características dos Latossolos foram discutidas anteriormente. No que concerne aos Gleissolos, para a produção agrícola destacam-se as limitações impostas pela presença do lençol freático a pouca profundidade. A aeração inadequada dificulta a difusão dos gases do solo para atmosfera e vice-versa, além de facilitar a formação de compostos bivalentes de Fe e Mn, que são tóxicos às plantas. Por outro lado, os Cambissolos de planícies aluviais não oferecem limitações quanto à erodibilidade, mas apresentam possibilidade de inundações, em razão do elevado nível do lençol freático, contudo menor que a dos Gleissolos (Oliveira, 1999).

O setor de produção agrícola da BD-SC (área equivalente à SBD-SC) é ocupado por canade-açúcar, laranja e pastagem e por algumas áreas de reserva legal (vegetação natural). A região da planície de inundação do rio Mogi-Guaçu praticamente não apresenta o desenvolvimento de culturas agrícolas. Nessa área, desenvolvem-se vegetação de várzea, capim (cobertura residual) e, também, mata ciliar. Esses diversos tipos de vegetação foram classificados como "Pasto + Várzea”. A área da bacia de drenagem é ocupada por Pasto + Várzea (48\% da área total), citros (22\%), cana-de-açúcar (17\%), pastagem (9\%), e o restante, por vegetação nativa.

Aparentemente, o setor de produção agrícola se reduziu à área da SBD-SC. Não obstante, foi observada uma extensa área coberta por gramíneas na planície de inundação do rio MogiGuaçu. Talvez a área tenha sido utilizada ou ainda seja utilizada para pastagem. Não foi possível delimitar a exata divisão entre a área de pastagem e áreas cobertas por vegetação típica de áreas de alagamento. Por essa razão, o uso do solo da área, considerado incerto no levantamento do presente trabalho, foi intitulado "pasto+várzea”.

Outro fator marcante observado nessa unidade de estudo relacionou-se à fragmentação da mata ciliar na margem do rio Mogi-Guaçu. Esse processo foi observado, também, por Silva (2002) ao longo de todo o curso do rio. A autora observou, ao estudar os sedimentos da bacia hidrográfica desse rio, que várias medidas devem ser implementadas para a recuperação das 
diversas funções dos ecossistemas entre as quais o restabelecimento das metragens mínimas exigidas por lei para as matas ciliares.

Além dos possíveis riscos ambientais ocasionados pela utilização da parte baixa da BD-SC (planície de inundação) para atividade de pastagem, podem-se observar, também, o preparo do solo para o cultivo de cana-de-açúcar em região próxima à planície de inundação do rio MogiGuaçu (solo acinzentado, típico de áreas com maior proximidade do lençol freático) e a ocorrência de lagoas marginais na região da planície de inundação do rio Mogi-Guaçu em meio à produção agrícola (pastagem). Na área da BD-SC observam-se, ainda, uma atividade mineradora de areia e um porto de areia localizado na margem do rio Mogi-Guaçu (Fig. 114).

Na área da bacia de drenagem foram observados os mais baixos valores de PNE médio e PNE máximo de toda a área de estudo - 47,9 e 2407,6, respectivamente. Verificou-se, também, a maior percentagem de área inserida na classe 1 de PNE, 87,7\%. A região da BD-SC apresentou os valores mais baixos de declividade de toda a área de estudo, e essa característica influenciou diretamente os valores de PNE. Os locais que apresentaram maiores valores de PNE (Fig. 115) na bacia foram as regiões de maior declividade, principalmente na faixa de 3 a $8 \%$, e com maiores valores do fator LS, variando de 1 a 5 . Na região a montante da bacia, com altitudes mais elevadas, foram encontrados pontos com maiores valores de PNE.

Os resultados de ERE, $\underline{\mathrm{A}}$ e PRE apresentaram configuração semelhante aos de PNE. Na região de maior declividade, de maiores valores de LS e na região a montante, os valores obtidos foram mais elevados do que no restante da área.

Os valores médios e os valores totais mais elevados de perda de solo da BD-SC ocorreram nas declividades entre 3 e 8\% (Fig. 116). A perda total de solo foi elevada, também, na faixa de declividades de zero a 3\%, relacionando-se, provavelmente, à área da bacia constituída por esse intervalo de declividade, 1750 hectares - 80\% do total (Fig. 117).

Nas Figuras 118 e 119, pode-se observar a perda de solo em função das classes de solos identificadas na BD-SC. Entre os Latossolos, a perda foi proporcional à área ocupada pelas duas classes. Apesar de a associação entre Gleissolos e Cambissolos ocorrer em 26\% da área da bacia, os valores de erosão para esses solos foram extremamente baixos, média de 0,1 t/ha.ano e perda total de 51,3 ton/ano.

Os valores mais elevados de perda média e perda total de solo ocorreram nas áreas de produção de cana-de-açúcar e citros (Figs. 120 e 121). Nas demais áreas - pastagem, pasto + várzea e vegetação natural - os valores foram extremamente baixos.

A parte baixa da BD-SC, assim como ocorre na BD-LA, é formada pela planície de inundação do rio Mogi-Guaçu. Esse segmento é parcial ou totalmente inundado na época da 
cheia do rio recebendo, também, aporte de materiais particulados e sedimentos. Entretanto, foi observado que a erosão referente à parte baixa da BD-SC (63 ton/ano em 649 hectares) foi bem maior do que a verificada na parte baixa da BD-LA (1 ton/ano em 340 hectares). Além disso, houve diferença marcante das regiões a montante dessas bacias. As estimativas dos processos erosivos referentes à SBD-SC (5.158 ton/ano em 1.526 hectares) foram bem maiores do que as verificadas na parte baixa da BD-LA (47 ton/ano em 620 hectares).

Dessa forma, o uso agrícola da área a montante da bacia (SBD-SC) e de algumas áreas na parte baixa da BD-SC faz com que o risco provocado pelas cargas de sedimentos geradas na área da bacia seja bem mais elevado na região agrícola (margem esquerda do rio Mogi-Guaçu) do que na região ocupada pela EEJ (margem direita do rio). Salienta-se que não existem trabalhos sobre as áreas alagáveis e as lagoas marginais remanescentes da planície de inundação desse rio na margem esquerda, município de São Carlos.

No entanto, pode-se dizer que os riscos ambientais dessa unidade de estudo, relacionados aos processos erosivos, não foram tão elevados. Tendo em vista os baixos valores de declividade e a maior parte da área ser caracterizada pela presença de latossolos, os valores de PNE foram extremamente baixos. Observa-se, dessa forma, que as características naturais da BD-SC são menos favoráveis aos processos erosivos do que as características encontradas na BD-LA. A média da estimativa de erosão para a BD-SC, 2,4 ton/ha.ano, encontra-se abaixo do limite de tolerância de perda de solo por erosão e foi bem menor do que as médias obtidas para a MBHBF e MBH-G.

Seria extremamente interessante a realização de trabalhos de pesquisa para a avaliação geocronológica dos sedimentos das lagoas marginais do rio Mogi-Guaçu, localizadas no município de São Carlos (área da BD-SC), para posterior comparação com os resultados obtidos por Albuquerque et al. (2000) e Simões Filho et al. (2000) nas lagoas localizadas na EEJ (área da BD-LA), em função dos diferentes usos do solo nas bacias de drenagem.

Apesar de os riscos relacionados aos processos erosivos não terem sido tão elevados nessa unidade de estudo, outros riscos relacionados às atividades agrícolas como lixiviação profunda de agroquímicos, conforme foi observado para a MBH-G, não foram contemplados neste trabalho. Foi observado o plantio de cana-de-açúcar em áreas próximas à planície de inundação do rio Mogi-Guaçu, assim como possíveis áreas de pastagem inseridas nessa área alagável. Os solos pouco profundos, característicos dessas áreas, compõem, juntamente com as áreas cultivadas, um cenário extremamente favorável à contaminação química das águas subsuperficiais. 


\section{Hipsometria $\langle m\rangle$}

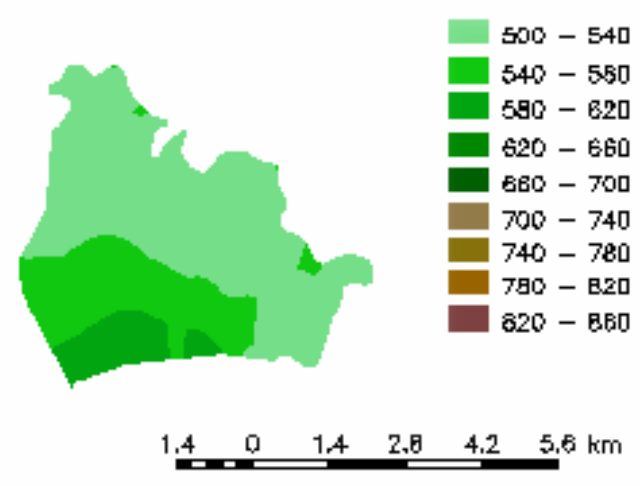

(A)

$$
\text { Solos }
$$

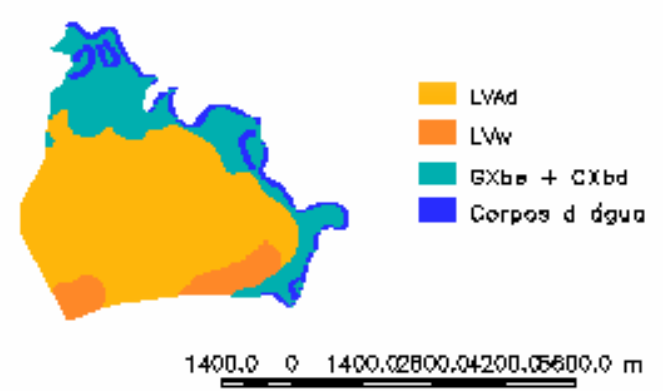

(C)

\section{Clinografia}

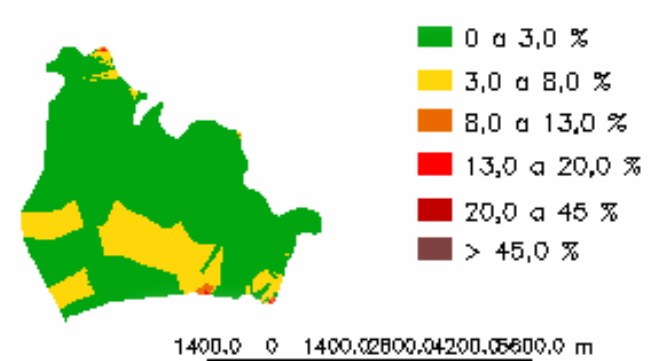

$1400,0 \quad 0 \quad 1400.02800,04200,05600.0 \mathrm{~m}$

Uso do Solo

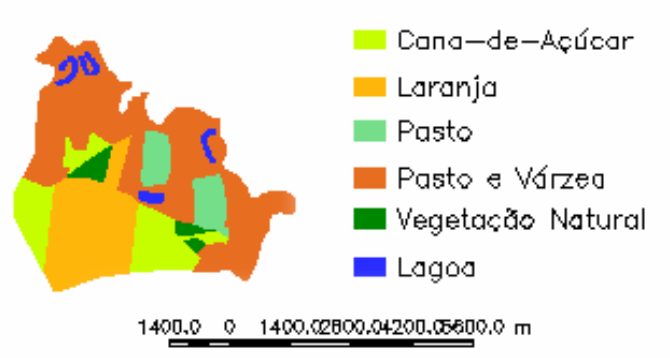

(D)

Org. Ricardo Tezini Minoti (2006)

Projeção UTM - Zona 23S / Datum Horizontal: Córrego Alegre, MG

Fig. 113. Bacia de drenagem de São Carlos (BD-SC). 


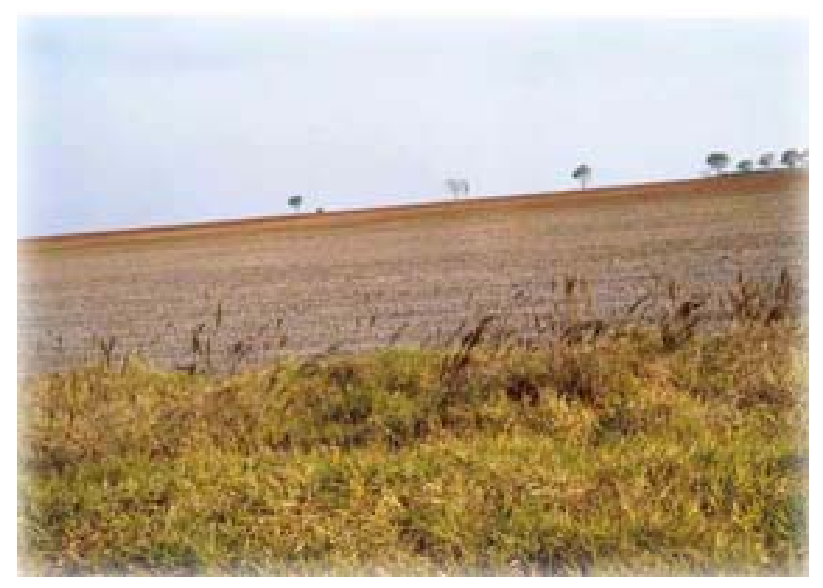

(a)

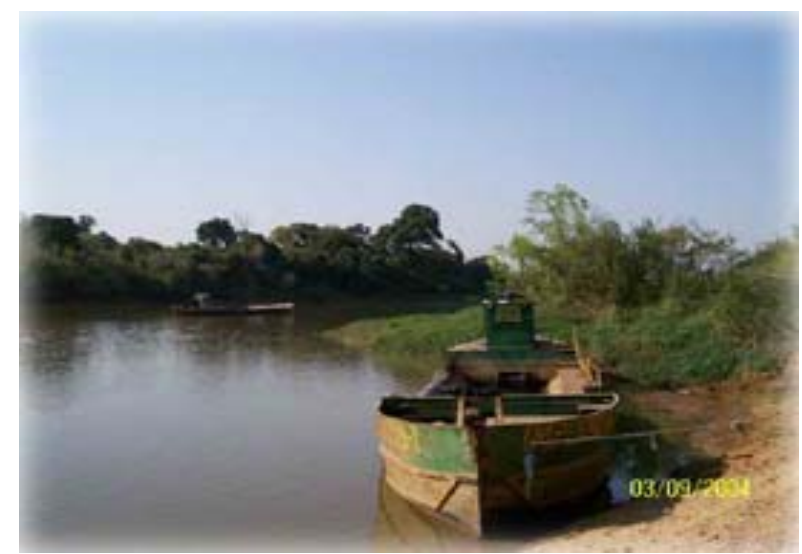

(c)

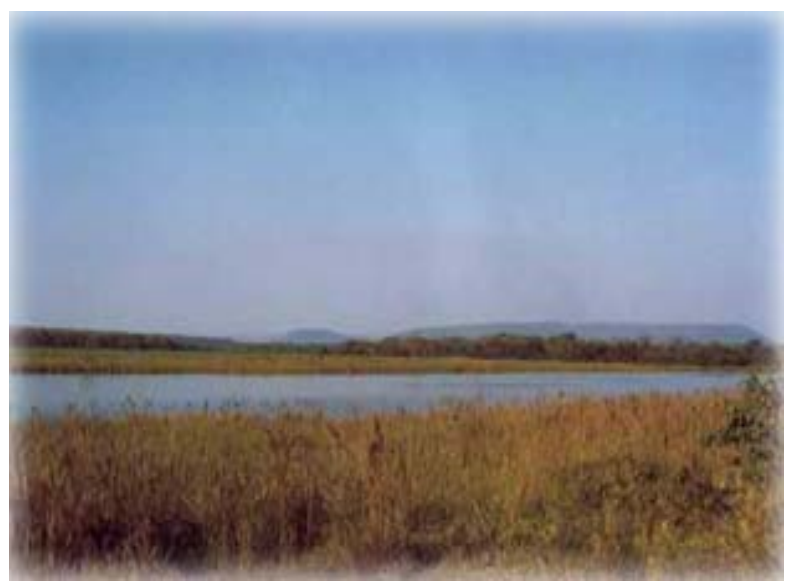

(b)

Figura 114. Diferentes áreas da Bacia de Drenagem de São Carlos.

(a) Preparo do solo para o cultivo de cana-deaçúcar em região próxima a planície de inundação do rio Mogi-Guaçu.

(b) Lagoa marginal na região da planície de inundação do rio Mogi-Guaçu.

(c) Porto de areia no rio Mogi-Guaçu.

Org. Ricardo Tezini Minoti (2006) 


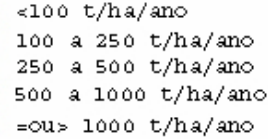

500 a $1000 \mathrm{t} / \mathrm{ha} / \mathrm{ano}$

$=$ ous $1000 \mathrm{t} / \mathrm{h} 2 /$ ano

(A)

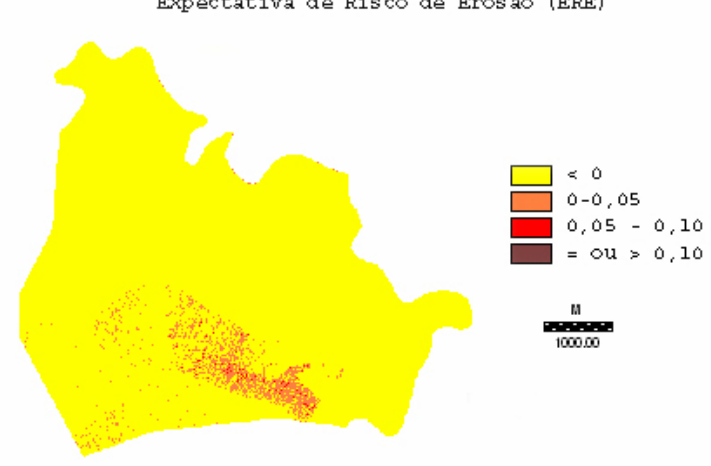

Perda de solo por Erosão Laminar (a)

potencial de Risco de Erosāo Laminar

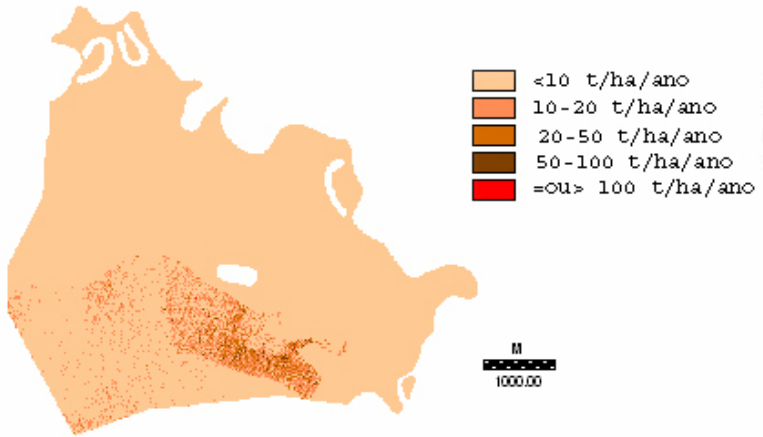

(C)

(B)

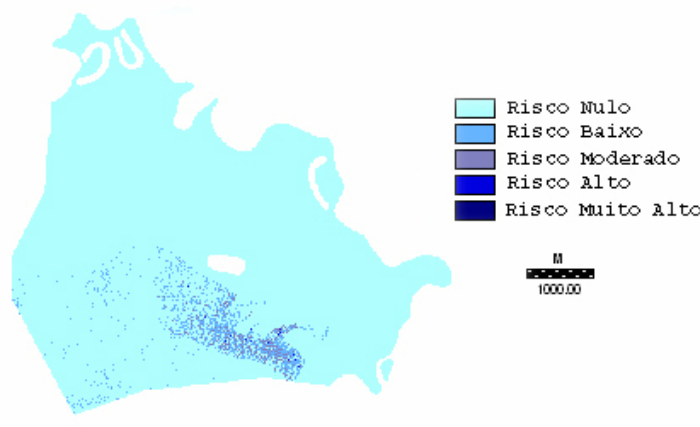

(D)

\section{Org. Ricardo Tezini Minoti (2006)}

Projeção UTM - Zona 23S / Datum Horizontal: Córrego Alegre, MG

Fig. 115. Bacia de drenagem de São Carlos (BD-SC). 


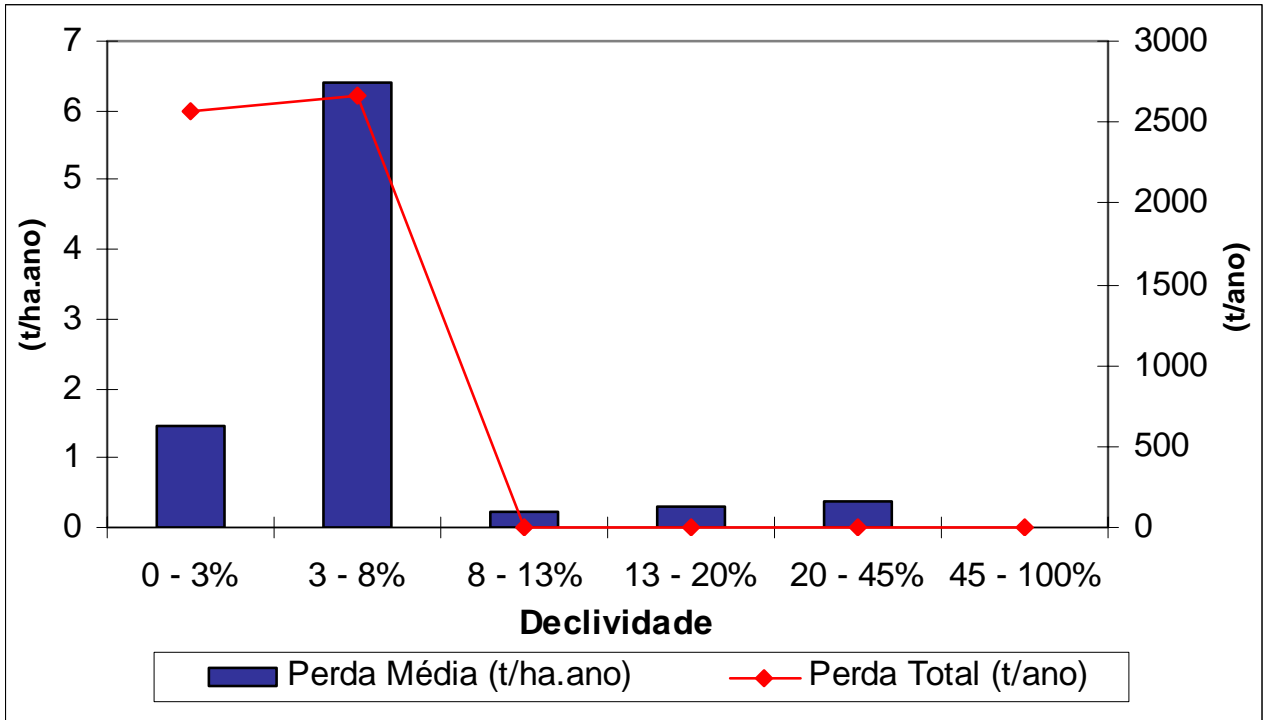

Figura 116 Perdas média e total de solo da Bacia de Drenagem de São Carlos (BD-SC) nos intervalos de declividade.

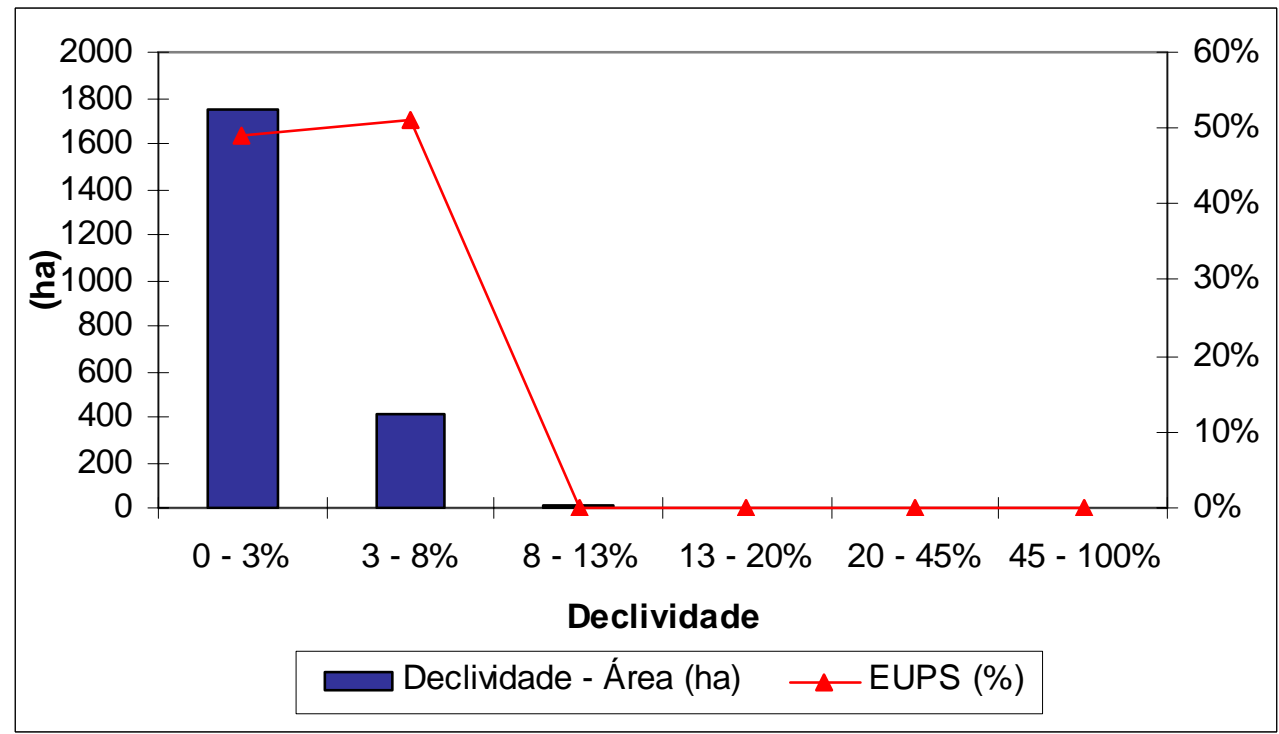

Figura 117. Área dos intervalos de declividade (ha.) e percentagem da perda total de solo na BD-SC (EUPS). 


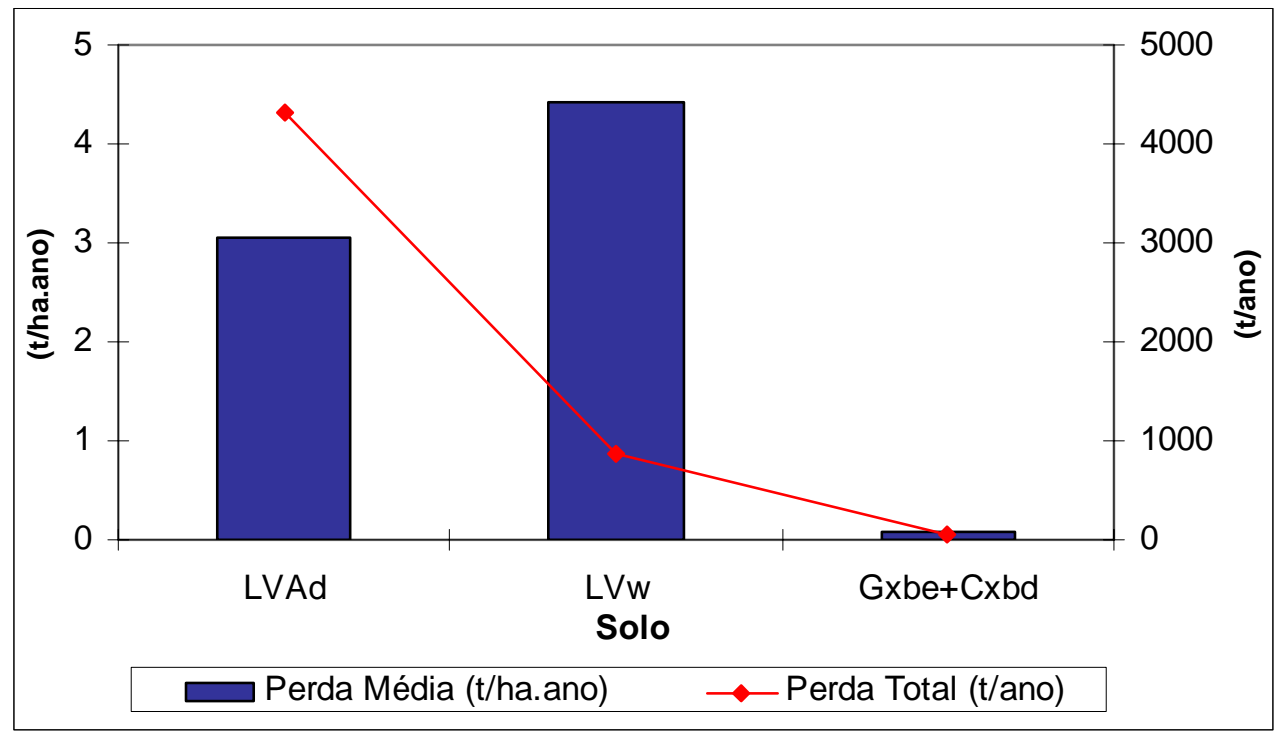

Figura 118. Perdas média e total de solo da Bacia de Drenagem de São Carlos (BD-SC) referentes aos tipos de solo.

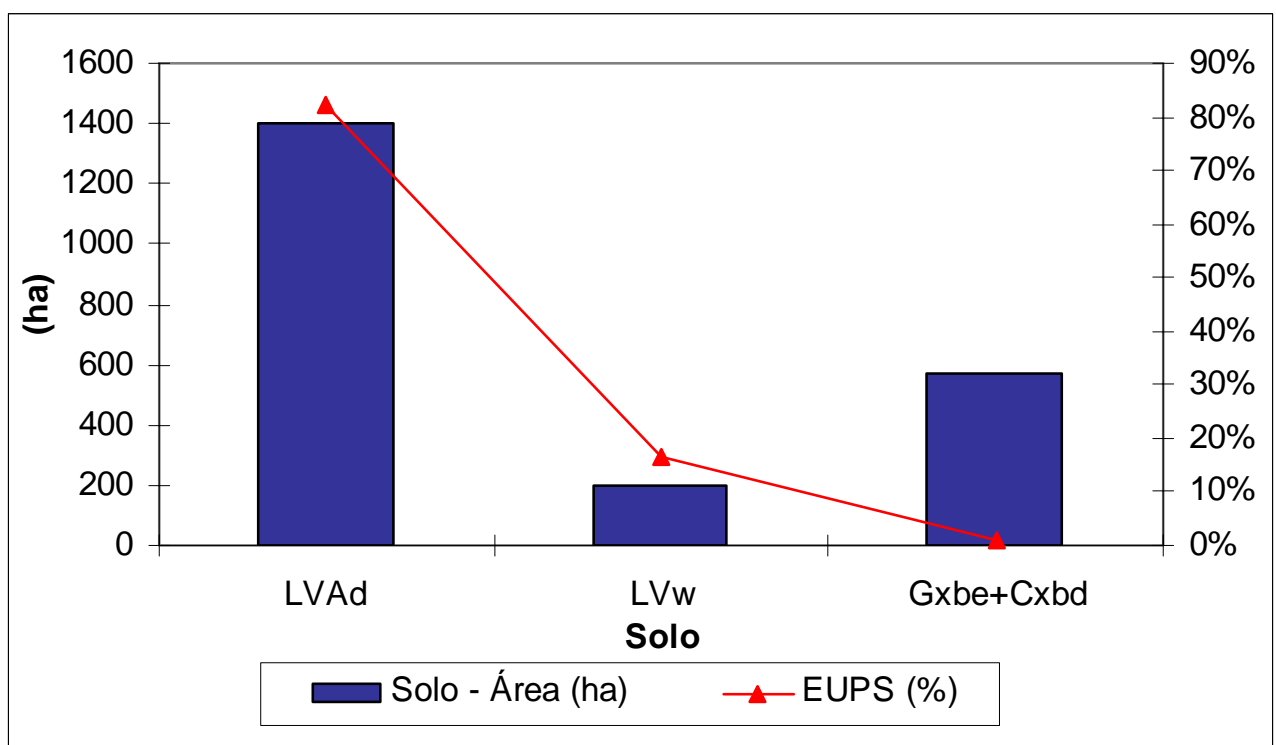

Figura 119. Área ocupada pelos diferentes tipos de solos (ha.) e percentagem da perda total de solo na BD-SC (EUPS). 


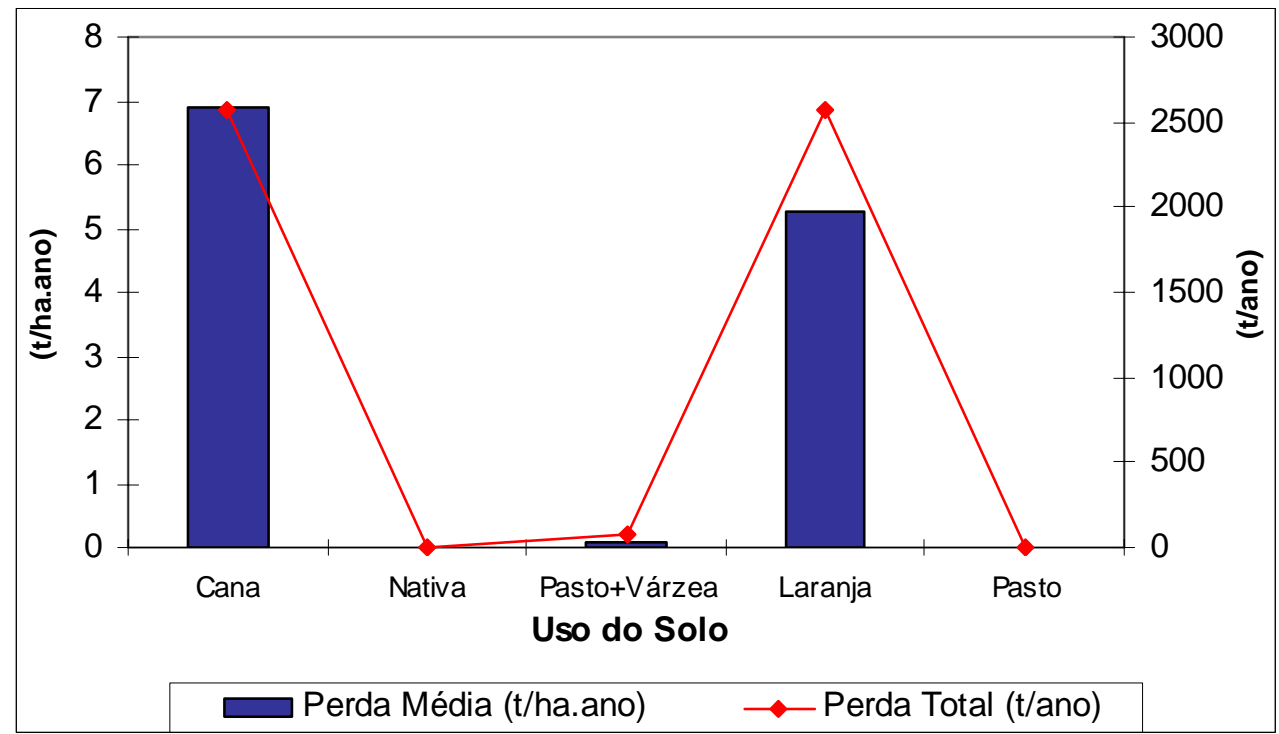

Figura 120. Perdas média e total de solo da Bacia de Drenagem de São Carlos (BD-SC) referentes aos tipos de uso do solo.

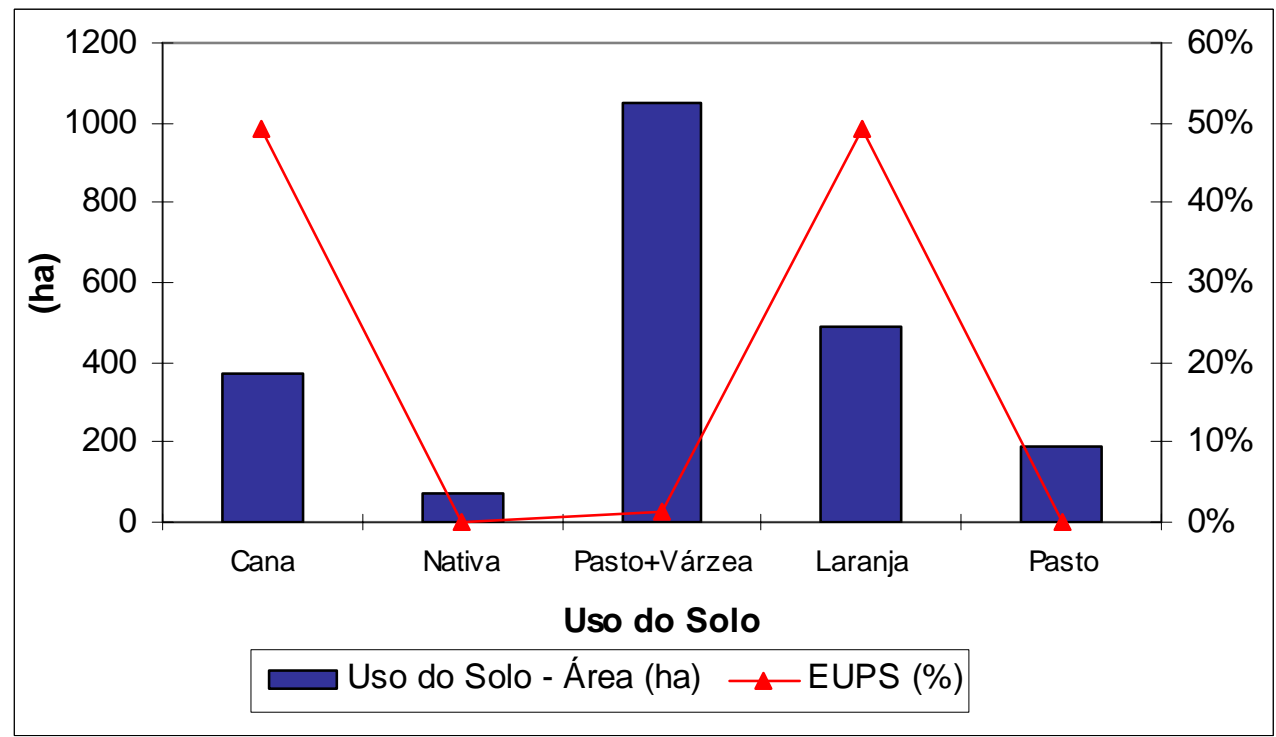

Figura 121. Área ocupada pelos diferentes tipos de solo (ha.) e percentagem da perda total de solo na BD-SC (EUPS). 